Rahel Katzenstein

\title{
Schule und Zivilreligion
}

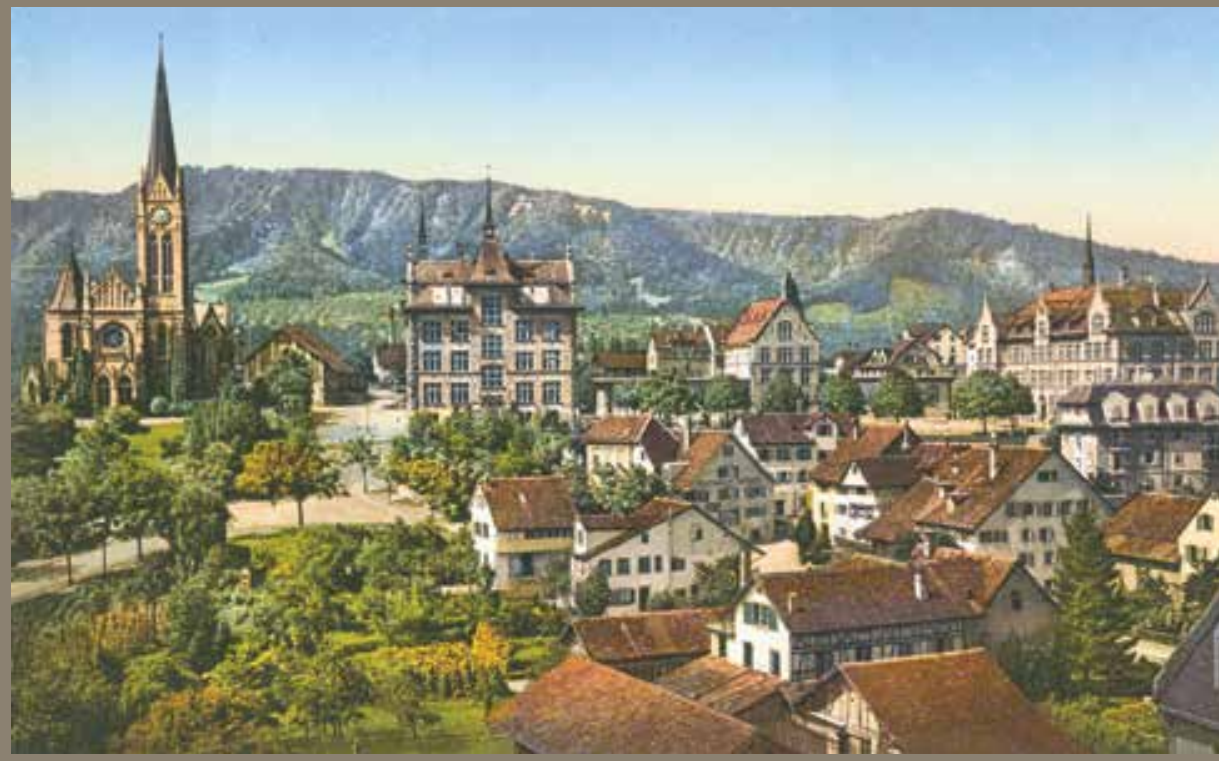

Die Diskussion über den schulischen Religionsunterricht im Kanton Zürich 1872 und 2004

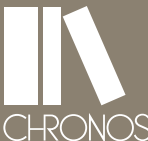


Rahel Katzenstein

\section{Schule und Zivilreligion}

Die Diskussion über den schulischen Religionsunterricht im Kanton Zürich 1872 und 2004 
Publiziert mit Unterstützung des Schweizerischen Nationalfonds zur Förderung der wissenschaftlichen Forschung.

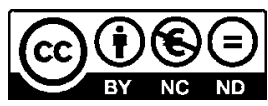

Informationen zum Verlagsprogramm:

www.chronos-verlag.ch

Umschlagbild: Fotochromkarte «Zürich-Wiedikon. Kirche mit den Bühlschulhäusern», um I 900 .

(C) 2018 Chronos Verlag, Zürich

ISBN 978-3-0340-I 470-0

DOI I $0.33057 /$ chronos. 470 


\section{Inhalt}

$1 \quad$ Einleitung $\quad$ I 3

I.I Gesellschaftliche Erwartungen an eine gesellschaftliche Einrichtung I3

$\begin{array}{lll}\text { I.2 Forschungsziel und Fragestellung } & \text { I7 }\end{array}$

I.3 Anlage der Untersuchung und Vorgehensweise I9

I.4 Klärung verwendeter Grundbegriffe 2 I

$\begin{array}{ll}\text { I.5 Quellenbasis } & 27\end{array}$

I.6 Stand der Forschung 28

I.6. I Schul-, Kirchen- und Politikgeschichte des Kantons Zürich 29

I.6.2 Schulischer Religionsunterricht 3 I

I.6.3 Zivilreligion 35

\section{Teil 1: Begriffliche und historische Rahmung}

2 Zivilreligion - Phänomen und Begriff 39

2.I Eine erste Annäherung: Unterscheidung zwischen Zivilreligion, politischer Religion und Staatsreligion $\quad 39$

2.2 Amerikanische und französische Zivilreligion 43

2.3 Zivilreligion und Republikanismus 45

2.4 Was ist das Religiöse an Zivilreligion? 52

2.4. I Ecole laïque 53

2.4.2 Säkulare Kulte als Mittel der öffentlichen Erziehung 59

2.4.3 Traditionell religiöse Symbolik und Praktiken im öffentlichen Raum 6I

$\begin{array}{ll}2.5 & \text { Grundwerte als Zivilreligion }\end{array}$

2.6 Bestimmung des Begriffs Zivilreligion 66

3 Die zürcherische Volksschule im Spannungsfeld zwischen Kirche und Staat 7 I

3.I Vom Wandel des Verhältnisses zwischen Staat und Kirche im Kanton Zürich 7 I

3.2 Die Entstehung der modernen öffentlichen Schule 79

3.3 Zur Geschichte des schulischen Religionsunterrichts
im Kanton Zürich I 800-2016 
Teil 2: Die Diskussion um den schulischen Religionsunterricht um 1872

$4 \quad$ Ausgangslage 93

4.I Politische Situation: Aufschwung der Demokratischen Bewegung 93

$\begin{array}{ll}4.2 & \text { Religionspolitische Situation }\end{array}$

4.3 Innerkirchliche Richtungsstreitigkeiten 98

4.4 Politische und religiöse Richtungen und ihre Verflechtungen I०4

$5 \quad$ Das abgelehnte Unterrichtsgesetz von $1872 \quad 107$

$\begin{array}{ll}\text { 5.I Erziehungsdirektor Johann Caspar Sieber } & \text { I07 }\end{array}$

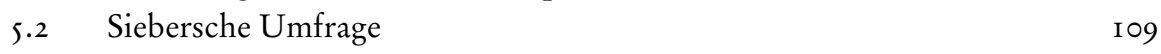

$5 \cdot 3$ Vom ersten handschriftlichen Unterrichtsgesetzentwurf zur

5.4 Umstrittene Punkte II 3

5.5 Gründe für die Verwerfung des Unterrichtsgesetzes I I4

6 Kontroverse Themen in der Diskussion um den schulischen $\begin{array}{ll}\text { Religionsunterricht um } \mathbf{1 8 7 2} & \text { I I } 7\end{array}$

6. I Mitbestimmungsrecht bei Lehrplan und Lehrmittel I 8

6.2 Wer unterrichtet - der Lehrer oder der Pfarrer? I 23

6.3 Religiöse, konfessionslose oder religionslose Schule? I 29

6.4 Obligatorium I 52

6.5 Religiöse Erziehung: Eine Aufgabe der öffentlichen Schule? I60

6.6 Was soll im schulischen Religionsunterricht vermittelt werden? $\quad$ I67

6.6.I Biblische und andere Geschichten? I68

$\begin{array}{ll}\text { 6.6.2 Kontroverse Altes Testament } & \text { I70 }\end{array}$

$\begin{array}{ll}\text { 6.6.3 Kontroverse Wundergeschichten } & \text { I75 }\end{array}$

7 Zivilreligiöse Erwartungen in der Diskussion um den schulischen

$\begin{array}{ll}\text { Religionsunterricht } \mathbf{1 8 7 2} \text { - eine Analyse } & 177\end{array}$

7.I Funktionale Ausdifferenzierung und weltanschaulich-religiöse $\begin{array}{ll}\text { Heterogenität als Voraussetzung von Zivilreligion } & \text { I77 }\end{array}$

7.2 Spannungsfeld zwischen Religionsfreiheit und der Evokation von $\begin{array}{ll}\text { gesellschaftlicher Einheit } & \text { I } 83\end{array}$

7.2.I Fehlendes Spannungsbewusstsein angesichts der konfessionellen $\begin{array}{ll}\text { Homogenität der Gesellschaft } & \text { I } 84\end{array}$

7.2.2 Auflösung der Spannung durch Evokation von Einheit I85

7.2.3 Aufrechterhaltung der Spannung durch Förderung eines institutionellen Pluralismus 
7.3 Paradoxie von Zivilreligion: Gesellschaftliche Ausdifferenzierung und Auflösung der Sphärengrenzen

7.4 Negation der historischen Kontingenz und Partikularität von

Universalitätsansprüchen

7.5 Zwei Typen von Zivilreligion

7.5.I Vergleich mit dem französischen Idealtypus von Zivilreligion

7.5.2 Vergleich mit dem amerikanischen Idealtypus von Zivilreligion

Teil 3: Die Diskussion um den schulischen Religionsunterricht um 2004

8 Vom Widerstand gegen die geplante Abschaffung von Biblischer Geschichte zur Einführung des obligatorischen Faches Religion und Kultur

9 Kontroverse Themen in der Diskussion um den schulischen

Religionsunterricht um 2004

9. I Mitbestimmungsrecht über Lehrplan und Lehrmittel

9.2 Ausbildungsanforderungen:

Wer darf Religion und Kultur unterrichten?

9.3 Obligatorium

9.4 Religionsunterricht, Ethikunterricht oder Werteerziehung? 239

9.5 Die Rede von den Werten

9.5.I Die Allgegenwart der Werterhetorik

9.5.2 Wertneutralität

9.6 Aufgabe der öffentlichen Schule?

9.6. I Integration und Toleranz als Rezepte für das friedliche Zusammenleben? 253

9.6.2 Orientierung und Identitätsbildung

10 Zivilreligiöse Erwartungen in der Diskussion um den schulischen

Religionsunterricht im 21. Jahrhundert

Iо. I Funktionale Ausdifferenzierung

I0.2 Religionsfreiheit und Streben nach gesellschaftlichem Zusammenhalt ein Spannungsfeld

I0.2. I (K)ein Bewusstsein für Spannung

10.2.2 Ausklammerung der Spannung und die Evokation von Einheit

I0.2.3 Bewusster Umgang mit Spannung und Förderung eines institutionellen Pluralismus

I0.3 Paradoxie von Zivilreligion 
I0.4 Universalitätsanspruch versus historische Kontingenz und Partikularität 282

ı.5 Zwei Typen von Zivilreligion

Io.6 Fazit Teil 3

\section{Teil 4: Ausblick}

$11 \quad$ Zivilreligiöse Erwartungen an die Schule - so what?

I I.I Zivilreligiöse Erwartungen als Indikator totalisierender Tendenzen

I I.2 Die semantische Unbestimmtheit der Werterhetorik

I I.3 Zivilreligion versus Pluralismus

Bibliographie

Ungedruckte Quellen

Gedruckte Quellen i 9. Jahrhundert

Gedruckte Quellen 2 I. Jahrhundert 309

Sekundärliteratur 


\section{Vorwort und Dank}

Wer die Schule hat, hat das Land.

Aber wer hat die bei uns in der Hand!

Kurt Tucholsky

Für uns ist

Gott Luft. Wir

atmen ihn ein.

Klaus Merz ${ }^{\mathrm{I}}$

Ich schreibe dieses Vorwort am Fusse des Mythen im dicken Nebel. Der Nebel bildet das Gefühl ab, das mich in all den Jahren der Beschäftigung mit meiner Dissertationsthematik begleitet hat: Ein Gefühl beständigen Herumirrens, Tastens und Suchens. Mein Ansinnen war, die mich umgebende Luft, die ich einatme und mein Leben lang eingeatmet habe und die wir in der Regel nicht wahrnehmen, sichtbar zu machen. Was mich leitete, war die Sehnsucht nach Klarheit. Ich wollte dem Selbstverständlichen und «Normalen» auf die Spur kommen, es der Unsichtbarkeit entreissen. Ich wollte die hohen an die Schule herangetragenen normativen Erwartungen zu verstehen suchen und zugleich mein Unbehagen gegenüber diesen zum Teil überrissenen Erwartungen ernst nehmen und ihm eine Sprache geben.

Wer wünscht nicht ein friedliches Miteinander aller Menschen? Wer erhofft nicht das Ende aller Kriege? Wer hat sich nicht schon beim Gedanken ertappt, dass, wenn alle Kinder im richtigen Geist erzogen würden, endlich der ersehnte Friede auf Erden einkehren könnte? «Shaping the generation of tomorrow», Erziehung zu Toleranz, das Verhindern von Kriegen durch das Einüben friedlichen Zusammenlebens im Schulzimmer. Dies sind Antworten angehender Lehrpersonen im 21. Jahrhundert zu Beginn ihres Studiums auf die Frage, was sie motiviere, den Beruf der Lehrerin oder des Lehrers zu ergreifen.

«Wer die Schule hat, hat das Land», ${ }^{2}$ schrieb treffend Kurt Tucholsky in der Wochenzeitschrift Die Weltbühne kurz nach dem Ende des Ersten Weltkrieges. Der Glaube an die Wirksamkeit der Schule ist das, was diejenigen eint, deren Vorstellungen von der guten Schule auseinanderdriften. In den Händen der 〈Falschen〉 wird die Schule - je nach Perspektive - jedoch zur Brutstätte

I Merz, Klaus (20I0). Aus dem Staub. Innsbruck: Haymon.

2 Tucholsky, Kurt (1919). Gesammelte Werke, Band I 1907-1924. Reinbek bei Hamburg: Rowohlt Verlag, S. 45 I-452. 
von «Spiessbürgern» (Tucholsky) oder wegen ihrer «Kuschelpädagogik»3 zum Hemmschuh für einen gelingenden Start ins Berufs- und Gesellschaftsleben. Die Schule ist Projektionsfläche und Prügelmädchen zugleich. An der Schule können sich die Gemüter erhitzen, nicht nur weil alle von Schulerfahrungen etwelcher Art berichten können, sondern auch weil sie mit 〈Heilserwartungen〉 aufgeladen wird.

Man mag mit Tucholskys Ansicht über die Schule nicht einverstanden sein, dem Beginn seines Gedichtes wird man aber dennoch nicht absprechen wollen, die an die Schule gerichtete normative (zivilreligiöse) Erwartungshaltung sowie deren mögliche Gefahren prägnant auf den Punkt gebracht zu haben. Die Verbreitung der Haltung, die Tucholsky in seinem Gedicht zum Ausdruck bringt, historisch aufzuzeigen - zumindest in der öffentlichen Diskussion im Kanton Zürich -, darum geht es in dieser Arbeit.

Diese Arbeit hätte nicht entstehen können ohne eine Vielzahl von Menschen, die mich in den verschiedenen Arbeitsphasen unterstützt haben. Der erste Dank gebührt Prof. Dr. Fritz Osterwalder, Betreuer und Erstgutachter dieser Dissertation. Er hat mich allererst auf die Idee gebracht und mich ermutigt, meine philosophischen und theologischen Interessen im Rahmen einer Dissertation mit meinen historisch-erziehungswissenschaftlichen Fragen zu verbinden. Ohne ihn hätte ich mich nie in dieses Abenteuer gewagt und schon gar nicht in ein Archiv. Seine genaue Lektüre verschiedener Teile meiner Arbeit und die daraus resultierenden kritischen Rückmeldungen und vielen praktischen (Literatur-) Tipps waren enorm wertvoll. Von grösster Bedeutung für mich waren aber die vielen anregenden Gespräche.

Prof. Dr. Elmar Anhalt bin ich zu Dank verpflichtet für die Bereitschaft, das Zweitgutachten der Dissertation zu verfassen, sowie für die Beschäftigung mit meiner Arbeit anlässlich von Kolloquien am Institut für Erziehungswissenschaft in Bern. Frau Claudia Nipp danke ich für die Bereitstellung von Transkriptionen, die sie im Rahmen ihrer Bachelorarbeit erstellt hat. Danken möchte ich auch meinen Kolleginnen und Kollegen am Institut für Erziehungswissenschaft Bern, die mich während meiner Assistenzzeit am Lehrstuhl für Allgemeine und Historische Erziehungswissenschaft zu Beginn der Dissertationsphase in zahlreichen (Apéro-)Gesprächen im Parterre des altehrwürdigen Muesmattschulhauses ins 〈historische Denken〉 eingeführt haben.

Herrn Stefan Kern und Herrn Jonas Gross von der Forschungsbibliothek Pestalozzianum sowie Frau Karin Huser und ihrem Team vom Staatsarchiv Zürich

3 Pieren, Nadja (20I 2). Auftrag der Volksschule: Lebenstauglichkeit, Mitmenschlichkeit, Berufs- und Wirtschaftstauglichkeit. Online verfügbar unter www.svp.ch/news/artikel/referate/ auftrag-der-volksschule-lebenstauglichkeit-mitmenschlichkeit-berufs-und-wirtschaftstauglichkeit (25. 7. 20I8). 
danke ich für ihre stets freundliche und geduldige Unterstützung bei der Suche nach meinen Quellen.

Ein grosser Dank gilt Hans-Rudolf Wiedmer vom Chronos Verlag und seinem Team für die freundliche, flexible und gelassene Form der Zusammenarbeit. Speziell danken möchte ich meinen Eltern, Hans und Marlène KatzensteinHuggel. Sie haben durch ihre liebevolle Erziehung und eine von materiellen Sorgen und Leistungsdruck unbeschwerte Schulzeit den Boden gelegt, Neugierde zu entwickeln, ohne die Wissenschaft keinen Ausgangspunkt hätte. Andere Menschen wertzuschätzen und ihre Denk- und Handlungsweisen zu verstehen, ohne vorschnell zu urteilen, war beiden ein Anliegen. In besonderem Masse habe ich ihnen daher das Interesse und die Fähigkeit, Sachverhalte zu analysieren, die Welt aus verschiedenen Perspektiven zu betrachten und nach Zusammenhängen zu suchen - ebenfalls eine Grundlage wissenschaftlichen Arbeitens -, zu verdanken. Danken möchte ich auch meinen Schwiegereltern Gret und Hans Corrodi-Senn für ihr Interesse, das sie mir und meiner Arbeit entgegengebracht haben, und die daraus resultierenden Gespräche.

«Muesch nöd dä Doktär machä!», sagt man in der Schweiz einem Menschen, der sich intensiv mit einer Sache beschäftigt und etwas ganz präzise machen will. Ich habe «den Doktor gemacht» - und staune manchmal selbst darüber. Dass ich bis zum Schluss durchhielt, war nur möglich dank wunderbaren Menschen, die mir auch in Krisenzeiten auf ihre je eigene Art halfen, den Blick für das Wesentliche nicht zu verlieren bzw. wiederzugewinnen. Ganz besonders nennen möchte ich hier Esther Blessing, Henk Geertsema, Peter Klein, Christian Rutishauser SJ, Sr. Elisabeth Maria Sauter und meine treuen Freundinnen Angela Heller, Cornelia Schnabel, Iris Schröder und Christine Reinhardt.

Zuletzt bleibt noch der Dank an denjenigen Menschen, der mir vor zwölf Jahren versprochen hat, in guten wie in schweren Zeiten $\mathrm{zu}$ mir zu halten: Johannes Corrodi Katzenstein. Seine Unterstützung lässt sich schwer in Worte fassen. Er war wohlwollender Leser und ärgster Kritiker zugleich, anregender und herausfordernder Diskussionspartner in unzähligen Gesprächen zu allen Tages- und Nachtzeiten, massgeblich an der Endredaktion des Manuskripts beteiligt, Troubleshooter bei Computerproblemen. Und vor allem: Er hat die Spannungen mit ausgehalten (und zuweilen gar verschärft), die entstehen, wenn man den Dingen auf den Grund gehen und Ambivalenzen nicht einfach einseitig auflösen will. 


\section{$1 \quad$ Einleitung}

\subsection{Gesellschaftliche Erwartungen an eine gesellschaftliche Einrichtung}

«Internet wird zur Sex-Falle für Kinder - Pro Juventute fordert Schulfach Facebook», titelte der Blick im Jahre 2013. "Jugendliebe ohne Respekt. Gewaltprävention an der Schule», ${ }^{2}$ hiess ein Artikel der Neuen Zürcher Zeitung (NZZ) im Januar 20I6. Und die Luzerner Zeitung vom September 2017 schrieb gar: «Schwingen soll in den Schulsport». ${ }^{3}$ Die Erwartungen an die öffentliche Schule sind vielfältig. Die Erwartungen an die öffentliche Schule sind hoch. Nebst den grundlegenden Kulturtechniken wie Lesen, Schreiben, Rechnen wird Gesundheitsvorsorge, Gewaltprävention, der rechte Umgang mit neuen Informationstechnologien, mit Sexualität und Geld oder die Förderung einer traditionellen schweizerischen Sportart wie das Schwingen gefordert. Vielleicht liegt es in der Natur der öffentlichen Schule, dass sie hohe Erwartungen weckt. In der Schweiz besucht die Mehrheit aller Kinder die öffentliche Schule. Es mag deshalb naheliegend erscheinen, von dieser Institution zu erhoffen, die meisten zukünftigen Bürgerinnen und Bürger und erwachsenen Mitglieder der Gesellschaft zu erreichen und im richtigen Geist erziehen und bilden zu können. Die lange Liste dessen, was die Schule alles leisten soll, erstaunt deshalb nicht. Ebenso wenig erstaunt es, wenn kritisiert wird, die Schule werde mit Anforderungen überladen. ${ }^{4}$

Die vorliegende Arbeit stellt eine ganz bestimmte Art normativer Erwartungen in den Fokus, die an die öffentliche Schule herangetragen werden und die sich in Form von solchen Schlagzeilen ausdrücken wie: «Die Schule als Integrationsfabrik» ${ }^{5}$ oder "Schule soll christliche Werte vermitteln». ${ }^{6}$ Es ist eine Erwartungshaltung, die ihren Nährboden im Spannungsfeld von gesellschaftlicher Ausdifferenzierung und Religionsfreiheit einerseits und im Bemühen um poli-

I Blick, 9. 2. 2013, www.blick.ch/news/schweiz/internet-wird-zur-sex-falle-fuer-kinder-projuventute-fordert-schulfach-facebook-id2 198988.html (30. I. 2018).

2 NZZ, 22. I. 2016.

3 Luzerner Zeitung, 4. 9. 2017, www.luzernerzeitung.ch/nachrichten/zentralschweiz/zug/ schwingen-soll-in-den-schulsport;artI78322, I095443 (30. I. 2018).

4 Das Phänomen hoher Erwartungen an die öffentliche Schule ist allerdings nichts Neues, wenn man zum Beispiel an Heinrich Zschokkes bekannte Rede «Volksbildung ist Volksbefreiung» denkt, die er I 836 vor dem Volksbildungsverein in Lausen hielt (Zschokke I 836).

5 NZZ, 4. 12. 2015.

$6 \mathrm{NZZ}, 23 \cdot 3 \cdot 2008$. 
tische Einheit und gesellschaftliche Integration bzw. Kohäsion andererseits hat. Ich nenne diese Erwartungshaltung zivilreligiös. Sie gedeiht dort, wo zum einen die Trennung von Bürgerrecht und Bekenntnispflicht als moderne, freiheitliche Errungenschaft erachtet wird, die es zu schützen gilt, zum andern aber zugleich der Verlust der politischen Einheit und Stabilität befürchtet wird, weil ein auf religiös-weltanschaulicher Ebene vereinheitlichendes Band fehlt. Seit die öffentliche Schule nicht mehr unter kirchlicher, sondern unter staatlicher Aufsicht steht, wurde - so die hier vertretene Ausgangsthese - eine solch einheitsstiftende Funktion bis heute immer wieder von der öffentlichen Schule erwartet.

Die an die Schule gerichtete normative Erwartungshaltung steht in engem Zusammenhang mit den im Laufe der Zeit sich verändernden Vorstellungen darüber, wer für Bildung und Erziehung der Kinder zuständig sein soll Familie, Kirche, Staat oder ist es eine Aufgabenteilung dieser unterschiedlichen Institutionen? Einen informativen Überblick in diese Thematik gibt Lucien Criblez' Einleitung zum Sammelband Bildungsraum Schweiz. ${ }^{7}$ Der Staat hat sich gemäss Criblez als Träger der Schule in den Nationalstaaten des i9. und 20. Jahrhunderts durchgesetzt. Doch wurde dessen Legitimation «als Schulträger und Schulorganisator» immer wieder auch in Frage gestellt. Dies «zunächst vor allem von kirchlicher Seite, später auch von anderen, meist weltanschaulich orientierten Schulträgern». ${ }^{8}$ Der Philosoph Walther Ch. Zimmerli sieht in Zukunft «neben Kirche und Staat auch zunehmend privatwirtschaftliche Einrichtungen als Treiber und Betreiber von Bildungsinstitutionen». ${ }^{9}$ Gemäss Criblez wurde die letzte grosse Debatte zu dieser Thematik von der neoliberalen Wirtschaftstheorie angestossen. Die Ökonomen Thomas Straubhaar und Manfred Winz (1992) forderten zu Beginn der I990er Jahre in ihrer Studie des schweizerischen Bildungswesens aus ökonomischer Sicht die Privatisierung desselben. ${ }^{10}$ Mit der sogenannt freien Schulwahl wird vom Staat eine andere Funktion gefordert. So soll dieser nicht alleiniger Träger der Schule sein, sondern alle Trägerschaften der Schule (staatliche und private) in gleicher Weise finanzieren, so dass die Eltern ohne finanzielle Einschränkungen für ihre Kinder unter verschiedenen Schulangeboten das ihnen passende wählen können. Criblez weist darauf hin, dass die Legitimation des Staates als Schulträger und -organisator zuerst von kirchlicher Seite hinterfragt worden war. ${ }^{11}$

Dieser Hinweis scheint mir wichtig, damit in der von neoliberalem, ökonomischem Denken dominierten aktuellen Diskussion dieser Thematik nicht der

7 Vgl. Criblez 2008b.

8 Criblez 2008b, I0.

9 Zimmerli 2006, I7; vgl. auch Criblez 2008b, 9.

ı० Straubhaar/Winz i 992; vgl. auch Criblez 2008b, ı०.

I I Criblez 2008b, io. 
religiös-weltanschauliche Gesichtspunkt vergessen geht. Ein kurzer Blick auf die Entwicklung des niederländischen Schulsystems zeigt, dass die Forderung nach finanzieller Gleichstellung der sprivaten> konfessionellen Schulen mit der Staatsschule nicht von ökonomischen Gedanken geleitet war, sondern von weltanschaulich-religiösen. Während in Frankreich zur Zeit der Revolution das Projekt einer republikanischen staatlichen Einheitsschule am Widerstand der Eltern scheiterte, setzte es sich in den Niederlanden ganz zu Beginn des I9. Jahrhunderts durch. ${ }^{12}$ Mit dem Wiederaufleben orthodox calvinistischer Lehren um I 820 kam es zum sogenannten Schulstreit, weil die orthodox protestantischen Eltern Mühe gegenüber der in der Staatsschule vermittelten aufklärerischen, deistischen, vorgeblich allgemeinen Religion bekundeten und den König um Erlaubnis baten, auf eigene Kosten konfessionelle Schulen gründen zu dürfen. Diese Bitte erfüllte der König jedoch nicht. Als Folge dieses Schulstreites wurden I9I7 die privaten konfessionellen Schulen mit der Staatsschule gleichgestellt. ${ }^{13}$ In diesem niederländischen Schulstreit spiegelt sich der Konflikt zwischen staatlich-weltanschaulichen und religiös-weltanschaulichen Ansprüchen an die Schule. Die Indienstnahme der Schule zu staatlichen Zwecken, das heisst zur Bildung einer nationalen Einheit, hat durch die Vermittlung einer scheinbar für alle gültigen allgemein menschlichen Religion unverkennbar eine bestimmte Homogenisierung zum Ziel, die mit einem spezifisch christlichen Glaubensverständnis im Konflikt steht.

Mit der Indienstnahme der öffentlichen Schule zu staatlichen Zwecken beschäftigen sich beispielsweise auch die Bildungshistoriker Fritz Osterwalder und

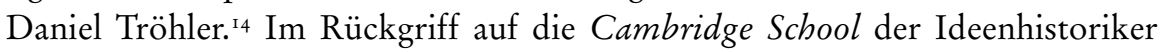
John G. A. Pocock und Quentin Skinner bedienen sie sich dazu beide des Topos Republikanismus. Pococks Ansatz - die «Sprache des Republikanismus» - dient Tröhler in seinem Buch Republikanismus und Pädagogik dazu, das Verhältnis

I 2 Vgl. Glenn 2002, 23-3 I (zu Frankreich) und 38 ff. (zu den Niederlanden).

I3 Vgl. Hardegger 2005, I6; vgl. Glenn 2002, 53. Gemäss Glenn stellte der politische Führer der orthodoxen Protestanten, Guillaume Groen van Prinsterer (I80I-I 876), das Problem zu Beginn des Schulstreites folgendermassen dar: Aus der Erziehung als einem in der Verfassung festgeschriebenen staatlichen Interesse sei Erziehung zu einem Gegenstand staatlicher Kontrolle geworden. Dies mit dem angeblichen Ziel, die nationale Einheit zu gewährleisten. Mit dem Ziel eines friedlichen und einheitlichen Miteinander sollte in der öffentlichen Schule «a general religion, a Deism with Christian vocabulary and coloration» (van Prinsterer zit. in Glenn, 53) gelehrt werden. Für orthodoxe Christen war eine solche Lehre nicht akzeptabel, da Gott nicht unabhängig von Christus erkannt werden kann. Die Folge einer intendiert nicht konfessionellen Schule war, dass sie sich gegen alle Arten des Christentums richtete (vgl. ebd.). Es ist bemerkenswert, dass die Niederlande im I9. Jahrhundert als Vorbild für eine staatliche Einheitsschule galten und im 20. Jahrhundert als Vorbild für staatlich finanzierte Privatschulen (vgl. ebd., $3^{8}$ ).

I4 Vgl. ebenfalls De Vincenti/Grube 20 I I. 
von Politik und Pädagogik bei Pestalozzi zu verdeutlichen. ${ }^{\text {ss }}$ Tröhler bemerkt kritisch, dass, obwohl im Zentrum des Republikanismus das Ideal des citizen bzw. Fragen nach der bürgerlichen Tugend gestanden seien, die Bedeutung des Republikanismus für die Pädagogik bisher noch nicht adäquat bearbeitet worden sei. Ebenfalls mit explizitem Bezug auf Pocock vertritt Osterwalder in seinem Buch Demokratie, Erziehung und Schule die These, dass sich im I 8. Jahrhundert «im Rückgriff auf den antiken und humanistischen Republikanismus» ${ }^{16}$ ein Verständnis des Verhältnisses von Politik und Erziehung herausgebildet habe, das auch noch in aktuellen bildungspolitischen Diskussionen wirksam sei. Diese These prüft Osterwalder an pädagogischen Problemen der Gegenwart; beispielsweise an der Frage nach der «Moral als Lerngegenstand der Schule», der «Demokratisierung durch Schule», der «Trägerschaft der Bildung» oder der «Einheitlichkeit der Bildung». ${ }^{17}$ Tröhler zielt in dieselbe Richtung, wenn er in seinem Aufsatz Classical Republicanism, Local Democracy, and Education am Beispiel der Entwicklung der öffentlichen Schule im Kanton Zürich zwischen I 770 und I 870 Motive des klassischen Republikanismus aufspürt. Er spitzt die Sache jedoch noch zu, wenn er die These aufstellt, dass «in the process of institutional secularization and democratization the religious energy behind this process was not eclipsed but rather was (partly) translated into the sanctification of the democratic republic - or the Promised Land in which public education was to play a crucial role». ${ }^{18}$

Gemäss Tröhler geschah die Indienstnahme öffentlicher Erziehung zur Verbreitung republikanischer Ideale sowohl von Seiten des aristokratisch-elitären Republikanismus wie auch des demokratischen Republikanismus. Der aristokratisch-elitäre Republikanismus stellte zwar das aristokratische System auf institutioneller Ebene nicht in Frage, wollte es aber durch die Tugendhaftigkeit der politischen Führer legitimiert sehen. Der demokratische Republikanismus hingegen forderte gleiche demokratische Mitbestimmungsrechte für alle Bür-

is Vgl. Tröhler 2006, 9.

I6 Osterwalder 20I I.

17 Ebd.

I8 Tröhler 20I I, I 54. Tröhler führt in seinem Text nicht aus, was er mit «sanctification» meint. Indem er jedoch die Entwicklung der Zürcher Volksschule in den Kontext des «Zwinglianismus» stellt, ist davon auszugehen, dass dieser Ausdruck von daher zu interpretieren ist. Zwingli wollte den Staat vom Wort Gottes geleitet haben und wies den Pfarrern das Wächteramt zu (vgl. Schmid I 994, I 99). Bis ins I 8. Jahrhundert kann in Zürich von einer Staatskirche gesprochen werden. Man sprach von der «alleinseligmachenden reformierten Kirche», die durch die Erstarrung der reformatorischen Bewegung nur noch durch Zwangsmassnahmen meinte, bewahrt werden zu können (vgl. Schmid I994, 200). Durch den institutionellen Säkularisierungsprozess wurde, so interpretiere ich Tröhler, die demokratische Republik an die Stelle der himmlischen gesetzt. Zu klären wäre, ob und gegebenenfalls wie der Ausdruck «sanctification» bzw. Heiligung in jener Zeit von den relevanten Akteuren selbst verwendet wurde. 
ger - nicht nur für diejenigen der Stadt, sondern auch für die Landbürger. Der Hauptzweck der Schule wurde folglich auch nicht mehr in der Bildung und Erziehung zur Tugendhaftigkeit der zukünftigen Führungselite der Republik gesehen. ${ }^{19}$ Obwohl die republikanische Rhetorik in Diskussionen über die öffentliche Schule eine lange Tradition hatte, fand sie während der liberalen Ära der repräsentativen Demokratie keinen Eingang auf Gesetzes- oder Verfassungsebene. Erst mit der neuen Kantonsverfassung von i 869 wurden die erzieherischen Ambitionen des Republikanismus auch offiziell implementiert. So wurde in Art. 62 der Kantonsverfassung von i 869 nicht bloss «die Förderung der allgemeinen Volksbildung» als staatliche Aufgabe festgeschrieben, sondern ebenso die Förderung «der republikanischen Bürgerbildung». ${ }^{\circ}$

Der Grund dafür, dass in der vorliegenden Arbeit nicht Republikanismus als zentraler Topos verwendet wird, sondern Zivilreligion, ist nicht darin zu suchen, dass damit auf einen gänzlich anderen Sachverhalt verwiesen werden soll, als beispielsweise Tröhler oder Osterwalder in ihren diesbezüglichen Untersuchungen vor Augen haben: die Indienstnahme der öffentlichen Schule zu staatlichen Zwecken. Indem hier nach normativen Erwartungen zivilreligiöser Art gefragt wird, die an die öffentliche Schule herangetragen werden, soll der Fokus expliziter auf die weltanschaulich-religiöse Dimension gelenkt werden. Diese Dimension streift Tröhler bei seiner Suche nach dem klassischen Republikanismus in der Entwicklung der öffentlichen Schule im Kanton Zürich nur am Rande, wenn er beispielsweise von der «sanctification of the democratic republic» spricht. Mit dem Topos Zivilreligion rücken auch die religiösen Ressourcen, deren sich der Staat bedient, in den Blick.

\subsection{Forschungsziel und Fragestellung}

Diese Arbeit verfolgt ein doppeltes Forschungsinteresse. Das primäre Forschungsziel hat einen erziehungshistorischen Fokus. Es besteht in der Darstellung und Analyse öffentlicher Diskussionen um den schulischen Religionsunterricht um I872 und um 2004 im Kanton Zürich. Um I872 wurde im Zusammenhang mit einem neuen Unterrichtsgesetz über die Abschaffung des konfessionell-dogmatischen Religionsunterrichts diskutiert. Um 2004 bot die geplante Abschaffung des Faches Biblische Geschichte im Zusammenhang mit Sparmassnahmen und die Einführung des obligatorischen Schulfaches Religion und Kultur Anlass zu regen öffentlichen Diskussionen. Die diese Arbeit leiten-

I9 Vgl. Tröhler 20I I, I 54 .

20 Verfassung des eidgenössischen Standes Zürich vom I 8. April I 869, Art. 62. Vgl. Tröhler 20I I, I $63 \mathrm{f}$. 
den Fragen, die sich im Zusammenhang mit meinem zu Beginn ausgeführten grundsätzlichen Erkenntnisinteresse stellen, sind folgende:

- Inwiefern und auf welche Weise manifestieren sich im Kanton Zürich in den öffentlichen Diskussionen um den schulischen Religionsunterricht in den Jahren um I 872 und um 2004 zivilreligiöse Erwartungen an die öffentliche Schule?

- Wo zeigen sich im inhaltlichen Vergleich der beiden Diskussionen Kontinuitäten und Diskontinuitäten?

Der schulische Religionsunterricht steht im Fokus, weil ich davon ausgehe, dass zivilreligiös aufgeladene Erwartungen an die öffentliche Schule in potenzierter Form im Zusammenhang mit dem schulischen Religionsunterricht manifest werden. Dies bedeutet jedoch keineswegs, dass diese Art normativer Erwartungshaltung nicht auch im Zusammenhang mit anderen Fächern zum Ausdruck kommen kann. ${ }^{21}$

Das sekundäre Forschungsziel hat einen mehr gesellschaftsphilosophischen Charakter und besteht darin, mögliche Probleme einer mit zivilreligiösen Erwartungen aufgeladenen öffentlichen Schule zu identifizieren. Diesen Themenbereich werde ich ausblicksartig und in knapper Form am Schluss der Arbeit aufgreifen.

Die Untersuchungen führen mich am Ende der vorliegenden Arbeit zu folgendem Ergebnis: In der Diskussion über den schulischen Religionsunterricht im Kanton Zürich um I 872 manifestiert sich die distinkt zürcherische Form von Zivilreligion im Gewand der liberalen Theologie. Die Analyse der Diskussion über den schulischen Religionsunterricht zu Beginn des 2I. Jahrhunderts führt $\mathrm{zu}$ folgendem Befund: Zwei Formen von Zivilreligion können ausgemacht werden - eine liberaltheologische und eine aufklärerisch-freidenkerische. Die liberal-theologische Form ist bereits aus dem 19. Jahrhundert bekannt. Die aufklärerisch-freidenkerische hat sich auch bereits im 19. Jahrhundert mit beispielsweise einer Figur wie Johann Caspar Sieber angebahnt, fand aber damals noch keine grossflächige Verbreitung. Beiden Formen von Zivilreligion gemeinsam ist ein gewisses Streben nach gesellschaftlicher Homogenisierung und die Indienstnahme der öffentlichen Schule zu einem überhöhten Zweck, indem von der Schule Friedensförderung oder gesellschaftliche Integration erwartet wird.

2I So rief zum Beispiel das vom Erziehungsrat beauftragte Geschichtslehrmittel des theologisch-liberalen Pfarrers Friedrich Salomon Vögelin in den Jahren I 874/75 einen grossen Sturm der Entrüstung hervor (vgl. Greiner 1933, I03 f.). Als Parallele in neuerer Zeit sei auf die Kontroverse um das im Jahr 2006 erschienene Geschichtslehrmittel Hinschauen und Nachfragen verwiesen, dem die Erkenntnisse der Unabhängigen Expertenkommission Schweiz - Zweiter Weltkrieg (UEK) zu Grunde liegen. Die Ergebnisse dieses Expertenberichts stiessen auf nationalkonservativer Seite auf Kritik, die sich auch gegen das Lehrmittel richtete (vgl. Sperisen/ Schär 20I3, I89 f.). 
Im gesellschaftsphilosophischen Teil der Arbeit werden folgende drei Thesen formuliert und ansatzweise erläutert: I) Zivilreligiöse Erwartungen haben die öffentliche Schule primär als Erziehungsinstitution im Blick und sind somit Ausdruck totalisierender Tendenzen (Unterkapitel I I.I). 2) Die zur Evokation gesellschaftlicher Einheit bemühte Rede von Werten ist semantisch unbestimmt und steht in der Gefahr, reale Machtverhältnisse und machtförmige Interessen zu überdecken (Unterkapitel I I.2). 3) Zivilreligiöse Tendenzen stehen pluralistischen Tendenzen entgegen und gefährden eine echte Multikulturalität und Multireligiosität (Unterkapitel I I.3). Dieser Teil der Arbeit ist primär als Impuls für weitergehende Diskussionen gedacht und erhebt nicht den Anspruch, dieses Themenfeld zu durchleuchten.

\subsection{Anlage der Untersuchung und Vorgehensweise}

Obwohl im Zentrum dieser Untersuchung öffentliche Diskussionen zum schulischen Religionsunterricht stehen, interessiert hier nicht der schulische Religionsunterricht per se. Diese Arbeit hat keine religionspädagogischen Ambitionen, obwohl sie zentrale Gedanken und Einsichten namhaften Religionspädagogen zu verdanken hat. Diese Studie hat vielmehr den Anspruch, durch die Analyse dieser Diskussionen exemplarisch zur kritischen Reflexion über - auch aktuelle - normative Erwartungen an die öffentliche Schule anzuregen. Die gewählte historische Zugangsweise basiert auf der Annahme, dass ohne das Wissen darüber, wie das, was ist, geworden ist, gegenwärtige Vorstellungen hinsichtlich des normativen Auftrags der öffentlichen Schule weder verstanden noch beurteilt noch diesbezüglich verantwortbare Entscheide gefällt werden können.

In dieser Untersuchung werden zwei Zeitpunkte herausgegriffen - die Jahre um I 872 und um 2004. Der Zeitpunkt i 872 wurde gewählt, weil die Diskussionen rund um das neue Schulgesetz, das im April i 872 vors Volk kam, in engem Zusammenhang mit der im Jahre i 869 angenommenen neuen Kantonsverfassung stand. Der Zeitpunkt 2004 wurde gewählt, weil im September 2004 eine Volksinitiative eingereicht wurde, die die Beibehaltung des Schulfaches Biblische Geschichte verlangte, das aus Spargründen abgeschafft werden sollte. Unabhängig von Spargedanken wurde bereits im Jahr 2002 eine bildungsrätliche Kommission für ein für die Oberstufe geplantes neues Schulfach namens Religion und Kultur eingesetzt, das dann gemäss einem bildungsrätlichen Beschluss des Jahres 2006 auch für die Primarstufe für obligatorisch erklärt worden ist.

Der Vergleich zweier öffentlicher Diskussionen mit ihren unterschiedlichen historischen Kontexten ist spannend und problembehaftet zugleich. Ein solcher Vergleich ermöglicht die Sichtbarmachung von Kontinuitäten und Brüchen. In 
aktuellen Diskussionen über den normativen Auftrag der öffentlichen Schule Denkmuster des 19. Jahrhunderts auszumachen, mag durch die Erkenntnis des Ausmasses der Verhaftung der Gegenwart im I9. Jahrhundert ernüchternd wirken. Zugleich lässt sich der untersuchte Zeitraum durch den Kontrast mit einer anderen Zeit sowie durch das Herausarbeiten von Unterschieden besser verstehen. Die Problematik eines solchen Vergleichs besteht in der Frage nach der vielleicht nicht unmittelbar ersichtlichen Vergleichbarkeit von Diskussionen, die in verschiedenen historischen Situationen stattgefunden haben. Ein solcher Vergleich erfordert deshalb in besonderer Weise die historische Kontextualisierung der zwei zu analysierenden Diskussionen. Dies bedeutet, dass sowohl die Vor- und Nachgeschichten dieser Diskussionen berücksichtigt werden müssen (vgl. Kapitel 5 und 8) als auch die Diskussionen in die jeweiligen gesellschaftlichen, politischen und religionspolitischen Situationen einzubetten sind (vgl. Kapitel 3 und 4).

Ob Geschichtswissenschaft dazu dienen kann und soll, dass sich aus der Geschichte lernen lässt, will ich hier nicht beurteilen. Diese Arbeit hat einen bescheideneren Anspruch: Sie soll als eine Art Auslegeordnung verstanden werden, die einen Beitrag dazu leistet, aktuelle Diskussionen besser zu verstehen, und im besten Falle ein Problembewusstsein für normative Erwartungshaltungen an die öffentliche Schule weckt.

Diese Auslegeordnung entsteht durch die Analyse der öffentlichen Diskussionen im 19. und 21. Jahrhundert, die je in zwei Schritten erfolgt. In einem ersten Schritt werden die diskutierten Hauptpunkte benannt und die verschiedenen Argumente dargestellt (vgl. Kapitel 6 und 9). In einem zweiten Schritt werden die entsprechenden Diskussionen nach zivilreligiösen Tendenzen abgesucht (vgl. Kapitel 7 und Io). Der diachrone Vergleich findet jeweils direkt bei der Darstellung der Diskussion des 2I. Jahrhunderts statt.

Der Begriff der Zivilreligion dient in dieser Arbeit als heuristische Brille, um herauszukristallisieren, welche Erwartungen in den Diskussionen um den schulischen Religionsunterricht zu den zwei Untersuchungszeitpunkten von den verschiedenen beteiligten Akteuren - politische, kirchliche, schulische, private - an die öffentliche Schule herangetragen wurden. In der einschlägigen und überaus umfangreichen Literatur zur Thematik Zivilreligion ist kein Konsens über die Definition dieses Begriffs auszumachen. Deshalb muss meine Verwendung des Ausdrucks zu Beginn erläutert werden, damit sie ihren Zweck als Analyseinstrument erfüllen kann (vgl. Kapitel 2). Die Auseinandersetzung mit diesem Ausdruck und den damit einhergehenden Begriffen und ihren jeweiligen Entstehungskontexten, die angesichts der Fülle von Literatur jedoch keinesfalls erschöpfend zu sein beansprucht, hat zum Ziel, den Blick zu schärfen für die spezifische Situation im Kanton Zürich. Da der Begriff der Zivilreligion 
in anderen historischen Kontexten entwickelt worden ist und unterschiedliche Entwicklungslinien sichtbar sind, kann dieser Begriff für die Zürcher Situation nicht einfach übernommen werden, sondern muss ausgehend von der anfänglichen Bestimmung durch eine genaue Betrachtungsweise der Situation im Kanton Zürich entfaltet werden.

Eine solche Vorgehensweise kann allfälligen Einwänden methodischer Art entgegengehalten werden. Ein solcher Einwand könnte darin bestehen, dass der Ausdruck Zivilreligion zu Beginn so definiert wird, dass er in den Diskussionen dann auch tatsächlich zu finden ist. Diesem Einwand kann entgegnet werden, dass durch die fluide Verwendungsweise dieses Ausdrucks nicht die Situation einem Begriff angepasst wird, sondern umgekehrt. Ein zweiter Einwand könnte die durch den Begriff Zivilreligion in gewisser Hinsicht vorgegebene Blickrichtung betreffen, die - so der mögliche Einwand - eine adäquate Erfassung der Diskussionen verunmögliche. Einem solchen Einwand ist mit der dieser Untersuchung zu Grunde liegenden geschichtsphilosophischen Grundhaltung zu begegnen: Geschichtswissenschaft betrachte ich nicht als eine rein deskriptive Wissenschaft. Und wenn keine reine (historische) Beobachtung möglich ist, dann kann auch keine historische Untersuchung perspektivenlos erfolgen. Durch die anfängliche Begriffsbestimmung kann aber zumindest die Perspektive transparent gemacht werden. Da ich unter dem Begriff Auslegeordnung eine möglichst sachliche Darstellung verstehe, aber nicht in die entgegengesetzte Falle der präskriptiven Haltung tappen will, scheint es mir wichtig, meine Verwendung grundlegender Begriffe zu Beginn transparent zu machen.

\subsection{Klärung verwendeter Grundbegriffe}

Da ich dem in dieser Untersuchung in heuristischer Absicht verwendeten Ausdruck Zivilreligion ein eigenes Kapitel widme (vgl. Kapitel 2), gehe ich an dieser Stelle nicht weiter darauf ein. Bei den anderen im Folgenden explizierten Ausdrücken werde ich mich auf die Darstellung der Art und Weise, in der ich sie in dieser Arbeit verwende, beschränken. Auf die Geschichte und Bedeutungsvielfalt der jeweiligen Begriffe einzugehen, ist im Rahmen dieser Arbeit nicht möglich.

\section{Religion und Weltanschauung}

Über den Religionsbegriff gibt es bekanntlich keinen Konsens, weder unter Theologinnen noch unter Religionswissenschaftlern noch unter Philosophinnen. Gemeinhin wird Religion mit Gott oder Göttern und kultisch-rituellen Formen in Verbindung gesetzt, während davon ausgegangen wird, dass Weltanschauun- 
gen zur Deutung der Gesamtwirklichkeit ohne jeglichen Transzendenzbezug auskämen. ${ }^{22}$ Der Pythagoräismus, in dem die als göttlich betrachteten Zahlen angebetet wurden, ${ }^{23}$ oder Karl Marx, der das Bewusstsein als göttlich bezeichnete, ${ }^{24}$ sind bloss zwei Beispiele, die illustrieren sollen, dass diese Unterscheidung allerdings nicht so trennscharf ist. Das Verständnis von Religion und Weltanschauung des evangelischen Theologen Eilert Herms scheint mir dagegen sehr einleuchtend und ich werde dieses hier übernehmen. Nach Herms bezeichnen die beiden Begriffe zwar nicht dasselbe, doch sind sie in funktionaler Hinsicht «identisch» ${ }^{25}$ oder zumindest «Spielarten desselben». ${ }^{26}$ Beide Begriffe beziehen sich auf «Gewissheiten bzw. Überzeugungen über den Ursprung, die Verfassung und Bestimmung der Welt und des menschlichen Daseins in ihr, die innerhalb des menschlichen Lebens zielwahlorientierend fungieren». ${ }^{27}$

Während jeder Mensch eine Weltanschauung besitzt, die freilich äusserst vage oder sogar unbewusst sein kann, trifft dies für die Religion nicht zu. Nicht jede Weltanschauung ist eine Religion, hingegen ist jede Religion eine Variante von Weltanschauung. Religion unterscheidet sich von anderen, nicht religiösen Weltanschauungen oft dadurch, dass sie auch den kultischen Aspekt und den mehr oder weniger bewussten Glauben an etwas, das als göttlich erachtet wird, einschliesst. Herms drückt dies folgendermassen aus: «Religiöse Überzeugungen sind lediglich durch ein gemeinsames Inhaltsmerkmal verbundene Elemente aus der Klasse weltanschaulicher Überzeugungen, nämlich solche, die nicht die Auskunft über den Ursprung des Daseins verweigern. Aber das Themenspektrum (die universale Verfassung von Welt und Mensch, ihr Ursprung und ihre Bestimmung), die Funktion (Orientierung von Zielwahlen) und die Konstitution (nicht aus Beobachtung, sondern aus der Besinnung auf das Selbsterleben) ist bei allen Religionen dasselbe wie bei Weltanschauungen.» ${ }^{28}$

22 Vgl. Herms i 999, $22 \mathrm{I}$.

23 Der den Zahlen von den Pythagoräern zugeschriebene göttliche Status drückt sich beispielsweise im Gebet an die Zahl Zehn aus: «Bless us, divine number, thou who generatest gods and men! O holy, holy tetraktys, thou that containest the root and the source of the eternally flowing creation! For the divine number begins with the profound, pure unity until it comes to the holy four; then it begets the mother of all, the all-comprising, the all-bounding, the first-born, the never-swerving, the never-tiring holy ten, the keyholder of all.» (Dantzig I967, 4I).

24 In der Vorrede zu seiner Dissertation schreibt Karl Marx: «Die Philosophie verheimlicht es nicht. Das Bekenntnis des Prometheus: haplô logô, tous pantas echthairô theous [mit einem Wort, ich hasse alle Götter] ist ihr eigenes Bekenntnis, ihr eigener Spruch gegen alle himmlischen und irdischen Götter, die das menschliche Selbstbewußtsein nicht als die oberste Gottheit anerkennen. Es soll keiner neben ihm sein.» (Marx 1983, 46).

25 Herms I999, 22 I.

26 Ebd., I73.

27 Ebd., $22 \mathrm{I}$.

28 Herms 2002, I7. 
Herms' Verständnis von Weltanschauung und Religion ist eingebunden in eine Handlungstheorie. So bindet er die Handlungsfähigkeit einer Person einerseits an ein empirisches Verständnis der konkreten Handlungssituation und andererseits an bestimmte Grundannahmen bezüglich Herkunft, Beschaffenheit und Ziel menschlichen Lebens sowie der Welt. Was eine Person sich als Ziel setzt und welche Handlungen sie zur Erreichung dieses Zieles vollzieht bzw. unterlässt, ist nach Herms abhängig von diesen Grundannahmen. Deshalb kann Herms «Weltanschauung bzw. Religion als Bedingungen der menschlichen Handlungsund Interaktionsfähigkeit» ${ }^{29}$ betrachten und ich folge ihm hierin. Daraus folgt, dass es keine menschlichen Aktivitäten gibt, die weltanschaulich-religiös neutral sind..$^{\circ}$ Diese Sichtweise ist für diese Arbeit insofern von Bedeutung, als bei der Analyse der Situation immer auch die weltanschaulich-religiösen Grundannahmen der jeweiligen an der Diskussion beteiligten Akteure mitberücksichtigt werden müssen. ${ }^{31}$

\section{Gesellschaft, Staat, Öffentlichkeit}

Den Begriff Gesellschaft verwende ich im Sinne Niklas Luhmanns als ein soziales System, das aus verschiedenen Teilsystemen besteht, die entsprechend spezifischer Funktionen ausdifferenziert sind. Gesellschaft kann insofern nur als Verhältnis seiner Teilsysteme bzw. Sphären gefasst werden. Luhmann spricht aber auch von der «Gesamtgesellschaft», die er als «soziale Umwelt jedes ihrer Teilsysteme» versteht, und betont, dass auf dieser Ebene «die Funktionen nicht differenziert werden» können. ${ }^{32}$ In diesem Sinn fungiert der Begriff der Gesamtgesellschaft nicht als deskriptiv empirischer Begriff, sondern als Grenzbegriff. Dieses Gesellschaftsverständnis hat einen direkten Einfluss auf das Verständnis des Begriffs der Zivilreligion wie in Unterkapitel 2.5 noch genauer erläutert wird.

Den Staat verstehe ich als eine gesellschaftliche Sphäre - die rechtlich-politische - und nicht als eine die anderen gesellschaftlichen Sphären umfassende, höhere Sphäre. Das Proprium dieser Sphäre besteht darin, die anderen gesellschaftlichen Teilsysteme in rechtlicher (und nicht in ethischer oder religiöser) Hinsicht zu integrieren. Dies geschieht, indem der Staat Rahmenbedingungen für den geregelten Austausch zwischen den verschiedenen gesellschaftlichen Sphären schafft. Das von mir vertretene Staatsverständnis wird in Unter-

29 Herms I 999, 22 I.

30 Vgl. ebd., 232; hierzu auch Clouser 2005 .

3 I Fritz Osterwalder und Karl Weber nennen dies Programmatik (vgl. Osterwalder/Weber 2004, I 2).

32 Luhmann 2004, I $86 \mathrm{f}$. 
kapitel I I.I gestützt auf den politischen Philosophen Jonathan Chaplin noch vertiefter dargestellt.

Der Begriff der Öffentlichkeit ist eng verwandt mit dem Begriff der Gesellschaft. Die eine Öffentlichkeit gibt es ebenso wenig wie die Gesellschaft. Mit der gesellschaftlichen Ausdifferenzierung muss auch von einer Vielfalt von Öffentlichkeiten ausgegangen werden. ${ }^{33}$ So gibt es politische, religiöse, ökonomische usw. Öffentlichkeiten. Innerhalb dieser Bereiche sind natürlich weitere institutionelle Öffentlichkeiten zu spezifizieren. Zudem durchdringen sich diese Öffentlichkeiten wechselseitig. Dies zeigt sich insbesondere am Einfluss der medialen Öffentlichkeit. Doch auch die mediale Öffentlichkeit, die meist im Blick ist, wenn der Ausdruck Öffentlichkeit verwendet wird, ist wesentlich verknüpft mit Medieninstitutionen. Somit ist auch die mediale Öffentlichkeit Teil einer bestimmten gesellschaftlichen Sphäre und nicht identisch mit der Gesamtgesellschaft. Diese kurze Klärung der Verwendungsweise des Begriffs Öffentlichkeit hat keinerlei Anspruch, auch nur annähernd einen Überblick der Debatte um den Begriff der Öffentlichkeit zu bieten. Sie hat primär den Zweck, darauf aufmerksam zu machen, dass die Rede von der Öffentlichkeit mit ihrem einheitsevozierenden Charakter bereits einen symbolischen Gehalt transportiert, der analytisch zu hinterfragen ist.

\section{Säkularität versus Säkularismus bzw. säkular versus säkularistisch}

Ich orientiere mich bei der Klärung dieser Ausdrücke primär am Werk des Philosophen Charles Taylor sowie am evangelischen Theologen Ingolf U. Dalferth. Taylor bezeichnet die klassischen Säkularisierungsthesen von Emile Durkheim und Max Weber als Subtraktionstheorien, weil sie auf der Annahme eines Kausalzusammenhangs zwischen Moderne und Säkularität basieren, der die moderne Zivilisation mit dem Wegfall religiöser Illusionen und die Erkenntnis beschränkender Horizonte erklärt. Taylor erachtet es jedoch nicht als Widerspruch, modern und religiös zugleich zu sein, und ich folge ihm hierin. ${ }^{34}$ Taylor unterscheidet in seinem monumentalen Werk A Secular Age verschiedene Verwendungsweisen des Ausdrucks Säkularisierung bzw. Säkularität (secularity). Säkularität kann zum einen im Sinne der Trennung von Kirche und Staat bzw. einer Ausdifferenzierung der gesellschaftlichen Sphären verstanden werden. In einer zweiten Bedeutung ist mit Säkularität auch ein Rückgang des traditionellen christlichen Glaubens und der Glaubenspraxis gemeint, der sich konkret zum Beispiel darin zeigt, dass immer weniger Menschen Gottesdienste besuchen.

33 Vgl. Dalferth 2015, 38.

34 Vgl. Taylor 2007, 2 I f. Die klassische Säkularisierungsthese wurde nicht bloss von Taylor, sondern beispielsweise auch vom Soziologen José Casanova (1994) kritisiert bzw. inhaltlich differenziert. 
$\mathrm{Zu}$ diesen zwei gängigen Verwendungsweisen führt Taylor noch ein drittes Verständnis von Säkularität ein: der Glaube an Gott als eine Möglichkeit neben anderen Lebensorientierungen. ${ }^{35}$ Mit der Einführung dieses dritten Verständnisses von Säkularität wendet sich Taylor gegen die These des notwendigen Rückgangs der Religion in der Moderne und die damit einhergehende Meinung, dass irrational sei, wer an Gott glaube.

Als kritische Vertiefung des Ansinnens von Taylor kann Dalferths Analyse des Säkularitäts-Begriffs in seinem Buch Transzendenz und säkulare Welt gesehen werden. Die Ambiguität im Ausdruck säkular wird oft gar nicht bemerkt, ist aber von grosser Tragweite für ein besseres Verständnis der gleichnamigen Debatte. Das Schillern des Ausdrucks säkular rührt daher, dass dieser erstens sowohl deskriptiv wie auch normativ verwendet wird; dass zweitens der Übergang vom deskriptiven zum normativen Gebrauch häufig unklar ist und dass drittens der normative Gebrauch abhängig von der jeweiligen Position sowohl im positiven als auch im negativen Sinn erfolgen kann. So kann der Ausdruck Säkularismus auf eine Position verweisen, die mit dem Säkularen oder der Säkularität etwas Positives verbindet und mit allem, was dem entgegensteht, etwas Negatives. Es kann damit aber auch das Gegenteil gemeint sein, beispielsweise eine für verwerflich gehaltene areligiöse oder gar antireligiöse Ideologie. ${ }^{36}$ «Offenkundig hängt der normative Sinn dieser Ausdrücke davon ab, ob sie von einem säkularen oder nicht-säkularen Standpunkt aus gebraucht werden, ob diejenigen, die sie verwenden, sich selbst also auf Seiten des positiv verstandenen Säkularen oder des positiv verstandenen Nicht-Säkularen verorten.»37

Dalferth weist ebenfalls auf die wichtige Unterscheidung hin zwischen dem Verständnis von «säkular〉, das sich am vertikalen Gegensatz göttlich/weltlich orientiert und dem Verständnis von «säkular», das vom horizontalen Gegensatz religiös/säkular bestimmt wird. Im ersten Fall wird Säkularität im Kontext der Transzendenz des Göttlichen bzw. der qualitativen Unterscheidung zwischen Schöpfer und Schöpfung gesehen und demnach als Weltlichkeit im Sinne von

35 Vgl. Taylor 2007, I ff.

36 Vgl. Dalferth 20I5, $22 \mathrm{f}$. Als Beispiel für die Verwendung von ¿Säkularismus` in einem negativen Sinn sei hier auf Wolfgang Sander (2018) verwiesen. Sander diskutiert in seinem jüngst erschienenen Artikel Schulische Bildung zwischen Religion und Säkularismus den Säkularismus als «das säkulare Gegenstück zum religiösen Fundamentalismus». Sowohl den Säkularismus wie auch den religiösen Fundamentalismus charakterisiert er als «eine Pathologie der Moderne» (Sander 2018, 190). Pointiert beschreibt er den Säkularismus gar als bildungsfeindlich «wegen seines radikal verkürzten, dennoch aber apodiktisch als wahr behaupteten Wissenschaftsverständnisses, seiner Neigung zu einem geschlossenen, sich selbst immunisierenden Weltbild, in dem offene Fragen und fundamentale Erkenntnisprobleme durch blosse Bekenntnisse überspielt werden, und durch die Tendenz zur Intoleranz gegenüber anderen, religiösen Weltverständnissen» (Sander 2018, 193).

37 Dalferth 2015, 23. 
Schöpfung und im Unterschied zum Schöpfer bzw. zu einer transzendenten Wirklichkeit verstanden. Dieses Verständnis «gehört zum Christentum seit seinen Anfängen». ${ }^{8}$ Im zweiten Fall wird «Säkularität als säkulare Weltlichkeit»39 interpretiert. Der Kontext so verstandener Säkularität ist die «Entdeckung der Weltlichkeit des Weltlichen» und ist Teil des Entwicklungsprozesses der Moderne. Sie wird als «Abbau oder Zurückdrängung des Religiösen in der Gesellschaft und im menschlichen Leben entfaltet».40 Auf dem Hintergrund der ersten (theologischen) Unterscheidung ist der Prozess der Säkularisierung als «Wiedereintritt der Unterscheidung göttlich/weltlich auf Seiten des Weltlichen ${ }^{4 \mathrm{I}} \mathrm{zu}$ charakterisieren, der innerbalb des Weltlichen zur Differenz religiös/säkular führt. So gesehen kann Säkularität in der heute verbreiteten Verwendungsweise von «säkular〉 im Sinne von «nicht religiös〉 nicht eigentlich verstanden werden ohne Rückbezug auf eine theologische Grundunterscheidung. Zudem wird auch deutlich, warum theologisch gesehen «säkular» nicht einfach etwas Negatives bezeichnen muss.

Um in der vorliegenden Arbeit den Übergang zwischen einer deskriptiven und normativen Ebene im Zusammenhang mit der Säkularitätsthematik deutlich zu machen, werde ich konsequent zwischen 〈Säkularismus〉 und 〈Säkularität〉 bzw. 〈säkularistisch〉 und «säkular〉 unterscheiden. Die Ausdrücke Säkularität und säkular werde ich als deskriptive Ausdrücke verwenden, und zwar im eben genannten Sinne als nicht religiös, die aber den Bezug zur theologischen Differenz implizieren. Im Unterschied dazu dienen 〈Säkularismus〉 und «säkularistisch〉 als normative Ausdrücke zur Bezeichnung von tendenziell areligiösen oder antireligiösen Ideologien.

\section{(Schulischer) Religionsunterricht}

Wenn ich in dieser Arbeit von schulischem Religionsunterricht spreche, fasse ich darunter jeglichen Unterricht an der öffentlichen Schule, der in irgendeiner Form Religion(en) und/oder Weltanschauung(en) explizit zum Thema macht. Das, was ich als schulischen Religionsunterricht bezeichne, wurde jedoch zu verschiedenen Zeiten unterschiedlich benannt: ${ }^{42}$ Moral und Religion (Lehrplan I 838), Religion (Lehrplan i 861), Biblische Geschichte und Sittenlehre (Lehrplan I905), Biblische Geschichte (Lehrplan 199I), Religion und Kultur (Lehrplan 2004: Sekundarstufe I bzw. 2006: Primarstufe).

38 Ebd., 24.

39 Ebd., 23.

$4 \circ$ Ebd., $23 \mathrm{f}$.

4 I Ebd., 25 .

42 Für die folgende Auflistung stütze ich mich auf Fries 2010. 


\subsection{Quellenbasis}

Entsprechend der Anlage dieser Arbeit, die öffentlichen Diskussionen um den schulischen Religionsunterricht um I 872 und um 2004 darzustellen und zu analysieren, umfasst der Quellenkorpus Dokumente, anhand deren diese Diskussionen fassbar werden. $\mathrm{Da}$ ist einerseits die mediale Öffentlichkeit, deren Wirksamkeit im I9. Jahrhundert primär in Zeitungen, ${ }^{43}$ Flugschriften, Traktaten und Büchern sichtbar wurde; im 20. Jahrhundert nebst Zeitungen und Zeitschriften auch auf diversen Kanälen im Internet, zum Beispiel auf persönlichen Webseiten in Form von Blogs. Die rechtlich-politische Öffentlichkeit manifestiert sich in Protokollen von Sitzungen politischer Gremien wie des Regierungs-, Kantonsoder Gemeinderats; die weltanschaulich-religiöse Öffentlichkeit wird sichtbar in Protokollen der kirchlichen Synoden, Kirchenzeitungen und im 2 I. Jahrhundert ebenfalls auf Webseiten weltanschaulicher Gruppierungen wie beispielsweise derjenigen der Freidenkerbewegung. Die Öffentlichkeit des Bildungswesens manifestiert sich in Erziehungs- und Bildungsratsbeschlüssen.

Natürlich gibt es auch Überschneidungen der verschiedenen Öffentlichkeiten. Die Antworten auf den im November I 869 im Amtsblatt des Kantons Zürich abgedruckten Katalog von 42 Fragen («Bekanntmachung der Erziehungsdirektion») zu einem neuen Unterrichtsgesetz sind ein Beispiel dafür. Sie stammen von einer Vielzahl von Akteuren - individuellen und kollektiven - in den unterschiedlichsten gesellschaftlichen Sphären: Schulbehörden (Gemeindeschulpflegen, Schulkapitel, Bezirksschulpflegen, Sekundarschulpflege), Vereine (Christlicher

43 Für das I9. Jahrhundert stütze ich mich hauptsächlich auf die zwei grössten und renommiertesten Zeitungen des Kantons Zürich. Zum einen auf das Publikationsorgan der Liberalen, die Neue Zürcher Zeitung (NZZ), zum andern auf den Landboten, das Publikationsorgan der demokratischen Bewegung. Die NZZ wurde 1780 unter dem Namen Zürcher Zeitung gegründet als ein einem aufklärerischen Gedankengut verpflichtetes Nachrichtenblatt. Im Jahre i 82 I kam es zu einer Namensänderung. Die nun Neue Zürcher Zeitung genannte Zeitung wurde unter der Leitung von Paul Usteri zu einem liberalen Kampfblatt, das sich gegen Zensur und Sonderbund und für den Bundesstaat einsetzte. Nach I 848 vertrat die NZZ im Eisenbahnstreit die Linie von Alfred Escher. Das Ende der Ära Escher führte I 868 zu einer existentiellen Gefährdung des Blattes. Um dessen Niedergang zu verhindern, gründeten Zürcher Liberale die AG NZZ (vgl. Maissen 20I5). Der Landbote wurde I 836 in Winterthur als liberales Wochenblatt für die Zürcher Landschaft gegründet. Ab dem Jahre i 857 erschien er täglich als Blatt der jungliberalen Richtung. Bekannte Redaktoren waren u. a. Johannes Scherr (der Bruder des für Zürich wichtigen liberalen Erziehungsreformers Ignaz Thomas Scherr) und Jakob Dubs (Regierungsrat, Erziehungsrat und Verfasser des Schulgesetzes von I 859). Unter der redaktionellen Leitung von Salomon Bleuler wurde Der Landbote «zum führenden Organ der Demokratischen Bewegung mit nationaler Bedeutung und zum Organ der kant. Demokratischen Partei (DP)» (Bürgi 2008a). Wichtige Mitredaktoren waren der Sozialphilosoph und Neukantianer Friedrich Albert Lange (von I 866-i 870 ) und ab i 877 der Pfarrer, Politiker und zum Führungskreis der Demokraten gehörende Gottlieb Ziegler (vgl. Bürgi 2008a). 
Verein, Landwirtschaftlicher Verein, Gemeindeverein, Frauenverein, Lehrerverein, demokratischer Verein, gemeinnützige Gesellschaft usw.) sowie am Schulwesen interessierte Bürger, das heisst Einzelpersonen. Die Antworten auf diese 42 Fragen wurden meines Wissens bisher noch nicht gesamthaft ausgewertet. In der vorliegenden Arbeit wurden die Antworten auf die den schulischen Religionsunterricht betreffende Frage vier berücksichtigt (vgl. Kapitel 6 und 7). Ein weiteres Beispiel, in dem sich das Zusammenspiel verschiedener gesellschaftlicher Sphären deutlich manifestiert, ist die Publikation von in politischen Gremien gefassten Entscheiden in den Zeitungen. Da im Untersuchungszeitraum im Kantonsrat bloss Beschlussprotokolle verfasst wurden, sind die Zeitungsberichte über die Kantonsratssitzungen viel informativer als die Protokolle. Der Vergleich der zwei grossen Zeitungen - NZZ und Der Landbote - zeigen eine relativ ausgewogene Berichterstattung in beiden Quellen.

Die Textgattungen der verschiedenen in dieser Arbeit verwendeten Quellen sind sehr unterschiedlich: Kurze Zeitungsberichte stehen neben längeren Traktaten und Vorträgen; jemand spricht als Vertreter einer Institution oder als Privatperson; Originalton versus Paraphrase in Zeitungen (z. B. von Kantonsratsbeiträgen). Die Heterogenität der Quellen lässt sich jedoch nicht vermeiden, ohne die vielgestaltige Situation aus den Augen zu verlieren. ${ }^{44}$

\subsection{Stand der Forschung}

Die Auseinandersetzung mit der leitenden Frage dieser Arbeit erforderte die Bearbeitung verschiedener Themenfelder. Insbesondere drei Bereiche haben sich als zentral erwiesen. Da der Kanton Zürich im Blickpunkt der Arbeit steht, ist zum einen die Schulgeschichte dieses Kantons von Bedeutung, die jedoch nicht unabhängig von der Politik- und der Kirchengeschichte behandelt werden kann. Als zweite Thematik ist das weite Feld der Zivilreligion zu nennen. Da die Thematik am schulischen Religionsunterricht abgehandelt wird, ist als Drittes auch die Literatur zum schulischen Religionsunterricht in der Schweiz und im Speziellen im Kanton Zürich in den Blick zu nehmen. Die Forschungsliteratur in all diesen Bereichen ist kaum mehr zu überblicken, weshalb ich hier nur diejenige Literatur vorstellen werde, die für meine Forschungsfrage unmittelbar von Bedeutung ist.

44 Von heutigen Regeln abweichende Orthografie wurde in den Zitationen nicht korrigiert und auch nicht ausgewiesen. 


\subsubsection{Schul-, Kirchen- und Politikgeschichte des Kantons Zürich}

Eine zusammenhängende Schulgeschichte für die Schweiz kann nach wie vor als Desiderat bezeichnet werden, was wohl die Folge der kantonalen Hoheit über das Schulwesen ist. Es liegen jedoch mit den Sammelbänden von Badertscher/ Grunder (1997) und Criblez/Jenzer/Hofstetter/Magnin (1999) Ansätze dafür vor. ${ }^{45}$ Die Schulgeschichte wie auch die allgemeine Geschichte des Kantons Zürich sind im schweizweiten Vergleich hingegen recht gut erforscht. Die in den Jahren zwischen I 880 und 1930 zahlreich entstandenen Arbeiten zur Zürcher Volksschule sind primär aus einer liberalen Siegerperspektive verfasst, die das Jahr I 832 - in diesem Jahr wurde das erste staatliche Schulgesetz erlassen - als Wiege der modernen Volksschule feiern und damit einen abrupten Wechsel von einer vormodernen Schule in einem peniblen Zustand zu einer modernen, guten Schule suggerieren, die man dem politischen, liberalen Herrschaftswechsel zu verdanken habe. ${ }^{4}$ Diese Art von einseitiger Geschichtsschreibung wird in aktuelleren Schulgeschichtsschreibungen zu vermeiden gesucht. In der durch die I75-Jahr-Feier 2007 motivierten Publikation Zukunft bilden. Die Geschichte der modernen Zürcher Volksschule sind die verschiedenen Beiträge nach Sachthemen strukturiert und es wurde bewusst «auf eine politische Epochierung der Geschichte der modernen Volksschule» ${ }^{47}$ verzichtet. Die beiden Herausgeber dieser Jubiläumsschrift, Daniel Tröhler und Urs Hardegger, nehmen als Beginn der modernen Zürcher Volksschule deshalb nicht das Jahr I 832 an, sondern gehen von einem Entstehungszeitraum von I00 Jahren - zwischen I770 und I870aus. Diese Datierung widerspiegelt die Überzeugung, dass sich Schule nicht auf Grund neu erlassener Gesetze entwickelt, sondern diese Gesetze vielmehr das sichtbare Ergebnis einer umfassenderen gesellschaftspolitischen Entwicklung sind, die sich auch auf die Schule auswirkt. ${ }^{8}$ Alexandra Bloch Pfister (2007) ist in ihrer Studie über den Professionalisierungsprozess der Zürcher Volksschullehrkräfte zwischen 1770 und I9I4 ebenfalls dem Ansatz verpflichtet, dass die «im ausgehenden i8. Jahrhundert einsetzenden Wandlungen eher als eine der Voraussetzungen des Durchbruchs der liberalen Bewegung zu bezeichnen sind» und die moderne Volksschule nicht «ein Ergebnis der Regeneration darstellte».49 Auch Andrea De Vincenti-Schwab belegt mit ihren Untersuchungen über die Zürcher Landschulen, dass «bereits am Ende des I 8. Jahrhunderts recht gut und

45 Vgl. Bloch Pfister 2007, 25.

46 Vgl. Wettstein 1907; Erziehungsrat des Kantons Zürich 1933; Frey 1953.

47 Tröhler/Hardegger 2008, I I.

48 Tröhler/Hardegger 2008, Iof.

49 Bloch Pfister 2007, I0. 
flächendeckend funktionierende Landschulen» existiert haben, die «als tatsächliche Vorläufer der Volksschule betrachtet werden» ${ }^{\circ}$ müssen.

Zum Verhältnis von Bildung und der in den I86oer Jahren aufkommenden zürcherischen Demokratischen Bewegung liegt eine Dissertation von Thomas Koller (1987) vor. ${ }^{\text {I }}$ Das Programm der Demokratischen Bewegung im Kanton Zürich sowie die Ideen führender Exponenten dieser Bewegung - Salomon Bleuler, Friedrich Salomon Vögelin, Johann Caspar Sieber und Friedrich Albert Lange - werden darin differenziert und materialreich nachgezeichnet. Für die vorliegende Arbeit von Bedeutung ist insbesondere die detaillierte Darstellung des Realisierungsversuchs dieser demokratischen Ideen, die sich im Unterrichtsgesetz von I 872 konkretisierten. Über den umtriebigen Pfarrer, Erziehungsrat und späteren Ordinarius für Kunst- und Kulturgeschichte Friedrich Salomon Vögelin existiert von Alexander Isler (1892), einem seinen Lehrer sehr verehrenden ehemaligen Schüler, eine eher volkstümlich verfasste Biographie. ${ }^{22}$ Eine systematisch-historische Arbeit über Vögelin mit einem grossen Fundus von Literatur wurde von Walter Betulius (1956) vorgelegt. Über die pädagogischen Ansichten des Sozialphilosophen Friedrich Albert Lange (1975) existiert von Joachim H. Knoll eine Art Kompilation seiner diesbezüglichen Texte, die allerdings unverständlicherweise vom Herausgeber überarbeitet und gekürzt worden sind. Ebenfalls zu erwähnen ist der von Joachim H. Knoll und Julius Schoeps (1975) herausgegebene Sammelband über Lange, in dessen Beiträgen Langes vielfältige Aktivitäten beleuchtet werden. Dem passionierten Zürcher Schulreformer und späteren Erziehungsdirektor Johann Caspar Sieber widmete Michael Köhler (2003) eine Monographie, die anschaulich über dessen Leben und Engagement berichtet. Der Autor ist seinem Protagonisten offenkundig sehr zugetan, so dass stellenweise gewisse Tendenzen ins Hagiographische auszumachen sind. Ideologische Einseitigkeit mit umgekehrten Vorzeichen gegenüber Sieber wird Martha Greiner (1933) vorgehalten, wenn sie in ihrer Dissertation Sieber eine atheistische Einstellung unterstellt. ${ }^{33}$ Im Unterschied zu anderen Schulgeschichten aus dieser Zeit vermag sie sich in ihrer Untersuchung bedingt durch ihre Fragestellung jedoch vom Charakter einer Ereignisgeschichte zu lösen und zeichnet aus einer historischen Perspektive die Entwicklung der Schule im Verhältnis zu Staat und Kirche nach.

Einen guten Überblick über die kirchliche Situation in der Schweiz gewährt Rudolf Pfisters dreibändige Kirchengeschichte der Scbweiz (1984). Für die vor-

50 Vgl. De Vincenti-Schwab 2008, is; De Vincenti 2015.

s I Hinsichtlich der Demokratischen Bewegung der I 860er Jahre sei weiter auf die Forschungen von Martin Schaffner (1982) verwiesen.

52 Vgl. Betulius 1956, I.

53 Vgl. Koller $1987,90$. 
liegende Arbeit von Bedeutung ist insbesondere Kapitel i 8 im dritten Band über die protestantischen kirchlichen Richtungen und Freikirchen. Da die Diskussion um das neue Unterrichtsgesetz von i 872 mitten in den Kulturkampf hineinfällt, bietet ebenfalls Peter Stadlers (1984) ausführliches Kompendium über den Kulturkampf in der Schweiz einen reichen Materialschatz. Zum Verhältnis von Kirche und Staat im Kanton Zürich und dessen geschichtlichen Voraussetzungen ist Hans Heinrich Schmids (1994) Darstellung sehr erhellend. Zum besseren Verständnis des «zürcherischen Protestantismus an der Wende vom Liberalismus zur Demokratie» trägt Jakob Streulis Dissertation (I948 \& I950) bei. Streulis historische Abhandlung bietet einen schier unerschöpflichen Fundus an Quellenmaterialien, doch zuweilen ist sein Stil etwas ausschweifend und grenzt ans Anekdotische. Eine prägnante Darstellung aktueller staatskirchenrechtlicher Entwicklungen auch im Zusammenhang mit den Diskussionen über die 2006 in Kraft gesetzte neue Kantonsverfassung findet sich bei Röhl (2006).

\subsubsection{Schulischer Religionsunterricht}

Einen guten Überblick über die Geschichte des Verhältnisses der Zürcher Volksschule zur Religion bietet der Beitrag von Urs Hardegger (2008b) im Band Zukunft bilden. Die Geschichte der modernen Zürcher Volksschule. ${ }^{4}$ Hardegger spannt den Bogen von I 830 bis in die Gegenwart. Zudem widmet er ein Kapitel auch einem in Zürich bisher eher vernachlässigten Thema: Dem «Verhältnis der Volksschule zur katholischen Kirche»."s Alexandra Bloch (I999) skizziert "Gründe und Weg der Entstehung des ab i 83 I praktizierten laizistischen Unterrichts» im Kanton Zürich sowie die «Stellung des Religionsunterrichts in der Volksschule im I9. Jahrhundert» ${ }^{6}$ in ihrem Beitrag für den Sammelband Eine Schule für die Demokratie. Zur Entwicklung der Volksschule in der Schweiz im I9. Jabrbundert. Zur Ausführung ihrer These, dass sich ein laizistischer Unterricht ab i 83 I «ziemlich reibungslos» durchsetzen liess, weil «er in Grundzügen bereits bekannt» war, beschäftigt sich Bloch auch mit «der Veränderung der Methodik des Religionsunterrichts». ${ }^{7}$ Dies ermöglicht ebenfalls einen ersten kleinen Einblick in den Katechismusunterricht des I 8. Jahrhunderts. Eine ausführliche Darstellung der Unterrichtspraktiken des ausgehenden i 8 . und

54 Die Publikation dieses Sammelbandes zur Geschichte der Zürcher Volksschule war von den Vorbereitungen zur 175-Jahr-Feier der ersten modernen Schulgesetzgebung von I 832 motiviert.

$55 \mathrm{Zu}$ dieser Thematik existiert vom selben Autor auch eine an der Universität Zürich im Jahr 2005 eingereichte unveröffentlichte Lizentiatsarbeit mit dem Titel Katholizismus und Zürcher Volksschule am Beispiel der Auseinandersetzung um das Fach Biblische Geschichte und Sittenlebre nach 1900.

56 Bloch I999, I43.

57 Ebd. 
beginnenden 19. Jahrhunderts findet sich in der Dissertation von Andrea De Vincenti (2015). Interessant ist die im Kapitel 2 über die «Lernbereiche» erfolgende Problematisierung De Vincentis der «Versuche, Schule überhaupt als Religionsunterricht zu fassen». ${ }^{58}$ De Vincenti bestreitet nicht, dass das primäre Bildungs- und Erziehungsziel die Vermittlung sittlich-religiöser Lerninhalte war, doch berge diese «schnelle Etikettierung» die Gefahr, dass Lesen, Schreiben oder Rechnen zu wenig als eigenständige Lernbereiche wahrgenommen würden, die auch mit anderen Inhalten - nicht bloss religiösen - gelehrt und gelernt werden konnten. De Vincenti untersucht Religion in ihrer Studie jedoch nicht als ausdifferenzierten Lernbereich, "weil er in den Quellen für den untersuchten Zeitraum noch kaum als solcher in Erscheinung trat».59

Mit der Geschichte des schulischen Religionsunterrichts in der Schweiz im I9. und 20. Jahrhundert hat sich insbesondere Martina Späni befasst. Zu dieser Thematik existieren von ihr in verschiedenen Sammelbänden kurze Aufsätze. Die konfessionelle Prägung der öffentlichen Schule und die unterschiedlichen Entwicklungen in den verschiedenen Kantonen sind schlaglichtartig Thema eines kurzen Aufsatzes im Sammelband Geschichte der Erziehung und Schule in der Schweiz im 19. und 20. Jabrbundert (Späni 1997). Die Entkonfessionalisierung der Volksschulen in der Schweiz im I9. Jahrhundert thematisiert Späni (1999) in ihrem Beitrag im Sammelband Eine Schule für die Demokratie. In ihrem neusten Aufsatz zu dieser Thematik - erschienen in einem Band über Augustin Keller - beschäftigt sich Späni (2005) mit der Frage, was unter Säkularisierung im Zusammenhang mit Schule zu verstehen sei. Nach einer kurzen Annäherung an den Begriff Säkularisierung fasst sie die Charakteristika des Säkularisierungsprozesses der Schulen in zwei Punkten grob zusammen. I) Die Veränderung des Verständnisses und der Inhalte öffentlicher Erziehung: «Der salte> religiös-moralische Schulzweck und die Lerninhalte wurden relativiert, reformiert und diversifiziert. Es wurde ein neues Verständnis öffentlicher Erziehung etabliert». 2) Die staatliche Monopolisierung der Aufsicht und Leitung der Schulen, wodurch «die Schulleitungs- und Schulaufsichtsfunktionen der Kirche gänzlich $»^{60}$ zurückgedrängt wurden. Späni betont jedoch, dass diese beiden Merkmale «nicht den vollständigen Ausschluss von Religion und Kirche aus dem öffentlichen Bildungswesen mit sich ${ }^{61}$ brachten.

Ansgar Jödicke und Andrea Rota (20I0) befassen sich aus religionswissenschaftlicher Perspektive mit dem schulischen Religionsunterricht, und zwar in einer vom Schweizerischen Nationalfond unterstützten Studie mit dem Titel

58 De Vincenti 2015, 68.

59 Ebd.

60 Späni 2005, $43 \mathrm{f}$.

6 I Ebd., 44 . 
Unterricht zum Thema Religion an der öffentlichen Schule. Jödicke und Rota beschäftigen sich in diesem Projekt «mit den jüngsten Reformen des «Religionsunterrichts in der Schweiz». Trotz dem föderalistischen System in der Schweiz erkennen sie in den Reformen überkantonale Tendenzen. Relevant für die vorliegende Arbeit ist Jödicke und Rotas Befund, der sich auf eine vergleichende Studie von Fallanalysen stützt, dass der offizielle Einfluss der grossen christlichen Kirchen zurückgehe, «auch wenn Ideen der liberalen christlichen Theologie wirksam bleiben». ${ }^{62}$ Aus historischer Perspektive komme ich in dieser Arbeit zu einem ähnlichen Resultat (vgl. Unterkapitel I0.6). Von aktueller Bedeutung ist ebenfalls die von Andrea Rota und Stefan Müller (2015) initiierte Artikelserie, in der die Entwicklung des Religionsunterrichts in der Schweiz während des 19. und 20. Jahrhunderts untersucht werden soll. «Mittels einer diachronen Perspektive» streben Rota und Müller «die Situierung sowohl jüngster Reformen des Religionsunterrichts als auch der sie begleitenden Debatten in einem breiteren historischen Kontext» an. Dies soll auch «die Identifizierung von Brüchen und Kontinuitäten in diesem Unterrichtsbereich ${ }^{63}$ ermöglichen.

Aus juristischer Perspektive ist auf die jüngst erschienene Habilitationsschrift von Lorenz Engi (2017) Die religiöse und ethische Neutralität des Staates $\mathrm{zu}$ verweisen. In Paragraph I 2 dieses umfangreichen Werks mit dem Titel «Neutralität und Bildung» ist ein Kapitel dem Religionsunterricht gewidmet. Sowohl der konfessionelle wie auch der religionskundliche Unterricht, der im Rahmen der Schule erteilt wird, werden auf die Vereinbarkeit mit dem staatlichen Neutralitätsgebot überprüft. ${ }^{64}$ Auf diesem Hintergrund unterstreicht Engi im Hinblick auf den konfessionellen Unterricht die Freiwilligkeit. Die Anfragen von anderen als christlichen Religionsgemeinschaften, ebenfalls einen konfessionellen Religionsunterricht in der Schule anbieten zu können, beurteilt Engi skeptisch. Er tendiert zu einer «Neutralisierung des schulischen Bereichs gegenüber konfessionellen Einflüssen». ${ }^{65}$ Hinsichtlich eines religionskundlichen

62 Jödicke/Rota 2010, 2.

63 Rota/Müller 2015, 27.

64 In der Bundesverfassung tritt der Ausdruck religiöse Neutralität nicht auf. Dieser Ausdruck wird jedoch in der Rechtssprechung verwendet. Gemäss Engi «bündelt das Neutralitätsgebot objektive Gehalte des Grundrechts» (Engi 2017, 175) wie beispielsweise die Glaubens- und Gewissensfreiheit oder Rechtsgleichheit und Diskriminierungsverbot. Auf kantonaler Ebene hingegen ist die Pflicht zur Neutralität des Schulwesens «verfassungs- und gesetzesrechtlich ausdrücklich verankert» (ebd., 268). So heisst es in Art. I I 6 Abs. 2 folgendermassen: «Diese [die öffentlichen Schulen - Verf.] sind den Grundwerten des demokratischen Staatswesens verpflichtet. Sie sind konfessionell und politisch neutral.»

65 Engi 2017, 28I. Der Begriff der Neutralisierung bedürfte einer weiteren Klärung. Die unreflektierte Parallelisierung von Neutralität und Neutralisierung ist zumindest fragwürdig. Denn staatliche Neutralität kann nicht die Neutralisierung weltanschaulich-religiöser Überzeugungen - verstanden im Sinne einer Entleerung von bestimmten Positionen - zum Ziel haben, ohne sowohl die positive Religionsfreiheit als auch den Bildungsanspruch zu verletzen. 
Unterrichts verweist Engi darauf, dass nicht vollständig klar sei, ob dieser «dem verfassungsrechtlichen Verbot des obligatorischen religiösen Unterrichts $\mathrm{zu}$ entsprechen vermag». ${ }^{66} \mathrm{Er}$ erachtet einen «strikt religionsneutral» ${ }^{67}$ gestalteten Unterricht jedoch als mit Art. Is Abs. 4 der Bundesverfassung vereinbar. Engis Werk gibt in juristischer Hinsicht einen sehr guten Überblick über die gesamtschweizerische Situation und Diskussion. Die Möglichkeit eines strikt weltanschaulich-religiös neutralen Unterrichts wird jedoch eher als Desiderat vorausgesetzt als real aufgewiesen.

Eine Darstellung zu aktuellen Entwicklungen des schulischen Religionsunterrichts im Kanton Zürich findet sich in der Dissertation von Karin Furer (2OI2). Furer beschäftigt sich explizit nicht mit der Frage, «welchen Platz Religion an den öffentlichen Schulen einnehmen darf und was insbesondere religionskundliche Bildung leisten kann und was nicht». ${ }^{68}$ Vielmehr interessiert sie im Vergleich zwischen dem «separierten Modell» im Kanton Zürich und dem im Grossteil Frankreichs bekannten «integrierten Modell» ${ }^{69}$ die Art und Weise, "wie über ein entsprechendes Modell religionskundlicher Bildung verhandelt wird». ${ }^{\circ}$ Der Ausarbeitungsprozess des Faches «Religion und Kultur» im Kanton Zürich wird hier genaustens nachgezeichnet.

Der zum Untersuchungszeitpunkt dieser Arbeit erreichte Diskussionsstand über das Unterrichtsfach Religion und Kultur ist in dem von Ralph Kunz, Matthias Pfeiffer, Katharina Frank-Spörri, Jozsef Fuisz (2005) herausgegebenen Sammelband Religion und Kultur - Ein Schulfach für alle? zu finden. Diese Publikation versammelt Überlegungen, die im Jahre 2004 anlässlich einer von der Pädagogischen Hochschule Zürich und der Universität Zürich organisierten Tagung zu ebendieser Thematik vorgetragen worden sind. Nebst den Herausgebenden finden sich darin Beiträge des Erziehungswissenschaftlers Jürgen Oelkers, der Religionspädagogen Karl Ernst Nipkow und Friedrich Schweitzer, ${ }^{71}$ des Religionswissenschaftlers Ansgar Jödicke und des Theologen und Kirchenrechtlers Cla Reto Famos u. a. Acht Jahre nach dieser Tagung erschien unter der Leitung von Charles Landert (2012) ein Bericht über die Evaluation der Einführungsphase des neuen

66 Ebd., 286.

67 Ebd.

68 Furer 20I2, I.

69 Furer spricht für den Grossteil Frankreichs von einem «integrierten Modell», weil «religionskundliche Aspekte in vorhandene Fächer integriert wurden», während im Kanton Zürich «ein eigenes «separates〉 Fach geschaffen wurde» (Ebd., 3).

70 Ebd., 4 .

7I Interessant ist der Hinweis von Schweitzer (2005b), dass auch im laizistischen Frankreich, das in den staatlichen Schulen keinen Religionsunterricht kennt, Veränderungen im Tun sind. So werde zunehmend erkannt, «dass Friede und Toleranz ohne religiöse Bildung nicht erreichbar sind, weshalb nun Wege gesucht werden, wie eine solche religiöse Bildung in anderen Fächern gewährleistet werden kann» (Schweitzer 2005b, 164). 
Unterrichtsfaches Religion und Kultur. Die wissenschaftliche Evaluation wurde vom Bildungsrat in Auftrag gegeben. Der ebenfalls von der Bildungsdirektion erteilte Auftrag für ein «Obergutachten zur fachwissenschaftlichen Überprüfung der Evaluation von Landert Partner ${ }^{72}$ erging an die beiden Erziehungswissenschaftler Dietrich Benner und Roumiana Nikolova (2013). Benner und Nikolova problematisieren in ihrem Gutachten die Grundentscheidungen des Evaluatorenteams von Landert Partner. Eine dieser Grundentscheidungen besagt, dass von den drei Lern- und Lehrformen (learning/teaching in religion, from religion und about religion) an der öffentlichen Schule bloss ein learning/teaching about religion legitim sei. Eine Zusammenfassung dieses Obergutachtens findet sich in Form eines Vortrags, den Benner im November 2013 vor dem Bildungsrat gehalten hat, abgedruckt in Benner (2014) Bildung und Religion. Dieser Band beinhaltet eine Zusammenstellung von verschiedenen Beiträgen Benners zu dieser Thematik; so zum Beispiel auch eine Stellungnahme zum brandenburgischen Unterrichtsfach LER (Lebensgestaltung - Ethik - Religionskunde), in dem sich Benner mit der erziehungs- und bildungstheoretischen Legitimationsproblematik von Schule und Unterricht beschäftigt und die heiklen Erwartungen an dieses Fach unter anderem am Begriff der «Lebensgestaltung» zur Disposition stellt: «Pädagogisch zu verantwortender Unterricht soll einen Beitrag zur Urteilskraftbildung leisten, nicht aber direkten Einfluss auf die Lebensgestaltung der Schülerinnen und Schüler nehmen [...] Niemand kann von sich unter demokratischen Bedingungen sagen, er sei kundig in Fragen der praktischen Lebensführung eines Andern».73

Der Erziehungswissenschaftler Johannes Bellmann (2006) spitzt die Problematik des Pflichtfachs LER noch zu, wenn er in seiner Diskussion unterschiedlicher Begründungsfiguren religiöser Bildung an öffentlichen Schulen LER als Beispiel für die «zivilreligiöse Instrumentalisierung von Religion als Orientierungshilfe im Dienste des Gemeinsinns» ${ }^{74}$ anführt.

\subsubsection{Zivilreligion}

Bellmann beruft sich dabei auf den Theologen Rolf Schieder (1997), der bereits in den I990er Jahren die Thematik Schule und Zivilreligion in einem äusserst aufschlussreichen Aufsatz diskutiert hat. Man erhält darin einen informationsreichen Einblick in die Geschichte der Zivilreligion in den USA und in Deutschland. In einer Fussnote erwähnt Schieder sogar die Wertedebatte in Deutschland, die er als «ein funktionales Äquivalent für die amerikanische Debatte über <civil religion / public philosophy»»7s bezeichnet. Ein Kapitel ist

72 Bildungsratsbeschluss vom I9. I2. $2013,4$.

73 Benner 20I4, I03.

74 Bellmann 2006, 210.

75 Schieder 1997, 626, Anm. 6. 
der Klärung des Säkularisierungsbegriffs sowie der Frage nach dem religiösen Element der Zivilreligion gewidmet. Zum Schluss problematisiert er am Beispiel des brandenburgischen Unterrichtsfachs LER (Lebensgestaltung - Ethik - Religionskunde) einen staatlichen Zivilreligionsunterricht. Schieder plädiert «für Zurückhaltung und Besonnenheit auf dem Feld der Werteerziehung» ${ }^{6}$ und für einen rein religionskundlichen Unterricht. Letzteres wirkt angesichts der sonst sehr differenzierten Analyse jedoch etwas unterreflektiert, da hier nicht einmal mögliche Anfragen an einen solchen Unterricht aufgeworfen werden. Ebenfalls aus erziehungswissenschaftlicher Perspektive bezieht sich Heinz-Elmar Tenorth (1999) in seinem Aufsatz Schule-Religion-Zivilreligion auf diesen Aufsatz von Schieder. Er konstatiert, dass Schieder zwar das Problem der Nähe von (protestantischer) Religion und Zivilreligion sehe, aber bloss «vor einer bestimmten Tendenz der Werterziehung» ${ }^{77}$ warne und nicht vor deren Gleichsetzung. Durch die Fokussierung auf einen wertreflektierenden anstatt wertvermittelnden Unterricht angesichts der Pluralität von Wertvorstellungen verschärfe sich aber die durch die Nähe von (protestantischer) Religion und Zivilreligion entstandene Problemlage noch mehr. Tenorth interpretiert die Erwartungen der protestantischen Religionspädagogen etwas spitz, aber wohl nicht falsch: «Angesichts der Pluralität der Welt soll die Schule dennoch Universalismus und Konsens darstellen und thematisierbar halten, freilich im Medium des Pluralen und ohne Glaubenserziehung zu intendieren»..$^{8}$ Der Aufsatz endet mit einer Anprangerung der übersteigerten Erwartungen an die Lehrpersonen, auf die die Spannung zwischen Bildung und Werteerziehung abgewälzt werde. Will man sich einen Überblick über die Väter (Mütter sind mir bisher keine begegnet) des Zivilreligionsbegriffs verschaffen, dann sei hier auf die von Heinz Kleger und Alois Müller (1986) herausgegebene Aufsatzsammlung verwiesen, in welche zentrale Aufsätze der Protagonisten dieser Diskussion wie Robert N. Bellah, Hermann Lübbe oder Niklas Luhmann Eingang gefunden haben.

76 Ebd., 640.

77 Tenorth I999, I8 I.

78 Ebd. 
TEIL 1

BEGRIFFLICHE UND HISTORISCHE RAHMUNG 


\section{Zivilreligion - Phänomen und Begriff}

\subsection{Eine erste Annäherung: Unterscheidung zwischen Zivilreligion, politischer Religion und Staatsreligion}

Sprachlich gesehen wird im Ausdruck Zivilreligion das Nomen Religion durch den Ausdruck zivil (von lat. civitas, civilis) weiterbestimmt, was bürgerlich, staatlich, öffentlich, staatsbürgerlich heissen kann. ${ }^{{ }}$Es liegt daher nahe, Zivilreligion mit politischer Religion oder Staatsreligion zu identifizieren, was auch häufig geschieht, da es über die richtige Verwendung des Begriffs Zivilreligion keinen gesellschaftlichen oder wissenschaftlichen Konsens gibt. Die von Hans Maier vorgenommene Unterscheidung zwischen diesen drei verschiedenen Begriffen «nach Herkunft und historischem Hintergrund $»^{2}$ scheint mir zur Präzisierung des Begriffs Zivilreligion sehr hilfreich.

Bevor ich auf die Typologie Maiers eingehe, zuerst jedoch noch eine Vorbemerkung. Seit Eric Voegelin oder Raymond Aron wird der Begriff der politischen Religion meist in Bezug auf totalitäre Regimes des 20. Jahrhunderts verwendet, insbesondere für den Nationalsozialismus und den Leninismus bzw. Stalinismus. ${ }^{3}$ Mit seinem weiter gefassten Anwendungsbereich, der antike Verhältnisse einschliesst, trägt Maier einerseits zur Klärung des Sachverhalts bei, läuft andererseits aber Gefahr, ein modernes Religionsverständnis, das auf einer Ausdifferenzierung von Staat und Kirche basiert, auf die Antike zurückzuprojizieren und somit einer anachronistischen Verzerrung Vorschub zu leisten. Ist man sich jedoch bewusst, dass das heute übliche Verständnis von Religion - eine Kombination von Glaubensüberzeugung und kultischer Praxis - modernen Ursprungs ist, dann kann man aus seinen Ausführungen einigen Gewinn ziehen.

Maier bezeichnet als politische Religion «einen Religionstypus, der in einer politischen Gemeinschaft wurzelt - so sehr, dass er ohne diese politische Fundierung nicht existieren könnte». ${ }_{4}$ Insofern er von einer «elementaren Symbiose» zwischen «Staat und Religion»'s spricht, könnte man auch umgekehrt sagen, dass

I Vgl. Seitter 2003, i Is.

2 Maier 2007 [1995].

3 Vgl. Voegelin I993; Bohmann 2009; Behrens 1997. Gemäss Gerda Bohmann haben sowohl Aron wie auch Voegelin den Ausdruck politische Religion später fallen gelassen und durch andere Ausdrücke ersetzt: Voegelin mit ‘moderne politische Gnosis〉 bzw. «Ersatzreligion〉 und Aron durch «säkulare Religion` (vgl. Bohmann 2009, 3).

4 Maier 2007 [1995], I73.

5 Ebd. 
der Staat ohne den religiösen Kult nicht existieren kann. Bekannteste Beispiele für einen solchen Stadt- und Staatskult in der Antike sind die griechische Polis und das republikanische und kaiserliche Rom. Der Götterkult und das Wohl der politischen Gemeinschaft sind hier aufs Engste miteinander verbunden. Bei einem symbiotischen Verhältnis können jedoch die Partner eines solchen Verhältnisses nur aus einer Aussenperspektive auseinandergehalten werden. Ein solcher Blick von aussen ergibt sich durch die philosophische Frage nach dem Wesen der Götter und ihrer Natur. Zu denken ist hier beispielsweise an die Kritik Platons an den Götterfabeln Homers. Oder später dann an die Unterscheidung Marcus Terentius Varros zwischen politischer Theologie und mythischer und physischer Theologie. Die politische Theologie hat nach Varro eine Mittlerfunktion zwischen der Volksreligion (mythische Theologie) und der vom polytheistischen Götterglauben gereinigten Religion der Philosophen. ${ }^{6}$ Erst «in der Fremdwahrnehmung durch Philosophie und Theologie wird die antike kultisch-kollektive Identität zur <politischen Religion>».7 So gesehen sind Ansätze zu einer funktionalen Ausdifferenzierung der Gesellschaft bereits in der Antike zu finden. Mit dem Christentum tritt die Spannung zwischen Religion und Staat bzw. Imperium noch deutlicher hervor: Der Kult der politischen Gemeinschaft und die kultische Verehrung des transzendenten, christlichen Gottes werden unterschieden und sind nicht integrierbar. Maier erinnert in diesem Zusammenhang an das Zinsgroschengleichnis im Matthäus-Evangelium: Mit der Frage, ob es erlaubt sei, dem Kaiser Steuern zu zahlen, wollen die Pharisäer Jesus überführen. Auf das Bild des Kaisers auf der Geldmünze verweisend, antwortet Jesus: «So gebt dem Kaiser, was dem Kaiser gehört, und Gott, was Gott gehört!» (Mt 22,2 I ). Zwar gehorchten die frühen Christen der politischen Obrigkeit und beteten trotz der Ablehnung des Kaiseropfers auch für den Kaiser und das Heil des Reiches, doch verstanden sie den Kaiser als einen weltlichen und nicht als einen göttlichen Herrscher. Kein weltlicher Herrscher darf sich aus christlicher Sicht absolut setzen. ${ }^{8}$

Der zweite hier zu beschreibende Typus von Religion ist die Staatsreligion oder die kirchenförmige Religion wie Maier historisch präziser formuliert. Sie entsteht durch die «Privilegierung des Christentums durch Konstantin und Theodosius».9 Im Unterschied zur politischen Religion kann die kirchenförmige Religion unabhängig von einem politischen System existieren. Nur eine solch staatsunabhängige Religion ermöglicht es einem Staat oder Imperium, diese Form von Religion entweder als Staatsreligion anzuerkennen oder als staats-

6 Ebd., $173 \mathrm{f}$.

7 Ebd., I73.

8 Vgl. ebd., I72.

9 Ebd., I74. 
feindliche Religion zu verfolgen (so zum Beispiel geschehen unter Diokletian). Zur Eigenart des Typus Staatsreligion gehört gemäss Maier jedoch nicht nur die Eigenständigkeit, sondern auch die «Suprematie der Religion gegenüber dem Staat». ${ }^{\circ}$ Der Staat erhält eine dienende Rolle «als Anwalt und weltlicher Arm der Kirche». ${ }^{\text {II }}$ Diese Eigenständigkeit und Suprematie der Religion bzw. der Kirche gegenüber dem Staat hat sich natürlich erst im Laufe der Zeit herausgebildet. Als Stationen auf diesem Weg nennt Maier den mittelalterlichen Investiturstreit, die zunehmende Bedeutung des Papstamtes und der Konzilien, die Bildung von Völkern und Staaten durch die verbindende christliche Lehre, ihre Gebote und Rechtsnormen und das von ihr ausgehende Denken und Fühlen. ${ }^{\mathrm{I} 2}$ Erst durch die durch die Reformation ausgelöste Glaubensspaltung änderte sich dieses Verhältnis und drehte sich sogar um. ${ }^{\mathrm{I}}$ Durch den Streit um die vera religione partikularisierte sich das einstmals nationenübergreifende Christentum in nationalen Formen und verlor nach und nach seine Vormachtstellung gegenüber dem Staat - «bis das System schliesslich in die entgegengesetzte Form des Staatskirchentums, der Superiorität des Staates über die Kirche», ${ }^{14}$ umschlug.

Der dritte Typus des hier unterschiedenen Verhältnisses von Religion und Politik ist die Zivilreligion. Wie zu Beginn dieses Kapitels erwähnt, verweist bereits der Name zurück auf die Antike. Dies sei - so Maier - nicht zufällig: Durch die Verbreitung des Christentums ging die einstmalige Einheit von Politik und Religion verloren und sollte nun durch eine Art staatliches Glaubensbekenntnis, das von allen Bürgern zu beachten ist, wiederhergestellt werden. ${ }^{15}$ Rousseau, der als der erste Theoretiker der Zivilreligion gilt, formulierte in seinem contrat social die Dogmen einer zivilen oder bürgerlichen Religion, die er für das Funktionieren des Staates als notwendig erachtete. Als Gewährsmänner für sein Ansinnen zog Rousseau im religiösen Bereich Mohammed und im weltlichen Bereich Thomas Hobbes bei. Mohammeds politisches System (und das seiner Nachfolger - der Kalifen -, solange sie sich an seine Regierungsform hielten) rühmte er für dessen Einheitlichkeit, es basierte nicht auf der christlichen Unterscheidung zwischen Gott und Kaiser. Und Hobbes rühmte er dafür, dass dieser als einziger christlicher Denker gewagt habe, «die beiden Köpfe des Adlers wieder zu

Io Ebd.

I I Ebd.

I2 Vgl. ebd.

I 3 Es muss erwähnt werden, dass Maier in seiner Darstellung nach dem Schisma zwischen Westund Ostkirche im Jahr I054 offensichtlich nur noch die Westkirche im Blick hat. Somit kann auch die Unterscheidung zwischen Staatsreligion und Staatskirche sinnvollerweise nur auf Westeuropa angewendet werden.

I4 Maier 2007 [1995], I74.

is Vgl. ebd., i75. 
vereinigen und alles auf eine politische Einheit zurückzuführen». ${ }^{16}$ Rousseau war der Überzeugung, dass ohne eine solche politische Einheit weder Staat noch Regierung prosperieren können. ${ }^{17}$ Dies hat zur Folge, dass je mehr es gelingt, gesellschaftlich-politische Homogenität zu erzeugen, Zivilreligion und politische Religion (verstanden im Sinne totalitärer Regimes) in terminologischer Hinsicht ineinander übergehen.

Im 20. Jahrhundert wurde Rousseaus Konzept erneut diskutiert. Insbesondere dank dem Soziologen Robert N. Bellah, der zur Beschreibung der religiösen Dimension der amerikanischen politischen Kultur den von Rousseau entlehnten Begriff civil religion verwendete und mit seinem 1967 erschienenen Aufsatz Civil Religion in America eine weltweite akademische Debatte auslöste. ${ }^{18}$ Niklas Luhmann führte den Begriff Zivilreligion 1978 in den deutschen Sprachraum ein und dieser wurde ziemlich rasch dann auch von Hermann Lübbe aufgenommen und diskutiert. ${ }^{19}$

Bevor nachfolgend auf den Unterschied zwischen Rousseaus Verständnis von Zivilreligion und heutigen Vorstellungen von Zivilreligion eingegangen wird, soll an dieser Stelle nochmals kurz der Unterschied zwischen politischer Religion (im Verständnis von Maier) und Zivilreligion zusammengefasst und etwas zugespitzt werden: Politische Religion verweist auf ein symbiotisches Verhältnis zwischen Religion und politischer Gemeinschaft. Das eine kann ohne das andere nicht bestehen und im strikten Sinne kann hier deshalb auch noch nicht zwischen Religion und politischer Gemeinschaft als zwei distinkten gesellschaftlichen Sphären unterschieden werden. Zivilreligion hingegen setzt die Ausdifferenzierung zwischen Staat und Kirche voraus und kann hinter dieses historische Faktum nicht mehr zurück. Doch soll die verlorengegangene Einheit zwischen politischer und religiöser Sphäre mittels zivilreligiösen Glaubens wiederhergestellt werden.

Auf gesellschaftliche Ausdifferenzierung als Voraussetzung für Zivilreligion geht Hermann Lübbe in seinem Aufsatz Staat und Zivilreligion. Ein Aspekt politischer Legitimität ein, in dem er auf einen fundamentalen Unterschied zwischen Rousseaus Verständnis von Zivilreligion, das dieser in seinem contrat social ausgeführt hat, und heutigen Vorstellungen von Zivilreligion verweist. Rousseaus Zivilreligion beinhaltet eine Bekenntnispflicht der explizit formulierten zivilreligiösen Glaubensartikel. ${ }^{20}$ Dies hat zur Folge, dass das Toleranzgebot

I6 Rousseau 2008 [1762], I45.

17 Vgl. ebd., I 44 f.; Maier 2007 [1995], I75.

I 8 Vgl. Lübbe 2004, I95.

I9 Vgl. Schieder 2004, 7I 5 .

20 Die bürgerliche Religion soll nach Rousseau aus vier positiven und einem negativen Dogma bestehen. Die vier positiven Dogmen sind: «Die Existenz der allmächtigen, allwissenden, wohltätigen, vorhersehenden und sorgenden Gottheit, das zukünftige Leben, das Glück der 
nicht für diejenigen gilt, die von diesem Bekenntnis abweichen. Sowohl der Gottlose als auch wer zu sagen wagt, es gäbe kein Heil ausserhalb der Kirche, muss aus dem von Rousseau propagierten freien Staat verstossen werden, da er als Feind der Gesellschaft gilt. ${ }^{21}$ Lübbe weist Rousseaus Zivilreligion insofern eine "voraufgeklärte Verfassung» ${ }^{22} \mathrm{zu}$, als Religionsfreiheit in Bezug auf Zivilreligion nicht als Bürgerrecht eingeklagt werden kann. Im Gegensatz dazu setzt «vollendete religionspolitische Aufklärung» ${ }^{23}$ zur Beförderung der bürgerlichen Moral keine Bekenntnispflicht voraus. Da Bürgerrecht und Bekenntnis(pflicht) im heutigen Verständnis von Zivilreligion klar getrennt werden, beschreibt Lübbe Zivilreligion als «Religion nach religionspolitisch vollendeter Aufklärung».24 Oder anders gesagt: Zivilreligion setzt Religionsfreiheit voraus bzw. Religionsfreiheit fördert die Entstehung einer Zivilreligion. ${ }^{25}$ Denn in einer religiös homogenen Gesellschaft trägt die vorherrschende religiöse Tradition massgeblich zum gesellschaftlichen Zusammenhalt bei. Bricht diese religiöse Einheit auseinander (Europa) oder war gar nie existent (Amerika), stellt sich die Frage, wer oder was diesen gesellschaftlichen Zusammenhalt gewährleisten kann, und eine mögliche Antwort auf diese Frage ist: Zivilreligion.

\subsection{Amerikanische und französische Zivilreligion}

Zivilreligion ist jedoch keineswegs gleich Zivilreligion. Unterschiedliche Spielarten von Zivilreligion lassen sich gut am Vergleich zwischen der französischen und der amerikanischen Zivilreligion aufzeigen. Während die Französische Revolution einen zutiefst antiklerikalen Impetus hatte und auf diesem Hintergrund

Gerechten und die Bestrafung der Bösen sowie die Heiligkeit des Gesellschaftsvertrags und der Gesetze.» Die negativen Dogmen beschränkt Rousseau auf ein einziges: «die Intoleranz» (Rousseau 2008, I 5 I).

2I Rousseau schreibt im Kapitel über die «bürgerliche Religion»: «Es gibt daher ein rein bürgerliches Glaubensbekenntnis, dessen Artikel festzusetzen dem Souverän zukommt, nicht regelrecht als Dogmen einer Religion, sondern als Gesinnung des Miteinander, ohne die es unmöglich ist, ein guter Bürger und ein treuer Untertan zu sein. Ohne jemand dazu verpflichten zu können, sie zu glauben, kann er jeden aus dem Staat verbannen, der sie nicht glaubt; er kann ihn nicht als Gottlosen verbannen, sondern als einen, der sich dem Miteinander widersetzt und unfähig ist, die Gesetze und die Gerechtigkeit ernstlich zu lieben und sein Leben im Notfall der Pflicht zu opfern. Wenn einer, nachdem er öffentlich ebendiese Dogmen anerkannt hat, sich so verhält, als ob er sie nicht glaube, soll er mit dem Tode bestraft werden; er hat das grösste aller Verbrechen begangen, er hat vor den Gesetzen gelogen.» (Rousseau 2008 [1762], I I I).

22 Lübbe 2004, 197.

23 Ebd.

24 Ebd.

25 Vgl. ebd. 
eine antichristliche Zivilreligion aufzubauen versuchte, kann die amerikanische Zivilreligion weder als antiklerikal noch als antichristlich bezeichnet werden. ${ }^{26}$ Der französische Laizismus fordert eine strikte Trennung von Politik und Religion. In Amerika hingegen impliziert die Trennung von Kirche und Staat keineswegs eine von der religiösen Dimension vollständig gereinigte politische Sphäre. ${ }^{27}$ Es ist zwar verfassungsmässig (First Amendment) geregelt, dass der Kongress kein Gesetz erlassen dürfe, das zur Errichtung einer Staatsreligion führe oder das die freie Religionsausübung verbiete. Zugleich aber wird die politische Sphäre einer universalen und transzendenten Wirklichkeit unterstellt, der gegenüber sie sich letztlich zu verantworten hat. ${ }^{28}$ Im Unterschied zur Verfassung, in der die Bezugnahme auf Gott gänzlich fehlt, nimmt die Unabhängigkeitserklärung Bezug auf die Naturgesetze und «Gott als den Herrn der Natur». ${ }^{29}$ Des Weiteren ist die Rede von einem Schöpfer, der alle Menschen mit gewissen unveräusserlichen Rechten ausgestattet hat. ${ }^{30}$ Ein zentraler Unterschied zur französischen Zivilreligion ist also die explizite Bezugnahme auf einen über der Nation stehenden Gott, an dessen Ziel die Nation gemessen wird und durch das sie erst ihre Existenzberechtigung erhält. Ebendiese Bezugnahme «auf eine überpolitische Souveränität» ${ }^{31}$ erachtete Bellah als ein Kennzeichen des politischen Lebens Amerikas. Seine Behauptung, dass es in Amerika eine Zivilreligion gebe, rechtfertigte er damit, dass auf höchster politischer Ebene religiöse Symbolik eingesetzt werde. ${ }^{32}$ Für Bellah war Zivilreligion - zumindest anfänglich - positiv konnotiert. Er schien Zivilreligion als eine Religion zu verstehen, die die Spannung zwischen Religionsfreiheit und der von der politischen Moral geforderten transzendenten Ausrichtung aushält oder in sich vereint; als

26 Vgl. Bellah 2004a, 32.

27 Vgl. ebd., 22.

28 Vgl. Schieder 2004, 7I5.

29 Unabhängigkeitserklärung der Vereinigten Staaten, zit. in Bellah 2004b, 50.

$30 \mathrm{Ob}$ dieser Gott ein christlicher Gott ist, bleibt allerdings umstritten. Für Bellah ist er «ein eindeutig biblischer Gott, der viel mehr ist als ein erstes Naturprinzip, der einzelne menschliche Individuen erschafft und sie mit Gleichheit und Grundrechten ausstattet» (Bellah 2004b, 50). Darin äussert sich zumindest ein Deismus im deutlichen Unterschied zu den französischen Aufklärern, die nicht mehr von Gott reden, sondern höchstens noch von einem höchsten Wesen.

3 I Bellah 2004b, 50 .

32 Als Beispiele nennt er die Antrittsreden Washingtons und Jeffersons oder die Abschiedsrede Washingtons, in denen sich die Rhetorik der Unabhängigkeitserklärung spiegle (vgl. Bellah 2004b, 5० f.). Als zeitgenössisches Beispiel (Bellahs erster Artikel erschien zum ersten Mal im Jahre 1967) geht Bellah in seinem ersten Aufsatz ausführlich auf die Antrittsrede John F. Kennedys vom 20. Januar 196I ein. Ziemlich zu Beginn seiner Rede spricht Kennedy beispielsweise vom Glauben, «dass die Menschenrechte nicht der Grosszügigkeit des Staats entspringen, sondern aus der Hand Gottes stammen» (Bellah 2004a, I9). 
eine Spannung, in der die eigentümliche Geschichte Amerikas, die man als Geschichte von Religionsflüchtlingen beschreiben könnte, zum Ausdruck kommt. Die französisch-laizistische Spielart von Zivilreligion kann mit Bellahs Verständnis von Zivilreligion als religiöser Symbolik im politischen Raum nicht adäquat erfasst werden. Um die französische Zivilreligion zu verstehen, ist im Folgenden ein Blick auf den französischen Republikanismus nötig. Dieser Einblick wird auch die Brisanz der Zivilreligionsthematik für die Pädagogik verdeutlichen.

\subsection{Zivilreligion und Republikanismus}

Die erneute Diskussion des für das moderne politische Denken bedeutsam gewordenen Begriffs des Republikanismus ist John G. A. Pocock und Quentin Skinner zu verdanken. ${ }^{33}$ Für Pocock bildet der «klassische» Republikanismus (bzw. der Bürgerhumanismus ${ }^{34}$ ) den Ausgangspunkt für eine Revision der anglo-amerikanischen politischen Tradition, deren «liberale» Interpretation bis dahin unbestritten war. ${ }^{35}$ Mit dem Ziel, den Einfluss dieses Bürgerhumanismus auf das anglo-amerikanische Denken aufzuzeigen, beschäftigte sich Pocock mit den norditalienischen Republiken der Renaissance. In seiner Analyse der politischen Sprache stellt Pocock in der Stadtrepublik Florenz die Herausbildung eines neuen politischen Denkens fest, das im Rückgriff auf das Ideal der antiken Stadtstaaten - eine Gemeinschaft von gleichen, autonomen und wehrhaften aktiven Bürgern - entstanden sei und das sich in ähnlicher Weise auch in den <schweizerischen> Stadtrepubliken herausgebildet habe. ${ }^{36}$

Innerhalb des Republikanismus sind zwei 〈Linien〉 zu unterscheiden: eine liberal-demokratische und eine altrepublikanische. Es sind insbesondere die Charakteristika der altrepublikanischen Linie, die dabei helfen, den Begriff Zivilreligion genauer zu fassen. Anhand der Darstellung von Schulprogrammen der französischen Revolutionszeit lassen sich diese zwei Ausprägungen des Republikanismus gut illustrieren und zentrale Aspekte von Zivilreligion aufzeigen. Die im i 8. Jahrhundert in aufklärerischen Kreisen vieldiskutierten Vorstellungen von Demokratie, Volkssouveränität, individuellen Freiheitsrechten, Rechtsgleichheit der Bürger usw. finden in Europa zur Zeit der Französischen Revolution erstmals konkrete Umsetzungsversuche. Die Gesellschaft sollte von Grund

33 Die beiden Ideenhistoriker John G. A. Pocock und Quentin Skinner gelten als Begründer der sogenannten Cambridge School.

34 Der Ausdruck Republikanismus anstelle von Bürgerhumanismus (civic humanism) setzte sich erst seit den I980er Jahren, insbesondere in den USA, durch (vgl. Sewing 1993, I6).

$35 \mathrm{Vgl}$. Sewing 1993 , Is.

36 Vgl. Sewing 1993, Is ff.; Bütikofer 2006, I I 3. 
auf umgestaltet werden und in diesem Prozess wurde (schulischer) Bildung und Erziehung eine prominente Rolle zugesprochen. Ohne Einwirkung auf die Erziehung und die Reorganisation des Schulwesens wurde die Verwirklichung der in der Déclaration niedergeschriebenen politischen Postulate nicht als möglich erachtet. ${ }^{37}$ Es ging nicht bloss um einige Reformen im Bildungswesen, sondern darum, wie Bronislaw Baczko in seiner ideengeschichtlichen Untersuchung pädagogischer Projekte zur Zeit der Französischen Revolution zeigt, das alte Bildungssystem gänzlich zu zerstören, um auf dessen Trümmern ein völlig neues aufzubauen. ${ }^{38}$

Johannes Clessienne weist jedoch darauf hin, dass das Unterrichtswesen in den Generalständen und der Nationalversammlung verhältnismässig spät diskutiert worden sei, obwohl die Protagonisten der Revolution Erziehung und Bildung als äusserst bedeutsam angesehen hätten und es eine Vielzahl von Vorschlägen für die Neugestaltung des Schul- und Unterrichtswesens gegeben habe. ${ }^{39}$ Bedeutsam sowohl für das französische wie auch das schweizerische Schulsystem war Marie Jean Antoine Nicolas de Caritat Marquis de Condorcets (1743-I794) Rapport sur l'organisation générale de l'instruction publique, den dieser in seiner Funktion als Vorsitzender des Unterrichtsausschusses im April I792 der gesetzgebenden Versammlung vorlegte. Zwar wurde Condorcets Rapport in der gesetzgebenden Versammlung nicht diskutiert, da der König just zu diesem Zeitpunkt Österreich den Krieg erklärt hatte, ${ }^{4}$ und so auch nie umgesetzt..$^{41}$ Dennoch beeinflusste er

37 Vgl. Schepp 1989, 56.

38 Vgl. Baczko 2000, i7 f. und 26; Bütikofer 2006, i I 7 .

39 Vgl. Clessienne 20I 2, 47. Erst im September 179r legte Charles Maurice Talleyerand-Périgord ein Programm für das Unterrichtswesen vor. Aus zeitlichen Gründen musste die Diskussion darüber jedoch vertagt werden. Bei der Ausarbeitung der Verfassung von i79I wurde bloss eine Absichtserklärung verfasst, der gemäss ein öffentliches und allen Bürgern gemeinsam zugängliches Schulwesen einzurichten sei, das in den für alle Menschen notwendigen Bereichen kostenlos sein sollte. I792 wurde aus dem Nachlass von Marquis de Mirabeau dessen Discours de l'instruction publique veröffentlicht, der einen ersten Entwurf eines Schulgesetzes enthält, der aber im Parlament nicht beraten wurde (vgl. Clessienne 20I 2, 47).

40 In der Darstellung von Clessienne gibt es eine kleine Ungereimtheit: Auf den Seiten 47 und 48 schreibt er, dass Condorcet als Sprecher der Unterrichtskommission am 20. und 21. April I 792 in der Assemblée legislative den «Rapport» vorgelegt habe, dieser dann aber nicht habe diskutiert werden können. Auf Seite 49 hingegen schreibt Clessienne, Condorcet habe den «Rapport» im Juni vor der französischen Nationalversammlung verlesen, doch habe er infolge Kriegsausbruch nicht diskutiert werden können. Die Angabe Juni ist wohl falsch, da Frankreich am 20. April Österreich den Krieg erklärt hatte.

4I Im Dezember 1792 kam das Schulprogramm von François Lanthenas und Gilbert Romme in der Nationalversammlung zur Diskussion, das sich stark an Condorcets Plan anlehnte und dessen organisatorische Gliederung im Wesentlichen übernahm, ausser der umstrittenen $\mathrm{Na}$ tionalen Gesellschaft der Gelehrten. Dies ist nicht verwunderlich, da Romme als Mitglied der gesetzgebenden Versammlung an Condorcets Bericht mitgearbeitet hatte. Im Mai 1793 wurde das erste Elementarschulgesetz erlassen und im Sommer 1793 legte Romme wieder in Anlehnung an Condorcet ein inhaltliches Konzept für die Primarschulen vor, das Hans-Christian 
das französische Schulsystem, indem er nachfolgende Konzepte inspirierte, insbesondere auch dasjenige des Bildungsministers der Dritten Republik, Jules Ferry (1832-1893). Auch das schweizerische Schulsystem ist von Condorcet beeinflusst. Hans-Christian Harten bezeichnet Condorcets Rapport gar als «das bedeutendste bildungspolitische Dokument der Revolution überhaupt».42 In die Schweiz kam Condorcets bildungspolitisches Gedankengut durch Friedrich Albert Stapfer, den Bildungsminister der Helvetischen Republik.

Condorcet propagierte ein fünfstufiges Schulsystem: Primärschulen, Sekundärschulen, Institute, Lyzeen (Hochschulen) und als höchste Stufe die Nationale Gesellschaft ${ }^{43}$ der Wissenschaften und der Künste.44 Das vertikale, standesgeprägte Schulwesen sollte durch ein meritokratisches, prinzipiell nach oben hin durchlässiges System ersetzt werden. Die vom Gesetz als berechtigt anerkannte politische Gleichheit sollte auch tatsächlich hergestellt und der Unterricht (zumindest auf der Primärstufe) deshalb allen Bürgern aller Gesellschaftsschichten ermöglicht werden und somit kostenlos sein. ${ }^{45}$ Indem Condorcet auf staatsbürgerliche Gleichheit abzielte, war sein Programm im Unterschied zu den Programmen von Talleyrand und Mirabeau, die das ständische Gesellschaftssystem nicht in Frage stellten, viel radikaler. ${ }^{4}$

Diesbezüglich noch radikaler war das Unterrichtsprojekt von Louis-Michel Lepeletier (I760-I793), ${ }^{47}$ das Robespierre im Juli 1793 in den Konvent einbrachte und anhand dessen sich typische Merkmale des Alt-Republikanismus vermut-

Harten als eine Verbindung zwischen nutzenbezogenem Unterricht und politischer Bildung mit einem «rationalistischen, antiklerikalen und antireligiösen Konzept» (Harten 1990, 43) beschreibt. Weder darf Religionsunterricht erteilt werden, noch dürfen ehemalige Geistliche als Lehrer unterrichten, selbst dann nicht, wenn sie den Eid auf die Verfassung abgelegt haben (vgl. Clessienne 20I 2, 47; Bütikofer 2006, I20; Harten 1990, 43).

42 Harten $1990,30$.

43 Die sogenannte société nationale war im Konvent umstritten. Es wurde befürchtet, die ehemalige Herrschaft des Klerus werde nun durch eine Elite von Gelehrten ersetzt (vgl. Bütikofer, I I9, Anm. I 50; Harten 1990, 42).

44 Vgl. Condorcet I966 [1792], 23.

45 Vgl. ebd., 20.

46 Talleyrand forderte kein Schulobligatorium, sondern bloss die Kostenlosigkeit des Unterrichts, wobei für die höheren Schulen Beiträge zu entrichten gewesen wären. Damit wäre den unteren sozialen Schichten der Besuch höherer Schulen verwehrt gewesen. Gemäss Bütikofer wurde allerdings von namhaften Forschern wie Baczko und Harten bezweifelt, ob Talleyrands Rapport überhaupt von ihm stamme. Mirabeaus Rapport et projet de décret sur l'organisation générale de l'instruction publique, der gemäss Bütikofer im Anschluss an Talleyrands Projekt in der gesetzgebenden Versammlung verlesen wurde, war bezüglich der Möglichkeit von sozialem Aufstieg noch konservativer, insofern auch für die Elementarschule Schulgeld verlangt worden wäre (vgl. Bütikofer 2006, I I 8).

47 Der Abgeordnete Louis-Michel Lepeletier, Marquis de Saint-Fargeau, und Anhänger der Partei Robespierres fiel einem Attentat der Royalisten zum Opfer und wurde im Verlauf des Jahres 1793 neben Marat zu einer prominenten Figur des «Kultes der Märtyrer der Freiheit» (Harten I990, 44). 
lich am deutlichsten veranschaulichen lassen. Lepeletier reagierte mit seinem Erziehungsplan auf die verschiedenen Vorschläge und Entwürfe zur Organisation des öffentlichen Unterrichts, die in die Berichte von Talleyrand und Condorcet Eingang gefunden hatten. Zur Erreichung seines Ziels, «ein ganz neues Volk [zu] schaffen», ${ }^{8}$ gingen ihm diese Pläne zu wenig weit. Während er die letzten drei Stufen des vierstufigen Schulsystems (Sekundärschulen, Institute und Lyzeen) als für «sehr weise entworfen» 49 befand, übte er hinsichtlich der ersten Stufe, der Primärschule, grundlegende Kritik. Condorcets Rapport habe sich lediglich auf den Unterricht beschränkt, das heisst, auf die Vermittlung wissenschaftlich abgesicherten Wissens - die lumières $^{\circ}{ }^{\circ}$-, und habe die Erziehung, das heisst, die Charakterbildung, ausser Acht gelassen. ${ }^{15} \mathrm{Um}$ aber die Gesellschaft von Grund auf umzugestalten bzw. die Nation neu zu schaffen und «Menschen, Bürger, Republikaner» zu bilden und das «Heil der Republik» ${ }^{52} z u$ ermöglichen, sei eine nationale Erziehung gefordert, und zwar so früh als möglich. An Condorcets Plan kritisierte er mitunter, «dass bis zum sechsten Jahr das Kind dem bewachenden Auge des Gesetzgebers entschlüpft und dass dieser wichtige Abschnitt des Lebens den bestehenden Vorurteilen und den alten Irrtümern überlassen bleibt». ${ }^{33}$ Die Kinder sollten deshalb bereits ab dem fünften Lebensjahr in die Obhut des Staates gegeben werden. ${ }^{54}$

In dieser Kritik tritt ein Unterscheidungsmerkmal zwischen der von Condorcet vertretenen eher liberal-demokratischen Spielart des Republikanismus und der eher altrepublikanischen Auffassung Lepeletiers deutlich hervor: Im Unterschied zu Condorcet hatte der Staat bei Lepeletier einen viel umfassenderen Anspruch auf seine zukünftigen Bürger, der via Schule als verlängerten Arm des Staates eingelöst werden sollte. In den von Lepeletier propagierten staatlichen Erziehungshäusern sollten die Kinder beider Geschlechter und aller sozialen Schichten zwischen 5 und I 2 (Mädchen nur bis II) auf Kosten der Republik gemeinschaftlich erzogen werden. «Unter dem heiligen Gesetz der Gleichheit» stehend, sollten ausnahmslos alle «dieselbe Kleidung, dieselbe Nah-

48 Lepeletier I949 [1793], I2I.

49 Ebd., I22.

$50 \mathrm{Vgl}$. Osterwalder 201 I, I 29.

5 I Vgl. Lepeletier I949 [1793], I 22.

52 Ebd., I 24.

53 Ebd., I 22.

54 Eine solch altrepublikanische Sicht wie bei Lepeletier findet sich im $2 \mathrm{I}$. Jahrhundert beispielsweise bei Gewerkschaftsvertretern. So geht der langjährige Redaktor der Zeitschrift vpod bildungspolitik Ruedi Tobler sogar noch über die Forderung von Lepeletier hinaus, wenn er in der I 57 . Ausgabe fordert: «Bildung kann nicht erst mit dem Alter von vier Jahren beginnen, die EDK (Schweiz. Erziehungsdirektorenkonferenz) muss auch für das Alter von null bis vier Verantwortung übernehmen [...]» (Tobler 2008, 2I). 
rung, denselben Unterricht, dieselbe Sorgfalt»ss erhalten. Die Forderung nach einem solch umfassenden und homogenisierenden staatlichen Einfluss auf die Kinder begründete Lepeletier hauptsächlich mit drei Argumenten: Erstens mit Ungleichheiten bezüglich der Länge des Schulweges - insbesondere Stadt/ Land-Unterschiede - und den Vermögensverhältnissen der Eltern, was beides dazu führe, dass Landkinder infolge eines weiteren Schulwegs und Kinder unvermögender Eltern, die ihre Kinder als Arbeitskraft benötigen, den Unterricht nicht gleich häufig besuchen könnten wie andere Kinder. Als zweiten und gewichtigeren Schwachpunkt des Condorcet-Planes erachtete er jedoch die Vernachlässigung der Förderung einer adäquaten körperlichen Entwicklung. Dazu reichten die im Plan erwähnten gymnastischen Übungen nicht aus. Vielmehr müsse dazu eine beständige Lebensweise, gesunde Nahrung und gemässigtes Arbeiten gewährleistet werden können. Der Staat will also nicht bloss die Inhalte des Unterrichts bestimmen, sondern darüber hinaus auch die Lebensweise seiner zukünftigen Bürger. Doch zur radikalen Umgestaltung der Gesellschaft reicht selbst dies nicht. Ohne Gesinnungswandel der Bevölkerung ändert sich nichts. Deshalb kritisierte Lepeletier an Condorcets Rapport als dritten Punkt, dass der schulische Einfluss bezüglich der Vermittlung einer einheitlichen Moral zu gering sei, da die Kinder täglich nur wenige Stunden in der Schule verbrächten und in der restlichen Zeit den Lastern und Irrtümern usw. ihrer Umgebung ausgeliefert seien. ${ }^{56}$

Die unterschiedliche Rolle, die Condorcet und Lepeletier dem Staat in der Erziehung seiner zukünftigen Bürger zugesprochen haben, ist nicht abzulösen von ihren je unterschiedlichen Verständnissen von Freiheit und Gleichheit. Condorcet scheint die individuelle Freiheit viel mehr zu gewichten als Lepeletier, der stärker im Denken des traditionell römischen Republikanismus verwurzelt scheint. Freiheit bedeutet demnach Freiheit der Republik und als tugendhaft gilt, wer seine individuellen Interessen dem Wohl der Republik unterordnen kann bzw. das Wohl der Republik zu seinem eigenen Interesse macht. Diese unterschiedlichen Freiheitsverständnisse äussern sich beispielsweise darin, dass in Lepeletiers Vorstellung den Eltern möglichst jeder Einfluss auf ihre Kinder abgesprochen werden soll, während ihnen Condorcet diesbezüglich mehr Freiheit zugesteht. Gerade weil Condorcet die Meinungsfreiheit hochachtet, forderte er, dass im öffentlichen Unterricht «nicht die Lehre irgendeines religiösen Glaubens zuzulassen»,57 sondern eine allgemeine Moral zu vermitteln sei, die auf den Prinzipien der Vernunft basiere. In seiner Begründung dafür zeigt sich auch deutlich das unterschiedliche Verständnis von Gleichheit. Während bei

55 Lepeletier I949[1793], I25.

56 Vgl. ebd., I $22 \mathrm{ff}$.

57 Condorcet I966 [1792], 47. 
Lepeletier das aufklärerische Postulat der Gleichheit in Richtung Gleichmacherei gedehnt wird, meint es bei Condorcet zunächst Gleichheit vor dem Gesetz. Gemäss Condorcet anerkenne die Verfassung «das Recht jedes Individuums auf Wahl seines Glaubens» und damit «eine vollständige Gleichheit zwischen allen Einwohnern Frankreichs» ${ }^{8}$ hergestellt werden könne, dürften im öffentlichen Unterricht keine Dogmen einer bestimmten religiösen Richtung vermittelt werden, da sonst gewisse Eltern vor den Kopf gestossen würden. Die Kinder können in den entsprechenden Kirchen und von den entsprechenden Predigern religiös unterwiesen werden. Damit könnten die Eltern «welches [sic] auch ihre Meinung über die Notwendigkeit dieser oder jener Religion sei, ohne Abneigung ihre Kinder in die nationalen Unterrichtsanstalten schicken [...]; und die öffentliche Gewalt wird nicht in die Rechte des Gewissens eingreifen unter dem Vorwand, es aufzuklären und zu leiten».99

Ein solches Modell ist einerseits natürlich nur möglich auf dem Hintergrund der Überzeugung, dass es möglich sei, Religion und Moral voneinander zu trennen. Andererseits ist es sicherlich auch Ausdruck von Condorcets Fortschrittsoptimismus, der sich unter anderem darin äussert, dass in seinem Plan explizit auch der Erwachsenenbildung Relevanz zugesprochen wird. Aus der Perspektive Condorcets war es wohl bloss eine Frage der Zeit, bis alle Menschen das Licht der Aufklärung erblickt haben würden und der nicht auf Vernunft gegründete religiöse Glaube verschwunden sein wird.

Offenbar wurde der von Robespierre eingebrachte Plan Lepeletiers im Konvent als ein zu radikaler staatlicher Eingriff in die Familiensphäre erachtet, obwohl dessen Ideen zur Verbesserung der Situation der Armen durchaus bedenkenswert erschienen. So wurde zwar zuerst ein Dekret erlassen, das die prinzipielle Möglichkeit solch staatlicher Anstalten vorsah, doch sollte kein Obligatorium $\mathrm{zu}$ deren Besuch festgelegt werden. Damit war natürlich Lepeletiers Grundgedanke völlig aufgeweicht und das Dekret wurde einige Wochen später auch wieder aufgehoben. ${ }^{60}$

Wie zu Beginn dieses Unterkapitels erwähnt, sollte insbesondere die Darstellung des altrepublikanischen Schulprogrammes von Lepeletier der Klärung des Begriffs Zivilreligion dienen. Als zentrale und für die weitere Diskussion relevante Charakteristika sind folgende zwei Punkte festzuhalten: I) Der umfassende Anspruch des Staates auf seine zukünftigen Bürger. So wird die Tätigkeit des Staates nicht auf die Sicherung von Leben und Eigentum seiner Bürger und der politischen Gerechtigkeit und Gleichheit beschränkt. Vielmehr soll der Staat auch auf die Gesinnung seiner Bürger Einfluss nehmen. 2) Zu diesem Zweck

58 Ebd., 46.

59 Ebd., 47.

$60 \mathrm{Vgl}$. Harten I990, $46 \mathrm{f}$. 
wird die Schule in den Dienst des Staates genommen. Als Zweck der Schule wird nicht bloss die Vermittlung grundlegender Kulturtechniken wie Lesen, Schreiben und Rechnen angenommen, sondern weit darüber hinaus die Vermittlung einer aufklärerischen, nationalen Einheitsmoral.

Demgegenüber steht die liberal-demokratische Linie eines Condorcets, der sich der Gefahren gesinnungsethischer Einflussnahme durch den Staat eher bewusst $\mathrm{zu}$ sein schien. In der ersten seiner cinq mémoires sur l'instruction publique betonte er die historische Kontingenz von Staatsverfassungen und verwies auf die Gefahr, die entsteht, wenn die angehenden Bürger in der Schule dazu angehalten werden, die Inhalte der Staatsverfassung analog religiöser Doktrinen in blindem Enthusiasmus als mit den Prinzipien der universalen Vernunft übereinstimmend $\mathrm{zu}$ glauben und zu verehren. "Voilà ce que vous devez adorer et croire, alors c'est une espèce de religion politique que l'on veut créer; c'est une chaîne que l'on prépare aux esprits, et on viole la liberté dans ses droits les plus sacrés, sous prétexte d'apprendre à la chérir. ${ }^{61}$

Auch wenn Condorcet den Ausdruck Zivilreligion nicht benutzte, sondern von politischer Religion sprach, verweist er hier genau auf den Kern der Sache. Einige Seiten weiter im selben Text warnt Condorcet explizit vor den Vertretern einer Nationalerziehung - im Visier hat er insbesondere Voltaire und Rousseau -, die im Volk einen blinden Glauben an die Gesetze und die Verfassung zu fördern suchten, ohne sich selbstkritisch zu fragen, «comment ils peuvent être si sûrs que ce qu'ils croient est ou sera toujours la vérité? De qui ils ont reçu le droit de juger où elle se trouve? Par quelle prérogative ils jouissent de cette infaillibilité qui seule peut permettre de donner son opinion pour règle à l'esprit d'un autre?» ${ }^{62}$

Condorcet geht sogar so weit, die aufklärerischen Nationalisten mit religiösen Fanatikern zu vergleichen: «Sont-ils plus certains des vérités politiques que les fanatiques de toutes les sectes croient l'être de leurs chimères religieuses?» ${ }^{63}$ Erst gegen Ende des i9. Jahrhunderts wurden Teile von Condorcets Bildungssystem in Frankreich implementiert. Dies ist Jules Ferry, dem Bildungsminister der Dritten Republik, zu verdanken, der sich bei der Darlegung seines Schulprogramms klar zu Condorcets Bildungssystem bekannte. ${ }^{64}$ Doch trotz dieses Bekenntnisses sind deutliche Unterschiede zu Condorcet festzustellen, so dass Ferrys Schule gewissermassen als eine Mischform der zwei republikanischen Linien anzusehen ist.

6I Condorcet I989 [179I], 68.

62 Ebd., 70.

63 Ebd., 71. Hätte Condorcet seine kritischen Einwände auf sich selbst angewendet, hätte er wohl auch seinen eigenen Glauben an «eine allgemeine Vernunft in Frage stellen müssen, die ja erst die Möglichkeit einer «religiös-neutralen` Schule eröffnet. Dieses Problemfeld kann an dieser Stelle jedoch nicht weiter erörtert werden.

64 Vgl. Osterwalder 201 I, I 35; Osterwalder 1998. 


\subsection{Was ist das Religiöse an Zivilreligion?}

Die altrepublikanischen ${ }^{65}$ und liberal-demokratischen Traditionen lassen sich als unterschiedliche Antworten auf die ungelöste Frage nach Einheit und Integration in einer zunehmend heterogenen und ausdifferenzierten Gesellschaft verstehen. Individuelle Freiheit gewährende autonome Vernunft bildet das Leitmotiv liberal-demokratischen Denkens, während quasireligiöse Einflussnahme auf den ganzen Menschen zur Gewährleistung der gesellschaftlichen Einheit, die alt-republikanische Linie kennzeichnet.

Was die im Titel dieses Kapitels gestellte Frage betrifft, habe ich nicht vor, den religiösen Aspekt von Zivilreligion mittels einer allgemeinen, abstrakten Definition von Religion zu erläutern. ${ }^{66}$ Insofern meine Thematisierung von Zivilreligion immer historisch gebunden ist, das heisst, sowohl einen zeitlichen wie auch einen geografischen Ort hat, ist auch «Religion` an eine ganz konkrete Instanz gebunden: Im Frankreich des 18. und 19. Jahrhunderts war es die katholische Kirche gegen deren Dominanz und Kollaboration mit dem Königshaus sich der Unmut der französischen Revolutionäre richtete. In den USA, die Bellah in seinen Forschungen vor Augen hatte, war es der protestantische Denominationalismus. Des Weiteren richte ich zur Erhellung des Religiösen von Zivilreligion meine Aufmerksamkeit auf einen spezifischen Aspekt von Religion bzw. der katholischen Kirche (oder in den USA den Mainstream-Protestantismus): auf ihre sozial-politische Funktion, die ihr zugesprochen wird. Die Kirche bindet zusammen, was sonst in der Gesellschaft - insbesondere in einer ständischen - nicht ersichtlich zusammengehört bzw. weltlich gesehen auch nicht zusammengehören soll. Durch die Taufe erhält jeder Mensch Anteil am Leib Christi oder wird - anders formuliert - Teil einer grösseren, umfassenderen Einheit - der Gemeinschaft der Heiligen. Dieses einheitsstiftende Moment ist das religiöse Element der Zivilreligion, das auf verschiedene Art und Weise säkular umgedeutet wurde. Verschiedene Formen solch säkularer Umdeutungen der sozial-politischen Funktion von Religion sollen in den folgenden Unterkapiteln dargestellt werden.

65 Ich verwende die etwas sperrigen Bezeichnungen altrepublikanisch und liberal-demokratisch, um die zeitgenössisch-amerikanische Verwendung von republikanisch bzw. liberal davon abzugrenzen. Diesen Hinweis verdanke ich Fritz Osterwalder.

66 Üblicherweise können zwei Zugänge zur Bestimmung von «Religion` ausgemacht werden: ein funktionaler und ein substantieller. Im ersten Fall versucht man sich dem Begriff der Religion zu nähern, indem man auf Funktionen bestimmter gesellschaftlicher Überzeugungen und Praktiken achtet. Im zweiten Fall steht meist der Glaube an die Existenz übernatürlicher Entitäten im Fokus, z. B. der Glaube an Gott oder Götter. Beide Zugänge sind mit Schwierigkeiten behaftet, auf die einzugehen im Rahmen dieser Arbeit nicht möglich ist. Zu meinem Vorverständnis von Religion bzw. religiöser Überzeugung sei auf Unterkapitel I.4, S. 2 I f. verwiesen. 


\subsubsection{Ecole laïque}

Die Darstellung der Grundgedanken der Ende des 19. Jahrhunderts in Frankreich zur Zeit der Dritten Republik entstandenen école laïque hat für die Thematik dieser Arbeit eine doppelte Bedeutung. Zum einen kann damit beispielhaft - und zeitgleich zur Diskussion im Kanton Zürich über die Abschaffung des konfessionellen Religionsunterrichts in der öffentlichen Schule anlässlich eines neuen Unterrichtsgesetzes - die Indienstnahme der öffentlichen Schule für eine säkulare Ideologie gezeigt werden. Zum andern gibt es über Ferdinand Buisson, den engsten pädagogischen Berater Jules Ferrys, ${ }^{67}$ eine direkte Beziehung zur Schweiz. Ferdinand Buisson (I84I-I932) war von I 866 bis I 870 Philosophieprofessor an der Akademie in Neuenburg. ${ }^{6}{ }^{\mathrm{E}} \mathrm{Er}$ begründete in der Westschweiz den liberalen Protestantismus. Dass die zwei Vorträge Die biblische Geschichte in der Volksschule (I 869a) und Das Freie Christenthum und die Kirche der Zukunft (I869b) schnell ins Deutsche übersetzt wurden, lässt darauf schliessen, dass Buisson auch in der Deutschschweiz einen hohen Bekanntheitsgrad hatte. Buissons Manifeste du christianisme libéral wurde beispielsweise von Antistes Diethelm Georg Finsler ${ }^{69}$ an der Geistlichkeitssynode des Kantons Zürich vom 23./24. November 1869 diskutiert $^{70}$ und seine Vorträge wurden in einschlägigen Zeitschriften kommentiert. ${ }^{71}$ Buisson kehrte 1870 nach Frankreich zurück, wo er I 878 als Generalinspektor des öffentlichen Unterrichts unter Jules Ferry die Laisierung des Schulwesens durchführte..$^{72}$

In der folgenden kurzen Darstellung der école lä̈que folge ich den Ausführungen von Fritz Osterwalder, der in seinem Aufsatz Demokratie und laizistische Schule - die religiöse Grenze der Laizität auf der Basis einer Vielzahl von Dokumenten aufzeigt, dass das laizistische Schulkonzept von Jules Ferry einer «Sakralisierung der Schule»73 gleichkommt und der von Ferry und Buisson propagierte Moralunterricht «nicht als eine Laisierung der Schule, sondern als

67 Jules Ferry war von I 879 bis I 883 mit kurzen Unterbrüchen Bildungsminister und I 880/8 I sowie I 883-I885 Ministerpräsident der Dritten Republik. Man könnte Ferry als Vater der laizistischen Schule bezeichnen. In Frankreich wird heute noch die öffentliche Primarschule «l'école de Jules Ferry» genannt (Osterwalder 20 I I, I35).

68 Da Buisson den im Zweiten Kaiserreich geforderten Eid verweigerte und deshalb keine Stelle erhielt, entschied er sich, in die Schweiz ins Exil zu gehen (vgl. Fatio 2004).

69 Diethelm Georg Finsler (ı 8 19-1 899) war der letzte Antistes der Zürcher Kirche. Theologisch gesehen stand er zwischen den Orthodoxen und den Reformern. Von I 868 bis I 869 gehörte er dem Verfassungsrat an und von I 873 bis I 896 dem Zürcher Kantonsrat (vgl. Weibel 2005).

$70 \mathrm{Vgl}$. Amtlicher Auszug aus Protokollen der Zürcherischen Geistlichkeit, 23./24. I I. I 869.

7I In Der Kirchenfreund von i 869 sind verschiedene Artikel zum Thema «Buisson's Auftreten und Folgen» zu finden. Ein Bericht über die Verhandlungen zwischen Herrn Buisson und Herrn Godet beginnt mit: «Ce buisson ne fleurira pas à Neuchâtel» (Der Kirchenfreund vom 8. I. I 869,59$)$.

72 Vgl. Fatio 2004.

73 Osterwalder 1998, I 3 I. 
eine Sakralisierung des Staates und der Gesellschaft ganz im Sinne der protestantischen Gemeinde, die in der Bruderschaft der Gläubigen die weltliche Kircheninstitution heiligt ${ }^{74} \mathrm{zu}$ verstehen ist.

Bereits I 870 - also zeitgleich zur zürcherischen Diskussion über das neue Unterrichtsgesetz - stellte Ferry in einem Vortrag vor der Société pour l'éducation primaire zum Thema L'égalité d'éducation Condorcets Grundgedanken der Schule dar, wie er sie dann in der Dritten Republik auch zu verwirklichen suchte. ${ }^{75} \mathrm{Um}$ die eben wieder neu errungene Demokratie zu erhalten, ${ }^{76}$ muss die Gesellschaft gemäss Ferry von einem «esprit d'ensemble»77 zusammengehalten werden. Die Aufgabe, einen solchen Gemeinschaftsgeist zu vermitteln, kommt in Ferrys Programm der öffentlichen Schule zu, die von den Kindern aller Gesellschaftsschichten gemeinsam besucht werden soll. ${ }^{8}$ Insofern nach Ferry Rechtsgleichheit die Grundlage und das Wesen der Demokratie ausmacht und aus seiner Sicht Erziehungsungleichheit Rechtsgleichheit verhindert, wird Leben und Tod der Demokratie so gleichsam von der Schulfrage abhängig gemacht. 79

Bereits die Rede von einem Geist der Gleichheit zeigt, dass Ferrys Gleichheitskonzept über Condorcets Konzept von Rechtsgleichheit bzw. dasjenige des frühen Liberalismus hinausgeht. ${ }^{80}$ Ferry ging es nicht bloss darum, das Individuum vor staatlichem Zugriff in die individuellen Freiheitsrechte - beispielsweise das Recht auf freie Ausübung des eigenen religiösen Glaubens - zu schützen. Die Aufgabe des Staates bestimmte Ferry im Jahre I 880 in einer Diskussion über die konfessionelle Neutralität der Schule in der Abgeordnetenkammer (Chambre des députés) explizit auch positiv. Um die Republik zu erhalten, sollte über die Institution Schule sichergestellt werden, dass die Kinder entsprechend den Idealen der Französischen Revolution erzogen werden. Aus demselben Grund sollten Leitung und Aufsicht der Schule nicht mehr den Geistlichen überlassen werden, «qui ont [...] des opinions séparées des nôtres par un si profond abîme». ${ }^{81}$ Im selben Jahr äusserte Ferry im Senat die Ansicht, dass der Staat sich

74 Ebd., I35 f.

75 Vgl. ebd., I 16 ; Osterwalder 201 I, I35.

76 Nach der Niederlage im Französisch-Preussischen Krieg und der Gefangenschaft Napoleons III. wurde im September 1870 in Paris die Dritte Republik ausgerufen und somit das 2. Kaiserreich beendet.

77 Ferry i996a, 65.

78 «Je vous défie de faire jamais de ces deux classes une nation égalitaire, une nation animée de cet esprit d'ensemble et de cette confraternité d'idées qui font la force des vraies démocraties, si, entre ces deux classes, il n'y a pas eu le premier rapprochement, la première fusion qui résulte du mélange des riches et des pauvres sur les bancs de quelque école.» (Ferry 1996a, 65).

79 Vgl. Ferry 1996a, 63; Osterwalder 201 I, I 35 ff.

80 Vgl. Osterwalder $201 \mathrm{I}, \mathrm{I} 36$.

8 I Ferry 1996b, 36; vgl. Osterwalder 1998, i 22 f. 
gegenüber religiösen und wissenschaftlichen Doktrinen neutral zu verhalten habe. In zwei Bereichen aber sei staatliche Neutralität nicht angebracht: «c'est la morale et c'est la politique, car, en morale comme en politique, l'État est chez lui; c'est son domaine, et, par consequent, c'est sa responsabilité.» ${ }^{82}$ Bezeichnend für den umfassenden Anspruch, den Ferry dem Staat entgegen traditionell liberaler Überzeugungen zuschrieb, ist auch seine Terminologie. Er spricht vom «l'État enseignant et surveillant», ${ }_{3} 3$ in dessen Verantwortungsbereich Politik und Moral klar gehören. Dem Staat kommt eine aktive Rolle in der Vermittlung der richtigen, sprich: republikanischen Moral zu. Dies mit der politischen Begründung, dass nur so die Republik bestehen könne. Dies ist mithin auch Ferrys Hauptargument für die Bildung des weiblichen Anteils der Bevölkerung, für die er sich bereits in seiner Rede von I 870 eingesetzt hatte, obwohl er sich, wie Osterwalder herausstreicht, I 858 in der Conférence Molé explizit gegen die Bürgerrechte der Frauen ausgesprochen habe. ${ }^{8}$ Anders als Condorcet, der sich für die Bildung der Frauen einsetzte, weil diese gleichermassen vernunftbegabt seien wie die Männer, ${ }^{85}$ geht Ferrys Argumentation für die «égalité d'éducation» in seiner zu Beginn erwähnten programmatischen Rede von i 870 in eine ganz andere Richtung. Die Frau erzieht die Kinder und sie erzieht sie religiös. Durch schulische Bildung soll sie dem Einfluss der Kirche entzogen werden, um ebenfalls ihre Kinder im republikanischen Geist erziehen zu können. Von der richtigen Bildung der Frauen wird gar «l'éxistence de la société actuelle» abhängig gemacht: "Celui qui tient la femme, celui-là tient tout». ${ }^{86}$

Osterwalder formuliert sehr pointiert Ferrys Verständnis der Laizität der Schule, die von ihm «nicht negativ, durch die Abwesenheit des Bezuges zu Religion und Kirche» bestimmt wird, «sondern positiv, durch eine Alternative dazu [...], die einheitlich in der ganzen Bevölkerung durch die Schule verankert wird». ${ }^{87}$ Die öffentliche Schule ersetzt in dem Sinn die Kirche und die christlichen bzw. katholischen Schulen, die bisher einen gemeinsamen Geist anerzogen haben. Deshalb erachtet Ferry als zentrale Aufgabe der Schule auch den Moralunterricht, dessen Aufgabe darin besteht, «de lui [l'enfant] révéler la grande famille à laquelle il appartient et qui s'appelle la patrie». ${ }^{88}$ In einem Brief an die Lehrer schreibt Ferry im Jahre I883, dass das Gesetz (vom 28. März) die Vermittlung spezifischer Dogmen im obligatorischen Unterricht untersage, zugleich aber

82 Ferry i996a, 409.

83 Ebd.

84 Vgl. Osterwalder I998, I 22; vgl. Legrand I96 I, 203.

85 Condorcet i989 [i79I], $73 \mathrm{ff}$.

86 Ferry i996a, 74 .

87 Osterwalder i998, I 27.

88 Ferry i996a, 68. 
moralische und zivile Erziehung an die erste Stelle setze ${ }^{89}$ In solchen Äusserungen zeigt sich das überhöhte Staatsverständnis Ferrys deutlich. Dem Staat wird weit mehr als eine rechtliche Funktion zugeschrieben. Er wird als moralische Gemeinschaft betrachtet, deren Einheit durch die «éducation nationale» gewährleistet werden soll. In dieser Nationalerziehung mache der Moralunterricht «la dignité de votre profession ${ }^{90}$ aus, schreibt Ferry im selben Brief an die Lehrer. Die grundlegenden moralischen Regeln werden als gleichermassen universell angesehen wie grammatikalische oder mathematische Regeln. Eine laizistische Schule sei keineswegs eine Schule ohne Moral, wie Ferry gegenüber seinen Gegnern betonte, die ihm dies zum Vorwurf machten. Vielmehr werde in der laizistischen Schule die einzig richtige Moral vermittelt: «Permettez-moi de vous le dire, la vraie morale, la grande morale, [...] c'est la morale sans épithète. La morale $[\ldots]$ dans notre société française après tant de siècle de civilisation, n'a pas besoin d'être definie. La morale est plus grande quand on ne la définit pas, elle est plus grande sans épithète.»"

Die richtige Moral ist gemäss Ferry eine Moral ohne Bezugnahme auf Gott und auf ein Dogma, denn einzig eine solche von Gott und Dogmen befreite Moral könne im Zeitalter der empirischen Wissenschaften Einheit schaffen. Ferry geht von einer unwandelbaren, festen und einheitlichen Moral aus, die einen Gegenpol zur Staatsreligion bildet. Damit steht er im Kontrast zu Condorcets Verständnis von Moralunterricht. Condorcet will die Moralität der Gesetze gerade nicht als absolut vermitteln, sondern als wandelbar. ${ }^{92}$ Ferry strebt mit der Vermittlung dieser unwandelbaren Moral danach, sowohl die Utopien der militanten Egalitaristen wie auch die falschen Vorstellungen der kirchlichen Religionen zu vertreiben - aufklärerischer Exorzismus sozusagen: «si vous voulez chasser des esprits les utopies, si vouls voulez émonder les idées fausses, il faut que vous fassiez entrer dans l'esprit et dans le cœur de l'enfant des idées vraies sur la société où il doit vivre, sur les droits qu'il doit exercer».93

Die Schule als verlängerten Arm des Staates zielt ab auf das 〈Herz〉, auf die Umgestaltung des ganzen Menschen. Es erstaunt deshalb nicht, wenn Ferry in seinem Brief an die Lehrer ganz in Analogie zur biblisch-kirchlichen Sprache von Mission und Apostolat - «de mission et d'apostolat»94 - der Lehrer spricht. Obwohl er sogleich abschwächend anfügt, sie würden keineswegs als «l'apôtre d'un nouvel Évangile»95 verstanden, überzeugt dies nicht so ganz. Denn einige

89 Ferry 1996b, 108.

90 Ebd., ro9.

91 Jules Ferry zit. in Legrand i96 I, i 55.

92 Vgl. Osterwalder 1998, I 26 f.

93 Ferry 1996b, 53.

94 Ebd., I Iо.

95 Ebd. 
Zeilen weiter unten heisst es, dass die Lehrer als Hilfskraft des Familienvaters mit «force et autorité» 96 sprechen sollen, wenn es um unbestrittene Wahrheiten hinsichtlich einer gesellschaftlichen Einheitsmoral gehe. Was anderes als ein neues Heilsversprechen impliziert die Vermittlung der republikanischen Moral? Wenige Jahre zuvor forderte Ferry in einer Rede an einem Lehrerkongress (I 880) von diesen, sich nicht politisch zu betätigen. Im Dienste der Vermittlung der republikanischen Einheitsmoral stehend, sollten sie sich nicht in politische Streitereien verwickeln lassen, die trennen, anstatt $\mathrm{zu}$ einen. Es ist in diesem Zusammenhang nicht übertrieben, wie Osterwalder dies tut, die Lehrer als «moderne Heilige» $97 \mathrm{zu}$ bezeichnen, wenn Ferry Aussagen macht wie «l'éducateur sera désormais chose sacrée»..$^{8}$

In Anlehnung an den Erziehungswissenschaftler Louis Legrand erklärt Osterwalder Ferrys religiös aufgeladenen Anspruch an die öffentliche Schule und ihre Lehrer mit dessen Nähe zum Positivismus von Auguste Comte (I798-i 857). Affinitäten zu Comte habe Ferry auch offen zugestanden, obwohl er sich von gewissen Tendenzen des späteren Comte deutlich distanziert habe. ${ }^{99}$ Comte gilt als einer der Begründer der Soziologie. Am besten bekannt ist seine organologische Theorie der Menschheitsentwicklung in drei Stadien, das sogenannte Dreistadiengesetz, demnach die Menschheit drei aufeinanderfolgende Stadien durchläuft - das theologische, das metaphysische und das wissenschaftliche. Das erste Stadium erachtete Comte als notwendigen Startpunkt der geistigen Entwicklung des Menschen. In dieser Phase erklärt der Mensch in seiner Suche nach den Ursachen für die verschiedensten Phänomene scheinbare Anomalien im Universum mit übernatürlichen Akteuren. Das zweite Stadium unterscheidet sich vom ersten dadurch, dass die übernatürlichen Akteure durch abstrakte Entitäten ersetzt werden. Das letzte Stadium ist schliesslich dadurch gekennzeichnet, dass die Frage nach den Ursachen nicht mehr gestellt wird, sondern die Aufmerksamkeit bloss noch auf die den Phänomenen zu Grunde liegenden Gesetze gerichtet ist. ${ }^{100}$ Somit kommt in diesem letzten Stadium den modernen Wissenschaften prägende Kraft und Macht zu. Dieses teleologische Dreistadiengesetz macht deutlich, dass es Comte um weit mehr ging als um eine blosse Wissenschaftstheorie. Er entfaltet eine neue Gesellschaftsordnung, in der die soziale Einheit durch die Akzeptanz der Wissenschaft gewährleistet werden sollte. Eine Funktion, die bis dahin die Kirche erfüllte, wird umbesetzt. Comte spricht gar von einer «église positiviste», in der die Wissenschaftler in einer Art

96 Ebd.

97 Osterwalder 1998, I 28.

98 Ferry 1996a, 444.

99 Vgl. Osterwalder 1998, г 30.

I00 Bourdeau 2015. 
Dauer-Konzil ihre spirituelle Macht ausüben. In einer späteren Phase wandte sich Comte von der Vorstellung ab, dass die Wissenschaft aus sich heraus soziale Einheit stiften könne. Leitend wurde die Vorstellung, dass Voraussetzung für die gesellschaftliche Reorganisation nicht wissenschaftliche Erkenntnis sei, sondern ein nach sozialer Einheit strebendes Gefühl, das allerdings zuerst von der Religion abgelöst werden müsse. In seiner I 848 erschienenen Schrift Discours sur l'ensemble du positivisme legt Comte gemäss Osterwalder dar, dass sich die Wissenschaft diesem Gefühl unterordnen müsse, um zum Fortschritt der Menschheit und zu einer Neugestaltung der Gesellschaft beitragen zu können. Aus diesen Überlegungen folgte für Comte die Schaffung einer zwar wissenschaftlich konstruierten neuen Menschheitsreligion, die aber auf einem sozialen Gefühl beruht und nicht mehr auf der Verabsolutierung der Rationalität. Osterwalder weist darauf hin, dass Comte vor der Verfassung des Discours sur l'ensemble die positive Wissenschaft als Alternative zur Religion und Metaphysik erachtete, während sie im Discours sur l'ensemble zu einer der traditionellen Religion völlig entgegenstehenden neuen Gefühlsreligion geworden sei. ${ }^{\text {Ior }}$

Gemäss Osterwalder lernte Ferry das Denken Comtes durch die Lektüre des Discours sur l'ensemble kennen. Von diesem Denken ist vieles in sein laizistisches Schulprogramm eingeflossen. Der Vermittlung des «esprit d'ensemble», die Ferry als grundlegende Aufgabe der Schule erachtete, liegt die Vorstellung zu Grunde, dass einzig die Implementierung der von Comte entfalteten Menschheitsreligion einheitsstiftend wirken könne. Mit Comte bemängelte Ferry in seiner Freimaurerrede an der christlichen Religion, dass diese nicht wissenschaftlich gestützt sei und eine personalistisch-individualistische Ausrichtung habe, anstatt eine organisch-gesellschaftliche Glückseligkeit anzustreben. ${ }^{102}$ Auf dem Hintergrund dieser Kritik lässt sich auch Ferrys Bestreben einordnen, die Institution Schule von Staat und Politik unabhängig zu halten. Nach Comte kommt der wissenschaftlichen Bildungsanstalt «das Apostolat der gesellschaftlichen Ordnung zu», das als «pouvoir spirituel» über den Parteiquerelen um die weltliche Macht, die «pouvoir temporel», steht. Die Schule erhält den Auftrag, die bis anhin auf individuelle Erlösung - im christlichen Sinn - ausgerichteten menschlichen Seelen auf die Gemeinschaft hin auszurichten. ${ }^{103}$ In seiner Freimaurerrede betonte Ferry deutlich den Unterschied zwischen der christlichen Religion und der sogenannten Menschheitsreligion. Während im christlichen Ideal der Dienst an Gott allem zu Grunde liege und handlungsleitend sei, liege

Ior Vgl. Osterwalder 1998, I 29.

I02 Vgl. ebd., I30.

I03 Vgl. ebd., I3 I. 
in der Menschheitsreligion der Dienst an der Menschheit allen Handlungen zu Grunde und durchdringe die Erziehung eines wahren Dieners der Menschheit. ${ }^{104}$ Osterwalder formuliert pointiert, dass Ferrys stark an Comte orientierter Laizismus nicht eine Trennung der Schule von Kirche und Religion impliziere, sondern vielmehr «die christliche Religion durch die Religion der gesellschaftlichen Ordnung, den katholischen Klerus durch das wissenschaftlich-pädagogische Apostolat» ${ }^{10}$ ersetze. Indem die «école laïque» ein "pouvoir moral» sei, übernimmt sie die Funktion, die bisher der Kirche zukam.

Die Analyse des Erziehungshistorikers Osterwalder ist derjenigen des politischen Philosophen Eric Voegelin verblüffend ähnlich, wenn Letzterer in seinem Buch Politische Religionen im Kapitel «Ekklesia» die Fortführung des Kirchengedankens überall dort sieht, «wo die innerweltlich gewordenen partikulären Gemeinschaften die Gleichheit und Brüderlichkeit aller Glieder der Gemeinschaft anerkennen, und zwar auch dort, wo sich die Gemeinschaften und Bewegungen scharf antikirchlich und antichristlich einstellen bis zur Einführung einer neuen Staatsreligion, wie in der französischen Revolution». ${ }^{106}$ Gemäss Voegelin wurde die Idee der Solidarität von den laizistischen Denkern der Dritten Republik als säkularisierte christliche Caritas gedeutet. ${ }^{107}$

Weiter oben habe ich bereits erwähnt, dass Voegelin den Begriff politische Religion für totalitäre Regimes des 20. Jahrhunderts verwendete. Die Darstellung der école lä̈que in diesem Unterkapitel diente jedoch der Annäherung an den Begriff Zivilreligion. Der Unterschied zwischen politischer Religion und Zivilreligion ist freilich fliessend. Ein fundamentaler Unterschied zwischen politischer Religion und Zivilreligion besteht jedoch darin, dass Zivilreligion nicht hinter die in der Neuzeit errungene Trennung zwischen Bürgerrecht und Bekenntnis zurückwill, während Vertreter politischer Religionen gerade die Verschmelzung staatspolitischer und religiöser Identität anstreben.

\subsubsection{Säkulare Kulte als Mittel der öffentlichen Erziehung}

Ebenso wie die kirchlich-christlichen Inbalte republikanisch-säkular transformiert worden sind, gab es zu Revolutionszeiten solche Transformationsbestrebungen auch auf kultischer Ebene. Das Feiern von Festen als Mittel der öffentlichen Erziehung wurde bereits in den allerersten Projekten der Constituante geplant. Talleyrand versuchte noch national-patriotische und christliche Feste miteinander zu verbinden. Mit der Zeit kam jedoch der Gedanke auf, die traditionellen religiösen Feste durch patriotisch-pädagogische zu ersetzen. Als Beispiel

I०4 Vgl. ebd.

Ios Ebd.

I06 Voegelin I993, 34.

I07 Vgl. ebd. 
dafür ist der protestantische Geistliche Jean-Paul Rabaut Saint-Etienne zu nennen, der im Dezember 1792 im Konvent einen Erziehungsplan präsentierte, der demjenigen Condorcets völlig entgegengesetzt war: Anstatt einer strikten Trennung von Schule und traditioneller Religion plädierte er für die Transformation der traditionellen religiösen Erziehung in eine republikanische. ${ }^{108}$ Rabaut hält an einem Schulunterricht (l'instruction publique) zur Vermittlung der lumières fest. Doch soll dieser Unterricht zwingend durch eine nationale Erziehung (éducation nationale) ergänzt werden, die der Charakterbildung - Rabaut spricht von «former le cœur» ${ }^{109}$ - dient. Diese Nationalerziehung sprengt den Rahmen des traditionellen in Schulgebäuden stattfindenden Unterrichts. Sie findet draussen statt - auf öffentlichen Plätzen und in öffentlichen Hallen und umfasst alle Altersstufen und Geschlechter: «L'éducation nationale demande des cirques, des gymnases, des armes, des jeux publics, des fêtes nationales, le concours fraternel de tous les âges et de tous les sexes, et le spectacle imposant et doux de la société humaine rassemblée.» ${ }^{110}$

An diesen vielgestaltigen gemeinschaftlichen Anlässen sollen alle Bevölkerungsschichten teilnehmen und dadurch einerseits das nationale Zusammengehörigkeitsgefühl gestärkt und andererseits die neue aufklärerische Moral vermittelt werden. «Tous recevaient les mêmes impressions par les sens, par l'imagination, par la mémoire, par le raisonnement, par tout ce que l'homme a de facultés, et par cet enthousiasme que l'on pourrait appeler la magie de la raison..$^{111}$

Rabaut spricht nicht von ungefähr von der «Magie der Vernunft»: Das «Geheimnis» der sinnlich-emotionalen Berührung der Massen mittels Katechismen, Prozessionen, Zeremonien, Predigten, Hymnen usw. hätten schon die (römischkatholischen) Priester gekannt und sie für ihre Zwecke eingesetzt. Warum sollten nun, so Rabaut, die katholischen Rituale und «Methoden» nicht für die Durchdringung der Bevölkerung mit der republikanischen Moral benutzt werden? «[...] ne saurions-nous pas faire pour la liberté et la vérité, ce que vous avez fait si souvent pour l'erreur et l'esclavage?» ${ }^{112}$

Auf diesem Hintergrund ist es wenig erstaunlich, wenn das staatliche Gebäude, in welchem jeden Sonntag die patriotischen Hymnen gesungen, Diskurse über Moral abgehalten und von den «Moral-Beamten» («officiers de morale») die Rechte und Pflichten der Bürger vorgetragen werden sollten, den Namen Temple national erhalten sollte. Diese öffentliche nationale Erziehung sollte im Mittelpunkt stehen und der schulische Unterricht darauf bezogen werden. Die

I08 Vgl. Harten I990, $47 \mathrm{f}$.

I09 Rabaut Saint-Etienne 2000 [1792], 297.

I I $\mathrm{Ebd}$.

I I I Ebd., 296 f.

I 2 Ebd., 297. 
Kinder hätten die Erklärung der Menschenrechte und die wichtigsten zivilen Hymnen auswendig zu lernen. Und am «Fest der Kinder», jeweils am I. Sonntag im Juli, sollten sie an einer öffentlichen Prüfung darüber befragt werden. ${ }^{\mathrm{I}} 3$

Im Zuge dieser Transformation von christlich-religiösen Inhalten und Methoden zu zivil-religiösen wurden als methodisch-didaktische Hilfsmittel in Analogie zu den christlich-religiösen Katechismen republikanische Katechismen ${ }^{114}$ entwickelt, die viele Lehrer - wie zuvor die religiösen Katechismen - auswendig lernen liessen. ${ }^{\text {Is }}$

\subsubsection{Traditionell religiöse Symbolik und Praktiken im öffentlichen Raum}

Mit der Darstellung von Jules Ferrys laizistischer Schule wurde in Unterkapitel 2.4. I Zivilreligion als Gegen-Religion zur traditionellen christlich-katholischen Religion beschrieben. Der religiöse Anspruch der katholischen Schule, den Menschen in seiner Gesamtheit inklusive seiner Seele zu ergreifen, wurde beibehalten, aber mit einem neuen, säkular-nationalen Inhalt gefüllt. Das Ziel der laizistischen Schule bestand nicht mehr darin, die Kinder zu gottgefälligen Menschen zu erziehen, sondern zu staatstüchtigen, republikanischen Bürgern. Wie im Unterkapitel 2.4.2 gezeigt wurde, gab es in Frankreich zu Revolutionszeiten

II 3 Ebd. $299 \mathrm{f}$.

I 4 Ein helvetisches Beispiel für einen solchen republikanischen Katechismus ist der von GabrielAntoine Miéville verfasste Helvetische Katechismus, das heisst, die «Erklärung der helvetischen Konstitution in Fragen und Antworten», der 1798 in Luzern erschien. Das erste Kapitel mit der Überschrift «Einleitung oder von der Umschaffung Helvetiens» beginnt mit folgenden Fragen: «Wie heisst man das, was itzt in der Schweiz, oder in Helvetien vorgeht? Antwort. Man heisst es die Umschaffung Helvetiens; Fr. Worauf bezieht sich diese Umschaffung [...]? Ant. Sie bezieht sich auf die Regierung Helvetiens. Die Art und Weise, wie in jedem Lande der Schweiz die Obrigkeiten gewählt wurden und wie sie das Volk regierten, wird gänzlich abgeändert; Fr. Was wird itzt der Schweiz für eine Regierung gegeben? Ant. Eine freye Regierung $[\ldots]$ Fr. Was hatte die Schweiz, die Verfassung und Regierung betreffend, bisher für einen Zustand? Ant. Es war hierinn in keinem Staate in der Welt eine so grosse Ungleichheit, wie in der Schweiz. [...] Alle Regierungsarten fand man in dem kleinen Lande der Schweiz. In mehreren Kantonen war die Aristokratie eingeführt, wo nur einige das Regiment führten, die einander selbst erwählten, oder gar erblich, ohne Rücksicht auf Fähigkeit und Tugend, einander in der Regierung folgten; in andern war eine vollkommene Demokratie». (Miéville $\mathrm{I} 798,3 \mathrm{ff}$. .). Es ist jedoch anzumerken, dass dieser Katechismus nicht einmal in den Schulen des revolutionären Kantons Waadt verwendet wurde, da sein Inhalt als politisch zu heikel angesehen wurde (vgl. Tosato-Rigo 2009, 70).

I Is Insofern zur Revolution das Postulat der politischen Partizipation gehörte, waren neue Unterrichtsmethoden gefragt, welche die erforderten kognitiven Fähigkeiten befördern sollten. Harten betont jedoch, dass diese «neuen» Unterrichtsmethoden keineswegs Innovationen waren, sondern vielmehr die «forcierte Weiterentwicklung einer Bewegung, die ihren Ursprung im Ancien Régime hatte» (Harten 1990, 106). Dass man dennoch gerade in der Volksschule beim traditionellen Memorieren blieb, erklärt Harten damit, dass die meisten Bürger weder Bücher kannten noch lesen konnten und mittels des Auswendiglernens das neue aufklärerisch-republikanische Gedankengut im kollektiven Gedächtnis verankert werden konnte (vgl. Harten 1990, 108). 
und ebenso in der Dritten Republik Bestrebungen, auch im kultischen Bereich das traditionell Christliche ins Säkular-Nationale umzuwandeln. Zivilreligion kann so gesehen als Transformation des traditionell Christlich-Religiösen ins National-Religiöse verstanden werden.

Demgegenüber impliziert das amerikanische Verständnis von Zivilreligion nicht wie im laizistisch-französischen Fall die Transformation der traditionell christlichen Institutionen, Inhalte und Kulte mit dem Ziel, diese letztendlich auszumerzen. Den traditionell christlich-religiösen Gehalten und Kulten wird nichts entgegengesetzt, sondern sie werden vielmehr im politischen Raum zu säkular-nationalen Zwecken eingesetzt.

Der Blick soll nun wieder auf die Verhältnisse in der Schweiz gerichtet werden. Im Zusammenhang mit der Frage, wie neutral die Rechtsprechung des schweizerischen Bundesgerichts in Glaubens- und Weltanschauungsfragen ist, erörterte der Rechtswissenschaftler Andreas Kley in einem Aufsatz die interessante Frage, ob zivilreligiöse Akte gerichtlich angefochten werden könnten. Könnte beispielsweise eine Zuhörerin einer bundesrätlichen Rede, in die zivilreligiöse Elemente eingewoben worden sind, mit Rekurs auf Art. 25 a des revidierten Verwaltungsverfahrensgesetzes «die Behauptung aufstellen, dass die Verwendung christlicher Elemente die Pflicht des Staates zur religiösen Neutralität im Sinne eines subjektiven Abwehranspruches aus Art. is Abs. I BV verletze und insofern 〈widerrechtlich〉 sei?» ${ }^{116}$ Kley beantwortet die Frage verneinend. Für den Zweck dieser Untersuchung interessiert jedoch weniger Kleys Antwort als vielmehr sein für seine Argumentation vorausgesetztes Verständnis von Zivilreligion und seine Vorstellung des Zweckes, den diese erfüllen soll. Sich auf Robert N. Bellah stützend, beschreibt Kley Zivilreligion als «ein Gefüge von Glaubensaussagen, Symbolen und Ritualen, das unabhängig vom kirchlichen Kontext in der politischen Kultur eines Staates benutzt wird». ${ }^{117} \mathrm{Zu}$ den Phänomenen so verstandener Zivilreligion gehören nach Kley «die Verwendung von religiösem Vokabular in Verfassungs- und Gesetzestexten (z. B. die invocatio Dei in der Präambel der Bundesverfassung), die Verwendung von Bibelzitaten in politischen Reden, die Gestaltung von staatlichen Feiern nach dem Vorbild kirchlicher Liturgien oder die Schaffung von nationalen Gedenkstätten nach dem Muster religiöser Heiligtümer». ${ }^{\text {I } 8}$

II 6 Kley 2008, 96.

I I7 Kley 2008, 89. Kley beschäftigt sich in diesem Aufsatz unter anderem mit der Frage, ob die bisher in der Rechtsprechung ausgeblendete Zivilreligion durch Art. 25 a des 2007 revidierten Verwaltungsverfahrensgesetzes Berücksichtigung finden und zivilreligiöse Akte gerichtlich angefochten werden könnten (vgl. Kley 2008, 89 ff.).

I 8 Kley 2008, 89 . 
Den Zweck von Zivilreligion sieht Kley in ihrer stabilisierenden Funktion. Zwar drücke sich die Herrschaft des freiheitlichen Staats in Gesetzen, Gerichtsurteilen und behördlichen Anordnungen aus, doch sei es ein Irrtum zu glauben, ein Rechtsstaat könne existieren, ohne dass sich die ihm unterworfenen Menschen freiwillig an die Gesetze und die Anordnungen hielten. Der freiheitliche Charakter ginge verloren - bzw. mutierte zur Anarchie oder Diktatur -, wenn die Bürgerinnen und Bürger nur mittels staatlichen Zwangs zur Befolgung der staatlichen Ordnung gebracht werden müssten. ${ }^{\text {I9 }}$ In Anlehnung an David Hume ${ }^{120}$ erachtet Kley Gehorsam gegenüber dem demokratischen Staat und dessen Gesetzen vielmehr als «eine Frage der Meinung, der Überzeugung und des Glaubens, dass diese Herrschaft, die da demokratisch und rechtsstaatlich ausgeübt wird, rechtmässig, gerecht und letzten Endes von einer höheren Macht gewollt» ${ }^{\mathrm{I} I}$ sei. Die Zivilreligion werde benötigt, um ebendiese Meinung, Überzeugung und den Glauben an die politische Herrschaft zu unterstützen und zu befördern. Dies geschieht durch explizite Verweise - und häufig auch durch implizite Anspielungen - auf die traditionelle religiöse Ordnung, die im Christentum darauf beruhe, «dass es nach dem Leben auf der Welt letztlich ein erlöstes ewiges Leben bei Gott» gebe. Kley spricht der traditionellen Religion eine zivilisierende Funktion zu, indem sie den Menschen «die Einhaltung der göttlichen Ordnung auferlegt und ihnen einen festen Sitten- und ideellen Rahmen gibt». ${ }^{122}$ Genau dieses sittliche und ideelle Band benötige der freiheitliche Staat, damit sich die Menschen freiwillig der demokratischen Ordnung unterordneten. Die Zivilreligion wirke «der Masslosigkeit, dem Egoismus und dem unbändigen Trieb der Menschen nach materiellen Genüssen entgegen». ${ }^{123}$ Kley verweist diesbezüglich erneut auf Bellah, der John Adams, den zweiten Präsidenten der USA, zitierte, um die Notwendigkeit von Zivilreligion zu erläutern: «Wir haben keine Regierung, die mit genügend Macht ausgestattet wäre, um gegen menschliche Leidenschaften anzukommen, die nicht von der Moral und der Religion im Zaum gehalten werden.» ${ }^{124}$

Anstatt Zivilreligion wie in der französischen Spielart als Gegenreligion zu verstehen, wird in dem hier von Kley vorausgesetzten, amerikanischen Verständnis von Zivilreligion von der traditionellen christlichen Religion politischen $G e-$

I19 Ebd.

I 20 «Regierung gründet sich [...] ausschliesslich auf Meinung» (David Hume, Politische und ökonomische Essays, zit. in Kley 2008, 90).

I 2 I Kley 2008, $89 \mathrm{f}$.

I 22 Ebd., 90.

I 23 Ebd.

I 24 Bellah 2004b, 56; vgl. Kley 2008, 90. 
brauch gemacht. Zivilreligion ist so gesehen auf lebendige traditionell-religiöse Gemeinschaften angewiesen. Sie zehrt von deren Ressourcen.

Hier stellt sich mir die Frage, was geschieht, wenn die Inhalte der traditionellen Religionen in Vergessenheit geraten und nur noch eine geringe Minderheit darüber Bescheid weiss und ihr Leben danach ausrichtet. Wird der Zivilreligion, wie Kley dies tut, stabilisierende Funktion unterstellt, dann wäre in diesem Fall die Stabilität des freiheitlichen Staates in Frage gestellt. Die These legt sich nahe, dass das durch das Wegbrechen der traditionellen Religionen entstandene Vakuum durch die Rhetorik der Werte gefüllt worden ist. Die Verwendung und die Funktion des Wertbegriffs in der Diskussion um den schulischen Religionsunterricht werden in den Kapiteln 9 und io dargestellt und diskutiert. Niklas Luhmann stellte zwischen Zivilreligion und der Grundwertedebatte eine Verbindung her, die im folgenden Unterkapitel jedoch noch kurz dargestellt werden soll.

\subsection{Grundwerte als Zivilreligion}

Obwohl Luhmann, wie bereits weiter oben erwähnt wurde, als derjenige gilt, der den Begriff Zivilreligion aus dem amerikanischen (civil religion) in den deutschen Sprachraum eingeführt hatte, erhält Zivilreligion durch die Verbindung mit der Grundwertedebatte bei ihm eine etwas andere Bedeutung als bei Bellah. ${ }^{125}$ Während Bellah unter ¿Zivilreligion> religiöse Symbolik versteht, die unabhängig von religiösen Institutionen Teil der politischen Kultur ist, ${ }^{126}$ bezeichnet ¿Zivilreligion〉 gemäss Luhmann «Mindestelemente eines religiösen oder quasireligiösen Glaubens ...], für den man bei allen Mitgliedern der Gesellschaft Konsens unterstellen» ${ }^{127}$ könne. Dazu gehöre «die Anerkennung der in der Verfassung kodifizierten Wertideen», ${ }^{128}$ die in der deutschen politischen Diskussion «Grundwerte» genannt werden, zum Beispiel «Vorstellungen über Gerechtigkeit, Fairness, Durchsetzungswürdigkeit des Rechts, Gleichheit des Zugangs aller zu allen Funktionen». ${ }^{\mathrm{I} 2}$

Aus systemtheoretisch-soziologischer Perspektive wird die gegenwärtige Gesellschaft gemäss Luhmann als funktional ausdifferenzierte analysiert. ${ }^{1{ }^{\circ} \circ}$ Dies bedeutet, dass «die〉 Gesellschaft aus verschiedenen Teilsystemen besteht, die ent-

I $25 \mathrm{Vgl}$. Schieder 2004, 715.

I 26 Vgl. ebd.

I 27 Luhmann 2004, I75.

I 28 Ebd.

I 29 Ebd.

I 30 Vgl. ebd., I 86. 
sprechend spezifischer Funktionen ausdifferenziert sind. Eine solch spezifische Funktion kann nur innerhalb eines solchen Teilsystems einen relativen Primat vor anderen Funktionen erhalten. Zugleich aber - Luhmann betont, dass dies oft übersehen werde - sei «die Gesamtgesellschaft als soziale Umwelt jedes ihrer Teilsysteme ein eigenes System, und auf dieser Ebene können die Funktionen nicht differenziert werden». ${ }^{\mathrm{I}}{ }^{\mathrm{I}}$

Abhängig davon, ob die Gesellschaft als «Umwelt ihrer Teilsysteme oder als Gesamtheit dieser Teilsysteme fungiert», ${ }^{132}$ ist sie immer eine undifferenzierte und eine differenzierte zugleich. Luhmann zeigt hinsichtlich der Religionsthematik sogleich auch das Problem auf, das sich mit einer solchen Analyse ergibt. Einerseits ist «aus den Allgemeinbestimmungen der Gesellschaft oder der Sozialität die religiöse Komponente» ${ }^{133}$ begrifflich nicht einfach zu eliminieren, auch wenn diese sich noch so säkularisiert gibt; andererseits lassen sich mit «Formulierungen über allgemeingesellschaftliche Religiosität» ${ }^{134}$ nicht erfassen, was Hochreligionen und religiös anspruchsvolle Menschen unter Religiosität verstehen. Denn ein differenziertes religiöses Bewusstsein entwickelt sich nur in gesellschaftlichen Teilsystemen. Eine allgemeine säkulare Zivilreligion leistet diesbezüglich zu wenig.

Ausgehend von der Unterscheidung zwischen allgemeiner religiöser Sensitivität, «die mit Sozialität schlechthin gegeben ist», und «innergesellschaftlichen Sonderformen», ${ }^{135}$ wie zum Beispiel Religionsgemeinschaften, kann sich Zivilreligion nur auf die Gesamtgesellschaft beziehen. Alle religiösen Besonderheiten und Unterschiede werden auf Teilsysteme innerhalb der Gesellschaft zurückgeführt. Das Verhältnis von Gesellschaft und Religion wird analog begriffen wie das Verhältnis von Gesellschaft und Wirtschaft, Gesellschaft und Politik, Gesellschaft und Erziehung oder Gesellschaft und Wissenschaft. Es gibt eine Vielfalt gesellschaftlicher Sphären, die je bestimmte Funktionen erfüllen und das Verhältnis der Gesamtgesellschaft zu diesen einzelnen Sphären ist bei allen gleich, insofern es ein Verhältnis von einem Ganzen zu einem Teil ist. Gemäss Luhmann kann in einer modernen Gesellschaft «das Ganze und Allgemeine nicht mehr das Eigentliche sein» so wie in Theoriemodellen der ständischen Tradition, «nach denen das Ganze das Höchste und das Beste und der Endzweck» ${ }^{136}$ war.

I3 I Ebd., i 87.

I 32 Ebd.

I 33 Ebd.

I 34 Ebd.

I35 Ebd.

I 36 Ebd., I 88. 
Insofern sich Zivilreligion auf die Gesamtgesellschaft bezieht, kann sie nicht als eine Religion neben anderen behandelt werden. Es steht dem Einzelnen deshalb nicht im selben Sinne frei, sich zur zivilen Religion zu bekennen wie beispielsweise zur christlichen, jüdischen oder islamischen. Der Zivilreligion wird im Unterschied zu dem, was gemeinhin als Religion bezeichnet wird, ein gesellschaftlicher Wertekonsens unterstellt. Luhmann geht davon aus, dass jede sprachliche Kommunikation «mit der Unterstellung eines Wertkonsenses operiert», da ein solcher überhaupt erst «die Selektion spezifischer Themen ${ }^{137}$ ermögliche. Wobei damit allerdings kein empirisch überprüfbarer Konsens gemeint ist, sondern eine laufend in Anspruch genommene Prämisse. $\mathrm{Da}$ dieser Konsens jedoch bloss unterstellt wird, zeigen sich unweigerlich Differenzen, sobald versucht wird, diesen Konsens zu konkretisieren bzw. in Worte zu fassen. Luhmann vergleicht Zivilreligion mit neutralem Licht, dessen Farben erst sichtbar werden, wenn es gebrochen wird. Wenn ich richtig sehe, bedeutet dies, dass die Konkretisierung von Zivilreligion jeweils nur aus einer bestimmten Perspektive gemacht werden kann und damit seinen vermeintlich allgemeinen und neutralen Charakter verliert. Luhmann stellt am Ende seines Artikels über Zivilreligion deshalb die berechtigte Frage, ob Zivilreligion überhaupt formulierbar sei. In der aktuellen Diskussion um Grundwerte werde Formulierbarkeit unterstellt, doch aus systemtheoretischer Sicht lässt sich die Antwort auf diese Frage nach Luhmann nicht eindeutig beantworten. ${ }^{1{ }^{38}}$

\subsection{Bestimmung des Begriffs Zivilreligion}

Das nun folgende Unterkapitel hat zum Ziel, die Erkenntnisse der vorangegangenen Auslegeordnung zu den verschiedenen Aspekten und Verständnissen von Zivilreligion so zu ordnen und zusammenzufassen, dass der Begriff Zivilreligion seinen heuristischen Zweck der Analyse der Diskussion des schulischen Religionsunterrichts erfüllen kann. Meine Arbeitsdefinition von Zivilreligion werde ich in fünf Punkten darlegen:

I. Zivilreligion ist ein Phänomen der Säkularisierung, insofern sie zum einen eine (zumindest in Ansätzen) funktional ausdifferenzierte Gesellschaft voraussetzt oder zumindest in diese Richtung weisende Bestrebungen und zum andern eine religiös-weltanschaulich heterogene Gesellschaft, in der Religionsfreiheit 
herrscht. Unter gesellschaftlicher Ausdifferenzierung ist die Differenz zwischen Staat und Gesellschaft bzw. zwischen Staat und den unterschiedlichen gesellschaftlichen Sphären wie die religiöse, ökonomische oder familiäre gemeint. Dies im Unterschied zum corpus christianum der Vormoderne, in dem Staat und Kirche eine Totalität bildeten. ${ }^{139}$ Hermann Lübbe spricht von Zivilreligion als «Religion nach religionspolitisch vollendeter Aufklärung» ${ }^{140}$ und meint damit die Trennung von Bürgerrecht und Bekenntnis. Eine solche Trennung impliziert die funktionale Ausdifferenzierung der politischen und religiösen Sphäre, das heisst die Anerkennung unterschiedlicher Aufgabenbereiche religiöser Gemeinschaften und des Staats.

2. Zivilreligion ist im Spannungsfeld zwischen gesellschaftlicher Ausdifferenzierung und Religionsfreiheit einerseits und dem Bemühen um politische Einheit und Integration andererseits anzusiedeln und wird als mögliche Antwort auf dieses ungelöste Problem angesehen. Geht man davon aus, dass im Mittelalter die Kirche und ihre religiösen Praktiken die gesellschaftliche Klammer bildete, stellt sich die Frage, wie in einer Gesellschaft, in der die Kirche und deren Inhalte an Bedeutung und Macht verloren haben, der gesellschaftliche Zusammenhalt gewährleistet werden kann.

3. Es sind zwei verschiedene Idealtypen von Zivilreligion $\mathrm{zu}$ unterscheiden: der französische und der amerikanische Typus. Im französischen Typus wird Zivilreligion als säkular-republikanische Gegenreligion zur traditionellen christlich-kirchlichen - in Frankreich insbesondere in ihrer gallikanischen Ausprägung - Religion verstanden. Der Anspruch des christlichen Glaubens, den ganzen Menschen mitsamt seiner Seele zu ergreifen, wird beibehalten, aber mit einem neuen, säkular-nationalen Inhalt gefüllt. Dieser Typus von Zivilreligion wurde am Beispiel der école laïque von Jules Ferry illustriert. Deren Ziel ging weit darüber hinaus, den Kindern die notwendigen Kulturtechniken beizubringen, damit sie sich am demokratischen Prozess zu beteiligen vermögen und somit ihre Pflichten als Bürger einer Republik erfüllen können. Der Auftrag der Schule bestand nach Ferry vielmehr darin, die traditionelle in der Öffentlichkeit wirksame christliche Religion zu ersetzen, indem sie den Kindern die richtige Moral, das heisst, die republikanische Einheitsmoral, vermittelt. Dieser Typus von Zivilreligion setzt die Überzeugung voraus, dass die Stabilisierung der Herrschaft des freiheitlich-republikanischen Staates einen in der Schule zu vermittelnden «esprit d'ensemble» bedingt. Kurzgefasst lässt sich Zivilreligion dieses Typus als eine Transformation des traditionell

I 39 Vgl. Maier 2007 [1995].

I 40 Lübbe 2004, I 97. 
Christlich-Religiösen ins National-Religiöse beschreiben und insofern mit Osterwalder als eine Sakralisierung des Staates und der Gesellschaft oder mit Voegelin als eine Re-Spiritualisierung des Innerweltlichen bezeichnen. ${ }^{141}$ Der Staat wird zu einer Glaubensgemeinschaft. Der amerikanische Typus von Zivilreligion impliziert dagegen nicht wie im laizistisch-französischen Fall die Transformation der traditionell christlichen Institutionen, Glaubensinhalte und Kulte mit dem Ziel, diese letztendlich auszumerzen. Den traditionell christlich-religiösen Glaubensinhalten und Kulten wird nichts entgegengesetzt. Sie werden vielmehr im politischen Raum zu säkular-nationalen Zwecken eingesetzt. Anstatt Zivilreligion als Gegenreligion zu verstehen, wird von den Glaubensinhalten, Symbolen und Ritualen der traditionellen Religionen bzw. Konfessionen politischer Gebrauch gemacht. So gesehen ist Zivilreligion auf lebendige traditionell-religiöse Gemeinschaften angewiesen und zehrt von deren Ressourcen. Ein gemeinsames Bekenntnis ist nicht nötig, da im denominationalistischen Amerika Transzendenz mindestens in Form eines Deismus unterstellt und davon ausgegangen wird, dass alle Menschen einer Religionsgemeinschaft bzw. Denomination angehören.

4. Zivilreligion hat einen paradoxen Aspekt: Sie setzt funktionale gesellschaftliche Ausdifferenzierung voraus, trägt zugleich aber in sich Tendenzen zur Auflösung ebendieser Grenzen gesellschaftlicher Sphären. Der Grund dafür liegt darin, dass einerseits die freiheitliche Errungenschaft der Trennung von Bürgerrecht und Bekenntnis beibehalten werden soll, andererseits aber zugleich das Streben nach der Wiederherstellung der idealisierten antik-römischen symbiotischen Einheit von Politik und Religion zum Programm gehört, da von der Annahme ausgegangen wird, dass politische Verfahren allein nicht genügten, um die freiheitlichen Errungenschaften des modernen liberaldemokratischen Nationalstaates aufrechtzuerhalten, sondern der freiheitliche Staat in irgendeiner Form auf vorpolitische Grundlagen angewiesen sei. ${ }^{142}$ Eine solche Auflösungstendenz zeigt sich insbesondere beim französischen Typus.

5. Ein weiteres Indiz für Zivilreligion ist, wenn das, was gemeinhin als universal erachtet wird - zum Beispiel die 〈Vernunft〉oder das 〈Humanum〉 - staatlich unterstützt bzw. als notwendig für das staatliche Funktionieren erachtet wird.

I4 I Vgl. Osterwalder 1998, I35 f.; Voegelin 1993, 34; Katzenstein 2013, I 8 ff.

I42 Vgl. Maier 2007 [1995]; Müller 2005, 45. 
Kulminationspunkt eines zivilreligiösen Glaubens ist, wenn die historische Kontingenz und Partikularität jeglichen Anspruchs auf Universalität negiert wird. ${ }^{143}$

I43 Die historische Wandelbarkeit dessen, was als universal bzw. partikular gilt, kann am Beispiel der Begriffe Konfession und Religion aufgezeigt werden. Im 19. Jahrhundert hatten Konfessionen (protestantisch, katholisch usw.) den Status des Partikularen, während «Religion` auf etwas Universales, allgemein Menschliches hinzuweisen schien. Insofern aber Religion im Westeuropa des 19. Jahrhunderts christlich - wenn auch nicht christlich im konfessionellen Sinn - gedacht worden war, kann aus der Perspektive multireligiöser, pluralistischer Gesellschaften des 2I. Jahrhunderts so verstandener Religion keinen universalen Charakter mehr zugeschrieben werden. Denn keine spezifische Religion oder Weltanschauung kann universalen Charakter beanspruchen. Heute kommt dem Glauben an die Würde der Menschen, die sich in den Allgemeinen Erklärungen der Menschenrechte ausdrückt, universale Bedeutung zu. Aus nicht westlicher, globaler Perspektive kann natürlich auch dieser Glaube an die Menschenwürde als weiteres um Anerkennung buhlendes spartikulares Universales b betrachtet werden. Die vermeintlich klare Unterscheidung zwischen partikular und universal fällt vollends in sich zusammen, wenn man sich vergegenwärtigt, dass der partikulare jüdisch-christliche biblische Glaube, um nur ein Beispiel zu nennen, einen universalen Anspruch hat, wenn er davon ausgeht, dass jeder Mensch als Ebenbild Gottes gleich geschaffen ist. Dieser Glaube wird de facto nicht von allen Menschen geteilt. Dies ist aber auch nicht der Fall hinsichtlich eines ‘Humanum〉 oder einer <universalen Religion` oder irgend etwas, das universalen Charakter beansprucht. 


\section{Die zürcherische Volksschule im Spannungsfeld zwischen Kirche und Staat}

Die Situierung der öffentlichen Diskussionen um den schulischen Religionsunterricht Ende des 19. und Anfang des 21. Jahrhunderts in der Geschichte der Volksschule des Kantons Zürich basiert auf der Annahme, dass historische Ereignisse und Prozesse - sowohl vergangene wie auch gegenwärtige - nicht adäquat verstanden werden können, ohne ihre Vorgeschichte zu kennen. Dieser historische Einblick hat aber nicht den Anspruch, die Entwicklung der zürcherischen Volksschule und die damit zusammenhängenden historischen Gegebenheiten umfassend darzulegen. Der Blick fokussiert auf die Bereiche, die im Zusammenhang dieser Arbeit von Belang sind. Da sich die öffentliche Schule im Kanton Zürich im spannungsvollen Wechselspiel zwischen Kirche und Staat entwickelt hat, soll als Erstes die Veränderung des Verhältnisses zwischen Kirche und Staat im Kanton Zürich seit der Reformation in den Blick genommen werden (Unterkapitel 3.I). Als Zweites interessiert der Säkularisierungsprozess der Volksschule (Unterkapitel 3.2). Die Veränderung der Aufsicht über die Schule ist in diesem Zusammenhang ein zentraler Aspekt. Da im Fokus dieser Arbeit die Diskussion um den schulischen Religionsunterricht steht, soll als Drittes die Geschichte des schulischen Religionsunterrichts überblicksartig dargestellt werden (Unterkapitel 3.3).

\subsection{Vom Wandel des Verhältnisses zwischen Staat und Kirche im Kanton Zürich}

Bis ins 19. Jahrhundert bestand im Kanton Zürich zwischen Kirche und Staat ein enges Verhältnis. Die Kirche wurde als Teil des Staates betrachtet. Kirchen- und Staatsbürgerschaft fielen zusammen und sowohl kirchliche als auch bürgerliche Gesetze wurden vom Staat erlassen. Der Rat bestimmte sowohl über Ordnung und Organisation der Kirche als auch über ihre Lehre. Gemäss Hans Heinrich Schmid schwebte Zwingli eine Art Theokratie vor, in dem Sinne, «dass letztlich das Wort Gottes den Staat leiten sollte». ${ }^{1}$ Den Pfarrern wies er das «Wächteramt» 
zu. Sie hatten die Obrigkeit zu beraten und zu ermahnen und der Gemeinde anzuzeigen, wenn der Rat nicht gottgemäss handelte. ${ }^{2}$

Bis zum Ende des i 8. Jahrhunderts kann von einer Staatskirche gesprochen werden. Dies war nach Schmid die Folge einer Erstarrung der reformatorischen Bewegung. Die Haltung, dass der reformatorische Geist nur noch mit Zwangsmassnahmen bewahrt werden könne, führte «zu einem von Kirche und Staat gemeinsam getragenen aristokratischen Absolutismus. Die Gewalt der Regierung wurde beinahe schrankenlos, und die Kirche diente als deren Werkzeug zur Erhaltung des Gehorsams der Untertanen».3

Die Räte wurden auf die evangelische Lehre verpflichtet, es bestand ein Zwang zum Kirchenbesuch, die Zensur wurde eingeführt und Kirchen- und Sittenmandate erlassen. Innerkirchlich entstand eine geistig enge Orthodoxie und religiöse Intoleranz. Man sprach "von der alleinseligmachenden reformierten Kirche» ${ }^{4}$ und 1755 wurde ein Polizeimandat erlassen, demgemäss die Heirat mit einer Katholikin zum Verlust der bürgerlichen Rechte führte. ${ }^{5}$

Die Französische Revolution hatte auch Auswirkungen auf das Verhältnis zwischen Kirche und Staat im Kanton Zürich: Sowohl die Helvetische Verfassung als auch die darauf folgende Mediationsverfassung ${ }^{6}$ garantierten Glaubens- und Gewissensfreiheit. Die Kirche aber blieb weiterhin der Obrigkeit unterstellt und besass nach wie vor die Aufsichtsfunktion über Sitte und Ehrbarkeit, Anstand beim Gottesdienst, die Sitten der Jugend und über die Schule. Neu aber war, dass man auch von Staatsbürgern ausging, die sich nicht zur reformierten Religion bekannten. So heisst es im Kirchengesetz von i 803 in Art. I: «Der Canton Zürich, in wie weit er sich zur reformirten Religion bekennt, macht eine, unter einer Aufsicht stehende Kirche aus.»’ Gemäss Schmid ist dieser Artikel als ein erster Schritt zur Unterscheidung von Staat und Kirche zu verstehen. Dass überhaupt ein spezielles Kirchengesetz erlassen worden sei, deute darauf hin, dass die Zürcher Kirche «als Grösse eigenen Wesens und eigenen Rechts zu verstehen sei. Die bisherige reine Staatskirche wandelt sich zur 〈Kirche im Staat〉». ${ }^{8}$

Die erste liberale Zürcher Staatsverfassung von I83 I, angestossen durch den Ustertag von I 830, tangierte auch das Verhältnis von Kirche und Staat. Es kam

2 Vgl. ebd.

3 Ebd., 200.

4 Ebd., 200.

5 Vgl. ebd.

6 In Art. 20 der Mediationsverfassung heisst es: «Die Verfassung sichert die Religionen, die im Kanton Zürich ausgeübt werden» (Mediationsverfassung von I 803, zit. in Schmid I994, 202). Gemäss Schmid nahm Art. 20 der Mediationsverfassung Bezug auf die Tatsache, dass das katholische Rheinau seit 1798 und das zum Teil katholische Dietikon seit I 803 zum Kanton gehörten (vgl. Schmid I 994, 202).

7 Kirchengesetz von I803, Art. I, zit. in Schmid I994, 201.

8 Schmid I994, 202. 
zu einer deutlichen Unterscheidung, wenn auch nicht Trennung, von Kirche und Staat. So heisst es in Paragraph I des Kirchengesetzes von I83 I: "Die Zürcherische vom Staat anerkannte Landeskirche ist die Gesammtheit aller zur christlichen Religion nach dem evangelisch-reformirten Lehrbegriffe sich bekennenden Einwohner des Cantons.»9

Im Unterschied zum Kirchengesetz von I 803 sind es nun die reformierten Einwohner des Kantons, die die Kirche «ausmachen» und nicht mehr der Kanton, soweit «er sich zur reformirten Religion bekennt». ${ }^{\circ}$ Die Kirche wurde vom Staat in ihrer Existenz und ihrem Auftrag offentlich anerkannt und war somit nicht mehr Staatskirche. Dennoch blieb die rechtliche Beziehung zwischen Staat und Kirche bestehen: «Die Zürcherische Kirche ist nach ihrem inneren Wesen und Wirken selbstständig, äusserlich aber dem Staat untergeordnet und

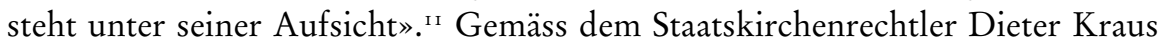
wurde erstmals zwischen rein kirchlichen Angelegenheiten wie beispielsweise Gottesdienst, kirchlichem Religionsunterricht, Seelsorge oder Liturgie und äusseren kirchlichen Angelegenheiten wie zum Beispiel die Kirchenorganisation unterschieden. Beschlüsse über innerkirchliche Angelegenheiten wurden von der Kirchensynode gefasst. Der eigentliche Rechtsetzungsakt konnte jedoch nur vom Grossen Rat vorgenommen werden, wobei Synodalbeschlüsse als bindend angeschaut wurden. Dies im Unterschied zu Gutachten der Synode zu äusseren Angelegenheiten. Den Inhalt dieser Gutachten konnte der Grosse Rat ignorieren. ${ }^{12}$

Im Zuge dieser Entflechtung zwischen Kirche und Staat wurde die Kirche von verschiedenen Verpflichtungen befreit, die sie bis anhin im Namen der staatlichen Obrigkeit ausgeübt hatte: Das Schul-, Armen- und Rechtswesen musste als staatliche Aufgabe neu organisiert werden. Die Kirche entzog sich deshalb aber nicht jeglicher Verantwortung gegenüber dem Staat. ${ }^{13}$ Es kam jedoch zu einer Ausdifferenzierung von politischer Gemeinde, Schulgemeinde und Kirchgemeinde. Zudem ermöglichte das Gesetz auch den Kirchenaustritt, ohne dass damit der Verlust der bürgerlichen Rechte einherging. Damit konnte

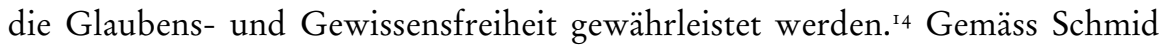
waren damit «Kirche und Staat ihrem Auftrag und ihrem Bestand nach bereits

9 Zit. nach Schmid I994, 204.

I0 Kirchengesetz von I 803, Art. I, zit. in Schmid I994, 201.

I I Kirchengesetz von I 83 I, $\mathbb{S}$, zit. in Schmid I994, 204.

I2 Vgl. Kraus I993, I55.

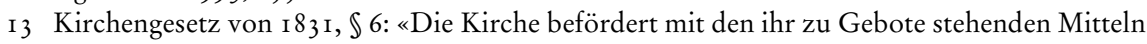
die Wohlfahrt des Staates.» (Zit. in Schmid I994, 205.)

I4 Vgl. Schmid I994, $204 \mathrm{f}$. 
weitgehend getrennt, auch wenn sie in ihren Rechtsgrundlagen und ihren Organisationsstrukturen weiterhin miteinander verbunden bleiben». ${ }^{\text {Is }}$

Jakob Streuli betont in seiner Dissertation, dass die Entstehung des zürcherischen Rechtsstaates zu einem grossen Teil der Kirche zu verdanken sei. Sie habe mit der Erfassung der Bevölkerung nach allen juristischen Gesichtspunkten die Voraussetzungen für den Rechtsstaat geschaffen. Gemäss einer Verordnung aus dem Jahre i 862 führten die Pfarrer vier verschiedene Personenregister (Tauf- und Geburts-, Konfirmanden-, Ehe-, Totenregister), zwei Familienregister (Bürger und Niedergelassene wurden unterschieden), ein pfarramtliches Verzeichnis für Ehe- und Paternitätssachen sowie ein Katechumenenverzeichnis. Zudem hatten die Pfarrer auch Personalausweise auszustellen. Ab I 876 übernahmen Zivilstandsbeamte diese Aufgaben. Dem Stillstand (der Kirchenpflege) kam auch noch im liberalen Staat grössere Bedeutung zu als dem Gemeinderat: Er war Armen-, Waisen-, Vormundschaftsbehörde und Bestattungswesen, war verantwortlich für den Bau und Unterhalt der Drittklassstrassen usw. Der Pfarrer war Präsident des Stillstandes. Ab I 830 war er kraft seines Amtes auch Vorsitzender der Schulpflege. ${ }^{16}$

I 86I wurde für die reformierte Kirche ein neues Kirchengeset ${ }^{17}$ erlassen, und dies zum Anlass genommen, auch die Verhältnisse der Katholiken erstmals gesetzlich zu ordnen. Inzwischen waren im Gebiet des Kantons Zürich vier katholische Pfarreien zu verzeichnen (Rheinau, Dietikon, Zürich und Winterthur) und wegen der Niederlassungs-, Handels- und Gewerbefreiheit hatte die Zahl der Katholiken im Kanton zugenommen. I 862 wurde das Kloster Rheinau aufgehoben. Aus dem Vermögen des Klosters wurde Geld für einen katholischen Kirchenfonds ausgeschieden, der den bestehenden Gemeinden zugutekommen sollte und vom Zürcher Staat verwaltet werden musste. Im «Gesetz betreffend das katholische Kirchenwesen» wurde festgeschrieben, dass aus den bisherigen vier Pfarreien (Rheinau, Dietikon, Zürich und Winterthur) vier öffentlich-rechtliche Kirchgemeinden mit Steuerrecht zu bilden seien. Wie das reformierte Gesetz basierte auch das katholische auf dem Gemeindeprinzip. Da die katholische Kirche keinen Kirchenrat hatte, übernahm der Regierungsrat die Funktionen einer kantonalen Kirchenbehörde. Dem Bischof wurden im Gesetz keine Rechte

Is Schmid 1994, 205 .

I6 Streuli I950, $57 \mathrm{f}$.

I7 Gemäss Dieter Kraus erwies sich die am 20. August I86I vorgenommene Revision des Kirchengesetzes von I 83 I als Rückschritt hinsichtlich der kantonalkirchlichen Autonomie. Der Grosse Rat sah sich angesichts einer weitgehenden Übereinstimmung von Kantons- und Kirchenvolk nicht bloss als Repräsentant der politischen Gemeinschaft, sondern auch der kirchlichen und beanspruchte deshalb wieder mehr Mitspracherecht auch in sogenannt innerkirchlichen Belangen. Dieser «Rückschritt» wurde dann aber durch die Kantonsverfassung wieder aufgehoben (vgl. Kraus I993, I55, Anm. 20). 
zugesprochen, vor allem auch da Zürich seit i 8 I 4 nicht mehr zu einem regulären Bistumsverbund gehörte. Die öffentlich-rechtliche Anerkennung war auf die vier Gemeinden beschränkt und eine katholische Landeskirche gab es noch nicht. Aber ein erster Schritt in diese Richtung war getan. ${ }^{18}$

Die neue demokratische Zürcher Staatsverfassung von I 869 bekräftigte in Artikel $63^{19}$ die Glaubens-, Kultus- und Lehrfreiheit aller kirchlichen Gemeinschaften und nicht nur der Landeskirche. Damit war gemäss Schmid der Übergang von der Staatskirche zur Landeskirche für die reformierte Zürcher Kirche vollzogen. Das frühere Staatskirchentum wurde zwar erneut und definitiv abgelehnt; zugleich wurde aber auch der Vorschlag abgelehnt, die Landeskirche den anderen kirchlichen Gemeinschaften gleichzustellen und alle Beziehungen zwischen Kirche und Staat aufzulösen (die sogenannte Trennung von Kirche und Staat). Im Unterschied zu den anderen kirchlichen Gemeinschaften wurde die evangelisch-reformierte Kirche weiterhin durch staatliches Gesetz geordnet. Die Anerkennung als Landeskirche verlieh der reformierten Kirche zwar das Steuerrecht, doch war damit auch verbunden, dass sich der Staat hinsichtlich Organisation und Aufsicht über die Kirche gewisse Rechte vorbehielt. ${ }^{20}$ Indem die reformierte Kirche durch staatliches Gesetz geordnet blieb, verpflichtete der demokratische Staat die in sich selbstständige Kirche damit auf die Grundelemente der Demokratie, was auch die innerkirchliche Gewährleistung der Glaubens- und Gewissensfreiheit zur Folge hatte. Schmid macht explizit darauf aufmerksam, dass die Forderung, Glaubens- und Gewissensfreiheit auch im innerkirchlichen Bereich einzuhalten, ein kirchenrechtliches Unikum sei. Die Anwendung dieser Bestimmung sei allerdings nur einmal eingefordert worden, und zwar bezüglich der Taufe in der Kirchenordnung von I905. ${ }^{21}$

Nach Schmid spiegelt sich der Übergang von der Staatskirche zur Landeskirche innerkirchlich und theologisch im Aufkommen des von Schleiermacher geprägten Begriffs der «Volkskirche».22 Der Grundgedanke, der sich in diesem Begriff ausdrückt, besagt, dass die Kirche grundsätzlich das gesamte Volk umfasst und

I8 Vgl. Schmid I994, $205 \mathrm{f}$.

19 Zürcher Staatsverfassung I869, Art. 63: «Die Glaubens-, Kultus- und Lehrfreiheit ist gewährleistet. Die bürgerlichen Rechte und Pflichten sind unabhängig vom Glaubensbekenntnisse. Jeder Zwang gegen Gemeinden, Genossenschaften und Einzelne ist ausgeschlossen. Die evangelische Landeskirche und die übrigen kirchlichen Genossenschaften ordnen ihre Kultusverhältnisse selbständig unter Oberaufsicht des Staates. Die Organisation der erstern, mit Ausschluss jedes Gewissenszwanges, bestimmt das Gesetz. Der Staat übernimmt im Allgemeinen die bisherigen Leistungen für kirchliche Bedürfnisse.» (Zit. in Kölz 2000, 87 f.; Hans Sträuli i 902,233 f.)

20 Vgl. Schmid I994, 209.

2 I Dies wird weiter unten im Unterkapitel 7.I auf S. I79 f. noch genauer erläutert; vgl. Schmid 1994, $207 \mathrm{f}$.

22 Vgl. Schmid I994, 209. 
die Kirche nicht von ihren Trägern (Staat bei Staatskirche oder Bekennende bei Bekenntniskirche) definiert wird, sondern von ihrem Auftrag her (Verkündigung und Spenden der Sakramente). Die Adressaten der Verkündigung sind potentiell alle Menschen. Die Kirche ist offen für das gesamte 〈Volk〉. Die Kirche ist in dieser Sichtweise "weder eine Einrichtung des Staates noch ein privater Verein. Die Kirche ist vielmehr eine eigens gestiftete Grösse mit eigenem Auftrag, einem öffentlichen Auftrag, einem Auftrag am Volk, was dann auch dem Staat zugute kommt». ${ }^{23}$

Das Kirchenorganisationsgesetz von I895 brachte einige Neuerungen: Es wurde eine gemischte Synode geschaffen, welche die bis anhin reine Geistlichkeitssynode ersetzte; Synodalbeschlüssen über innerkirchliche Belange wurde Rechtsverbindlichkeit zugestanden; die Synode erhielt das Vorschlagsrecht für Änderungen des Organisationsgesetzes und der Kantonsrat wurde verpflichtet, bei Gesetzesvorlagen, welche die Landeskirche betreffen, ein Synodalgutachten einzuholen. Die Synode erarbeitete auf dieser Grundlage einen Entwurf für ein neues Organisationsgesetz, das 1902 angenommen wurde. Innerhalb des Rahmens dieses staatlichen Gesetzes erhielt die Kirche das Recht, innerkirchliche Angelegenheiten selbstständig $\mathrm{zu}$ ordnen und $\mathrm{zu}$ verwalten. Die detaillierten Bestimmungen zum staatlichen Kirchengesetz wurden von der Synode in der Kirchenordnung von I905 erlassen, die bis 1967 Gültigkeit hatte. ${ }^{24}$ Diese Kirchenordnung musste jedoch dem Regierungsrat zur Prüfung der Verfassungsund Gesetzmässigkeit vorgelegt werden. Wie die regierungsrätliche Intervention hinsichtlich der Taufe in der Kirchenordnung von i90s zeigte, war die Unterscheidung zwischen inneren und äusseren Angelegenheiten der Kirche nicht sehr trennscharf (vgl. Unterkapitel 7.I, S. I79 f.). Sie verweist auch auf die bloss relative Autonomie der evangelischen Landeskirche und dass «ihr immer noch keine Rechtspersönlichkeit zukam». ${ }^{25}$ Dass zwei der sieben Kirchenräte noch bis I963 durch den Kantonsrat gewählt werden mussten, war ebenso ein Indiz für die immer noch relativ starke Verflechtung von Kirche und Staat. ${ }^{26}$

I963 wurden nach jahrzehntelangen Vorarbeiten vom Zürcher Stimmvolk eine Verfassungsänderung ${ }^{27}$ sowie zwei neue Kirchengesetze - ein evangelisch-reformiertes ${ }^{28}$

23 Schmid 1994, 202.

$24 \mathrm{Vgl}$. Kraus i993, is 5 f.

25 Famos 2007, 53.

26 Vgl. Kraus i993, i6I, Anm. 47.

27 Mit derselben Verfassungsänderung wurde auch das kirchliche Frauenstimmrecht eingeführt (vgl. Kraus 1993, I58).

28 Gestützt auf das neue evangelisch-reformierte Kirchengesetz von 1963 wurde 1967 eine vollständig überarbeitete evangelisch-reformierte Kirchenordnung vom Kirchenvolk angenommen. Sie war massgeblich vom theologisch liberalen und in der Demokratischen Bewegung des i9. Jahrhunderts verwurzelten Pfarrer Gotthard Schmid geprägt (vgl. Hans Heinrich Schmid I988). 
und ein römisch-katholisches - angenommen. ${ }^{29}$ Mit Art. 64 der Verfassung von I963 (Fassung vom 7. Juli) wurden die evangelisch-reformierte, die römisch-katholische sowie die christkatholische Kirche und ihre Gemeinden öffentlich-rechtlich anerkannt. ${ }^{\circ}$ Staatskirchenrechtlich gesehen kam nun diesen drei Kirchen dieselbe Stellung zu und alle drei verfügten über das Recht, Kirchensteuern zu erheben. Die anderen religiösen Gemeinschaften werden über das Privatrecht geregelt. ${ }^{31}$ Für die katholische Kirche kam mit dieser Verfassung ein langer Integrationsweg ins Zürcher Staatswesen zum Abschluss. Denn mit dem Kirchengesetz von i 863 wurde den Katholiken zwar die freie Ausübung des katholischen Kultes garantiert und die katholischen Kirchgemeinden Rheinau, Dietikon, Zürich und Winterthur anerkannt. Damit verbunden war jedoch nicht die öffentlich-rechtliche Anerkennung der katholischen Kirche. Die Folge war, dass Zürcher Katholiken mit ihren Staatssteuern indirekt das kirchliche Leben ihrer reformierten Mitbürger unterstützten, für ihr eigenes kirchliches Leben aber von den Schweizer Katholiken abhängig waren. ${ }^{32}$ Dazu kam, dass nachdem I 870 im I. Vatikanischen Konzil die Unfehlbarkeit des Papstes dogmatisch festgehalten worden war, I 873 sich die katholische Gemeinde Zürich von der römisch-katholischen Kirche löste und zur christkatholischen Gemeinde wurde. Da alle bisherigen Rechte der römisch-katholischen Gemeinde Zürichs an die christkatholische Gemeinde Zürich überging, war die römisch-katholische Kirche in Zürich eine Zeitlang offiziell nicht mehr vertreten bzw. organisierte sich privatrechtlich. ${ }^{33}$

I975 wurde eine «Kantonalzürcherische Volksinitiative für die Trennung von Staat und Kirche» lanciert, die aber 1977 in der Volksabstimmung durchfiel. I99 I wurde erneut eine Trennungsinitiative initiiert, die I995 in der Volksabstimmung ebenfalls abgelehnt wurde. ${ }^{34}$ I 996 begann die gesetzgeberische Arbeit zur Neuregelung des Verhältnisses zwischen Kirchen und Staat. Sie mündete in die Abstimmung vom 30. November 2003, bei der die Stimmberechtigten im Kanton Zürich über drei kirchenpolitische Vorlagen abstimmen konnten: die Neuregelung des Verhältnisses zwischen Kirchen und Staat in der Kantonsver-

29 Vgl. Famos 2007, 55. Diese Neuregelungen wurden von Freidenker-Kreisen beim Bundesgericht angefochten, aber ohne Erfolg (vgl. Kraus 1993, I 5 ).

30 «[...] Die evangelisch-reformierte Landeskirche und ihre Kirchgemeinden, eingeschlossen die französischen Kirchgemeinschaften, die römisch-katholische Körperschaft und ihre Kirchgemeinden sowie die christ-katholische Kirchgemeinde Zürich sind staatlich anerkannte Personen des öffentlichen Rechts. [...]» (Zürcher Kantonsverfassung, Art. 64 in der Fassung vom 7. Juli 1963, zit. in Schmid 1994, 2 I 2).

3 I «[...] Für die öffentlich-rechtlich nicht anerkannten religiösen Gemeinschaften gelten die Bestimmungen des Privatrechts» (Zürcher Kantonsverfassung, Art. 64 in der Fassung vom 7. Juli 1963, zit. in Schmid 1994, 21 3).

32 Vgl. Altermatt I989, I88.

33 Vgl. Schmid I994, 2 I ; Kraus 1993, I 57.

34 Vgl. Kraus 1993, I69. 
fassung, eine Kirchengesetzvorlage, die primär die drei Zürcher Landeskirchen betraf, und das Gesetz über die Anerkennung von Religionsgemeinschaften (Anerkennungsgesetz). Alle drei Vorlagen wurden abgelehnt. Auf Verfassungsebene ging es primär um drei Neuerungen. Zum einen hätten neben den drei Landeskirchen auch weitere Religionsgemeinschaften öffentlich-rechtlich anerkannt werden sollen. Des Weiteren hätten alle anerkannten Religionsgemeinschaften weitreichende Autonomie erhalten, die insbesondere das Stimm- und Wahlrecht tangiert hätte. Die anerkannten Religionsgemeinschaften hätten beispielsweise das Stimmrecht ab einem Alter von sechzehn oder auch für Ausländer einführen können. Und als Drittes hätten die «historischen Rechtstitel» durch staatliche zweckgebundene Beiträge, zum Beispiel für Engagement im sozialen, kulturellen oder bildenden Bereich, ersetzt werden sollen. Diese Verfassungsänderung hätte die Grundlage für die beiden Gesetzesvorlagen (Kirchen- und Anerkennungsgesetz) gebildet, die das Verhältnis zwischen den Religionsgemeinschaften und dem Staat im Detail hätten regeln sollen. Alle drei Vorlagen zielten darauf ab, die öffentlich-rechtlich anerkannten Religionsgemeinschaften und die bisher nicht öffentlich-rechtlich anerkannten Religionsgemeinschaften - lutherische, serbisch-, griechisch- und russisch-orthodoxe Kirche, die jüdische und die muslimische Religionsgemeinschaft - gleich zu behandeln. ${ }^{35}$

Im Februar 2005 haben die Zürcher Stimmberechtigten die vollständig revidierte Kantonsverfassung angenommen, die diejenige von i 869 ersetzte. Die staatskirchenrechtlichen Bestimmungen sind im ı०. Kapitel geregelt. ${ }^{36}$ Darin wird das Ergebnis der Volksabstimmung vom 30. November 2003 berücksichtigt, in der sowohl auf Verfassungs- als auch auf Gesetzesebene die Neuregelung des Verhältnisses zwischen Staat und Kirchen bzw. weiteren Religionsgemeinschaften verworfen wurde. Gemäss Röhl liegt mit dieser Verfassung hinsichtlich des Verhältnisses von Staat und Kirchen bzw. weiteren Religionsgemeinschaften keine Neuregelung vor, sondern «eine Fortentwicklung des heutigen Zustands». ${ }^{37}$ Wie bis anhin sind die kirchlichen Körperschaften bloss im Rahmen des kantonalen Rechts autonom. Die Kirchgemeinden hingegen leiten ihre Autonomie nicht aus der Kantonsverfassung, sondern aus dem Kirchengesetz und insbesondere aus den Kirchenordnungen ab. Neu sind jedoch die kantonalen kirchlichen Körperschaften in zwei Bereichen unmittelbar auf Grund der Verfassung autonom: zum einen hinsichtlich der Regelung des Stimm- und Wahlrechts in innerkirchlichen

35 Vgl. Zurlinden 2015, 78 .

36 Die neue Kantonsverfassung von 2005 enthält drei Bestimmungen, die das Verhältnis zwischen Staat und Kirchen bzw. weiteren Religionsgemeinschaften unmittelbar regeln: Art. I 30 KV betrifft die kirchlichen Körperschaften, Art. I3 I KV betrifft die weiteren Religionsgemeinschaften und Art. I45 KV betrifft den Übergang vom bisherigen zum neuen Recht (vgl. Röhl 2006, 202).

37 Röhl 2006, 208. 
Belangen; zum andern hinsichtlich der Festlegung der Zuständigkeit für die Neubildung, den Zusammenschluss und die Auflösung von Kirchgemeinden..$^{8}$ Während der zweite Punkt auf dem Hintergrund der Entflechtung von Kirche und Staat folgerichtig erscheint und unbestritten war, erstaunt, gemäss Röhl, die den kirchlichen Körperschaften eingeräumte Stimm- und Wahlrechtsautonomie. Denn im Vorfeld der Abstimmung von 2003 wurde argumentiert, dass diese ein Türöffner für das allgemeine Ausländerstimmrecht sei. ${ }^{39}$ Art. I 30 Abs. $4 \mathrm{KV}$ ermöglicht neu, einen Teil der Steuererträge einer negativen Zweckbindung zu unterstellen. Damit sind die Steuererträge der juristischen Personen gemeint, womit verhindert werden soll, dass deren Steuereinnahmen für kultische Zwecke verwendet werden. ${ }^{\circ}$ Art. I 3 I KV trägt die Überschrift «Weitere Religionsgemeinschaften». Da 2003 insbesondere der Widerstand gegen das Anerkennungsgesetz zum Scheitern der drei Kirchenvorlagen geführt hat, wurde dieses Abstimmungsergebnis in der neuen Kantonsverfassung insofern berücksichtigt, als die Anerkennung auf zwei (kleine) jüdische Gemeinden beschränkt wurde: die Israelitische Kultusgemeinde und die Jüdische Liberale Gemeinde. Die Anerkennung dieser zwei jüdischen Gemeinden in Art. I 3 I hat jedoch nicht dieselbe Rechtswirkung wie die Anerkennung der drei kirchlichen Körperschaften in Art. I 30. So werden die beiden jüdischen Gemeinden keine Körperschaften öffentlichen Rechts, sondern behalten ihren Status als privatrechtliche Vereine.

\subsection{Die Entstehung der modernen öffentlichen Schule}

Die traditionelle Schulgeschichtsschreibung nennt als Geburtsjahr der modernen Zürcher Volksschule das Jahr I 832.4 In diesem Jahr wurde das zürcherische Schulsystem zum ersten Mal durch ein staatliches Gesetz geregelt, zu dem es infolge der am Ustertag von i 830 geforderten neuen kantonalen Verfassung kam, die im März I 83 I mit deutlicher Mehrheit vom Volk angenommen worden war. ${ }^{42}$ Wie bereits im Einleitungskapitel erwähnt wurde, suggeriert die aus der liberalen Siegerperspektive verfasste traditionelle Schulgeschichtsschreibung einen plötzlichen Wandel von einer vormodernen zu einer modernen Schule. Ich folge Daniel Tröhler - und damit der neueren Schulgeschichtsschreibung -, der die Entwicklung der modernen öffentlichen Schule im Kanton Zürich in den Zeitraum

38 Vgl. Verfassung des Kantons Zürich vom 27. Februar 2005, Art. I30 Abs. 2 lit. a und b.

39 Vgl. Röhl 2006, 203.

40 Vgl. ebd., 205.

4 I Vgl. Guggenbühl 1933 .

42 Vgl. Tröhler 2008, 56. 
zwischen i 770 und I 870 datiert. ${ }^{43}$ Häufig wurde in Gesetzen festgeschrieben, was bereits lange vorher auf kommunaler Ebene eingeführt worden war. So wie es bereits vor I 832 Bestrebungen gab, die Schule zu modernisieren, war das Schulwesen auch nach 1832 von vormodernen Elementen geprägt. ${ }^{44}$ Die nach 1870 folgenden Änderungen und Reformen sind gemäss Tröhler als Weiterentwicklung von etwas bereits Bestehendem anzusehen. ${ }^{45}$ Im Folgenden sind bloss die wesentlichen Etappen erwähnt, die im Zusammenhang mit der Ausdifferenzierung zwischen Kirche, Staat und Schule von Bedeutung sind..$^{6}$

Bis ins Jahr I798 kam die oberste Aufsicht über das gesamte Schulwesen im Kanton Zürich - inklusive dem Landschulwesen - dem grösstenteils aus Klerikern bestehenden Gremium der Obersten Schulherren zu. Die Aufsicht über das Landschulwesen war jedoch noch wenig ausgebaut. I637 wurde für den Kanton Zürich die erste Landschulordnung erlassen, die für alle Schulen «uff der Landschaft» gelten sollte. Zur selben Zeit gaben sich einige Gemeinden eigene Schulordnungen. 1778 wurde im Zuge einer Reorganisation des städtischen Schulwesens von den obersten Schulherren eine neue Landschulordnung erlassen. Bloch nennt als wesentliche Neuerungen die Verlängerung der Schulzeit, die Einführung einer Repetierschule und die strengere Kontrolle des Unterrichtsbesuchs. Doch nach wie vor war der Pfarrer für den Vollzug der Verordnungen verantwortlich, obwohl zum ersten Mal auch der Land- und Obervogt als Vollzugsinstanz erwähnt worden sei. ${ }^{47}$ Untersuchungen von Andrea de Vincenti und Norbert Grube zeigen jedoch, dass die Gemeinden bereits im i 8. Jahrhundert erstaunlich basisdemokratisch und eigenständig funktionierten. Die Analyse einer Umfrage bei Pfarrern an drei Pfarrkapiteln in den Jahren 1770/71 führte zum Ergebnis, dass entgegen den offiziellen Regelungen - die Wahl der Lehrer oblag de jure dem Examinatorenkonvent, der aus einem Teil des Gremiums der Obersten Schulherren bestand - die Landgemeinden de facto das Recht beanspruchten, ihre Lehrer selber zu wählen..$^{8}$

$\mathrm{Zu}$ einer strukturellen Neuorganisation des Schulwesens kam es erst während und nach der Helvetik. I 803 erliess der Kanton Zürich ein neues Schulgesetz. Der gesellschaftliche Ausdifferenzierungsprozess und die veränderten Staatsvorstellungen nach 1789 machten sich im Kanton Zürich beispielsweise in der Gründung einer zivilen Behörde, des Erziehungsrates, bemerkbar. Im Unterschied zum Gremium der Obersten Schulherren, das bis I 798 gewirkt hatte und

43 Tröhler 20II, I53.

$44 \mathrm{Vgl}$. Tröhler/Hardegger 2008, Io f.

45 Tröhler 20I I, I 53.

46 Bei der folgenden Darstellung stütze ich mich primär auf Bloch (1999) und Tröhler (2008).

47 Bloch I999, I $24 \mathrm{ff}$.

48 De Vincenti/Grube 201 I, 285 ff. 
vorwiegend aus Klerikern bestand, konnten neben den bisherigen Mitgliedern der ältere von den zwei Bürgermeistern, Antistes, Rektor des Gymnasiums und zwei Mitgliedern des kleinen Rats - die übrigen acht Mitglieder auch weltlichen Stand haben und mussten vom Grossen Rat gewählt werden. Neu wurden is Schulinspektoratsstellen geschaffen, die als Aufsichtsorgane über die Primarschulen zu wirken hatten. Die is dafür neu eingeführten Schulinspektoratskreise wurden jedoch an die bestehende Struktur der Dekanate angepasst. Analog zur Aufgabe der Dekane kam den Schulinspektoren ebenfalls eine Vermittlungsfunktion zwischen der obersten Behörde und den Pfarrern, die nach wie vor die unmittelbaren Schulaufseher vor Ort waren, zu. ${ }^{49}$

Im März I 83 I wurde die neue Verfassung vom Volk angenommen. Die Artikel 20, 70, 79 und 86 dieser Staatsverfassung waren für die Schule von grosser Bedeutung. In Artikel 20 wurde die moderne Schule als Volksschule definiert und nicht als staatliche Schule, wie Tröhler betont.. ${ }^{50}$ In Artikel 70 wurde als Aufsichtsbehörde «über die sämmtlichen Schulanstalten des Cantons» der Erziehungsrat (heute: Bildungsrat) genannt. Im Unterschied zu den anderen europäischen Ländern bestand der Erziehungsrat nicht aus staatlichen Beamten, sondern aus einer vom Parlament gewählten ehrenamtlichen Behörde. Artikel 70 erwähnte nicht bloss die "Organisation des Erziehungswesens», sondern ebenfalls «die Errichtung einer Schulsynode». ${ }^{\text {sI }}$ Die Lehrersynode ist eine Art Lehrerparlament und gemäss Tröhler «ein weltweites Unikum».52 Die Schulsynode wurde vom Juristen Conrad Melchior Hirzels3 initiiert. Mit ihr sollte es gelingen, die Schule von der Kirche zu emanzipieren, ohne sie zu einer staatlichen Institution zu machen. Organisationsmässig orientierte man sich dennoch an der Kirche, da diese die einzige grosse, vom Staat teilweise unabhängige Institution war. Analog zur Synode der Geistlichkeit sollte es für alle Lehrkräfte eine Versammlung geben. Die durch die Verfassung festgelegte Garantie für eine eigene Lehrerversammlung erhöhte natürlich das Selbstbewusstsein der Lehrer. ${ }^{54}$ Während in Artikel 70 der Erziehungsrat als schulische Aufsichtsbehörde für den gesamten Kanton genannt wurde, bestimmte Artikel 79 die Schulaufsicht in

Vgl. Bloch 1999, $\mathrm{i} 26 \mathrm{f}$.

50 Vgl. Tröhler 2008, 57. In Artikel 20 der Staatsverfassung für den eidgenössischen Stand Zürich vom ı०. März I 83 I heisst es: «Sorge für die Vervollkommnung des Jugendunterrichts ist Pflicht des Volkes und seiner Stellvertreter».

I I Staatsverfassung für den eidgenössischen Stand Zürich vom Io. März I 83 I, Art. 70.

52 Tröhler 2008, 57.

53 Conrad Melchior Hirzel (1793-I 843) wurde mit der neuen Staatsverfassung von I 83 I Regierungsrat und erster Präsident des Erziehungsrates. Ein Jahr später wurde er Bürgermeister, das heisst, Regierungsratspräsident des Kantons Zürich. Der konservative Umsturz im Jahre I 839 kostete ihn alle Ämter (vgl. Tröhler 2008, 57).

54 Vgl. Tröhler 2008, 57. 
den kantonalen Bezirken - die sogenannte Bezirksschulpflege - und Artikel 86 diejenige in den Gemeinden - die sogenannte Gemeindeschulpflege.

Im Anschluss an die Verfassung wurden noch im selben Jahre durch den vom Parlament gewählten Erziehungsrat mehrere Gesetze erlassen, die für die Entwicklung der Volksschule wichtig waren: die eigene Geschäftsordnung, die Gesetze über die Organisation der Bezirksschulpflegen und der Gemeindeschulpflegen, das Gesetz über die Lehrerbildung und das Gesetz über die Schulsynode. Am 2. Oktober I 832 wurde schliesslich das Gesetz über die Organisation des gesammten Unterrichtswesens im Canton Zürich vom Regierungsrat in Kraft gesetzt. Die gesetzlichen Grundlagen für die Zürcher Volksschule waren damit gesetzt. Tröhler verweist in seiner Darstellung auf den öffentlichen Charakter der zürcherischen Volksschule. ¿Öffentlichkeit〉 meint hier, dass die Aufsicht über das Schulwesen nicht primär von Staatsbeamten ausgeführt wird, sondern durch vom Stimmvolk direkt gewählte Repräsentanten aus dem Stimmvolk.ss

Was es bedeutete, dass die Schule bis I83 I eine kirchliche Institution war, beschreibt Urs Hardegger kurz und knapp: «Offene Stellen wurden von der Kanzel verlesen, der Lehrer musste den Kirchenchor leiten und das Vorsingerund Sigristenamt übernehmen, die Schule war mit der Konfirmation beendet, schwere Disziplinarfälle waren dem Pfarrer zu melden und der Pfarrer beteiligte sich am Schuljahresschlussexamen.» ${ }^{6}$

Der Entflechtungsprozess zwischen Kirche und Schule vollzog sich über mehrere Jahrzehnte. Sigristen- und Lehrerstelle wurden bereits im Jahre I833 getrennt und die Verpflichtung der Lehrer zur Übernahme der Vorsingerstelle wurde im Jahre I 838 auf Druck der organisierten Lehrerschaft aufgehoben. ${ }^{57}$ Das Gesetz betreffend die Organisation der Bezirksschulpflege von i 83 I sah folgende Zusammensetzung der sieben Mitglieder vor: zwei durch ihr Kapitel gewählte Geistliche, zwei von der Lehrerversammlung des Bezirks gewählte Lehrer und drei von der Bezirksversammlung gewählte Einwohner. Gemäss Gesetz über die Organisation der Gemeindeschulpflege umfasste diese neben dem Pfarrer, dem kraft seines Amtes der Vorsitz zugesprochen wurde, mindestens vier Gemeindemitglieder, darunter auch den Lehrer. Erst mit dem neuen Schulgesetz von I859 wurde die kirchliche Zweiervertretung in der Bezirksschulpflege aufgehoben und i 865 fiel die Regelung, dass der Pfarrer von Amtes wegen Präsident der Gemeindeschulpflege zu sein hatte..$^{8}$ Damit war die Schule organisatorisch gesehen von der Kirche gelöst.

55 Vgl. ebd., 58.

56 Hardegger 2008b, 42.

57 Vgl. Tröhler 2007, 57 f.; Bloch 1999, I48.

58 Vgl. Bloch I999, I 28 f.; Tröhler 2008, 58 f. 


\subsection{Zur Geschichte des schulischen Religionsunterrichts im Kanton Zürich 1800-2016}

Ihre Untersuchungen über Wissensordnungen von Zürcher Unterrichtspraktiken zwischen I77I und I834 führten die Erziehungswissenschaftlerin Andrea De Vincenti zur Frage, ab wann es überhaupt sinnvoll ist, von schulischem Religionsunterricht zu sprechen. De Vincenti kritisiert den «Gemeinplatz, vormoderne Schulcurricula hätten beinahe ausschliesslich aus Religionsunterricht bestanden».99 Sie erklärt diese verbreitete Vorstellung mit der «etwas anachronistischen Annahme einer konsistenten Kontur religiöser Lerninhalte im Sinne eines Faches».60 Wenn die kulturellen Grundfähigkeiten wie Lesen und Schreiben anhand religiöser Inhalte vermittelt worden waren, dann wäre so gesehen alles Religionsunterricht gewesen - oder auch nichts. De Vincenti bestreitet keineswegs, «dass die Vermittlung sittlich-religiöser Lerninhalte insgesamt das primäre Bildungs- und Erziehungsziel war», doch diese «schnelle Etikettierung» verstellt ihrer Ansicht nach «den Blick auf eine differenzierte Wahrnehmung zeitgenössischer Unterrichtsziele und -praktiken». ${ }^{61}$ Das regelmässige Vorkommen von Lesen, Schreiben und Rechnen in den Unterrichtspraktiken könnte aus ihrer Sicht nicht erklärt werden, wenn Religion das primäre Unterrichtsziel gewesen wäre. Interessant ist, dass in den von De Vincenti untersuchten Quellen Religion noch kaum als «ausdifferenzierter Lernbereich ${ }^{62}$ in Erscheinung getreten war. Im Fragebogen der Umfrage von I77I war von Buchstabieren, Lesen, Auswendiglernen, Schreiben oder Rechnen die Rede, aber nicht von Religion und in den Berichten der neu eingerichteten Laienschulpflegen auf Bezirksebene seien im Jahre I 834 die Fragen des Katechismus immer noch mit den Fähigkeiten im Buchstabieren und Lesen rapportiert worden, während biblische Geschichte meist zusammen mit der vaterländischen Geschichte genannt worden sei. «Die Verwendung des Begriffs Religionsunterricht erscheint indes erst dann sinnvoll, wenn er als Unterricht in einem ausdifferenzierten Bereich verstanden wird. Erst dann vermag er nämlich eine gewisse Unterscheidung herzustellen.» ${ }^{63}$

De Vincenti bemerkt, dass noch I 834 die Ausdifferenzierung des Religionsunterrichts zu einem eigenen Fachbereich wenig fortgeschritten war. Zum einen seien schulische Inhalte, die man heute dem Fach Religion zuweisen würde, den Lernbereichen Lesen oder Geschichte zugesprochen worden. Zum andern sei der eigentliche Religionsunterricht als Aufgabe des Pfarrers verstanden worden

59 De Vincenti $2015,68$.

60 Ebd.

6 I Ebd., 69.

62 Ebd.

63 Ebd., 69 f. 
und dem schulischen Religionsunterricht habe man primär eine propädeutische Funktion im Hinblick auf den kirchlichen Religionsunterricht des Pfarrers zugewiesen. ${ }^{6}$ Dieses Verständnis des schulischen Religionsunterrichts spiegelte sich im Gesetz über die Organisation des gesammten Unterrichtswesens von 1832 wider. "Religionsbildung» wird darin in Paragraph 4 bei den Lehrgegenständen als vierter und letzter Punkt genannt, nach Elementarbildung (I), Realbildung (2), Kunstbildung (3). Unter Religionsbildung fällt: «Biblische Geschichte im Auszuge; Weckung und Entwicklung sittlicher und religiöser Gefühle und Begriffe als Vorbereitung auf den kirchlichen Religionsunterricht».65

Obwohl die Berichte der Bezirksschulpflege von I 834 noch nicht auf ein ausgereiftes und eigenständiges Fach Religion hindeuten, zeigt sich im Unterrichtsgesetz das Ansinnen, Religion zu einem Schulfach neben andern zu machen, in der Aufzählung der vier verschiedenen Lehrgegenstände. Aufschlussreich ist auch die Reihenfolge der Lehrgegenstände: «Religionsbildung» wird als letzter Lehrgegenstand genannt. Die Marginalisierung des Faches Religion zeigt sich gemäss Anna-Verena Fries noch deutlicher im Allgemeinen Unterrichtsplan für die Primarschulen des Kantons Zürich - dies ist der erste staatliche Lehrplan für die Volksschule. ${ }^{66}$ In diesem Lehrplan wird das Fach als Moral und Religion bezeichnet. Religion macht bloss die Hälfte des Faches aus und steht nicht an erster, sondern an zweiter Stelle. Zudem wird das Fach Moral und Religion in der Anordnung der Fächer im Lehrplan an letzter Stelle nach Sprache, Zahl, Form, Realien und Kunstbildung genannt. Als Drittes fallen bei der Beschreibung der Inhalte die Vorgaben für das Fach Religion knapper als für die anderen Fächer aus. Und zuletzt zeigt sich die Marginalisierung auch in der Stundendotation, die im Vergleich zu den anderen Fächern für das Fach Religion relativ gering ausfiel. Auf der Unterstufe wurden I 4 Stunden für Sprache, je s Stunden für Zahl und Form und 3 Stunden für Moral und Religion (total 27 Stunden) berechnet. Auf der Mittelstufe wurden bei gleichbleibender Stundenzahl bloss noch 2 Stunden für Moral und Religion berechnet. Gemäss Verordnung zum Unterrichtsgesetz sollte der Unterricht jedoch mit einem Gebet beginnen und mit einem Gebet oder Lied enden. Das Schuljahr sollte zudem durch den Pfarrer in der Kirche eröffnet werden. ${ }^{67}$

64 Vgl. ebd., 70.

65 Gesetz über die Organisation des gesammten Unterrichtswesens im Canton Zürich von I $832, \$ 4$.

66 Vgl. Fries 2008, 97.

67 Vgl. Fries 2010, 4. Ich folge auch in den nachfolgenden Angaben zu Lehrplanzahlen den Angaben von Anna-Verena Fries (2010). Tröhler (2007) macht deutlich, dass häufig übersehen werde, dass mit der liberalen Staatsverfassung von I 83 I keineswegs ein «liberal-laizistischer» Staat geschaffen worden sei. Die Marginalisierung von Religion im Schulunterricht habe keine laizistische Spitze gehabt (vgl. Tröhler 2007, 57). 
Gemäss Bloch wurde bereits Mitte der I830er Jahre der Religionsunterricht der neuen Lehrer «als mangelhaft, kalt und unpassend beanstandet und diente als zentrales Argument der gegen die liberale Regierung gerichteten Putschbewegung von I $839{ }^{\Perp 6}{ }^{68}$ Noch vor dem Umsturz im Herbst 1839 begegnete man dieser Kritik im Sommer desselben Jahres mit einer Gesetzesänderung: An den Alltagsschulen sollte der Religionsunterricht auf mindestens drei Stunden pro Woche festgelegt werden und von den Lehrern wurde verlangt, «einen christlich-religiösen Sinn in den Schülern zu wecken und zu befestigen». ${ }^{69}$ Zudem wurde festgesetzt, dass die religiösen Lehrmittel in einer Kommission bestehend aus Mitgliedern des Erziehungs- und Kirchenrates vorbereitet und anschliessend vom Erziehungsrat erlassen werden sollten. Mit der durch den September-Putsch an die Macht gekommenen konservativen Regierung wurde dieser Punkt noch weiter verschärft. Die Lehrmittel mussten nun durch beide Behörden genehmigt werden..$^{\circ}$

Dies änderte sich wieder mit dem neuen Unterrichtsgesetz von I859. Dem Kirchenrat kam hinsichtlich Lehrplan und Lehrmittel bloss noch Begutachtungsrecht $\mathrm{zu}$ und dem Erziehungsrat wurde alleinige diesbezügliche Entscheidungsgewalt zugesprochen auch hinsichtlich des Religionsunterrichts. ${ }^{71}$ Auf diese Weise wurde der kirchliche Einfluss zurückgebunden. Während im Unterrichtsgesetz von I 832 "Religionsbildung» bei den Lehrgegenständen an letzter Stelle genannt wurde, rückte «christliche Religions- und Sittenlehre» ${ }^{22} \mathrm{im}$ Unterrichtsgesetz von I 859 an die erste Stelle vor. Auch im vollständig revidierten Lehrplan von i 86I, der im Unterschied zum vorhergehenden anstatt sieben Seiten dreissig As-Seiten füllte, erhielt Religion mehr Gewicht. Das Fach trug nun «Religion` im Titel und betraf eine Sache - die Religion - und weder Moral noch Ethik. Die Vorgaben für das Fach Religion waren viel ausführlicher als im Lehrplan von $1838.7^{73}$

In der Kantonsverfassung von I 869 und der Bundesverfassung von I 874 wurde die Glaubensfreiheit festgeschrieben. Dies führte dazu, dass einige Lehrer und Schulpflegen Religion nicht mehr unterrichten bzw. anbieten wollten. Dagegen schritt der Erziehungsrat I 879 mit einem Kreisschreiben ein. Gemeinden, die die Einstellung des Religionsunterrichts nicht beschlossen, sollten weiterhin

68 Bloch i999, I48.

69 Gesetz betreffend einige Modificationen in den bestehenden Gesetzen über das Unterrichtswesen vom 27. 6. I 839 (StAZ III Ea I), zit. in Bloch I999, I 49.

$70 \mathrm{Vgl}$. Bloch i999, I49.

7I Gesetz über das gesammte Unterrichtswesen des Kantons Zürich vom 23. Dezember I 8 59, $\$ 69$.

72 Gesetz über das gesammte Unterrichtswesen des Kantons Zürich vom 23. Dezember I859, $\$ 65$.

73 Vgl. Fries 2010, 4 . 
Religionsunterricht anbieten dürfen. Dieser durfte jedoch für die Kinder nicht obligatorisch sein und der Lehrer durfte diese Aufgabe zurückweisen. Und sowohl für den Pfarrer als auch den Lehrer, der diesen Unterricht erteilte, galt, dass «konfessionelle Besonderheiten» dabei zurückzutreten hätten. ${ }^{74}$

Mit der Teilrevision des Unterrichtsgesetzes im Jahre I 899 wurde die Ergänzungsschule abgeschafft und die Alltagsschule von sechs auf acht Jahre verlängert. Der Religionsunterricht in der 7. und 8. Klasse sollte jedoch weiterhin durch den Pfarrer erteilt werden. Die Lehrmittel für diese Stufe wurden von der Kirche in Zusammenarbeit mit dem Staat erlassen. Für die 7. und 8. Klasse erhielt der Kirchenrat für den Unterricht in biblischer Geschichte und Sittenlehre weiterhin das Begutachtungsrecht bei Lehrplan und Lehrmitteln.75 Als Folge dieser Gesetzesänderung wurde im Jahre I905 ein neuer Lehrplan in Kraft gesetzt. Es war der erste umfassende Lehrplan seit der Gründung der Volksschule. Die Überlegungen zu Didaktik, Pädagogik, Disziplin und Organisation galten neu sowohl für die Primar- wie auch die Sekundarstufe. Im Lehrplan integriert war ebenso der Zweckparagraph, den man aus dem Gesetz - wohl um es nicht zu gefährden - entfernt hatte. Dieser Lehrplan war abgesehen von kleinen durch Schulreformen bedingte Ergänzungen und Anpassungen in Kraft bis ins Jahr I99I. Das Fach Religion wurde im Vergleich zum Lehrplan von i 86I jedoch wieder stark zurückgenommen. Dies zeigte sich gemäss Fries folgendermassen: Zum einen wurde das Fach umbenannt in «Biblische Geschichte und Sittenlehre». Mit dieser Neubenennung wurde die Stossrichtung des Faches verdeutlicht: Die Vermittlung biblischer Geschichten und der Sitten und weniger die Auseinandersetzung mit Religion, das heisst, die Beschäftigung mit dem Glauben, mit Gott und der Kirche. Zum andern ging der Umfang der Beschreibung des Unterrichtsstoffs von zwei As-Seiten im Lehrplan von I86I auf eine A5-Seite zurück. Der Beschreibung des Stoffs wurde jedoch neu eine sich auf die gesamte Primarschule beziehende Einleitung vorangestellt, die das Ziel des Faches bezeichnete: Es gehe in diesem Fach um edle Gesinnung, die innerhalb wie ausserhalb der Schule gelebt werden müsse. Zudem wurde auf die Glaubens- und Gewissensfreiheit verwiesen. Doch weiterhin stand das Fach an erster Stelle in der Aufzählung der Lehrgegenstände, was bis 1991 so blieb. ${ }^{76}$

Die Neubenennung des Faches änderte nichts an der Tatsache, dass Lehrmittel und Lehrmethode des Faches nach wie vor evangelisch-reformierten Vorstellungen entsprach. In der folgenden Darstellung des Unmuts der römischkatholischen Bevölkerung beziehe ich mich auf die Arbeit von Urs Hardegger (2008b). Durch die Einwanderung katholischer Gastarbeiter hatte sich der

74 Kreisschreiben des Erziehungsrats, vom I 5. I. I 879, zit. in Bloch 1999, I49.

$75 \mathrm{Vgl}$. Gesetz betreffend die Volksschule vom i i. Juni I 899, $\mathbb{S} \$ 27$ und 28.

76 Vgl. Fries 2008, 100 f.; Fries 2010, 6. 
Anteil der katholischen Bevölkerung zwischen i 850 und I930 von 2,6 Prozent auf 2 I,7 Prozent massiv erhöht. Aus katholischer Sicht sollte der Bibelunterricht zwingend von einem katholischen Pfarrer erteilt werden. Zudem wurde dieser Unterricht in den Arbeitervierteln, in denen viele Katholiken lebten, häufig von Lehrkräften erteilt, die kommunistisch oder sozialistisch gesinnt waren. Auslöser für einen offenen Konflikt zwischen Schule und katholischer Kirche war der im Februar 1920 in allen katholischen Kirchen des Bistums Chur verlesene Fastenhirtenbrief von Bischof Georgius Schmid. Der Bischof forderte erstens die gesetzliche Berechtigung, christliche, konfessionelle Schulen zu führen; zweitens, es katholischen Geistlichen zu ermöglichen, konfessionellen Religionsunterricht in den öffentlichen Schulen während der Schulzeit und in den Schulgebäuden abzuhalten; drittens, die Erlaubnis, neben der Staatsschule freie, christliche Schulen einzurichten mit Kostenübernahme durch den Staat. Zur Eskalation kam es, als in der Gemeinde Oerlikon katholische Geistliche die Kinder vom Besuch des Bibelunterrichtes $\mathrm{zu}$ dispensieren versuchten. Als Reaktion auf ein Schreiben der Gemeindeschulpflege, die sich über das Vorgehen der katholischen Geistlichen beschwerte, verschickte der Erziehungsrat an alle Schulbehörden ein Kreisschreiben. Darin wurde das Recht auf Dispensation ausdrücklich anerkannt. Die Folge war eine von der katholischen Kirche organisierte Massendispensation. Gemäss Hardegger standen die Lehrkräfte wie auch die meisten politischen Parteien den katholischen Forderungen ablehnend gegenüber. Sobald jedoch der Druck der Kirche nachliess, nahmen wieder etwas mehr Kinder am schulischen Bibelunterricht teil. ${ }^{77}$

Da auf der Oberstufe der Unterricht in Biblischer Geschichte von evangelisch-reformierten Fachkräften erteilt wurde, nahmen katholische und andersgläubige Kinder an diesem Unterricht nicht teil. I963 wurde ein neues Kirchengesetz in Kraft gesetzt, in dem die römisch-katholische und die christkatholische Kirche öffentlich-rechtlich anerkannt wurden. Auf den Unterricht in Biblischer Geschichte hatte dies jedoch noch längere Zeit keine Auswirkungen. Dieser wurde weiterhin von reformierten Fachlehrpersonen erteilt. Die römisch-katholischen Jugendlichen erhielten kirchlichen Unterricht im Rahmen der Schule. I965 wurde eine erziehungsrätliche Kommission beauftragt, den Unterricht in Biblischer Geschichte und Sittenlehre an der Primarschule und der Oberstufe zu untersuchen. Das Resultat für die Primarschule war die Aufteilung des Faches Biblische Geschichte und Sittenlehre in zwei Fächer: «Biblische Geschichte» und «Lebenskunde». Während das Fach Lebenskunde als ein von allen Kindern obligatorisch zu besuchendes Fach erklärt wurde, sollten die Eltern ihre Kinder vom Fach Biblische Geschichte unter Berufung auf die Glaubens- und Gewis- 
sensfreiheit abmelden können. Für die Oberstufe präsentierte die Kommission keine Lösung, worauf eine neue paritätische Kommission eingesetzt wurde, die I976 in einem Zwischenbericht sechs denkbare Modelle und deren Vor- und Nachteile erörterte: «Religionsunterricht ausserhalb der Schule; Konfessioneller Unterricht im Raum der Schule; Lebenskunde als schulisches Fach, Biblische Geschichte als kirchlicher Unterricht; Gleiche Lösung wie für die Primarschule; Konfessioneller Unterricht im Rahmen der Schule; Konfessionell-kooperativer Unterricht im Rahmen der Schule». ${ }^{78}$

Der Erziehungsrat empfahl, das Modell des konfessionell-kooperativen Religionsunterrichts weiterzubearbeiten. Die Vernehmlassungsergebnisse sprachen jedoch dagegen. Auch das Kompromissmodell von I980 fand in der erneuten Vernehmlassung keine deutliche Zustimmung. ${ }^{79}$ Der Religionsunterricht an der Oberstufe wurde im Zusammenhang mit der Gesamtrevision der Lehrpläne wieder aufgegriffen. Der Erziehungsrat entschied I987, «dass ein konfessionell getrennter Unterricht nicht Sache der Schule sein könne». ${ }^{\circ \circ}$ Erneut wurden die Kirchen eingeladen, gemeinsam mit der Erziehungsdirektion am Modell für den konfessionell-kooperativen Religionsunterricht weiterzuarbeiten. Der Erziehungsrat beschloss am 26. März ı99 I die Richtlinien für den konfessionellkooperativen Religionsunterricht an der Oberstufe. Mit dem Erlass des damals neuen Lehrplans durch den Erziehungsrat am 29. Oktober i99 I wurde der KokoRu an der Oberstufe verankert. ${ }^{8 \mathrm{r}}$

Der KokoRu musste von allen Schulen obligatorisch angeboten werden. Die Schülerinnen und Schüler galten alle als angemeldet, konnten aber von ihren Eltern gestützt auf die Glaubens- und Gewissensfreiheit vom Besuch dieses Unterrichts abgemeldet werden. Der KokoRu durfte von folgenden Personen erteilt werden: Theologinnen und Theologen der anerkannten Kirchen, Lehrkräfte der Oberstufe mit entsprechender Zusatzausbildung sowie Katechetinnen und Katecheten mit entsprechender Ausbildung. Die inhaltliche Zielsetzung des KokoRu wurde vom Bildungsrat folgendermassen beschrieben: «Der Konfessionell-kooperative Religionsunterricht (KokoRu) bringt religiöse und ethische Grundthemen zur Sprache. Er vermittelt Einblicke in die Welt der Bibel. Der Unterricht versteht sich als Auseinandersetzung mit religiösen und im besonderen christlichen Gedanken und Überlieferungen und untersucht deren kulturelle und gesellschaftliche Auswirkungen in unserem Lebenskreis. Das Gemeinsame

78 Erläuterungen des Bildungsrats zum Bildungsratsbeschluss vom i 5. 8. 2000, 2.

79 Die Einführung des konfessionell-kooperativen Religionsunterricht wurde auch ausserhalb der Schweiz kontrovers diskutiert, vgl. beispielsweise die kritische Schrift des damals an der PH Lörrach/D unterrichtenden katholischen Religionspädagogen Alfons Benning mit dem provokativen Titel Das trojanische Pferd im Religionsunterricht (vgl. Benning 1993).

80 Erläuterungen des Bildungsrats zum Bildungsratsbeschluss vom i 5. 8. 2000, 2.

8 I Vgl. Erläuterungen des Bildungsrats zum Bildungsratsbeschluss vom i 5. 8. 2000, I f. 
der Konfessionen, nicht das Trennende, wird ins Zentrum gestellt. Im KokoRu findet auch eine Auseinandersetzung mit Merkmalen, mit Vorstellungen und Ausdrucksformen anderer Religionen statt. Das Christentum steht inhaltlich jedoch im Zentrum.» ${ }^{82}$

An den zweiten Klassen der Oberstufe konnte der KokoRu durch eine Wochenlektion kirchlichen Unterrichts in den Räumen der Schule ergänzt werden. Zudem hatten die anerkannten Kirchen das Recht, "während der gesamten Oberstufe total vier halbe Unterrichtstage für kirchliche Projekte zu beanspruchen» mit dem Ziel, «eine konfessionelle Beheimatung der Jugendlichen in der eigenen Kirche zu unterstützen».83

Für die Primarstufe hatte der neue Lehrplan von i99 I folgende Auswirkungen: Das Fach Biblische Geschichte wurde an den Unterrichtsbereich Mensch und Umwelt angegliedert, aber nicht in diesen Bereich integriert. Konkret bedeutete dies, dass Biblische Geschichte wie Realien und Haushaltkunde aufgebaut und gegliedert wurde. Der Lehrplan wurde aber nicht von Projektgruppen des Unterrichtsbereichs entwickelt, sondern von Theologen. Gemäss Fries habe der Entscheid, Biblische Geschichte als gesondertes Fach beizubehalten, zu einer Bedeutungszunahme des Faches geführt. Doch obwohl das Fach formal gesehen den anderen Fächern gleichgestellt worden war, galt immer noch die Regelung, dass es ein Fach mit Abmeldemöglichkeit war. ${ }^{84}$ Obwohl das Christentum inhaltlich einen Schwerpunkt bildete, durfte es nicht von Kirchenvertretern oder -vertreterinnen unterrichtet werden. Seit I987 waren zudem Primarlehrpersonen nicht mehr verpflichtet, den Unterricht in Biblischer Geschichte zu erteilen. ${ }^{85}$

Am I 5 . August 2000 beschloss der Bildungsrat, den konfessionell-kooperativen Religionsunterricht in ein neues Fach namens «Religion und Kultur» überzuführen und eine Vernehmlassung durchzuführen. Der zeitliche Umfang sollte gleich bleiben wie beim KokoRu. Religion und Kultur sollte aber neu «als ordentliches, obligatorisches Schulfach zu konzipieren» ${ }^{86}$ sein. Aus diesem Grund sollte der Unterricht wie in allen anderen ordentlichen Schulfächern nur noch von ausgebildeten Lehrkräften erteilt werden dürfen. Zudem sollte Organisation und Aufsicht den Schulpflegen obliegen. Folgende Ziele wurden für das Fach formuliert: «Aufzeigen und Erleben unseres soziokulturellen und religiösen Umfelds; Vermittlung von Kenntnissen über Religionen und Weltanschauungen;

82 Erläuterungen des Bildungsrats zum Bildungsratsbeschluss vom i 5. 8. 2000, 2.

83 Ebd.

84 Fries $2010,8$.

85 Vgl. Auszug aus dem Protokoll des Regierungsrates des Kantons Zürich, Sitzung vom 26. 10. 2005: KR-Nr. $258 / 2005,2$.

86 Erläuterungen des Bildungsrats zum Bildungsratsbeschluss vom 23. 8. 2004, 2. 
Aufzeigen von verschiedenen religiösen und weltanschaulichen Ausdrucksformen; Auseinandersetzung mit der Sinnfrage aus der Sicht verschiedener Weltanschauungen und Religionen; Befähigung, eigene Wertvorstellungen zu klären und zu begründen; Bereitschaft wecken, eigene Wertentscheidungen zu hinterfragen.» ${ }^{87}$

Auf der Sekundarstufe I konnten die Gemeinden ab dem Schuljahr 2007/08 mit der Einführung des neuen Fachs Religion und Kultur beginnen, ${ }^{88}$ auf der Primarstufe ab dem Schuljahr 2008/09. ${ }^{89}$ Spätestens mit Beginn des Schuljahrs 20II/I 2 mussten alle Schulgemeinden mit der Einführung des Fachs sowohl auf Primar- wie auch auf Sekundarstufe begonnen haben. Per Ende Schuljahr 20I6/17 sollte die flächendeckende Einführung abgeschlossen sein und das Fach in allen Klassen der Volksschule des Kantons Zürich unterrichtet werden. ${ }^{\circ}$ Der genaue Entstehungsprozess des Schulfachs Religion und Kultur wird in Kapitel 8 noch detaillierter beschrieben werden.

87 Ebd.

88 Vgl. Bildungsratsbeschluss vom 4. I 2. 2006.

89 Vgl. Bildungsratsbeschluss vom 29. 6. 2007.

90 Vgl. Erläuterungen des Bildungsrats zum Bildungsratsbeschluss vom 7. 3. 2016. 
TEIL 2

DIE DISKUSSION UM DEN SCHULISCHEN RELIGIONSUNTERRICHT UM 1872 


\section{Ausgangslage}

Um die öffentlichen Diskussionen über den schulischen Religionsunterricht, die im Zusammenhang mit dem von Erziehungsrat Johann Caspar Sieber lancierten neuen Unterrichtsgesetz, das im April I 872 vor das Volk kam - und scheiterte -, einordnen und besser verstehen zu können, soll vor der Darstellung der eigentlichen Diskussion in Kapitel 6 die politische und religionspolitische Situation um I 870 beschrieben werden.

\subsection{Politische Situation: Aufschwung der Demokratischen Bewegung}

Wie in vielen anderen europäischen Staaten zeitigte die Julirevolution von Frankreich im Jahre I 830 auch in der Schweiz ihre Wirkung. Am legendären Ustertag von I 830 versammelte sich in Uster, der drittgrössten Stadt im Kanton Zürich, die Landbevölkerung, um gegen die jahrhundertealte Vorherrschaft der Stadt aufzubegehren und eine neue Verfassung zu fordern. Diese sollte ihnen dieselben Rechte wie der Stadtbevölkerung zugestehen. ${ }^{\mathrm{I}}$ Dieser Tag markiert den Beginn der liberalen Umwälzung, die sich in der Verfassung von I 83 I konkretisierte. Der Kanton Zürich wurde zu einem «Freystaat mit repräsentativer Verfassung», 2 aber noch ohne direkte Demokratie. Nach einer ersten, kurzen liberalen Phase (I83I-I839) und dem darauffolgenden kurzen konservativen Interregnum (I 839-I 844), folgte eine lange zweite liberale Phase (I 844-I869), die stark von einer Person dominiert wurde: Alfred Escher (I 819-1 882). ${ }^{3}$

Bevor ich auf die Ära Escher eingehe, soll kurz die Frage erörtert werden, was im Zürich des 19. Jahrhunderts eigentlich unter 〈Liberalismus〉 zu verstehen ist. Diese Frage drängt sich auf, wenn man sich vergegenwärtigt, dass Liberale - und mit Alfred Escher sogar ein Wirtschaftsliberaler - die Gründung eines Staatsverlags befürwortet und genehmigt hatten. ${ }^{4}$ In seinem Buchbeitrag Politischer Liberalismus und staatlicher Lebrmittelvertrag? prüft Daniel Tröhler wie liberal die Liberalen waren.' Auf dem Hintergrund seiner langues/paroles-Analyse kommt

I Vgl. Tröhler 2008, 56.

2 Stadler 1986, I73.

3 Vgl. Illi 2015 .

4 Auf Antrag der Schulsynode gründete der Erziehungsdirektor Alfred Escher im Jahre I 8 5 I den Lehrmittelverlag Zürich.

5 Tröhler $200 \mathrm{Ib}, \mathrm{I} 3$. 
er zum Schluss, «dass die «Liberalen` um die Mitte des I9. Jahrhunderts nicht als Vertreter des politischen Liberalismus, sondern vielmehr in der Tradition der Schweiz bzw. der Alten Eidgenossenschaft stehend als Repräsentanten des Republikanismus zu deuten sind. Die Distanz der «Liberalen` zum Liberalismus nach I 830 kann $[\ldots]$ an drei Beispielen nachgewiesen werden: dem Ausbau der Staatsgewalt, der rechtlichen Diskriminierung der Frau und den Rede- und Versammlungsverboten für kritische Geister». ${ }^{6}$

An anderer Stelle schreibt Tröhler weiter, dass «die politische Partei〉, die sich selber liberal nannte, $[\ldots]$ primär eine Bewegung gegen Aristokratie und Klerus [war], die sich der Sprache des (klassischen) Republikanismus bediente und diese mit dem Christentum als Moralreligion vermengte».?

Während der klassische politische Liberalismus die Rolle des Staates auf den Schutz von Eigentum und Leben beschränkt haben wollte, wurde im I9. Jahrhundert dem Staat im Liberalismus zürcherischer Prägung eine viel umfassendere Rolle zugesprochen, die auch die weltanschaulich-religiöse Dimension beinhaltete. Da bereits im einleitenden Unterkapitel I.I der Topos Republikanismus in Bezug auf Pädagogik erörtert wurde, werde ich diese Thematik an dieser Stelle nicht weiterverfolgen und nach diesem kurzen Liberalismus-Exkurs zur Ära Escher zurückkehren.

Escher kumulierte eine erstaunliche Anzahl von politischen Ämtern: Er war Mitglied des Grossen Rates, Regierungsrat, Bürgermeister, Erziehungsdirektor und Nationalrat. Sein Wirtschaftsliberalismus drückte dieser Zeit den Stempel auf. ${ }^{8}$ Escher setzte seine Macht konsequent für die Interessen von Besitz und Bildung ein. Deswegen und auch wegen seiner Ämterkumulation blieb Kritik nicht aus. Gemäss Markus Bürgi setzte Escher «Fortschritt im Interesse der Wirtschaft einseitig mit Fortschritt im Dienste der Allgemeinheit gleich und vernachlässigte die sozialen Folgen der von ihm geprägten Entwicklung». ${ }^{9}$ Der Grosse Rat regierte zwar im Namen des Volkes, aber unabhängig von ihm. Im Grossen Rat dominierten Vertreter von Handel und Industrie. Dies hatte zur Folge, dass sich Arbeiter, Kleingewerbe und Landwirtschaft benachteiligt und machtlos fühlten. ${ }^{10}$ Auf dem Hintergrund dieses Unmuts gedieh in den I $850 / 60 e r$ Jahren

6 Ebd., is f.

7 Ebd., 33.

8 Eines der wichtigsten Tätigkeitsfelder Eschers war der Eisenbahnbau. Um die dafür nötigen finanziellen Mittel unabhängig von ausländischem Einfluss zu organisieren, gründete er mit Gleichgesinnten die Schweizerische Kreditanstalt (SKA), heute Credit Suisse genannt (vgl. Bürgi 2005).

9 Bürgi 2005.

Io Vgl. Largiadèr 1944, I 56. 
die Demokratische Bewegung. ${ }^{\text {II }}$ Die wirtschaftliche und soziale Lage sollte verbessert werden und dem Volk direkte Mitsprache ermöglicht werden. ${ }^{12}$ I 863 tauchte die Frage nach einer Verfassungsrevision auf. I 865 wurde über die Teilrevision der Verfassung abgestimmt. Sechs der sieben neuen Verfassungsartikel wurden angenommen. Von Bedeutung ist in diesem Zusammenhang insbesondere die Einführung der Möglichkeit der Volksinitiative für eine Verfassungsreform. In den Grossratswahlen von i 866 legte die Demokratische Bewegung zu. i 868 wurde die Totalrevision der Verfassung mit 50000 gegen 7000 Stimmen angenommen und ein Verfassungsrat eingesetzt. In den Verfassungsratswahlen erhielten die Demokraten eine Zweidrittelsmehrheit, wodurch das sogenannte «System Escher» ziemlich erschüttert wurde. ${ }^{13} \mathrm{Zu}$ den Mitgliedern des Verfassungsrates und zur Führungselite der Demokratischen Bewegung $^{14}$ gehörten unter anderem Johann Caspar Sieber, Lehrer und führender Kopf der Demokraten, der Sozialphilosoph und Neukantianer Friedrich Albert Lange und Friedrich Salomon Vögelin, den Jakob Streuli als «Hoftheologen» ${ }^{\text {Is }}$ der Demokraten bezeichnete. Die Verfassungsrevision berührte verschiedenste Themenbereiche. Im Zusammenhang mit dem Kirchenartikel (Art. 63 der Kantonsverfassung von I869) stand unter anderem die Neubestimmung des Verhältnisses zwischen Staat und Kirche zur Diskussion. Eine Veränderung des Verhältnisses zwischen Staat und Kirche warf auch Fragen hinsichtlich des schulischen Religionsunterrichts auf.

I I Gemäss Anton Largiadèr war es Salomon Bleuler (I 829-1886), der die verschiedenen unzufriedenen und oppositionellen Stimmen zur demokratischen Partei gesammelt hat. Für die Nationalratswahlen von I 860 führte er eine Reihe unzufriedener Männer zusammen: Den Schriftsteller Gottfried Keller, Friedrich Scheuchzer, Johann Caspar Sieber und Karl Walder (vgl. Largiadèr 1944, I 5 f.). Zur Entstehung der direkten Demokratie in der Schweiz siehe auch Rolf Graber (2017). Im Kapitel über die Demokratische Bewegung in Zürich verweist Graber auf die von den Initianten bewusst gezogene «Kontinuitätslinie zwischen der liberalen Bewegung von I 830 und der demokratischen Opposition von I 867》 (Graber 2017, I39). Mit dem Datum der geplanten Volksversammlungen (22. November) sollte an den Ustertag erinnert werden. Der «Kampf der Liberalen gegen die Aristokratie» wurde mit «dem Kampf der Demokraten gegen die Geldaristokratie» (Graber 2017, 139) verglichen.

I2 Vgl. Koller 1987, I4.

I 3 Vgl. ebd., i6 f.

I4 Rudolf Braun weist darauf hin, dass «parteipolitische Ordnungsbegriffe wie 〈liberal», «radikal-demokratisch, <demokratisch> [...] in dieser Zeit weder ein festfixiertes politisches (inklusive sozialpolitisches) Programm von einiger Dauerhaftigkeit, noch eine Parteiorganisation mit stabilem Trägerkreis und Institutionen beinhalteten. Die modernen Parteiapparate und politischen Interessenverbände mit ihren spezifischen, zweckgerichteten Organisationsgefügen, Institutionen und Medien der Einflussnahme auf die politische Willensbildung beginnen sich erst in den letzten drei Jahrzehnten des I9. Jahrhunderts auszuformen.» (Braun 1965, I66).

is Streuli 1948, 22. 
Bevor ich jedoch auf die religionspolitische Situation zu sprechen komme, soll an dieser Stelle noch kurz die Debatte um die Revision der Bundesverfassung erwähnt werden. Obwohl diese zeitgleich auf nationaler Ebene stattfand, tangierte die nationale Verfassungsdebatte die zürcherische Diskussion um den schulischen Religionsunterricht im Zusammenhang eines neuen Unterrichtsgesetzes nicht, und zwar aus folgendem Grund: Der erste Entwurf für eine neue Bundesverfassung scheiterte in der Volksabstimmung vom I2. Mai I 872. Gemäss Lucien Criblez wurde der religiöse Unterricht in der ersten Revisionsdiskussion von I 870/72 nicht thematisiert, da man diese Thematik dem Artikel über die Glaubens- und Gewissensfreiheit subsumierte. ${ }^{16}$ Erst im zweiten Anlauf ${ }^{17}$ wurden Formulierungen in die Bundesverfassung aufgenommen, die den schulischen Religionsunterricht tangierten. Als Grund dafür sieht Criblez hinsichtlich der konfessionellen Artikel eine Radikalisierung der Positionen im Parlament auf Grund des Kulturkampfes. Zwar sei die Formulierung in Artikel 27, dass der Unterricht in den öffentlichen Schulen von den «Angehörigen aller Bekenntnisse ohne Beeinträchtigung ihrer Glaubens- und Gewissensfreiheit besucht werden» könne (BV, I874, Art. 27), auch eine Folge der Einführung der Niederlassungsfreiheit in der Bundesverfassung, aber zudem sei sie «auch als Spitze im Kulturkampf gegen den Ultramontanismus gedacht ${ }^{18}$ gewesen. In der zweiten Revisionsfassung der Bundesverfassung wurde die Schule jedoch auch im Zusammenhang mit den konfessionellen Artikeln 49 und $5 \mathrm{I}^{19}$ berücksichtigt, die intensive Diskussionen hervorriefen. Auf dem Hintergrund der Unverletzlichkeit der Glaubens- und Gewissensfreiheit hiess es in Artikel 49: «Niemand darf zur Theilnahme an einer Religionsgenossenschaft, oder an einem religiösen Unterricht, oder zur Vornahme einer religiösen Handlung gezwungen, oder wegen Glaubensansichten mit Strafen irgend welcher Art belegt werden» (BV, I874, Art. 49).

Zum Zeitpunkt der hitzigen Diskussionen um diese den schulischen Religionsunterricht tangierenden Artikel in der Bundesverfassung war das Unterrichts-

I6 In Artikel 48 der ersten Fassung der Bundesverfassung hiess es: «Die Glaubens- und Gewissensfreiheit ist gewährleistet. Niemand darf in der Ausübung der bürgerlichen oder politischen Rechte um der Glaubensansicht willen beschränkt oder zur Vornahme einer religiösen Handlung angehalten oder wegen Unterlassung einer solchen mit Strafen belegt werden. [...] Die Glaubensansichten entbinden nicht von der Erfüllung der bürgerlichen Pflichten» (Bundesgesetz Verfassungsrevision, I872, Art. 48, zit. in Criblez 2008a, 93).

I7 Die Revisionsverhandlungen wurden nach den Nationalratswahlen vom Herbst I 872 wieder aufgenommen (vgl. Criblez 2008a, 89).

I8 Criblez 2008a, 94 .

I9 In Artikel 5 I wurde dem «Orden der Jesuiten» und den «ihm affillierten [...] Gesellschaften» die Aufnahme in der Schweiz verweigert und «ihren Gliedern jede Wirksamkeit in Kirche und Schule untersagt» (BV, I 874, Art. 51). Dieser Artikel wurde in der Volksabstimmung vom 20. Mai 1973 aufgehoben. 
gesetz im Kanton Zürich, das einen konfessionslosen Religionsunterricht vorgesehen hätte, in der Volksabstimmung bereits gescheitert. Deshalb werde ich die nationale Verfassungsdiskussion in dieser Arbeit nicht weiter berücksichtigen.

\subsection{Religionspolitische Situation}

Gemäss dem Rechtswissenschaftler Alfred Kölz wurde das Verhältnis von Staat und Kirche im Kanton Zürich noch vor «den Kulturkampf entfachenden Beschlüssen des Ersten Vatikanischen Konzils von I $870{ }^{20}$ geregelt. Laut Kölz standen dem Verfassungsrat drei Möglichkeiten zur Regelung dieses Verhältnisses offen: I) Die Beibehaltung der offiziellen reformierten Landeskirche. Diese sollte durch eine aus Pfarrern und Laien gebildeten gemischten Kirchensynode gestärkt werden. 2) Die völlige Trennung von Staat und Kirche. Dies wurde vom früheren Pfarrer und Landbote-Redaktor Gottlieb Ziegler vorgeschlagen und von verschiedenen einflussreichen Personen wie beispielsweise dem Demokraten Johann Caspar Sieber sowie dem Sozialdemokraten Karl Bürkli unterstützt. ${ }^{21}$ 3) Ein Kompromiss ${ }^{22}$ zwischen den zwei ersten Standpunkten: Die bisherige Rechts- und Organisationsform der Landeskirche sollte bewahrt werden, allerdings ohne diese als solche zu erwähnen. ${ }^{23}$ Dabei sollte jedoch die individuelle Glaubens-, Kultus- und Lehrfreiheit der Einzelnen und der Ausschluss jeden kirchlichen $Z$ wanges gegen sie ausdrücklich garantiert werden. Damit verbunden waren auch Säkularisierungsmassnahmen. ${ }^{24}$

Bei der ersten Beratung im Verfassungsrat erhielt der Kompromissvorschlag am meisten Stimmen. Die Nichterwähnung der Landeskirche wurde im Volk jedoch heftig angefochten und es wurden Petitionen lanciert, die sich gegen die Abschaffung der Landeskirche zur Wehr setzten, zum Beispiel die «Affolterer Petition». Der Verfassungsrat gab diesen Forderungen nach. Mit der Zürcher Staatsverfassung von I869 wurde in Artikel 63 die Glaubens-, Kultus- und Lehrfreiheit nicht nur der Landeskirche, sondern auch aller anderen kirchlichen Gemeinschaften bekräftigt. Zudem wurde darin auch jeder Zwang gegen

20 Kölz 2000, 53.

2 I Vgl. ebd., $53 \mathrm{f}$.

22 Der Kompromissvorschlag für den Kirchenartikel der neuen Verfassung von I 869 lautete folgendermassen: «Die kirchlichen Gemeinschaften ordnen ihre Kultusverhältnisse selbständig unter Oberaufsicht des Staates. Der Staat übernimmt im allgemeinen die bisherigen Leistungen für kirchliche Bedürfnisse.» (Zit. in Sträuli I902, 236.)

23 Vgl. Sträuli i902, $235 \mathrm{f}$.

24 Die Bürger erhielten neu das Recht, die Ehe durch einen bürgerlichen Zivilstandsbeamten schliessen zu lassen. Die Führung der Eheregister wurde dem Staat übertragen. Die Kirche war jedoch weiterhin für die Friedhöfe und das Armenwesen zuständig (vgl. Kölz 2000, 54 f.). 
Gemeinden, Genossenschaften und Einzelne ausgeschlossen. Zugleich wurde aber auch der Vorschlag abgelehnt, die Landeskirche den anderen kirchlichen Gemeinschaften gleichzustellen und jegliche Beziehungen zwischen Kirche und Staat aufzulösen. Im Unterschied zu den anderen kirchlichen Gemeinschaften blieb die reformierte Landeskirche durch staatliches Gesetz geordnet. ${ }^{25}$ Zur selben Zeit wie die Diskussion über eine neue kantonale Verfassung fand auch die bereits I845 schweizweit angestossene innerkirchliche Diskussion um den Antrag auf Streichung des Apostolikums aus der Taufagenda ein Ende, der damals noch keine Mehrheit fand. I854 regte der liberale Theologe Alois Emanuel Biedermann ${ }^{26}$ die diesbezügliche Diskussion in Zürich an. I 868 wurde in Zürich dann eine revidierte Liturgie mit je zwei Formularen für Taufe und Abendmahl angenommen. Die Verpflichtung auf das Apostolikum war in den meisten Landeskirchen Ende der I870er Jahre aufgehoben. ${ }^{27}$ Die reformierte Landeskirche ist bis heute eine bekenntnisfreie Kirche.

\subsection{Innerkirchliche Richtungsstreitigkeiten}

Neue theologische Strömungen, die sich auf die Erkenntnisse der historisch-kritischen Theologie beriefen und sich als theologisch-kirchlicher Liberalismus im schweizerischen Protestantismus auf vielfache Weise verbreiteten, führten in der zweiten Hälfte des i9. Jahrhunderts innerhalb der reformierten Landeskirche $\mathrm{zu}$ innerkirchlichen Richtungsstreitigkeiten..$^{28}$ Folgende zwei Hauptrichtungen sind zu unterscheiden: Auf der einen Seite die Positiven ${ }^{29}$ und auf der anderen

25 Vgl. Schmid 1994, 207. Vgl. ebenfalls die Ausführungen im Unterkapitel 3.I über den Wandel des Verhältnisses zwischen Kirche und Staat. Die in der Schlussabstimmung angenommene Version des Kirchenartikels 63 wurde in Unterkapitel 3.I, Anm. I9 zitiert.

26 Alois Emanuel Biedermann (I8I9-I885) und Alexander Schweizer (I808-I888) waren die führenden Vertreter der liberalen Theologie und der Vermittlungstheologie. Sie stützten das liberale Repräsentativsystem und gehörten zum engsten Kreis Alfred Eschers. Interessant ist, dass Friedrich Salomon Vögelin theologisch gesehen ein Schüler Biedermanns war, sich aber politisch den Demokraten anschloss.

27 Vgl. Gebhard 201 I.

28 Pfister 1984, 260.

29 Manchmal werden die Positiven auch Orthodoxe genannt, wobei mit Theodore M. Vial darauf hinzuweisen ist, dass der Begriff Orthodoxie in der Schweiz am passendsten auf die Zeit der Konsensus-Formel angewendet wird. Die Konsensus-Formel ist ein Glaubensbekenntnis, das I675 gegen verschiedene Häresien verfasst worden war. Wenngleich sich die 〈Orthodoxen〉 des 19. Jahrhunderts in Gegnerschaft zum theologischen Liberalismus an herkömmlichen Positionen festhielten, waren die Diskussionspunkte andere als im 17. Jahrhundert. Ein zentraler Punkt im I9. Jahrhundert war die Orientierung am altkirchlichen Glaubensbekenntnis anstelle einer bekenntisfreien Kirche. Gemäss Vial ist die Orthodoxie des I 9. Jahrhunderts das Resultat pietistischer und humanistischer Einflüsse auf die frühere Orthodoxie des 17. Jahrhunderts (vgl. Vial 2004, 66). 
Seite die Reformer bzw. theologisch Liberalen. Eine dritte Richtung bildeten die Vermittler, «eine Gruppe von Theologen und Laien, welche die Anliegen beider Seiten aufzunehmen und in die Glaubenslehre und in die Kirche einzubringen versuchte». ${ }^{3 \circ}$

In der folgenden Darstellung dieser theologischen Richtungsstreitigkeiten folge ich weitgehend Paul Schweizer. Gemäss Schweizer ist mit dem 〈Positiven〉

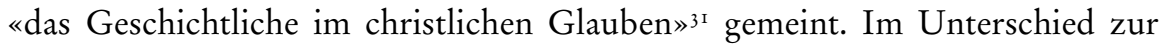
liberalen Theologie, die «das Prinzip des Christentums, das Geistige» betont, will die positive Theologie «die Tatsachen des Heils und der Heilsgeschichte als das Wesentliche und Unumstössliche» ${ }^{22}$ verstanden wissen. Die Heilsereignisse, von denen die biblischen Geschichten erzählen und die im Apostolischen Glaubensbekenntnis zusammengefasst sind - Inkarnation, Kreuzestod Jesu als Akt der Versöhnung, leibliche Auferstehung Christi, Christi Himmelfahrt als Herrschaftübernahme -, sollen als historische Tatsachen verstanden werden, das heisst, als in Zeit und Raum geschehene Ereignisse. ${ }^{33}$ Die von Hegel inspirierte liberale Theologie hingegen wollte «sich vom bloss Geschichtlichen lösen [...], um sich der philosophisch-theologischen Spekulation hinzugeben».34

In Deutschland gab es zwischen der liberalen Theologie und der kirchlichen Praxis nur wenige Berührungspunkte. Die liberalen Christen fanden sich in Minoritätsgemeinden zusammen. In der Schweiz und insbesondere in Zürich war dies anders. Die liberale Theologie verbreitete sich auch in den Kirchgemeinden. Häufig waren es sogar die positiven Christen, die in die Minderheitsposition gerieten. In Deutschland kam es zu Spaltungen zwischen wissenschaftlicher Theologie und kirchlichem Amt. In der Schweiz hingegen wurde die liberale Theologie von liberalen Pfarrern auch von der Kanzel verkündet. Gemäss Paul Schweizer haben dies die beiden Zürcher Theologen Alexander Schweizer und Alois Emanuel Biedermann ermöglicht. ${ }^{35}$ In seiner Abhandlung über Friedrich Salomon Vögelin - Theologe, Pfarrer, Politiker, Sozialreformer, Kunst- und Kulturhistoriker - arbeitete Walter Betulius überzeugend auch dessen Rolle im Liberalisierungsprozess der Zürcher Kirche heraus. Vögelin war ein Schüler Biedermanns und gilt als einer der ersten Pfarrer, die das an der Universität längst verbreitete und diskutierte theologisch liberale Denken auch von der Kanzel predigten und somit unters Volk brachten. Der Protest blieb nicht aus. ${ }^{36}$ Vögelin stellte jedoch nicht bloss die bisher im Volk massgebende Glaubenslehre

30 Pfister 1984,265 .

3 I Schweizer 1972, 3 I f.

32 Ebd., I I2.

33 Ebd.

34 Ebd., 8.

$35 \mathrm{Vgl}$. ebd.

36 Vgl. Betulius 1956, 25 f.; Pfister 1984, 262 f.; Campi 2008, 72. 
in Frage, sondern griff auch die bestehende kirchliche Ordnung an, indem er das Glaubensbekenntnis im Gottesdienst nicht mehr verwendete, noch bevor die Geistlichkeitssynode von I 868 entschieden hatte, sich von der Verbindlichkeit des Apostolikums zu lösen. ${ }^{37}$

Ein grosser Streitpunkt zwischen Liberalen und Positiven war die $W u n d e r-$ frage, die aus einem unterschiedlichen Naturverständnis resultierte. ${ }^{3}$ Die liberalen $^{39}$ Theologen versuchten den christlichen Glauben mit dem Verständnis der modernen Naturwissenschaften in Übereinstimmung zu bringen und betrachteten die Natur als einen geschlossenen Kausalzusammenhang. Die biblischen Wundererzählungen wurden als Bruch der Kausalgesetze verstanden, den man auf dem Hintergrund eines modernen wissenschaftlichen Weltbildes nicht für möglich erachten konnte. Deshalb hielt man aus liberaler Sicht die biblischen Wunder für unmöglich bzw. tat sie als Legenden oder Mythen ab..$^{\circ}$ Demgegenüber lehnten die positiven Theologen ein solch mechanisches Naturverständnis zu Gunsten eines Raumes, der für Gottes Wirken offen ist, ab. Man betonte die Freiheit Gottes, der, wenn er will, ins gewöhnliche Naturgeschehen eingreifen kann. Allerdings wurde ein solch wunderbarer göttlicher Eingriff nicht als eine Durchbrechung der Naturgesetze verstanden, die es als solche aus positiver Perspektive gar nicht gibt, sondern als Geschehnisse höherer Ordnung. Gottes Eingriff geschieht nie gegen die Naturordnung, sondern immer im Einklang mit der Natur, was aber vom Menschen nicht ganz verstanden werden kann, da man Gottes Eingreifen als göttliches Geheimnis betrachtete. ${ }^{41}$

Hinsichtlich des Gottesverständnisses betonten die liberalen Theologen die Immanenz Gottes und weniger seine Transzendenz. Obwohl - oder gerade weil auch sie davon ausgingen, dass Gott von der Welt wesentlich verschieden ist, sahen sie ihn dennoch als ihr «einwohnend» an. Gemäss Pfarrer Heinrich Lang, ${ }^{42}$ einem der Führer der theologisch-liberalen Bewegung, unterscheidet sich Gott

37 Vgl. Campi 2008, 72.

38 Vgl. Schweizer i972, i 2.

39 Es ist anzumerken, dass die liberale Theologie keinen monolithischen Block bildete und sich längst nicht in allen Punkten einig war. Ein Punkt der Uneinigkeit betraf zum Beispiel das Schriftverständnis. Eine verbreitete Ansicht innerhalb der liberalen Theologie war, dass die Bibel nicht als Wort Gottes verstanden wurde, sondern als ein von Menschen verfasstes Buch; von Menschen, die Gott auf eine besondere Weise erfahren hatten. Der theologisch Liberale Heinrich Hirzel vertrat jedoch wie sein Lehrer Alexander Schweizer eine dynamische Inspirationslehre (vgl. Schweizeri972, ro2 f.).

40 Vgl. Schweizer i972, ioo.

4 I Vgl. ebd., i 2.

42 Heinrich Lang (I 826-г876) flüchtete i 848 aus Deutschland in die Schweiz. Ab i 863 war er Pfarrer in Meilen im Kanton Zürich, ab I 87 I Pfarrer in St. Peter in Zürich. Von I 872 bis I 876 amtete er als Zürcher Kirchenrat. Er war der erste Präsident des Schweizerischen Vereins für freies Christentum. Publizistisch betätigte er sich als Redaktor der Zeitschrift Zeitstimmen aus der reformirten Kirche der Schweiz (1859-1 871) (vgl. Kuhn 2007b). 
von der Welt durch seine Geistigkeit. Sein Einwohnen in der Welt begründete er mit seiner Allgegenwart. Lang lehnte ausdrücklich den Deismus, den Theismus wie auch den Spinozismus ab. Die Frage, wann und wie Gott die Welt erschaffen habe, erachteten die liberalen Theologen nicht als eine theologische, sondern als eine naturwissenschaftliche Frage. Als theologische Fragen zugelassen wurden jedoch Fragen nach dem Woher und dem Wozu. ${ }^{43}$ Bei den positiven Theologen sieht Paul Schweizer einen mystischen Zug, insofern ein «Ineinandergreifen von Transzendenz und Immanenz» ${ }^{44}$ vorwiege, wobei in positiven Laienkreisen mehr die Überweltlichkeit Gottes betont worden sei.

Ein weiterer entscheidender Trennungspunkt zwischen der liberalen und der positiven Theologie war die unterschiedliche Beantwortung der Frage nach Jesus Christus. Zentrales Merkmal der liberalen Christologie war die Betonung der Menschlichkeit Christi. Jesus wurde als der erste Christ gesehen, der vorbildund prophetenhaft nach christlichen Prinzipien gelebt hatte. Dementsprechend war die Suche nach dem sogenannten historischen Jesus, das heisst dem irdischen Jesus, ein wichtiges Anliegen der liberalen Theologie.45 Dieses Anliegen verfolgte auch der bereits genannte, umtriebige Friedrich Salomon Vögelin. Sein Wirken beschränkte sich nicht bloss auf das Predigen von der Kanzel. Mit einer Gruppe von aufklärerischen Lehrern aus Uster entwickelte er ein Lehrbuch mit dem Titel: Die Geschichte Jesu und der Ursprung der christlichen Kirche. Für das Volk und die böberen Volksschulen dargestellt. ${ }^{46}$ Dieses Lehrbuch hatte zum Ziel, die von David Friedrich Strauss inspirierte liberale Theologie auch in der Schule zu vermitteln. ${ }^{47}$ Die Versuche der Liberalen, Jesus die Göttlichkeit zu nehmen und ihn als blossen Menschen, als Propheten, zu verstehen, wurden von den Positiven abgelehnt. Für sie war der Glaube an die historische Realität des biblischen Jesus zentral..$^{8}$

Das Bemühen der Positiven ging dahin, das traditionelle Christentum zu erhalten, dessen Integrität sie durch die von den Liberalen verursachte Verweltlichung

43 Vgl. Schweizer 1972, iо I f.

44 Ebd., ins.

45 Vgl. ebd., 106.

46 Vögelin I867, III.

47 Wie in Kapitel 6 noch deutlich werden wird, spielte Vögelin in der Diskussion um den schulischen Religionsunterricht eine zentrale Rolle. In einem Aufsatz (Katzenstein 20I7) zeige ich anhand einer Analyse von Vögelins Predigten und Reden auf, dass sein Denken trotz seiner aufklärerischen, theologisch liberalen Ausrichtung sowie seiner radikal-demokratischen politischen Gesinnung antimoderne, gesellschaftlich dedifferenzierende Züge aufweist. Die enge Freundschaft zwischen Vögelin und Johann Caspar Sieber, dem Initiator des Unterrichtsgesetzes, das I 872 vors Volk kam, mag als Ausdruck einer fast symbiotischen Verhältnisbestimmung von Kirche und Schule gesehen werden, die interessanterweise von zwei Männern vertreten worden war, die beide die Schule von der Vorherrschaft der Kirche befreien wollten.

48 Schweizer 1972, i 6. 
in Frage gestellt sahen. Da sich die Positiven jedoch nicht von der Landeskirche abspalten wollten, sahen sie sich genötigt, zwischen Kirche als Institution und Kirche als Glaubensgemeinschaft, zwischen ecclesia und ecclesiola, zu unterscheiden und die ecclesiola in der ecclesia zu stärken. ${ }^{49}$ Diesem Zweck diente die I 837 gegründete Evangelische Gesellschaft des Kantons Zürich. Sie ging aus einem Kreis um Georg Gessner ( $1765-1843$ ), dem damaligen Antistes der Zürcher Kirche, hervor. Theologisch gesehen stand Gessner der Erweckungsbewegung und der bibel- und bekenntnisorientierten Richtung nahe. Er hatte sich I 839 auch gegen die Wahl von David Friedrich Strauss an die Universität Zürich gewandt. Vorbild für die evangelische Gesellschaft in Zürich war diejenige in Basel: Gleichgesinnte sollten in der Landeskirche gesammelt und missionarische und diakonische Aufgaben übernommen werden..$^{\circ}$ Als Bekenntnisgrundlage wurde das Apostolische Bekenntnis und die Zweite Helvetische Konfession gewählt. ${ }^{\text {sI }}$ Die Evangelischen Gesellschaften verstanden sich jedoch nicht als kirchliche Gegengesellschaften, sondern innerhalb der Landeskirche als Gegenbewegungen zu den bibelkritisch-rationalen Strömungen. ${ }^{22}$ Das Publikationsorgan der Evangelischen Gesellschaft war das Evangelische Monatsblatt, ${ }^{53}$ das I95 I von der Zeitschrift Der Kirchenfreund, welche die Anliegen der Positiven für die gesamte deutschsprachige Schweiz vertrat, abgelöst wurde. ${ }^{54}$ Fast zur selben Zeit wie die Evangelische Gesellschaft wurde 1839 der Christliche Verein zur Erhaltung des evangelisch-reformierten Christenglaubens in den Volksschulen gegründet. Anlass für diese Gründung war die Berufung des liberalen Theologen

49 Vgl. ebd., i I I.

50 Die r 858 gegründete Kranken- und Diakonissenanstalt Neumünster und die r 886 eröffnete Herberge Zur Heimat gingen auf Anregungen der Evangelischen Gesellschaft zurück (vgl. Pfister 1984, 196).

5 I Vgl. Pfister 1984, 195.

52 Vgl. ebd., I88; Fritsche \& Lemmenmeier 1994, I 54. I 847 gab sich die Evangelische Gesellschaft neue Statuten. Präsident war Hans Kaspar Usteri. Als Förderer der Evangelischen Gesellschaft stand jedoch Diethelm Salomon Hofmeister (I8I4-I893) im Vordergrund, der mehrere öffentliche Ämter innehatte: Erziehungsrat, Vorsteher der Schulpflege der Stadt Zürich (г 86I-I 874), Präsident der Blinden- und Taubstummenanstalt Zürich. An seiner Seite standen Johann Peter Lange - vehementer Gegner von Strauss - und Auguste Ebrard, beides Neutestamentler der Universität Zürich. Des Weiteren sind die zwei Nichttheologen Hans Heinrich Spöndlin (Rechtsanwalt und Mitbegründer des Evangelischen Seminars Unterstrass) und Ulrich Stutz (Geologe) zu nennen. Auf dem Land trat eine Vielzahl von Pfarrern und Kirchengliedern der Evangelischen Gesellschaft bei. Die Evangelische Gesellschaft gründete auch Minderheitsgemeinden mit eigenen Predigern, z. B. Uster I 866 oder I 873 St. Anna in Zürich (vgl. Pfister 1984, 195 f.).

53 Paul Schweizer schreibt, das «Evangelische Monatsblatt» sei von i 867 an erschienen (vgl. Schweizer 1972, I I 2). Dies muss ein Versehen gewesen sein, da er im Literaturverzeichnis als Erscheinungsdauer des Evangelischen Monatsblattes die Jahre i $845-1858$ angibt (vgl. ebd., 27I) und immer wieder aus dem Evangelischen Monatsblatt zitiert mit Angaben aus früheren Jahren.

54 Schweizer 1972, i i f. 
David Friedrich Strauss an die Universität Zürich, sowie «die Verhältnisse im Staatsseminar Küsnacht».5s Bald nach der Gründung des Christlichen Vereins wurde dieser durch die Wirren des sogenannten Züriputsches von seinen Zielen abgelenkt und war die kommenden 30 Jahre nicht mehr aktiv. Erst i 868 wurde der Verein wieder zum Leben erweckt. Auf Initiative des Juristen Hans Heinrich Spöndlin (I812-I872) wurde I 869 das Freie Evangelische Lehrerseminar Zürich-Unterstrass gegründet. Als Kontrast zum staatlichen Lehrerseminar in Küsnacht hatte diese private Institution zum Ziel, die Lehrer im Geist des positiv-biblischen Christentums auszubilden. Aus den Kreisen des Christlichen Vereins gingen weitere Schulgründungen und Anstalten hervor, zum Beispiel die Freie Schule Zürich oder die Anstalt für Epileptische. ${ }^{6}$

Neben den Liberalen und Positiven gab es auch noch eine Gruppe von Theologen, die zwischen diesen beiden Richtungen zu vermitteln versuchten. $\mathrm{Zu}$ diesen sogenannten Vermittlern gehörten der Schleiermacher-Schüler Alexander Schweizer, den Paul Schweizer zu den «Linksvermittlern» zählt, Theodor Keim, von I 860 bis I 873 Professor für Neues Testament an der Universität Zürich, Pfarrer Georg Finsler, von i 866 bis i 895 letzter Antistes der Zürcher Kirche, und Johannes Hirzel, Pfarrer in Bauma von I 846 bis I 878 . Die beiden Letzteren zählt Paul Schweizer zu den «Rechtsvermittlern».57 Die Zeitschrift der Vermittler war das vom Basler Vermittlungstheologen Rudolf Hagenbach redigierte Kirchenblatt. Gemäss Paul Schweizer bestand das Anliegen der Vermittlungstheologen darin, «zwischen dem Historischen des Christentums und den gegenwärtigen Zeitanschauungen» bzw. «zwischen dem sogenannten objektiv Gegebenen und der subjektiven Aneignung des Glaubensgutes» ${ }^{8}$ zu vermitteln.

Neben diesen Richtungsbildungen innerhalb der Landeskirche gab es zudem verschiedene Freikirchen, die, aus dem Ausland kommend, auch in der Schweiz immer mehr Fuss fassten: die Methodisten (Beginn in Zürich I 856), die Baptisten (Gründung in Zürich I 849), die Heilsarmee (seit I 882). Auch die Pilgermission St. Chrischona nahm gemäss Pfister teilweise freikirchliche Züge an. ${ }^{99}$ Der klassische Pietismus (zumindest derjenige des I 8. Jahrhunderts) war in Zürich gemäss Paul Schweizer nicht so gewichtig. Mit dem Fraumünsterpfarrer Hans Kaspar Ulrich, der I768 gestorben war, sei «auch der Herrnhutische Geist in Zürich erloschen». ${ }^{60}$

55 Zurlinden I915, I29.

$56 \mathrm{Vgl}$. ebd.

57 Vgl. Schweizer 1972, i25 f.

58 Ebd., I25.

59 Vgl. Pfister 1984, $270 \mathrm{ff}$.

60 Vgl. Schweizer 1972, I7. 


\subsection{Politische und religiöse Richtungen und ihre Verflechtungen}

Gemäss Streuli hatten die meisten Zürcher Geistlichen der Demokratischen Bewegung gegenüber eine eher ablehnende Haltung eingenommen, auch wenn sie sie nicht gänzlich verurteilten. Beide theologischen Richtungen waren sich einig darüber, dass die Demokratische Bewegung ihren Erfolg dem Verfall von Sitte und Glaube verdanke, und verurteilten einhellig insbesondere deren Methode, das Verfassen von Pamphleten, ${ }^{61}$ mit der dieser Verfall ausgenützt worden sei. Von den beiden theologischen Hauptrichtungen stand die Orthodoxie der Demokratischen Bewegung am wenigsten ablehnend gegenüber. ${ }^{62}$

Während sich der liberale Pastoralverein I 868, als die Totalrevision der Verfassung gegen das System Escher mit 50000 gegen 7000 Stimmen bejaht worden war, «einmütig hinter das $\left\langle\right.$ System $»^{63}$ stellte, zerfiel die Orthodoxie in drei Gruppen. Die einen liefen zu den Demokraten über, andere, wie beispielsweise Melchior Römer ${ }^{64}$ und Georg von Wyss, ${ }^{65}$ «kollaborierten» und bloss ein kleiner Teil trat in Opposition. Obwohl Römer sich entgegen der demokratischen Linie für die Beibehaltung des Bekenntnisses einsetzte, passte er den Demokraten doch besser, so dass sie den liberalen Eugen Escher (I83I-1900), Anhänger von Alfred Escher, in einer Kommission durch ihn ersetzten. Römer wurde I 869 zum Stadtpräsidenten gewählt. Gemäss Streuli war bei dessen Wahl die «Koalition zwischen Konservativen und Demokraten gegen Eugen Escher augenscheinlich» ${ }^{66}$ Insbesondere Georg von Wyss schätzten die Demokraten sehr.

6I Ein bekanntes Beispiel solcher Pamphlete sind die vom Juristen Friedrich Locher anonym erschienenen Pamphlete Die Freiberren von Regensberg. Locher prangerte darin Missstände im escherschen Verwaltungs- und Justizsystem an. Der entstehenden Demokratischen Bewegung lieferte er damit politische Schlagwörter. Dennoch distanzierten sich die Demokraten von ihm wegen seines aggressiven Kampfstils. Auf Grund seiner späteren Kampfschriften verlor er sogar sein Anwaltspatent (vgl. Bürgi 2008b).

62 Vgl. Streuli i950, 483 .

63 Ebd.

64 Melchior Römer (183 I-1895) absolvierte das Studium der Rechte in Zürich und Berlin und promovierte 1855 in Zürich. Er hatte verschiedene Staatsämter inne: I857-186I Adjunkt des Statthalteramts. I 859-I 86I Mitglied des Grossen Stadtrats, I 86I-I 889 des Kleinen Stadtrats, I 869-I 889 Stadtpräsident von Zürich, I 862-I887 liberaler Kantonsrat, I 872-I887 Nationalrat. Einige Jahre amtete er als Leiter der Zentrumsfraktion. I 886 erhielt er die goldene Verdienstmedaille der Stadt Zürich (vgl. Peter-Kubli 20I2).

65 Georg von Wyss ( 18 1 6 - 1893 ) trat I 839 nach der konservativen Wende in den Staatsdienst ein: I 842-I 847 Zweiter Staatsschreiber, I 845-I 879 Mitglied des Grossen Stadtrats von Zürich, I 848-1 883 Mitglied des Zürcher Grossrats bzw. Kantonsrats. Wyss gehörte zur Führungselite der konservativen Opposition im Kanton Zürich und war Mitglied des Eidgenössischen Vereins. Wyss war I 84 I ein Gründungsmitglied der Allgemeinen Geschichtsforschenden Gesellschaft. Ab i 850 war er Dozent an der Universität Zürich, ab i 870 ordentlicher Professor und von I 872 bis I 874 deren Rektor (vgl. Suter 2013).

66 Streuli I950, 484 . 
Er wurde von ihnen in ihre Spezialkommissionen gewählt und zum Ordinarius befördert, was die Liberalen stets verhindert hatten. Die Orthodoxie war jedoch auch in der Opposition gespalten: Während die einen zu den Liberalen hielten, gingen die andern selbstständig vor. Letztere hatten ihr Zentrum in der Evangelischen Gesellschaft. ${ }^{67}$

Die Vertreter der orthodoxen Theologie waren der Demokratischen Bewegung nach Streuli auch in politischer Hinsicht näher als die liberalen Theologen. So setzten sich beispielweise die Orthodoxen im Jahre i 868 für das proportionale Wahlsystem ein. Insbesondere «in wirtschaftlich-sozialer Beziehung standen die Orthodoxen den Demokraten bedeutend näher als die liberalen Theologen». ${ }^{6}$ I 868 wurde in einer orthodoxen Synodalproposition die liberale Wirtschafts- und Sozialpolitik angegriffen. Der Proponent erachtete als zentrale Ursache der sozialen Notstände das liberale Volkswirtschaftssystem, das «die Anwendung moralischer Grundsätze geradezu ausschliesse». ${ }^{69}$ Insofern aus orthodoxer Perspektive einzig die Liebe als nationalökonomisches Prinzip anerkannt worden sei, ging die Orthodoxie «mit den Demokraten einig in der Forderung nach einem staatlichen Interventionsrecht».7० Dieser Proponent forderte «die Erlassung gesetzlicher Vorschriften zum Schutze der Arbeiter und der Jugend, staatliche Schiedsgerichte bei Arbeitskonflikten und eine Staatsbank». ${ }^{71}$ In sozialer Hinsicht seien die Orthodoxen gemäss Streuli «am stärksten 〈links»» ${ }^{72}$ gestanden.

Die liberalen Theologen hingegen stützten das liberale Repräsentativsystem. Laut Streuli gehörten «ihre Führer, Biedermann und Schweizer, [...] zum engsten Kreis Alfred Eschers, und als die demokratische Bewegung kam, zu deren grössten Gegnern». ${ }^{33}$ Schweizer konnte die direkte Demokratie nicht mit der christlichen Lehre von der Obrigkeit in Übereinstimmung bringen. Eine Volksversammlung war für ihn «ein Volkshaufe, der dem organischen Volksganzen gegenübertritt». ${ }^{74}$ Schweizer erachtete den Staat als eine Willenseinheit. Dieses Ideal sah er am vollkommensten in der Monarchie erreicht. «Das in kleinen

67 Vgl. ebd.

68 Ebd., 485 .

69 Ebd.

70 Ebd.

$7 \mathrm{I}$ Ebd.

72 Ebd., 486.

73 Ebd. In seiner Funktion als Kirchenrat holte Alfred Escher im Jahre i 850 den Kopf der liberalen Theologie, Alois Biedermann, von Basel nach Zürich. Der Schleiermacherschüler Alexander Schweizer und Escher bestimmten in dieser Zeit das Verhältnis von Kirche und Staat. Hinsichtlich theologischer Angelegenheiten - auch in der Besetzung von Lehrstühlen war Schweizer oberste Autorität. Bekannte liberale Theologen, mit denen bald nach I 845 die Pfarrstellen besetzt wurden, waren Johann Kaspar Zollinger, Johann Ludwig Spyri, Heinrich Hirzel, Fries, Hiestand u. a. (vgl. Streuli 1950, 67).

74 Alexander Schweizer zit. in Streuli 1950, 486. 
Verhältnissen doppelt heftige Parteiwesen, die Wandelbarkeit der Volksgunst» 75 schreckten ihn ab. Die Gefahr der Demokratie sah er «vor allem darin, dass die Masse aus Eigennutz handle und stimme, die Lasten auf die überstimmten wenigen abwälze und auf deren Kosten leichter leben wolle -, solange dort etwas zu finden sei». ${ }^{6}$ Durch die neuen Abstimmungs- und Wahlrechte erhielt die Masse der Individuen eine Bedeutung, die ihr im Liberalismus nicht zugekommen war. Den Gegensatz zwischen Liberalen und Demokraten ortet Streuli jedoch auch auf weltanschaulicher Ebene: «Der Liberalismus glaubte an eine der Welt zu Grunde liegende geistige Einheit. Die Demokraten suchten diese im empirischen Naturzusammenhang. Im Liberalismus war die Einheit, in der sich der Einzelne als Moment geltend zu machen hatte, vorausgesetzt. An der Schranke, die die liberale Freiheit umgab, liess sich nicht rütteln. Eine grössere Freiheit zerstörte die Voraussetzungen des Liberalismus. Der Liberalismus verlor seine Wahrheit im Augenblick, wo die Freiheit zu gross wurde».77

Die Diskussionen über den schulischen Religionsunterricht im Zusammenhang mit dem schliesslich abgelehnten Unterrichtsgesetz von I 872 müssen auf dem Hintergrund der unterschiedlichen politischen und religiösen Richtungen und deren Verflechtungen gelesen werden, um deren Vehemenz einordnen zu können.

77 Ebd., 490. 


\section{$5 \quad$ Das abgelehnte Unterrichtsgesetz von 1872}

Der nach der Annahme der neuen Kantonsverfassung vom i 8. April i 869 erarbeitete Entwurf für ein neues Unterrichtsgesetz, das in der Volksabstimmung vom I4. April I 872 Schiffbruch erlitten hatte, war stark geprägt von den Vorstellungen des damaligen demokratischen Erziehungsdirektors Johann Caspar Sieber. Ich werde deshalb im Folgenden als Erstes kurz Sieber vorstellen, als Zweites auf die von Sieber lancierte Umfrage, die dem Entwurf des Gesetzes vorausging, eingehen, als Drittes die Redaktionsgeschichte aufzeigen, dann als Viertes die umstrittenen Punkte sowie als Fünftes die Gründe für die Verwerfung des Unterrichtsgesetzes darlegen. ${ }^{1}$

\subsection{Erziehungsdirektor Johann Caspar Sieber}

Johann Caspar Sieber (182I-I 878) wuchs auf einem Bauernhof bei Zürich auf. Er besuchte das Lehrerseminar in Küsnacht, dessen Leiter, Ignaz Thomas Scherr, ${ }^{2}$ prägenden Einfluss auf ihn hatte. Von I 84 I bis I 843 (während des konservativen Interregnums von I 839 bis I 847) war er Sekundarlehrer in Wetzikon. Wegen seiner antiklerikalen Einstellung, die er vor den Schülern nicht nur nicht verbarg, sondern diese bewusst antiklerikale Aufsätze ${ }^{3}$ verfassen liess, wurde er der Amtspflichtverletzung für schuldig befunden und deswegen entlassen. Er erhielt ein fünfjähriges Berufsverbot für den Kanton Zürich. Von I 845 bis I 847 war er Lehrer in Murten, wurde von dort aus politischen Gründen - Agitation gegen die konservative Regierung und radikale Forderungen - aber mehrmals weggewiesen. Im Jahre I 848 beteiligte er sich als Freiwilliger gegen Freiburg am

I Ich folge bei den Darstellungen in diesem Kapitel grösstenteils den Ausführungen von Thomas Koller (1987) und Michael Köhler (2003).

2 Ignaz Thomas Scherr (I80I-1870) war Seminardirektor, Erziehungsrat, Verfasser von Lehrmitteln und Unterrichtsgesetzen. Der Sieg der Konservativen nach dem Züriputsch von I 839 führte zu seiner Entlassung als Seminardirektor (vgl. Bloch Pfister 2007, 279; 308).

3 In der Urteilsbegründung wurden auch Passagen aus Aufsätzen zitiert. Ein Beispiel sei hier genannt: «Akt. 2 I. p. I2. $\mathrm{N}^{\circ}$ 4I in dem Aufsatze, betitelt: «An die Jünglinge des schweizerischen Vaterlandes〉 〈Hasst das Tyrannenjoch und die Despotie. Verschmäht die Pfaffenherrschaft und die Aristokratie. Seit die Feinde der Freiheitsunterdrücker, der Pfaffen und der Zopfbürger. Hasset die Schwarzen, welche das Volk immer im Schlamm der Dunkelheit und Finsternis halten wollen. Hanget nicht an den Pfaffen, wie an den Göttern [...] verfolget die, welche immer Nacht verbreiten wollen, also den Pabst [sic], die Jesuiten samt andern Schwarzen, die nur dem Schlechten und Bösen folgen usw.»» (Zit. in Köhler 2003, 27.) 
Sonderbundskrieg. I 850 kehrte er in den Kanton Zürich zurück, wo er wieder als Lehrer arbeitete. Er war ein Anhänger des Frühsozialisten Johann Jakob Treichler. Von I 854 bis I 858 war Sieber im Zürcher Grossrat. Ab I 860 gehörte er zu den Vorkämpfern der Demokratischen Bewegung. I860-186I amtete er als Präsident der Zürcher Schulsynode. Wegen seiner radikalen Äusserungen und Publikationen war er immer wieder in Prozesse verwickelt. I 864 gründete er das demokratische Wochenblatt Der Unabhängige und fungierte auch als dessen Redaktor. Mangels genügender Verbreitung musste das Blatt jedoch bereits I 868 wieder eingestellt werden. Dies obwohl illustre Männer wie Friedrich Salomon Vögelin, Salomon Bleuler oder Friedrich Albert Lange als Verfasser von Artikeln mitwirkten. I 868 wurde Sieber in den Verfassungsrat gewählt. Als Mitglied der sogenannten $35 \mathrm{er}$ Kommission, welche die Verfassungsrevision vorbereitete, gilt er als einer der Väter der neuen Kantonsverfassung von I 869. In dieser 35 er Kommission war er Mitglied der Subkommission für Schul- und Kirchenfragen. Nach der Annahme der Verfassung wurde Sieber I869 im zweiten Wahlgang in den Regierungsrat gewählt. Sieber wurde das Ressort Erziehung zugewiesen. Dies vermutlich wegen seiner langjährigen Tätigkeit als Lehrer und als Akteur in verschiedenen schulpolitischen Funktionen. Als Erziehungsdirektor stand er sieben Erziehungsräten vor, die alle Mitglieder des radikal-demokratischen Lagers waren. Unter diesen zum Beispiel Friedrich Albert Lange, der intellektuell führende Kopf der Demokratischen Bewegung. Nach dem Scheitern des Unterrichtsgesetzes in der Volksabstimmung wurde Sieber im Juni abgewählt. Doch noch im selben Jahr wurde er infolge einer Ersatzwahl wiedergewählt. ${ }^{4}$

Obwohl Sieber bei den einen mit seinen radikalen Ansichten anstiess, wurde er von anderen aufs Höchste verehrt. Die Art der Verehrung nahm zum Teil groteske Formen an. Reinhold Rüeggs eröffnete einmal einen Brief mit: «Geliebter Herr u. Heiland Jesu Sieber!» ${ }^{6}$ Im Verfassungsrat wurde Sieber «Moses» der Verfassung genannt und Kantonsräte verfassten im Ratssaal pathetische Gedichte an und über ihn. ${ }^{7}$ Die Verehrung ging über den Tod hinaus. Es heisst, dass am Tag seiner Beerdigung im Januar I 8785000 Leute am Trauerzug zum Friedhof Neumünster teilgenommen hätten. Eine weitere Groteske im Zusammenhang mit Sieber ereignete sich fast 40 Jahre nach seinem Ableben: Die demokratische Kantonalpartei von Uster und der Vorstand des kantonalen Lehrervereins be-

4 Vgl. Streuli I948, 2 I; Koller 1987, 75; Bürgi 20ı ı; Köhler 2003, I 44 f.

5 Reinhold Rüegg (1842-1923) war Lehrer im Kanton Zürich, Teil der Demokratischen Bewegung, Mitglied des Verfassungsrates, Redaktor unter anderem des Landboten und des Grütlianers. In seinen Reiseschilderungen berichtet er von der Pariser Kommune und einem Treffen mit Karl Marx (vgl. Bürgi 2010).

6 Brief von Rüegg an Sieber, zit. in Koller 1987, 74.

7 Vgl. Koller 1987, 74. 
antragten, dass die Gebeine Siebers von Zürich nach Uster umgebettet würden. Dem Antrag wurde stattgegeben. Doch ob es dann tatsächlich zu dieser Umbettung gekommen war, ist gemäss Köhler offen. ${ }^{8}$

\subsection{Siebersche Umfrage}

In seiner Funktion als Erziehungsdirektor begann sich Sieber bald mit einer «radikalen Änderung des Schulgesetzes zu beschäftigen».9 Trotz der durch die neue Kantonsverfassung entstandenen Veränderungen entsprach die Organisation der Schule noch keineswegs den Vorstellungen, die sich Sieber von einer modernen Schule gemacht hatte. Bereits im November I 869 verfasste Sieber einen Katalog mit 42 Fragen, der am 26. November I 869 im Amtsblatt des Kantons Zürich publiziert wurde. Der Aufruf, «Wünsche und Ansichten bezüglich der Neugestaltung des Schul- und Unterrichtswesens» zu äussern, erging «an Gemeinden und Schulbehörden, Vereine und Gesellschaften, Lehrer und Professoren und an jeden einzelnen Bürger». ${ }^{10}$

Eine solche Schulumfrage war an sich kein Novum. Bereits in den Jahren I77I/72 wurde von der Moralischen Gesellschaft ein Fragebogen zu Schule und Unterricht lanciert, der an alle Zürcher Pfarrgemeinden gesendet worden war. Die Pfarrer hatten diese Fragen in ihrer Funktion als Schulaufseher zu beantworten und ihre Antworten an die kirchliche Verwaltung zu übermitteln. ${ }^{11}$ Auch in anderen Kantonen gab es solche Schulumfragen. Der aargauische Erziehungsrat veranlasste 1798 eine kantonale Umfrage über den Zustand der Schulen. Diese Umfrage diente ein Vierteljahrhundert später Philipp Albert Stapfer, dem Minister der Künste und Wissenschaften der Helvetischen Republik, als Vorlage für seine im Jahr 1799 «helvetisch flächendeckend geführte Umfrage über den Zustand des Volksschulwesens». ${ }^{12}$

Die Absichten der verschiedenen Schulumfragen waren jedoch unterschiedlich. Die Verbesserung des sittlichen Verhaltens der Landbevölkerung stand im Hintergrund der Zürcher Schulumfrage von I771/72. Denn die Hungerkrise der I 770 er Jahre wurde von den meisten Zürcher Pfarrern als Strafe Gottes für unsittliches Verhalten interpretiert. ${ }^{13}$ Die stapfersche Schulenquête hatte wie andere Umfragen, die bereits im Ancien Régime erhoben worden waren, einen dop-

8 Vgl. Köhler 2003, is If.

9 Köhler 2003, I 37.

I0 Bekanntmachung der Erziehungsdirektion vom 22. Nov. I 869, 2.

I I Vgl. De Vincenti-Schwab 2008, I7.

I2 Bütikofer 2006, 60.

I 3 Vl. De Vincenti-Schwab 2008, i7. 
pelten Zweck: Zum einen ging es um eine Bestandesaufnahme der tatsächlichen Schulzustände. Zum andern sollten die Pfarrer, die für die Beantwortung der Fragen verantwortlich waren, zu gezielten Beobachtungen angeleitet werden, an die sie ohne Fragebogen nicht gedacht hätten. ${ }^{14}$

Im Unterschied zur stapferschen Enquête und zu den Umfragen des Ancien Régime war die Umfrage Siebers von einem demokratischen Impuls geleitet. Das Volk sollte in den Entstehungsprozess des geplanten neuen Unterrichtsgesetzes eingebunden werden. In diese Richtung zielte zumindest die offizielle Begründung, die in der Begleitschrift zum Katalog folgendermassen lautete: «Von der Überzeugung geleitet, dass eine volksthümliche Gesetzgebung nicht anders zu Stande kommen kann als durch unmittelbare Anregungen und Willensäusserungen aus dem Volke selbst heraus, erachtet es die Erziehungdirektion als ein Pflichtgebot, die ernste Arbeit der Revision des Schulwesens dadurch einzuleiten, dass sie die Initiative aller Volkskreise aufruft.» ${ }^{15}$

Koller hebt hervor, dass man das Verfahren in formaler Hinsicht durchaus demokratisch nennen könne. Hinsichtlich des Inhalts träten jedoch «die 〈Direktiven〉 deutlich hervor». ${ }^{16}$ Die 42 Fragen würden nicht grundlos «Siebersche Fragen» genannt. ${ }^{17}$ Koller formuliert das Motto Siebers für das Unterrichtsgesetz etwas zugespitzt folgendermassen: «Verfassung, Scherr und Volksmeinung - insofern sie sich an Verfassung und Scherr orientiert! Diese Haltung kommt in den 42 Fragen sehr deutlich zum Ausdruck. Sie sind, gelinde gesagt, tendenziös gestellt.» ${ }^{18}$ Als Beispiel sei hier die für die Thematik dieser Arbeit relevante Frage 4 zitiert: «Ist im Hinblick auf die Bestimmungen des Art. 63 der Verfassung die Stellung des Religionsunterrichtes der Schule $\mathrm{zu}$ ändern? Darf er das dogmatische Element und bis zu welchen Grenzen in sich aufnehmen? ${ }^{19}$ Es ist ziemlich klar, dass aus Siebers Sicht Teilfrage eins mit einem deutlichen «Ja!» und Teilfrage zwei mit einem klaren «Nein!» beantwortet werden müsste.

Den Schwerpunkt des Katalogs bilden Fragen zur Volksschule. Die Fragen I-27 beziehen sich explizit auf die Volksschule. Doch auch in den anderen Bereichen - Mittelschule und Hochschule - gibt es Fragen, die das Volksschulwesen tangieren. Dies passt zum zentralen Anliegen Siebers, den Ausbau der Volksschule voranzutreiben und auch den Unterricht auf den höheren Stufen der

I4 Vgl. Bütikofer 2006, 60; Bloch 1997, 257.

Is Bekanntmachung der Erziehungsdirektion vom 22. Nov. I869.

I6 Koller 1987, 16ı. Köhler erwähnt in seiner Monographie über Sieber diese bloss formale Anwendung demokratischer Prinzipien nicht und meint gar: «Sieber verhielt sich mit seiner Volksbefragung streng demokratisch.» (Köhler 2003, I37).

I7 Koller 1987, I6r.

I 8 Koller 1987, I 58 .

I9 Bekanntmachung der Erziehungsdirektion vom 22. November I 869, 3. 
Volksschule allen zugänglich zu machen. Sieber sieht «die Zeit der Erfüllung» dafür nun gekommen, «sobald der Bürger ein weiteres bescheidenes Opfer für die Zukunft seiner Kinder auf den Altar der Bildung legen will». ${ }^{20}$ Auf Grund der Wortwahl lässt sich eine gewisse Tendenz Siebers, die Schule zu sakralisieren, nicht negieren.

Koller hat die 42 Fragen auf ihren Inhalt hin untersucht und kommt auf sieben zentrale Themenbereiche, die Sieber ein Anliegen zu sein schienen. Sieber habe nach Meinungen gefragt bezüglich: «a) der wöchentlichen Unterrichtszeit, der Entlastung der unteren Stufen von Stoff und der Verlängerung der Alltagsschule (2, 3, I0); b) dem dogmatischen Element im Religionsunterricht (4); c) der Fortbildungsschule für Kinder vom i 5.-I7. Altersjahr (I I); d) der Zivilschule bzw. der Haushaltungsvorschule (I 2); e) der verbesserten und ausgedehnten Lehrerbildung (I4, I5, I6, I 8, 37, 4I); f) der obligatorischen Sekundarschule, bzw. der Ausweitung der Sekundarschule zu einem propädeutischen Unterricht im Hinblick auf einen späteren Besuch der wissenschaftlichen Berufsschulen an Hochschule und Polytechnikum (24); g) der Reorganisation der Mittelstufe im Sinne einer Reduktion der Typen und einer Dezentralisation der Standorte (28, 29, 30, 3 I, 32, 34).» Nach Koller decken sich diese Themenbereiche mit dem «bildungspolitischen Forderungskatalog Siebers». ${ }^{21}$

Bis zum I. Februar I 870 hatten die am Schulwesen Beteiligten und Interessierten Zeit, zu den Fragen Stellung zu beziehen. Das Echo war enorm. Koller zählte I 57 eingereichte Petitionen. In den Schulkapiteln wurden die sieberschen Fragen in mehrstündigen Sitzungen diskutiert. Eine grosse Meinungsvielfalt wurde deutlich. Koller bemerkt, dass die Fronten in diesem frühen Stadium der Diskussion jedoch noch nicht verhärtet waren. ${ }^{22}$

\subsection{Vom ersten handschriftlichen Unterrichtsgesetzentwurf zur Abstimmungsvorlage}

Der Unterrichtsgesetzentwurf, der dem Volk zur Abstimmung vorgelegt worden war, hatte bis dahin einige Veränderungen erfahren. Im Unterschied zu früheren Arbeiten zum sieberschen Unterrichtsgesetz, ${ }^{23}$ die angeben, dass der Entwurf Siebers den Erziehungs- und Regierungsrat durchlaufen habe, ohne wesentlich verändert worden zu sein, zeigt Koller auf, «dass der Entwurf im Zuge der Diskussion in den Erziehungsbehörden und in der Regierung sehr

20 Bekanntmachung der Erziehungsdirektion vom 22. November I 869, I f.

2 I Koller 1987, I60.

22 Vgl. Koller 1987, i62 ff.

23 Vgl. Frey 1953, I37; Kreis 1933, 485. 
wohl Veränderungen erfahren [hatte] und zwar, zumindest aus der Sicht des Erziehungsdirektors, wesentliche». ${ }^{24}$

Die erste überlieferte Variante des Unterrichtsgesetzes ist ein undatierter, handschriftlicher Entwurf. Nach der Einschätzung Kollers lag diese erste Entwurfsvariante Ende Juli I 87 I vor, denn von März bis Juni wurde das Gesetz von der Erziehungsdirektion erarbeitet. Im Vergleich mit Siebers bildungspolitischen Vorstellungen, die verschiedenen anderen Quellen zu entnehmen sind, sieht Koller in diesem Entwurf eindeutig die Handschrift Siebers: «Analysiert man diesen ersten Entwurf Siebers, so muss man sagen, dass niemand, auch der wohlwollendste und freundlichste Betrachter nicht, ruhigen Gewissens behaupten kann, der Entwurf sei auf breitester demokratischer Basis entstanden. ${ }^{25}[\ldots]$ Denn, gesetzt auch, man kennte die auf die 42 Fragen eingegangenen Petitionen nicht, könnte man allein durch einen Vergleich mit dem Sieberschen Forderungskatalog, wie er sich aus seiner publizistischen Tätigkeit und seinen Aktivitäten in den Organen der zürcherischen Lehrerschaft herauskristallisiert, erkennen, dass es sich bei seinem Entwurf um eine kompromisslose Variante handelt, von der unmöglich erwartet werden kann, dass sie die Zustimmung aller finden wird.» ${ }^{26}$

Am I9. August I 87 I wird der vom Erziehungsrat diskutierte Entwurf offiziell in der Öffentlichkeit publiziert. ${ }^{27}$ Am 20. und 22. August fand im Erziehungsrat die Schlussberatung des gesamten Entwurfes statt. Anschliessend wurde der Entwurf dem Regierungsrat überwiesen. Gemäss Koller haben die Beratungen im Erziehungs- und Regierungsrat zu drei substantiellen Veränderungen und zwei ebensolchen Ergänzungen geführt: I) Im Passus der einleitenden Bestimmung «Der Staat errichtet die zur allgemeinen Ausbildung der Jugend bis in's Mündigkeitsalter erforderlichen Unterrichtsanstalten» wurde die Formel «bis in’s Mündigkeitsalter» gestrichen. Damit wurde verunmöglicht, auch das Jugendalter per Gesetz vollständig für die öffentliche Schule zu erfassen. 2) Die Aussichten für das von Sieber geplante Obligatorium wurden vermindert, da die Möglichkeit gegeben war, die Sekundarschule bereits nach der 2. Klasse zu verlassen. Damit war das neunjährige Schulobligatorium durchbrochen. 3) Den Lehrern wurde

24 Koller 1987, i79.

25 Dies behauptete Salomon Vögelin im Lebenslauf von Sieber (vgl. Koller 1987, 194).

26 Koller 1987, 194. Eine ausführliche Beschreibung des Inhaltes des ersten handschriftlichen Entwurfes sowie ein detaillierter Vergleich der verschiedenen Varianten können bei Koller nachgelesen werden (vgl. Koller 1987, I 80-203).

27 Vgl. Koller 1987, I 96 und 209 f. Bereits am 8. August meldete der Landbote, er besitze einen Entwurf, den er aber noch nicht vorstellen wolle, da es im Erziehungsrat wohl noch zu Änderungen kommen werde. Er schien jedoch seine Meinung geändert zu haben, denn am 9. und Io. August wird der Entwurf im Landboten bereits abgedruckt. Damit war der Startschuss für die öffentliche Diskussion gegeben (vgl. Koller 1987, 209). 
eine viel schlechtere Stellung eingeräumt, als Sieber ihnen im ersten Entwurf zugedacht hatte. Ergänzend wurden zum einen Arbeiterbildungskurse verankert und zum andern den Frauen ermöglicht, sich für die Elementarschulstufe, das heisst die I.-3. Klasse, als Lehrerinnen ausbilden zu lassen. ${ }^{28}$

Hinsichtlich des Religionsunterrichts, der für diese Arbeit von zentraler Bedeutung ist, wurde in den Beratungen des Erziehungs- und Regierungsrates nichts Substantielles verändert. Die Erziehungsdirektion hoffte, einem Streit um den schulischen Religionsunterricht dadurch auszuweichen, dass sie diesen im neuen Unterrichtsgesetz gar nicht mehr explizit erwähnte. Deshalb wurde im Zweckartikel die Erziehung zum «sittlich religiösen» Menschen durch Erziehung zum «sittlich guten» Menschen ersetzt. ${ }^{29}$ In den Beratungen des Erziehungsrates wurde am Zweckartikel nichts verändert, aber die moralisierende Tendenz in den Lehrplänen der verschiedenen Stufen konkretisiert. Dies geschah auf Gymnasialstufe in Form des Faches Ethik (Paragraphen 7I und 76); auf der Primar- und Sekundarstufe unter der Rubrik «Die Lehrgegenstände» mittels der Formulierung: «Anregungen und Belehrungen aus dem Gebiete des sittlichen und geistigen Lebens» (Paragraphen 44 bzw. 25). $3^{\circ}$ Die kontroversen Diskussionen über den erziehungsrätlichen Versuch, den Religionsunterricht zu eliminieren, wurden erst in den kantonsrätlichen Beratungen und in der Öffentlichkeit geführt. Im Kantonsrat wurde der Entwurf in den Sitzungen vom 8. Januar bis I. Februar und vom 20. bis 2 I. Februar durchberaten. ${ }^{31}$

\subsection{Umstrittene Punkte}

Koller und Köhler weichen in ihrer Wahrnehmung der Themen, die nach ihrer Auffassung besonders umstrittene Punkte waren, insbesondere an einem Punkt voneinander ab. Nach Koller sind hauptsächlich drei Themen kontrovers diskutiert worden: I) Die Erweiterung der Alltagsschule;32 2) der Religionsunterricht;33 3) die Akademisierung der Lehrerbildung. ${ }^{34}$ Nicht im gleichen Masse zu reden gegeben hatten seiner Meinung nach folgende Punkte: die Zivilschule, das Schulinspektorat, die Erneuerungswahlen, die Besoldungsartikel, die Gestaltung des Literargymnasiums und die Einrichtung eines Technikums. Die Organisation der zürcherischen Lehrerschaft in einer Synode sowie das Problem der höheren

28 Vgl. Koller i $987,200 \mathrm{ff}$.

29 Vgl. ebd., I85.

30 Vgl. ebd., $199 \mathrm{f}$.

3 I Vgl. Bericht des Regierungsrats zu den Abstimmungsvorlagen, I. März I 872.

32 Vgl. Koller i987, 2 is ff.

33 Vgl. ebd., $223 \mathrm{ff}$.

34 Vgl. ebd., $228 \mathrm{ff}$. 
Mädchenbildung habe man als wenig diskussionswürdig erachtet.35 Köhler nennt als besonders umstrittene Punkte bloss die Erweiterung der Alltagsschule und die Akademisierung der Lehrerbildung. ${ }^{36}$ Den Religionsunterricht erwähnt Köhler interessanterweise weder als besonders umstrittenen Punkt in der Unterrichtsgesetzdiskussion noch als sonst wichtiges Thema von Sieber. Bloss indirekt in einem Zitat Friedrich Salomon Vögelins, das Köhler anführt, wird auch bei Köhler ersichtlich, dass der geplante konfessionslose Religionsunterricht nicht von allen gutgeheissen wurde. ${ }^{37}$ Im Unterschied zu Köhler weist Koller in seinem Kapitel über Siebers bildungspolitischen Forderungskatalog auf eine «markante Idee» hin, die «Sieber mit Leidenschaft» vertreten habe und die sich in seiner Stellung zum Religionsunterricht ausdrückte: «Der Religionsunterricht der Volksschule soll so weit als möglich dem Einfluss der Kirche entzogen,

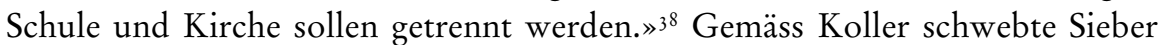
«eine von der Kirche unabhängige, sittlich-ethische Erziehung der Jugend vor, ohne jedoch, wie ihm Martha Greiner unterschiebe, ${ }^{39}$ einen Unterricht zu propagieren, der sich an atheistischen Vorstellungen orientiert».40

Es gehe ihm «nicht um eine Verleugnung Gottes - das wäre Atheismus - sondern es geht darum, unkritisch tradierte Dogmen der Kirche von der Schule fernzuhalten».4 Der Einfluss von Thomas Scherr, David Friedrich Strauss und Friedrich Salomon Vögelin werden an diesem Punkt deutlich sichtbar.

\subsection{Gründe für die Verwerfung des Unterrichtsgesetzes}

Über die beiden umstrittensten Artikel - Verlängerung der Alltagsschule (Paragraph I०) und Lehrerbildung an der Hochschule (Paragraph I00) - konnte einzeln abgestimmt werden. Man wollte nicht das gesamte Gesetz wegen dieser zwei umstrittenen Punkte gefährden. Doch schliesslich wurden sowohl die Paragraphen Io und roo abgelehnt wie auch das gesamte Gesetz. Nach der Abstimmung suchte man nach Ursachen für die Niederlage. Über die Gründe für die Ablehnung von Paragraph Io war man sich einig: Die Bauern und Arbeiter

35 Vgl. ebd., 24I.

36 Vgl. Köhler 2003, I 38.

37 Vgl. Köhler 2003, I $40 \mathrm{f}$.

38 Koller 1987, 90.

39 Martha Greiner schreibt in ihrer Dissertation Der Wandel des Verhältnisses von Staat und Kirche zur Volksschule des Kantons Zürich: «In den Beratungen beider Behörden [Kantons- und Erziehungsrat] kommt eine starke antikirchliche Tendenz zum Ausdruck, der atheistische Erziehungsdirektor war umgeben von Gesinnungsgenossen.» (Greiner 1933, 92).

40 Koller 1987, 90.

$4 \mathrm{I}$ Ebd. 
befürchteten einen zu grossen Verdienstausfall, wenn ihre Kinder, anstatt auf dem Hof oder in der Fabrik zu arbeiten, die Schule hätten besuchen müssen. ${ }^{42}$ Die Ursachen für die ablehnende Haltung gegenüber der Lehrerbildung an der Hochschule waren weit schwieriger zu eruieren. Als sachliche Gründe nennt Koller Zweifel an der Eignung einer Hochschulbildung zum Erlernen des Lehrerberufs, die hohen Kosten und organisatorische Schwierigkeiten, die mit der Einführung der Lehramtsschule verbunden gewesen wären. Nach Koller hätten aber auch irrationale Aspekte eine Rolle gespielt: die Abwehr gegen den akademisch gebildeten Lehrer und die Furcht vor dem Erstarken der Lehrerschaft zu einer «unkontrollierbaren progressiven politischen Macht»43 im Staate. Möglicherweise hatten auch diejenigen Kreise gegen die Hochschulbildung gestimmt, die an der Sonderstellung von Hochschule und Professorenschaft festhalten und die Lehr- und Lernfreiheit der Hochschule nicht durch die Einbindung von Fachschulen gefährden wollten. ${ }^{44}$

Am unklarsten sind die Gründe, die zur Ablehnung des von den beiden umstrittensten Artikeln befreiten Unterrichtsgesetzes geführt hatten. Zum einen vermutet Koller einen eher unreflektierten allgemeinen Zweifel an den Neuerungen dieses Gesetzes. Zum andern sieht er aber konkrete Vorbehalte gegenüber bestimmten Artikeln am Werk - insbesondere gegenüber denjenigen, die den Religionsunterricht, die Schulaufsicht und die Fortbildungsschule betroffen hätten. Für die Kantonsschullehrer sei möglicherweise auch die geplante Aufhebung der lebenslänglichen Anstellung ein Grund gewesen, gegen das gesamte Unterrichtsgesetz zu stimmen. Koller denkt jedoch, dass ein grosser Anteil der Nein-Stimmen der Organisation des Religionsunterrichts gegolten habe. Diese Meinung teilt auch der von ihm zitierte Lehrer Schneebeli, der im Rückblick

Bereits die Ausgangslage für das Unterrichtsgesetz war ungünstig. I 870 - zu Beginn der Diskussionen über das Unterrichtsgesetz - wurde über ein von den Demokraten unterstütztes neues Fabrikgesetz abgestimmt und dieses abgelehnt. Männer, Frauen und Kinder sollten vor übermässiger Nutzung ihrer Arbeitskraft geschützt werden. Insbesondere den Schutz der Kinder hatte man im Blick: Nachtarbeit wollte man nur noch für männliche Arbeiter ab i6 erlauben. Der erste Entwurf wollte Nachtarbeit sogar nur für volljährige Männer gestatten. Schüler der Alltagsschule sollten gar nicht zur Arbeit in der Fabrik zugelassen werden. Für I I- bis I 2-jährige Kinder hätte eine Arbeitszeitbeschränkung von 6 Stunden eingeführt werden sollen und für I 3- bis I 5-jährige eine Arbeitszeit von ro Stunden. Des Weiteren hiess es im Gesetzesentwurf, dass die Kinder unmittelbar vor dem Besuch der Ergänzungsschule nicht in der Fabrik arbeiten dürfen. Die Gegner des Gesetzes schürten im Volk die Angst, dass nach dem Fabrikgesetz das Unterrichtsgesetz und die Verlängerung der Alltagsschule käme und sie dadurch in ihrer Existenz bedroht würden. In der Tat war es so, dass um I 870 im Zürcher Oberland nur Familien mit 2-4 verdienenden Kindern einigermassen ihre Bedürfnisse befriedigen konnten (vgl. Koller 1987, I7 I f.).

43 Koller 1987, 260.

44 Ebd., $259 \mathrm{f}$. 
auf die Abstimmung als wesentliche Ursache für die Verwerfung des gesamten Gesetzes die Absichten Siebers hinsichtlich des Religionsunterrichts sah. ${ }^{45}$ Nebst inhaltlichen Gründen nennt Koller noch drei weitere Aspekte, die sich ungünstig auf das Abstimmungsverhalten ausgewirkt haben könnten. Erstens die vielen Propagandaveranstaltungen im Vorfeld, in denen die Redner, insbesondere auch Sieber, manchmal das Mass des Verträglichen verloren hätten. Zweitens fanden zur selben Zeit wie die Debatte um das Unterrichtsgesetz die Bundesrevisionsdiskussionen statt. Dies hatte zur Folge, dass einige gemässigte Demokraten in Bern engagiert waren und deshalb nicht in Zürich eingesetzt werden konnten. Drittens die konservative Grundhaltung des Volkes, die die Demokraten bereits bei der dem Unterrichtsgesetz vorangegangenen Niederlage zur Fabrikgesetzgebung feststellen mussten. ${ }^{46}$

Monokausale Erklärungsversuche müssen durch andere ergänzt werden. Kollers Darstellung überzeugt durch die Berücksichtigung einer Reihe von Aspekten, die zur Verwerfung des sieberschen Unterrichtsgesetzes geführt hatten. Auf dem Hintergrund meines Forschungsinteresses - die Frage nach den zivilreligiösen Erwartungen an den schulischen Religionsunterricht - und meinen diesbezüglichen Forschungen scheint es mir sehr plausibel, dem Religionsunterricht eine wichtige Bedeutung in den Überlegungen der Stimmbürger für ein Ja oder ein Nein beizumessen. Denn wie in Kapitel 4 gezeigt worden ist, handelte es sich hier nicht bloss um einen Kampf auf politischer Ebene zwischen liberal und demokratisch Gesinnten, sondern ebenso um einen (innerkirchlichen) Kampf auf weltanschaulich-religiöser Ebene zwischen theologisch Liberalen und Positiven, der zu dieser Zeit im Vergleich zu heute noch enorme Mobilisierungskraft besass.

Im Zentrum dieser Arbeit stehen jedoch nicht die möglichen Gründe für die Ablehnung des Unterrichtsgesetzes. Vielmehr interessiert die Frage nach den zivilreligiösen Erwartungen, die sich in der Diskussion um den schulischen Religionsunterricht im Zusammenhang mit der Abstimmung über dieses Unterrichtsgesetz manifestierten. Es folgen nun die eigentlichen Hauptkapitel dieser Arbeit: Kapitel 6 dient der Darstellung der verschiedenen Themen, die in der öffentlichen Diskussion über den schulischen Religionsunterricht im Zusammenhang mit dem Unterrichtsgesetz diskutiert worden waren. Kapitel 6 bildet auch die Grundlage dafür, in Kapitel 7 nach möglichen zivilreligiösen Aspekten in der Diskussion zu suchen. 


\section{Kontroverse Themen in der Diskussion um den schulischen Religionsunterricht um 1872}

Die durch die neue Kantonsverfassung von I869 erfolgte weitere Entflechtung - wenn auch nicht Trennung - von Kirche und Staat tangierte auch die öffentliche Schule. Das Verhältnis von Schule und Religionsunterricht musste neu diskutiert werden. In der öffentlichen Diskussion um den schulischen Religionsunterricht lassen sich in den von mir untersuchten Quellen sechs wechselseitig verbundene Hauptthemen herauskristallisieren, die kontrovers diskutiert wurden:

I. Die zentrale Frage nach der organisatorischen Hoheit über den schulischen Religionsunterricht. Wem sollte das Mitbestimmungsrecht bei Lehrplan und Lehrmittel zukommen? Den Erziehungsbehörden (sprich: dem Staat) oder der Kirche? Oder sollte es hinsichtlich des schulischen Religionsunterrichts zwischen beiden Institutionen eine Aufgabenteilung geben?

2. Eng verknüpft mit der Frage nach der organisatorischen Hoheit über den Religionsunterricht war die Frage, wer dieses Fach zu erteilen befugt sei: der Lehrer oder der Pfarrer?

3. Angesichts konfessioneller Gräben und innerkirchlicher Richtungsstreitigkeiten stellte sich die Frage nach der Art der schulischen Erziehung. Durfte die öffentliche Schule, die von allen Kindern sollte besucht werden können, in Anbetracht unterschiedlichster religiöser Vorstellungen zur religiösen Erziehung einen Beitrag leisten? Oder sollte sich die Schule auf die Erziehung zur Sittlichkeit beschränken? Unter denjenigen, die einen schulischen Religionsunterricht befürworteten, war jedoch die Art des schulischen Religionsunterrichts umstritten: eine konfessionell-dogmatische oder nicht konfessionelle religiöse Unterweisung?

4. Untrennbar mit der dritten Frage verbunden war die Frage, ob der schulische Religionsunterricht obligatorisch sein dürfe oder müsse.

5. Die vielleicht fundamentalste Frage, die im Zusammenhang mit dem schulischen Religionsunterricht diskutiert wurde, war die Frage nach dem Zweck der öffentlichen Schule. Am Zweckartikel bzw. an der Frage, ob die Schule mitzuwirken habe, die Kinder zu sittlich guten oder zu sittlich religiösen Menschen zu erziehen, entzündeten sich die Gemüter.

6. Last, but not least stand auch der Inhalt des schulischen Religionsunterrichts zur Debatte. Sollte die Sittenlehre im Zentrum stehen oder die Religionslehre? Sollten biblische Geschichten oder moralisch religiöse Erzählungen vermittelt 
werden? Kontrovers diskutiert wurden insbesondere auch das Alte Testament und die Wundergeschichten.

Diese sechs Themen sind alle aufs Engste miteinander verbunden und wurden de facto auch häufig miteinander und durcheinander diskutiert. Die von mir vorgenommene Abstraktion einzelner Themen hat zum Ziel, der Diskussion gewisse Konturen zu verleihen, sie fassbarer zu machen und vor allem auch einen Vergleich mit der Diskussion über den schulischen Religionsunterricht im 2I. Jahrhundert zu ermöglichen. Gewisse Überlappungen bei der Darstellung sind nicht zu vermeiden.

\subsection{Mitbestimmungsrecht bei Lehrplan und Lehrmittel}

In Paragraph 58 des Unterrichtsgesetzes von I 859, das bis ins Jahr I 899 in Kraft war, heisst es, dass die Alltagsschule sechs und die Ergänzungsschule drei Jahre dauere. ${ }^{I}$ Die Paragraphen 69-7I sind speziell dem Religionsunterricht gewidmet. Paragraph 69 enthält die Bestimmungen über «Lehrplan und Lehrmittel für den Religionsunterricht in der allgemeinen Volksschule», die «wie für die übrigen Lehrfächer, von dem Erziehungsrathe entworfen» wurden. Im Unterschied zu den anderen Fächern waren jedoch Lehrplan und Lehrmittel für den Religionsunterricht «vor deren definitiven Feststellung dem Kirchenrathe zur Begutachtung zu übermitteln, welcher seinerseits ein Gutachten der Kirchensynode oder ein Gutachten der geistlichen Kapitel über dieselben zu erheben» hatte. Nach Eingang dieser Gutachten beschloss der «Erziehungsrath bei Feststellung von Lehrplan und Lehrmitteln für den Religionsunterricht in der Alltagsschule die zweckmässig erscheinenden Abänderungen definitv». Bei Festsetzung von Änderungen für die Ergänzungsschule musste er diese noch dem Kirchenrat zur Genehmigung unterbreiten. ${ }^{2}$ Dies bedeutete, dass bezüglich Änderungen die Alltagsschule betreffend dem Erziehungsrat endgültige Entscheidungsgewalt zugesprochen wurde, während im Falle der Ergänzungsschule die endgültige Fassung von beiden Gremien - Erziehungsrat und Kirchenrat - abgesegnet werden musste. Konnten sich diese beiden Gremien nicht einigen, musste eine Kommission eingesetzt werden, die zu gleichen Teilen mit Vertretern beider Gremien besetzt war. Diese Kommission hatte eine einvernehmliche Lösung

I «Ausserdem sind alle der Alltagsschule entlassenen Kinder, sofern sie nicht eine höhere Schule besuchen, bis zur Konfirmation verpflichtet, wöchentlich eine Stunde die Singschule zu besuchen, welche am Sonntage oder an einem Werktage gehalten wird zur genauern Einübung der in der Kirche zu singenden Choräle und Vervollkommnung im Figuralgesange» (Gesetz über das gesammte Unterrichtswesen des Kantons Zürich I $859, \$ 58)$.

2 Gesetz über das gesammte Unterrichtswesen des Kantons Zürich I 8 59, $\$ 69$. 
anzustreben. Konnte auch auf diesem Weg keine Lösung gefunden werden, entschied in letzter Instanz der Regierungsrat (vgl. Paragraph 69). Paragraph 70 legte fest, dass in der Ergänzungsschule der Religionsunterricht durch den Pfarrer erteilt werde. Da diesbezüglich zur Alltagsschule nichts steht, ist davon auszugehen, dass in der Alltagsschule der Religionsunterricht durch den Lehrer erteilt werden sollte.

Mit dem neuen geplanten Schulgesetz sollte die Ergänzungsschule aufgehoben und die Alltagsschule verlängert werden. Folgt man der Logik des bisherigen Gesetzes, wonach in der Alltagsschule hinsichtlich des schulischen Religionsunterrichts dem Erziehungsrat endgültige Entscheidungsgewalt zugesprochen worden war, müsste im neuen Gesetz diese Bestimmung auch für die erweiterte Alltagsschule (7.-9. Klasse) gelten. Und in der Tat heisst es im Gesetzesentwurf für das neue Schulgesetz (Antrag des Regierungsrats), der im Landboten abgedruckt wurde, unter Paragraph is: «Der Unterrichtsstoff jeder Klasse wird, in Bezug auf Auswahl, Umfang, Gliederung, Lehrziel und planmässiges Fortschreiten durch den obligatorischen Lehrplan und die obligatorischen Lehrmittel, die auf jedes Unterrichtsfach täglich zu verwendende Zeit nach dem vom Erziehungsrath gutgeheissenen Lektionsplan bestimmt.»3

Es ist weder von einem Begutachtungsrecht und schon gar nicht von einem Genehmigungsrecht des Kirchenrates die Rede. Der Grund dafür liegt jedoch nicht bloss in der Verlängerung der Alltagsschule, sondern auch darin, dass der Entwurf für das neue Unterrichtsgesetz gar keinen Religionsunterricht im eigentlichen Sinn mehr vorsah. So ist unter den Lehrgegenständen nicht mehr wie im Unterrichtsgesetz von I 859 das Fach «christliche Religions- und Sittenlehre» (Paragraph 65) aufgeführt. Dieses Fach wurde im Entwurf für das neue Unterrichtsgesetz ersetzt durch «Anregungen und Belehrungen aus dem Gebiete des sittlichen und geistigen Lebens». ${ }^{4}$ Die diesbezüglich geführten Kontroversen werden in Unterkapitel 6.3 genauer dargestellt, obwohl natürlich die Frage, wer in der verlängerten Alltagsschule für die inhaltliche Bestimmung des schulischen Religionsunterrichts bzw. Sittlichkeits- und Moralunterrichts zuständig sein soll, nicht unabhängig von der Klärung der inhaltlichen Ausrichtung dieses Faches erläutert werden kann. In diesem Unterkapitel werde ich mich dennoch auf die Darstellung der Diskussion um die Frage nach der inneren Organisation dieses Faches konzentrieren, das ich einfachheitshalber, wenn auch sachlich nicht ganz korrekt, Religionsunterricht nennen werde. Sogar der Klerus war in der Frage gespalten, wer über die innere Organisation dieses Faches bestimmen darf und soll.

3 Der Landbote, i7. I0. I871, Hervorhebung R. K.

4 Gesetz betreffend das gesammte Unterrichtswesen des Kantons Zürich, Antrag des Regierungsrathes, $\mathbb{S}$ I4, Punkt I, zit. in Der Landbote, I7. I0. I87I. 
In der Synodalverhandlung der zürcherischen Geistlichkeit vom I4./I 5 . November I 87 I votierte eine Minderheit für den Antrag der beiden liberalen Pfarrer Heinrich Langs und Conrad Wilhelm Kambli, ${ }^{6}$ demgemäss die Organisation des Religionsunterrichts in der Volksschule «auf allen Punkten Sache der Erziehungsbehörden»7 sei. Daraus folgerten Lang und Kambli, dass der Religionsunterricht ab dem 7. Schuljahr nicht mehr per se Aufgabe des Pfarrers zu sein habe, sondern diese Aufgabe durchaus auch vom Lehrer übernommen werden könne: «Vom 7. Schuljahr an ertheilen die Pfarrer den Religionsunterricht, wenn nicht die Schulgenossen resp. ihre Organe die Ertheilung dieses Unterrichts den Lehrern übertragen.» ${ }^{8}$

Die Mehrheit der Geistlichkeits-Synode stimmte jedoch für eine Aufgabenteilung zwischen Kirche und Schule: In der I.-6. Klasse solle der Religionsunterricht der Schule überlassen werden. ${ }^{9}$ Für die 7.-9. Klasse wurde gefordert, dass gewisse Bestimmungen die Lehrgegenstände betreffend nicht aufgenommen werden: auf Primarschulstufe der Paragraph I4, I, auf Sekundarschulstufe entsprechend Paragraph 25, I ( Anregungen und Belehrungen aus dem Gebiete des sittlichen und geistigen Lebens») und auf Gymnasialstufe die Paragraphen 7I und 76 (Ethik). Hingegen sollte «für diese Schulstufen die Ertheilung des Religionsunterrichtes durch die Kirche im Anschlusse an den Schulorganismus vom Unterrichtsgesetze ausdrücklich ermöglicht» ${ }^{10}$ werden.

Diese Thematik wurde auch in Leserbriefen diskutiert. In der NZZ warnte ein Einsender davor, die an alle Kirchenpflegen des Kantons gerichtete Petition der Gemeindekirchenpflegen Hütten und Oberrieden zu unterzeichnen. Die Petition forderte gemäss diesem Einsender, dass christlicher Religionsunterricht als Lehrfach im Schulgesetz aufgeführt werde und dieser in der Alltagsschule wie bisher von den Lehrern, in der Ergänzungs- und Sekundarschule jedoch von den Pfarrern erteilt «und auf letzterer Stufe ausschliesslich durch die Kirche organisirt werden ${ }^{11}$ sollte. Ein solches Begehren sei jedoch ein «Rückschritt»,

5 Vgl. Anm. 42 im Unterkapitel 4.3.

6 Conrad Wilhelm Kambli (I 829-I9I4) studierte Theologie in Zürich und Berlin. Er war Vikar in Wetzikon und Pfarrer in Illnau, Horgen (I863-I 884) und St. Gallen; ab I894 Dekan. Er war ein Vertreter der liberalen Theologie und mit Alois Emanuel Biedermann befreundet. Die Vorstellung eines christlichen Wirtschaftssystems lehnte er ab, setzte sich aber für eine christlich motivierte Sozial- und Wirtschaftsethik ein (vgl. Kuhn 2007a).

7 Amtlicher Auszug aus Protokollen der Synode der Zürcherischen Geistlichkeit, I 5 . I I. I 87I, 34.

8 Ebd.; Obwohl Pfarrer Lang die Erziehungsbehörden und nicht die Kirche als für den schulischen Religionsunterricht verantwortlich erachtete, betonte er in seinem Vorschlag, dass der Religionsunterricht «ein wesentlicher Faktor des Volksschulwesens auf allen seinen Stufen» (ebd., 33) sei und dass dies in den betreffenden Abschnitten des Unterrichtsgesetzes erwähnt werden müsse.

9 Vgl. NZZ, 2. I 2. I871.

Io Amtlicher Auszug aus Protokollen der Synode der Zürcherischen Geistlichkeit, I 5. I I. I871, 36.

I I NZZ, 26. I2. I87I. 
$\mathrm{da}$ «die Schulbehörden von dem Einflusse, den ihnen das bisherige Gesetz auf Organisation des Religionsunterrichtes in der Ergänzungs- und Sekundarschule gestattet, ausgeschlossen würden. Nun kann man doch aber gewiss einer Erziehungsbehörde nicht zumuthen, ein Fach organisch in ihre Schulen einzureihen, zu dessen innerer Organisation sie gar nichts zu sagen haben soll.» ${ }^{12}$

Von der Kirchenpflege Hedingen liegt eine Stellungnahme zu dieser Petition vor, die in dieselbe Richtung zielte wie obiger Leserbriefschreiber. Die Kirchenpflege wünschte, «dass die Organisation des Religionsunterrichtes für die Ergänzungs- \& Sekundarschulen in allen Punkten ganz Sache der Erziehungsbehörden bleibe, die hierüber auch zu wachen haben, \& dass der Religionsunterricht bei diesen beiden Schulstufen den Geistlichen übergeben werde, wenn nicht die Schulgenossen od. ihre Organe denselben den Lehrern übertragen.» ${ }^{13}$

Ein anderer Leserbriefschreiber erachtete die obengenannte Petition der Gemeindekirchenpflegen Hütten und Oberrieden im Gegensatz dazu gerade nicht als Rückschritt, sondern vielmehr als einen Fortschritt, da sie den Forderungen der neuen Kantonsverfassung entspreche. Für diesen Einsender war es klar, dass der Religionsunterricht auf der bisherigen Alltagsschule ( I.-6. Klasse) von der Schulbehörde organisiert werden sollte, da sich der Religionsunterricht auf dieser Stufe «noch auf dem allgemeinen Boden sittlicher Anregungen und bibelgeschichtlicher Mittheilungen bewegt». Zugleich sei es einleuchtend, dass die innere Organisation des Religionsunterrichts auf der höheren Stufe «den kirchlichen Behörden zukommen soll, weil der Unterricht auf dieser höhern Stufe nothwendig spezieller kirchlich werden muss, und nach der neuen Verfassung die Staatsbehörden auf die Gestaltung der innerkirchlichen Dinge nicht mehr unmittelbar einwirken sollen.» ${ }^{14}$

Diakon Spyri, ${ }^{15}$ der nach eigenen Worten «seit 24 Jahren in unserer Geistlichkeitssynode zur liberalen Minderheit» gehörte und «Schule und Kirche für zwei auf dasselbe Ziel hinstrebende Anstalten» hielt, die «uns beide gleich lieb»

I 2 Ebd.

I 3 Stellungnahme der Kirchenpflege Hedingen, dat. i87 I (Eingaben und Antworten von Privaten betreffend Religionsunterricht). Diese Stellungnahme findet sich im StAZH bei den Eingaben und Antworten auf die 42 Fragen Siebers, bezieht sich aber auf Grund des Datums eher auf die Diskussion um die erste Fassung des Unterrichtsgesetzes.

I4 NZZ, 29. I 2. I 87 I.

Is Johann Ludwig Spyri (1822-1895) hat in Zürich Theologie studiert. Er war Vikar in Wald, Pfarrverweser in Fischenthal, Pfarrer in Altstetten und von 1865 bis 1875 Diakon in der Kirchgemeinde Neumünster in Zürich. Von I850 bis I853 war er im Zürcher Kantonsrat, I875 amtete er als Chef des Statistischen Büros der schweizerischen Nordostbahn. Die Schweizerische Zeitschrift für Gemeinnützigkeit wurde von ihm I 860 gegründet. I $875-$ I 890 war er Präsident der Schweizerischen Gemeinnützigen Gesellschaft (vgl. Schumacher 20I3) Er war der Schwager von Johanna Spyri und der Vater von Emilie Kempin-Spyri, der ersten Schweizer Juristin (vgl. Delfosse 2008). 
sind, und «die Lehrer als unsere Mitarbeiter an demselben Werke» ${ }^{16}$ erachtete, präsentierte in seinem Traktat Der Religionsunterricht und der Entwurf des neuen Schulgesetzes des Kantons Zürich. Ein Wort zur Verständigung einen Vermittlungsvorschlag zwischen dem Entwurf des neuen Schulgesetzes und dem Gegenvorschlag der Mehrheit der Geistlichkeitssynode. Die Geistlichkeitssynode forderte, dass in der 7.-9. Klasse kein schulischer Religionsunterricht stattfinde, sondern dieser von der Kirche erteilt werde, die Schule aber sowohl die dafür nötige Zeit im Stundenplan als auch die Räumlichkeiten zur Verfügung stelle. Die Gewissensfreiheit in Artikel 63 der Verfassung werde damit insofern berücksichtigt, als niemand gezwungen werde, an diesem Unterricht teilzunehmen. Dagegen argumentierte Spyri ähnlich wie der oben zuerst zitierte Leserbriefschreiber, «dass, wenn der Staat Zeit und Raum für den Unterricht auf dieser Mittelstufe gibt, er sich kaum mit einer so losen Verbindung begnügen kann, sondern dass das Verlangen berechtigt ist, den ganzen Religionsunterricht organisch in den übrigen Unterrichtsplan einzureihen.» ${ }^{17}$

Spyri unterschied in seinem Vermittlungsvorschlag drei Stufen: In der I.-6. Klasse ist der Religionsunterricht alleinige Sache der Schule. Dieser wird durch den Lehrer erteilt und die Kirche verzichtet «auf jede Mitwirkung bei Festsetzung des Lektionsplanes und Ausarbeitung der Lehrmittel». ${ }^{18}$ Die zweite Stufe, das heisst 7.-9. Klasse, die «ihrer ganzen Natur nach Schule und Kirche [berührt], die erstere als Vollendung ihres Unterrichtes, die letztere als Unterbau des Unterrichtes des letzten Jahres, sie ist für beide gleich wichtig». ${ }^{19}$ Weil der Unterricht jedoch in der Schule stattfindet, ist er hinsichtlich Lehrplan, Lehrmittel und Aufsicht den Schulbehörden untergeordnet und die kirchlichen Organe haben sowohl für die erste als auch die zweite Stufe bloss ein Begutachtungsrecht. Allerdings sollte der Unterricht gemäss Spyris Vorschlag auf der zweiten Stufe von Geistlichen erteilt werden, «die aber für denselben [Unterricht] Lehrer der Schule sind, wie die übrigen Lehrer auch und unter Vorbehalt der Bestimmungen der Verfassung. Es ist überdies Alles dogmatisch Konfessionelle von dem Unterricht auszuschliessen». ${ }^{20}$ Die dritte Stufe bildete nach Spyri die Unterweisung, die «ganz Sache der Kirche» ${ }^{21}$ sei, was meinte, dass sowohl Lehrplan und Lehrmittel wie auch die Aufsicht über den Unterricht allein den kirchlichen Behörden zukomme.

I6 Spyri i 872, 3 .

I7 Ebd., I3.

I 8 Ebd.

I9 Ebd., I 3 f.

20 Ebd., I4.

2 I Ebd. 
In der Fassung, die schliesslich zur Abstimmung gelangte, wurde Spyris Vermittlungsvorschlag zumindest teilweise beherzigt. So sollte der Religionsunterricht in der 7.-9. Klasse vom Ortsgeistlichen erteilt werden. Dabei sollte alles Dogmatische und Konfessionelle ausgeschlossen und Lehrplan und Lehrmittel durch den Erziehungsrat festgesetzt werden. Von einem Begutachtungsrecht seitens der kirchlichen Organe bezüglich Lehrplan und Lehrmittel war aber auch hier nicht mehr die Rede. ${ }^{22}$ Bezüglich der Organisation des Religionsunterrichts verlor die Kirche somit eindeutig an Einfluss.

Hinsichtlich des Mitbestimmungsrechts beim schulischen Religionsunterricht können zusammengefasst folgende drei Positionen genannt werden: I) Der schulische Religionsunterricht ist auf allen Stufen der Volksschule gänzlich Sache der Erziehungsbehörden (vgl. Pfr. Lang und Pfr. Kambli). 2) Die Forderung nach einer Aufgabenteilung zwischen Schule und Kirche, die sich am Kriterium Stufe/Alter orientiert: Die I.-6. Klasse liegt gänzlich im Verantwortungsbereich der Erziehungsbehörden, während die 7.-9. Klasse gänzlich in den Verantwortungsbereich der kirchlichen Behörden gehört. So gesehen findet in den oberen Klassen gar kein eigentlicher schulischer Religionsunterricht statt, sondern ein kirchlicher (vgl. Mehrheit Geistlichkeitssynode). 3) Vermittlungsvorschlag: Die Verantwortung liegt für alle neun Klassen gänzlich bei den Erziehungsbehörden. Den kirchlichen Behörden wird jedoch für alle neun Klassen (Alltagsschule und Ergänzungsschule) Begutachtungsrecht hinsichtlich Lehrplan und Lehrmittel zugestanden.

\subsection{Wer unterrichtet - der Lehrer oder der Pfarrer?}

Die im Unterkapitel 6.I dargestellte Diskussion um die Frage, wer für die innere Organisation des Religionsunterrichts zuständig sei, wurde, wie sich gezeigt hat, nicht losgelöst von der Frage, wer dieses Unterrichtsfach erteilen soll, debattiert. Untersucht man die Antworten auf die siebersche Umfrage von I 869 hinsichtlich dieser Frage, stellt sich unter denjenigen, die nicht gänzlich gegen einen staatlichen Religionsunterricht waren, als Mehrheitsmeinung eine nach Alter geteilte Verantwortung zwischen Schule und Kirche heraus: Der Lehrer erteilt weiterhin den schulischen Religionsunterricht in der Alltagsschule (г.-6. Klasse), während die Verantwortung für die nachfolgenden Stufen dem Geistlichen obliegt. ${ }^{23}$ Es gab auf der einen Seite allerdings einzelne

22 Vgl. Gesetz betreffend das gesammte Unterrichtswesen des Kantons Zürich, 2 I. Februar I 872 (Abstimmungsvorlage), \I4.

23 Vgl. Gemeindeschulpflegen Wald (Bezirk Hinwil), Thalwil (Bezirk Horgen), Russikon (Bezirk Pfäffikon), Mönchaltorf (Bezirk Uster); Gemeindsverein Mönchaltorf (Bezirk Uster), 
Stimmen, die auch auf Alltagsschulstufe den Religionsunterricht vom Geistlichen erteilt haben wollten. ${ }^{24}$ Auf der anderen Seite gab es aber auch diejenigen, die der Meinung waren, der Lehrer habe nicht bloss in der Alltagsschule, sondern auch in der Ergänzungsschule (7.-9. Klasse) den Religionsunterricht zu halten. ${ }^{25}$

Diakon Spyri beschäftigte sich in seinem oben erwähnten Traktat ${ }^{26}$ eingehend mit dieser Frage. Die Ansicht, dass bei einer zunehmenden Entflechtung von Kirche und Staat der Geistliche als Repräsentant der Kirche nicht mehr befugt sei, schulischen Religionsunterricht zu erteilen - auch nicht auf den oberen Stufen -, entkräftet Spyri mit dem Argument, der Geistliche sei «gar nicht mehr der Repräsentant der Kirche, sondern ein Lehrer, der der Kirche dient». ${ }^{27}$ Umgekehrt seien aber auch die Lehrer religiös geprägt. Die Lehrer «sind nicht farblos, sondern zählen sich zu dieser oder jener religiösen Gemeinde, von denen $\mathrm{zu}$ schweigen, die grundsätzlich von keiner Religion wissen wollen, und bei denen es doch etwas eigenthümlich wäre, wenn sie unsern Kindern Religionsunterricht ertheilen sollten». ${ }^{28}$ Den einzigen Unterschied zwischen Lehrer und Pfarrer sieht Spyri in der Fachkompetenz des Pfarrers hinsichtlich des Gegenstandes Religion, die dem Lehrer als Allrounder notgedrungen abgehe. Spyri weist zudem hin auf die «Thatsache, dass auch extreme Richtungen von relativen Laien viel einseitiger verfolgt werden, als von eigentlichen Fachmännern; so ist z. B. ein pietistischer Geistlicher viel weniger einseitig als ein pietistischer Lehrer». ${ }^{29}$

Über die Frage, ob Geistliche schulischen Religionsunterricht erteilen dürfen, wurde auch im Kantonsrat debattiert. Das Argument, Geistliche seien Fachmänner der Religion, konterte Vögelin ${ }^{30}$ in der Kantonsratsdebatte vom I I. Januar

Eingaben und Antworten der Bezirksschulpflegen i 870; Gesellschaft Bülach, Eingaben und Antworten von Vereinen i 870.

24 Vgl. J. Hech, dat. Seuzach, 30. I. I870, Eingaben und Antworten von Privaten I 870.

25 Vgl. Schulkapitel Uster (Bezirk Uster) und Affoltern (Bezirk Affoltern), Eingaben und Antworten der Bezirksschulpflegen I 870.

26 Vgl. Spyri i 872.

27 Ebd., 8.

28 Ebd., 8 f.

29 Ebd., 9.

30 In der NZZ wird der Redner Hr. Professor Vögeli genannt. Obwohl es in Zürich auch einen Historiker namens Vögeli (I810-I874) gab, der I 870 ausserordentlicher Professor an der Hochschule Zürich wurde (vgl. Moser 20I3), kann mit ziemlicher Sicherheit davon ausgegangen werden, dass hier nicht dieser Vögeli gemeint ist, sondern Friedrich Salomon Vögelin. In der Berichterstattung des Landboten über dieselbe Kantonsratsdiskussion ist denn auch von Prof. Vögelin die Rede, der am Schluss seines Votums gesagt haben soll, «dass er, wenn er noch Amtsgeistlicher wäre, alle diese Dinge vermuthlich etwas anders beurtheilen würde» (Der Landbote, I 3. I. I872). F. S. Vögelin wurde im Jahre I 870 zum ausserordentlichen Professor für Kunst- und Kulturgeschichte an die Universität Zürich berufen (vgl. Betulius 1956). 
gemäss Berichterstattung der NZZ folgendermassen: "was aber an der Religion Fachstudium ist, das wollen wir gerade in der Schule nicht, sondern nur sittlich-religiöse Anregung.»31 Im selben Votum legte Vögelin auch seine von Spyri abweichende Überzeugung dar, dass, obzwar es zum Teil richtig sein möge, dass Lehrer als theologische Laien ihre religiösen Ansichten fanatischer verträten, in der Regel «die Geistlichen als Fachmänner fanatischer seien».32 Es gebe eingestandenermassen auch areligiöse Lehrer, doch «wenn dies wäre, so wird sich ein solcher Lehrer schon von vornherein sträuben, den Religionsunterricht zu ertheilen».33

Nun aber nochmals zurück zu Spyri, der in seinem Traktat auch ein zweites Argument dafür, den Religionsunterricht in der 7.-9. Klasse den Geistlichen wegzunehmen, zu entkräften versucht. Spyri kann es zwar teilweise nachvollziehen, dass die Einheit der Klassenführung gefährdet sei, wenn zwei Personen, der Pfarrer und der Lehrer, an derselben Klasse unterrichten. Zugleich kann er einem Lehrerwechsel aber auch etwas Positives für die Schüler abgewinnen. So könne «der Eintritt einer andern Kraft in der Schule wolthätig»34 wirken. Und Spyri begegnet dem Einwand, dass die Lehrer, zumal sie eine wissenschaftliche Bildung haben, ebenso wie die Geistlichen geeignet seien, auf den oberen Stufen Religionsunterricht zu erteilen, mit einem deutlichen «Nein! Der Mensch kann eben nicht Alles in gleicher Weise. So wenig z. B. ein Geistlicher im Stande wäre, so ohne weiteres Unterricht in der Sprache und im Rechnen bei einem Kinder der ersten Klasse der Elementarschule zu ertheilen, wie das jeder Primarlehrer ohne grosse Mühe thut [...], ebenso wenig ist ein Lehrer befähigt, den Fachunterricht in der Religion zu ertheilen, wie das ein gebildeter Geistlicher zu thun im Stande ist.»35 Spyri betont jedoch, dass damit keineswegs eine Verachtung des Lehrers verbunden sei: «Wir achten den Stand der Lehrer zu hoch, um nicht annehmen zu müssen, dass ihnen die Beschränkung des Wissens und das Prinzip der Theilung der Arbeit ganz bekannte und auch anerkannte Dinge wären.» ${ }^{36}$

Ferner verweist Spyri auf einen seiner Ansicht nach grundlegenden Unterschied zwischen Lehrer und Pfarrer, nämlich die moralische Vorbildhaftigkeit des Geistlichen: «[...] bei dem Geistlichen fallen Amt und Beruf so zusammen, dass daraus Eine Persönlichkeit, die vielleicht im Leben ihre eckigen und unangeneh-

3 I NZZ, I2. I. I872. Im Landboten wird Vögelins Votum auf folgende Weise wiedergegeben: «Wir brauchen nicht sogenannte Fachmänner in dieser Disziplin, auch nicht Störung im ganzen Organismus der Schule, sondern Einheit.» (Der Landbote, I 3. I. I872).

32 NZZ, I2. I. I 872.

33 Ebd.

34 Spyri I 872, 9.

35 Ebd., Iо.

36 Ebd. 
men Seiten haben kann, wird, die aber um dieser Einheit willen, wie keine andere Person geeignet ist, gerade den Religionsunterricht zu ertheilen, da ja dessen Einfluss auf dem Eindrucke der Persönlichkeit ruht.»37 Als Gegenbeispiel führt Spyri einen Lehrer an, der ab und an einen Schluck über den Durst trinkt. Man möge deswegen «die Achseln zucken». Dieses Laster werde den betroffenen Lehrer jedoch nicht daran hindern, erfolgreich Mathematik oder Geographie zu unterrichten. Problematisch hingegen wäre es, wenn dieser Lehrer Religionsunterricht oder Anregungen aus dem sittlichen und geistigen Leben erteilen würde. «Damit soll nicht gesagt sein, dass es nicht Lehrer gebe, die wir höher achten als manche Geistliche, oder dass die letztern etwa ohne Sünden seien; aber wenn so etwas vorkäme, so dürfte ein solcher Geistlicher nicht nur nicht mehr Religionsunterricht ertheilen, sondern er müsste überhaupt abtreten.» ${ }^{8}$ In dieser aus heutiger Sicht etwas fragwürdigen Unterscheidung zwischen Lehrer und Pfarrer werden insbesondere zwei Dinge deutlich: einerseits die Annahme einer engen Verquickung zwischen Religion und Moral, andererseits, dass es im Religionsunterricht um mehr geht als um Wissensvermittlung bzw. dass Spyri den schulischen Religionsunterricht als den Ort der Persönlichkeits- und Charakterbildung ansieht.

In seiner Argumentation für die Beibehaltung der Geistlichen in der Volksschule nennt Spyri noch einen weiteren zu berücksichtigenden Aspekt: die Arbeitslast. Müssten die Lehrer gemäss neuem Unterrichtsgesetz auch auf den oberen Stufen den Religionsunterricht erteilen, nehme diese für die Lehrer zu, während sie für die Geistlichen massiv abnehme, da man ihnen nur noch eine Stunde zugestehe. Dazu komme auch noch, dass man den Geistlichen auch die Zivilstandsregister und das Armenwesen wegnehmen wolle; «man lässt ihnen die Predigt und die Seelsorge und nimmt ihnen 3/4 des Religionsunterrichtes weg».39 Spyri fürchtet, dass die Geistlichen so nicht bloss entbehrlich, sondern zu einer «abzuschüttelnden Last» würden.

Diese Furcht war nicht ganz unbegründet: Gegenüber dem Vorwurf, mit dem neuen Unterrichtsgesetz wolle man «nicht bloss die Religion, sondern auch die Geistlichen aus der Schule hinaustreiben», äusserte Sieber am I०. Januar I 872 in einer Rede im Kantonsrat unverblümt die Meinung, dass die Schule «ihren Weg ohne kirchliche Leitung finden» werde und dass er wünsche, «dass künftig die Kirche der Schule ihren eigenen Weg zu gehen erlaube». Der Einfluss der Geistlichen solle aber nicht gänzlich beseitigt werden. In der Zivilschule sei der Ort 
für das Wirken der Geistlichen, wobei auch dort nicht der Ort sei, «dogmatische und konfessionelle Händel» auszutragen..$^{\circ}$

Tags darauf, in der Kantonsratssitzung vom I I. Januar I872, erinnerte Pfarrer Wolf $[\mathrm{f}]^{4 \mathrm{I}}$ im Kantonsrat daran, "dass die Geistlichen nicht die schwarzen bildungsfeindlichen Elemente sind, wie man sie geschildert hat, sondern die freundlichen Gehülfen der Lehrer». Wolff war damit einverstanden, «dass das Konfessionelle auf dieser Schulstufe wegfalle», doch war es ihm ein Anliegen zu bemerken, «dass schon jetzt solche Geistliche, die in anderem Sinne lehren, zu den Ausnahmen gehören».42 Auch ein anderer Pfarrer namens Kägi erhob sich gegen den negativen Ruf des Klerus. Die zürcherische Geistlichkeit habe um die zürcherische Volksschule grosse Verdienste: «sie griff den Lehrern meistens fördernd unter die Arme und lieh ihrem Wirken eine wohlthuende Unterstützung; diese Wohlmeinenheit hätte heute bessere Anerkennung verdient.»43 Ein Lehrer namens Frei bezog sich auf das Votum von Pfarrer Kägi und erklärte, warum die Lehrer den Religionsunterricht gerne selber erteilen wollten. Die Autonomie bzw. Alleinherrschaft des Lehrers werde seiner Ansicht nach durch den Pfarrer gestört: «Schon der Eintritt eines 2. Lehrers in die Schule ist störend; noch mehr, wenn dieser sein Fach in einem andern Geiste ertheilt. Der Lehrer will Alles nach bestimmten Gesetzen erklären, der Geistliche bezieht sich auf das Wunderbare im Alten und Neuen Testamente. Früher brachte man beinahe nur religiösen Stoff in die Schule, heute soll es anders sein; wir wollen einen Religionsunterricht, der psychologisirt ist und darum muss die biblische Geschichte, der Katechismus und das Testament weg erkannt werden. Wir hoffen eine vollständige Lostrennung der Schule von der Kirche, sowie dass die Mitwirkung der Kirche bei Abfassung religiöser Lehrmittel ganz und gar aufhöre. Wir haben bereits einen vollständig geordneten religiösen Lehrstoff, der allen Bedürfnissen genügen kann.»44

Vögelin verdeutlichte in derselben Kantonsratsdebatte den Unterschied zwischen den Forderungen der Kirche und denjenigen des Unterrichtsgesetzent-

40 NZZ, I I. I. I 872.

4I Vermutlich ist hier Philipp Heinrich Wolff (I 822-I903) gemeint, obwohl in der NZZ nur von einem «Pfarrer Wolf» die Rede ist. In der Berichterstattung des Landboten über diese Kantonsratssitzung wird aber ein Wolff genannt (vgl. Der Landbote, I 3. I. I 872). Philipp Heinrich Wolff absolvierte sein Vikariat am Fraumünster in Zürich und war von I 849 bis I 903 Pfarrer in Weiningen. Er war Zunftmeister der Schiffsleutezunft und von I 853 bis I903 Kantonsrat. Wolff gilt als Vater des schweizerischen Tierschutzes: Er war mitbeteiligt an der Gründung des Zürcher Tierschutzvereins und des Schweizerischen Zentralvereins zum Schutz der Tiere und amtete als Präsident der Gesellschaft zur Gründung eines Zoos in Zürich (vgl. Lüthi 20I3).

42 NZZ, I 2. I. I 872.

43 Ebd.

44 Ebd. 
wurfs folgendermassen: «Die Kirche dringt darauf, dass das Religiöse neben dem Sittlichen hergehe; der Entwurf will, dass eine Sittlichkeitslehre gegeben werde, die überall her genommen werden kann.» Seiner Ansicht nach kommt dem Lehrer (und nicht dem Pfarrer) die Aufgabe zu, diese «allgemeine> Sittenlehre dem Kind zu vermitteln: «Der ganze Unterricht ist ein Organismus, und keine Gewalt ausser der Schule soll darauf massgebend einwirken».45

Fraglich allerdings ist, wer oder was die Schule ist. Insofern die Schule als Institution organisiert werden muss, stellt sich unweigerlich die Frage, welche Instanz bzw. welche Instanzen für deren Organisation zuständig sein soll(en). Die Kirche darf es gemäss Vögelin nicht mehr sein. Mit seiner Argumentation, dass «keine Gewalt ausser der Schule» auf den Unterricht einwirken dürfe, müsste Vögelin allerdings konsequenterweise nicht bloss den Einfluss der Kirche, sondern auch den Einfluss staatlicher Gewalt auf den Unterricht kritisieren. Der staatliche Einfluss sollte mit dem Entwurf für das neue Unterrichtsgesetz sogar noch vergrössert werden. Denn während im damals noch bestehenden Unterrichtsgesetz von I859 von den sieben Mitgliedern des Erziehungsrates zwei von der Schulsynode gewählt werden konnten - allerdings unter Vorbehalt der Bestätigung durch den Grossen Rat ${ }^{46}$-, steht im Entwurf zum neuen Unterrichtsgesetz nichts mehr von einer Wahl durch die Schulsynode. Es heisst lediglich noch: «Der Direktion des Erziehungswesens ist ein Erziehungsrath von sechs Mitgliedern beigegeben, welche vom Kantonsrathe nach seiner Integralerneuerung auf die Dauer von 3 Jahren gewählt werden».47 Wie ich im Unterkapitel 7.2.2 anhand einer Rede Vögelins über das Schulobligatorium zeigen werde, hatte Vögelin allerdings sehr wohl ein Bewusstsein für das Spannungsfeld, das sich im Hinblick auf die individuellen Freiheitsrechte angesichts eines staatlichen Schulobligatoriums eröffnet.

45 Ebd.

46 Vgl. Gesetz über das gesammte Unterrichtswesen des Kantons Zürich, 23 . Dezember I 8 59, \ 2.

47 Gesetz betreffend das gesammte Unterrichtswesen des Kantons Zürich (Antrag des Regierungsrathes), $\mathbb{I}$ I I , veröffentlicht in Der Landbote, 20. I0. I87 I. 


\subsection{Religiöse, konfessionslose oder religionslose Schule?}

In den zwei vorangehenden Unterkapiteln 6.I und 6.2 wurden die Diskussionen um die Frage nach der Organisation des Religionsunterrichtes sowie die Frage danach, wer diesen Unterricht zu erteilen befugt ist, dargelegt. Den Antworten auf diese Fragen liegt ein grundsätzlicher Entscheid hinsichtlich der Frage zu Grunde, ob Religionsunterricht überhaupt einen Ort in der öffentlichen Schule haben soll oder ob dieser nicht vielmehr durch einen blossen Sittenunterricht zu ersetzen sei. Die Antwort auf diese Frage ist noch auf eine grundlegendere zurückzuführen, nämlich auf die Frage, was angesichts der Spannung zwischen staatlich-politischen und religiös-weltanschaulichen Interessen ganz allgemein als zentrale Aufgabe der öffentlichen Schule anzusehen ist (vgl. Kapitel 6.5). Bevor jedoch dieser Aspekt der Debatte beleuchtet wird, soll in diesem Unterkapitel zunächst die Diskussion um folgende zwei Fragekreise erörtert werden: zum einen die Frage, ob in der öffentlichen Schule Religionsunterricht oder vielmehr Sittenunterricht zu erteilen sei (vgl. 6.3.I), und zum andern die Frage nach der Art des Religionsunterrichts - ob konfessionell-dogmatischer oder konfessionsloser -, so denn Religionsunterricht in der Schule überhaupt ein legitimes Schulfach sein sollte (vgl. 6.3.2).

Der Autor des neuen Unterrichtsgesetzes, Johann Caspar Sieber (I 82 I-I 878), versuchte bereits als Mitglied des Verfassungsrates den Religionsunterricht verfassungsmässig aus dem Curriculum der öffentlichen Schule zu streichen. Sein Vorstoss war allerdings chancenlos, da im Verfassungsrat befürchtet wurde, dass dies für die Mehrheit der Bevölkerung ein Grund sein könnte, die neue Verfassung als Ganzes abzulehnen. Es wurde deshalb beschlossen, die Schulartikel in der Verfassung in einem neuen Unterrichtsgesetz zu konkretisieren. Für dieses Projekt war dann ebenfalls Sieber in der Funktion als Erziehungsrat verantwortlich..$^{8}$

Konkret entzündeten sich die Gemüter in der Vernehmlassungsphase bezüglich dieser Thematik an den Paragraphen 2 und $\mathrm{I}_{4}$ des neuen Unterrichtsgesetzes. In Paragraph 2 heisst es: "In Unterstützung der Familienerziehung hat die Volksschule dazu mitzuwirken, die Kinder aller Volksklassen zu geistig thätigen, bürgerlich tüchtigen und sittlich guten Menschen heranzubilden».49 Im Unterrichtsgesetz von I 859 heisst die entsprechende Passage unter Paragraph 50 jedoch: «Die Volksschule soll die Kinder aller Volksklassen [...] zu geistig thätigen, bürgerlich tüchtigen und sittlich religiösen Menschen bilden.» ${ }^{\circ}$ "Sittlich

48 Vgl. Greiner 1933, 91.

49 Vgl. Der Landbote, I7. I0. I871, Hervorhebung R. K.

s० Gesetz über das gesammte Unterrichtswesen des Kantons Zürich, 23. Dezember I 8 59, Hervorhebung R. K. 
religiös» sollte durch «sittlich gut» ersetzt werden. Der Antrag des Kirchenrates auf Änderung des Paragraphen 2 wurde in der Synodalverhandlung der zürcherischen Geistlichkeit diskutiert. ${ }^{\text {II }}$

Der andere Stein des Anstosses war Paragraph I4, in welchem die Lehrgegenstände der Primarschule genannt werden. In der entsprechenden Passage im damals noch bestehenden Unterrichtsgesetz von i 859 wird in Paragraph 65 bei der Aufzählung der Lehrgegenstände an erster Stelle «christliche Religionsund Sittenlehre» aufgeführt. ${ }^{2}$ Im Entwurf zum neuen Schulgesetz heisst es in Paragraph I 4 unter Absatz i jedoch bloss noch: «Anregungen und Belehrungen aus dem Gebiete des sittlichen und geistigen Lebens».53 Das Ansinnen der Verfasserschaft des Unterrichtsgesetzentwurfes, den Religionsunterricht aus dem Volksschulunterricht zu eliminieren, zeigt sich in dieser Formulierung unmissverständlich.

\subsubsection{Religionsunterricht versus Sittenlehre}

Obwohl die Frage, ob in der öffentlichen Schule bloss Sittenunterricht anstatt Religionsunterricht erteilt werden soll, meist nicht losgelöst von der Frage nach der Art des Religionsunterrichts (vgl. 6.3.2) erörtert wurde, werde ich in diesem Unterkapitel den erstgenannten Aspekt, das heisst die «Stellung» des schulischen Religionsunterrichtes, aus methodischen Gründen dennoch für sich betrachten. Ich beginne mit den Antworten auf die siebersche Umfrage und werde anschliessend die Diskussionen im Zusammenhang mit dem Unterrichtsgesetzentwurf darstellen.

Da die erste Teilfrage von Frage vier der sieberschen Umfrage die «Stellung» des schulischen Religionsunterrichtes im Blick hatte, ${ }^{54}$ ist $\mathrm{zu}$ diesem Aspekt der Diskussion entsprechend viel Quellenmaterial vorhanden. Auf der einen Seite des Meinungsspektrums befinden sich diejenigen, die die Beibehaltung des Religionsunterrichts in der bisherigen Form wünschten. Dies allerdings mit unterschiedlichen Schwerpunkten und Begründungen. In den Stellungnahmen der einen wurde explizit ein christlicher Religionsunterricht gefordert.ss Die Gemeindeschulpflege von Richterswil schrieb beispielsweise: «Der Religions-

5I Vgl. Amtlicher Auszug aus Protokollen der Synode der Zürcherischen Geistlichkeit, I 5. I I. I87i; vgl. auch Der Landbote, I9. I I. I87I.

52 Vgl. Gesetz über das gesammte Unterrichtswesen des Kantons Zürich, 23. Dezember I 859.

53 Gesetz betreffend das gesammte Unterrichtswesen des Kantons Zürich (Antrag des Regierungsrathes), $\mathbb{S}$ I4, veröffentlicht in Der Landbote, I7. I0. I87I.

54 Der erste Teil der Frage 4 der sieberschen Umfrage lautet: «Ist im Hinblick auf die Bestimmungen des Art. 63 der Verfassung die Stellung des Religionsunterrichtes der Schule zu ändern?» (Bekanntmachung der Erziehungsdirektion vom 22. November I 869).

ss Vgl. Schulpflege Stammheim (Bezirk Andelfingen); Schulpflege Hütten (Bezirk Horgen), Eingaben und Antworten der Bezirksschulpflegen i 870, StAZH, U 8.i.Ia. 
unterricht soll \& darf in keinem Falle aus der Schule entfernt werden, derselbe soll auf gesunden christlichen Grundsätzen ruhen».56 Ähnlich klingt die Vernehmlassungsantwort der Schulpflege von Uetikon, einer Richterswil gegenüberliegenden Seegemeinde: «Wir empfehlen für unsere Volksschule, deren Rayon mit demjenigen unserer evang. reform. Landeskirche zusammenfällt, einen gesunden, christlichen Religionsunterricht auf biblischer Grundlage, ungefähr in bisheriger Weise.» ${ }^{77}$

Die Schulpflege Stammheim spezifizierte ihre Forderung nach einem christlichen Religionsunterricht mit der Art, wie dieser erteilt werden soll: «Der christliche Religionsunterricht als Unterricht in der biblischen Geschichte ist als unerlässliches Bildungsmittel beizubehalten.» ${ }^{8}$ Unter den Befürwortern der Beibehaltung des schulischen Religionsunterrichts war die Meinung verbreitet, dass dieser Unterricht kein dogmatisch-konfessioneller sein sollte. Dieser Aspekt der Diskussion wird im folgenden Unterkapitel 6.3.2 noch eigens erörtert. Als Argument für die Beibehaltung des schulischen Religionsunterrichts wurde in den Antworten auf Siebers Umfrage vielfach Gemütsbildung genannt. So schrieb beispielsweise die Gemeindeschulpflege Schönenberg: «Der Religionsunterricht ist nach unsrem dafürhalten auf allen Stufen beizubehalten. Denn religiöses Leben ist ohne religiösen Unterricht nicht möglich. Neben dem Verstand wird namentlich dem Gemüthe durch denselben die gehörige Nahrung zugeführt.»s9 Die Gemeinde- und Sekundarschulpflege Niederhasli wünschte ebenfalls «die bisherige Stellung des Religionsunterrichtes der Schule» mit der Begründung: «Dieser Unterricht ist den Lehrern lieb, damit kann man sehr auf das Gemüth der Kinder einwirken.» ${ }^{60}$ Auch das Schulkapitel Regensberg sprach sich «für Beibehaltung des Religionsunterrichtes als obligat. Fach der Volksschule aus», da dieser «zur Gemüthsbildung nöthig» sei und die «Schule durch Beseitigung dieses Faches ein fruchtsames Element verlieren ${ }^{6 \mathrm{r}}$ würde. Ein weiteres Argument für die Beibehaltung des schulischen Religionsunterrichts kam von der Gemeindeschulpflege Dorf: «Wir würden sehr bedauern, wenn der Religionsunterricht aus der Primarschule entfernt würde, indem dadurch die Schule beim Volke an Kredit verlöre, u. der Sectirerei in die Hand gearbeitet würde.» ${ }^{62}$

56 Vgl. Gemeindeschulpflege Richterswil (Bezirk Horgen), Eingaben und Antworten der Bezirksschulpflegen i 870, StAZH, U 8.r.ra.

57 Vgl. Schulpflege Uetikon (Bezirk Meilen), ebd.

58 Vgl. Schulpflege Stammheim (Bezirk Andelfingen) und Schulpflege Hütten (Bezirk Horgen), ebd.

59 Vgl. Gemeindeschulpflege Schönenberg (Bezirk Horgen), ebd.

60 Vgl. Gemeinde- und Sekundarschulpflege Niederhasli (Bezirk Regensberg), ebd.

6I Vgl. Schulkapitel Regensberg (Bezirk Regensberg), ebd.

62 Vgl. Gemeindeschulpflege Dorf (Bezirk Andelfingen), ebd. 
Ich vermute, dass diese Schulpflege die Gründung von privaten konfessionellen Schulen befürchtete, sollte in der öffentlichen Schule kein Religionsunterricht mehr angeboten werden. Man scheint hier offenbar geglaubt oder gehofft zu haben, mit dem schulischen Religionsunterricht einer möglichen strukturellen religiösen Pluralisierung entgegenwirken zu können. Der schulische Religionsunterricht war Angehörigen von Freikirchen tatsächlich ein Dorn im Auge, weil die in diesem Unterricht vermittelte religiöse Überzeugung nicht der ihren entsprach. Als Beispiel sei hier Herr J. J. Hofer ${ }^{63}$ erwähnt, der von der Gemeindeschulpflege Dorf vermutlich als Sektierer angeschaut worden wäre. Hofer stellte den Antrag, den Religionsunterricht entweder gänzlich wegzulassen oder einen Artikel ins Gesetz aufzunehmen, gemäss dem Eltern, «welche mit dem Religionsunterrichte, der in der Schule ertheilt wird, nicht übereinstimmen, nicht gehalten sind, ihre Kinder in diesen Unterricht zu schiken.» ${ }^{64}$ Hofer pochte auf das Recht der Eltern, ihre Kinder gemäss ihren eigenen religiösen Überzeugungen zu erziehen, «vorausgesetzt, dass diese Lehre nicht unsittlich oder staatsgefährlich sei, z. B. nicht mormonisch oder jesuitisch». ${ }^{65}$ Auch der Verein jüngerer Lehrer stellte den Antrag, den Religionsunterricht aus der Primarschule zu entfernen. Zum einen aus Rücksicht auf Artikel 63 der neuen Kantonsverfassung, da sie es als unmöglich erachteten, «von diesem Unterricht all das fern zu halten, was dogmatischen Charakter hat». Zum andern «im Interesse des Religionsunterrichtes überhaupt, der naturgemäss erst bei einer reiferen Altersstufe beginnen soll». ${ }^{66}$

Während es Hofer nicht primär um die Abschaffung des schulischen Religionsunterrichts ging, sondern vielmehr um elterliche Freiheitsrechte, das heisst um das Recht, die Kinder nach den eigenen religiösen Vorstellungen zu erziehen und somit das Recht, die eigenen Kinder dem schulischen Religionsunterricht zu entziehen (vgl. auch die Diskussion um das Obligatorium im Unterkapitel 6.4), befanden sich auf der anderen Seite des Meinungsspektrums diejenigen, die den Religionsunterricht in der bisherigen Form abschaffen wollten zu Gunsten eines «sittlichen Unterrichts». Die Schulpflege Grüningen erachtete beispielsweise

63 J. J. Hofer schreibt zu Beginn seines Antrags: «Wie Ihnen bereits bekannt ist, bin ich in religiöser Richtung von der Staatskirche getrennt und habe, von dem Rechte des Art. 63 der Verfassung Gebrauch machend, auch meine Kinder dem Religionsunterrichte der Schule entzogen, welches Recht mir aber von der Schulbehörde bestritten wurde, weshalb gegenwärtig ein Recurs bei dem hohen Erziehungsrathe anhängig ist.» (J. J. Hofer, Eingaben und Antworten von Privaten betreffend Religionsunterricht, StAZH, U 8.I.4).

64 Ebd.

65 Ebd.

66 Verein jüngerer Lehrer, Zürich, 8. Febr. 1870, Eingaben und Antworten von Vereinen, StAZH, U 8.I.3. 
«Bildung zu wahrer Sittlichkeit» ${ }^{67}$ als Ziel des Religionsunterrichts. Diese Forderung gründete auf der Annahme, dass sittliche Bildung vom Dogma unabhängig sei. Die Gemeindeschulpflege Wädenswil forderte, dass «der Religionsunterricht an geschichtlichen Stoff anschliessend die ethischen Grundwahrheiten enthalten [solle], wie sie namentlich in so reichem Masse und erhabener Weise von unserm göttlichen Meister uns überliefert worden sind». ${ }^{68}$

Nach Ansicht von Lehrer Rüegg war unter Religionsunterricht «heutzutage sittliche Anregung, Erziehung zum Schönen \& Guten zu verstehen». Die Lehre von Jesus als Gottessohn und die Geschichte seines Opfertodes bildeten seiner Meinung nach «eine Anschauung, die nicht mehr als allgemein gelten und kaum für das heranwachsende Geschlecht noch als passender Bildungsstoff gelten kann». Rüegg befasste sich auch mit der Frage, ob es dazu eines besonderen Unterrichtsfaches bedürfe und verneinte diese Frage: «Nein! Religion ist in Allem $\&$ soll in Allem sein. Religion waltet in der Schweizer-, wie in der allgemeinen Geschichte. Erzählen sie nicht Thaten des Edelmuthes, der kindlichen Liebe, der Überzeugungstreue, der Barmherzigkeit, der Aufopferung, des biedersten Bruderseins und ist der Geist, der in solchen Thatsachen sich ausspricht, nicht Religion? Läugnen lässt sich aber nicht, dass viele der wirksamsten Erzählungen doch in den Rahmen der eigentlichen Geschichte nicht aufgenommen werden können \& dass man sittlich bildende \& eigentlich geschichtliche Erzählungen nicht identifizieren kann. Ebenso wird eine Auswahl schöner Gedichte für sittliche Bildung von mächtigem Einflusse sein \& nach meiner Ansicht wärs somit eine Sammlung solcher Erzählungen \& Gedichte unter dem Titel Sittlicher Unterricht> an die Stelle des Religionsunterrichtes zu setzen.» ${ }^{69}$

Insofern Rüegg von «Sittlichkeit» als etwas allgemein Menschlichem ausging, klingt sein Plädoyer sehr ähnlich wie dasjenige von Ferdinand Buisson. Es muss hier jedoch offenbleiben, ob Rüegg von Buisson beeinflusst war, der in einem Vortrag forderte, die biblische Geschichte abzuschaffen und sie «durch die Geschichte der Menschheit ${ }^{70}$ zu ersetzen. Gegen einen Unterricht, in dem bloss moralische Geschichten behandelt würden, gab es freilich Gegenstimmen. Die Gemeinde- und Sekundarschulpflege Bauma inklusive sämtlicher Lehrer der Gemeinde äusserten ihre Überzeugung, dass das «rein Dogmatische» nicht in die Volksschule, «sondern auf eine höhere Stufe» gehöre. Dennoch seien «biblische

67 Gemeindeschulpflege Grüningen (Bezirk Hinwil), Eingaben und Antworten der Bezirksschulpflegen i 870 , StAZH, U 8.I.ra.

68 Gemeindeschulpflege Wädenswil (Bezirk Horgen), Eingaben und Antworten der Bezirksschulpflegen I 870, StAZH, U 8.r.ia.

69 Lehrer Rüegg, Enge, dat. I. Febr. I 870. Eingaben und Antworten von Privaten i 870, StAZH, U 8.I.4.

70 Buisson I869a, 86. In Unterkapitel 6.6.2 wird die diesbezügliche Position Buissons noch genauer erläutert. 
Geschichten, pädagogisch bearbeitet \& zweckmässig ausgewählt[,] bloss moralischen Erzählungen vorzuziehen». ${ }^{71}$

Ähnlich facettenreich verlief fast zwei Jahre nach der sieberschen Umfrage die Diskussion über den sieberschen Unterrichtsgesetzentwurf. Die zürcherische Geistlichkeit sprach sich in ihrer Synode trotz ihrer heterogenen Zusammensetzung einmütig gegen «die Beseitigung des Religions-Unterrichtes» ${ }^{22}$ aus und beschloss eine Eingabe an den Kantonsrat. Gründe für die Beseitigung des Religionsunterrichts seien von den Behörden nicht genannt worden, sie seien aber unschwer zu erkennen, heisst es in der Eingabe der Kirchensynode. Zum einen liege es «in dem Bestreben der Neuzeit, den Staat mit der Schule von der Kirche zu trennen», zum andern «an dem allgemein anerkannten Prinzip der Glaubensfreiheit, wonach zum Besuche des Religionsunterrichtes kein Kind gesetzlich verpflichtet werden» ${ }^{73}$ könne. Doch keiner dieser Gründe nötigte aus Sicht der Kirchensynode zu den Konsequenzen, die im Entwurf für das Unterrichtsgesetz gezogen worden waren. Die «religiöse Anlage» sei «eine allgemein menschliche und soll wie alle übrigen edeln Anlagen der Kindesnatur von der Schule angefasst und entwickelt werden. Der Unterricht, der dieser Anlage entspricht, arbeitet daher nicht etwa bloss der Kirche vor, sondern bildet einen wesentlichen Faktor des Volksschulunterrichtes überhaupt und ist sowohl die innerste Vertiefung als die schönste Weihe desselben. Auch das bürgerliche und humane Interesse fordern ihn».74

Als Gewährsleute für diese These werden Pestalozzi und Scherr angeführt, die den «Religionsunterricht als die Krone alles Volksschulunterrichtes» 75 bezeichnet hätten, obwohl beide nicht im Sinne gehabt hätten, für die Kirche zu arbeiten. Des Weiteren wird auf den Kanton Aargau verwiesen, in dem «die Trennung von Schule und Kirche aufs Gründlichste durchgeführt worden» sei und der «dennoch die Einführung eines für die gesammte Jugend ohne Rücksicht auf die Konfession geeigneten Religionsunterrichtes in sämmtlichen Schulen statuirt» ${ }^{6}$ habe. Es sei vorauszusehen, dass auch der geplante Sittlichkeitsunterricht nicht ohne religiöse Elemente auskommen könne und dass in die Lehrmittel für diesen Unterricht auch biblische Stoffe aufgenommen würden. Deshalb gebühre «es

7I Gemeinde- und Sekundarschulpflege Bauma (Bezirk Pfäffikon), Eingaben und Antworten der Bezirksschulpflegen i 870, StAZH, U 8.r.ı.

72 Eingabe der Kirchensynode zu dem Gesetzesentwurf betreffend das Unterrichtswesen, I I. Dezember I87I, I.

73 Ebd.

74 Ebd., 2.

75 Ebd.

76 Ebd. 
sich, der Sache den richtigen Namen zu geben und grundsätzlich den Religionsunterricht als Lehrfach anzuerkennen».77

Die Kirchensynode erwähnte in ihrer Eingabe auch das Recht der Glaubensfreiheit, das als Argument gegen den Religionsunterricht angeführt werde. Von den Verfassern des Unterrichtsgesetzentwurfes werde offenbar befürchtet, dass es zu «einer verderblichen Scheidung unter den Kindern und einer nicht zu duldenden ungleichen Stellung derselben zur Schule» komme, weil auf Grund dieses Rechts niemand zum Religionsunterricht gezwungen werden könne. Man glaube nun, diesen befürchteten Missstand dadurch beseitigen zu können, dass das religiöse Element im Unterricht zu Gunsten des sittlichen beseitigt werde, und somit «alle Kinder zur Annahme dieses veränderten Unterrichtes verpflichten» zu können. Dagegen wandte die Kirchensynode ein, dass im Kanton bisher nur wenige Kinder dem Religionsunterricht ferngeblieben seien und «die Einführung einer blossen Sittenlehre» diesen Umstand eher noch verstärken als vermindern würde. Abgesehen davon sei in der Verfassung «neben der Glaubens- auch die Gewissensfreiheit» festgeschrieben «und da der Inhalt der Sittenlehre ebenso sehr das Gewissen in Anspruch nimmt, wie der Inhalt der Religionslehre den Glauben, so ist von nun an weder in der einen noch in der andern Richtung ein staatlicher Zwang ausführbar»..$^{8}$

Die Kirchensynode schien in ihrer Eingabe keineswegs zu negieren, dass der schulische Religionsunterricht mit der Glaubensfreiheit konfligieren könne. Aber ebensowenig schien sie davon auszugehen, dass ein sogenannt reiner Sittenunterricht das Gewissen nicht tangiere. Somit - so die Argumentation der Kirchensynode - müsste mit Berufung auf das Recht auf Gewissensfreiheit auch eine Dispens von der Sittenlehre verlangt werden können.

Die Kirchensynode unterbreitete dem Kantonsrat in ihrer Eingabe drei Vorschläge: I) Für die Primarschüler vom I.-6. Schuljahr sollte es in Paragraph I4 nicht «Anregungen und Belehrungen aus dem sittlichen und geistigen Lebens» heissen, sondern "Anregungen und Belehrungen aus dem sittlich-religiösen Gebiete», wobei explizit noch angefügt wurde: «immerhin mit Vorbehalt des Art. 63 der Staatsverfassung». ${ }^{9}$ 2) In den 7.-9. Klassen (Primarschule, Sekundarschule und Gymnasium) sollte die «Ertheilung des Religionsunterrichtes durch die Kirche im Anschlusse an den Schulorganismus vom Unterrichtsgesetze ausdrücklich ermöglicht» ${ }^{8 \circ}$ werden. Dies anstelle der im Entwurf geforderten

77 Ebd.

78 Ebd., $2 \mathrm{f}$.

79 Ebd., 5; vgl. Amtlicher Auszug aus Protokollen der Synode der Zürcherischen Geistlichkeit, I 5. II. I871, 36 .

80 Eingabe der Kirchensynode zu dem Gesetzesentwurf betreffend das Unterrichtswesen, I I. Dezember i 87i, 5 . 
Sittenlehre in der Primar- und Sekundarschule (vgl. Paragraphen I 4, I und 25,I) und der Ethik im Gymnasium (vgl. Paragraphen 7I und 76 $6^{81}$ ). 3) In Paragraph 2 sollten die Worte «sittlich guten Menschen» durch «sittlich religiösen Menschen ${ }^{82}$ ersetzt werden.

In der Kantonsratsdebatte über den Entwurf des Unterrichtsgesetzes Anfang Januar I 872 begründete Regierungsrat Sieber die Rede von «sittlich gut» anstatt «sittlich religiös» damit, dass man «jeden Anstoss bei anders Gläubigen vermeiden und dadurch der Verfassung gerecht werden ${ }^{8_{3}}$ wolle. Folgt man der Berichterstattung in der NZZ und dem Landboten, nahm Sieber jedoch nicht Bezug auf das von der Kirchensynode vorgebrachte Argument, dass auch ein 〈reiner〉 Sittenunterricht die Gewissensfreiheit tangieren könne.

Zur Verteidigung des Vorschlags der Kirchensynode hinsichtlich der Formulierung von Lemma I des Paragraphen I4 (Anregungen und Belehrungen aus dem Gebiete des geistigen und sittlichen Lebens) stellte Pfarrer Scheller tags darauf in der Kantonsratsdebatte vom I0. Januar I 872 die Unabhängigkeit von Sittlichkeit und Religion als fraglich hin. Zum einen monierte er, dass «Belehrungen aus dem Gebiete des geistigen Lebens» zu geben, Aufgabe jedes Unterrichtsfaches sei und insbesondere des Faches Geschichte. Zum andern liege das Hauptgewicht auf dem Ausdruck «sittlich», was zeige, dass man «eine rein abstrakte Sittenlehre voraus[setze]». Eine solche sei aber «in solcher Form ein Unding». Gemäss Scheller gibt es «keine von allem Religiösen losgelöste Sittenlehre, sie wurzelt nun einmal überall in einer bestimmten religiösen Form. Man entgegnet vielleicht, es gebe doch sittlich gute Menschen, ohne bestimmte religiöse Anschauung zu haben; das Faktum ist richtig, nicht aber der Schluss. Dass es solche Menschen gibt, beweist noch keineswegs, dass Sittlichkeit der religiösen Grundlage entbehren könne. Auf die Art jedes Menschen wirken Tausende von Faktoren ein, die nicht von seinem Willen abhängig sind, und so haben auch jene, wenn schon selbst zu keiner bestimmten Religion oder Konfession zählend, sich doch zahlreichen religiösen Einwirkungen nicht entziehen können.» ${ }^{8_{4}}$

Scheller stellte als Fazit den Antrag, entweder die Religionslehre anstatt der Sittenlehre zu belassen oder dann diese Passage, das heisst Lemma I von Paragraph I4, ganz aus dem Entwurf zu streichen. Trotz seiner Kritik vertrat Scheller

8 I In der Eingabe der Kirchensynode wird bezüglich des Ethikunterrichtes explizit auf den $\$ 76$ verwiesen, der die Lehrgegenstände des Realgymnasiums aufzählt. Gemäss des im Landboten vom I9. I0. I 87 I veröffentlichten Entwurfs, steht in $\$ 76$ nichts von Ethik. Das Fach Ethik wird nur in $\ 7 \mathrm{I}$, der sich auf das Literargymnasium bezieht, erwähnt.

82 Eingabe der Kirchensynode zu dem Gesetzesentwurf betreffend das Unterrichtswesen, I I. Dezember I 871,5 .

83 NZZ, 9. I. I 872 ; vgl. auch Der Landbote, Iо. I. I 872.

84 NZZ, I I. I. I 872 . 
die Meinung, dass die Organisation des Religionsunterrichts Sache der Schule und nicht der Kirche sei.

Diakon Spyri verteidigte in seiner Schrift Der Religionsunterricht und der Entwurf des neuen Schulgesetzes des Kantons Zürich. Ein Wort zur Verständigung ebenfalls den Änderungsvorschlag der Kirchensynode, die folgende Passage forderte: "Anregungen und Belehrungen aus dem Gebiete des religiösen und sittlichen Lebens».85 Zwar könne er auf dem Hintergrund der in Paragraph 63 der Kantonsverfassung verankerten Glaubens- und Gewissensfreiheit die Motivation der Verfasser des Unterrichtsgesetzentwurfs verstehen, den Religionsunterricht in der Schule mit Sittenlehre zu ersetzen, «die losgelöst von aller Religion, dasjenige enthalten sollte, was allen Religionen gemeinsam als gute, edle Sitte sich ergebe, was daher Niemanden in seiner religiösen besonderen Auffassung störe, und das daher auch als Gemeingut für alle Religionen obligatorisch erklärt werde könne». ${ }^{86}$ Gegen eine solche Argumentation wandte Spyri nun allerdings ein, dass es nicht bloss auf sittlichem Gebiet, «sondern auch auf dem Glaubensgebiete Berührungen» gebe und dass ein guter Religionslehrer auf den höhern Stufen sowohl auf diesbezügliche Gemeinsamkeiten als auch auf Unterschiede aufmerksam machen müsse. Während in der Eingabe der Kirchensynode die Verschiedenheit menschlicher Auffassungen sowohl in religiöser wie auch in sittlicher Hinsicht betont wurde, legte Spyri in seinem Traktat den Fokus auf religiöse wie auch sittliche Gemeinsamkeiten. Wie Pfarrer Scheller war auch Spyri der Überzeugung, dass sich Religion und Sittenlehre nicht voneinander trennen lassen: «Die letztere kann nur aus der Religion aufgebaut werden. Die Religion bildet den Grund und innersten Kern aller Sitte. So ist denn auch die Sittenlehre, die im Entwurf vorgeschlagen wird, nichts Anderes als Religionsunterricht». ${ }^{87}$

Den blossen Sittlichkeitsunterricht kritisierte er noch auf eine andere Weise. Er erachtete die Idee, «durch eine Sammlung von Lebensbildern von Erfindern den nöthigen Stoff» für den Sittenunterricht zu liefern, als problematisch, da dieser «für 9 Jahre nicht nur zu beschränkt ist, sondern seinen Zweck ganz verfehlt; denn eine Geschichte der Erfindungen ist für diese Altersstufen viel zu hoch und das Sittliche, auf das es für die Jugend ankommt, ist in allen diesen Lebensbildern dasselbe, so dass, wer ein paar gelesen hat, nach der sittlichen Seite hin alle kennt.» ${ }^{88}$

Ein Einsender, der Diakon Spyris Traktat in der NZZ besprach, vertrat die Ansicht, dass angesichts der Tatsache, dass die Mehrheit der Einwohner des

85 Spyri i 872, 5, Hervorhebung R. K.

86 Ebd.

87 Ebd.

88 Ebd. 
Kantons Protestanten seien - gemäss Verfasser waren von 285876 Einwohnern 263785 protestantischer Konfession -, «eine vollständige Scheidung von Kirche und Schule nicht indizirt, zudem fast unmöglich [sei], da der weitaus grösste Theil der Lehrer ja zu jenen Protestanten gehört». ${ }^{89}$ Der Einsender pflichtete Spyri bei, dass der Gesetzesentwurf auf eine «neutrale Sittenlehre» abziele. Dagegen wandte der Einsender ein, dass auch wenn das entsprechende Lehrmittel für diesen Zweck verfasst werde, «bei seiner Anwendung, wenn der Lehrer überhaupt religiös ist, daraus ein Religionsunterricht von selbst werden» $9^{\circ}$ würde. Seiner Ansicht nach «stehen auch die Lehrer soweit sie religiöse Interessen haben, nicht ausserhalb der Strömungen der Zeit, und werden ihre Ansichten der Lehrmeinungen sich unwillkürlich geltend machen». Aus diesem Grund könne man anders gesinnte Eltern nicht zwingen, ihre Kinder in diesen Unterricht zu schicken, ebenso wenig «als wenn derselbe von Geistlichen ertheilt würde».9 ${ }^{91}$ Dieser Einsender ging also davon aus, dass wenn der Sittenunterricht von einem religiösen Lehrer erteilt wird, dieser notwendigerweise $\mathrm{zu}$ einem Religionsunterricht mutiere. Es scheint, als ob der Einsender nicht an die Möglichkeit eines konfessionslosen Religionsunterrichts glaubt, wenn er schreibt, dass die "Ansichten der Lehrmeinungen sich unwillkürlich geltend machen».92 Widersprüchlich erscheint demgegenüber allerdings die Aussage, dass er mit Spyri die Auffassung teile, dass alles dogmatisch Konfessionelle vom Unterricht auszuschliessen sei.

Etwas anders argumentierte in der NZZ vom 25. November i871 ein anderer Einsender gegen einen blossen Sittenunterricht. Er unterscheidet (in schleiermacherschem Geiste93) zwischen Religion und konfessioneller Kirchenlehre und folgert aus dieser Unterscheidung, dass die Rede von Anregungen und Belehrungen aus dem Gebiete des sittlich-religiösen Lebens keineswegs einen konfessionellen Religionsunterricht zu bedeuten habe. Die Eliminierung des Ausdrucks «religiös» erwecke den Anschein, «als wollten sie die Religion überhaupt aus dem Jugendunterricht verbannen, und als gehörte Irreligiosität nothwendig zum fortgeschrittenen demokratischen Standpunkt». Sollte in der Schule kein Religionsunterricht mehr angeboten werden, dann müsse seiner Ansicht nach die Kirche in die Bresche springen. Der Einsender befürchtete jedoch, dass dann der kirchliche, fakultative Religionsunterricht verkümmern könnte, da fraglich sei, ob die Kirche weiterhin Schullokale benützen dürfe.

89 NZZ, 9. I2. I87I.

90 Ebd.

9I Ebd.

92 Ebd.

$93 \mathrm{Vgl}$. Schleiermacher 20I 2, $20 \mathrm{ff}$. 
Einer der Exponenten der theologisch Liberalen, Pfarrer Heinrich Lang, befasste sich in der von ihm herausgegebenen Zeitschrift Zeitstimmen aus der reformirten Kirche der Schweiz mit dem Religionsunterricht in der Volksschule. Rhetorisch geschickt beginnt er damit, dass er auf dem Hintergrund der Religionsfreiheit das Motiv der Verfasser des Schulgesetzesentwurfs für «die Entfernung des Religionsunterrichtes aus der Staatsschule», ${ }^{94}$ nicht nur nachvollziehen, sondern auch billigen könne. Insofern gemäss Verfassung alles Bürgerliche «vom Religiösen und Kirchlichen» unabhängig zu sein habe und die Schule «ein bürgerliches Institut» sei, müsse sie demnach "unabhängig sein von jeder Religionslehre».95 Glaubens- und Gewissensfreiheit bedeutete für Lang «Trennung des Staates und mit ihm der Staatsschule von der Kirche». ${ }^{96}$ Langs Ausführungen machen deutlich, dass er die Schule mit einer staatlichen Institution identifizierte. Wie das Beispiel der Niederlande zeigt, ${ }^{97}$ führt die Trennung von Kirche und Schule jedoch nicht logisch zwingend zur Identifikation von Staat und Schule. Davon wird weiter unten in Unterkapitel Io.I (S. 262) noch die Rede sein.

Obwohl Lang die Trennung der Schule von der Kirche keineswegs in Frage stellte, kämpfte er dezidiert dagegen, «dass die Schule das Religiöse überhaupt ausschliesse und nur das Sittliche pflege»..$^{8}$ Dies hielt er weder für natürlich noch für möglich. Denn «das Sittliche ist nicht bloss in der bisherigen menschheitlichen Entwicklung überall mit dem Religiösen unabtrennbar verbunden gewesen, sondern es ruht auch immer auf religiösen Wurzeln und mündet auch überall in's Religiöse ein».99

Entfernte man alles Religiöse - Lang nennt als Beispiele das Gefühl der Andacht, ein tief empfundenes Morgenlied, Erzählungen, in welchen Macht und Segen des Gottvertrauens dargestellt werden, oder Musterstücke der Literatur, in denen religiöse Vorstellungen, die Worte Gott oder Vorsehung vorkommen - gänzlich aus dem Unterricht, würde dieser völlig kahl. Der «Religionsunterricht als ein besonderes Fach» sollte von der Schule ausgeschlossen werden, «aber das Religiöse selbst, soweit es das Gefühl anregt, das Gewissen weckt, den Charakter

94 Lang I87I, 4I9.

95 Ebd. Zum Thema Glaubensfreiheit und Unterrichtszwang schreibt Lang auf derselben Seite: «Der Staat nimmt auf und zwingt in seine Schule die Kinder aller Konfessionen und Glaubensrichtungen, das Kind des Christen neben dem Judenkinde, des Katholiken neben dem Kinde des Reformirten, des Methodisten neben dem Kind der Landeskirche, des Freidenkers neben dem Kind des Pietisten - welche Religionslehre soll er entwerfen, die allen diesen Glaubensüberzeugungen gerecht wird? Und doch ist er von dem Augenblick an, da er die Glaubensfreiheit unter seine Grundbestimmungen aufgenommen hat, allen die gleiche Rücksicht schuldig» (Lang I87I, 4I9).

96 Ebd.

97 Zum Schulstreit in den Niederlanden vgl. Unterkapitel I.I, S. I 5.

98 Lang I871, 420.

99 Ebd. 
bildet, kann sie nicht entbehren». ${ }^{100}$ Gemäss Lang sollte es möglich sein, in der Volksschule zwischen Theologie und Religion zu unterscheiden. Aus diesem Grund plädierte er auch dafür, dass es im Unterrichtsgesetz heissen soll «Anregungen aus dem Gebiete des sittlich-religiösen Lebens», ohne dass er deswegen die Glaubensfreiheit in Frage gestellt sah. ${ }^{101}$

\subsubsection{Konfessionell-dogmatischer versus konfessionsloser Religionsunterricht}

Das sogenannte «dogmatische Element» war ein zentrales und umstrittenes Thema in der Diskussion um den schulischen Religionsunterricht. Entweder war man dafür oder dagegen. Selten aber wurde expliziert, was eigentlich unter dem «dogmatischen Element» verstanden wurde. Die Bedeutung schien selbstverständlich zu sein. So wurde auch die diesbezügliche Frage im sieberschen Fragebogen nicht erläutert: «Darf er [der Religionsunterricht] das dogmatische Element und bis zu welchen Grenzen in sich aufnehmen?» ${ }^{102}$ Einige Antworten fielen entsprechend oberflächlich aus. Die Gemeindeschulpflege Wald schrieb beispielsweise: «Im Unterrichte selbst soll das historische Element vorwalten, das dogmatische in den Hintergrund treten, wenn nicht ganz wegfallen.» ${ }^{103}$ Die Antwort der Gemeindeschulpflege und der Lehrerschaft von Unterstrass war noch kürzer: «Der dogmatische Religionsunterricht ist aus der Schule zu entfernen.» ${ }^{104}$ Die Gemeindeschulpflege Turbenthal und die Sekundarschulpflege des

I00 Ebd.

IOI Eineinhalb Jahre zuvor vertrat Lang in den Zeitstimmen in einem Artikel mit dem Titel Die religionslose Schule die Ansicht, dass es in der Volksschule nicht bloss kein gesondertes Fach für Religion mehr geben, sondern generell der Wissensstoff nicht in gesonderten Fächern gelehrt werden solle. Denn dies sei nicht produktiv: «Die Volksschule verzichte auf ihr gelehrtes Fächerwerk, mit welchem sie den jungen Geist mehr erdrückt, als entbindet; sie verfolge ausschliesslich den Zweck, den sie allein genügend erreichen kann; die formale Bildung der Geistesthätigkeiten»(Lang ı870, 86). Natürlich müsse «die formale Bildung der Geistesthätigkeiten» immer an einem bestimmten Stoff geübt werden, da sich der Geist nur an der Welt bilde. Doch der Stoff und dessen Aneignung sei jeweils nie Zweck, sondern immer bloss Mittel: «Das Lesebuch enthalte nicht diese von Pädagogen am Schreibtisch nach moralischen Schablonen fabrizirten Geschichten, nicht Auszüge aus den verschiedenen Gebieten des Wissens, sondern klassische Stücke unserer besten deutschen Schriftsteller, welche nach Form und Inhalt geeignet sind, die Intelligenz zu wecken, den Gesichtskreis zu erweitern, das Gefühl zu beleben und zu veredeln, den Willen zu begeistern und zu stärken, welche eben nach diesen Gesichtspunkten sowohl auszuwählen, als zu behandeln wären. Werden sich in einer solchen Sammlung Stücke religiösen Inhalts nicht von selber einfinden? Religiöse Lieder, an denen die neuere Literatur viel reicher ist, als man gewöhnlich meint? Lebensbilder religiöser Charaktere, eines Spener, Franklin, Pestalozzi u. a.? Wer wollte an solchen religiösen Stoffen sich stossen, welcher Kirche und welcher theologischen Richtung er angehöre? Wer möchte hier sich über Glaubenszwang beklagen?» (Lang I 870, 86 f.).

I02 Bekanntmachung der Erziehungsdirektion (42 Fragen) I 869, Frage 4 Teil 2.

I03 Gemeindeschulpflege Wald (Bezirk Hinwil), Eingaben und Antworten der Bezirksschulpflegen i 870, StAZH, U 8.I.ra.

I०4 Gemeindeschulpflege und Lehrerschaft von Unterstrass (Bezirk Zürich), ebd. 
36. Kreises hatten die sieberschen Fragen gemeinsam beraten. Sie kamen zum Schluss, dass der schulische Religionsunterricht weiterhin obligatorisch sein sollte, dass aber angesichts von Paragraph 63 der Kantonsverfassung «auf den Stufen der Alltags- \& Ergänzungsschule wo möglich das dogmatische Element ausgeschlossen bleibe». ${ }^{\text {Ios }}$ Die Gemeindeschulpflege Weiningen und die Mittwochsgesellschaft forderten: «Das dogmatische Element soll möglichst in den Hintergrund treten, dagegen Sittenlehre und allgemein religiöse Unterhaltung vorherrschen.» ${ }^{106}$ Es gab aber auch dem «dogmatischen Element» gegenüber positiv eingestellte Stimmen. Die Gemeinde- und Sekundarschulpflege Ossingen meinte, «dass bei einem lebendigen, gemütsbildenden Religionsunterricht das dogmatische Element nicht gänzlich umgangen werden» könne. Sie betonten jedoch, dass «die Art und Weise, in welcher dasselbe auftritt, wesentlich von der Person des Lehrers abhängt, und der Gesetzgeber dasselbe deshalb unmöglich genau vorschreiben ${ }^{107}$ könne. Sie waren deshalb der Ansicht, dass keine neue Bestimmung zu treffen sei.

Neben eher undifferenzierten Antworten hinsichtlich des dogmatischen Elements sind auch Antworten zu finden, in denen zumindest der Versuch unternommen wurde, das eigene Verständnis des Ausdrucks dogmatisches Element zu spezifizieren. Die Gemeindeschulpflege Feuerthalen betonte, dass die Schule «den religiösen Ansichten u. Überzeugungen d. Eltern» Rechnung zu tragen bzw. diese zu schonen habe. Der Religionsunterricht könne ihrer Ansicht nach «das dogmatische Element beibehalten bis zu der Grenze, wo protestantische u./ katholische Lehre auseinandergehen». Es war dieser Schulpflege jedoch ein Anliegen, dass «die Lehrer ihre Subjektivität, ihre spezifischen Ansichten beim Religionsunterricht nicht geltend machen». Sei dies gewährleistet, gebe es keinen Grund am bisherigen Religionsunterricht etwas zu ändern. Andernfalls hätten sie sich «eher religionslose Schulen, d. h. Schulen ohne Religionsunterricht» ${ }^{108}$ gewünscht. Die Bezirksschulpflege Winterthur schrieb: «Sofern man unter dem dogmatischen Element die Lehre von den religiösen Wahrheiten überhaupt versteht, ist derselbe im Unterricht der Primarschule nicht zu vermeiden; dagegen soll das konfessionelle Element im weitesten Sinn des Wortes vom Unterricht der Primarschule ausgeschlossen werden.» ${ }^{109}$ Aus diesen Antworten schliesse ich, dass nicht die Vermittlung religiöser Dogmen per se als problematisch erachtet worden war, sondern bloss die Vermittlung derjenigen Dogmen, mit denen konfessionelle Unterschiede manifest gemacht wurden. Ähnliche Töne kamen auch

Ios Gemeinde- und Sekundarschulpflege Turbenthal (Bezirk Winterthur), ebd.

Io6 Gemeindeschulpflege Weiningen und Mittwochsgesellschaft (Bezirk Zürich), ebd.

I07 Gemeinde- und Sekundarschulpflege Ossingen (Bezirk Andelfingen), ebd.

I08 Gemeindeschulpflege Feuerthalen (Bezirk Andelfingen), ebd.

ı०9 Bezirksschulpflege Winterthur (Bezirk Winterthur), ebd. 
von der Schulpflege Oberwinterthur: «Der Religions-Unterricht der Schule ist nicht zu ändern. Sofern unter «dogmatisches Element〉 der Inhalt allgemein religiöser Wahrheiten zu verstehen ist, kann dieser nicht fehlen; dagegen ist aller Dogmatismus, alles Confessionelle zu vermeiden $u$. dem kirchlichen Unterricht zuzuweisen.» ${ }^{10}$

Die Bezirksschulpflege Andelfingen setzte «Dogmatik> in einen engen Zusammenhang mit der (akademischen) Theologie und kam zum folgendem Schluss: «Dogmatisches in dem Sinne, wie dieser Ausdruck von der Theologie verstanden wird, ist schon aus pädagogischen Gründen von der Schule ferne zu halten. Der Religionsunterricht soll auf den Stufen der Primarschule keinen kirchlich konfessionellen Charakter haben, sondern er soll, wie bis anhin sittlich religiöse Gefühle wecken u. zu bestimmten religiösen Begriffen ausbilden.» ${ }^{111}$

Was diese Bezirksschulpflege jedoch genau mit «Dogmatik〉 assoziierte, lässt sich nur vermuten. Es sind wohl theologische Lehrmeinungen gemeint, in denen sich die reformierten und katholischen Theologen nicht einig waren, zum Beispiel hinsichtlich der Ekklesiologie oder der Sakramentenlehre. Doch schien es der Andelfinger Bezirksschulpflege nicht bloss um die Vermeidung konfessioneller Differenzen gegangen zu sein, sondern auch um den Unterschied zwischen Kognition und Emotion. Pädagogische Gründe wurden gegen ein einseitig kognitivistisches Religionsverständnis ins Felde geführt und ein liberales von Schleiermacher geprägtes Religionsverständnis wurde sichtbar: Religion bezieht sich auf das Gemüt. Die Gemeindeschulpflege und der Gemeindsverein Mönchaltorf waren in ihrer Antwort konkreter, insofern sie Ausdrücke wie Gott, Sünde oder Erlösung als dogmatische Begriffe bezeichneten. Die Verwendung dieser Ausdrücke sahen sie in einem Religionsunterricht als unvermeidlich an. Sie unterschieden jedoch eine alltägliche Verwendung dieser Ausdrücke von einer systematischen Verwendung (vermutlich meinte die oben erwähnte Bezirksschulpflege Andelfingen dies, wenn sie von Dogmatik im Sinne der Theologie sprach): «Ein Religionsunterricht ohne alle \& jede Dogmen ist unmöglich; der Religionslehrer kann es nicht ausweichen, von Gott, von Seelen \& Unsterblichkeit, von zeitlicher \& ewiger Bestimmung, von Tugend, Sünde \& Vergeltung, von Erlösung etc. zu reden, \& das alles sind dogmatische Begriffe. Wir verstehen daher diese Frage in dem Sinn: ob das spezifisch- $\&$ systematische dogmatische, oder wie man es auch nennt, das dogmatisirende Element aufzunehmen sei? - \& $\mathrm{da}$ antworten wir mit einem entschiedenen Nein.» ${ }^{\mathrm{I}{ }^{2}}$

Es gab auch einige Antworten, die explizit den Umstand problematisierten, dass unklar sei, was unter dem dogmatischen Element zu verstehen sei. Die

I Io Schulpflege Oberwinterthur (Bezirk Winterthur), ebd.

I I I Bezirksschulpflege Andelfingen (Bezirk Andelfingen), ebd.

I 2 Gemeindeschulpflege und Gemeindsverein Mönchaltorf (Bezirk Uster), ebd. 
Gemeinde- und Sekundarschulpflege Niederhasli schrieb als Antwort: «Der Begriff 〈Dogma ist ein sehr wager, man kann daher nicht genau bestimmen, bis zu welchen Grenzen der Religionsunterricht das dogmatische Element aufnehmen dürfe. Man will in dieser Beziehung keinen Druck, keine Bestimmung, welche dem Inhalt des $\ 63$ der Verfassung zuwieder wäre.» ${ }^{113}$

Eine Person, die die Fragen sehr ausführlich beantwortete, meinte, man müsse, um die Frage nach dem dogmatischen Element im Unterricht beantworten zu können, sich eigentlich zuerst darüber verständigen, «was unter dem dogmatischen Element zu verstehen sei; gibt es doch Dogmen nicht bloss in der Religion, sondern auch auf dem philosophischen Gebiete und im gemeinen Leben. Nach unserer Ansicht von Dogma und Religion gibt es gar keinen Religionsunterricht ohne dogmatische Elemente. Will man mit den Kindern von Gott, von Jesus reden, will man mit ihnen eine Geschichte des alten oder neuen Testaments lesen, so wird das selten, ja nie möglich sein ohne Anwendung und Aufstellung dogmatischer Glaubenssätze. Sogar alle Moral, in die man gegenwärtig wenigstens theilweise den Religionsunterricht will übergehen lassen, hat ihre wahre, tiefe Begründung nur in dogmatischen Sätzen. Unsere Antwort lautet deshalb: das dogmatische Element kann im Religionsunterricht nicht wegfallen. Es kann sich nur fragen: wie weit und auf welche Weise darf es vorkommen?» ${ }^{14}$ Nach Ansicht dieser Person sollten in der Volksschule «nur die einfachsten, verständlichsten, einleuchtendsten Begriffe christlichen Glaubens» gelehrt werden. Diese sollten auch nicht explizit als Dogmen, sondern eingekleidet in biblische Geschichten vermittelt werden. Insbesondere sollten «die lehrreichen, tröstlichen, verstandes- und gemüthsbildenden Geschichten alt- und besonders neutestamentlicher Offenbarung und christlichen Lebens» thematisiert werden. Diese Person warnt zum einen davor, den Religionsunterricht «in blosse Moral» zu verflüchtigen, und zum andern davor, ihn «künstlich aller religiösen Bestimmtheit und Konkretheit» zu entkleiden, «um ihn desto eher für alle obligatorisch erklären zu dürfen». ${ }^{\text {115 }}$

Aus den eingegangenen Antworten auf die siebersche Umfrage lässt sich zur Frage des dogmatischen Elements zusammenfassend Folgendes festhalten: Auf der einen Seite wurde die (Entdogmatisierung) des schulischen Religionsunterrichts erörtert und die Frage gestellt, wie ein Religionsunterricht ohne inhaltliche Bestimmtheit möglich sein sollte. Ein von allen Dogmen entkleideter Religionsunterricht wurde aus dieser Perspektive als zumindest fragwürdig erachtet. Demgegenüber standen die Stimmen, die sittliche Bildung als von

I 3 Gemeinde- und Sekundarschulpflege Niederhasli (Bezirk Regensberg), ebd.

I 4 Privatperson (29 Seiten ohne Namen), Eingaben und Antworten von Privaten, StAZH, U 8.I.2.

IIs Ebd. 
religiösen Dogmen unabhängig erachteten und insofern gar keinen eigentlichen Religionsunterricht mehr wünschten. ${ }^{116}$ Auf der anderen Seite wurde das dogmatische Element problematisiert. Dies primär aus zwei Gründen: Zum einen wurden Dogmen als potentiell konfliktträchtig erachtet, weil sich an ihnen die konfessionellen Unterschiede zeigen. Zum andern wurde mit der Betonung religiöser Gefühle, die der schulische Religionsunterricht zu wecken habe, meist implizite Kritik an auswendig zu lernenden abstrakten Lehrsätzen deutlich, die das religiöse Gefühl und das Gemüt nicht ansprächen.

Interessanterweise muss anhand gewisser Antworten geschlossen werden, dass die bisherige Praxis des schulischen Religionsunterrichts hinsichtlich der Frage nach dem dogmatischen Element von vielen gar nicht als problematisch erachtet worden war. Auch bisher habe der Schwerpunkt auf den biblischen Geschichten gelegen und seien nicht die konfessionellen Lehrmeinungen betont worden. Die Gemeindeschulpflege Gossau kam zum Schluss, dass das dogmatische Element «bisher so schwachbetont worden [sei], dass wir auch in diesem Punkte keine Änderung wünschen». ${ }^{17}$ Auch die Gemeindeschulpflege Männedorf meinte: «Der Religionsunterricht sollte wie bis jetzt ertheilt, das geschichtliche Element die Hauptsache und das dogmatische auf das absolut Nothwendigste beschränkt werden». ${ }^{18}$ Das Geistlichkeitskapitel des Bezirks Regensberg problematisierte in seiner Eingabe ebenfalls den Begriff der Dogmatik und meinte: «Bei diesem Punkte wird es darauf ankommen, was man eigentlich unter Dogmatik verstehe. ¿Dogmatisch〉 im engern Sinn war auch bis anhin der Religionsunterricht in der Schule nicht, auch nicht in der Ergänzungsschule, weil überall geschichtlicher Stoff behandelt werden musste. Bliebe es so, so dürfte auch für die Zukunft die Befürchtung eines 〈dogmatischen> Unterrichtes hinwegfallen.» ${ }^{119}$

Die Schulpflege Glattfelden schrieb gar, dass auch der Inhalt des Unterrichts der sechsten Klasse - «Einführung in den Lehrgehalt des Evangeliums durch ausführliche Betrachtung und sorgfältige Erklärung von Gleichnissen und Aussprüchen Jesu» - «allgemein ohne dogmatische Färbung gegeben worden [sei], so dass wenigstens in hier dieser Unterricht unbedenklich nicht nur von Kindern von sektirerischen Eltern sondern selbst von Katholiken und Israeliten besucht worden ist». ${ }^{\text {I20 }}$

I 6 Vgl. Schulpflege Grüningen (Bezirk Hinwil), Eingaben und Antworten der Bezirksschulpflegen I870, StAZH, U 8.r. Ia.

I 7 Gemeindeschulpflege Gossau (Bezirk Hinwil), ebd.

I 8 Gemeindeschulpflege Männedorf (Bezirk Meilen), ebd.

I 9 Geistl. Capitel des Bezirkes Regensberg, Dielsdorf, den 5. Jan. I 870, Eingaben und Antworten von Vereinen I 870, StAZH, U 8.r.3.

I 20 Schulpflege Glattfelden (Bezirk Bülach), Eingaben und Antworten der Bezirksschulpflegen i 870, StAZH, U 8.r.ra. 
Gleichwohl wurden in einigen Antworten die religiösen Lehrmittel erwähnt, die umzuarbeiten seien, damit «mehr auf Bildung des Herzens \& Gemüthes hingewirkt werden» könne. Die Bezirksschulpflege Pfäffikon hielt die «bisherigen relig. Lehrmittel [...] in dieser Richtung für verfehlt \& daher untauglich» und forderte, dass «in dieser Richtung besseres geschaffen ${ }^{121}$ werde. Nichtsdestoweniger ist zu fragen, ob Sieber mit seinen Suggestivfragen mögliche oder bloss vermeintliche Probleme eines konfessionell-dogmatischen Religionsunterrichts nicht teilweise selbst heraufbeschworen hatte, um damit seine geplanten Reformen legitimieren zu können.

In einem ersten Schritt habe ich die Antworten auf die siebersche Umfrage nach den Ansichten zur Frage nach der Art des schulischen Religionsunterrichts untersucht. In einem zweiten Schritt sollen nun auch die Diskussionen im Zusammenhang mit dem Entwurf des Unterrichtsgesetzes auf diese Frage hin näher besehen werden.

Ausgangspunkt der Diskussion in der Kirchensynode war die Unterscheidung zwischen Alltagsschule und höheren Schulstufen (Ergänzungs- und Sekundarschule). Unter den Geistlichen schien die Ansicht weitgehend unbestritten zu sein, dass auf den höheren Stufen (7.-9. Klasse) der Religionsunterricht dogmatisch-konfessioneller Art sein müsse bzw. dürfe, dort aber auch von der Kirche und nicht der Schule erteilt werde. Die Kontroverse zwischen konfessionellem und konfessionslosem Religionsunterricht bezog sich deshalb primär auf die Alltagsschulstufe (I.-6. Klasse). Die im Entwurf des Unterrichtsgesetzes geplante Überweisung des Religionsunterrichts auf allen Stufen an kirchliche Organe bezeichnete Pfarrer Wachter ${ }^{122}$ in seiner Proposition über den Religionsunterricht an der Versammlung der Kirchensynode vom I 4./ I s. November I 87 I als Danaergeschenk. Die «religiöse Anlage des Kindes» habe ein Recht auf Religionsunterricht in der Schule, und dieser sollte «in der Alltagsschule für die verschiedenen Confessionen gemeinsam obligatorisch sein, auch im Interesse der anzustrebenden Einigung der Confessionen». ${ }^{23}$ Möglicherweise befürchtete Wachter, dass ohne schulischen Religionsunterricht viele Kinder keinen Religionsunterricht mehr erhielten, da viele Eltern ihre Kinder nebst der Schule nicht noch zusätzlich für den kirchlichen Religionsunterricht entbehren wollten. Doch sollte der Religionsunterricht obligatorisch sein, dann durfte er nach Massgabe der Verfassung nicht konfessionell sein. In seiner Replik auf Wachters Proposition betonte Diakon Fay in derselben Versamm-

I 2 I Bezirksschulpflege Pfäffikon (Bezirk Pfäffikon), ebd.

I 22 Pfarrer Rudolf Wachter (I835-I9I9), Verfasser der Chronik von Wipkingen und von I87I bis I 898 Pfarrer in der Gemeinde Wipkingen (vgl. www.alt-zueri.ch/turicum/strassen/w/ wachterweg/wachterweg.html).

I 23 Amtlicher Auszug aus Protokollen der Synode der Zürcherischen Geistlichkeit, I 4. I I. I 87 I, 26. 
lung die Wichtigkeit «der Anschauung der heiligen Schrift». Religiöse Gesinnungsbildung erachtete Fay als zentrale Aufgabe des Religionsunterrichts. Aus diesem Grund sollte in der Schule «nicht blosse Moral mit Ausschluss alles Dogmatischen» gelehrt werden und er forderte deshalb «einen einfachen biblischen Unterricht». ${ }^{124}$

Der Vorschlag von Vögelin in der Kantonsratsdebatte vom i I. Januar I 872 wurde vom Landboten als eine "Art Vermittlungsantrag» ${ }^{125}$ bezeichnet. Vögelin kam den Geistlichen mit seinem Vorschlag insofern entgegen, als er die «Anregungen und Belehrungen aus dem Gebiete des geistigen und sittlichen Lebens» mit dem Ausdruck «religiös» ergänzte. Dafür betonte er im Unterschied zum Entwurf explizit, dass «alles Dogmatische und Konfessionelle» ${ }^{26}$ auszuschliessen sei. In der am Schluss vom Kantonsrat verabschiedeten Version hiess es dann: «Anregungen und Belehrungen aus dem Gebiete des geistigen, sittlichen und religiösen Lebens, mit Ausschluss alles Dogmatischen und Konfessionellen und unter Vorbehalt des Art. 63 Absatz I und 2, der Verfassung. Dieser Unterricht wird für die siebente bis neunte Klasse unter Festsetzung des Lehrplans und der Lehrmittel durch den Erziehungsrath vom Ortsgeistlichen ertheilt. ${ }^{127}$

Der Landbote kommentierte diese Veränderung von Paragraph I 4 als «seltsames Gebilde» und fragte, ob dies «eine korrekte Lösung des Knotens» ${ }^{\mathrm{I} 2}$ sei. Dass «an die Religionspostulate» eine Konzession gemacht würde, sei voraussehbar gewesen, «aber die Konzession macht ein kurioses Gesicht». Als seltsam erachtete der Autor offenbar, dass der Religionsunterricht beibehalten und in der 7.-9. Klasse von Geistlichen erteilt werden sollte, zugleich aber alles Dogmatische ausgeschlossen und die Kompetenz für die Lehrmittel der staatlichen Behörde zugesprochen werde, um der Glaubens- und Gewissensfreiheit in der Verfassung Rechnung zu tragen. Der Autor führte seine Vorbehalte nicht aus, doch deutet die Verwendung von Adjektiven wie «kurios» und «seltsam» darauf hin, dass er den konfessionslosen Religionsunterricht zumindest als fragwürdig erachtete. Darauf deutet auch sein Kommentar zum Entscheid des Kantonsrates bezüglich des Paragraphen 25 über die Sekundarschule: «Es ist, wie wenn die Versammlung etwas von diesem Fragezeichen gefühlt habe, als sie bei der Sekun-

I 24 Amtlicher Auszug aus Protokollen der Synode der Zürcherischen Geistlichkeit, I4. I I. I87I, 3 O.

I25 Der Landbote, I3. I. I872.

I 26 Exakter Wortlaut von Vögelins Änderungsvorschlag: «Anregungen und Belehrungen aus dem Gebiete des geistigen, sittlichen und religiösen Lebens mit Ausschluss alles Dogmatischen und Konfessionellen und zur Förderung der Humanität» (NZZ, I2. I. I872; vgl. auch Der Landbote, I3. I. I872).

I 27 Der Landbote, I4. I. I 872.

I 28 Ebd. 
darschule mit grosser Mehrheit freie Hand und freie Wahl gab, die Geistlichkeit beizuziehen oder nicht.» ${ }^{129}$

Es ist nun aber keineswegs so, dass die Befürworter eines konfessionslosen Religionsunterrichts alle gleich argumentierten. Zumindest zwei verschiedene Argumentationslinien sind $\mathrm{zu}$ unterscheiden: die sittlich-moralische und die religiös-liberale. Anhand von Äusserungen Johann Caspar Siebers und Konrad Furrers sollen diese zwei Linien beispielhaft aufgezeichnet werden. ${ }^{130}$

Aus der Sicht Siebers hatte der sogenannte Religionsunterricht einzig einen ethisch-moralischen Zweck. In der Kantonsratsdebatte über das Unterrichtsgesetz forderte Sieber deshalb die Trennung von Schule und «landeskirchlicher Religion»: «Wir wollen weder dogmatische noch konfessionelle Händel in der Schule. Die Religion nach dogmatischem Zuschnitt ist nicht Zweck der Schule, sondern die humanitäre und sittliche Ausbildung der künftigen Staatsbürger. Der ganze organische Unterricht gehört dem Lehrer der Volksschule. Die Religion soll nicht aus der Primarschule weg, aber es genügt, wenn die ethische Grundlage geboten, wenn das religiöse Element in einer dem Jugendalter entsprechenden und mit dem übrigen Unterricht harmonirenden Weise behandelt wird.» ${ }^{\mathrm{I}} \mathrm{I}$

Bürgerbildung und nicht religiöse Bildung schien Sieber als zentrale Aufgabe der Schule zu erachten. Sieber ging offenbar von der Prämisse aus, dass die ethische Grundlage von der religiösen abgetrennt werden könne bzw. ethische und religiöse Bildung unabhängig voneinander zu vermitteln seien. Es scheint, als ob hier, im Unterschied zu religiösen Glaubenssätzen, die immer als potentiell kontrovers angeschaut wurden, von einer allgemein anerkannten Ethik ausgegangen wurde. Oder anders formuliert: Sieber muss davon ausgegangen sein, dass Moralunterricht per se weltanschaulich-religiös neutral sei, da ansonsten ähnliche Konflikte sich auch in diesem Bereich zeigen würden. Wie bereits oben erwähnt (vgl. Unterkapitel 5.4 und Unterkapitel 6.3), hatte Sieber mit dem neuen Unterrichtsgesetz eigentlich einen reinen Moralunterricht, der den traditionellen Religionsunterricht ersetzen sollte, intendiert.

I 29 Ebd.

I30 Die Quellen, auf die ich mich im Folgenden beziehe, sind von der Gattung her sehr unterschiedlich. Zur Darstellung von Furrers Argumentationsgang rekurriere ich primär auf ein von ihm verfasstes 40-seitiges Traktat zum schulischen Religionsunterricht. Zur Darstellung von Siebers Überlegungen standen mir nur kurze Zeitungsartikel über dessen Voten im Kantonsrat zur Verfügung. Die Protokolle des Kantonsrats waren zu dieser Zeit bloss Beschlussprotokolle und die Berichte in den Tageszeitungen sehr viel ausführlicher und auch einigermassen ausgewogen.

I 3 I Der Landbote, I3. I. I 872. 
Pfarrer Konrad Furrer ${ }^{132}$ aus Uster formulierte sein Plädoyer für einen konfessionslosen Religionsunterricht in einem Traktat mit dem Titel Der confessionslose Religionsunterricht, das 1872 in Zürich gedruckt wurde. ${ }^{133}$ Dieses Traktat ist Zeugnis für einen liberal-christlichen Zugang zu dieser Thematik und für ein schleiermachersches Religionsverständnis. Wie Friedrich Schleiermacher unterscheidet Furrer zwischen Religion auf der einen und Konfessionalismus und Dogmatismus auf der anderen Seite, ${ }^{134}$ zwischen «der Glaubenslehre und dem Glauben selbst», ${ }^{135}$ zwischen Theorie und Leben oder zwischen Theologie und Religion. ${ }^{136}$ Diesen Unterscheidungen liegt die Überzeugung zu Grunde, dass die «religiöse Anlage» ${ }^{137}$ das ist, was den Menschen als Menschen auszeichnet, er somit mit allen Menschen teilt und was ihn vom Tier unterscheidet. Mit dieser religiösen Anlage ist die allen Menschen gegebene Möglichkeit gemeint, Gemeinschaft mit Gott zu haben. Und Gott ist gemäss Furrer «immer und überall an sich der gleiche». Da sich nun aber die Eigenschaften der religiösen Anlage - «Feinheit, Tiefe und Stärke» ${ }^{13^{8}}$ - von Mensch zu Mensch unterscheiden und die Anlage auch verkümmern kann, werden die «immerdar gleichen Wirkungen Gottes» ${ }^{139}$ von Mensch zu Mensch unterschiedlich empfunden. Die für die göttliche Offenbarung sensibleren Menschen werden als religiöse Genies bezeichnet, die «der nach Gott verlangenden Menschheit» ${ }^{140}$ als Vorbilder und Lehrer dienen. «Unser religiöser Genius» ${ }^{141}$ sei Jesus Christus, von dessen Geiste unser innerstes Fühlen, Denken und Wollen mitbestimmt sei, unabhängig davon, «ob wir uns dessen bewusst sind oder nicht». ${ }^{142}$ Die Errungenschaften

I 32 Konrad Furrer (1838-1908) war nach einer Palästinareise im Jahre I863 Pfarrer in Baar, Schlieren, Uster (I870) und St. Peter (I876). Ab I889 wurde er zum ausserordentlichen Professor für Altes Testament und Allgemeine Religionsgeschichte an der Universität Zürich ernannt. Theologisch ist er gemäss Mathys «unter den frommen, undoktrinären Liberalen einzuordnen». Sein Buch Wanderungen durch das heilige Land gilt auf Grund seiner präzisen Beobachtungen auch noch heute als eine spannende Quelle über die Zustände des damaligen Palästina. I 879 erhielt er den Ehrendoktortitel der Universität Bern (Mathys 2006).

I 33 Ob dieses Traktat noch vor der Abstimmung im April I 872 oder erst danach erschienen ist, konnte ich nicht eruieren.

I34 Vgl. Furrer i 872, 7 .

I35 Ebd., I 2.

I 36 Vgl. ebd., 8.

I 37 Ebd., I3.

I 38 Ebd.

I39 Ebd., I4.

$140 \mathrm{Ebd}$.

I4 I Ebd. Es ist allerdings nicht ganz klar, worauf sich dieses «unser» bezieht. Ist damit «die Menschheit gemeint oder bloss die Menschen der christlich-abendländischen Kultur? Letztere Interpretation würde Furrer zu einem Kulturrelativisten stempeln, der davon ausgeht, dass andere Völker bzw. religiöse Gemeinschaften andere religiöse Genies hätten, an denen sie sich orientieren. Diese Frage muss hier offenbleiben.

I 42 Ebd. 


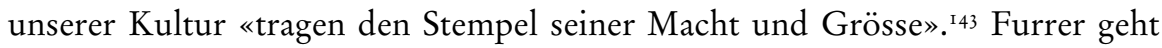
davon aus, dass alle Menschen vom selben (christlichen) Geist beseelt sind und dass «ein religiöses Lebensgesetz in uns Allen waltet». ${ }^{\text {I44 }}$ Dieser alle Menschen verbindende Geist und dieses «Gefühl der Abhängigkeit von einer höhern unsichtbaren Macht» ${ }^{145}$ nennt Furrer Religion. Furrer verweist sogar auf ethnologische Forschungen, die bewiesen hätten, dass es kein Volk ohne Religion (so verstanden) gebe.

Furrer stellt das Aufstellen theologischer Theorien dem «Leben mit Gott» gegenüber. Konfessionelle Streitigkeiten über unterschiedliche dogmatische Verständnisse hätten das Feuer göttlicher Liebe ausgelöscht und anstelle «die düstere Gluth des Fanatismus» entfacht. Den krassen Unglauben erklärt er als Reaktion auf den Fanatismus. Der Ungläubige schütte sozusagen das Kind mit dem Bade aus, weil er nicht fähig sei, bestimmte theoretisch-dogmatische Vorstellungen zu unterscheiden vom «ewige[n] göttliche[n] Leben in der menschlichen Seele». ${ }^{146}$ Furrer sieht in diesem Fanatismus auch die Ursache dafür, dass sich der Islam in Vorderasien gegenüber dem Christentum habe durchsetzen können. Der Confessionalismus habe auch den Siegeszug der Reformation aufgehalten. Zuerst sei «ohne dogmatische Aengstlichkeit an die ewig gleichen Bedürfnisse des Herzens nach vollem Frieden in Gott» appelliert worden, doch schon bald ging der Streit zwischen Lutheranern und Reformierten um das Abendmahl los. Und auch in der Gegenwart trage der Confessionalismus die Schuld, dass sich die «verklärende Macht» der Religion «im Volksleben» ${ }^{147}$ nicht entfalten könne. Furrer betont jedoch, dass dies nicht bloss der Fehler des konservativen Dogmatismus sei, sondern es «auch einen rationalistischen Dogmatismus» gebe, der «ebenso roh, ebenso geist- und gemüthlos, ebenso irreligiös wie jeder andere» sei. Die Tradition werde kritisiert und der Wunderglaube attackiert, doch dabei gehe die Hauptsache vergessen, «die arme Seele mit dem Reichthum göttlicher Liebe zu durchdringen». ${ }^{148}$ Kurz und bündig: «Nicht die Religion zerklüftet, sondern der Confessionalismus und Dogmatismus». Im Interesse der Religion, das heisst, um der Erfahrung «der Lebensgemeinschaft des Menschen mit Gott» ${ }^{\text {I49 }}$ willen, muss der Dogmatismus oder Konfessionalismus bekämpft werden.

Aus diesem Grund plädierte Furrer auch für einen konfessionslosen Religionsunterricht. Gegen den Einwand, dass ein konfessionsloser Religionsunterricht

I43 Ebd., I5.

I44 Ebd.

I45 Ebd., I 3. Die Anspielungen auf Schleiermacher sind unmissverständlich (vgl. Schleiermacher 2008, $32 \mathrm{ff}$.).

I 46 Furrer I 872, 9.

I 47 Ebd., I०.

I 48 Ebd., I I.

I49 Ebd., 7. 
ein Widerspruch in sich sei, «weil jede Aussage einer religiösen Wahrheit eine Confession, d. h. ein Bekenntniss enthalte», ${ }^{\text {s5o }}$ wandte Furrer ein, dass der Ausdruck Konfession in der Kirchengeschichte einen Sinn erhalten habe, der nicht mit der etymologischen Herkunft des Wortes identisch sei. Ebenso habe auch der Ausdruck «konfessionslos» durch die historische Entwicklung eine spezifische Bedeutung erhalten. Pädagogisch argumentierend, grenzt Furrer den konfessionslosen Religionsunterricht von einer bestimmten Lernmethode $a b$, «die darauf abzielt, das Kind mit abgeschlossenen, auswendig gelernten, unverstandenen Lehren zu beschweren, ihm eine Anzahl fertiger Begriffe und damit die Vorstellung beizubringen, als wären ihm alle Räthsel im Himmel und auf Erden gelöst». ${ }^{\text {I I }}$

In seinem Verständnis von Religionsunterricht soll das Kind jedoch «eine möglichst reiche und vielseitige Anschauung des sittlich-religiösen Lebens empfangen, dessen Schönheit und Herrlichkeit empfinden lernen, damit dem Göttlichen, das vor seinem geistigen Auge leuchtet, antworte das freudige, obwohl noch unbewusste Verlangen des eigenen Gemütes nach den höchsten, gottgewollten Zielen des menschlichen Daseins». ${ }^{152}$ Erst später, wenn das Kind «einen reichen Schatz sittlich-religiöser Anschauungen gesammelt hat», sollen ihm die Vernünftigkeit der eigenen Konfession und Dogmatik vermittelt werden. Dabei soll aber immer auch der Unterschied «zwischen der Glaubenslehre und dem Glauben selbst» ${ }^{153}$ verdeutlicht werden.

Hinter dem Einwand, ein konfessionsloser Religionsunterricht sei langweilig und ohne Tiefgang, da er nicht über «saft- und kraftlose Allgemeinheiten» herauskomme und somit kein Verständnis «für die feinsten religiösen Vorgänge» ${ }^{154}$ öffne, die sowohl auf der Eigentümlichkeit der Person als auch auf einer bestimmten dogmatischen Überzeugung basierten, steht gemäss Furrer die Vorstellung, dass den Kindern ein gewisses Minimum an dogmatischen Kenntnissen beigebracht werden müsse. Seiner Ansicht nach ist dies jedoch unmöglich, da zwischen liberalen und konservativen Theologen auf allen Ebenen Dissens herrsche und somit kein gemeinsamer kleinster Nenner, dem alle christlichen Parteien zustimmen könnten, gefunden werden könne. ${ }^{\text {Is }}$ Aus diesen Äusserungen kann geschlossen werden, dass für Furrer Religionsunterricht Gewissheiten $\mathrm{zu}$ vermitteln habe und somit im Religionsunterricht nur sogenannt unangefochtene, allgemeine menschliche Gewissheiten gelehrt werden dürften.

I 50 Ebd., II.

Is I Ebd.

I 2 Vgl. ebd., I $2 \mathrm{f}$.

I 53 Ebd., I 2.

I 54 Ebd.

I5s Ebd., I $2 \mathrm{f}$. 
Im Unterschied zu einem solchen Verständnis stünde die Vorstellung, dass die Aufgabe des Religionsunterrichts in der Vermittlung dogmatischer Unterschiede bestehe. Trotz seiner grundsätzlich theologisch liberalen Position wurde Furrers Traktat über den konfessionslosen Religionsunterricht auch von Seiten der Positiven "warme Begeisterung» ${ }^{156}$ entgegengebracht. Dies insbesondere auch, weil er nicht nur die Konfessionslosigkeit betonte, sondern im Unterschied zu Sieber zugleich am Religionsunterricht festhalten wollte. In Kapitel 7 wird zu untersuchen sein, inwiefern Furrers Überzeugung, dass Religion bzw. schulischer Religionsunterricht grundlegend für das Funktionieren des Staatswesens sei, ein Indiz für eine zivilreligiöse Einstellung sein könnte. ${ }^{\text {I57 }}$

Bereits weiter oben, am Ende der Darstellung der Ergebnisse der sieberschen Umfrage, wurde die Frage aufgeworfen, inwiefern es Sieber tatsächlich um einen konfessionslosen Religionsunterricht $\mathrm{zu}$ tun war und nicht vielmehr um die Ersetzung des schulischen Religionsunterrichts durch einen reinen Sittenunterricht. In diese Richtung zielte nach der Abstimmung ein Artikel im Volksblatt für die reformirte Scbweiz, in welchem das Traktat von Konrad Furrer über den konfessionslosen Religionsunterricht besprochen wurde. Der Autor meinte, man ziele eigentlich gegen die Religion als solche und die Konfession werde bloss vorgeschoben. «Von wirklich Confessionellem enthält auch der gegenwärtig im Kanton Zürich geltende Unterricht sehr wenig, indem er bis zur Confirmationsvorbereitung im Grunde nur historisch gehalten ist.» ${ }^{\text {I5 } 8}$

Zwei Monate später wurde im selben Blatt die Debatte über den konfessionslosen Religionsunterricht noch weiter zugespitzt, indem ziemlich pointiert spezifiziert wurde, was man unter Konfessionslosigkeit verstanden haben wollte. Konfessionslosigkeit sei nämlich dann erreicht, «wenn wir recht konfessionell geworden sind, protestantisch konfessionell, denn was ist der Protestantismus Anderes als die Rückkehr von der Tradition und den Menschensatzungen zum ursprünglichen Evangelium. Diesen sehr konfessionellen Grundsatz geben wir nicht auf und haben ihn nicht aufzugeben. Ueber Konfessionalismus ist nur da zu klagen, wo Menschenwerk und Menschenlehre höher gestellt wird als das ursprüngliche Evangelium. Wird aber, wie es nach Furrer und Heuer den Anschein hat, unter konfessionslosem Religionsunterricht die Forderung eines pädagogisch ertheilten Unterrichts verstanden, wogegen Niemand etwas einzuwenden

I 56 Volksblatt für die reformirte Kirche der Schweiz, I9. I0. I 872.

I 57 Furrer macht an gewissen Stellen die Wichtigkeit religiöser Bildung für das staatliche Zusammenleben deutlich: «Das Vaterland braucht nicht bloss geschickte, sondern sittlich tüchtige, charakterfeste Bürger, die Begeisterung genug haben, für ideale Lebenszwecke jedes Opfer zu bringen. Es verliert daher die staatliche Gemeinschaft ihre besten Grundlagen, wenn das religiöse Gemüthsleben verwahrlost wird, sei es, dass es verkümmert durch trostlosen Nihilismus oder durch endlose Zersplitterung.» (Furrer I 872, 5).

I 8 Volksblatt für die reformirte Kirche der Schweiz, 5. I0. I 872, I87. 
und welcher Jedem nicht nur frei steht, sondern zur Pflicht gemacht ist, so ist der Ausdruck schlecht gewählt. Das hat mit der Konfession Nichts zu thun. Wir sagen daher zu der ganzen Phraseologie über den konfessionslosen Unterricht: Rayez ce mot de vos papiers! Fort mit der Phrase! ${ }^{159}$

\subsection{Obligatorium}

Hauptanlass für die kontroverse Diskussion um das Obligatorium des schulischen Religionsunterrichts bot die in Artikel 63 der Kantonsverfassung garantierte Glaubens-, Kultus- und Lehrfreiheit. Auf den Umstand, dass die neue Zürcher Staatsverfassung von I 869 nicht zu einer klaren Trennung zwischen Kirche und Staat führte - die Landeskirche wurde den anderen kirchlichen Gemeinschaften nicht gleichgestellt und blieb durch staatliches Gesetz geordnet (vgl. Unterkapitel 3.I) -, wurde ebenfalls häufig rekurriert.

In den Antworten auf die siebersche Umfrage waren die Meinungen über das Obligatorium sehr durchmischt und praktisch alle denkbaren Möglichkeiten waren vertreten. Das eine Extrem forderte dezidiert ein Obligatorium auf allen Schulstufen mit der Begründung, dass der Religionsunterricht «ein wesentliches Mittel der Erziehung zur Sittlichkeit und Religiosität» ${ }^{160}$ sei oder «ein unentbehrliches u. unersetzbares Hülfsmittel [...] für die Bildung des Gemüthes». ${ }^{\text {16I }}$ Einzig die Gemeindeschulpflege Enge argumentierte mit der Beibehaltung des bisherigen Religionsunterrichts damit, dass Artikel 63 der Kantonsverfassung «nach unserer Ansicht die Jugend nicht betreffen kann». ${ }^{162}$ Warum die Glaubensund Kultusfreiheit nur für Erwachsene gelten sollte, erläutert die Gemeindeschulpflege Enge jedoch nicht weiter. Das andere Extrem forderte mit Verweis auf die Richtungsstreitigkeiten bereits innerhalb der Landeskirche die gänzliche Aufhebung des «Religionsunterrichts-Zwangs»: «Angesichts der Differenzen welche auch unter den Gliedern u. Lehrern der bisherigen Landeskirche in den Grundlagen der christlichen Glaubenslehre bestehen, halten Unterzeichnete es für einen Akt der Gerechtigkeit, wenn nicht allein für Glieder ausserkirchlicher religiöser Genossenschaften, sondern für Alle, ohne Ausnahme der Religionsunterricht für nicht obligatorisch erklärt wird. Wir wünschen diese Bestimmung nicht allein hinsichtlich des eigentlich konfessionellen Unterrichts von Seiten

I 59 Volksblatt für die reformirte Kirche der Schweiz, I4. I 2. I 872, 229.

I60 Gemeindeschulpflege Turbenthal und Sekundarschulpflege des 36. Kreises (Bezirk Winterthur), Eingaben und Antworten der Bezirksschulpflegen i 870, StAZH, U 8.I.Ia.

16I Gemeindeschulpflegen Stadel, Weiach, Bachs, Neerach \& Riedt; Sekundarschulpflege Stadel inkl. Lehrer (Bezirk Regensberg), ebd.

I62 Gemeindeschulpflege Enge (Bezirk Zürich), ebd. 
der Geistlichen der Landeskirche, sondern auch hinsichtlich desjenigen in der Bibl. Geschichte in den untern Primarklassen. Es ist allgemein bekannt, dass die tiefen Differenzen, welche in religiöser Hinsicht unsre gegenwärtige Zeit kennzeichnet, namentlich in der Auffassung des übernatürlichen Inhalts der Ev. Geschichte bestehen u. es kann nicht gefordert werden, dass Eltern ihren Kindern eine ihrer Überzeugung nach falsche Auffassung denselben beibringen lassen müssen; auch dürfte es nicht sehr pädagogisch erscheinen, den Schülern einen Unterricht zu geben, welcher sofort von den Eltern u. später auch von den Religions-Lehrern desavouirt werden müsste. ${ }^{163}$

Neben diesen beiden extremen Meinungsrichtungen gab es eine Vielzahl von Zwischenstufen. Die Gemeindeschulpflegen sowie die Sekundarschulpflege des Wahlkreises Schöfflisdorf verlangten das Obligatorium nur für die Primarschule. Nach der Alltagsschule sollten mit Verweis auf Artikel 63 der Kantonsverfassung Dispensationen möglich sein. Das Obligatorium begründeten sie mit dem einheitsstiftenden Moment des Religionsunterrichts: «Die Schule darf sich nicht ausschliesslich entweder auf Verstandes- oder Gemüthsbildung beschränken: Gemüth ohne Verstand ist nur der halbe Mensch, aber Verstand ohne Gemüth ist weniger als der halbe Mensch. Beides muss einander durchdringen. Dem gemüthstiefen sinnigen Lehrer bietet fast aller realistische Unterricht Gelegenheit zur Gemüthsbildung. Aber alles Zerstreute, Einzelne verlangt eine Einheit. Diese Zusammenfassung ist der Religionsunterricht. Gemüthsbildung kann nur die gesammte sittliche, religiöse und ästhetische Ausbildung des Geisteslebens sein. [...] Unser Staat ist ein christlicher Staat; es soll daher die Schule dem jungen Christen die Grundzüge der christl. Religion einprägen, damit er sich mit Hülfe derselben eine feste Überzeugung über sein religiösmoralisches Verhalten bilden kann, und sich nicht bloss blindlings von einer meist unsichren religiösen Ansicht des Elternhauses bestimmen lassen muss.» ${ }^{164}$

Die Gemeindeschulpflege und der Gemeindsverein Mönchaltorf erachtete es nicht «bloss für ein Recht, sondern auch für eine Pflicht der Gesetzgebung, den Besuch dieses Unterrichtes in Alltags-, Ergänzungs- \& Unterweisungsschule als obligatorisch zu erklären.» Die Mönchaltorfer betonten jedoch, dass dieser Unterricht nicht der Vermittlung einer systematischen Dogmatik zu dienen habe. Dies sei dem Konfirmandenunterricht vorbehalten und dürfe auch dort nur in Massen vorkommen (vgl. auch Unterkapitel 6.3.2). Einzig der Konfirmandenunterricht dürfe deswegen als fakultativ gesehen werden, aber nur «insofern

I63 Dieses Dokument wurde von einer Vielzahl von Privatpersonen unterschrieben, dat. Zürich den 30. Jan. 1870 (Eingaben und Antworten von Privaten I 870, StAZH, U 8.I.2).

I64 Gemeindeschulpflegen des Wahlkreises Schöfflisdorf und Sekundarschulpflege Schöfflisdorf (Bezirk Regensberg), Eingaben und Antworten der Bezirksschulpflegen r870, StAZH, U 8.I.Ia. 
die Eltern sich darüber ausweisen, dass sie auf einem anderen Wege für den Abschluss der religiösen Jugendbildung ihrer Kinder sorgen.» ${ }^{165}$

Verschiedene Bezirks- und Gemeindeschulpflegen, zum Beispiel Meilen, Glattfelden oder Wetzikon, befanden, dass auch auf Stufe Ergänzungsschule und Sekundar - im Unterschied zur Alltagsschule, wo dies nur Nicht-Christen gestattet werden sollte - die nicht zur Landeskirche gehörenden Eltern ihre Kinder vom Religionsunterricht dispensieren lassen können sollten, da dieser auf dieser Stufe vom Geistlichen erteilt würde. Doch ähnlich wie die Mönchaltorfer und verschiedene andere forderten auch sie vom Staat, dass dieser von den Eltern den Nachweis verlange, «dass sie in dieser wichtigen Periode ihre Kinder nicht ohne religiös-sittliche Fortbildung lassen». ${ }^{66}$ Eine Minderheit des Lehrerkapitels Winterthur wünschte dringend eine Änderung der Stellung des Religionsunterrichts. Da die Staatsschule die Kinder aller Bürger umfasse, sollte sie «nichts lehren, was nur irgend einem den Besuch unmöglich machte». Ihrer Ansicht nach sollte der Religionsunterricht nur in den ersten vier Schuljahren obligatorisch sein. «Die übrigen Schulstufen erhalten ihren Religionsunterricht durch den Geistlichen, u. es sind zum Besuche desselben nur die Kinder der Glieder der Landeskirche verpflichtet.» Die Mehrheit im Lehrerkapitel Winterthur forderte wie bis anhin ein Obligatorium auf der Elementar-, Real- und Ergänzungsstufe, wobei dieser Unterricht «wo möglich jede dogmatische Färbung verlieren» ${ }^{167}$ sollte. Erst auf Unterweisungsstufe sollte das dogmatische Element berücksichtigt werden.

In den Antworten auf die siebersche Umfrage gingen insbesondere von privater Seite einige sehr ausführliche Erörterungen zum schulischen Religionsunterricht ein. Eine Privatperson beschäftigte sich eingehend mit der Frage, wie sinnvoll Religionsunterricht an der Schule überhaupt sei. Sie nannte verschiedene Punkte, die gegen einen schulischen Religionsunterricht sprechen: I. Angesichts von Artikel 63 der Kantonsverfassung wäre nur noch ein fakultativer Religionsunterricht gerechtfertigt gewesen, doch ein solcher hätte verschiedene Nachteile: Das «zarte Band [...] zwischen Lehrer und Schüler» würde gelöst, «das Gefühl des Einsseins unter den Schülern» unterdrückt und «die Schulordnung durch das Gehen und Kommen der Schüler» gestört; 2. "Die religiöse Seite des Kindes» könne auch unabhängig von der Schule «gehörig gepflegt werden». Das Christentum stürbe ohne schulischen Religionsunterricht nicht aus; 3. Der Religionsunterricht als ein schulisches Fach neben anderen laufe Gefahr, seinen Reiz zu verlieren. Deshalb stelle sich die Frage, ob nicht «die Religion eher Macht über das kindliche Gemüth gewinnen» könnte, wenn das religiöse Leben «neben und ausser der Schule» gepflegt würde; 4. Die Schule könne mit ihrem

I65 Gemeindeschulpflege und Gemeindsverein Mönchaltorf (Bezirk Uster), ebd.

I66 Bezirksschulpflege Meilen (Bezirk Meilen), ebd.

I67 Lehrerkapitel Winterthur (Bezirk Winterthur), ebd. 
Religionsunterricht ohnehin nicht allen gerecht werden: «Als Schule des Staates, der Alle umfasst, will und sollte sie eine Schule für Alle sein, kann es aber in der Religion nicht, nicht für die Katholiken, die Juden, nicht für die Negativen, wenn ein positiver Lehrer, nicht für die Positiven, wenn ein negativer Lehrer da ist»; 5. Der Grund, dass man sich überhaupt mit der Frage eines schulischen Religionsunterrichts befasse, sei historischer Art, weil die jetzige Schule aus der alten Kirchenschule, «der reinen und blossen Religionsschule», hervorgegangen sei und nicht «anderweitig aus den civilisatorischen Bestrebungen des christlich modernen Zeitalters»; 6. Man müsse sich fragen, warum die Kinder noch in der Schule religiös geprägt werden sollten, wenn es für diesen Zweck eigene Institutionen wie die Kirche und andere religiöse Gemeinschaften gebe, die häufig nicht unbedingt im selben Geist unterrichteten. Angesichts dessen, dass auf Grund von Artikel 63 der Kantonsverfassung der Religionsunterricht in der Schule nicht mehr obligatorisch sein könne, und angesichts der eben dargelegten Überlegungen kam diese Person zum Schluss, dass der Religionsunterricht eigentlich von der Schule abgesondert werden müsste. Trotz den vielen Argumenten, die nach Ansicht dieser Person gegen die Beibehaltung des schulischen Religionsunterrichts sprachen, befürwortete diese Person aber dennoch den Religionsunterricht in der Volksschule. Zu viele Argumente sprächen dafür: I. Das Volk habe sich an eine Schule mit Religionsunterricht gewöhnt. Die Entfernung desselben würde «von vielen als ein zu kühner Bruch mit der ganzen Tradition und dem christlichen Charakter unseres zürcherischen Volkes angesehen und verurtheilt», umso mehr, da dieses «in seiner grossen Mehrheit zur Landeskirche gehört und an der christlich-reformierten Religion als der wahren festhält»; 2. Religion sei auch «für die Schule das Gebiet auf welchem sie am Meisten die Schüler fesseln, die Waffe, mit der sie am leichtesten über das Kind Herr werden, die Würze und Weiche, mit der sie das ganze Schul- und Kinderleben weihen und heiligen, ja verklären kann».

Es seien «die besten, edelsten Lehrer, die auch ein inneres, heiliges Band, ein Band nicht bloss allgemeiner menschlicher Liebe und Zärtlichkeit, zwischen sich und ihren Schülern zu knüpfen wissen», die es am meisten bedauern würden, wenn ihnen der Religionsunterricht genommen würde. «Allerdings könnten sie [die Lehrer] auch ohne Religion auf dem Schulplan Mittel und Wege finden, religiös die Kinder anzuregen; aber es müsste das bemühende Gefühl über sie kommen, dass man ihnen ein heiliges Recht nehme, das Recht: gerade das, was aller soliden Erziehung zu Grunde liegen muss, auch direct von sich aus mit den Kindern verarbeiten zu dürfen.» ${ }^{168}$

I68 Privatperson (29 Seiten ohne Namen), Eingaben und Antworten von Privaten, StAZH, U 8.I.2. 
An den detaillierten Ausführungen dieser Privatperson zeigt sich das Beharrungsvermögen romantisch verklärender Erwartungen an die Religion sehr deutlich.

Ein Topos, der von einigen im Zusammenhang mit dem Obligatorium bemüht wurde, war der christliche Staat. Ein Pfarrer, der als Einzelperson auf die Umfrage antwortete, erachtete beispielsweise die Möglichkeit, sich vom Religionsunterricht dispensieren zu lassen, durchaus für notwendig, argumentierte aber dezidiert für einen christlichen Religionsunterricht, «da unser Staat noch nicht aufgehört hat ein christlicher und speziell ein evangelischer zu sein». ${ }^{169}$ Der schulische Religionsunterricht sollte aus dieser Sicht nicht für die Sonderbedürfnisse einer Minderheit geopfert werden.

Die allermeisten Antworten der sieberschen Umfrage zum Obligatorium richteten sich dafür oder dagegen, Schulkinder zum schulischen Religionsunterricht zu zwingen. Daneben sind aber auch zwei in eine andere Richtung zielende Forderungen zu finden. Die einen forderten bloss ein Obligatorium für Lehrer, aber nicht «für Kinder von Eltern, die aus irgend welchen [...] Gründen jene vom Besuch dieses Unterrichts wollen ferngehalten wissen». ${ }^{170}$ Andere wollten das Obligatorium nicht nur auf Einzelpersonen angewendet sehen, sondern auch auf das Fach. Damit sollte die Schule verpflichtet werden, das Fach Religion unter ihren Lehrgegenständen zu behalten. Die Gemeindeschulpflege Seebach bedauerte allerdings, dass die Verfassung es anders religiösen Eltern ermögliche, ihren Kindern anderen Religionsunterricht erteilen zu lassen. Und noch mehr bedauerten sie, dass «völlig irreligiösen Eltern» mit der neuen Kantonsverfassung die Möglichkeit gegeben werde, ihre Kinder «ohne allen \& jeden Religionsunterricht aufwachsen zu lassen». ${ }^{171}$

Das Meinungsspektrum in der etwas konkreter geführten Diskussion über den Unterrichtsgesetzentwurf war ähnlich breit wie bei den Antworten auf die Umfrage Siebers. Diakon Spyri beschäftigte sich in seinem Traktat Der Religionsunterricht und der Entrourf des neuen Schulgesetzes des Kantons Zürich (vgl. auch die Unterkapitel 6.I und 6.3.I) unter anderem mit der Frage, warum man sich mit einer prinzipiellen Lösung so schwertue, die darin bestünde, den Religionsunterricht der Kirche zu überlassen. Spyri nennt dafür zwei Gründe: Zum einen sei die Bevölkerung zu wenig durchmischt, so dass eine solch scharfe Trennung zwischen Kirche und Schule nicht als notwendig erachtet werde. Zum andern, und dies sei der wichtigere Grund, habe die Schule «das mehr oder weniger klare Gefühl, dass sie den Religionsunterricht nicht aufgeben darf, ohne

I69 Pfarrer Schuster, dat. Hombrechtikon, 3. Februar i 870, ebd.

I70 Gemeindeschulpflege Altstetten (Bezirk Zürich), Eingaben und Antworten der Bezirksschulpflegen I 870, StAZH, U 8.r.ra.

I7I Gemeindeschulpflege Seebach (Bezirk Zürich), ebd. 
ein köstliches Kleinod zu verlieren; wenn sie ihn aufgibt, so verliert sie einen grossen Theil ihres erziehenden Charakters und sinkt, wenn auch nicht ganz, zu einer blossen Unterrichtsanstalt herab.» ${ }^{172}$

Dass die Mehrheit die Beibehaltung des schulischen Religionsunterrichts befürworte, hielt Spyri deshalb für verständlich. Sollte aber Artikel 63 der Verfassung Rechnung getragen werden, durfte der schulische Religionsunterricht seiner Ansicht nach nicht obligatorisch sein, unabhängig davon, ob dieser von Geistlichen oder Lehrern erteilt werde. ${ }^{173}$ Spyri wies mit seiner Diagnose dem Religionsunterricht einen zentralen Stellenwert als erzieherisches Fach zu. Insofern er jedoch die Ansicht äusserte, dass ohne Religionsunterricht die Schule bloss unterrichtende, aber keine erzieherische Funktion habe, suggeriert er, dass der Religionsunterricht unerlässlich ist, wenn die Schule eine erzieherische Funktion haben soll.

Ein Einsender spitzte in der NZZ die Problematik des Obligatoriums zu. Werde auf der Sekundar- und Ergänzungsschulstufe der staatliche Religionsunterricht durch den Lehrer erteilt, entstünden zwei Arten von Religionsunterricht: ein staatlicher, obligatorischer (Lehrer) und ein nicht obligatorischer, kirchlicher (Pfarrer). Der Einsender prangerte an, dass unter dem Deckmantel eines angeblich religionslosen Sittenunterrichts die «zürcherische Staatstheologie» über die Verfassung gesetzt werde, ihre Lehren als «unfehlbar, und ihre Schulbüchlein über das 〈Gebiet des sittlichen und geistigen Lebens〉 zu Staatskatechismen» ${ }^{174}$ würden. Diejenigen Eltern, die diese Staatstheologie nicht teilten, könnten auf Grund des Obligatoriums trotz der von der Verfassung garantierten Glaubensfreiheit, ihre Kinder nicht vom schulischen Religionsunterricht dispensieren lassen. Dieser Einsender schien also nicht an die Möglichkeit eines religionslosen Sittenunterrichts geglaubt $\mathrm{zu}$ haben, sondern vielmehr dem Staat ideologische Absichten zu unterstellen, die dieser mit dem obligatorischen, sogenannt religionslosen Sittenunterricht erreichen wolle.

Obwohl die Befürworter des Obligatoriums unterschiedlich argumentierten, schien die Annahme der Möglichkeit eines konfessionslosen, nicht dogmatischen Religionsunterrichts die meisten zu einen. Grundsätzlich in der Linie von Sieber und Vögelin stehend, wies Statthalter Schäppi im Kantonsrat auf den Zwiespalt in Artikel 63 der Verfassung hin, in dem sich der Kompromiss zwischen der Forderung nach einer strikten Trennung von Kirche und Staat und

I72 Spyri i $872,6$.

I73 «Wie also jetzt die Sachen noch liegen, hat unser Volk Recht, wenn es den Religionsunterricht als Lehrgegenstand der Schule behält, dabei aber nach $\$ 6_{3}$ der Verfassung Niemanden zwingt, denselben zu besuchen, sondern den Eltern gestattet, für dieses Bedürfnis nach ihrer inneren Ueberzeugung wol unter Angabe, durch wen der Unterricht ertheilt werde, zu sorgen.» (Spyri i 872,7$)$.

I74 NZZ I87I, 25. II. I87I. 
der Beibehaltung der Landeskirche widerspiegle. Im Unterschied zu Vögelin war Schäppi gegen das «religiös» im Paragraphen I4, da sich darin ebendieser Zwiespalt manifestiere. Denn die in der Kantonsverfassung in Artikel 63 festgeschriebene Glaubens-, Kultus- und Lehrfreiheit gab den Bürgern auch das Werkzeug in die Hand, ihre Kinder vom staatlichen Religionsunterricht dispensieren zu lassen, womit «das Obligatorium durchbrochen» ${ }^{175}$ wäre. Die radikalste Forderung wäre seiner Ansicht nach die völlige Trennung von Schule und Religion gewesen. Doch so weit wollte er nicht gehen: «Ich will nicht religionslose, sondern nur konfessionslose Schulen; denn die Religion ist weiter als die Kirche. Wenn man diese Scheidung vornimmt, so kann ich ganz gut zum Religionsunterricht stimmen. In der Forderung eines sittlich-religiösen Unterrichtes steckt aber eben noch die Idee des dogmatischen Unterrichts. [...] Es ist mir auffallend, dass die Kirche so viel Anstrengungen macht, die Schule noch am Faden zu halten. Wir sollen nun einmal die Schule im Interesse des Staates gestalten und von andern Autoritäten frei machen.» ${ }^{176}$ Mit einem konfessionslosen Religionsunterricht schien es ihm möglich, ein Obligatorium zu legitimieren. Angesichts der Forderung Schäppis, «die Schule im Interesse des Staates» zu gestalten und zugleich einen schulischen Religionsunterricht anzubieten, scheint die Rede des vorher erwähnten Einsenders von einer «Staatstheologie» nicht gänzlich aus der Luft gegriffen.

Während Schäppi mehr staatspolitisch argumentierte, verteidigte Kantonsrat Frei von Uster in der Versammlung der Arbeiter-Union von Uster den Entwurf des Unterrichtsgesetzes gegen Stimmen, die behaupteten, «man wolle die Religion in der Schule abschaffen», mit pädagogischen Argumenten. Klar, wolle man religiöse Bildung, «aber eine solche, welche mit den Entwicklungsgesetzen des kindlichen Geistes im Einklang steht; wir wollen mit den rechten Hülfsmitteln ohne Zuthun der Geistlichkeit den kindlichen Geist auch in diesem Zentralpunkte, wo alle Unterrichtsfächer sich gipfeln, zu fördern suchen.» ${ }^{177}$

Aus dieser Perspektive erscheint der Religionsunterricht nicht als lästiges $\mathrm{Ne}$ benfach, sondern vielmehr als das zentrale Fach, in dem alle anderen Fächer kulminieren. Konsequenterweise konnte Frei auf dem Hintergrund des Verfassungsartikels aber nur für Religionsunterricht in der öffentlichen Schule plädieren, wenn er entweder einen konfessionslosen, nicht dogmatischen Religionsunterricht für möglich hielt, das heisst, von einem christlichen Kern ausging, dem die Anhänger aller christlicher Konfessionen zustimmen können, und/oder ein Religionsverständnis im Sinne Schleiermachers teilte, das heisst, annahm, dass

I75 Der Landbote, I3. I. I 872.

I76 NZZ, I2. I. I 872 .

I77 Der Landbote-Sonntags-Blatt, 3 I. I 2. I 87 I. 
es etwas allgemein Religiöses gebe, das in allen Menschen, unabhängig von ihrer religiös-historischen Zugehörigkeit, geweckt werden könne.

Auch Vögelin betonte in einem Votum in der Kantonsratsdebatte, dass es nicht «im Interesse des Obligatoriums» liege, «die Religion wegzustreichen». Die Trennung von Religion und Sittlichkeit sowie die Vermittlung einer abstrakten Sittenlehre erachtete Vögelin zumindest auf den unteren Schulstufen als unmöglich. In diesem Punkt gab er damit einigen kirchlichen Petitionen und Stimmen recht. Im Unterschied zur kirchlichen Auffassung wollte Vögelin aber den mit dem neuen Unterrichtsgesetz intendierten schulischen Religionsunterricht ganz klar vom kirchlichen Verständnis von Religionsunterricht unterschieden wissen. Während die Kirche «die Religion als etwas ganz Eigenartiges auch in der Schule behandeln» wolle, ziele die «moderne Schule» auf Sittenlehre ab, wobei diese nur «mit Beiziehung und Benutzung der fördernden Elemente aus allen Gebieten» ${ }^{178}$ gelingen könne. Bei Vögelin erhielt die Religion offensichtlich eine instrumentelle Funktion (vgl. unten, S. I65). Der Religionsunterricht hatte aus dieser Sicht nur insofern Berechtigung in der öffentlichen Schule, als er als notwendig für einen erfolgreichen Sittenunterricht erachtet worden war.

Nun gab es aber auch Vertreter des Obligatoriums, die ein solch instrumentelles Religionsverständnis nicht teilten, sondern vielmehr im Sinne Schleiermachers mit der religiösen Anlage ${ }^{179}$ des Kindes argumentieren, die ein Anrecht auf Religionsunterricht habe. Auf diese Weise argumentierte beispielsweise Pfarrer Wachter, als er in der Synode der zürcherischen Geistlichkeit «im Interesse der anzustrebenden Einigung der Confessionen» für einen für die Angehörigen der verschiedenen Konfessionen gemeinsamen und obligatorischen Religionsunterricht in der Alltagsschule plädierte. ${ }^{180}$

I78 Der Landbote, I3. I. I 872.

179 Der Einfluss Schleiermachers manifestierte sich in dieser Diskussion immer wieder in unterschiedlicher Weise. In der dritten Rede seiner Religionsschrift vertrat Schleiermacher die Überzeugung, dass jeder Mensch mit einer «religiösen Anlage» geboren werde: «Der Mensch wird mit der religiösen Anlage geboren wie mit jeder anderen, und wenn nur sein Sinn nicht gewaltsam unterdrückt, wenn nur nicht jede Gemeinschaft zwischen ihm und dem Universum gesperrt und verrammelt wird - dies sind eingestanden die beiden Elemente der Religion - so müsste sie sich auch in jedem unfehlbar auf seine eigenen Art entwickeln» (Schleiermacher 2012, I33).

I80 Amtlicher Auszug aus Protokollen der Synode der Zürcherischen Geistlichkeit, I 4. I I. I87I, 26. 


\subsection{Religiöse Erziehung: Eine Aufgabe der öffentlichen Schule?}

Der Zweckartikel des Entwurfs für das neue Unterrichtsgesetz (Paragraph 2) war wegen eines der kürzesten Wörter - des Ausdrucks gut - umstritten. Dass die Schule mitzuwirken habe, «die Kinder aller Volksklassen zu geistig thätigen und bürgerlich tüchtigen» Menschen heranzubilden, stand nicht in Frage; auch nicht, dass die Kinder zu sittlichen Menschen erzogen werden sollten. Umstritten aber war, ob die Kinder, so wie es im Unterrichtsgesetz von I859 stand, zu sittlich religiösen oder, wie Erziehungsrat Sieber dies in seinem Entwurf vorgeschlagen hatte, zu sittlich guten Menschen erzogen werden sollten. Was stand hier zur Debatte? Was war mit sittlich gut und sittlich religiös gemeint?

Nach Winfried Böhm bezeichnet Sittlichkeit «die freie Entscheidung des Menschen für das Gute, Wahre (und Schöne), die weder der Beliebigkeit und Willkür noch der Determination und dem Zwang unterliegt». ${ }^{181}$ Sollte durch die Ergänzung des sittlich mit den Adjektiven gut oder religiös die Art des Guten und Wahren spezifiziert werden - das moralisch Gute und Wahre und das religiös Gute und Wahre? Oder impliziert Sittlichkeit bereits das moralisch Gute und mit dem Adjektiv religiös wurde auf die Quelle alles Guten, Wahren und Schönen verwiesen? Sollte zwischen einem bloss sittlichen Menschen und einem sittlichen plus guten bzw. einem sittlichen plus religiösen Menschen unterschieden werden? Worin bestünde der Unterschied? Blosse Sittlichkeit als Kenntnis und Befolgung der (lokalen schweizerisch-zürcherischen) Sitten, während das Attribut gut auf die universale moralische Bestimmung des Menschen bzw. mit dem Attribut religiös auf dessen religiöse Bestimmung verwiesen wird? Im bis dahin noch gültigen Schulgesetz von I 859 war die Rede vom sittlich religiösen Menschen. Im Rahmen dieser Arbeit kann nicht eruiert werden, wie es im Zuge der Verfassung des Schulgesetzes von I859 zu dieser Formulierung kam. Es ist deshalb meine Vermutung, dass damit ausgedrückt werden sollte, dass das Menschsein sich nicht in der Sittlichkeit - durchaus auch im Sinne von Moralität und nicht bloss im Sinne von konventionellen Sitten und Gebräuchen zu verstehen - erschöpft, sondern auch noch eine religiöse Dimension besitzt und/ oder die Sittlichkeit bzw. die (universale) Moral als von der Religion abhängig betrachtet worden war.

Es geht hier nun nicht primär darum, die genauen Verwendungsweisen dieser Formulierungen zu rekonstruieren, sondern darzustellen, was der Unterschied zwischen 〈gut und 〈religiös〉 in Bezug auf das Verständnis der Aufgabe der Schule bzw. des schulischen Religionsunterrichts implizierte. Die Vielschichtigkeit der Kontroverse um den schulischen Religionsunterricht lässt sich möglicherweise 
am besten anhand dieser Frage verdeutlichen. Die Schwierigkeit bei der Analyse dieser Debatte ist jedoch, dass in den von mir untersuchten Quellen von Religion und Religionsunterricht gesprochen wurde, meist ohne dass die jeweiligen Autoren - Redner an Versammlungen, Verfasser von Zeitungsartikeln usw. - jeweils explizit erläuterten, was genau sie mit diesen Ausdrücken verbinden. Dies kann häufig nur aus dem Kontext erschlossen werden.

Die unterschiedliche Verwendungsweise von «Religion〉 bzw. das unterschiedliche Verständnis von 〈religiös liegt auch den unterschiedlichen Vorstellungen dessen, worin das Ziel des schulischen Gefässes namens Religionsunterricht bestehen soll, zu Grunde. Aus dem Streit um die adäquate Formulierung des Zweckartikels im geplanten neuen Unterrichtsgesetz könnte geschlossen werden, dass diejenigen, die für die Formulierung sittlich religiös im Zweckartikel plädierten, einen konfessionell-dogmatischen Religionsunterricht wünschten und diejenigen, die für sittlich gut votierten, sich eher für den konfessionslosen Religionsunterricht starkmachten oder gar für einen reinen Sittenunterricht. So einfach ist nun aber die Sachlage nicht: Wie zu zeigen ist, gab es unter den Vertretern von sittlich religiös sowohl Befürworter eines konfessionellen als auch Befürworter eines konfessionslosen Religionsunterrichts. Umgekehrt gab es auch unter den Vertretern von sittlich gut solche, die für einen reinen Sittenunterricht plädierten, das heisst eine sogenannte religionslose Schule befürworteten, und andere, die einen Religionsunterricht bevorzugten, wenn auch einen konfessionslosen. Langer Rede, kurzer Sinn: Der sogenannte konfessionslose Religionsunterricht wurde sowohl von denjenigen gutgeheissen, die im Zweckartikel sittlich gut befürworteten, als auch von denjenigen, die sittlich religiös befürworteten. Dies kann damit erklärt werden, dass in den von mir bearbeiteten Quellen 〈Religion〉 in sehr unterschiedlichen Bedeutungen verwendet worden war:

I. Religion im deistischen Sinn: Glaube an Gott oder Götter, der bzw. die aber nicht handelnd in die Geschichte eingreift bzw. eingreifen; 2. Religion im christlichen, nicht konfessionellen Sinn: Im Unterschied zum deistischen Gott ist der christliche Gott ein Gott, der in seiner Schöpfung gegenwärtig ist und handelt («eingreift»). Religion im christlichen, nicht konfessionellen Sinn verstanden, basiert auf dem Glauben an einen von jeglichen dogmatischen Streitigkeiten unberührten oder sogar unberührbaren Kern. Meist war dieses Religionsverständnis von Schleiermacher beeinflusst; 3. Religion im konfessionellen Sinn: Wenn von Konfessionen die Rede war, waren traditionellerweise die reformierte oder katholische Konfession gemeint. ${ }^{182}$ Angesichts der innerkirchlichen Rich-

I 82 Die christkatholische Richtung setzte sich in der katholischen Kirchgemeinde in Zürich erst I 873 durch (vgl. Unterkapitel 3.I). 
tungsstreitigkeiten (vgl. Unterkapitel 4.3) standen aber auch unterschiedliche innerkirchliche Strömungen - Positive versus theologisch Liberale - im Blick. Nicht zuletzt konnten auch freikirchliche Bewegungen (z. B. Methodisten) unter diesen Begriff gefasst werden.

Aus heutiger Perspektive läge es nahe, noch eine vierte Verwendungsweise von Religion zu nennen: Religion als Überbegriff für eine Vielfalt von religiösen Traditionen: Judentum, Islam, Hinduismus usw. Obwohl man auch im I9. Jahrhundert um die Vielfalt religiöser Traditionen wusste, existierte sie de facto in der zürcherischen Lebenswelt nicht und sie war deshalb auch nicht von erziehungspolitischem Interesse. Konrad Furrers Traktat Der confessionslose Religionsunterricht zeigt, dass es durchaus Stimmen aus christlich-liberalen Kreisen gab, die forderten, im konfessionslosen Religionsunterricht auch nicht christliche Texte zu behandeln. ${ }^{18_{3}}$ Dies aber nicht mit dem Ziel, verschiedene Religionen miteinander zu vergleichen, wie dies das sich im I9. Jahrhundert herausgebildete Fach vergleichende Religionswissenschaft sich zur Aufgabe gestellt hat, sondern mit dem Ziel zu zeigen, dass die «wahre Religion», die «von Anbeginn der Menschheit an nie gefehlt» und die sich in ihrer ganzen «Fülle in Christus geoffenbart hat», sich auch «ausserhalb der jüdischen und christlichen Sphäre» ${ }^{184}$ manifestiert. Als Beispiele wurden sowohl die Schriften antiker Autoren wie zum Beispiel Plato oder Cicero als auch diejenigen anderer Religionen oder Philosophien erwähnt. Die Forderung, sich im schulischen Religionsunterricht auch mit religiösen Texten aus dem nicht christlichen Kulturkreis zu beschäftigen, soll in Unterkapitel 6.6. I noch eingehender erwähnt werden. Da diese verschiedenen Religionen und Philosophien zwar bekannt, aber für die allermeisten Zürcherinnen und Zürcher nicht Teil ihrer Lebenswelt waren, werde ich das Verständnis von Religion im Sinne eines Überbegriffs für eine Vielfalt religiöser Traditionen im nun folgenden Schema nicht berücksichtigen.

Mit diesem Schema soll die Auswirkung unterschiedlicher Verständnisse sowohl von Religion als auch der Verhältnisbestimmung zwischen Religion und Moral auf die Forderung nach einer spezifischen Art des Religions- bzw. Moralunterrichts verdeutlicht werden. Anhand konkreter Beispiele soll dieses Schema expliziert werden.

Die Vertreter der Radikal-Demokraten sind tendenziell der Katgorie I oder 2 zuzuordnen. Sieber beispielweise, der bereits im Rahmen der Verfassungsrevision den Antrag gestellt hatte, den Religionsunterricht durch die Verfassung aus dem Curriculum der Volksschule zu streichen, ${ }^{185}$ kann sicherlich als prototypischer Vertreter der Kategorie I gelten, in der die Moralität der Menschen als

I 83 Vgl. zur Biographie Furrers die Anm. I 32 auf S. I 48.

I 84 Furrer I 872, 35 .

I85 Vgl. Greiner I933.9I. 
sittlich
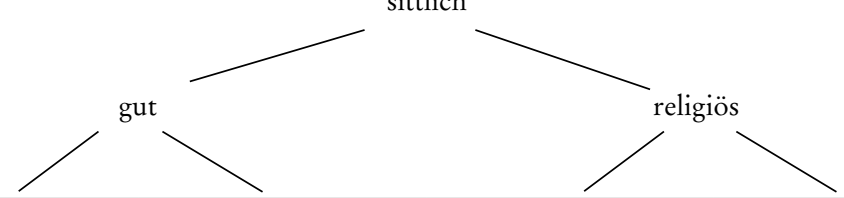

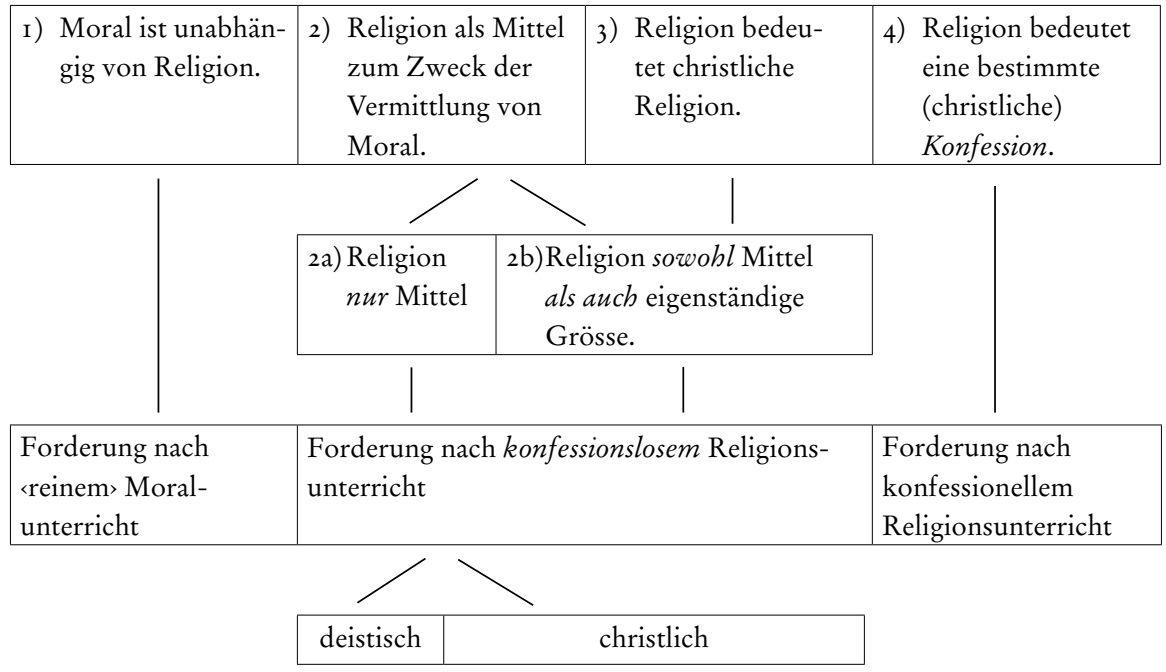

unabhängig von Religion bzw. religiöser Erziehung oder religiösem Glauben gesehen wird. Gemäss Koller schwebte Sieber «eine von der Kirche unabhängige, sittlich-ethische Erziehung der Jugend vor». ${ }^{186}$ Im Unabhängigen, der von Sieber herausgegebenen Wochenzeitung, machte Sieber I 865 deutlich, dass theologische Fakultäten aus seiner Sicht überflüssig seien: «Der Fortschritt der Kultur der Menschheit hängt nicht vom Glauben ab, sondern vom Stand der Erkenntnis der Natur». ${ }^{187}$ Die Schule inklusive des schulischen Religionsunterrichts sollte seiner Ansicht nach der kirchlichen Aufsicht entzogen werden. I 867 hiess es im Unabbängigen hinsichtlich des Religionsunterrichts in einem Artikel über die Lehrmittelfrage, «dass in der Primarschule [...] der Religionsunterricht Vorbereitungsunterricht sein soll, der sich anschliesst an Erzählungen moralischen und religiös. Inhalts, aus Geschichte und gewöhnlichem Leben». ${ }^{88}$

I 86 Koller 1987, 90. Es ist allerdings zu fragen, wie reflektiert seine diesbezügliche Haltung war: Ging es Sieber primär um die Entkoppelung von Schule und Kirche und ihren «unkritisch tradierten Dogmen» (Koller 1987, 90) oder glaubte er tatsächlich an die Unabhängigkeit von Religion und Moral? Streng genommen lässt sich dies aus seiner Forderung nach einer reinen sittlich-ethischen Erziehung nicht folgern.

I 87 Der Unabhängige (Besprechung von Wittstocks «Schulemancipation»), 4. 8. I865.

I 88 Der Unabhängige, I9. 7. I867. 
Die Unterscheidung «zwischen dem eigentlichen Religionsunterricht und der religiösen Vorbildung» schien grundlegend, da sie «von gesundem pädagogischen Takt und einer höhern Auffassung der christlichen Religion selbst» zeuge. Am Ende des Artikels wurde nochmals deutlich formuliert, dass es bereits «durchs Gesetz indizirt [sei], die Sittenlehre, weil für die Schüler verständlicher, fasslicher und darum auch bildender» in der Primarschule zu berücksichtigen und die Religionslehre erst in der Ergänzungsschule, «da erst auf dieser Stufe die allseitige Befähigung für einen eigentlichen Religionsunterricht vorhanden $»^{189}$ sei. Sieber blieb seiner Linie treu, als er in der Kantonsratsdebatte über den Paragraphen 14 des neuen Unterrichtsgesetzes die Ansicht äusserte, dass die Religion nicht aus der Primarschule gestrichen werden solle, es aber genüge, «wenn die ethische Grundlage geboten, wenn das religiöse Element in einer dem Jugendalter entsprechenden und mit dem übrigen Unterricht harmonirenden Weise behandelt $»^{190}$ werde, und forderte: «Wir wollen weder dogmatische noch konfessionelle Händel in der Schule. Die Religion nach dogmatischem Zuschnitt ist nicht Zweck der Schule, sondern die humanitäre und sittliche Ausbildung der künftigen Staatsbürger». ${ }^{191}$

In Kategorie 2 sind diejenigen einzuordnen, für die zwischen Religion und Moral eine Mittel-Zweck-Relation besteht. Religion bzw. religiöser Glaube und religiöse Erziehung werden für die Vermittlung von Moral als notwendig erachtet. Prinzipiell liesse sich innerhalb von Kategorie 2 nochmals unterscheiden zwischen einem Verständnis, gemäss dem sich Religion in seiner Mittel-Funktion erschöpft (2a), und einem Verständnis, das Religion nebst seiner Mittel-Funktion auch als eine eigenständige Grösse sieht (2b). Beide Verständnisse wären mit der Forderung nach einem konfessionslosen Religionsunterricht kompatibel.

Diese Zweck-Mittel-Relation zwischen Religion und Moral wird beispielhaft bei denjenigen sichtbar, die in ihren Antworten auf die siebersche Umfrage «Bildung zur wahren Sittlichkeit» oder «sittlich moralische Bildung» als «Zweck des Reli. Unt.» ${ }^{192}$ bezeichneten oder den «Religionsunterricht als ein wesentliches Mittel der Erziehung der Kinder zu sittlich tüchtigen Bürgern \& somit als nothwendiges Fach des Volksschulunterrichtes» ${ }^{193}$ erachteten. Etwas detaillierter, da mehr Quellenmaterial vorhanden, lässt sich Kategorie 2 am Beispiel des Hoftheologen der Radikal-Demokraten, F. S. Vögelin, illustrieren. Das untersuchte Quellenmaterial lässt jedoch kein eindeutiges Urteil zu über die Zuordnung zu

I 89 Ebd.

I90 Der Landbote, I3. I. I 872.

I9I Ebd.

I92 Schulpflege Grüningen und Sektionskonferenz Grüningen-Gossau (Bezirk Hinwil), Eingaben und Antworten der Bezirksschulpflegen i 870, StAZH, U 8.r.Ia.

I93 Bezirksschulpflege Horgen (Bezirk Horgen), ebd. 
Kategorie 2a oder 2b. In einem Votum im Kantonsrat zur Debatte über Ziffer I in Paragraph I4 des Entwurfes für das Unterrichtsgesetz ("Anregungen und Belehrungen aus dem Gebiet des sittlichen und geistigen Lebens») beschäftigte Vögelin sich zunächst mit dem Verhältnis der Paragraphen 2 (Zweckbestimmung der Volksschule) und I4 (Lehrgegenstände). Er plädierte für das «sittlich gut» und gegen das «sittlich religiös» in Paragraph 2 mit der Begründung, dass in diesem Paragraphen «lediglich die Zweckbestimmung für die Schule formulirt» sei und «sittlich gut» diesen Zweck vollständig beschreibe. ${ }^{194}$ Dies bedeutet, dass Vögelin die Erziehung zum sittlichen und nicht zum religiösen Menschen als Zweck der Volksschule erachtete. Er war jedoch deswegen nicht gänzlich gegen Religion in der Volksschule. Als Mittel zur Erreichung von Sittlichkeit erachtete er Religionsunterricht als durchaus opportun. Dies begründet er damit, dass «sich auf den unteren Schulstufen Religion und Sittlichkeit nicht trennen [lassen] und es [...] unmöglich eine abstrakte Sittenlehre geben [könne]. [...] Von den geistigen Anregungen das Religiöse auszuschliessen», erachtete er jedoch als «unpraktisch». ${ }^{195}$ Wobei Vögelin unter «Religion» keineswegs dasselbe wie die traditionelle «Kirche» verstanden wissen wollte: «Die Kirche wollte allerdings die Religion als etwas ganz Eigenartiges auch in der Schule behandeln, die moderne Schule will Sittenlehre, aber mit Beiziehung und Benutzung der fördernden Elemente aus allen Gebieten.» ${ }^{196}$

In dieser Passage tritt der instrumentelle Charakter, den Vögelin der Religion im Zusammenhang mit den schulischen Erziehungszielen zusprach, deutlich zutage: Die in der Schule zu vermittelnde Religion hatte einzig im Dienste der Sittenlehre zu stehen und somit in Vögelins Logik von allem Trennenden befreit zu werden. In einem Referat an einer vom Zentralausschuss der zürcherischen Gewerkschaften und Arbeitervereine organisierten Volksversammlung in der neuen Reitschule beschrieb Vögelin Religion folgendermassen: «Wir Alle kennten das wunderbare Gefühl, wenn wir Angesichts der Schöpfung und ihrer Wunder uns vom grossen Geiste angeweht und erfasst fänden, dass ein Unendliches um uns und in uns wohne; wenn die Wunder der Schöpfung uns ergriffen, wenn die Strahlen der Menschenliebe in uns eindrängen, wenn wir im Nebenmenschen den Bruder erkennten - dann lebe in uns die Religion.» Vögelin kritisierte die Priester, die diese Gefühle mit einem System verbinden und von Herrgott und Teufel sprächen. «Anstatt auf die eigene Kraft, verweise man den Menschen auf Wunder und geheimnisvolle Einflüsse.» Vögelin for-

194 Der Landbote, I 3. I. I 872.

I95 Ebd. Bezüglich der Mittel zur Erreichung des Zweckes der Volksschule - sittliche Erziehung - näherte sich Vögelin der Auffassung von Pfr. Scheller und einem Teil der kirchlichen Petitionen (Eglisau, Stadel, Neumünster) an (vgl. ebd.).

I96 Ebd., I3. I. I872. 
derte, dass in der Schule nur das gelehrt werde, «was zur Belebung des religiösen Gefühls bereits in der Menschenbrust wohne, dass nicht das Konfessionelle und Dogmatische, nicht das in den Schulen gepredigt werde, was die Menschen scheide, sondern, was sie verbinde». ${ }^{197}$

Ich habe Vögelin als Beispiel für Kategorie 2 vorgestellt. Auch Diakon Spyri würde sich dafür eignen (vgl. Unterkapitel 6.3). Beide sind typische Vertreter der liberalen Theologie (vgl. Unterkapitel 4.3). Deswegen müsste man sie aber ebenso auf der Grenze zwischen 2 und 3 ansiedeln. Denn insofern in der liberalen Theologie Religion sowohl christliche Religion als auch ein allgemein menschliches Gefühl war, versuchte sie den Unterschied zwischen 2 und $3 \mathrm{zu}$ überbrücken bzw. unkenntlich zu machen.

Als Beispiel für Kategorie 3 ist Pfarrer Konrad Furrer zu nennen, da er im Unterschied zu Vögelin und Spyri in seinem Traktat trotz seiner Offenheit und seinem Respekt für andere Religionen und Philosophien (vgl. Unterkapitel 6.6.I) explizit das Evangelium Jesu Christi als «höchstes Object alles religiösen Unterrichtes» bezeichnete und Religion für ihn so eindeutig christliche Religion bedeutete. $\mathrm{Zu}$ nennen ist auch die Eingabe der Gemeindeschulpflegen und Sekundarschulpflege Schöfflisdorf, die die Meinung vertraten, dass «unser Staat» ein christlicher Staat sei und «daher die Schule dem jungen Christen die Grundzüge der christl. Religion einprägen [soll], damit er sich mit Hülfe derselben eine feste Überzeugung über sein religiösmoralisches Verhalten bilden kann, und sich nicht bloss blindlings von einer meist unsichren religiösen Ansicht des Elternhauses bestimmen lassen muss». ${ }^{198}$ Ebenso könnte die Schulpflege Fehraltdorf hier genannt werden, die es für eine «heilige Aufgabe der Volksschule [hält], dass sie der Jugend die Grundlehren des Christenthums mit Sorgfalt u. Ernst einpflanze». Dies sehen sie auch als «Bedingung [...] eines glücklichen bürgerlichen Lebens». ${ }^{199}$

Der Kategorie 4 sind diejenigen zuzuordnen, die angesichts der innerkirchlichen Richtungsstreitigkeiten auf allen Stufen die Aufhebung des «Religionsunterrichts-Zwangs» forderten, weil sie der Auffassung waren, dass man von den Eltern nicht verlangen könne, ihre Kinder in einen Religionsunterricht zu schicken, in dem eine ihrer Ansicht nach falsche «Auffassung des übernatürlichen Inhalts der Ev. Geschichte» ${ }^{200}$ vermittelt werde. Ein Bewusstsein für die konfessionellen (und innerkonfessionellen) Unterschiede hatten natürlich auch die aus positiv-

I97 NZZ, 9. 4. I 872.

I98 Gemeinde- und Sekundarschulpflegen Schöfflisdorf (Bezirk Regensberg), Eingaben und Antworten der Bezirksschulpflegen i 870, StAZH, U 8.ı.ı.

199 Schulpflege Fehraltdorf (Bezirk Pfäffikon), ebd.

200 Dieses Dokument wurde von einer Vielzahl von Privatpersonen unterschrieben, dat. Zürich den 30. Jan. I 870 (Eingaben und Antworten von Privaten i 870 , StAZH, U 8.I.2). 
pietistischen Kreisen stammenden Begründer und Leiter des evangelischen Lehrerseminars in Unterstrass. Nach Ansicht Bachofners, dem ersten Direktor des evangelischen Lehrerseminars in Zürich-Unterstrass, genügten ein paar wöchentliche Religionsstunden nicht, «das Christenthum muss vielmehr der eigentliche Mittelpunkt der Schule werden». ${ }^{201}$ Mit 〈Christentum〉 war hier jedoch nicht wie bei Vögelin ein allgemein menschliches Gefühl gemeint, sondern ein konkreter biblisch-christlicher Glaube und eine evangelische Frömmigkeit.

Neben der kontrovers diskutierten Frage nach Moral- und/oder religiöser Erziehung spielte auch das Verhältnis zwischen Verstandes- und Gemütsbildung eine wichtige Rolle im Zusammenhang mit der Frage nach der Aufgabe der öffentlichen Schule. Gemütsbildung als Ziel der öffentlichen Schule wurde in den Antworten auf die Umfrage Siebers auffallend häufig erwähnt. Sozusagen im selben Atemzug mit der Gemütsbildung wurde der Religionsunterricht genannt als der zentrale Ort, in dem diese stattfinden könne und sollte. Die Gemeindeschulpflege Volketswil bringt dieses Ansinnen auf den Punkt: «Eine Volksschule ohne Relig. Unterricht wäre herabgewürdigt u. verstümmelt, da die Religion das vornehmste Mittel zur Gemüthsbildung ist.» ${ }^{202}$ Und die Gemeinde- und Sekundarschulpflege Fischenthal begründete ihr Anliegen, «dass in der Alltagsschule die biblischen Geschichten in Verbindung mit den üblichen Erzählungen behandelt werde, dass der Religionsunterricht der Alltagsschule gleichsam ein biblisch religiöser Anschauungsunterricht sein soll [...]» damit, dass «eine richtige Verstandes- \& Gemüthsbildung nur in harmonischer Verbindung beider erreicht werden kann und eine richtige Gemüthsbildung aber nur auf Grund des Religionsunterrichtes möglich ist». ${ }^{203}$

\subsection{Was soll im schulischen Religionsunterricht vermittelt werden?}

Die Frage nach dem konkreten Inhalt des schulischen Religionsunterrichts wurde insbesondere in der Geistlichkeitssynode, kirchlichen Zeitungen und in Furrers Traktat Der confessionslose Religionsunterricht erörtert. Dem Fragebogen von Sieber können - entsprechend der sehr eingeschränkten und geschlossenen Fragestellung ${ }^{204}$ - nur sehr wenige Antworten auf diese Frage entnommen werden. Es wurde beispielsweise pädagogisch argumentiert, dass die Aufsichtsbehörden

20I Volksblatt für die reformirte Kirche der Schweiz, 2. 3. I 872, 38.

202 Gemeindeschulpflege Volketswil (Bezirk Uster), Eingaben und Antworten der Bezirksschulpflegen i 870, StAZH, U 8.r.ia.

203 Gemeinde- und Sekundarschulpflege Fischenthal, (Bezirk Hinwil), ebd.

204 «Ist im Hinblick auf die Bestimmungen des Art. 63 der Verfassung die Stellung des Religionsunterrichtes der Schule zu ändern? Darf er das dogmatische Element und bis zu welchen Grenzen in sich aufnehmen?» (Bekanntmachung der Erziehungsdirektion, 22. I I. I 869, 3). 
besser darüber wachen sollten, «dass den Ergänzungsschülern nicht zu viel religiöser Memorirstoff aufgebürdet werde, wie es jetzt vielerorts geschieht».205 In den anderen untersuchten Quellen wurden folgende drei Fragen eingehender erörtert: Erstens, ob der schulische Religionsunterricht bloss biblische Geschichten zum Inhalt haben soll oder auch Geschichten aus anderen Religionen und Kulturen. Zweitens, welche biblischen Geschichten auszuwählen seien insbesondere die Frage, ob das Alte Testament in den Lehrplan aufgenommen werden sollte -, und drittens die Frage nach dem dogmatischen Element. Im schulischen Kontext waren damit insbesondere sogenannt metaphysische Spekulationen über das Wesen Jesu gemeint und, damit im Zusammenhang stehend, die Wundergeschichten.

\subsubsection{Biblische und andere Geschichten?}

In ihrer Antwort auf die Frage 4 der Umfrage Siebers aus dem Jahre i 869 meinte die Gemeindeschulpflege Hombrechtikon, sie halte «den Religionsunterricht mit christlicher und biblischer Grundlage für unentbehrlich in der Volksschule» ${ }^{206}$ und verlangte explizit, dass keine Änderungen am bisherigen Modus des schulischen Religionsunterrichts vorgenommen würden. Demgegenüber setzte sich Furrer in seinem Traktat Der confessionslose Religionsunterricht dafür ein, dass der Religionsunterricht sich nicht auf biblischen Stoff beschränke, da der «göttliche Geist» nicht bloss in den biblischen Gestalten gewirkt habe, «sondern in der Menschheit wirkt als ewige Macht». Die Jugend solle das religiöse Leben in seinen verschiedenen Formen verstehen lernen, «damit sie um so eher aus dem Streit über Theorien und Kirchensatzungen zur Gewissheit der ewigen religiösen Wahrheit gelange». Furrer kritisierte die Vermischung von religiösem und allgemeingeschichtlichem Unterricht: Für den Religionsunterricht brauche es nur den Stoff, «der die Jugend zur Religion, d. h. zur vollen Lebensgemeinschaft mit Gott heranbilden hilft». ${ }^{207}$ Furrer erwähnt in seinem Traktat eine Vielzahl von Schriften, deren Lektüre seiner Ansicht nach zur Erreichung dieses Ziels beitragen helfen. Als Beispiele aus der alten Kirche nennt er: Polycarp, Origenes, Chrysostomus, Augustinus. Genannt werden auch Beispiele aus dem Mittelalter: Giacopone da Todi, Franz von Assisi, Elisabetha von Thüringen, Johanna von Orleans. Ebenso Personen und historische Ereignisse aus der Neuzeit: die Französische Revolution, Washington, Wilberforce, Elisabetha Fry, Pestalozzi, Luther, Zinzendorf, Schleiermacher usw. Des Weiteren forderte er

205 Lehrer U. Gasser, dat. Windlach, Stadel, d. 29. Januar i 870, Eingaben und Antworten von Privaten I 870, StAZH, U 8.I.2.

206 Gemeindeschulpflege Hombrechtikon (Bezirk Meilen), Eingaben und Antworten der Bezirksschulpflegen i 870 , StAZH, U 8.r.ra.

207 Furrer I872, 31. 
nicht bloss das Singen von Liedern, sondern auch die Auseinandersetzung mit moderner Dichtung: Neben Luther, Gerhard Tersteegen und Angelus Silesius nannte er deshalb auch Shakespeare, Schiller und Goethe. Gegen die Einwände von Leuten, die «sittlich-religiöses Leben nur in der überlieferten kirchlichen Form» anerkennen, erinnerte er an Paulus: «Schliesslich Brüder: Was immer wahrhaft, edel, recht, was lauter, liebenswert, ansprechend ist, was Tugend heisst und lobenswert ist, darauf seid bedacht!» (Phil 4,8$).{ }^{208}$

Auch Werke ausserhalb der jüdisch-christlichen Sphäre sollten gemäss Furrer im Religionsunterricht beachtet werden. Bereits die Kirchenväter hätten «auch im heidnischen Altertum Spuren vom Wirken desselben Geistes» ${ }^{209}$ anerkannt. Das «Anschauen des sittlich-religiösen Aufstrebens in ausserchristlichen Gemeinschaften» trage zu «grösserer Klarheit über das Wesen der Religion an sich» bei und helfe, «milder und wahrer die Menschen zu beurtheilen». Furrer betont jedoch, dass es ihm dabei nicht um eine «oberflächliche Vermischung aller Religionen» ${ }^{20}$ gehe. Furrer zählt eine Vielzahl von Beispielen aus der nichtjüdisch-christlichen Sphäre auf: Hellenen, homerische Gesänge, Hektor, Antigone von Sophokles, Sokrates, Plato. Er dachte auch an die Römer wie z. B. Seneca, Tacitus oder Marc Aurel, an das Totenbuch der Ägypter, vedische Hymnen oder die brahmanische Frömmigkeit. Zu Buddha fügte er an, dass zwar manches an Buddha an Jesus erinnere, deshalb aber nicht vergessen werden dürfe, dass «Buddha keine neue Religion, sondern ein neues philosophisches System aufgestellt und dass sein ganzes Wirken den Glauben an die Seelenwanderung zur Voraussetzung gehabt hat». ${ }^{\text {II }}$ Konfuzius wird genannt sowie Zarathustra, den er mit Mose vergleicht. Auch Mohammed und den Koran erwähnt er respektvoll: Nebst «fadestem und schwulstigem Geschwätz finden sich im Koran Aeusserungen tief religiöser Empfindung, z. B. «O Herr lege uns nicht mehr auf, als wir tragen können. Vergib uns, erbarme dich unser, du bist der beste Erbarmer.»». ${ }^{212}$ Der Islam habe «ein Gefühl absoluter Abhängigkeit begründet». Zudem gebe es auch im Islam eine mystische Richtung (Rabiah, Rumi): «Wir sehen, die Sehnsucht nach voller Gemeinschaft mit Gott ist nicht bloss ein Eigenthum der christlichen Völker. Ueberall bestätigt sich die Wahrheit des tiefsinnigen evangelischen Wortes: ‘Der Wind weht, wo er will, und du hörst sein Tosen; aber du weisst nicht, woher er kommt, noch wohin er fährt. Also ist ein jeder, der aus dem Geiste geboren ist> (Joh. 3,8)». ${ }^{213}$

208 Ebd., $32 \mathrm{ff}$.

209 Ebd., 35.

2 10 Ebd., 36.

2 I I Ebd., $39 \mathrm{f}$.

2 I 2 Ebd., 4I.

213 Ebd., 42. 
Gegen die Absicht Furrers, nebst dem biblischen Stoff auch ausserbiblischen Stoff herbeizuziehen, wurden im Volksblatt für die reformirte Kirche der Schweiz «nicht kleine Bedenken» geäussert. Die Frage nach der Zeit für die Vermittlung dieses immensen Stoffes wurde gestellt. Des Weiteren wurde als fraglich erachtet, ob man bei der Schuljugend das nötige Verständnis «für diese religionsgeschichtlichen Erscheinungen» voraussetzen könne. Drittens wurde gefragt, ob ein solcher Überblick über die Religionsgeschichte, soweit eine solche überhaupt möglich sei, nicht eher seinen Ort zu Beginn des Konfirmandenunterrichts habe, «da, wo von der Religion überhaupt die Rede ist». Als vierter und wohl gewichtigster Einwand wurde «die Stellung, die man diesem Stoffe zu dem biblischen gibt», genannt, auf die alles ankomme. Wenn alle Wohltäter der Menschheit in eine Linie mit Moses, den Propheten und Christus gesetzt werden, dann sähe sich das Volksblatt veranlasst, sich dagegen auszusprechen, «denn auf diesem Wege müsste sich nach und nach der Unterschied zwischen christlich und nichtchristlich im Bewusstsein der Kinder und dann auch des Volkes verwischen». ${ }^{214}$

\subsubsection{Kontroverse Altes Testament}

Hinsichtlich des schulischen Religionsunterrichts stellte sich nicht bloss die Frage, ob neben den biblischen Schriften auch ausserbiblische Schriften zu behandeln seien. Es war bereits umstritten, welche der biblischen Schriften im Schulunterricht thematisiert werden sollten. In seiner Proposition an der Geistlichkeitssynode im November i 87 I forderte Pfarrer Wachter, dass die Bibel als Lehrmittel gebraucht werde, "welche ja der Jugend bekannt und lieb gemacht werden sollte, und bei welcher allein volle Freiheit der Bewegung für den Lehrer möglich sei». Er betonte jedoch, dass er eine in einem bestimmten Sinne zensurierte Bibel meine: eine «Jugend- und Volksbibel, in welcher das Anstössige und bloss Antiquarische oder grausame Bilder und alles für uns ganz Unverständliche weggelassen sei». ${ }^{215}$ Welche Teile aus seiner Sicht konkret weggelassen werden müssten, darüber äusserte er sich in seiner Proposition nicht.

Diesbezüglich etwas konkreter war die Schulpflege Schmidrüti-Sitzberg in ihrer Stellungnahme zu Frage 4 des sieberschen Fragebogens. Die Mehrheit der Schulpflegemitglieder wünschte, «es möchte die bibl. Geschichte, namentlich des alten Testaments, beziehungsweise die Geschichte von Israel, als Unterrichtsfach in den beiden ersten Abtheilungen, also den 6 ersten Jahresklassen unbeschadet

214 Volksblatt für die reformirte Kirche der Schweiz, 26. I0. I872, I98.

2 I 5 Amtlicher Auszug aus Protokollen der Synode der Zürcherischen Geistlichkeit, I4. I I. I87I. 
der religiösen Unterweisung wegfallen». ${ }^{216}$ Bloss eine Minderheit habe ihre Beibehaltung gewünscht. Aus Sicht der Mehrheit dieser Schulpflege sollten also nicht bloss einzelne «anstössige» Geschichten weggelassen werden, sondern gleich das gesamte Alte Testament. Konrad Furrer argumentierte in seinem Traktat genau gegen diejenigen Stimmen, die «den Werth des alten Testamentes für den Jugendunterricht auf's entschiedenste bestritten, ja dasselbe als ein für die Jugend verderbliches Buch bezeichne[n], indem es zahllose Stellen darin gebe, die bald gegen die moderne Weltanschauung, bald gegen ein geläutertes ethisches und religiöses Bewusstsein verstossen». ${ }^{217}$ Nach Ansicht Furrers betrifft diese Polemik jedoch «im Grunde nur eine rohe Behandlung der ehrwürdigen Schriftsammlung, eine scholastische Exegese, die hartnäckig wenigstens die kanonischen Bücher fast in jedem Buchstaben als gut und wahr vertheidigen will und auf solche Weise allerdings im bedauerlichsten Masse dogmatisch-confessionell verfährt». ${ }^{218}$

Das Alte Testament war für Furrer ganz klar «kein Kinderbuch». Es bedürfe «eines kundigen Meisters, um das aus demselben herauszuheben, was den kindlichen Geist in seiner Gemeinschaft mit Gott befördern kann». ${ }^{219}$ Wie Pfarrer Wachter erachtete auch Furrer es als wichtig, dass eine Auswahl an alttestamentarischen Schriften getroffen werde und man für die Jugend alles ausscheide, «was nur ein antiquarisches oder zeitgeschichtliches, aber kein unmittelbar sittlich-religiöses Interesse bietet» sowie, was «von den confessionellen und dogmatischen Parteien» ${ }^{220}$ umstritten sei. Dieser Zensur zum Opfer fallen würden bei Furrer beispielsweise die 6 I $_{3}$ Gebote und Satzungen im Pentateuch, die Geschlechtsregister oder die Beschreibung der Herrlichkeiten des Tempels Salomons; ebenso zum Beispiel die beiden Schöpfungsgeschichten, denn diese müssten aus seiner Sicht symbolisch gedeutet werden, was aber denen gegenüber ein Affront wäre, die an die Erschaffung der Welt in sechs Tagen glaubten oder aus Adams Sündenfall die Erbsündenlehre ableiteten. Problemlos und ohne symbolische Deutung könnten nach Furrer die Geschichten Josephs, Moses' - allerdings ohne die Wundergeschichten -, Josuas, Gideons, Ruths, Samuels oder auch Davids erzählt werden. Furrer war der Überzeugung, dass diese Geschichten «bei pädagogisch weiser Behandlung» ethisch und religiös wirksame Momente erzeugen könnten. Dies gerade deshalb, weil sie «keine Heiligenbilder» zeigen, sondern Menschen, «in denen neben vielen Schatten

216 Schulpflege Schmidrüti-Sitzberg (Bezirk Winterthur), Eingaben und Antworten der Bezirksschulpflegen i 870, StAZH, U 8.I.ra.

217 Furrer 1872, 19.

218 Ebd.

2 I9 Ebd., 2 I.

220 Ebd. 
der Endlichkeit unvergänglich lichte Züge inniger Gottesgemeinschaft sich ausgewirkt haben». ${ }^{221}$

Furrer versuchte mit viel Engagement und über viele Seiten hinweg seine Leserschaft davon zu überzeugen, dass es ein grosses Unrecht wäre, das Alte Testament aus einem konfessionslosen Religionsunterricht zu verbannen. Dennoch macht er am Ende seiner diesbezüglichen Ausführungen deutlich, dass er als «das höchste Object alles religiösen Unterrichtes» das Evangelium Jesu Christi erachte: «Wir sollen die Gesinnung des grossen Meisters in die Kinder einpflanzen, dass sie Gott erfahren, wie er, dass sie, ob auch in weit schwächerer Weise, so religiös empfinden, so glauben, lieben, hoffen, wie er gethan. [...] Gott ein Vater mit allen Attributen väterlicher Macht, Weisheit und Gnade, der Mensch sein Kind mit aller Verpflichtung zu rückhaltlosem Vertrauen, absoluter Demuth, unauslöschlicher tiefster Liebe.» ${ }^{222}$

Im Anschluss an Jesus Christus sollte gemäss Furrer auch Paulus erwähnt werden. Der Fokus sei dabei jedoch weniger auf dessen Theologie zu richten. Vielmehr sollte ein psychologisches Verständnis für seine seelischen Kämpfe erzielt werden, da es «doch dieselben sittlich-religiösen Probleme, mit deren Lösung ein jeder nach Gottes Frieden strebende Mensch zu ringen» habe. Idealismus und Gewissensangst nennt Furrer als Beispiele und stellt Paulus dar als «furchtlosen Streiter für eine Religion der Freiheit der Gesinnungstreue, des Universalismus».223

In deutlichem Kontrast zu Furrers Plädoyer für die Behandlung von biblischen Geschichten im konfessionslosen Religionsunterricht stand Ferdinand Buisson, der in einem in Neuenburg gehaltenen Vortrag mit dem Titel Die biblische Geschichte in der Volksschule für die gänzliche Abschaffung von Biblischer Geschichte in der Volksschule plädierte. ${ }^{224}$ Biblische Geschichten beeinflussten die kindliche Entwicklung des Geistes wie auch des Gewissens negativ. Diesen negativen Einfluss auf die Entwicklung des Geistes begründete Buisson damit, dass die biblischen Geschichten die Kinder nicht dazu führten, Gott «in den Gesetzen der physischen oder sittlichen Welt, nicht in der ewigen Harmonie der Gestirne, nicht in dem wunderbaren Bau der Blume oder des Insekts, nicht in dem Schauspiel der grossen Scenen des Weltalls [zu suchen], sondern in Gott

22 I Ebd., 24.

222 Ebd., 28.

223 Ebd., 30 .

224 Ferdinand Buisson hat sich zwar nicht direkt an der zürcherischen Diskussion um den schulischen Religionsunterricht im Zusammenhang mit dem geplanten neuen Unterrichtsgesetz beteiligt. Sein Vortrag, den er im Jahre i 869 gehalten hatte, wurde jedoch sehr bald ins Deutsche übersetzt und in deutschsprachigen Zeitungen rezipiert (vgl. Unterkapitel 2.4.I). Es ist deshalb sehr wahrscheinlich, dass sich auch Konrad Furrer mit diesem Vortrag beschäftigt hatte. 
weiss welchen Störungen, in Erschütterungen, welche, wenn sie stattgefunden, nur den Mangel an Vorsicht, die göttliche Wandelbarkeit und Ohnmacht bewiesen hätten». ${ }^{225}$

Mit den biblischen Geschichten werde in den Kindern noch mehr angeregt, was ohnehin «nur zu üppig schon wuchert: Phantasien, Hirngespinnste, Unkenntnis der Ursachen, Unbekümmertheit um die Regel, die Furcht anstatt des Gedankens, den Glauben statt des Wissens». ${ }^{226}$ Zugleich werde vermittelt, dass wer diese «Erzählungen, Doktrinen und Wunder» bezweifle, Gotteslästerung begehe und die Verdammnis verdiene. Als zentrales Erziehungsziel erachtete Buisson die Vermittlung der Vorstellung «von der Einheit, der Gleichheit, der Verwandtschaft der Menschen aller Racen und aller Zeiten, aller Klimate und aller Farben». ${ }^{227}$ Die Geschichte von der Auserwählung des Volkes Israel sah er aber damit in unauflöslicher Spannung stehend.

Die durch die biblischen Geschichten vermittelten Lehren beeinflussten nach Buisson auch die Gewissensentwicklung negativ. Als problematisch erachtete er beispielsweise «die Lehre von der Gnade, von der Auserwählung, der Prädestination, dem göttlichen Recht». ${ }^{228}$ Die Auserwählung des Volkes Israel habe Gott «als besonderes Werkzeug der Verbindung mit der Menschheit» gedient. Einzig sein freier Wille habe ihn dazu veranlasst. Bis zu Moses werde Gott als derjenige dargestellt, der zum Schutz der Seinen alles tue und dies «sogar gegen die Forderungen der elementarsten Moral. Er lässt seine Auserwählten überall und stets siegreich hervorgehen, sie mögen im Recht oder Unrecht sein». ${ }^{229}$ Zur Illustration nennt er die Geschichte von Abraham, der in Ägypten seine Frau Sara als seine Schwester ausgab, damit er wegen ihrer Schönheit nicht getötet würde, oder die Geschichte von Jakob, der alle verdrängt, die «nach Recht und Gerechtigkeit den Vorrang vor ihm haben müssten». ${ }^{230}$ Als moralisch höchst anstössig erwähnt Buisson die Geschichte der Opferung Isaaks. Diese Geschichte vermittle, dass man zwischen Gott und dem Sittengesetz unterscheiden müsse: «Die Voraussetzung, dass es einen ‘Willen Gottes〉 geben, dem man den Vorzug vor der Stimme des Gewissens geben müsse, sollte man sich hüten, im Gemüthe des Kindes aufkommen zu lassen, wenn man aus ihm nicht einen dunkeln Schwärmer, sondern einen redlichen Menschen und einen wahren Christen machen will. Der blinde Gehorsam gegen Gebote Gottes, die nicht vollständig mit denen der Pflicht übereinstimmen, das ist grade das entscheidende Merkmal des

225 Buisson I869a, 35 .

226 Ebd.

227 Ebd., II.

228 Ebd., 39.

229 Ebd., 40.

230 Ebd., 46. 
Fanatismus.» Wolle man die Geschichte von Isaaks Opfer «mit der Sittenlehre in Uebereinstimmung bringen», so dürfe man sie «nicht als eine wahre Geschichte, sondern als die hebräische Legende vortragen, welche an die Abschaffung der Menschenopfer erinnert, so wie dies bei den Griechen die Legende von der Iphigenie und bei anderen Völkern zahlreiche andere Legenden thun». ${ }^{231}$

Trotz diesen Geschichten erachtete Buisson die Bibel nicht als «ein Gesetzbuch der Unsittlichkeit», sondern als ein kostbares Buch, da dieses ermögliche, «von Zeitalter zu Zeitalter die stufenweise und langsame Entwicklung des Gewissens bei einem der merkwürdigsten Völker des Alterthums, von der Epoche der frühesten Barbarei an, bis zur Messianischen Aera zu verfolgen».232 Die Bibel könne für die Kinder dann ein Gewinn sein, wenn sie als Mittel verstanden werde, den Fortschritt des menschlichen Gewissens zu illustrieren. Würden aber die Bibeltexte so vermittelt, dass «alles gleichmässig und unbedingt göttlich sein muss», ${ }^{233}$ dann helfe auch das Abmildern oder Verändern gewisser Texte nichts. Buisson erachtet die Bibel auf Grund ihrer vielen anstössigen Geschichten als Schullektüre für ungeeignet. Er problematisiert zugleich aber auch den Ansatz, den Kindern eine von anstössigen Stellen gereinigte Bibel abzugeben, da auch eine solcherart zensurierte Bibel denselben Geist atme, den zu vermitteln es zu verhindern gelte. Den Kindern solle nicht die Geschichte eines Volkes erzählt werden, das zwar gross gewesen sei, aber «von der fortschreitenden Menschheit [...] längst überholt worden ist». Es solle vielmehr dafür gesorgt werden, dass die «Kinder mit vollen Zügen, in der Schule wie in der Familie, die Luft der Republik einathmen». Ihnen soll früh «von Recht und Pflicht, von Vaterland und Menschheit, von Freiheit, Gleichheit und Gegenseitigkeit» gesprochen werden. Lehrer und Schüler sollten nicht mehr «ihre Augen hinter sich auf einen kleinen Fleck Erde in Syrien» richten, sondern ihren «Geist und ihr Herz allem Herrlichen und Guten» gegenüber öffnen, woher auch immer es komme. Buisson beendet seinen langen Vortrag sehr dezidiert: «Schafft die biblische Geschichte $a b$ und ersetzt sie durch die Geschichte der Menschheit». ${ }^{234}$

Buissons radikale Forderung erinnert an Voltaire, in dessen Essai sur les moeurs anstelle des Heiligen Geist der menschliche Geist (l'esprit humain) rückt und somit die Heilsgeschichte durch die Menschheitsgeschichte ersetzt wurde. Erich Voegelin beschrieb diese säkulare Wende in der Geschichtsschreibung folgendermassen: «The corpus mysticum Christi has given way to the corpus mysticum humanitatis». ${ }^{235}$ In der zürcherischen Diskussion um den schulischen

23 I Ebd., 52.

232 Ebd., 53.

233 Ebd., 55 .

234 Ebd., $84 \mathrm{f}$.

235 Voegelin 1975, ro; vgl. auch Katzenstein 2013, $20 \mathrm{f}$. 
Religionsunterricht sticht insbesondere eine Person hervor, die eine ähnlich radikal-säkulare Ansicht vertrat wie Buisson: Dies ist Erziehungsrat Sieber, der bereits als Mitglied des Verfassungsrates die Abschaffung des Religionsunterrichts und einen reinen Sittenunterricht forderte. Ob er von Buisson beeinflusst war, muss hier jedoch Spekulation bleiben. ${ }^{236}$

\subsubsection{Kontroverse Wundergeschichten}

Die biblischen Wundergeschichten und die Frage nach dem Wesen Jesu Christi gehörten zu wesentlichen Streitpunkten zwischen Liberalen und Positiven, die auch auf die Diskussion um die Inhalte des schulischen Religionsunterrichts ausstrahlten. Pfarrer Konrad Furrer, den man wohl als gemässigten Liberalen bezeichnen könnte, war dezidiert der Ansicht, dass metaphysische Spekulationen über das Wesen Jesu Christi erst in der letzten Stufe des schulischen Unterrichts aufgeworfen werden sollten. Vorher «sollen die Kinder an der Freudigkeit, mit der sie selbst Gott ihren Vater nennen, ahnen lernen, warum Jesus aus innerster Gewissheit sich Sohn Gottes heissen konnte; sie sollen sich für ihn begeistern, sollen ihn lieb gewinnen von ganzem Herzen, dass er in allen stillen Stunden ihnen zum tröstenden, aufwärts ziehenden Freunde werde». ${ }^{237}$

Gerade weil Furrer den Aufbau einer persönlichen Beziehung zu Jesus Christus als wichtig erachtete, sollten aus seiner Sicht die sogenannten Wundergeschichten aus dem Curriculum weggelassen werden. Jesu geistige Hoheit wirke stärker ohne dieses «fremdartige Gewand», ${ }^{238}$ meinte er. Mobilität war ein weiteres Argument, das Furrer gegen die Thematisierung von Wundergeschichten im schulischen Religionsunterricht anführte. Kinder, die den Wohnort wechseln, würden mit Lehrern konfrontiert, die hinsichtlich der biblischen Wundererzählungen unterschiedliche Auffassungen hätten. Um den Kindern solche Irritationen zu ersparen, sollte man diese Thematik am besten gleich ganz weglassen. Auch ohne diese Wundererzählungen könne Jesus Christus nach Ansicht Furrers den Kindern problemlos nahegebracht werden: «Der Heldenmuth Jesu Christi, seine tiefe, innige Frömmigkeit, der unsagbar liebliche Hauch zartester Jugendlichkeit, die heilige Weihe, die über seinem ganzen Wesen ausgebreitet ist, die Freude, die aus ihm leuchtet, das Weh, das über ihn gekommen, der sonnige Friede Gottes in seinem Herzen, und der Fluch der Sünde, um dessentwillen dieses treuste Herz am Kreuz sterben muss, wahrlich, das ist genug, um ein unverdorbenes Gemüth zu innigstem Mitgefühl und voller Bewunderung zu entzünden und in andächtigem Schauen die Seligkeit eines erhöhten Daseins geniessen zu lassen.» ${ }^{239}$

236 Vgl. auch Anm. 224 auf S. 172.

237 Furrer 1872, 29.

238 Ebd.

239 Ebd., 30. 
Buisson erachtete es als zentrales Erziehungsziel, die Kinder daran zu gewöhnen nach empirischen Ursachen oder rationalen Gründen zu fragen. Nach seiner Meinung hätte jedoch die Erzählung von Wundergeschichten die gegenteilige Wirkung. Denn «gefährlich ist es, den Menschen auf den Kreuzwegen des Wunders zu Gott zu führen; d. h. ihn Gott durch die Einbildungskraft suchen zu lassen, anstatt dass er ihn durch die Vernunft einerseits und durch das Gewissen andererseits finden lerne». ${ }^{24}$

Die Wundergeschichten waren auch Thema in der Synode der Geistlichkeit, wobei diesbezüglich nicht argumentiert, sondern bloss Meinungen geäussert wurden. Pfarrer Wachter legte im Rahmen seiner Proposition auch einen Lehrplan für alle Schulstufen vor, worin deutlich wurde, dass «das Wunder jedenfalls nicht in den Unterricht der Alltagschule gehöre». ${ }^{24 \mathrm{I}}$ Demgegenüber entgegnete Diakon Fay in seiner Reflexion, «das Wunder aber dürfe nicht gestrichen werden». ${ }^{242}$

24I Protokoll der Synode der Zürcherischen Geistlichkeit, I4. I I. I 87I, 28.

242 Amtlicher Auszug aus Protokollen der Synode der Zürcherischen Geistlichkeit, I4. I I. I87I, 30 f. 


\section{Zivilreligiöse Erwartungen in der Diskussion um den schulischen Religionsunterricht 1872 - eine Analyse}

Die diese Arbeit leitende Frage, ob sich in der Diskussion um den schulischen Religionsunterricht anlässlich des Unterrichtsgesetzes von I 872 zivilreligiöse Aspekte zeigen, soll nun auf dem Hintergrund der im Unterkapitel 2.6 dargelegten Bestimmung des Begriffs Zivilreligion zu beantworten versucht werden. Ich orientiere mich bei dieser Analyse an den fünf Punkten dieser Begriffsbestimmung, die hier zusammenfassend nochmals genannt werden: I. Funktionale Ausdifferenzierung gesellschaftlicher Sphären; 2. Spannungsfeld zwischen Religionsfreiheit und Evokation von gesellschaftlicher Einheit; 3. Paradoxie von Zivilreligion: Die funktionale Ausdifferenzierung gesellschaftlicher Sphären ist vorausgesetzt, doch zugleich werden Tendenzen zur Auflösung ebendieser Grenzen freigesetzt; 4. Negation der historischen Kontingenz und Partikularität jeglichen Universalitätsanspruchs als Kulminationspunkt zivilreligiösen Glaubens; 5. Zwei Typen von Zivilreligion: der französische und der amerikanische Idealtypus.

\subsection{Funktionale Ausdifferenzierung und weltanschaulich-religiöse Heterogenität als Voraussetzung von Zivilreligion}

Der erste Punkt meiner Annäherung an den Begriff der Zivilreligion ist streng genommen nicht Teil der «Definition`, sondern identifiziert die Voraussetzungen, unter denen sich sinnvoll von Zivilreligion sprechen lässt. Zivilreligion setzt einerseits eine ausdifferenzierte Gesellschaft voraus und andererseits eine weltanschaulich-religiös heterogene Gesellschaft, in der schon ein gewisses Mass an Religionsfreiheit realisiert ist (vgl. Unterkapitel 2.6, S. 66 f.). Ausdifferenzierung bedeutet die voranschreitende Unterscheidung verschiedener gesellschaftlicher Sphären mit ihren Eigengesetzlichkeiten - primär die Unterscheidung zwischen Staat und Gesellschaft. Die Unterscheidung zwischen Staat und Gesellschaft ist grundlegend, damit innerhalb der Gesellschaft verschiedene Sphären unterschieden werden können. Erst diese Unterscheidung ermöglicht die Verhältnisbestimmung zwischen Staat und Kirche - oder anderen gesellschaftlichen Sphären. Unterscheidung bedeutet aber nicht zwingend Trennung. So kann ein Staat oder Kanton durchaus für die Kirche Steuern einziehen, ohne jedoch die inneren Angelegenheiten der Kirche mitzubestimmen. Religiös-weltanschau- 
liche Heterogenität ist eine weitere Voraussetzung von Zivilreligion, da nur dann überhaupt die Frage auftaucht, wie der gesellschaftliche Zusammenhalt angesichts unterschiedlicher Lebensorientierungen gewährleistet werden kann, worauf Zivilreligion eine mögliche Antwort ist. In diesem Kapitel soll erläutert werden, inwiefern diese beiden Voraussetzungen im Kanton Zürich um I870 tatsächlich gegeben waren.

Bis zur Helvetik kann streng genommen nicht von einer gesellschaftlichen Ausdifferenzierung gesprochen werden. Kirche und Staat bildeten seit der Reformation eine Einheit (cuius regio, eius religio) und die Kirche wurde nicht als institutionelle Macht einer eigenen gesellschaftlichen Sphäre - der religiösen erachtet, die eigenen Gesetzen folgt, sondern als Teil des Staates oder politischen Gemeinwesens. Kirchenmitgliedschaft und Staatsbürgerschaft waren eins und der Rat verfügte nicht bloss über die kirchliche Ordnung und Organisation, sondern auch über deren Lehre. ${ }^{1}$ Mit der Helvetik begannen sich die staatskirchlichen Strukturen allmählich aufzulösen. Die Helvetische Verfassung von 1798 wie auch die Mediationsverfassung von I 803 garantierten die Glaubens- und Gewissensfreiheit. Doch insbesondere der Erlass eines eigenen Kirchengesetzes im Jahre I 803 ist als erster Schritt zur Auflösung der Staatskirche und zur funktionalen Unterscheidung zwischen Staat und Kirche zu interpretieren. ${ }^{2}$ Der erste Artikel dieses Kirchengesetzes ${ }^{3}$ weist darauf hin, dass neu auch von Gemeinden ausgegangen wurde, die «sich nicht zur reformirten Religion bekennen» und somit auch nicht dieser Kirche angehörten. Seit 1798 gehörte das katholische Rheinau zu Zürich und seit I 803 auch das zum Teil katholische Dietikon. ${ }^{4}$ Ebenso setzt die Rede von einer «unter einer Aufsicht stehenden Kirche» die funktionale Unterscheidung zwischen Kirche und Staat voraus, da der Staat nur eine von ihm unterschiedene Grösse beaufsichtigen kann. 5 Doch erst $\mathrm{Pa}$ ragraph 2 des Kirchengesetzes von I83 I erlaubte explizit den Kirchenaustritt, ohne dadurch zugleich den Verlust der bürgerlichen Rechte nach sich zu ziehen. ${ }^{6}$ Als Indikator eines weiteren Ausdifferenzierungsschrittes kann Artikel 63 der Zürcher Staatsverfassung von 1869 angesehen werden, der zum einen die Glaubens-, Kultus- und Lehrfreiheit nicht nur der Landeskirche, sondern auch aller

I Vgl. Schmid 1994, I95; vgl. auch Unterkapitel 3.I, S. 7i f.

2 Vgl. Schmid I994, $20 \mathrm{I}$.

3 «Der Canton Zürich, in wie weit er sich zur reformirten Religion bekennt, macht eine, unter einer Aufsicht stehende Kirche aus.» (Kirchengesetz I 803, Art. I, zit. in Schmid I994, 201).

4 Vgl. Schmid 1994, 202.

5 Vgl. ebd., 20r $\mathrm{f}$.

6 «Wer seine Trennung von derselben förmlich erklärt, verliert das Recht, in kirchlichen Versammlungen zu rathen, zu stimmen, zu wählen, die Wählbarkeit zu kirchlichen Stellen und

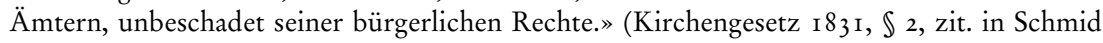
1994, 205). 
anderen kirchlichen Gemeinschaften bekräftigte und zudem auch jeden Zwang gegen Gemeinden, Genossenschaften und Einzelne ausschloss. Im Unterschied zu den anderen kirchlichen Genossenschaften blieb die Landeskirche gemäss Artikel 63 hinsichtlich ihrer Organisation jedoch durch staatliches Gesetz geordnet.7 Schmid weist nachdrücklich darauf hin, dass dies zur Folge hatte, dass der demokratische Staat die Landeskirche auf die Grundelemente der Demokratie verpflichtete und insbesondere «auf die auch innerkirchliche Gewährleistung der Glaubens- und Gewissensfreiheit». ${ }^{8}$

Wenn die Landeskirche Glaubens- und Gewissensfreiheit garantieren muss, dann stellt sich die Frage, inwiefern die Integrität der Landeskirche als Glaubensgemeinschaft gewährleistet ist oder werden kann. Eine Glaubensgemeinschaft wird dann als integrale Körperschaft respektiert, wenn sie innerhalb des Verfassungsrahmens ihre internen Angelegenheiten selber regeln und ihre eigenen Gesetze erlassen darf, ohne dazu von staatlich-politischen Entscheiden abhängig zu sein. Die Unterscheidung zwischen innen und aussen ist freilich nicht immer so eindeutig. Angewendet auf die Unterscheidung zwischen Kultus (innere Angelegenheit) und Organisation (äussere Angelegenheit), lässt sich diese Problematik am Beispiel der Taufpraxis sehr gut verdeutlichen. Aus theologischer Sicht ist der kultische Akt der Taufe seit urchristlichen Zeiten Zeichen der Zugehörigkeit zur christlichen Gemeinschaft und zugleich auch deren Bedingung. Als Kriterium der Mitgliedschaft gehört sie in den kirchlich-organisatorischen Bereich, die sich jedoch nicht von der kultischen Handlung loslösen lässt. Im Zusammenhang mit der Kirchenordnung von i90s akzeptierte der Regierungsrat den Satz in Paragraph 3 «Das religiöse Zeichen der Aufnahme in die christliche Kirche ist die heilige Taufe» auf dem Hintergrund der Verfassung gemäss Schmid «nur unter dem Vorbehalt, dass die Taufe juristisch tatsächlich nur als Zeichen und nicht etwas als Bedingung der Mitgliedschaft verstanden werde und demzufolge fakultativ sein müsse». ${ }^{9}$ Aus Sicht der Regierung hätte

7 Art. 63. der Kantonsverfassung von i 869: «Die Glaubens-, Kultus- und Lehrfreiheit ist gewährleistet. Die bürgerlichen Rechte und Pflichten sind unabhängig vom Glaubensbekenntnisse. Jeder Zwang gegen Gemeinden, Genossenschaften und Einzelne ist ausgeschlossen. Die evangelische Landeskirche und die übrigen kirchlichen Genossenschaften ordnen ihre Kultusverhältnisse selbständig unter Oberaufsicht des Staates. Die Organisation der erstern, mit Ausschluss jedes Gewissenszwanges, bestimmt das Gesetz.» (Zit. in Kölz 2000, 87 f. und Sträuli 1902, 233 f.)

8 Schmid I994, 207; vgl. auch Unterkapitel 3.I, S. 75. - Inwieweit die seit Mitte der I $840 e r$ Jahren schwelende Diskussion um die Entfernung des apostolischen Bekenntnisses aus der Taufagenda, dessen Verwendung I 868 in der zürcherischen Landeskirche dann auch tatsächlich für freiwillig erklärt worden ist, diesen Verfassungsentscheid mitbeeinflusst hat oder vielmehr umgekehrt die Diskussion um die Verfassung den Apostolikumsentscheid von I 868, kann in dieser Arbeit nicht entschieden werden.

9 Vgl. Schmid i 994, 208. 
die Taufe als Bedingung der Mitgliedschaft einen Gewissenszwang bedeutet und wäre deswegen mit der Verfassung in Konflikt geraten. Wenn die Kirche jedoch ihre eigenen Mitgliedschaftskriterien nicht selber definieren kann, sondern diese vom Staat bestimmen lassen muss, dann ist sie in ihrer Integrität beschnitten. Eine vergleichbare Verletzung der Sphärensouveränität würde stattfinden, wenn zum Beispiel die Kriterien für die Verleihung eines Master-Titels an einer Universität von einem politischen Gremium anstatt einem universitären bestimmt würden.

Die Problematik einer eingeschränkten Ausdifferenzierung von Kirche und Staat wurde auch in der Öffentlichkeit diskutiert, insbesondere von Seiten der Positiven. In den Monaten vor der Abstimmung über die neue Kantonsverfassung finden sich beispielsweise in der Zeitschrift Der Kirchenfreund gleich mehrere Beiträge zu dieser Thematik. Mitherausgeber J. Heer ${ }^{10}$ kritisierte in seinem Bericht über «Die zürcherische Synode» vom ıo. März I 869 die im Verfassungsartikel 63 gewählten Ausdrücke «Kultus- und Lehrfreiheit». Er sah in der Verwendung dieser Ausdrücke die Gefahr religiösen Wildwuchses. Denn damit werde nicht bloss jedem Menschen das Recht zugestanden, «nach seinem Wissen und Gewissen einen Glauben zu haben», sondern ebenso das Recht, diesen uneingeschränkt - das heisst, solange staatliche Zwecke dadurch nicht beeinträchtigt werden - in Kultus und Lehre zu bekennen und zu vermitteln. Heer befürchtete - und diese Furcht war auf dem Hintergrund des Aufruhrs um F. S. Vögelin in Uster nicht ganz unbegründet -, dass jeder Pfarrer in der Kirche erzählen könne, was ihm beliebe, ohne sich an irgendeine kirchliche Ordnung halten zu müssen. Mit dem so formulierten Verfassungsartikel wären aus seiner Sicht der Kirche rechtlich die Hände gebunden, eine solche Amtsperson zu massregeln. Heer fragte sich, warum «der Staat selbstverständlich innerhalb seiner Sphäre die Schranken gegen die Freiheit» ziehen dürfe, die seinen Zwecken zuwiderlaufe, die Kirche jedoch als intolerant bezeichnet werde, «wenn sie auf ihrem Gebiet dies auch für ein selbstverständliches Recht in Anspruch nimmt». ${ }^{\text {II }}$ Mit dem alternativen Ausdruck Religionsfreiheit sähe Heer die Gefahr gebannt, dass «innerhalb einer bestimmten bestehenden Religion, die in einer geschichtlich entstandenen Kirche in Kultus und Lehre zum Ausdruck kommt, durch die Anerkennung der Kultus- und Lehrfreiheit diese Gemeinschaft selbst aufgelöst

I0 J. Justus Heer (I840-I 886) war von I863 bis I865 Pfarrverweser und dann Pfarrer in Erlenbach. Ab i $88 \mathrm{I}$ amtete er als Mitglied des Zürcher Kirchenrats und I 885 promovierte er an der Universität Basel. Ab I 867 verfasste er als Mitherausgeber des Kirchenfreundes verschiedene theologische Artikel mit apologetischem Impetus. Er galt als positiver Theologe. Es war ihm jedoch ein Anliegen, zwischen einem biblisch-religiösen und einem naturwissenschaftlichen Weltbild klar zu unterscheiden (vgl. Stuber 2006).

I I Der Kirchenfreund, 2. 4. I 869, I 38, Anm. 2. 
und alle kirchliche Ordnung verunmöglicht [werde]». ${ }^{12}$ Mit diesen Einwänden drückte Heer sein Befremden gegenüber der Verletzung der Souveränität der kirchlichen Sphäre aus. Denn insofern die Kirche durch staatliches Gesetz geordnet ist, ist sie dem Staat untergeordnet und steht nicht als eine Sphäre eigenen Rechts neben dem Staat.

Korrespondent I. H. ${ }^{13}$ formulierte wenige Wochen zuvor in seinen Bemerkungen zu dem das Kirchenwesen betreffenden Artikel der neuen Zürcherischen Staatsverfassung seine in dieselbe Richtung zielenden Bedenken noch pointierter: «Indem der Staat den Gliedern der Landeskirche als Individuen, ja auch den Beamten der Kirche, die unbeschränkte Freiheit schützen will, nimmt er Andern die Freiheit, an dieser Landeskirche selber eine Glaubensgemeinschaft zu haben. Die Sache auf die Spitze getrieben könnte man sagen: der Staat verbietet der Landeskirche eine Kirche zu sein.» ${ }^{14}$ I. H. bringt hier die durch den besonderen Status der Landeskirche bedingte Einschränkung der Sphärensouveränität sehr deutlich zur Sprache. Eine Glaubensgemeinschaft im eigentlichen Sinne kann nicht bestehen, wenn ihr nicht zugestanden wird, ihre Mitgliedschaftskriterien selber zu bestimmen. Gemäss I. H. müsste in solch einem Fall eigentlich das durch die Verfassung garantierte Vereinsrecht angerufen werden, «da dieses doch wohl das Recht in sich begreift, bestimmte Statuten aufzustellen, denen die Mitglieder sich unterziehen müssen, oder ausgeschlossen werden können». is

Weil aber die Landeskirche als Volkskirche verstanden wurde - als eine Kirche für alle -, sollte es eben möglichst keine solchen Bestimmungen geben, denen die Mitglieder sich zwingend zu unterziehen haben bzw. die dazu berechtigen, jemanden auszuschliessen, der sich nicht an diese Bestimmungen hält. Doch gerade dieser Anspruch, eine Kirche für alle zu sein, kann dazu führen, dass ein Teil davon ausgeschlossen wird, nämlich diejenigen, die ein verbindliches Bekenntnis wünschen. In derselben Ausgabe des Kirchenfreundes drückt dies ein anderer (namenloser) Korrespondent folgendermassen aus: «Das zürcherische Volk [...] scheint zu merken, dass hier die Toleranz anfängt intolerant zu werden». ${ }^{16}$

Gemäss Schmid spiegelt sich der Übergang von der Staatskirche zur Landeskirche im Aufkommen des von Schleiermacher geprägten Begriffs der Volkskirche,

I2 Ebd., I 38 f.

I 3 Dieser als Korrespondent bezeichnete Autor wurde bloss mit den Initialen I. H. angegeben. Ich gehe davon aus, dass hier nicht Heer gemeint ist, da dieser korrekterweise mit den Initialen J. H. angegeben werden müsste.

I4 Der Kirchenfreund, 19. 2. I 869, 78.

is Ebd., 76 .

I6 Ebd., 83 . 
der durch Alexander Schweizer auch in Zürich Verbreitung fand. ${ }^{17}$ Mit dem Begriff der Volkskirche sollte ein Element der überkommenen Staatskirche in die neue Zeit hinübergerettet werden: der Grundsatz, dass die Kirche das ganze Volk umfassen sollte. Sie sollte sogar noch mehr als das sein: «Kirche durch das Volk. Kirche hin zum Volk. Kirche eines Volkes. Kirche für das Volk. Kirche für das Volksganze». ${ }^{18}$ Dahinter steht gemäss Schmid die Vorstellung, die Kirche von ihrem Auftrag her zu definieren und nicht wie bei der Staatskirche vom Staat oder bei einer Bekenntniskirche von den Bekennenden her. Der Auftrag ist die Verkündigung des Wortes Gottes und das Spenden der Sakramente. Da die Verkündigung sich jedoch an alle Menschen richtet, hat die Kirche für das ganze Volk offen zu sein und ihm zu dienen; und auch durch das Volk mitgestaltet zu werden. Aus volkskirchlicher Perspektive ist die Kirche weder eine staatliche Institution noch ein privater Verein, sondern eine Institution mit einem öffentlichen Auftrag, einem Volksauftrag, der jedoch auch dem Staat zugutekommen soll. ${ }^{19}$ Es ist dieses Konstrukt Volkskirche, das eine vollständige Ausdifferenzierung von Staat und Kirche verhindert.

Was impliziert dieser Befund nun für die in dieser Arbeit interessierende Frage nach Zivilreligion? Gemäss meinem Verständnis kann von Zivilreligion sinnvoll nur auf dem Hintergrund einer ausdifferenzierten Gesellschaft gesprochen werden. Doch wie sich gezeigt hat, war dies um I870 im Kanton Zürich nur teilweise der Fall, obwohl seit der Helvetik auf verschiedenen Ebenen Ausdifferenzierungsprozesse in Gang kamen und die Gesellschaft vielfältiger wurde, was sich auch auf institutioneller Ebene abbildete. I862 wurden die Ausnahmegesetze für Juden aufgehoben ${ }^{20}$ und die Israelitische Cultusgemeinde Zürich gegründet. ${ }^{21}$ I 863 wurde das «Gesetz betreffend das katholische Kirchenwesen» erlassen, das die vier bisherigen römisch-katholischen Pfarreien Rheinau, Dietikon, Zürich und Winterthur zu öffentlich-rechtlichen Kirchgemeinden mit Steuerrecht erhob und die Möglichkeit zuliess, weitere Kirchgemeinden zu bilden. ${ }^{22}$ Allerdings waren die Katholiken mit diesem Gesetz und auch der neuen Verfassung von i 869 nicht glücklich. Die verfassungsmässige Bestimmung, dass die Wahl bzw. Wiederwahl von Pfarrern durch

I7 Vgl. Schmid I994, $209 \mathrm{f}$.

I8 Ebd., 2 Iо.

I9 Vgl. ebd., 2 I०.

20 Auf eidgenössischer Ebene wurde erst mit der Teilrevision der Bundesverfassung von I 866 die Niederlassungsfreiheit und die volle Ausübung der Bürgerrechte gewährt und auch dies nur unter wirtschaftlichem Druck von aussen! Erst I 874 wurde die revidierte Bundesverfassung angenommen, die den Juden gleiche Rechte inkl. Religions- und Niederlassungsfreiheit garantierte (vgl. Erlanger 2013).

2 I Vgl. Brunschwig 2009.

22 Vgl. Schmid I994, 206. 
die Kirchgemeinde erfolgen sollte, war für die reformierte Kirche insofern ein Fortschritt, als damit der Einfluss von aussen beschnitten wurde. Für die Katholiken hingegen führte diese Bestimmung zu einem unmittelbaren Konflikt mit dem kanonischen Recht, gemäss dem der Pfarrer durch den Bischof und nicht durch die Gemeinde legitimiert wird. Des Weiteren sollte es für die Katholiken wegen des neuen obligatorischen Gesetzesreferendums schwieriger werden, neue Gemeinden zu gründen. ${ }^{23}$

Zusammenfassend lässt sich festhalten, dass infolge der bloss teilweisen Ausdifferenzierung von Kirche und Staat nur in eingeschränktem Sinn von Zivilreligion zu sprechen ist. Die Voraussetzungen für die Entwicklung von Zivilreligion sind aber dennoch gegeben, insofern ein zentraler Aspekt von Ausdifferenzierung, nämlich die Trennung von Bürgerrecht und Bekenntnispflicht, sich durchgesetzt hatte. Die spezifisch zürcherische Ausprägung von Zivilreligion soll in den folgenden Kapiteln herausgearbeitet werden, insbesondere auch in Abgrenzung zur liberal-theologischen Agenda, die von kirchlichen und staatlichen Funktionären portiert wurde.

\subsection{Spannungsfeld zwischen Religionsfreiheit und der Evokation von gesellschaftlicher Einheit}

Gemäss meiner Arbeitsdefinition des Begriffs der Zivilreligion (vgl. Unterkapitel 2.6, S. 67) ist Zivilreligion im Spannungsfeld zwischen gesellschaftlicher Ausdifferenzierung und Religionsfreiheit einerseits und dem Bemühen um gesellschaftliche Einheit und Integration andererseits anzusiedeln und wird oft als eine mögliche Antwort auf dieses ungelöste Problem angesehen. Ausgehend davon, dass lange Zeit die Kirche und ihre religiösen Praktiken die gesellschaftliche Klammer bildete, stellt sich die Frage, wie in einer Gesellschaft, in der die Kirche und ihre Inhalte zunehmend an Bedeutung und Kraft verlieren, der gesellschaftliche Zusammenhalt gewährleistet werden kann.

Nur wer das Fehlen eines die Gesellschaft einigenden sittlich-religiösen Bandes als Spannung erlebt, kann überhaupt, so meine These, zivilreligiöse Tendenzen entwickeln. Um meine Forschungsfrage, ob sich in der Diskussion um den schulischen Religionsunterricht zivilreligiöse Tendenzen zeigen, beantworten zu können, muss demnach nebst dem Aufweis einer zumindest in Ansätzen ausdifferenzierten Gesellschaft (vgl. Unterkapitel 7.I, S. I77) bei den Anwärtern für zivilreligiöse Tendenzen ein mehr oder minder ausgebildetes Bewusstsein dieser Spannung aufgezeigt werden. Das Bewusstsein einer 
solchen Spannung führt allein jedoch noch keineswegs $\mathrm{zu}$ zivilreligiösem Denken. Denn es gibt unterschiedliche Weisen, mit dieser Spannung umzugehen. Die rechtlich-politische Gemeinschaft als solche kann bereits als relative Einheit angesehen werden, ohne dass ein gemeinsamer (zivil)religiöser Glaube als konstitutiv für die erhoffte gesellschaftliche Einheit angenommen werden muss. Oder anders gesagt: Das Fehlen eines sittlich-religiösen vereinheitlichenden Bandes (oder zumindest dessen nachlassende Beständigkeit) muss keineswegs als Verlust betrachtet werden, sondern kann durchaus auch als positive Entwicklung in Richtung einer pluralistischen Gesellschaft begrüsst werden.

Im Folgenden soll anhand von Beispielen aufgezeigt werden, dass in der Diskussion um den schulischen Religionsunterricht sowohl Stimmen auszumachen sind, bei denen kein Bewusstsein für diese Spannung sichtbar wird (Unterkapitel 7.2.I), wie auch diejenigen, die die durch die Verfassung garantierte Glaubensund Gewissensfreiheit befürworteten, darin zugleich aber auch Spannungspotential im Hinblick auf die gesellschaftliche Einheit erblickten. Wie sich zeigen wird, gab es jedoch unterschiedliche Arten, mit dieser Spannung umzugehen (Unterkapitel 7.2.2 und 7.2.3).

\subsubsection{Fehlendes Spannungsbewusstsein angesichts der konfessionellen Homogenität der Gesellschaft}

Von der Wahrnehmung der Situation der Gesellschaft hängt ab, welche gesellschaftlichen Veränderungen angestrebt werden. Wer der Gesellschaft religiöskonfessionelle Homogenität attestiert oder unterstellt, wird sich nicht um gesellschaftliche Einheit in sittlich-religiöser Hinsicht bemühen. Ein Artikel im Volksblatt für die reformirte Schweiz bescheinigt, dass es Akteure gab, denen ein Bewusstsein für die Spannung zwischen Religionsfreiheit und der Evokation von gesellschaftlicher Einheit fehlte, weil ihrer Meinung nach das Zürcher Volk (noch) eine konfessionell-religiöse Einheit bildete. Dieser Artikel erschien ein paar Wochen nach der Abstimmung über das Unterrichtsgesetz. Als wesentlicher Grund für die Verwerfung des Unterrichtsgesetzes diagnostizierte der Verfasser neben der Abneigung des Volkes gegen die erweiterte Alltagsschule die verbreitete Wahrnehmung der Gesellschaft als konfessionelle Einheit, die zur Ablehnung des konfessionslosen schulischen Religionsunterrichts geführt habe. Die konfessionslose Schule sei ein «Begriff, der auf katholischem oder wenigstens paritätischem Boden sich gebildet hat und nun sehr übereilt auch da angewendet werden will, wo sozusagen das ganze Volk der gleichen und zwar der protestantischen Confession zugebört, in der das Element der Freiheit schon enthalten ist. Unser Volk hat ein noch viel bestimmteres konfessionelles Bewusstsein, als der oberflächliche Blick zu 
erkennen glaubt, und darum ist auch auf diesem Gebiet das Experimentiren übel angebracht». ${ }^{24}$

Das einheitsstiftende Moment sieht dieser Autor in der dem Protestantismus inhärenten Freiheit, die aus dieser Perspektive offenbar über allen innerreformierten Richtungsstreitigkeiten steht. Zugleich wird damit dem Katholizismus unterstellt, freiheitsfeindlich zu sein. Dem konfessionslosen Religionsunterricht scheint der Autor freiheitsfördernde und somit antikatholische Wirkung zuzuschreiben und ihn deshalb für katholische und paritätische Gebiete zu befürworten. Doch da die Freiheit in einem Kanton wie Zürich, in welchem praktisch alle Bürger reformiert sind, bereits gegeben ist, erübrigt sich nach dieser Logik auch ein konfessionsloser Religionsunterricht.

\subsubsection{Auflösung der Spannung durch Evokation von Einheit}

Der Verweis auf die einheitsstiftende Funktion der öffentlichen Schule und ihres Religionsunterrichts war in den Diskussionen um den schulischen Religionsunterricht ein beliebter Topos. Johann Heinrich Müller ${ }^{25}$ argumentierte im zürcherischen Verfassungsrat gegen den Vorschlag, den Religionsunterricht auf der Real- oder Sekundarstufe von den Geistlichen erteilen zu lassen, dahingehend, «dass die Einheit unter den Kindern nicht dadurch gestört werden sollte, dass man sie nach ihrer, resp. ihrer Eltern Religion, in ganz verschiedene Klassen trennt». ${ }^{26}$ Verfassungsrat Sieber argumentierte in derselben Sitzung im Anschluss an das Votum von Müller in dieselbe Richtung, wenn er betont, dass er ungern sähe, wenn «jede Konfession ihren Unterricht selbst ertheilen sollte. Das Auseinanderreissen der Kinder nach religiösen Parteien würde unendlich nachtheilig fortwirken auf das ganze Leben der Betreffenden». ${ }^{27}$

Die Ko-Existenz unterschiedlicher Konfessionen schien Sieber viel eher als Gefahr denn als Bereicherung oder auch nur als unvermeidliche Tatsache zu interpretieren. Um die religiöse Neutralität der Schule zu gewährleisten bzw. «den jeweiligen konfessionellen Standpunkt und Willen der Eltern» zu berücksichtigen, forderte Sieber sogar, den Religionsunterricht gleich gänzlich «aus dem Unterrichtsprogramm der Schule» ${ }^{28}$ auszuscheiden. Dies begründete er

24 Volksblatt für die reformirte Schweiz, 4. 5. I872, 90, Hervorhebung R. K.

25 Johann Heinrich Müller (I 829-189I) studierte Theologie in Zürich (1849-1853) und war Vikar, Verweser und Pfarrer in verschiedenen Gemeinden des Kantons Zürich. Er war Grossrat (I 862-I 869), Bezirksstatthalter von Hinwil (I 868-1 869), demokratischer Verfassungsrat und Mitglied der 35 er Kommission (I 868-I 869), Regierungsrat (I 869-1 877), Kantonsrat (I 883 bis I 887), Präsident der Sekundarschulpflege Fischenthal (i 862-I 864) und Benken (i 88 5-I 89 I), Bezirksschulpfleger (г 862-ı864). Müller galt als eine wichtige Figur der Demokratischen Bewegung (vgl. Bürgi 2009).

26 Verhandlungs-Protokoll des zürcherischen Verfassungsrathes, 9. 7. I 868, 4.

27 Ebd.

28 Verhandlungs-Protokoll des zürcherischen Verfassungsrathes, 8. 7. I 868, 9. 
damit, dass «der Standpunkt der Ausscheidung der Kinder in verschiedene Erziehungsanstalten nach den verschiedenen Konfessionen [...] nicht mehr haltbar [ist]; wir sind weiter gekommen und lassen sogar innerhalb einer Konfession den Dogmenzwang nicht mehr gelten». ${ }^{29}$

Verfassungsrat Bosshard forderte zwar nicht wie Sieber die Aufhebung des Religionsunterrichts, aber dass dieser «auf neutralem Boden» erteilt werde, «damit die Kinder nicht schon in den ersten Schuljahren nach Konfessionen sich unterscheiden». ${ }^{30}$ In Anbetracht dessen, dass die Schule «eine staatliche Anstalt» sei und eine staatliche Schulpflicht bestehe, müsse «man auch dafür sorgen, dass aller Eltern Kinder in die Schule gehen können». ${ }^{1}$ Bosshard hielt dies aber nur für möglich, wenn der Unterricht ihren religiösen Vorstellungen nicht widerspreche.

Wie bereits oben erwähnt (vgl. Unterkapitel 6.3, S. I 29), wurde im Verfassungsrat angesichts der Brisanz der Thematik hinsichtlich des Religionsunterrichts nichts entschieden und die Diskussion von der Verfassungsebene auf die Gesetzesebene verschoben. In den von mir gesichteten Quellen der auf dieser Ebene geführten Diskussion habe ich keine Stimmen gefunden, die durch die Kantonsverfassung in Artikel 63 garantierte Glaubens-, Kultus- und Lehrfreiheit grundsätzlich in Frage gestellt hätten. Über die Folgen dieses Verfassungsartikels hinsichtlich des schulischen Religionsunterrichts war man sich allerdings uneinig. In der Kantonsratsdebatte über Paragraph I4 des neuen Unterrichtsgesetzes wandte sich Pfarrer Scheller gegen die Ansicht, dass Artikel 63 der Verfassung «dazu zwinge, den Religionsunterricht aus der Schule wegzulassen».32 Zum Zeitpunkt der Entstehung dieses Verfassungsartikels sei es keinem Menschen eingefallen, ihm die jetzt übliche Interpretation zu geben. Artikel 63 spreche «nur aus, dass kein Vater gezwungen sei, seine Kinder am Religionsunterricht Theil nehmen zu lassen, wenn er nicht will; mit anderen Worten der Religionsunterricht ist nicht mehr obligatorisch».33

Der Verweis auf die Verfassung galt Scheller nicht als ausreichendes Argument für die Abschaffung des Religionsunterrichtes. Für die Beibehaltung des Religionsunterrichtes an der Schule sprach für Scheller, dass es «keine von allem Religiösen losgelöste Sittenlehre» ${ }^{4}$ gebe. Obwohl Scheller Zwang hinsichtlich des Religionsunterrichtes ganz klar ausschloss, betonte er gemäss der Berichterstattung im Landboten «die vorbereitende, versöhnende, sozial vermittelnde

29 Ebd.

30 Verhandlungs-Protokoll des zürcherischen Verfassungsrathes, 9. 7. I 868, $3 \mathrm{f}$.

3 I Ebd.

32 NZZ, I I. I. I872.

33 Ebd.

34 Ebd. 
Aufgabe der Schule und ihres Religionsunterrichtes».35 Zudem befürchtete er, dass ohne Religionsunterricht «die Herzens- und Gemüthsbildung der Jugend» leide und das Sektenwesen «erst recht zur Blüthe gedeihen» ${ }^{36}$ werde. Laut NZZ beendete Scheller seine Argumentation für den Religionsunterricht bzw. gegen Lemma I von Paragraph I4 folgendermassen: «Nimmt man aber dieser [Volksschule] den Religionsunterricht weg, so schlägt man der Schule den Kopf und die Glieder ab, es mangelt ihr das Einigende und Alles Beseelende, und es entgeht ihr die schönste Vermittlung mit dem Leben. Lasse man statt Feindschaft zwischen Kirche und Schule zu verkünden, beide Mächte gemeinsam in guten Treuen vereint arbeiten an der sittlichen Hebung des Volkes!»37

Nach dieser Auffassung steht der Religionsunterricht im Dienste der Sittlichkeit und hat einen einigenden Zweck. Interessant ist, dass Scheller Artikel 63 der Verfassung nicht im Sinne einer positiven, sondern bloss einer negativen Freiheit auslegt. Dies scheint bei allen, die die verbindende Funktion der Schule und im Speziellen des schulischen Religionsunterrichts betonen, der Fall zu sein. Eine die positive Freiheit berücksichtigende Auslegung von Artikel 63 könnte jedoch die Förderung einer Vielfalt von religiösen Bekenntnissen oder zumindest deren Institutionalisierung zur Folge haben. Ein religiöser Pluralismus scheint jedoch von dieser Seite her keineswegs fördernswert. Die Angehörigen der verschiedenen Konfessionen sollen lediglich in der Ausübung ihres Glaubens nicht gehindert werden. Das Spezifische, Konfessionelle scheint nicht im positiven Sinn als Bereicherung aufgefasst worden zu sein, sondern viel eher im negativen Sinn als einheitszerstörend. Aus dieser Sichtweise folgt die Forderung, im schulischen Religionsunterricht nicht die konfessionellen und dogmatischen Eigenheiten zu vermitteln, sondern vielmehr das, was die Menschen verbindet. Dieser Forderung verlieh auch Friedrich Salomon Vögelin deutlich Ausdruck in seiner Rede, die er wenige Tage vor dem Abstimmungstag über das Unterrichtsgesetz an einer von den Gewerkschaften und Arbeitervereinen organisierten Volksversammlung hielt (vgl. Unterkapitel 6.5, S. I65 f.).

Ähnlich argumentierte auch Pfarrer Konrad Furrer - Vögelins Nachfolger auf der Pfarrstelle in Uster - für einen konfessionslosen Religionsunterricht und gegen die Abschaffung des Religionsunterrichts in seiner Schrift Der confessionslose Religionsunterricht: «Nicht die Religion zerklüftet, sondern der Confessionalismus und Dogmatismus, $d$. h. die übertriebene Werthschätzung der abstracten Formeln, der Bilder und Vorstellungen, in die der reflektirende

35 Der Landbote, I3. I. I 872.

36 NZZ, i I. I. I 872 .

37 Ebd. 
Verstand die Erfahrungsthatsachen der Lebensgemeinschaft des Menschen mit Gott zu fassen sucht»..$^{8}$

Wie bereits weiter oben gezeigt wurde (vgl. Unterkapitel 6.3.2, S. I48), sind in Furrers scharfer Unterscheidung zwischen Religion und Dogmatik Anklänge an Schleiermacher nicht zu übersehen, auch wenn er selbst - zumindest in seinem Traktat über den konfessionslosen Religionsunterricht - nicht explizit darauf verweist. Da zwischen liberalen und konservativen Theologen auf allen Ebenen Dissens herrsche, sei es unmöglich, hinsichtlich dogmatischer Kenntnisse einen gemeinsamen kleinsten Nenner zu finden. ${ }^{39}$ Doch Religion bzw. die «sittlich-religiöse Anlage» ist, so Furrer, im Unterschied zu einer bestimmten Religion oder religiösen Ausprägung «dem Menschen angeboren».4 Er verweist in diesem Zusammenhang auf ethnologische Forschungen, die gezeigt hätten, dass es kein Volk ohne Religion gebe. Das, was den Menschen vom Tier unterscheide, sei «das Gefühl der Abhängigkeit von einer höhern unsichtbaren Macht».4 Furrer geht von einer Gemeinschaft zwischen Gott und Menschen aus, «die auf keinen confessionell-dogmatischen Voraussetzungen, sondern auf den von Gott eingepflanzten tiefsten Bedürfnissen des menschlichen Gemüthes beruht».42 Diese Überzeugung bildet denn auch die Grundlage für Furrers Programm des konfessionslosen Religionsunterrichts: Die Kinder sollen zu «einer Gottesgemeinschaft» herangeführt werden, «für die alle Bilder und Begriffsbestimmungen nur ein ungenügender Ausdruck sind; wecken wir in ihnen die hohen, heiligen Ahnungen des Unendlichen und Ewigen, schärfen wir ihr Gewissen und entflammen wir in ihnen die Begeisterung für die unsterblichen Güter des gottinnigen Lebens!»43

Furrer ignoriert weder wie das Volksblatt für die reformirte Schweiz vom 4. Mai I 872 in seiner Begründung für die Ablehnung des konfessionslosen schulischen Religionsunterrichts die konfessionelle Heterogenität noch die innerreformierten Richtungsstreitigkeiten (vgl. Unterkapitel 7.2.I). Doch er erachtet diese Unterschiede als auf der Oberfläche liegend. Das, was unter dieser trennenden Oberfläche liegt und alle Menschen vereint - die sittlich-religiöse Anlage bzw. ein tiefes Bedürfnis nach Gemeinschaft mit Gott -, soll im und durch den Religionsunterricht geweckt werden. Nebst pädagogischen und theologischen Argumenten spreche gemäss Furrer aber auch ein «patriotisches Interesse» für einen konfessionslosen Religionsunterricht. «Man rühmt vielfach die Toleranz

38 Furrer i $872,7$.

39 Vgl. ebd., I 2.

40 Ebd., I3.

4I Ebd.

42 Ebd., I5.

43 Ebd. 
unsers Zeitalters. Aber so lange man für den Glauben, der den Andern heilig ist, nur Urtheile des Hasses oder Spottes hat, so lange kann man von wabrer Toleranz nicht reden; denn diese gründet sich auf den Glauben an die innerste Einheit der sittlichen und religiösen Gesinnung bei aller Verschiedenheit der dogmatischen Kirchenlehre. [...] nur die Anerkennung einer auf Gleichbeit der Gesinnung gegründeten Gemeinschaft [kann] die Gefahr allgemeiner geistiger Auflösung und Zerfahrenheit bannen und uns damit vor dem Rückfall in sittliche Barbarei bewahren».44

Der Religionsunterricht wird hier explizit in den Dienst der Toleranzförderung und somit eines friedlichen und gesitteten gesellschaftlichen Zusammenlebens gestellt. Furrer betont die einheitsstiftende Funktion von Religion und hegt hohe Erwartungen an den Religionsunterricht, wenn er hofft, «dass in unsern Tagen die Religion vielmehr wieder die Geistesmacht werde, welche die Söhne des Vaterlandes aus aller Parteiung in politischen und socialen Fragen, in merkantilen und wissenschaftlichen Interessen zur Versöbnung und Einbeit zurückfübre, und dass über alle Hemmnisse triumphire der gottbegeisterten Liebe unsterbliche Kraft!»45

Unter anderem auch aus patriotischen Überlegungen setzt sich Furrer im Unterschied zu beispielsweise Ferdinand Buisson für die Verwendung von Schriften aus dem Alten Testament im Religionsunterricht ein (vgl. Unterkapitel 6.6.2). Zwar erachtet auch er nicht jede alttestamentliche Schrift als aus pädagogischer Sicht geeignet und plädiert für eine weise Auswahl. Doch sei die Geschichte des Volkes Israels dazu angelegt, «die Gefühle der Vaterlandsliebe zu wecken und zu heiligen, das Bewusststein von der Solidarität eines Volksganzen zu kräftigen und die göttlichen Gesetze, welche das Leben in grossen Kreisen beherrschen, zu wirksamer Anschauung zu bringen».46

Der Religionsunterricht soll also im Verständnis von Furrer weit mehr als bloss in den christlichen Glauben einführen. Ihm wird explizit auch eine in nationalpolitischer Hinsicht einheitsstiftende Funktion zugeschrieben. Insofern Furrer vom «Volksganzen» und der politischen Gemeinschaft als Integrationshorizont ausgeht, ist aber auch er immer noch in Partikularismen verhaftet - so könnten kritische Stimmen anmerken. Denn Volk verweist auf eine Gruppe von Menschen mit gleicher Kultur und Sprache und Vaterland auf eine konkrete politische Gemeinschaft mit territorialen Grenzen.

Diese Partikularismen versucht nun F. S. Vögelin zu transzendieren, indem er nichts weniger als «die Menschheit» als Integrationshorizont wählt. Dieses Anliegen wird in der Eröffnungsrede der Lehrersynode in Wädenswil, die

44 Ebd., 43, Hervorhebung R. K.

45 Ebd., 45, Hervorhebung R. K.

46 Furrer I 872, 25, Hervorhebung R. K. 
Vögelin I 879 als deren Präsident zum Thema Schulobligatorium hielt, besonders deutlich. ${ }^{47}$ Hier beschreibt Vögelin als Aufgabe des Staates und als Aufgabe jedes einzelnen Lehrers, «von seinem Lehrobligatorium Alles ferne zu halten, was an die Stelle des Allgemeinen das Partikularistische setzt, was dem Menschheitsziel nicht fördernd entgegenkommt».48 In dieser Rede tritt die Spannung zwischen der Betonung moderner Errungenschaften wie der individuellen Freiheitsrechte einerseits und dem Streben nach gesellschaftlicher Homogenität sowie einem Glauben an die menschliche Einheit andererseits besonders deutlich zum Vorschein. ${ }^{49}$

Im ersten Teil der Rede analysiert Vögelin ausführlich die Schwierigkeiten des Schulobligatoriums. Dieses bietet dann Konfliktpotential, wenn die «Familienansichten mit dem öffentlichen Geiste, wie er sich in den Schulen ausspricht und fortpflanzt, im Widerspruch stehen».50 Auf der Grundlage der modernen Kultur wird sich der Vater «auf das Selbstbestimmungsrecht des Individuums in geistigen Dingen berufen ${ }^{\text {`I }}$ und seine Kinder der Gefährdung durch entgegenstehende Lehren und Anschauungen entziehen wollen. Trotz der verständlichen Berufung des Vaters auf sein Selbstbestimmungsrecht sprechen für Vögelin zwei Gründe für ein Obligatorium: I) Es gelte nicht bloss das individuelle Selbstbestimmungsrecht des Vaters, sondern auch die individuelle selbstständige Entwicklung der Kinder zu schützen «gegenüber der Einengung in den Kreis geschlossener Familienansichten».52 2) Obwohl der Mensch einerseits zuerst Individuum und dann Familienmitglied ist, ist er andererseits «nicht blos Familienangehöriger, sondern Staatsangehöriger, Volksglied».53 Daraus folgt, dass nicht bloss die Familie, sondern auch der Staat Ansprüche an die Kinder hat. Dieser hat nicht nur das Interesse, dass die heranwachsende Generation seine Anschauungen kennenlernt, «sondern dass sie sie in sich aufnehme und weiter fortpflanze». 54

Nach dieser Argumentation für ein Schulobligatorium folgt in Vögelins Analyse eine erste, erstaunliche (Gegen-)Wendung. Gemäss Vögelin «gibt es noch

47 In der folgenden zusammenfassenden Darstellung dieser Rede orientiere ich mich an Katzenstein 2017.

48 Vögelin I 879, Pädagogischer Beobachter, Heft 39, 2.

49 Da die Spannung zwischen individuellen Freiheitsrechten und dem Streben nach gesellschaftlicher Einheit bei Vögelin deutlich zum Ausdruck kommt, werde ich im Folgenden ausführlich auf diese Rede eingehen, obwohl sie einige Jahre nach der Diskussion um das Unterrichtsgesetz von i 872 gehalten worden ist.

50 Vögelin I 879, Pädagogischer Beobachter, Heft 37, I.

5 I Ebd.

52 Ebd., 2.

53 Ebd.

$54 \mathrm{Ebd}$. 
einen weiteren Kreis des Daseins als den Staat, das ist die Welt»."ss So wie es keiner Familie möglich ist, den Staat zu ersetzen, kann auch kein Staat die Menschheitsgemeinschaft darstellen. Und so erhebt sich wie bei der Familie auch in Bezug auf den Staat die Frage: «Hat der Staat die Möglichkeit und hat er das Recht, seine Angehörigen durch obligatorische staatliche Bildung auf die ihm eigenthümlichen Gesichtspunkte einzuschränken?» ${ }^{6}$ Vögelin diskutiert diese Frage zuerst hinsichtlich des «Religions-Obligatoriums» und kommt zum Schluss, dass auf dem Hintergrund «der unaufhaltsam Platz greifenden Erkenntniss von dem Individualcharakter des religiösen Lebens» 57 ein $\mathrm{Ob}$ ligatorium für den schulischen Religionsunterricht nicht mehr opportun sei. Es dränge sich jedermann «das individuelle Wesen der Religion und die Unmöglichkeit auf, hier für Andere verpflichtende Gefühls oder Begriffsnormen aufzustellen, also irgend welchen Zwang in religiösen Dingen auszuüben». ${ }^{8}$ Der Staat werde deshalb «in seinem Schulobligatorium gerade auf denjenigen Faktor verzichten müssen, der früher als Grundlage aller Bildung galt, auf die Religionsbelehrungen».59

In einem zweiten Schritt diskutiert Vögelin diese Frage nun aber auch noch hinsichtlich der Moral. Um der Moral eine «von den Forderungen der konfessionellen Dogmatik unabhängige Stellung zu sichern», habe man die totale Unabhängigkeit der Moral von der Religion propagiert. Man habe «der Moral, genau wie kurz vorher der Religion, eine gewissermassen voraussetzungslose Allgemeinheit, Uebereinstimmung und Unwandelbarkeit» zugewiesen im Glauben, dass im Unterschied zur «konfessionellen resp. religiösen Beschränkung [...] in der Moral das allgemein Menschliche» verkündet werde. Diese «aller geschichtlichen und psychologischen Beobachtung widerstreitende Ansicht» könne man «heutzutage» gemäss Vögelin nicht mehr teilen. «Wenn aber in Wirklichkeit die Moral in unabtrennbarem Zusammenhang steht mit den [...] religiösen, mit den historischen und politischen Anschauungen des Einzelnen», stellt sich die Frage, «ob denn der Staat ein Recht habe, eine spezielle, von diesen und diesen Voraussetzungen bestimmte Moral als obligatorischen Lehrstoff für seine Angehörigen zu erklären». ${ }^{60}$

Diese kritische Frage stellt Vögelin nun auch noch bezüglich des Geschichtsunterrichts. Denn man müsse sich eingestehen, dass auch dieser «nicht, wie

55 Vögelin r 879, Pädagogischer Beobachter, Heft 39, I.

56 Ebd.

57 Ebd.

58 Ebd.

59 Ebd.

60 Ebd. 
man anzunehmen liebt, zu den objektiven ${ }^{61}$ Lehrfächern gehört, sondern zu denjenigen, welche eine individuelle Auffassung der Erscheinungen der Welt widerspiegeln. Und da auch diese individuelle Auffassung von religiösen und politischen Gesichtspunkten abhängig ist, so wäre nicht unmöglich, dass jene Konsequenz, die den Religionsunterricht vom Schulobligatorium ausschliesst und der die Moral auf die Länge wohl nicht widerstehen kann, dereinst auch den Geschichtsunterricht erreicht». ${ }^{62}$

Vögelin verwendet einen grossen Teil seiner Redezeit dazu, auf überzeugende Weise darzulegen, dass ein Schulobligatorium in einer Zeit, die so stark wie nie zuvor das Recht auf individuelle Entwicklung fordert, eigentlich nicht angebracht sei. Doch ganz zum Schluss seiner Rede vollzieht er erneut eine überraschende Wende - nun wieder zu Gunsten des Schulobligatoriums -, die allerdings argumentativ weit weniger überzeugt als der vorhergehende Gedankengang, in dem er die Problematik der Vermittlung von Religion, Moral und sogar Geschichte in einer obligatorischen Schule aufzeigt.

Vögelin beginnt seine Argumentation mit der Prämisse, dass die jetzige Zeit nicht bloss eine Zeit der grössten Individualisierung sei, sondern zugleich auch «das Zeitalter der grössten Assoziationsbestrebungen». Die Betonung der «geistigen Unabhängigkeit des Individuums» sieht Vögelin als «Nothwehr gegenüber der unwiderstehlichen Assoziationsbewegung. Dieser Bewegung wird auch das Bildungswesen sich unmöglich entziehen können. Man wird auch hier wieder zu gemeinsamen Grundlagen kommen, auf denen sich der Volksunterricht einheitlich und, dem Bedürfniss des Staates entsprechend, obligatorisch aufbauen lässt.» ${ }^{63}$

Vögelins Darlegungen erhalten hier unvermittelt einen fast beschwörenden Charakter. An dieser Stelle hat die Spannung zwischen individuellen Freiheitsrechten und dem Streben nach Einheit ihren Höhepunkt erreicht. Sie wird aber nicht durchgehalten, sondern sogleich einseitig in Richtung Vereinheitlichung aufgelöst. Denn trotz den von ihm im ersten Teil seiner Rede präzis beschriebenen Individualisierungstendenzen seiner Zeit, scheint es für Vögelin letztendlich

6I Dass Vögelin dem Geschichtsunterricht hier die Objektivität abspricht, ist auf den ersten Blick überraschend angesichts dessen, dass er sich in seiner Rechtfertigungsrede für sein Geschichtslehrmittel, die er im Auftrag der Erziehungsdirektion «in den Versammlungen der zürcherischen Schulkapitel» hielt und danach im Druck folgen liess, dafür rühmt, in seinem Lehrmittel nicht «die politische Anschauung einer bestimmten Partei» (Vögelin I874, 8) zu vertreten. Vielmehr seien darin «objektive Gesichtspunkte» aufgestellt und gewisse «unabänderliche Thatsachen fixirt» (Vögelin I874, I0; vgl. auch Greiner 1933, I04 f.) In diesen widersprüchlich scheinenden Aussagen zeigen sich Vögelins unterschiedliche Intuitionen, die er letztlich, wie ich weiter unten noch ausführen werde, nicht in ein kohärentes System zu bringen vermag (vgl. auch Katzenstein 2017).

62 Vögelin I 879, Pädagogischer Beobachter, Heft 39, I f.

63 Ebd., 2. 
doch nur eine Richtung zu geben, in die alle Menschen notwendigerweise streben und in diesem Streben sich vereinen werden. Die Tatsache, dass Menschen unterschiedliche Vorstellungen vom guten Leben haben, bestreitet Vögelin, wie im ersten Teil der Rede deutlich geworden ist, keineswegs - im Gegenteil. Doch er wertet sie $\mathrm{ab}$, indem er diese individuellen Vorstellungen als blossen Widerstandsversuch auf die letztlich unausweichliche gemeinschaftliche Bewegung hin zur nackten Wahrheit bezeichnet. Denn wohin die notwendige «Assoziationsbewegung» führt, wird am Ende der Rede deutlich, das einem eigentlichen Glaubensbekenntnis nahekommt: «Verehrte Kollegen! Was ist es, das unserm Wirken Freudigkeit, in allen Anfechtungen Halt, und die Zuversicht des schliesslichen Erfolges gibt? Es ist die tiefe Ueberzeugung, dass es eine über allen Zeitauffassungen und allen menschlichen Widersprüchen liegende Wahrheit gibt, der wir dienen. Die Geschichte lehrt, dass kein einzelner Mensch, kein Volk, keine Zeit sie für andere festzustellen vermag. Aber es ist eine nothwendige Voraussetzung unsers Denkens und alles unsers Wirkens, dass die vereinigte Arbeit einer Generation den dieser Zeit entsprechenden Wahrheitsgehalt zu Tage fördere, und dass wir, von Zeitalter zu Zeitalter fortschreitend, in der Annäherung an die ewige, hüllenlose Wahrheit begriffen sind». ${ }^{4}$

Hier tritt ein ungefilterter Zukunftsoptimismus zu Tage: Der Glaube an die eine Wahrheit, der die Menschbeit sich unvermeidlich annähern wird. Und in diesem Annäherungsprozess verdunsten die einstmals trennenden Unterschiede mehr und mehr ins Nichts. Die Vermutung drängt sich auf, hier - ähnlich wie bei Jules Ferry - einen positivistischen Wissenschaftsglauben am Werke zu sehen (vgl. Unterkapitel 2.4.I). So wie gemäss Comtes Dreistadiengesetz im letzten Stadium des Menschheitsprozesses nicht mehr nach den konkreten Ursachen der Phänomene gefragt wird, sondern sich die Aufmerksamkeit auf die den Phänomenen zu Grunde liegenden allgemeinen Gesetze richtet, scheint auch Vögelin von unveränderlichen Gesetzen auszugehen, die in generationen- und zeitübergreifender, gemeinschaftlicher Arbeit der scientific community immer mehr aufgedeckt werden. Insofern dabei nicht einer bestimmten Perspektive die alleinige Deutungshoheit zugesprochen wird, sondern davon ausgegangen wird, dass durch das Zusammenkommen verschiedenster sich ergänzender Perspektiven man sich der Wahrheit kontinuierlich annähert, könnte man von einem omniperspektivischen Ansatz sprechen. ${ }^{65}$

64 Ebd., 2.

65 Ein solch omniperspektivisches Denken scheint Ende des 19. Jahrhunderts in der Luft gelegen zu sein. So finden sich in Nietzsches Kritik an Kants «Ding an sich» ganz ähnliche Überlegungen. Das «Ding» ist nach Nietzsche nicht als transzendente, dem Menschen unzugängliche Entität zu denken, sondern als «Das», was es für alle Menschen ist: «Das «was ist das?> ist eine Sinn-Setzung von etwas Anderem aus gesehen. Die 〈Essenz〉, die 〈Wesenheit> ist etwas Perspektivisches und setzt eine Vielheit schon voraus. Zu Grund liegt immer, «was ist 
Relevant für die Diskussion um den schulischen Religionsunterricht ist die Beobachtung, dass Vertreter eines solch omnisperspektivischen Denkens tendenziell einen konfessionslosen Religionsunterricht für alle - natürlich mit Gewährleistung von Paragraph 63 der Kantonsverfassung, das heisst mit Dispensationsmöglichkeit - forderten, der die gesellschaftliche Einheit stärken sollte. Die Positiven, das heisst die Vertreter bekenntnistreuer Kreise, wandten sich hingegen gerade gegen einen solchen staatlichen, nach Vereinheitlichung strebenden Religionsunterricht und machten sich indirekt für einen institutionellen Pluralismus stark, indem sie zum Beispiel spezifisch christliche Freischulen - frei von Staat und Kirche - forderten.

\subsubsection{Aufrechterhaltung der Spannung durch Förderung eines institutionellen Pluralismus}

Während insbesondere von religiös-liberaler und radikaldemokratischer Seite her das einheitsstiftende Moment von Religion betont wurde, strebten bemerkenswerterweise die Positiven danach, das in der Verfassung verankerte Recht auf Glaubens- und Gewissensfreiheit auch auf institutioneller Ebene sichtbar werden zu lassen, indem sie sich sowohl für freie Kirchen wie auch freie Schulen einsetzten, die Lehrplan und Lehrmittel selber bestimmen können. Es mag aus heutiger Sicht erstaunen, dass nicht nur eine neoliberale Agenda für die Förderung privater Schulen sprechen kann. Heinrich Bachofner (I 828-I 897), der Direktor des evangelischen Lehrerseminars Unterstrass, ist ein gutes Beispiel, um die Gegenposition zum omniperspektivischen Ansatz zu illustrieren. Er forderte nicht bloss einen (positiv) christlichen Religionsunterricht, sondern christliche Schulen. ${ }^{66}$ In einem Vortrag, der sowohl im Volksblatt für die reformirte Schweiz wie auch im Evangelischen Wochenblatt zusammenfassend paraphrasiert worden war, argumentierte er dafür, dass das Christentum «der eigentliche Mittelpunkt der Schule werden» müsse. Denn die einseitige Ausbildung der Intelligenz errei-

das für mich?> (für uns, für alles, was lebt usw.) Ein Ding wäre bezeichnet, wenn an ihm erst alle Wesen ihr ‘was ist das? gefragt und beantwortet hätten. Gesetzt, ein einziges Wesen, mit seinen eigenen Relationen und Perspektiven zu allen Dingen, fehlte: und das Ding ist immer noch nicht 〈definirt>.» (Nietzsche 1999, I 40). Insofern es für Nietzsche kein perspektivenloses Denken zu geben scheint, könnte man ihn als Vordenker der Postmoderne bezeichnen. Allerdings fügen sich für Nietzsche die unterschiedlichen Perspektiven nicht automatisch zu einem harmonischen Ganzen! Für eine Diskussion der Thematik der Perspektivität bei Nietzsche aus pädagogischer Sicht siehe Anhalt 20 r 2 b.

66 Gemäss Hardegger (2008a) «stellte die Gründung von eigenen Sozial-, Bildungs- und Gesundheitseinrichtungen für pietistische Kreise den einzig möglichen Weg zur Einflussnahme auf das öffentliche Leben dar» (Hardegger 2008a, I 20), nachdem sie in politischer Hinsicht Minderheitsposition erlangt hatten. Mit der Gründung des Evangelischen Lehrerseminars Unterstrass im Jahre I 869 wurde das Ziel verfolgt, christliche Lehrer auszubilden, die ausgerüstet mit Bildung und Charakterfestigkeit die Bereitschaft aufwiesen, die «Irrthümer des Zeitgeistes» (Gründungsprotokoll I 869, 6, zit. in Hardegger 2008a, I 24) anzugehen. 
che den Zweck der Erziehung nicht, der darin bestehe, die Menschen «glücklich zu machen». Dazu reichten ein paar wöchentliche Religionsstunden nicht. Das Christentum müsse «in ganz anderer Weise in der Schule zur Geltung gebracht werden», als dies jetzt der Fall sei. Bachofner gestand auch ein, «dass es schwer sei, das Richtige zu treffen, indem man die Kinder nicht mit dem Christenthum übersättigen dürfe; er wollte auch nicht, dass man bei Lehrgegenständen, die in keine Beziehung zum Christenthum zu bringen seien, es an den Haaren herbeiziehe». ${ }^{67}$

Sein Anliegen einer christlichen Schule ${ }^{68}$ begründete Bachofner folgendermassen: Für die Volksschule werde ein Lehrstoff gefordert, der «I. zu einem bleibenden, nie veraltenden Wissensschatze des gesammten Volkes werden kann, weil er für alle vom höchsten Werth ist; 2. Eine Form hat, die das Kind in sich aufnehmen kann; 3. Die Gesichtspunkte in sich schliesst, von denen aus die Dinge dieser Welt in's wabre Licht treten, so dass der gesammte Unterricht in ibm seine Einheit hat. ${ }^{69}$

Gemäss Bachofner ist es «der Unterricht im Worte Gottes, der diesen Anforderungen entspricht, der die Herzen reinigt». Die christliche Schule bringe, «und das ist die Hauptsache, in die manigfaltigen Interessen des Schullebens eine Einheit und ist darum eine wahrhaft erziehende Schule, denn der ins Centrum gestellte biblische Stoff ermöglicht es, die verschiedenen Vorstellungen gegenseitig zu vergleichen, zu stützen, zu verstärken und zu verbinden, so dass sie zu einer Vorstellungsmasse werden, welche leicht reproduciert werden kann und darum den Willen zu bestimmen vermag»..$^{\circ}$

An dieser Stelle wird deutlich, dass es ein radikal unterschiedlicher Einheitsglaube des religiös liberalen Vögelin und des Positiven Bachofner ist, der den Ersten in Richtung eines institutionellen Monismus und den Zweiten in Richtung eines institutionellen Pluralismus plädieren lässt.

Das, was den Zusammenhang zwischen allem ermöglicht, war bei Bachofner eine eschatologische Realität, ein Mysterium: Gott, der sich in Christus offenbart und in den biblischen Schriften bezeugt wird. Bei Vögelin war es die Annahme einer «hüllenlosen Wahrheit», die sich im menschheitlichen Entwicklungsprozess

67 Volksblatt für die reformirte Kirche der Schweiz, 2. 3. 1872, 38.

68 Bachofner war allerdings der Überzeugung, «dass von der Verwirklichung einer solchen Schule, welche von dem evangelischen Seminar angestrebt werde, erst dann die Rede sein könne, wenn Hausväter in freien Gemeinschaften zusammentreten, um freie Schulen zu gründen, deren Lehrplan und Lehrmittel sie bestimmen. - Möglich, dass einmal die freie Schule kommt; es ist auch uns nicht ganz unwahrscheinlich, dass das Prinzip der Glaubens- und Gewissensfreiheit auch hier seine Konsequenzen ziehen werde; vorher aber muss die freie Kirche kommen; sie kann erst die freie Schule nach sich ziehen» (Volksblatt für die reformirte Kirche der Schweiz, 2. 3. 1872, 38).

69 Evangelisches Wochenblatt, 22. 2. I 872, Hervorhebung R. K.

70 Ebd. 
nach und nach erschliesst. Auch ein positiver Christ wie Bachofner wollte natürlich von der Wahrheit sprechen - zum Beispiel mit Bezug auf folgende Stelle im Evangelium nach Johannes: «Ich bin der Weg, die Wahrheit und das Leben» (Joh I 4,6); und umgekehrt war Vögelin kein gottloser Mensch. Doch wie sich Wahrheit erschliesst bzw. wie sich Gott offenbart, sahen beide unterschiedlich. Aus der Sicht eines Bachofners erschliesst sich Wahrheit zuerst und zunächst durch das Leben und Werk Jesu Christi. Aus der liberalen Sicht eines Vögelins ist der Ort der Offenbarung Gottes bzw. der einen «hüllenlosen Wahrheit» der wissenschaftliche Erkenntnisprozess. Das einheitsstiftende Moment hat sich bei Bachofner bereits offenbart, während dieses bei Vögelin erst entdeckt bzw. pädagogisch erzeugt werden muss.

Diese unterschiedlichen Einheitsverständnisse bieten eine Erklärung dafür, dass Bachofner nicht bloss einen christlichen Religionsunterricht forderte, sondern christliche Schulen. Das, was für Bachofner den Zusammenhang zwischen allem, was ist und zum Unterrichtsgegenstand werden kann, ermöglichte und darstellte, war der in Christus sich offenbarende und in den biblischen Schriften bezeugte Gott. Dies ist eine zutiefst perspektivische Sicht. Nur wenn die Welt aus dieser distinkt christlichen Perspektive betrachtet und erschlossen wird, erscheint sie im «wahren Licht» und deshalb braucht es Schulen, in denen explizit aus dieser Perspektive gelehrt und gelebt wird. Aus Vögelins omniperspektivischer Perspektive hingegen sollte in der Schule die Perspektivität gerade möglichst vermieden werden und das Allgemeine und der Menschbeit Förderliche gefördert werden, um so mitzuhelfen, die eine «hüllenlose Wahrheit» aufzudecken. ${ }^{7 \mathrm{r}}$

Die Unterschiedlichkeit der Einheitsverständnisse von Bachofner und Vögelin lassen sich auch auf grafische Weise verdeutlichen. Die Grafik für das Einheitsverständnis von Bachofner lässt sich folgendermassen beschreiben: geometrisch unterschiedliche grosse um eine Mitte herum konzentrisch angeordnete Kreise. Von dieser Mitte - der in Jesus Christus offenbarte Gott - her erschliesst sich alles. Die in einer geometrischen Darstellung nicht vermeidbare unterschiedliche räumliche Distanz der Kreise vom Mittelpunkt ist im übertragenen Sinne jedoch nicht räumlich gemeint, sondern verweist auf die qualitative Verschiedenheit der Dinge. Das Einheitsverständnis Vögelins lässt sich grafisch auf folgende Weise darstellen: eine Vielzahl von Strahlen - die unterschiedlichen weltanschaulich-religiösen Perspektiven -, die zu einer Spitze - die eine «hüllenlose Wahrheit»- hin zulaufen. Alle unterschiedlichen Perspektiven laufen auf diese eine Wahrheit zu.

7 I Die Aufgabe jedes einzelnen Lehrers besteht gemäss Vögelin darin, «von seinem Lehrobligatorium Alles ferne zu halten, was an die Stelle des Allgemeinen das Partikularistische setzt, was dem Menschheitsziel nicht fördernd entgegenkommt.» (Vögelin I879, Pädagogischer Beobachter, Heft 39, 2; vgl. auch Unterkapitel 7.2.2, S. I 89 ff.). 
Im ersten Fall sind Streitigkeiten darüber, wie denn diese Mitte, von der her sich alles erschliesst, richtig interpretiert wird, vorprogrammiert. Die Kirchengeschichte gibt davon beredtes Zeugnis. Doch auch der zweite Fall ist nicht frei von Problemen. Wenn sich die Wahrheit erst durch den wissenschaftlichen Erkenntnisprozess erschliesst, dann sind alle Menschen immer nur auf dem Weg zur Wahrheit, doch der vollständige Zugriff darauf ist allen verwehrt - von der einen Wahrheit sind alle Menschen zu jeder Zeit ausgeschlossen. Wie aber kann dann ein Vögelin wissen, was dem Menschheitsziel förderlich ist, ohne seine partikularistische Sicht der Dinge zur universalen zu machen?

Mit letzterer Frage wird auf eine Problematik hingewiesen, die von Seiten der Positiven auch im Zusammenhang mit dem konfessionslosen Religionsunterricht aufgeworfen worden ist. In einem Beitrag im Evangelischen Wochenblatt wurde die Vorstellung eines solch allgemein-menschlichen, neutralen Religionsunterrichts als höchst fragwürdig dargestellt, da ein Religionsunterricht ohne dogmatische Elemente sich von allem fern halten müsse, was in den Bereich des religiösen Glaubens gehört, und somit auch von aller Religion entleert und zu einem blossen Sittenunterricht reduziert würde. Die Lehrer eines konfessionslosen Religionsunterrichts «dürfen auch nicht wider andere Bekenntnisse, Religionslehren streiten, sonst bekommt auch ihr Religionsunterricht eine dogmatische und in seiner Art konfessionelle Färbung; dürfen auch nicht einmal mehr sagen: die Bibel sei nur Menschenwort, sonst lehren sie Dogmatik. Sie dürfen also nur, was allgemein für recht gilt, was zu einem sittsamen Wesen gehört, behandeln, alles weitere (Versöhnung, Vergebung der Sünde) gehört ja zum dogmatischen Element. Was wird vom Religionsunterricht noch übrig bleiben? Nichts, denn eine solche allgemeine Sittenlehre ist nicht Religion». ${ }^{2}$

Die theologisch-liberale Überzeugung eines Vögelins, dass beispielsweise auch die Reden Jesu Reden eines blossen Menschen seien, ${ }^{73}$ erweist sich aus dieser Sicht als eine dogmatische Position unter anderen. Und somit wird die Möglichkeit eines neutralen Religionsunterrichts negiert bzw. wird einem solchen Unterricht abgesprochen, Religionsunterricht zu sein. So gesehen ist auch die Vorstellung eines einheitlichen Volksganzen in Frage gestellt. Auf dieser Basis gibt es keinen Glauben, der als einheitsstiftendes Prinzip fungieren kann. Es gibt höchstens allgemeine Sitten und Gebräuche, aber keinen allgemeinen religiösen Glauben, durch den Integration hergestellt werden könnte.

In dieselbe Richtung argumentierte auch der Autor im Volksblatt für die reformirte Kirche der Schweiz. Seiner Ansicht nach war die Ersetzung des Religionsunterrichtes durch «Anregungen und Belehrungen aus dem Gebiete des

72 Evangelisches Wochenblatt, 6. 8. 1868, I $26 \mathrm{ff}$.

73 Vgl. Vögelin I867, III; vgl. auch Unterkapitel 4.3, S. Iо . 
sittlichen und geistigen Lebens» keineswegs neutraler oder weniger anstössig: «Denn «Anregungen aus dem Gebiete des sittlichen und geistigen Lebens〉 können das Gebiet der Religion und des Gewissens nicht unberührt lassen, sondern werden nothwendig, sei es in anerkennendem, sei es in polemischem Sinn, sich in ein Verhältnis setzen müssen zur Religionslehre der Kirche, so dass die Gefahr des Gewissenszwangs sich auch hier wiederholt.» ${ }^{4}$ Es würden, so der Gedanke, auch in diesem Fach bestimmte religiöse oder antireligiöse Überzeugungen vermittelt. Das bisher vorherrschende christlich-dogmatische Glaubensverständnis (Wunderglaube, Göttlichkeit Jesu usw.) werde ersetzt durch einen theologisch liberal gefärbten Humanismus. Die Problematik des Gewissenszwanges, der auch ein entdogmatisierter Religionsunterricht nicht entkomme, wurde auch im Blick auf die Geistlichen geäussert, die den Religionsunterricht in den höheren Klassen nach einem vom Erziehungsrat festgesetzten Lehrplan zu erteilen hätten: «Wenn aber dieser Lehrplan so einseitig ausfällt, dass die Geistlichen oder ein Theil derselben sich dadurch in ihren Ueberzeugungen und in ihrem Gewissen beeinträchtigt fühlen, wie dann? Gilt die Gewissensfreiheit nicht auch ihnen? Wird überdies der Geistliche im Religionsunterrichte von seiner konfessionellen Bestimmtheit absehen können? Bleibt der Paragraph so stehen, wie er jetzt ist, so wird er ein Zankapfel der schlimmsten Art werden und auf's Neue den Beweis leisten, dass Künsteleien zu nichts führen als zu neuem Streit.»7s

Der Verfasser dieses Artikels macht darauf aufmerksam, dass auch eine theologisch liberale Sicht eine bestimmte, andere Positionen ausschliessende Position darstellt und nicht religiös-weltanschaulich neutral ist und deshalb ebenso Konfliktpotential bietet, wenn beispielsweise ein Lehrer oder Geistlicher die Vermittlung dieser Position mit seinem Gewissen nicht vereinbaren kann. Möglicherweise begünstigt aber gerade die Annahme von sogenannt allgemein menschlichen Wissens- und Glaubensbeständen, die somit angeblich religiösweltanschaulich neutral sind, den paradoxen Aspekt von Zivilreligion, der im folgenden Unterkapitel genauer erläutert werden soll.

\subsection{Paradoxie von Zivilreligion: Gesellschaftliche Ausdifferenzierung und Auflösung der Sphärengrenzen}

Worin besteht die Paradoxie? Einerseits setzt Zivilreligion einen gewissen Grad an funktionaler, gesellschaftlicher Ausdifferenzierung voraus. So müssen zumindest die Bürgerrechte nicht mehr an die Bekenntnispflicht gebunden sein.

74 Volksblatt für die reformirte Kirche der Schweiz, 20. I. I 872, I 5.

75 Ebd. 
Radikale Trennung von Kirche und Staat ist dafür nicht notwendig, aber zumindest die Anerkennung dessen, dass diese zwei Institutionen zwei verschiedenen gesellschaftlichen Sphären angehören - der religiösen und der politischen. Andererseits trägt Zivilreligion in sich Tendenzen zur Auflösung der Grenzen zwischen diesen zwei Sphären, insofern die Herstellung einer idealisierten antikrömischen symbiotischen Einheit von Politik und Religion gewissermassen zu ihrem Programm gehört.

Am Beispiel Vögelins lässt sich das Paradox der Dedifferenzierung unterschiedlicher gesellschaftlicher Sphären (religiöse, politische, bildende) gut aufzeigen, auch wenn gewisse rechtliche Differenzierungen zwischen diesen Sphären von ihm als rechtmässig akzeptiert wurden. Insbesondere Vögelins Rede von der "Volksgemeinschaft», mit der er in einer im Jahre I865 erschienenen Predigtreihe mit dem Titel Die Gemeinschaft der Kirche und ibr Grund ${ }^{7}$ die Kirche zu identifizieren schien, deutet auf nivellierende Tendenzen hin. Dies bedeutet, dass durch die Identifikation von Volksgemeinschaft und Kirchengemeinschaft die Unterschiede zwischen Kirche als einer spirituell-fiduziären und Volk als einer kulturell-sprachlichen Grösse, zu der Vögelin möglicherweise sogar den territorialen Aspekt zählt, eingeebnet werden. In der Tradition von Alois Emanuel Biedermann stehend, fordert Vögelin eine möglichst weitherzige, bekenntnisfreie Kirche, die "Ausdruck aller sittlichen und religiösen Interessen eines Volkes»77 sein sollte. Völlig ohne Bekenntnis kommt aber auch die bekenntnisfreie Kirche nicht aus, wie der gleich nachfolgende Vorbehalt Vögelins zeigt: «Wer sich zum Grundgedanken der Kirche, zur verzeihenden Liebe, nicht mehr bekennen kann, den hat nicht die Kirche von sich, der hat sich selbst von der Kirche und von der Volksgemeinschaft ausgeschlossen.» ${ }^{8}$

Im Unterschied zu einer Bekenntniskirche wird gemäss Vögelin in einer bekenntnisfreien Kirche jedoch der Dissident nicht mehr von der Institution her ausgeschlossen, sondern er schliesst sich davon selbst aus. Insofern Vögelin nun aber Kirche und Volksgemeinschaft identifiziert, schliesst der Dissident sich nicht nur von der Kirche aus, sondern auch von der Volksgemeinschaft. Obwohl Vögelin mit den traditionellen kirchlichen Lehren kompromisslos brach und als Sympathisant der Radikaldemokraten sicherlich an der Trennung von Bürgerrecht und Bekenntnispflicht festhalten wollte, scheint er die einstige einheitsstiftende Funktion der Kirche und damit ihre staatspolitische Bedeutung dennoch nicht aufgeben zu wollen, wenn er die kirchliche Gemeinschaft sogar als höchste Form der Volksgemeinschaft bezeichnet.

76 Vögelin I 865 .

77 Ebd., 23.

78 Ebd., 48; vgl. dazu auch Betulius 1956, 2 I. 
Dedifferenzierende Tendenzen zeigen sich auch in Vögelins eigenwilliger Interpretation des Verhältnisses von Schule und Kirche. So anerkannte er zwar wie seine in Uster gehaltene Antrittspredigt ${ }^{79}$ von I 864 zeigt - die rechtliche Trennung von Schule und Kirche explizit als rechtmässig an, zugleich vertrat er jedoch den Gedanken, «dass Kirche und Schule innerlichst zusammengehören und Eins seien» als einen «unumstösslich wahren». ${ }^{80}$ Wie lassen sich diese zwei tendenziell widersprüchlichen Gedanken zusammen denken? Oder anders gefragt, warum sollte das, was als zusammengehörig angeschaut wird, getrennt werden? Die rechtliche Trennung von Schule und Kirche wurde nach Vögelin nötig, damit die Schule nicht weiterhin eine «von der Kirche abhängige, von fremden Zwecken geleitete Anstalt» ${ }^{{ }^{8}}$ bleibt. Die Umkehrung der bisherigen Verhältnisbestimmung zwischen Schule und Kirche, ohne die die von Vögelin propagierte Einheit von Kirche und Schule für ihn nicht denkbar gewesen wäre, erschien ihm jedoch offenbar keineswegs als problematisch. Der Kirche sprach er die Lehrautorität zu Gunsten der Schule ab, ohne in Betracht zu ziehen, dass die Kirche nun als von fremden Zwecken geleitet angesehen werden könnte: «Die Kirche soll Nichts lehren, was vor der Lehre der Schule nicht Stand hält». ${ }^{82}$ Die Schule sollte nun bestimmen, was in Schule und Kirche zu «verkünden» sei. Die genaue Verhältnisbestimmung sei aber nicht zentral, da «die Lehre der Kirche und die Lehre der Schule [...] vernünftigerweise nicht zweierlei sein $»^{8_{3}}$ könnten: «Es ist vielmehr der gleiche Gehalt, nur in der Form, nur in der Verarbeitung verschieden. Es ist die Summe des geistigen Besitzes eines Zeitalters, soweit derselbe beitragen kann zur Erziehung des Geschlechtes.» ${ }^{84}$

In seiner späteren, bereits oben erwähnten Predigtreihe Die Gemeinschaft der Kirche und ibr Grund spitzte Vögelin die Aussage, dass Kirche und Schule eigentlich dasselbe vermitteln bzw. vermitteln sollten, noch zu, indem er der Kirche den Auftrag zusprach, «eine Erziehungsanstalt des Volkes zu sein». Sie sei dies, wenn sie eine fort- und in der Religion wirklich voranschreitende Macht sei, was ihr leider lange Zeit gemangelt habe. Zwar bleibe die Wahrheit an sich immer die gleiche, ihre Erkenntnis nehme aber stetig zu, «so dass also auch die Kirche, die die Erkenntnis der Wahrheit vermitteln soll, stets fortschreiten ${ }^{85}$ müsse.

79 Vögelins Antrittspredigt vom 28. Februar r 864 trug den Titel Die Aufgaben des geistlichen Amtes in unserer Zeit.

80 Vögelin r 864, 335 .

8 I Ebd.

82 Ebd.

83 Ebd.

84 Ebd., $335 \mathrm{f}$.

85 Vögelin 1865,35 . 
Die Entgrenzung zweier unterschiedlicher, rechtlich distinkter Sphären - die religiöse und die erzieherisch-bildende - zeigt sich hier sehr deutlich. Indem Vögelin der Kirche dieselbe Funktion - eine erzieherisch-bildende - zukommen liess wie der Schule, sprach er der Kirche die traditionelle, heilsgeschichtliche Funktion ab bzw. wollte diese zu einer säkular-innerweltlichen transformieren. Der biblisch bezeugte Jesus Christus wird durch die für alle geltende «Eine Wahrheit» ersetzt. Im Vorwort zur Schrift Die Geschichte Jesu, die Vögelin zusammen mit dem aufklärerischen Lehrerkreis um Sieber in Uster verfasst hatte und das sowohl als Volksbuch wie auch als Lehrmittel verstanden werden wollte, schrieb er als Dank an die Lehrer: «Und wie mir die vielen bei dieser Arbeit gemeinschaftlich verlebten Stunden stets eine schöne Erinnerung bleiben werden, so sind sie mir auch das Pfand, dass sich die rechte und wahre Verständigung zwischen Volk, Schule und Kirche überall von selbst einstellen wird, wo man in Schule und Kirche nur aufrichtig der Volksbildung dient und nichts Anderes verfolgt, als die Eine Wahrheit, die für alle gilt.» ${ }^{86}$

Mit dem neuen Heilsverständnis erhielt nun auch die Schule als Vermittlerin der «Einen Wahrheit» eine Heilsfunktion. So gesehen lässt sich sowohl von einer Verschulung der Kirche als auch einer Verkirchlichung der Schule sprechen. ${ }^{87}$ Die stetige Annäherung an diese «Eine Wahrheit» ist insofern heilsfördernd, als sie - so zumindest Vögelins Annahme - volksverbindende und einheitsstiftende Wirkung hat. Die Sympathien zwischen Vögelin und dem aufklärerischen Lehrerkreis um Sieber sind auf diesem Hintergrund nicht erstaunlich. Man könnte fast sagen, dass sich der Ausdruck Kirche bei Vögelin zu einer religiösen Chiffre für Volksgemeinschaft gewandelt hatte. Ins gleiche Horn blies Sieber, indem er in seiner Zeitung Der Unabhängige Vögelin zu Wort kommen liess und die Kirche als «das höchste Band des ganzen Volkes [bezeichnete], in dem sich alle andern Unterschiede wieder aufheben». ${ }^{88}$

Vögelin und Sieber waren wichtige Figuren in der Demokratischen Bewegung. Angesichts dessen könnte man auf den Gedanken kommen, dass dedifferenzierende Tendenzen insbesondere auf dieser Seite des politischen Spektrums zu finden waren. Als Gegenbeispiel sei jedoch F. A. Lange genannt, der ebenso zu den führenden intellektuellen Köpfen der Demokratischen Bewegung zu zählen ist. Seine Gedanken zum Verhältnis von Schule, Staat und Kirche, die in der Einleitung zu den Vorlesungen über Pädagogik, die Lange im Wintersemester

86 Vögelin ז $867, \mathrm{X}$.

87 Vgl. Katzenstein 2017.

88 Der Unabhängige, 20. I. 1864. Diese Ausgabe der Zeitung trägt das Jahr I 864 als Datum. Doch dies ist vermutlich ein Druckfehler und es müsste eigentlich i 865 heissen. Denn ab der Ausgabe 8 (ebenfalls erster Jahrgang) wird mit i 86 s fortgefahren. 
I 871/72 vermutlich an der Universität Zürich hielt, ${ }^{89} \mathrm{zu}$ finden sind, deuten auf eine grössere Sensibilität für die Grenzen der verschiedenen gesellschaftlichen Sphären hin, als seine (ehemaligen) Kollegen in der Demokratischen Bewegung zeigten. Lange hiess weder eine ausschliesslich vom Staat geführte Schule gut noch die «Erhebung der Schule zu einer vom Staat unabhängigen Macht».9० Insbesondere sah er in der «Beherrschung des Erziehungswesens durch einen geschlossenen und hierarchisch gegliederten Lehrerstand unausbleiblich die Gefahr des Stillstandes und der Verknöcherung». ${ }^{91}$ In der Trennung der Schule von der Kirche hingegen sieht er «keine allgemeine und notwendige Forderung der Pädagogik, sondern nur eine notwendige Konsequenz des Zwiespaltes, in welchem das Kirchenwesen mit dem Kulturinhalt der Gegenwart geraten ist»..$^{2}$

Unter Kirche verstand Lange in diesem Zusammenhang «die religiöse Gemeinschaft schlechthin». Das heisst, die Trennung von Schule und Kirche bzw. religiöser Gemeinschaft sah Lange als historisch kontingent und nicht als prinzipiell notwendig an. Dazu passen Langes Notizen über die staatliche oder freie Verfassung von Schulen, die an dieser Stelle in seinem Vorlesungsmanuskript zu finden sind. Sie verdeutlichen seine Ansicht, dass «freie Schulen neben Staat und Kirche keineswegs unbedingt zu verwerfen ${ }^{93}$ seien.

In der Kantonsratsdebatte über das neue Unterrichtsgesetz zeigte sich Langes diesbezügliche Haltung im Zusammenhang mit seinem Vorschlag zu Paragraph I 34 , in welchem die «Stellung von Privatunterrichts- und Erziehungsanstalten zu den Staatsbehörden» geregelt werden sollte. Die Diskussion wurde angeregt durch Professor von Wyss (vgl. Anm. 65, S. I04), der grössere Freiheit für die Errichtung solcher Anstalten verlangte. Gemäss Landboten schlugen Oberrichter Schneider ${ }^{94}$ und Dr. Lange folgenden Mittelweg vor, der dann von allen gutgeheissen wurde: «Er [der Erziehungsrat] überwacht auch die Privat-

89 Die Einleitung zu Vorlesungen über Pädagogik ı871/72 ist in Auszügen abgedruckt in der von Joachim H. Knoll herausgegebenen Sammlung verschiedener Schriften Friedrich Albert Langes über Pädagogik. Es ist hier jedoch nicht vermerkt, wo er diese Vorlesungen gehalten hatte. Doch da Lange gemäss Koller ab dem Sommersemester i 870 bis zu seiner Berufung nach Marburg im Sommer I 872 an der Universität Zürich lehrte, gehe ich davon aus, dass auch diese Vorlesungen über Pädagogik in Zürich stattfanden (vgl. Koller 1987, 52).

90 Lange 1975 [1871/72], I37.

91 Ebd.

92 Ebd., Hervorhebung im Original.

93 Ebd., I37. In der Ausgabe von Joachim H. Knoll, der Langes Texte zur Pädagogik zusammengetragen und in überarbeiteter und teilweise gekürzter Form herausgegeben hat, ist bloss dieses Zitat aus den Notizen Langes abgedruckt. Die restlichen Notizen finden sich hier nicht. Albert Schneider (1836-1904) war ab I 878 ordentlicher Professor für römisches Recht an der Universität Zürich und von I 890 bis I 892 deren Rektor. I 866 amtete er als Oberrichter, I 870 als Handelsrichter. Ab i 862 war er liberaler Kantonsrat und ab I 893 Mitglied des Grossen Stadtrats. I 896 war er Präsident der Kirchensynode (vgl. Schmid 20 2). 
unterrichts- und Erziehungsanstalten, welche nur bei ungenügender Befähigung der Lehrer oder sittlichen Gefahr für die Schüler aufzuheben sind.»95

Es muss hier jedoch angefügt werden, dass auch Vögelin in realpolitischen Themen die Integrität der unterschiedlichen Sphären mit ihren Eigengesetzlichkeiten in gewissen Punkten durchaus anerkennen konnte. Seine diesbezügliche Differenzierungsfähigkeit zeigte sich beispielsweise im Jahre i 875 in einer Diskussion im Kantonsrat über die Freiheit der Privatschulen hinsichtlich der Wahl der Lehrmittel. Obwohl Vögelin persönlich nicht mit Privatschulen sympathisierte, setzte er sich dafür ein, dass diesen ihr Eigenleben belassen werde. ${ }^{96}$ Denn gemäss Vögelin hatte der Staat seine Kompetenzen bereits bei der Formulierung der Bedingungen, unter denen die Gründung einer schulischen Institution überhaupt erst ermöglicht wurde, überschritten. Die diesbezügliche Aufgabe des Staates sah er lediglich darin, dafür zu sorgen, dass auch die Privatschulen das der Volksschule vorgegebene Ziel erreichen. Wenn der Staat aber «auch noch den Weg vorzeichnen will, auf dem allein es erreicht werden darf, so ist das gleich verkehrt, wie die Forderung der katholischen Kirche: Du sollst selig werden; aber nur durch mich! Mit diesem Grundsatz habe ich auf kirchlichem und politischem Gebiete längst gebrochen und kann mich auch auf pädagogischem Gebiete nimmer mit ihm befreunden». ${ }^{77}$ Diese Rede war gegen seinen Freund Regierungsrat Sieber gerichtet und hatte offensichtlich Erfolg: Hinsichtlich der Lehrmittelwahl wurde den Privatschulen Freiheit zugesprochen..$^{8}$ Indem Vögelin dem Staat hier lediglich eine Aufsichtsfunktion zusprach, wies er ihn in seine Grenzen. ${ }^{99}$ Ganz anders sah dies eine Gruppe von Privatpersonen, ${ }^{100}$ die in ihrer Antwort auf die vierte Frage des sieberschen Fragebogens von i 869 zum neuen Unterrichtsgesetz deutlich machten, dass sie die Aufgabe des Staates nicht auf eine blosse Aufsichtsfunktion beschränkt haben wollten. Sie argumentierten für die

95 Der Landbote, 2. 2. I 872.

96 Zürcherische Freitagszeitung, 5. 3. I 875; vgl. auch Betulius 1956, I 2 I.

97 Zürcherische Freitagszeitung, 5. 3. I875.

98 Vgl. Betulius i956, г22.

99 Vögelin begründete seine von der seiner Parteifreunde abweichende Haltung mit seiner persönlichen Erfahrung: «Sie wissen, dass ich seinerzeit die öffentliche Laufbahn (als Pfarrer in Uster) in heftiger Oppositionsstellung gegen den Druck der Majorität (der GeistlichenSynode) begonnen habe. Aus jener Zeit ist mir unauslöschlich in Erinnerung geblieben, dass die innere Ueberzeugung eines jeden Menschen, namentlich aber eines jeden Lehrers sein unantastbares Heiligthum bleiben müsse, gleichviel ob sie gerade am Staats- oder Kirchenruder beliebt ist oder nicht. Ich würde mir nun selbst untreu werden, wenn ich diese Ueberzeugung, die ich einst unter dem Drucke, der auf mich ausgeübt werden wollte, empfangen und verfochten habe, jetzt verleugnen würde, wo ich, wenn ich so sagen darf, zur Macht gelangt bin, d. h. an der Leitung des staatlichen Unterrichtswesens einigen Antheil habe.» (Zürcherische Freitagszeitung, 5.3. 1875).

I00 Dieses Dokument wurde von einer Vielzahl von Privatpersonen unterschrieben, dat. Winterthur im Januar 1870 (Eingaben und Antworten von Privaten I870, StAZH, U 8.I.2). 
Beibehaltung des dogmatischen Elements im Religionsunterricht, weil sie der Ansicht waren, dass ohne dieses dogmatische Element der Religionsunterricht kein Religionsunterricht mehr wäre und die Schule somit religionslos würde. Als Folge einer solchermassen religionslosen Schule befürchteten sie die Gründung von Privatschulen. Damit würde ihrer Meinung nach der Staat jedoch seinen Einfluss verlieren. Diese Argumentation zeigt deutlich die erzieherische Funktion, die hier dem Staat zugedacht wurde.

Noch deutlicher zeigte sich ein solch aufgeladenes Staatsverständnis in der Antwort der Gemeinde- und Sekundarschulpflege des Wahlkreises Schöfflisdorf auf Siebers Frage 4 nach der Stellung des Religionsunterrichts in der Schule: «Unser Staat ist ein christlicher Staat; es soll daher die Schule dem jungen Christen die Grundzüge der christl. Religion einprägen, damit er sich mit Hülfe derselben eine feste Überzeugung über sein religiösmoralisches Verhalten bilden kann, und sich nicht bloss blindlings von einer meist unsicheren religiösen Ansicht des Elternhauses bestimmen lassen muss. Der Religionsunterricht der Alltagsschule soll jedoch keineswegs dogmatisch, sondern vielmehr ein allgemeines Bildungsmittel sein.» ${ }^{101}$

Dem Staat wurde hier eine religiöse Funktion - Vermittlung der christlichen Religion - zugeschrieben, die er mit Hilfe der Schule als seines verlängerten Armes ausüben sollte. Im Unterschied zur vorhergehenden Antwort der Gruppe von Privatpersonen sollte jedoch in der Alltagsschule zur Erreichung dieses Ziels nicht am dogmatischen Element festgehalten werden.

Als Kontrast zu diesen Beispielen von Entgrenzung gesellschaftlicher Sphären kann die Proposition von Pfarrer Heiz angeführt werden, der an der Geistlichkeitssynode im November i 869 auf dem Hintergrund der Diskussion um die Neugestaltung des Verhältnisses zwischen Staat und Kirche die Unabhängigkeit von Kirche und Staat hervorhob. Er sah «Staat und Kirche als zwei leuchtende Gestirne in friedlicher Konjunktur neben einander» und wandte sich gegen die «Theorie, dass der Staat alles in allem sei, also auch die Kirche gänzlich repräsentiere». ${ }^{102}$ Heiz verlangte eine Neuregelung des Verhältnisses zwischen Kirche und Staat dergestalt, «dass beide durchaus unabhängig von einander seien und sich gegenseitig Dienste leisten zumal auf dem Gebiete der Schule, welche beide bedürfen; der Staat solle nicht mehr über die Religion der Schule herrschen, sondern nur der Kirche Zeit zum Religionsunterricht in der Schule zu lassen, damit diese den ganzen Religionsunterricht der Volksschule übernehme». ${ }^{103}$

Iо I Alle Gemeindeschulpflegen und die Sekundarschulpflege des Wahlkreises Schöfflisdorf (Bezirk Regensberg), Eingaben und Antworten der Bezirksschulpflegen i 870, StAZH, U 8.I.Ia.

I02 Amtlicher Auszug aus Protokollen der Synode der Zürcherischen Geistlichkeit, 23. I I. I 869, 32.

Iо3 Ebd., 3 I. 
Ebenso forderte er auch auf universitärem Niveau, die Wahl der theologischen Lehrer der Kirche zu überlassen, da der Staat «keiner besondern theologischen Richtung Vorschub leisten dürfe, die Kirche jedoch durchaus höherer-wissenschaftlicher Lehranstalten bedürfe». ${ }^{104}$ Dieser Gedankenlinie folgend - dies sei hier kritisch angemerkt - hätte er allerdings auch gegen eine universitäre Pfarrausbildung sein müssen. ${ }^{\text {105 }}$

Pfarrer Heiz’ Plädoyer für die Anerkennung von Staat und Kirche als je eigene, souveräne gesellschaftliche Sphären kann jedoch nicht darüber hinwegtäuschen, dass hinsichtlich der Frage nach dem Verhältnis von Staat, Kirche und Schule innerhalb der zürcherischen Geistlichkeit kein Konsens bestand. So wandte sich Pfarrer Baiter von Knonau in seiner Reflexion von Heiz' Proposition gegen eine freie Kirche und setzte sich ein für «eine in den Staat wohl eingefügte Kirche», das heisst eine Staatskirche nach dem Modell Zwinglis: "Zwingli's Ideal sei auch das unsere, dass die religiös sittlichen Ideen sauerteigartig alles durchdringen sollten; wäre das einmal geschehen, so könnte sich vielleicht die Kirche nach Vollendung ihrer Aufgabe einst auflösen.» ${ }^{106}$ Die Ablösung der Kirche vom Staate erachtete Baiter für die Ausdehnung und Wirksamkeit der Kirche als schädlich. Als Folge einer Trennung zwischen Kirche und Staat befürchtete er auch die Ablösung der Schule vom Staat. Dagegen sollte jeder Zwang von Seiten der Kirche gegen irgendwelche Staatsbürger aufgehoben werden «mit der Ausnahme, dass ein Religionsunterricht in der Schule und zwar in der Alltagsschule durch den Lehrer, bleibe». ${ }^{107}$ Der Staat wird hier von Baiter als allen anderen gesellschaftlichen Sphären übergeordnet gedacht. Zugleich wird der Staat und in seinem Gefolge auch die Schule, die Baiter als verlängerten Arm des Staates zu verstehen schien, in sittlich-religiöser Hinsicht von der Kirche gelenkt und geprägt.

In diesem Unterkapitel habe ich versucht aufzuzeigen, dass in der Diskussion um den schulischen Religionsunterricht die Paradoxie von Zivilreligion deutlich zum Ausdruck kommt. Zum einen habe ich in den von mir untersuchten Quellen keine Indizien dafür gefunden, dass von irgend jemandem eine grundlegende Errungenschaft der Moderne - Trennung von Bürgerrecht und Bekenntnispflicht - kritisiert worden wäre und insofern eine basale Ausdifferenzierung von Staat und Kirche in Frage gestellt wurde. Zum andern habe ich anhand einiger Beispiele zu zeigen versucht, dass es trotz der Annahme einer grundsätzlichen Unterscheidung zwischen Staat und Kirche, zu einer Entgren-

I04 Ebd., 32.

I05 Diesen Gedanken habe ich Fritz Osterwalder zu verdanken.

I06 Amtlicher Auszug aus Protokollen der Synode der Zürcherischen Geistlichkeit, 23. I I. I 869, 34.

I07 Ebd., 35 . 
zung zwischen diesen zwei zentralen gesellschaftlichen Sphären kam und auch der Schule als einer distinkten Sphäre mit einer eigenen, strukturellen Leitfunktion wenig Rechnung getragen wurde. Anhand des Synodalbeitrags von Pfarrer Baiter und verschiedener zitierter Antworten auf die Fragen Siebers wurde beispielhaft gezeigt, wie Kirche und Schule als Funktionen - im Dienste der Vermittlung sittlich-religiöser Ideen - des Staates verstanden wurden. Die Analyse von Vögelins Predigten und Reden dienten dazu, anhand seines fast symbiotisch gedachten Verhältnisses zwischen Schule und Kirche - die Verkirchlichung der Schule und die Verschulung der Kirche -, dedifferenzierende Tendenzen aufzuzeigen.

\subsection{Negation der historischen Kontingenz und Partikularität von Universalitätsansprüchen}

Ein weiteres Indiz für Zivilreligion sehe ich dort, wo das, was gemeinhin als universal erachtet wird - wie oben angeführt zum Beispiel <Vernunft〉, 〈Humanum〉 oder 〈Transzendenz> -, als notwendig für das staatliche Funktionieren und das gesellschaftliche Zusammenleben erachtet wird. Der Kulminationspunkt zivilreligiösen Glaubens ist dann erreicht, wenn die historische Kontingenz und Partikularität von Universalitätsansprüchen scheinbar vollständig negiert oder verdrängt wird. ${ }^{108}$ In diesem Unterkapitel soll untersucht werden, inwiefern dieses Indiz für Zivilreligion in der Diskussion um den schulischen Religionsunterricht gegeben ist.

In einem gesellschaftlich ausdifferenzierten, modernen Gemeinwesen, das Glaubens- und Gewissensfreiheit garantiert, stellt sich die Frage, was an gemeinsamen Elementen bleibt. Obwohl der Ausdruck Landeskirche letztendlich nicht aus der Kantonsverfassung gestrichen worden war, konnte die reformierte Landeskirche angesichts von Freikirchen, nichtkirchlichen Menschen, anderskirchlichen und insbesondere auch angesichts der innerreformierten Streitigkeiten zwischen Positiven und Liberalen die gesellschaftliche Integration nicht mehr gewährleisten. Diese Aufgabe wurde nun der öffentlichen Schule zugemutet. Dass diese dazu beitragen sollte, die Kinder zu sittlichen Menschen zu erziehen, schien nicht kontrovers gewesen zu sein. Wie die unterschiedlichen Diskussionsbeiträge zeigen, bestand jedoch Uneinigkeit hinsichtlich der Frage, ob der Sittlichkeit abstraktuniversalen Charakter zukomme. Die Frage stellte sich, ob Sittlichkeit als unabhängig von der Angehörigkeit zu einer bestimmten religiösen Gemeinschaft oder einem bestimmten religiösen Glauben oder Nicht-Glauben zu denken sei. Diese Frage wurde unterschiedlich beantwortet. Während für die einen - beispielsweise

I08 Vgl. die Bestimmung des Begriffs Zivilreligion in Unterkapitel 2.6, Punkt 5. 
Pfarrer Scheller (vgl. S. ı 86) - Sittlichkeit nicht losgelöst von Religion denkbar war, gingen andere von einer universalen Sittlichkeit aus, die allen Menschen unabhängig von ihrer religiösen Zugehörigkeit bzw. Nicht-Zugehörigkeit eigen sei. ${ }^{109}$ An Furrer und Vögelin, deren Argumentationen ein solches universales Verständnis von Sittlichkeit in Anspruch nehmen, soll beispielhaft die Negation der Partikularität dieses Universalitätsanspruchs gezeigt werden. ${ }^{\text {10 }}$

Furrer wandte sich in seiner Schrift für einen konfessionslosen Religionsunterricht gegen die Vorstellung, dass der Staat bloss für «den Unterricht in den identischen Wissenschaften» (Mathematik und Naturkunde) zuständig sei, da diese Wissenszweige auf den allgemeinen Gesetzen der Logik basierten, aber nicht eingreifen dürfe «in die Geistesgebiete, wo die verschiedensten individuellen Ansichten relativ gleichberechtigt nebeneinander stehen, wie in der Religion». So gesehen müsste der Staat seiner Ansicht nach «auf Bildung der Gemüthsanlagen überhaupt verzichten, insofern das sittlich-religiöse Bewusstsein auch auf Behandlung der allgemeinen Culturgeschichte wesentlich influenziert und alle wahre Begeisterung ein religiöses Moment in sich schliesst». ${ }^{111}$

Furrer war jedoch der Überzeugung, es gebe für den Menschen sowohl «identische Denkgesetze» als auch «identische Gesetze des sittlich-religiösen Geistes»: «So gewiss es aber für das menschliche Wesen identische Denkgesetze gibt, ob auch Tausende unvernünftig reden, so gewiss auch identische Gesetze des sittlich-religiösen Geistes, möchte immerhin ein ganzes Zeitalter dieselben verkennen und missachten. Gerade wenn der Staat die grösste Kraft von seinen Bürgern heischt, beruft er sich unwillkürlich auf dieses identische sittlich-religiöse Bewusstsein und hofft auf der Herzen einmüthige Erhebung.» ${ }^{112}$

I09 Vgl. das Diagramm auf S. I63 anhand dessen die Auswirkung unterschiedlicher Verständnisse sowohl von Religion als auch der Verhältnisbestimmung zwischen Religion und Moral auf die Forderung nach einer spezifischen Art des Religions- bzw. Moralunterrichts verdeutlicht werden soll.

I I Als weiteres Beispiel für die Negation des Universalitätsanspruchs wäre auch Ferdinand Buisson zu nennen, der allerdings nicht direkt an der Zürcher Diskussion um den schulischen Religionsunterricht beteiligt war. In einem an Lehrer gerichteten Vortrag an der Universität Sorbonne stellte er als wichtige Aufgabe von Primarlehrpersonen die Entwicklung einer allgemein menschlichen intuitiven Moral dar: «Dans toutes les questions morales et sociales, tout se qui est intuitif est de votre ressort et fait partie de l'éducation populaire; le reste n'en est pas.» (Buisson I 9 I 2, 5) Buissons Rede von einer moralischen Intuition basiert auf einer klaren Unterscheidung zwischen einem Bereich, der allen Menschen qua ihrer Intuition zugänglich ist, und einem Bereich, den er als nicht allen Menschen zugänglich erachtet, da dieser das Resultat von Übung, Reflexion, Diskussionen und der Wissenschaft sei. Den allen Menschen zugänglichen Bereich der Intuition beschreibt er als «aussi vieille que l'humanité, innée à tous les cœurs, ancrée dans toutes les consciences, inséparable de la nature humaine, et par là même claire et évidente à tout homme» (Buisson I9I 2, 5). Osterwalder verweist auf die inhaltliche Unbestimmtheit dieser intuitiven Moral (vgl. Osterwalder 201 I, I 42 f.).

I I I Furrer, I872, 6.

II 2 Ebd. 
Im Zentrum von Furrers Argumentation für den konfessionslosen und undogmatischen Religionsunterricht steht die Überzeugung, dass dem Menschen qua Mensch die sittlich-religiöse Anlage angeboren sei. Dies im Unterschied zu einer spezifischen Konfession oder Religion, die Ausdruck partikularer kultureller und familiärer Gegebenheiten sind. Diese These stützt Furrer mit Verweisen auf angebliche ethnologische Forschungen, ${ }^{113}$ die bewiesen hätten, «dass es kein Volk gibt ohne Religion, dass selbst die Papua’s die ersten Spuren religiöser Empfindung zeigen, dass das Gefühl der Abhängigkeit von einer höhern unsichtbaren Macht auf der untersten Stufe der Gesittung den Menschen durch eine unermessliche Kluft vom Thiere scheidet. Die religiöse Anlage ist eine der grossen Eigenschaften, in denen sich durch den Wechsel der Zeiten und Geschlechter die Einheit und Selbigkeit der menschlichen Natur behauptet». ${ }^{114}$

Was Furrer an keiner Stelle in diesem 45 -seitigen Traktat reflektiert, ist die schleiermachersche und damit westlich christlich-romantische Interpretationskategorie - «das Gefühl der Abhängigkeit von einer höhern Macht» -, mit der die 〈Religion〉 der Papuas entdeckt und beschrieben wird. ${ }^{\text {II }}$ Nebst diesem unhinterfragten westlich christlichen Gedankenimport, stellen sich weitere grundsätzliche Fragen, wie zum Beispiel bestimmte Beobachtungen - bemalte Gesichter, Bewegungen zu Musik usw. - als «religiöse» Phänomene beschrieben werden können, ohne bereits vorauszusetzen, was man herausfinden möchte - in diesem Fall, ob allen Menschen eine religiöse Anlage angeboren sei und sich hier zeige.

Ein weiteres zentrales Element von Furrers Argumentation gegen den konfessionellen, dogmatischen Religionsunterricht ist die Unterscheidung zwischen Theologie und Religion. Die Theologie als Inbegriff des Konfessionalismus und Dogmatismus «zerklüfte» - nicht die Religion. ${ }^{116}$ Unter Theologie versteht Furrer die begrifflich-theoretische Zugangsweise, mit der die Erscheinungen des Lebens zu fassen versucht werden, und grenzt diese von vortheoretischen Erfahrungen ab, die beispielsweise musikalischen Genuss oder ästhetisches Erleben erlaubten, ohne das Wissen von Schallwellen oder Farbtheorien vorauszusetzen. Die «Lebensgemeinschaft des Menschen mit Gott» werde mit «abstracten Formeln» zu fassen gesucht und in ein System gezwängt. Aber, so Furrer: «Keine Sprache, keine Theorie vermag das Unendliche ganz zu begreifen. Es bleibt das erhabenste Reden von Gott nur ein Ringen das zu sagen, was eigentlich unsagbar. Darum wechseln Systeme, Confessionen; doch das religiöse Leben, das dem irdischen Dasein des Menschen seine höchste Weihe und Bedeutung gibt, bleibt

I 3 Furrer gibt keine diesbezüglichen Informationsquellen an. Vgl. auch Unterkapitel 7.2.2, S. I 88 .

II 4 Furrer I872, I3.

I I Vgl. auch Unterkapitel 6.3.2, S. I $48 \mathrm{f}$.

I 6 Furrer, I 872, 7; vgl. auch Unterkapitel 6.3.2, S. I 48 f. 
seinem innersten Wesen nach unvergänglich dasselbe. Im Interesse der Religion müssen wir den Dogmatismus oder Confessionalismus bekämpfen.» ${ }^{17}$

Da Furrer von Dogmatismus und Confessionalismus sprach, könnte es scheinen, als ob er die dogmatische Verhärtung einer bestimmten konfessionellen Tradition anprangerte. Seine Kritik ging jedoch vermutlich darüber hinaus und zielte auf jegliche dogmatische Bestimmtheit des Glaubensvollzugs. Denn Furrer schien Religion in romantisch-schleiermacherscher Manier, verstanden als reines Gefühl, vor dem sprachlichen und notwendigerweise ab-strabierenden - wörtlich verstanden als trennenden - menschlichen Zugriff bewahren zu können. Doch fragt sich natürlich, was denn noch bleibt, wenn man von diesem innersten, unvergänglichen Wesen alles Konkrete und Bestimmte und somit potentiell Trennende abzieht. Durch die Unterscheidung zwischen Theologie und Religion, das heisst durch den Versuch, das angeblich Universale - und gemäss Furrer eigentlich das Unsagbare - in Worte zu fassen, kommt Furrer nicht umhin, seine eigene, partikulare Sicht einfliessen zu lassen, anscheinend aber ohne sich dessen bewusst gewesen zu sein. Denn dann hätte ihm die innere Spannung der Aussage, dass der «Dogmatismus oder Confessionalismus» (i. e. partikulare Überzeugungen) «im Interesse der Religion» ${ }^{118}$ (i. e. eine ebenso partikulare Vorstellung, wenn auch von Universalität) zu bekämpfen sind, auffallen müssen. Wie bereits im Unterkapitel 7.2.2 beschrieben wurde, ist auch bei Vögelin ein ähnlich omniperspektivisches Denken auszumachen. In der Rechtfertigungsrede für sein Geschichtslehrmittel, die er I 874 vor den Versammlungen der zürcherischen Schulkapitel hielt, bezeichnete er die «historische Wahrheit» als «eine Wahrheit, die über dem Protestantismus und Katholizismus liegt, ja über allen Religionen und Parteien». Das Lehrmittel habe seinen Auftrag erreicht und «die Schule ein gutes Werk gethan», wenn es gelungen sei, in dem Kinde das Gefühl zu pflanzen, «dass die religiöse Ueberzeugung Sache der persönlichen Erfahrung und Entscheidung ist, und dass eben darum über dem kirchlichen das Menschheitsgefühl steht». Die Lehrer hätten die Aufgabe, den Kindern in begeisternden Stunden die ihnen «durch keinen Parteihass mehr zu raubende Überzeugung» zu vermitteln, «dass über allem Kampf und Streit die Toleranz steht; dass nicht Konfessionalismus das Ziel der Menschheit ist, sondern Humanität». ${ }^{19}$ Vögelin hatte bereits I 872 im Kantonsrat in der Diskussion um die Formulierung von Paragraph I 4 des Unterrichtsgesetzes (Unterrichtsgegenstände) nebst dem «Ausschluss alles dogmatischen \& konfessionellen» den Zusatz «\& zur Förderung der Humanität» ${ }^{120}$ gefordert. Es wird hier deutlich, wie die Menschlichkeit,

II 7 Furrer I872, 8 .

I 8 Ebd.

I 9 Vögelin I 874, I I.

I 20 Kantonsratsprotokoll vom I I. I. I 872 . 
das Menschheitsgefühl oder die Toleranz als das Allgemeine, Universale in Anspruch genommen wurden, das alle partikularen Konflikte unnötig und unmöglich macht. Vögelin ging also davon aus, dass das allgemein Menschliche allem Partikularen übergeordnet sei und dass, wer dieses 〈Humanum〉 vermittle, so gesehen nicht seine eigenen subjektiven Überzeugungen verkündige, sondern eben die sogenannte <objektive», «historische Wahrheit». Wie Furrer bedachte auch Vögelin die Perspektivität dieser Aussage nicht. Er blendete aus, dass so wie über sogenannte dogmatische Themen, das Abendmahl oder das Amtsverständnis zum Beispiel, ebenso auch über das rechte Verständnis von Menschlichkeit oder Toleranz gestritten werden kann, weil das Universale immer nur im Partikularen seinen Ausdruck findet und finden kann.

Dennoch scheint Vögelin im Unterschied zu Furrer hinsichtlich der Problematik von Universalitätsansprüchen eine grössere Sensibilität zu äussern. Zumindest deutet sein Ringen um eine Antwort auf die Frage nach der Legitimation eines Schulobligatoriums in seiner Rede von I 879 darauf hin. Zwar beendete er seine Rede als unkritischer Universalist mit der Überzeugung, dass die notwendige menschliche Bewegung hin zur hüllenlosen Wahrheit dem Volksunterricht gemeinsame Grundlagen ermögliche. Doch zuvor wird sein kritischer Universalismus deutlich, wenn er auf die Partikularität von Religion und Moral wie auch des Geschichtsunterrichts verweist (vgl. Unterkapitel 7.2.2, S. I90 ff.). Aus heutiger Perspektive vermag es allerdings zu erstaunen, dass Vögelin, obwohl er die Perspektivität im ersten Teil seiner Rede über das Schulobligatorium so emphatisch und als nicht zu leugnen beschreibt, seinen eigenen Glauben an «eine über allen Zeitauffassungen und allen menschlichen Widersprüchen liegende Wahrheit» ${ }^{221}$ nicht selber auch als perspektivisch gebunden $\mathrm{zu}$ anerkennen vermag. Dies ist wohl nur auf dem Hintergrund zu verstehen, dass er davon ausging, dass dies eben nicht sein individuell zu verantwortender Glaube sei, sondern der Menschbeitsglaube, der sich allen vernünftigen Menschen im Laufe der Zeit immer deutlicher offenbaren werde.

Zusammenfassend lässt sich die Negation der Partikularität von Universalitätsansprüchen bei Furrer und Vögelin in zwei Punkten festhalten: I) Sittlichkeit und Religiosität wurden als anthropologische Konstanten verstanden, deren Beschreibung jedoch (notwendigerweise) in einer partikularen Sprache erfolgte, ohne dass dieser Umstand nochmals eigens reflektiert worden wäre. 2) Das, was als Universales angesehen wurde (Toleranz oder Humanität), wurde nur in negativen Ausdrücken beschrieben - nicht dogmatisch, nicht konfessionell - und nicht positiv bestimmt. Eine Konkretisierung wurde somit vermieden und damit auch das unvermeidliche Einnehmen einer bestimmten Perspektive. 


\subsection{Zwei Typen von Zivilreligion}

In meiner Eingrenzung des Begriffs Zivilreligion im Unterkapitel 2.6 habe ich zwei Idealtypen unterschieden: die französische Version (Typus A) und die amerikanische Version (Typus B). Die französische Version der Zivilreligion habe ich als Gegenreligion zur traditionellen christlich-kirchlichen Religion beschrieben, wobei der Anspruch, den gesamten Menschen - mitsamt seiner Seele - zu ergreifen, beibehalten, aber mit einem neuen, säkular-nationalen Inhalt gefüllt wird. Demgegenüber wird in der amerikanischen Version von Zivilreligion den traditionell christlich-religiösen Glaubensinhalten, Symbolen und Kulten nichts entgegengesetzt. Vielmehr werden diese zu politischen, säkular-nationalen Zwecken eingesetzt. Das heisst, dass die amerikanische Form von Zivilreligion von den Ressourcen der traditionell-religiösen Gemeinschaften zehrt. In Reinform findet sich in der zürcherischen Diskussion weder die eine noch die andere Form von Zivilreligion. Ich werde jedoch im Folgenden zeigen, dass auf subtile Weise Elemente beider Typen hier vereint sind.

\subsubsection{Vergleich mit dem französischen Idealtypus von Zivilreligion}

Eine Gemeinsamkeit zwischen dem französischen Idealtypus und der Zivilreligion, wie sie sich im Kanton Zürich in der zweiten Hälfte des 19. Jahrhunderts zeigte, liegt in der Infragestellung der bisher jeweils vorherrschenden christlichen Tradition. Im Unterschied zum französischen Modell hatte diese Infragestellung jedoch keine antikirchliche und antiklerikale Spitze, da in Zürich diese Richtungskämpfe innerbalb der Landeskirche stattfanden. Entsprechend kann auch nicht im selben Sinn von einer Transformation der reformiert-christlichen Tradition in eine national-religiöse gesprochen werden, sondern viel eher von einer Transformation einer reformiert-positiven (bekenntnistreuen) Orientierung zu einer reformiert-liberalen. Man könnte sagen, dass durch die Verbreitung der liberalen Theologie - unter anderem durch F. S. Vögelin - zu einem Volksglauben, die eigenartige Situation einer Zivilreligion innerhalb der Kirche entstand. ${ }^{122}$ Auf Grund der klareren Trennung zwischen Kirche und Staat lässt sich im laizistischen Frankreich am Beispiel der Schule die Sakralisierung staatlicher Institutionen holzschnittartiger zeigen und beschreiben: Der staatlichen Institution

I 22 Es müsste genauer untersucht werden, inwiefern sich die liberale «Volkstheologie` eines Vögelins von derjenigen der akademischen Theologen unterschied. Alois Emanuel Biedermann (vgl. Anm. 26, S. 98) beispielsweise warf seinem einstigen Schüler in einem Brief die Neigung vor, es sich mit der sachlichen Begründung in seinen Predigten etwas zu leicht zu machen. Er zeige «eine Art Fanatismus, den «gläubigen` Widerspruch zu provozieren» (Biedermann, Brief vom 27. I0. 1864, zit. in Betulius 1956, I0). Dieser Frage kann jedoch im Rahmen dieser Arbeit nicht nachgegangen werden. Das heisst, ich behaupte hier nicht, dass jegliche liberale Theologie zwingend zivilreligiöse Formen annehmen muss. 
Schule kam die Aufgabe zu, dem Volk die <richtige> Moral, den esprit d'ensemble (vgl. Unterkapitel 2.4.I), das heisst eine republikanische Einheitsmoral, zu vermitteln. Die Schule übernahm hinsichtlich des einheitsstiftenden Moments die einstige Funktion der (römisch-katholischen) Kirche. Hinsichtlich des zu vermittelnden Inhalts wurde sie jedoch neu besetzt.

Im Unterschied dazu nahm im Kanton Zürich, bedingt einerseits durch die starke Verflechtung zwischen Landeskirche und Staat und andererseits durch die Idee der Volkskirche, das Phänomen der Zivilreligion in Zürich eine subtilere Form an (vgl. Unterkapitel 7.I). Was den zentralen Unterschied zwischen der idealtypischen französischen Zivilreligion und den zivilreligiösen Ausprägungen im Kanton Zürich ausmacht, ist die innerkirchliche Unterscheidung zwischen Bekenntniskirche und Volkskirche, wobei beide Kirchenverständnisse Spaltprodukte der überkommenen Staatskirche sind.

Mit der liberalen Wende der i 83 oer Jahre wurde die öffentliche Schule zu einer Institution unter staatlicher Aufsicht, womit die Kirche juristisch gesehen an Einfluss verlor. Ähnlich wie im französischen Modell wurde der Schule hinsichtlich des einheitsstiftenden Moments jedoch dieselbe Funktion wie der Kirche zugeschrieben. Durch die Identifikation von Kirche und Volksgemeinschaft, wie zum Beispiel bei Vögelin, wurde aber auch das Verhältnis zwischen Volkskirche und (Volks-)Schule im Unterschied zum französischen Modell von Zivilreligion sehr eng bestimmt, so dass nicht bloss von einer Verkirchlichung der Schule, sondern umgekehrt auch von einer Verschulung der (Volks-)Kirche gesprochen werden muss (vgl. Unterkapitel 7.3). Wenn Vögelin und Co. aber von Kirche sprechen, dann ist eine theologisch liberale Kirche gemeint und keine bekenntnistreue. Die zürcherische Ausprägung von Zivilreligion ist im Unterschied zur französischen Form eher als symbiotische Verschmelzung von Schule und reformiert-liberaler Volkskirche zu beschreiben denn als Transformation katholisch-kirchlicher Inhalte zu national-zivilreligiösen.

\subsubsection{Vergleich mit dem amerikanischen Idealtypus von Zivilreligion}

Die Geschichte der US-amerikanischen Ausprägung von Zivilreligion ist eng mit der Verfolgung der Täufer, ${ }^{123}$ des radikalen Flügels der Reformation, verbunden, die in Zürich massive Formen annahm. Die Verfolgung dieser

I 23 Die Täuferbewegung entstand im Zusammenhang mit der Niederschlagung der revolutionären Bewegung des Bauernkriegs (1525). Die Täufer bemühten sich um die Wiederherstellung des wahren Christentums und setzten sich für eine radikalere Reform ein. Sie distanzierten sich zunehmend von Luther und Zwingli. Zu den Merkmalen der Schweizer Brüder gehörte ihr Streben nach sichtbarer Besserung des Lebens, zu dem auch Gewaltlosigkeit zählte. Die Täufer verweigerten den offiziellen Kirchgang, den Eid und den Kriegsdienst. Mit ihrer Kritik an der religiös-sozialen Situation ihrer Zeit, zu der insbesondere auch die unheilvolle Allianz von Kirche und Obrigkeit gehörte, zogen sie den Zorn der politisch Mächtigen auf sich (vgl. Jecker 20I2). 
religiösen Nonkonformisten in Europa ist mitverantwortlich für die establishment clause des ersten Zusatzartikels der amerikanischen Verfassung. Diese Errichtungsklausel verbietet dem Kongress die Einführung einer Staatsreligion. Da viele Angehörige der amerikanischen Gründergeneration Nachfahren von Religionsflüchtlingen aus Europa waren, war es ihnen wichtig, dass es dazu im neuen Land nicht kommen sollte. Während die amerikanische Version von Zivilreligion auf der Trennung zwischen Kirche und Staat basiert, ist die zürcherische Version von Zivilreligion nicht ohne die aus der Staatskirche herausgewachsene Landeskirche zu denken, die bis heute keine klare Trennung zwischen Staat und Kirche erlaubt. Zudem sind in Zürich die Landeskirche und die anderen Religionsgemeinschaften nicht gleichgestellt, während in Amerika - zumindest de jure ${ }^{\mathrm{I2} 4}$ - keine Religionsgemeinschaft vom Staat bevorzugt behandelt werden darf.

Ein zentrales Merkmal des amerikanischen Typus von Zivilreligion ist die Verwendung von biblisch-religiöser Symbolik im öffentlichen Raum. Dies mag angesichts der verfassungsmässig verankerten Trennung von Staat und Kirche auf den ersten Blick erstaunen. Die Verfassung untersagt dem Staat, eine bestimmte Religion oder Konfession bevorzugt $\mathrm{zu}$ behandeln. Es ist jedoch verfassungsmässig nicht ausgeschlossen, auf eine vermeintlich von allen Bürgern geteilte, transzendente Wirklichkeit Bezug zu nehmen, der gegenüber sich die politische Sphäre zu verantworten hat. Nicht die Verfassung, aber die Unabhängigkeitserklärung von 1776 nimmt explizit auf einen über der Nation stehenden Gott Bezug (vgl. Unterkapitel 2.2).

Wie sieht es in Zürich hinsichtlich der Verwendung von religiöser Symbolik im öffentlichen Raum aus? Ihre Verwendung ist keineswegs tabu. Dies zeigt Konrad Furrers bereits oben dargelegte Argumentation für einen konfessionslosen Religionsunterricht (vgl. Unterkapitel 7.4, S. 207), die auf der Annahme basiert, dass es sowohl «identische Gesetze des sittlich-religiösen Geistes» wie auch «identische Denkgesetze» gebe. Dieses «identische sittlich-religiöse Bewusstsein» werde von Staatsmännern in besonders ernsten Stunden angesprochen: Gott, der Vater, das Gefühl der Abhängigkeit von seiner Allmacht, «das theuerste Kleinod des Vaterlandes, die Freiheit, die unter heissen Kämpfen errungen worden». Furrer verweist auch auf die Präambel der Bundesverfassung, in der es zu Beginn

I 24 De facto bedeutete dies allerdings nicht, dass die Angehörigen aller Religionsgemeinschaften gleiche Behandlung erfuhren. Man denke an den wachsenden Antikatholizismus im Zuge der zunehmenden Immigration von Katholiken, zum Beispiel aus Irland, der im 19. Jahrhundert in den USA Hochkonjunktur hatte. Charles Leslie Glenn zeigt in seinem Buch The Myth of the Common School am Beispiel des Bildungsreformers Horace Mann wie durch die Furcht vor den zunehmend nicht protestantischen Immigranten die öffentliche Schule eine fast «mythische» Bedeutung erhielt mit dem Ziel, die sfehlgeleiteten〉 Katholiken in die protestantische-amerikanische Kultur zu assimilieren (vgl. Glenn 2002, 66 ff.). 
heisst: «Im Namen Gottes, des Allmächtigen». Dass diese bisher niemand habe beseitigen wollen, begründete er folgendermassen: «Auch im freiesten Verkehr des Volkes, in seinen Festen und Gesängen klingen religiöse Gefühle an, die Blüthentage des öffentlichen Lebens mit höherer Weihe durchdringend. Sollte es denn nicht möglich sein, in dem noch unbefangen, unverbildeten Geist der Jugend ein identisches sittlich-religiöses Bewusstsein zu entfalten?» ${ }^{125}$

Die Annahme einer allen Menschen angeborenen sittlich-religiösen Anlage, deren Entfaltung aber offenbar einer gewissen (Nach-)Hilfe bedarf, diente Furrer als Begründung für die Verwendung religiöser Symbolik im öffentlichen Raum. In der Verwendung von (jüdisch-christlicher) religiöser Symbolik im öffentlich-politischen Raum scheint im Unterschied zum französischen Typus von Zivilreligion eine Gemeinsamkeit zwischen dem amerikanischen Typus und dem zürcherischen um I 870 zu bestehen. Fraglich aber ist, ob auch die Begründungsmuster für deren Verwendung ähnlich sind. Von meinen Quellen her lässt sich diese Frage nicht direkt beantworten. Es lassen sich jedoch zwei mögliche Begründungshorizonte in der zürcherischen Diskussion vermuten:

Für diejenigen, die kein Bewusstsein für die Spannung zwischen Religionsfreiheit und Einheit zeigten, war die Verwendung religiöser Symbolik im öffentlichen Raum insofern kein Problem, als ohnehin alle Einwohner als reformiert galten (vgl. Unterkapitel 7.2.I). Hier zeigt sich eine Parallele zum amerikanischen Idealtypus. In beiden Fällen wurde das fortdauernde Bestehen einer religiösen Einheit vorausgesetzt. Im amerikanischen Denominationalismus, in dem im Unterschied zur zürcherischen Version von Zivilreligion konfessionelle Differenzen zumindest offiziell kein politisches Gewicht haben, ist allerdings der Bezugsrahmen die christliche Religion in Zürich hingegen die (reformierte) Konfession.

Furrers Begründung für die Verwendung religiöser Symbolik im öffentlichen Raum - die Annahme einer sittlich-religiösen Anlage aller Menschen, ein allgemein menschliches religiöses Gefühl, zu deren Entfaltung diese Symbolik als notwendig erachtet wird - unterscheidet sich insofern von der amerikanischen, als sie nicht auf die reale Zugehörigkeit zu einer institutionell-religiösen Einheit verweist, sondern auf eine angenommene anthropologische Konstante rekurriert. 


\subsection{Fazit Teil 2}

Am Ende des zweiten Teils dieser Arbeit soll ein erstes Fazit gezogen und zusammenfassend die Frage beantwortet werden, ob und auf welche Weise in der Diskussion um den schulischen Religionsunterricht anlässlich der Volksabstimmung von I 872 für ein neues Unterrichtsgesetz zivilreligiöse Tendenzen sich abzeichnen. Die zusammenfassende Antwort orientiert sich an den fünf Punkten der in Kapitel 2 dargelegten genaueren Bestimmung und Eingrenzung des Begriffs der Zivilreligion.

I. Der Gedanke der Volkskirche hat sich als zentral herausgestellt für das Verständnis der kirchen- und schulpolitischen Situation im Kanton Zürich um I870, insofern er eine vollständige Ausdifferenzierung zwischen Kirche und Staat verhinderte. Ausgehend von der Bestimmung, dass die funktionale Ausdifferenzierung zwischen Kirche und Staat eine der zentralen Grundvoraussetzungen ist, um begrifflich kontrolliert von Zivilreligion zu sprechen, kann angesichts der nur teilweisen Ausdifferenzierung auch nur in einem eingeschränkten Sinn von Zivilreligion die Rede sein.

2. Dass das (vermeintliche) Fehlen eines die Gesellschaft einigenden sittlichreligiösen Bandes überhaupt als Problem wahrgenommen wird, wurde im Unterkapitel 7.2 als Voraussetzung für die Manifestation zivilreligiöser Tendenzen genannt. In der Diskussion um den schulischen Religionsunterricht drückte sich der Umgang mit dieser Spannung darin aus, dass die Verfechter eines konfessionslosen, dogmatikfreien Religionsunterrichts dessen einheitsstiftende und verbindende Funktion betonten sowie mit diesem Unterricht Toleranzförderung und die Förderung eines friedlichen und gesitteten gesellschaftlichen Zusammenlebens anstrebten. Den Integrationshorizont bildeten bei Pfarrer Konrad Furrer die politische Gemeinschaft und das Volksganze. Diese Partikularismen wurden bei Friedrich Salomon Vögelin durch die Rede von der Menschheit transzendiert und zugespitzt durch die Annahme einer hüllenlosen Wahrheit, der die Menschheit sich kontinuierlich annähere. Die Evokation von Einheit durch die Annahme einer solchen omniperspektivischen Schau ist ein zentrales Merkmal von Zivilreligion.

3. Die Verwischung der Grenzen gesellschaftlicher Sphären als weiteres Merkmal von Zivilreligion folgt aus dem vorhergehenden Punkt - der Evokation von Einheit. Es wurde zum einen gezeigt, wie Kirche und Schule als Organe des Staates - im Dienste der Vermittlung sittlich-religiöser Ideen - verstanden wurden. Zum andern wurden mit der Analyse von Vögelins Predigten und Reden dedifferenzierende Tendenzen anhand seines nahezu symbiotisch gedachten Verhältnisses zwischen Schule und Kirche aufgezeigt. Es gilt jedoch zu beachten, dass die Rede von einem Einheitsstreben wie auch von Dediffe- 
renzierung oder Verwischung der Grenzen in gewissem Sinne anachronistisch ist, angesichts der Tatsache, dass die gesellschaftlichen Sphären im Vergleich zum Anfang des 2r. Jahrhunderts weniger ausdifferenziert waren. Dennoch sind die beschriebenen Phänomene dem, was später im Vollsinn Zivilreligion heissen kann, sehr ähnlich.

4. Ein wenig ausgebildetes Bewusstsein für die Partikularität von Universalitätsvorstellungen ist ein weiteres Charakteristikum zivilreligiöser Tendenzen, das sich folgendermassen äussert: zum einen in der fehlenden Reflexion, dass alles, was als allgemein menschlich angenommen wird, zum Beispiel Sittlichkeit und Religiosität, notwendigerweise in einer partikularen Sprache erfolgen muss. Zum andern in der Verwendung von blossen Negativbeschreibungen nicht dogmatisch, nicht konfessionell - und der Vermeidung von konkreten, positiven Beschreibungen von zum Beispiel Toleranz oder Humanität, was notwendigerweise die Konturen einer bestimmten Interpretation würde sichtbar werden lassen.

5. In der Abgrenzung zum französischen und amerikanischen Typus von Zivilreligion kann die Eigenart der zürcherischen Form von Zivilreligion besonders deutlich aufgezeigt werden. Die innerkirchlichen Richtungsstreitigkeiten, der theologisch liberale Gedanke der Volkskirche und insbesondere der Wandel der liberalen Theologie von einer akademischen Richtung zu einem Volksglauben lassen die eigenartige Situation einer Zivilreligion innerbalb der Kirche entstehen. Im Unterschied zum französischen Idealtypus von Zivilreligion ist in Zürich deshalb eher von einer symbiotischen Verschmelzung von öffentlicher Schule und liberaler Volkskirche zu sprechen als von einer Transformation kirchlicher Inhalte zu national-zivilreligiösen. Einen zentralen Unterschied zum amerikanischen Typus von Zivilreligion, der auf der mehr oder weniger strikten Trennung von Kirche und Staat basiert, bildet das zürcherische Modell der Landeskirche. Eine Parallele zum amerikanischen Typus jedoch ist die in den Argumentationen für einen konfessionslosen Religionsunterricht deutlich gewordene Annahme einer allen Menschen angeborenen sittlich-religiösen Anlage, welche die Anrufung religiöser Bezugsgrössen wie zum Beispiel Gott den Vater im öffentlichen Raum legitimiert.

Als Schluss des zweiten Teils der vorliegenden Arbeit lässt sich folgende These festhalten: In der Diskussion um den schulischen Religionsunterricht im Kanton Zürich um I 870 zeigt sich die distinkt zürcherische Form von Zivilreligion im Gewand der liberalen Theologie. 
Teil 3

DIE DISKUSSION UM DEN SCHULISCHEN RELIGIONSUNTERRICHT UM 2004 


\section{Vom Widerstand gegen die geplante Abschaffung von Biblischer Geschichte zur Einführung des obligatorischen Faches Religion und Kultur}

Teil 3 beginnt mit einem Sprung ins 2 1 . Jahrhundert. In Kapitel 9 werden die kontrovers diskutierten Punkte in der Diskussion um den schulischen Religionsunterricht um 2004 dargestellt. Dieses Kapitel ist als diesbezügliche Einführung gedacht. Zum einen wird auf einige für das Verständnis der Diskussion bedeutsame Parallelen und Unterschiede der politischen und religionspolitischen Situation zwischen 1872 und 2004 verwiesen und zum andern werden die Hintergründe für den Entscheid, das Fach Biblische Geschichte an der Volksschule zu streichen, sowie der Weg zur Einführung des obligatorischen Faches Religion und Kultur erläutert.

Als wesentlicher Unterschied zwischen der Situation von i 870 und derjenigen von 2004 ist die Parteipolitik zu nennen. Wir erachten heute politische Parteien als eine Selbstverständlichkeit, so als hätte es diese immer schon gegeben. ${ }^{1}$ Diese bildeten sich in einem längeren Prozess jedoch relativ spät heraus. Gemäss Andreas Ladner entstanden Parteien im heutigen Sinne «in denjenigen Kantonen, in denen der Kampf um die Demokratisierung besonders früh und heftig einsetzte». ${ }^{2}$ Ladner erwähnt hier: St. Gallen, Baselland, Luzern, Wallis, Waadt und Bern. Auf nationaler Ebene war es die Sozialdemokratische Partei der Schweiz (SP), die sich I 888 als solche herausbildete. Die Freisinnig Demokratische Partei (FDP) zog I 894 nach und I9I 2 wurde die Christlichdemokratische Volkspartei (CVP) gegründet. Zur Gründung der Schweizerischen Volkspartei (SVP) kam es erst 1936. ${ }^{3}$ Dementsprechend gab es um I 870 im Kanton Zürich noch kein etabliertes Parteiensystem wie um 2004. Ein Vergleich hinsichtlich parteipolitischer Stellungnahmen zum schulischen Religionsunterricht ist aus diesem Grund nicht möglich.

Bemerkenswerte Parallelen zwischen 1870 und 2004 zeigen sich hinsichtlich politischer Ereignisse, die im selben Zeitraum stattfanden wie die Diskussionen um den schulischen Religionsunterricht. Um I 870 stand auf eidgenössischer Ebene die Gesamtrevision der Bundesverfassung zur Debatte (vgl. Unterkapitel 4.I). Am I. Januar 2000 trat wiederum eine vollständig revidierte Bundesverfassung in Kraft und am 2r. Mai 2006 wurde die Revision der Bildungsartikel in der

I Vgl. Feller 1958, 433.

2 Ladner 20I $4,363$.

3 Vgl. ebd. 
Bundesverfassung vom Volk gutgeheissen. Auf kantonaler Ebene haben die Stimmberechtigten des Kantons Zürich am 27. Februar 2005 die neue Kantonsverfassung angenommen. Diese ersetzte die Verfassung des eidgenössischen Standes Zürich vom I8. April I 869 und trat am I. Januar 2006 in Kraft. ${ }^{4}$

Als Parallele in religionspolitischer Hinsicht ist auf die Debatte über die Neuregelung des Verhältnisses zwischen Kirche und Staat zu verweisen, über die am 30. November 2003 abgestimmt wurde. Um I 870 stand im Zusammenhang mit der Revision der Kantonsverfassung ebenfalls eine Veränderung des Verhältnisses zwischen Staat und Kirche zur Diskussion. Ein zentraler Diskussionspunkt um I 870 war die Gleichstellung der Landeskirche mit den anderen kirchlichen Gemeinschaften sowie die Trennung von Kirche und Staat. 2003 wurden insbesondere die grössere Autonomie für die anerkannten Kirchen sowie die Möglichkeit der öffentlichen Anerkennung anderer, nicht christlicher Religionsgemeinschaften kontrovers diskutiert.

Um I 870 bot die Annahme der neuen Kantonsverfassung den konkreten Anlass für die öffentliche Diskussion um die Abschaffung des konfessionellen und dogmatischen Religionsunterrichts, da man schulische Belange nicht auf Verfassungsebene, sondern in einem neuen Unterrichtsgesetz regeln wollte. Die geplante Ersetzung der «christlichen Religions- und Sittenlehre» durch «Anregungen und Belehrungen aus dem Gebiete des sittlichen und geistigen Lebens» - oder in heutigen Worten: die Ersetzung des traditionellen Religionsunterrichts durch einen Moral-bzw. Ethikunterricht - war ideell-paradigmatisch motiviert. Im Unterschied dazu war es zu Beginn des 2 I. Jahrhunderts ein eher pragmatischer regierungsrätlicher Entscheid im Rahmen von Sparmassnahmen, der eine breite öffentliche Diskussion über den schulischen Religionsunterricht entfachte. ${ }^{6}$

4 Vgl. Röhl 2006, 200.

5 Vgl. Furler 2005, 2 I 2; vgl. ebenfalls die detaillierteren Ausführungen in Unterkapitel 3.I.

6 Es gibt jedoch auch Stimmen, die Kostengründe als primären Grund für die Abschaffung von Biblischer Geschichte an der Volksschule als fadenscheinig ansehen, da «das neu geplante Fach 〈Religion und Kultur kostenneutral angeboten werden» könne. Einem Leserbriefschreiber in der NZZ leuchtete beispielsweise nicht ein, «warum dasselbe nicht auch mit dem bisherigen Fach möglich sein sollte». Seiner Ansicht nach kann dies nur «dahingehend interpretiert werden, dass es den Bildungsverantwortlichen um jeden Preis darum geht, die ungeliebten christlichen Werte und insbesondere die scheinbar so gefährliche Bibel endlich aus den Schulstuben zu verbannen» (Leserbrief von Sven Zimmerlin, NZZ, 24. 5. 2004). Ähnlich klingt es auch in einem anderen Leserbrief: «Warum soll ein neues Fach her, wenn das bisherige angeblich aus Spargründen zum Freifach degradiert worden ist? Hier wäre ein Bekenntnis am Platz» (Leserbrief von Bruno Nüsperli, NZZ, 3. 6. 2004). Nüsperlis Leserbrief ist eine Reaktion auf den NZZ-Artikel «Zeit für ein Bekenntnis», in welchem der Autor am Ende seines Artikels von denjenigen, die «am alten christlich geprägten Bibelunterricht festhalten wollen», forderte, «zu bekennen, um was es ihnen wirklich geht» (NZZ, I4. 5. 2004). 
Um den aus dem Lot geratenen Staatshaushalt zu sanieren, waren alle kantonalen Direktionen aufgerufen, Sanierungsmassnahmen auszuarbeiten. Die «Aufhebung der Angebotspflicht für biblischen Unterricht», wie die Massnahme San 04.2I4 im Massnahmenkatalog der Bildungsdirektion genannt wurde, war bloss eine von 34 Massnahmen der Bildungsdirektion, die in der Medienmitteilung des Regierungsrates vom 8. Mai 2003 veröffentlicht wurden.7 3,2 Millionen Franken sollten mit dieser Massnahme eingespart werden, ${ }^{8}$ wobei zunächst nicht klar war, ob bloss der Konfessionell-kooperative Religionsunterricht (KokoRu) auf der Oberstufe oder auch der Unterricht in Biblischer Geschichte auf der Primarstufe von dieser Massnahme betroffen war. ${ }^{9}$ Da damit nur die Angebotspflicht für den Kanton wegfallen sollte, war es den politischen Gemeinden freigestellt, Biblische Geschichte freiwillig anzubieten und selbst zu finanzieren. Der Protest, den diese geplante Sparmassnahme auslöste, war im Unterschied zu deren pragmatischem Auslöser jedoch unverkennbar von ideellen Vorstellungen getragen. Der Kirchenrat der evangelisch-reformierten Kirche nahm bereits am 2r. Mai 2003 öffentlich gegen die Sparmassnahme Stellung und forderte die Beibehaltung des Religionsunterrichts. Er rief die verschiedenen kirchlichen Exponenten auf, sich mit Leserbriefen und Eingaben an die Bildungsdirektion für den Religionsunterricht einzusetzen. ${ }^{\circ 0}$ Am 24. Juni 2003 verabschiedete die reformierte Kirchensynode eine Resolution zuhanden der Bildungsdirektion und des Regierungsrates, in der das eigene Befremden über den Antrag des Regierungsrates ausgedrückt und dieser aufgefordert wurde, seinen Antrag

7 Die folgende, auswahlsweise Aufzählung einiger weiterer geplanter Sparmassnahmen der Bildungsdirektion soll zeigen, dass in den verschiedensten Bereichen der Bildungsdirektion (Verwaltung, Bildung und Soziales) drastische Massnahmen geplant waren und es deshalb berechtigt ist, die Aufhebung der Angebotspflicht für biblischen Unterricht als pragmatischen Entscheid zu bezeichnen: Reduktion des Personalbestandes um 5 Prozent in der Bildungsverwaltung (Nr. 208), Reduktion der Entschädigung der Bildungsräte (Nr. 2 I 3), Reduktion der Handarbeitslektionen auf der Primarschulstufe (Nr. 2 I 5), Anhebung der Klassengrössen um I, 5 Schülerinnen und Schüler (Nr. 2 I6), Abschaffung der Diplommittelschule (Nr. 22 I), Abschaffung der Hauswirtschaftskurse (Nr. 223), Senkung der Lektionenzahl für Schüler/-innen in der Mittelschule (Nr. 226), Redimensionierung universitärer Leistungen (Nr. 232), Verzicht auf Vorkurse an der Hochschule für Gestaltung (Nr. 234), teilweise Schliessung von Museen (Nr. 236), Schliessung Studiengang Dolmetscher (Nr. 237), Streichung Beiträge Musikschulen (Nr. 24I), Beitragsverzicht an Alimentenbevorschussung und Kleinkinderbetreuung (Nr. 244) usw. (Regierungsrat Kanton Zürich, Medienmitteilung vom 8. 5. 2003).

8 Vgl. Furler 2005, 2 I I.

9 Vgl. Protokoll der evangelisch-reformierten Kirchensynode vom 25. I I. 2003, Mitteilungen von Kirchenrätin Anemone Eglin, I 3.

ı० Vgl. ebd. Dieser Aufruf hatte zur Folge, dass die Bildungsdirektion täglich Post erhielt. Zum Beispiel einen Brief des Kirchenpflegepräsidenten von Bauma, den 259 Unterschriften von Kirchenpflege- und Schulpräsidien, Kantons- und Verfassungsräten zierten (vgl. Furler 2005, 2I2). 
zurückzuziehen. ${ }^{11}$ Am 4. Dezember 2003 verfasste auch die römisch-katholische Synode des Kantons Zürich eine Resolution mit derselben Stossrichtung. ${ }^{\mathrm{I2}}$ Das Anliegen, den Unterricht in Biblischer Geschichte beizubehalten, wurde jedoch nicht nur von den Kirchen, sondern auch seitens der Lehrkräfte und politischer Parteien unterstützt. Drei Mitglieder der Fraktion der Evangelischen Volkspartei (EVP) reichten am 22. September 2003 im Kantonsrat eine Motion ${ }^{13}$ ein mit der Aufforderung, «sicherzustellen, dass das Angebot des biblischen Unterrichtes an der Primarschule in allen Schulgemeinden erhalten bleibt». ${ }^{14}$ Der Regierungsrat beantragte jedoch dem Kantonsrat, diese Motion nicht zu überweisen, mit der Begründung, dass die Festlegung von Unterrichtsangeboten nicht in den Zuständigkeitsbereich des Kantonsrates falle und somit gemäss Paragraph I4 Abs. I KRG nicht motionsfähig sei. ${ }^{15}$ Der Zürcher Lehrerinnenund Lehrerverband (ZLV) und die Gewerkschaft Verband Personal Öffentlicher Dienste (VPOD) verfassten mit derselben Absicht wie die Motionäre gemeinsam eine Petition, für die innerhalb von zwei Monaten 20000 Unterschriften zusammenkamen. ${ }^{16} \mathrm{Da}$ sie jedoch wenig Hoffnung auf Gehör beim Kantonsrat hatten, reichten sie beim Regierungsrat zudem noch einen Rekurs gegen den Entscheid des Bildungsrates ein. ${ }^{17}$ Der Regierungsrat ging auf diese Rekurse jedoch nicht ein mit der Begründung, «dass vor dem Regierungsrat nur Anordnungen angefochten werden könnten, die für eine bestimmte Person oder Gruppe eine konkrete Rechtsbeziehung verbindlich regeln (sogenannte Verfügungen)». ${ }^{18} \mathrm{Nach}$ Ansicht des Regierungsrates waren diese Anforderungen nicht gegeben. ${ }^{19}$

Am I3. September 2004 wurde beim Regierungsrat eine von einem überparteilichen Komitee lancierte Volksinitiative - gemäss NZZ vom I4. September

I I Vgl. Protokoll der evangelisch-reformierten Kirchensynode vom 24. 6. 2003, I7 ff.

I 2 Vgl. Protokoll der römisch-katholischen Synode des Kantons Zürich vom 4. I2. 2003, Iof.

I 3 Die Motion KR-NR. 284/2003 wurde eingereicht von Hans Fahrni / Winterthur und Lisette Müller-Jaag / Knonau.

I4 Auszug aus dem Protokoll des Regierungsrates des Kantons Zürich, Sitzung vom I I. I 2. 2003.

is Vgl. ebd.

I6 Vgl. NZZ, 23. 2. 2004.

I7 Vgl. NZZ, 23. 2. 2004 und 5. 5. 2004.

I 8 NZZ, 5. 5. 2004.

I9 «Der Beschluss sei abstrakt und deshalb vom Regierungsrat nicht überprüfbar, erklärt Dieter Müller, stellvertretender Chef des Rechtsdiensts der Staatskanzlei, auf Anfrage. Der umstrittene Entscheid des Bildungsrats ist eine Änderung des Lehrplans, der den Gemeinden überlässt, ob sie den Bibelunterricht weiterhin als Freifach anbieten wollen. Der Lehrplan, der in der Kompetenz des Bildungsrats liegt, ist laut Müller ein Rechtssatz, vergleichbar mit einer Verordnung oder einem Gesetz. Und der Regierungsrat sei nicht berechtigt, die Rechtmässigkeit von Rechtssätzen zu überprüfen. Möglichkeiten, gegen den Entscheid des Bildungsrates vorzugehen, seien nur eine staatsrechliche Beschwerde beim Bundesgericht oder eine Volksinitiative» (NZZ, 5. 5. 2004). 
2004 mit 50000 Unterschriften $^{20}$ - eingereicht. ${ }^{21}$ Das Komitee erachtete diese hohe Zahl von Unterschriften - es wären bloss ı०००० Unterschriften notwendig gewesen - als Beweis dafür, «dass die Bevölkerung das Vermitteln von Grundwissen über Religion an der Primarschule für wichtig hält». ${ }^{22}$ Am I 9. September 2005 reichten drei Kantonsrätinnen ein dringliches Postulat ein. ${ }^{23}$ Sie forderten den Regierungsrat auf, dem Bildungsrat zu beantragen, «in den Lehrplan der Primarstufe ein eigenständiges und obligatorisches Fach 〈Religion und Kultur〉 aufzunehmen». ${ }^{24}$ Dieses Postulat wurde vom Regierungsrat im Sinne der Erwägung entgegengenommen. ${ }^{25}$ Am I4. Dezember 2005 stellte der Regierungsrat dem Kantonsrat den Antrag, die Volksinitiative für die Weiterführung des Faches Biblische Geschichte abzulehnen, dem Gegenvorschlag des Regierungsrates zuzustimmen und somit das dringliche Postulat KR-Nr. 258/2005 als erledigt abzuschreiben. Der Gegenvorschlag beinhaltete analog zur Oberstufe die Schaffung des Faches «Religion und Kultur» auf der Primarstufe mit einer Wochenstunde von der I. bis 6. Klasse. Der zentrale Unterschied zwischen dem bisherigen Fach Biblische Geschichte und dem neuen Fach wurde darin gesehen, «dass Religion und Kultur eine erweiterte Zielsetzung hat und als obligatorisches Fach ohne Abmeldemöglichkeit ausgestaltet werden soll. Damit soll das neue Fach für alle verbindlich werden. Analog zum Beschluss des Bildungsrates über das obligatorische Fach «Religion und Kultur auf der Oberstufe der Volksschule muss der Unterricht deshalb im Sinne des «teaching about religion> erfolgen». ${ }^{26}$

In finanzieller Hinsicht sah der Gegenvorschlag vor, dass der Unterricht in Religion und Kultur auf der Unterstufe (I. bis 3. Primarklasse) im Rahmen der Blockzeiten innerhalb des ordentlichen Pensums der Lehrpersonen erteilt werden sollte und die Lehrpersonen auf dieser Stufe nicht wie vorher beim Fach Biblische Geschichte für eine zusätzliche Lektion entlohnt würden. Ein Staatsbeitrag des Kantons sollte nur für die zusätzliche Lektion auf der Mittelstufe (4. bis 6. Klasse) aufgewendet werden. Die Volksinitiative forderte die Wiederherstellung der früheren Regelung, was für den Kanton jährliche Mehr-

20 Seltsamerweise steht im Antrag des Regierungsrates vom 24. I I. 2004, dass «die geprüften Unterschriftenbogen I 3624 Unterschriften» aufweisen, von denen I 423 als gültig beglaubigt worden sind (Antrag des Regierungsrates vom 24. I I. 2004, I483).

2 I Beginn der Unterschriftensammlung war der 20. März 2004 (vgl. Antrag des Regierungsrates vom 24. II. 2004, S. I483).

22 NZZ, I 4. 9. 2004.

23 Die Postulantinnen waren: Prof. Andrea Widmer Graf, Zürich, Yvonne Eugster, Männedorf, und Ursula Braunschweig-Lütolf, Winterthur.

24 Auszug aus dem Protokoll des Regierungsrates des Kantons Zürich vom i I. I 2. 2003, KR-Nr. $284 / 2003$, S. I. Zu «Entscheidung und Etappen der Umsetzung von «Religion und Kultur» als Schulfach an der Primarschule des Kantons Zürich ab 2003» siehe Furer 201 2, I99-202.

25 Vgl. Protokoll des Regierungsrates vom 26. I0. 2005, KR-Nr. $258 / 2005,3$.

26 Antrag des Regierungsrates vom I4. I2. $2005,7$. 
kosten von 3,2 Millionen Franken zur Folge gehabt hätte, während dem Kanton mit dem Gegenvorschlag jährliche Kosten von rund I,6 Millionen Franken entstehen sollten und somit zumindest die Hälfte des ursprünglichen Beitrages eingespart werden konnte. ${ }^{27}$

Der Antrag des Regierungsrates vom I4. Dezember 2005 wurde vom Kantonsrat in der Sitzung vom I 5. Januar 2007 behandelt. Der Kantonsrat folgte dem Antrag des Regierungsrates und empfahl, die Initiative zur Weiterführung von Biblischer Geschichte auf der Primarstufe abzulehnen. Als Gegenvorschlag wurde die Einführung des Faches Religion und Kultur auch in der Primarschule beschlossen. ${ }^{28}$ Der Kantonsrat stimmte in der Sitzung vom I 2. März 2007 dem neuen Text der Redaktionskommission für Paragraph 62 des Volksschulgesetzes zu. ${ }^{29}$ In der Folge zog das Initiativkomitee mit einem Schreiben vom 19. März 2007 die Volksinitiative zurück. ${ }^{30}$ Die Inkraftsetzung der Änderung in Paragraph 62 des Volksschulgesetzes wurde auf den I6. August 2008 festgesetzt, da kein Referendum dagegen ergriffen worden war. ${ }^{31}$ Gemäss Bildungsratsbeschluss vom 29. Juni 2007 durften die Schulgemeinden mit der Einführung des neuen Schulfaches Religion und Kultur an der Primarstufe ab Schuljahr 2008/09 beginnen, «sofern in allen Klassen eines Jahrgangs der Unterricht von Lehrpersonen mit der vorgeschriebenen Unterrichtsbefähigung erteilt wird».32 Die Einführung sollte jedoch spätestens bis im Schuljahr 20II/I2 erfolgen. Der Bildungsrat beauftragte die kantonale Lehrmittelkommission, Unterrichtsmaterialien für Religion und Kultur erarbeiten zu lassen. Da Religion und Kultur zu einem regulären Schulfach wurde und ab der 4. Klasse benotet werden sollte, mussten auch das Zeugnisreglement und die Zeugnisformulare geändert werden. ${ }^{33}$

27 Vgl. ebd.

28 Protokoll des Zürcher Kantonsrates vom I 5. I. 2007: Beschluss des Kantonsrates über die Volksinitiative für die Weiterführung des Faches «Biblische Geschichte» in der Primarschule, S. I 33 I 2; vgl. auch Furer 20I 2, 20 I.

29 Vgl. Protokoll des Zürcher Kantonsrates vom I 2. 3. 2007: Beschluss des Kantonsrates über die Volksinitiative für die Weiterführung des Faches «Biblische Geschichte» in der Primarschule, S. I43 I 5; Furer 20I 2, 20I.

30 Vgl. Direktion der Justiz und des Innern: Rückzug der Volksinitiative für die Weiterführung des Faches «Biblische Geschichte» an der Primarschule und Veröffentlichung des Gegenvorschlages des Kantonsrates betreffend Volksschulgesetz. In Amtsblatt vom i i. 5. 2007, 808 .

3 I 4I 2.100 Volksschulgesetz (VSG), OS 63 (2008), 475.

32 Beschluss des Bildungsrates vom 29. 6. 2007, Ziff. I.

33 Vgl. ebd., Ziff. IV und V. 


\section{Kontroverse Themen in der Diskussion um den schulischen Religionsunterricht um 2004}

Der thematische Vergleich der Diskussion um I 870 und derjenigen um 2004 zeigt, dass zu Beginn des 2 I. Jahrhunderts trotz I 30 Jahren zeitlicher Distanz viele ähnliche Fragen diskutiert worden sind wie in der zweiten Hälfte des 19. Jahrhunderts: Wer bestimmt über Lehrplan und Lehrmittel? Wer darf das neue Schulfach unterrichten? Soll es obligatorisch sein? Besteht ein Zusammenhang zwischen Religion und Moral? Worin besteht die Aufgabe der öffentlichen Schule und dient der schulische Religionsunterricht dem Zweck der öffentlichen Schule?

Wie in den folgenden Unterkapiteln gezeigt werden soll, sind zwar thematisch gesehen viele Übereinstimmungen sichtbar, doch in der Art der Argumentation zeigen sich Unterschiede. Ein gegenüber der Diskussion im I9. Jahrhundert neu auftauchender Aspekt ist die religionspädagogische Unterscheidung zwischen teaching about und teaching in, die insbesondere im Zusammenhang mit der Diskussion um das Obligatorium zentrale argumentative Bedeutung erlangte. Obwohl im I9. Jahrhundert in der öffentlichen Diskussion noch keine neudeutschen Ausdrücke verwendet wurden, wird im Folgenden zu prüfen sein, ob von der Sache her nicht dennoch analoge Unterscheidungen am Werk waren. Hier denke ich insbesondere an die Unterscheidung zwischen konfessionell-dogmatischem und konfessionslosem Religionsunterricht. Ein weiterer, neuer Aspekt in der Diskussion ist die (inflationäre) Rede von den Werten. Zwar hat die Rede von Werten in einem nicht ökonomischen Sinn im 19. Jahrhundert ihren Ursprung, ${ }^{1}$ doch in der Diskussion um den schulischen Religionsunterricht im Kanton Zürich um I 870 fand ich in keiner der von mir untersuchten Quellen deren Gebrauch. Diesen verschiedenen thematischen und begrifflichen Kontinuitäten und Diskontinuitäten werde ich im Folgenden nachgehen. Die Darstellung der Diskussion im 2 I. Jahrhundert beinhaltet zugleich auch immer einen kurzen Vergleich mit der Diskussion um I 870. 


\subsection{Mitbestimmungsrecht über Lehrplan und Lehrmittel}

Zwar wurde mit dem Schulgesetz von I 832 der Einfluss der evangelisch-reformierten Landeskirche auf die Volksschule massiv eingeschränkt, dennoch blieb die Kirche noch jahrzehntelang an der Volksschule mitbeteiligt - hinsichtlich des schulischen Religionsunterrichts gar bis ins 2 I. Jahrhundert. Der schulische Religionsunterricht erhielt von Anfang an eine Sonderstellung, was das kirchliche Mitbestimmungsrecht betraf. In Paragraph 2I des Unterrichtsgesetzes von I 832 wurde der Erziehungsrat beauftragt, «einen allgemeinen Unterrichtsplan $»^{2}$ aufzustellen. Von diesem allgemeinen Unterrichtsplan scheint aber der Religionsunterricht ausgenommen worden $\mathrm{zu}$ sein, wenn es am Ende von Paragraph 2I heisst: «In Hinsicht des Religionsunterrichtes werden die obern Kirchen- und Schulbehörden, auf den Antrag einer Commission des Kirchenund Erziehungsrathes, die erforderlichen Anordnungen unter Genehmigung des Regierungsrathes treffen.»3

Insofern gemäss diesem Paragraphen Kirchenrat und Erziehungsrat die Anordnungen für den Religionsunterricht zusammen zu treffen haben, scheint der schulische Religionsunterricht als gemeinsame Angelegenheit von Schule und Kirche betrachtet worden zu sein. Mit dem Gesetz über das gesammte Unterrichtswesen des Kantons Zürich von I 859, das bis I 899 gültig war, kam es diesbezüglich zu einem Säkularisierungsschritt. Gemäss Paragraph 69 des Unterrichtsgesetzes von i 859 sollten Lehrplan und Lehrmittel für den Religionsunterricht wie in allen anderen Fächern nur noch vom Erziehungsrat entworfen werden. Es kam aber auch I859 nicht zu einem gänzlichen Bruch zwischen Schule und Kirche. Denn dem Kirchenrat wurde für Lehrplan und Lehrmittel der Alltagsschule (г.-6. Klasse) immerhin noch das Begutachtungsrecht zugestanden und für diejenigen der Ergänzungsschule nebst dem Begutachtungsrecht sogar auch noch das Genehmigungsrecht. Dies bedeutete, dass für die Alltagsschule der Erziehungsrat alleine die definitive Fassung auf Basis der Änderungsvorschläge beschliessen konnte, während für die Ergänzungsschule Lehrplan und Lehrmittel von beiden Gremien - Erziehungs- und Kirchenrat - genehmigt werden mussten (vgl. Unterkapitel 6.I). Zu einem weiteren Säkularisierungsschritt kam es mit dem Gesetz betreffend die Volksschule von I 899, welches dem Kirchenrat auch

2 \21: «Der Erziehungsrath wird einen allgemeinen Unterrichtsplan aufstellen, nach welchem für jede Schule unter Genehmigung der Bezirksschulpflege durch die Gemeindsschulpflege in Zuzug des Lehrers ein Lectionsplan zu entwerfen ist, in welchem genau angegeben wird, wie viel und welche Stunden auf jeden der durch das Gesetz bezeichneten Lehrgegenstände verwendet und in welcher Reihenfolge sie vorgenommen werden» (Gesetz über die Organisation des gesammten Unterrichtswesens im Canton Zürich von I 832 ).

3 Gesetz über die Organisation des gesammten Unterrichtswesens im Canton Zürich von I 832, $\int 2 \mathrm{I}, 320$. 
für die 7. und 8. Klasse der Primarschule ${ }^{4}$ sowie die Sekundarschule bloss noch ein Begutachtungsrecht zuerkanntes und für die I.-6. Klasse der Primarschule die kirchliche Einflussnahme gänzlich ausschloss. Dieses Begutachtungsrecht des Kirchenrates wurde auch anlässlich der Teilrevision des Volksschulgesetzes von I 899 im Jahre I959 beibehalten. ${ }^{6}$

Mit dem neuen Lehrplan von i99 I wurde auf der Oberstufe der Konfessionellkooperative Religionsunterricht (KokoRu) verankert. Dieser KokoRu wird von der Schule verantwortet, aber in Zusammenarbeit mit den staatlich anerkannten Kirchen des Kantons Zürich durchgeführt. Die Tatsache, dass mit dem KokoRu nicht bloss die evangelisch-reformierte Kirche am schulischen Religionsunterricht mitbeteiligt war, sondern auch die anderen staatlich anerkannten Kirchen (die römisch-katholische und christkatholische Kirche), spiegelte sich in der Volksschulverordnung (VSV). Der VSV vom 3 I. März I900 wurde am ı. Dezember I 997 durch regierungsrätlichen Beschluss der Paragraph I 3 eingefügt, der folgendermassen lautet: «Der Lehrplan und die Lehrmittel für den konfessionell-kooperativen Religionsunterricht sind vor der Einführung den anerkannten Kirchen zur Begutachtung vorzulegen.»7 Obwohl auf Verordnungsebene das Begutachtungsrecht für Lehrplan und Lehrmittel des schulischen Religionsunterrichts auf alle anerkannten Kirchen ausgedehnt wurde - und nicht bloss auf den Kirchenrat der evangelisch-reformierten Kirche beschränkt blieb -, kam es mit dem Volksschulgesetz vom 7. Februar 2005, das dasjenige von i 899 ersetzte, auf Gesetzesebene zu einem weiteren Säkularisierungsschritt. Gemäss Paragraph 2 I dieses neuen Volksschulgesetzes erlässt der Bildungsrat den Lehrplan: «Dieser [der Lehrplan] regelt verbindlich die Stufenziele und die grundlegenden Inhalte des Unterrichts [...]». ${ }^{8}$ Das neue, obligatorische Schulfach Religion und

4 Mit dem Volksschulgesetz von I 899 wurde die Ergänzungsschule abgeschafft und die Alltagsschule um zwei Jahre verlängert (vgl. \I 5 im Gesetz betreffend die Volksschule, I r. Juni I 899).

5 \$28: «Der Lehrplan und die Lehrmittel für den Unterricht der 7. und 8. Klasse in biblischer Geschichte und Sittenlehre sind vor deren endgültiger Einführung dem Kirchenrate zur Begutachtung vorzulegen» und $\ 70$ (Sekundarschule): «[...] Lehrplan und Lehrmittel werden vom Erziehungsrate nach Einholung eines Gutachtens des Kirchenrates festgestellt» (Gesetz betreffend die Volksschule, i i. Juni i 899).

6 Die Teilrevision des Volksschulgesetzes im Jahre 1959 beinhaltete unter anderem eine veränderte Schulstruktur. Die bisherigen 8 Jahre Primarschule wurden abgelöst durch 6 Jahre Primarschule und nachfolgende 3 Jahre Oberstufe: Sekundar-, Real und Oberschule (vgl. $\$$ I bis, $\$$ I 8). In $\$ 63$ (betrifft nur die Oberstufe) des Volksschulgesetzes der Fassung vom 24. Mai I959 heisst es: «Die Festsetzung der Lehrziele, der Stoffprogramme und der Stundenzahlen erfolgt durch die vom Erziehungsrat zu erlassenden Lehrpläne. Der Lehrplan und die Lehrmittel für den Unterricht in Biblischer Geschichte und Sittenlehre sind vor der Einführung dem Kirchenrat zur Begutachtung vorzulegen» (Gesetz über die Abänderung des Gesetzes über die Volksschule vom i i. Juni i 899, 24. Mai 1959).

7 Eingefügt durch Regierungsratsbeschluss vom 10. Dezember 1997 (OS 54, 566), in Kraft seit I. Januar 1998.

8 Volksschulgesetz vom 7. Februar 2005. 
Kultur wird in diesem Gesetz bloss noch im Zusammenhang mit finanziellen Bestimmungen in Paragraph 62 erwähnt. Von einem Begutachtungs- oder Genehmigungsrecht der anerkannten Kirchen für das Schulfach Religion und Kultur ist in diesem VSG nicht mehr die Rede, denn Religion und Kultur gilt als ein Fach wie jedes andere auch.

Die Frage nach dem Mitbestimmungsrecht beim schulischen Religionsunterricht wurde zu Beginn des 21. Jahrhunderts im Unterschied zum 19. Jahrhundert nur am Rande diskutiert, aber sie wurde dennoch thematisiert. Mit einem Postulat im Kantonsrat - eingereicht von einem Vertreter der EDU und einem Vertreter der EVP - wurde versucht, der zunehmenden Säkularisierung auf struktureller Ebene zumindest auf Verordnungsstufe Einhalt zu gebieten. Die beiden Postulanten machten die «Gewichtung und Darstellung des Christentums im neuen Fach Religion und Kultur» zum Thema. Um zu gewährleisten, dass «das Christentum seiner Bedeutung entsprechend» gewichtet und im neuen Lehrmittel «Jesus Christus als zentrale Figur des Christentums [...] historisch und theologisch möglichst korrekt dargestellt» werde, forderten die Postulanten die Ernennung einer «Arbeitsgruppe aus Vertretern von Landes- und Freikirchen». Des Weiteren machten sie den Vorschlag, dass Paragraph I 3 der Verordnung betreffend das Volksschulwesen folgendermassen ergänzt werde: «Der Lehrplan und die Lehrmittel für das Fach Religion und Kultur [...] sind vor der Einführung den anerkannten Kirchen und den Freikirchen zur Mitsprache und Begutachtung vorzulegen.»9

Dieser Vorstoss war jedoch nicht von Erfolg gekrönt. Der Regierungsrat beantragte dem Kantonsrat, dieses Postulat nicht zu überweisen, und dieser folgte dem Antrag des Regierungsrates. ${ }^{10}$ So wie im neuen Volksschulgesetz von 2005 ist auch in der neuen Volksschulverordnung, die am 28. Juni 2006 in Kraft trat, nicht mehr die Rede von einem Begutachtungsrecht der anerkannten Kirchen.

Man kann also sagen, dass mit dem Inkrafttreten der Volksschulverordnung von 2006 die strukturelle Ausdifferenzierung zwischen Schule und Kirche vollzogen ist, die mit dem Unterrichtsgesetz von I 832 ihren Ausgang nahm. Die Kirchen haben seit diesem Zeitpunkt in keinem Bereich der Schule mehr ein Mitspracherecht. Fehlendes Recht auf Mitsprache hinsichtlich des schulischen Religionsunterrichtes bedeutet jedoch nicht das Fehlen jeglicher Einflussmöglichkeiten von Seiten der Kirchen bzw. Glaubensgemeinschaften. Am I3. September 200I beschloss der Bildungsrat für die Erarbeitung des Detailkonzeptes für das neue Schulfach eine bildungsrätliche Kommission zu bilden, zu der

9 Postulat KR-Nr. 354/2004 von Stefan Dollenmeier (EDU, Rüti) und Hans Fahrni (EVP, Winterthur).

Io Protokoll des Zürcher Kantonsrates, I 3. 2. 2006, S. 10502; vgl. auch Auszug aus dem Protokoll des Regierungsrates des Kantons Zürich, 22. I 2. 2004. 
auch kirchliche Kreise eingeladen wurden. Gemäss bildungsrätlichem Beschluss sollte diese Kommission folgendermassen zusammengesetzt sein: «Bildungsrat/ Bildungsrätin (Vorsitz) (I), Bildungsdirektion (Geschäftsstelle) (I-2), Vertreter/ Vertreterinnen grosser Glaubensgemeinschaften (6-9).» ${ }^{\text {I }}$

\subsection{Ausbildungsanforderungen: Wer darf Religion und Kultur unterrichten?}

Wer darf Religion und Kultur unterrichten: Pfarrer oder Lehrer? Diese Frage stand um I 870 zur Debatte, als diskutiert wurde, von wem der schulische Religionsunterricht erteilt werden dürfe (vgl. Unterkapitel 6.2). Das Volksschulgesetz von 1899 legte in Paragraph 26 fest, dass in den ersten sechs Schuljahren der Unterricht in Biblischer Geschichte und Sittenlehre vom Lehrer erteilt werde und so zu gestalten sei, «dass Schüler verschiedener Konfessionen ohne Beeinträchtigung der Gewissensfreiheit an demselben teilnehmen können». ${ }^{12}$ Gemäss Paragraph 27 desselben Volksschulgesetzes sollte im 7. und 8. Schuljahre der Unterricht in Biblischer Geschichte und Sittenlehre «in der Regel durch den Geistlichen der betreffenden Kirchgemeinde erteilt» werden.

Bis zur Einführung des Konfessionell-kooperativen Religionsunterrichts (KokoRu) auf der Oberstufe im Jahre i 99 I wurde der schulische Unterricht in Biblischer Geschichte auf der Oberstufe in der Regel von evangelisch-reformierten Fachlehrpersonen erteilt. Dies änderte sich auch nicht mit der Annahme eines neuen Kirchengesetzes im Jahre 1963, das neben der evangelisch-reformierten und christkatholischen Kirche auch die römisch-katholische Kirche als Person des öffentlichen Rechts anerkannte. Der schulische Religionsunterricht auf der Oberstufe fand weiterhin konfessionell getrennt statt. Für die römisch-katholischen Jugendlichen wurde im Rahmen der Schule ein kirchlicher Unterricht angeboten. ${ }^{13}$ Der KokoRu konnte durch Theologinnen und Theologen der anerkannten Kirchen, Lehrkräfte der Oberstufe mit entsprechender Zusatzausbildung und Katechetinnen und Katecheten mit entsprechender Ausbildung erteilt werden. ${ }^{14}$ Zwar waren die Schulbehörden für die Organisation und Aufsicht des KokoRus zuständig, doch Anstellungsfragen wurden «in Absprache mit den lokalen Kirchenbehörden vorbereitet». ${ }^{\text {Is }}$

I I Erläuterungen des Bildungsrats zum BRB vom I 3. 9. 200I, 4.

I 2 Gesetz betreffend die Volksschule, I I. Juni I 899.

I 3 Vgl. Erläuterungen des Bildungsrats zum BRB vom i 5. 8. 2000, I.

I4 Vgl. ebd., 3 .

is Ebd. 
Im Jahr 200I beschloss der Bildungsrat, auf der Sekundarstufe den KokoRu durch das Fach Religion und Kultur zu ersetzen. Im Jahre 2006 wurde dies auch für die Primarstufe beschlossen. Das Fach Religion und Kultur wurde auf der Primarstufe von Beginn an ausschliesslich von Lehrkräften mit einem Primarlehrerdiplom unterrichtet, da bis dahin auch das Fach Biblische Geschichte nur von ausgebildeten Primarlehrkräften erteilt worden war. Primarlehrpersonen, die in ihrer Ausbildung noch nicht für Religion und Kultur ausgebildet worden waren und dieses Fach unterrichten wollten, konnten bis 2016 an der Pädagogischen Hochschule eine Weiterbildung besuchen. ${ }^{16}$ Obwohl auf der Sekundarstufe derselbe Grundsatz wie für die Primarstufe galt, dass das Fach Religion und Kultur nur von Sekundarlehrpersonen mit einer abgeschlossenen Aus- oder Weiterbildung erteilt werden kann, war die Umsetzung dieses Grundsatzes zu Beginn der Facheinführung nicht ganz so einfach wie auf der Primarstufe, da nur wenige Sekundarlehrpersonen ein Interesse für eine diesbezügliche Weiterbildung bekundeten. Im Rahmen einer Übergangsregelung wurden deshalb auch ehemalige Fachlehrpersonen für den KokoRu, die kein Sekundarlehrerdiplom besassen, zur Weiterbildung für Religion und Kultur zugelassen. Diese Übergangsregelung wurde per I. Juli 20I2 aufgehoben und seit Schuljahr 2013/I4 sollten gemäss Bildungsratsbeschluss vom I9. März 20 I 2 für das Fach Religion und Kultur nur noch Lehrpersonen mit einem Sekundarlehrerdiplom zugelassen werden. ${ }^{17}$

Im Unterschied zur Diskussion um I 870 war zu Beginn des 21. Jahrhunderts nicht die Frage, wer - Pfarrer oder Lehrer - den schulischen Unterricht erteilen soll, ein zentraler Diskussionspunkt, sondern vielmehr die Frage, was von denjenigen, die dieses Fach unterrichten, hinsichtlich ihrer Ausbildung erwartet werden darf oder soll. Während sich um I 870 mit der Diskussion über die Frage, ob der Lehrer oder der Pfarrer den schulischen Religionsunterricht erteilen solle, die prinzipielle Unklarheit darüber manifestierte, in welchen Hoheitsbereich - Schule oder Kirche - der schulische Religionsunterricht gehört, scheint sich diese Frage zu Beginn des 2r. Jahrhunderts mit dem Entscheid für das obligatorische Schulfach Religion und Kultur weitgehend zu Gunsten der Schule geklärt zu haben. Allein schon die Obligatorischerklärung des Faches für alle Kinder legte nahe, dieses Fach nicht weiter von einer kirchlich beauftragten Person unterrichten zu lassen. Denn kirchlich Beauftragte gelten als Interessenvertreter einer bestimmten religiösen Gemeinschaft, und dies widerspricht

I6 Seit Herbstsemester 2017 wird an der Pädagogischen Hochschule Zürich eine Facherweiterung für Religionen, Kulturen, Ethik angeboten, welches das Weiterbildungsprogramm Qualifikation Religion und Kultur für die Primarstufe und die Sekundarstufe ablöst.

I7 Vgl. Bildungsratsbeschluss vom I9. 3. 2012. 
dem Verständnis der Aufgabe von Lehrpersonen einer öffentlichen Schule als «neutrale〉 Wissensvermittlerinnen.

Die «Neutralität der Lehrperson» wurde von der Freidenker-Vereinigung ${ }^{18}$ in ihrer Stellungnahme im Rahmen der Vernehmlassung zum geplanten Fach Religion und Kultur jedoch gerade problematisiert. Es wurde die Vermutung geäussert, dass «aufgrund ihrer Ausbildung und Verfügbarkeit wohl in erster Linie christliche Lehrkräfte zum Zuge» kämen, um dieses Fach zu unterrichten. Dies «würde eine neutrale Vermittlung von Sachwissen fast verunmöglichen, zumal ja Christen, wie manche Andersgläubige, von ihrer Religion dazu verpflichtet sind, diese zu empfehlen». Die Freidenker sahen das Problem jedoch nicht bloss in einer einseitigen Vermittlung, sondern auch darin, «dass den Lernenden ein verwässertes oder gar verzerrtes Bild von Religionen geboten wird, selbst wenn die besten friedensfördernden Absichten dahinter stehen mögen». In ihrem Fazit bezeichnen die Freidenker die «strikte Unparteilichkeit der Lehrperson» als unmöglich. Sie sei «zwar im Sinne der guten Absicht möglich, als de facto bestehende Haltung einer engagierten Lehrkraft aber eine Illusion». ${ }^{19}$ Der Gegenvorschlag der Freidenker besteht in einem Fach Lebenskunde oder Ethik, wie es zum Beispiel Berlin seit 1982 kennt.

Hier haben die Freidenker meines Erachtens einen wesentlichen Punkt getroffen. Es stellt sich jedoch die Frage, warum die für den schulischen Religionsunterricht angenommene Unmöglichkeit einer «strikten Unparteilichkeit der Lehrperson» nicht ebenso für das Fach Ethik - und überhaupt für alle anderen Schulfächer - als problematisch erachtet wird. Diese Thematik wird in Unterkapitel 9.4 noch eingehender erläutert werden.

Während die Freidenker die von den Lehrpersonen geforderte neutrale Haltung in Bezug auf das Fach Religion und Kultur zwar als prinzipiell wünschenswert, aber zugleich auch als faktisch unmöglich erachteten und deshalb das Fach als solches ablehnten, forderte das Co-Präsidium des Initiativkomitees der Volksinitiative für die Weiterführung des Faches Biblische Geschichte in seiner Medienmitteilung anlässlich des Rückzugs der Volksinitiative zu Gunsten der Einführung von Religion und Kultur, «dass von den Lehrpersonen, die den Unterricht in 〈Religion und Kultur〉 erteilen, keine 〈Gesinnungsneutralität〉 verlangt» werde, denn «Religiosität gehört zum Menschen und kann deshalb auch den Lehrkräften nicht abgesprochen werden». ${ }^{20}$

I 8 Genauer: Diese Stellungnahme wurde von den Sektionen Zürich und Winterthur der Freidenker-Vereinigung der Schweiz (FVS) verfasst.

I9 Freidenkervereinigung Schweiz, Stellungnahme von März 2006.

20 Komitee Volksinitiative für die Weiterführung des Faches Biblische Geschichte an der Primarschule, Medienmitteilung vom I 2. 3. 2007. 
Die Vielfalt, der mit dem neuen obligatorischen Fach an die Lehrpersonen herangetragenen Anforderungen, spiegelte sich in den entsprechenden Forderungen für eine adäquate Ausbildung. So begrüsste der Zürcher Lehrerinnen- und Lehrerverband (ZLV) in seiner Medienmitteilung vom 7. März 2006 explizit «die strengen Ausbildungsanforderungen, welche für die Lehrpersonen von Religion und Kultur vorgesehen sind [...]». ${ }^{21}$ Und im Kantonsrat betonte Elisabeth Scheffeldt (SP) in ihrem Votum zum Religionsunterricht, dass «eine sehr gute Ausbildung der Lehrpersonen» notwendig sei. Damit das neue Fach den hohen Ansprüchen genügen könne, brauche es «Lehrkräfte, die nebem dem fachlichen Wissen mit Diversität umgehen können, die religiöse, kulturelle und zivilisatorische Themen mit einer gewissen empathischen Distanz behandeln können, die ihren eigenen Standpunkt auch relativieren können, ohne beliebig zu werden. - Die grosse Spannbreite von Christentum als Leitkultur unserer Gesellschaft zu Toleranz gegenüber anderen Religionen, aber auch gegenüber einem Leben ohne Religion, ist eine Herausforderung an das neue Fach und an die Lehrpersonen».22

In der Umsetzungsphase von Religion und Kultur monierte der Freidenker Andreas Kyriacou gemäss Tages-Anzeiger, dass «trotz der Absage an den Bekenntnisunterricht $[\ldots]$ im Kanton Zürich nämlich nach wie vor missionierende Lehrer am Werk [seien]». ${ }^{23}$ Er bezog sich dabei auf einen medial publik gemachten Fall und die Zwischenbilanz einer Evaluation der Bildungsdirektion, gemäss der ein Teil der Lehrkräfte nach wie vor Bekenntnisunterricht betreibe. ${ }^{24}$ Die Piratenpartei blies ins selbe Rohr, als sie in ihrem Positionspapier ihre Bedenken darüber äusserte, dass das Fach Religion und Kultur «von denselben Personen unterrichtet [werde], die zuvor konfessionellen Unterricht geführt hatten». Zudem erachteten sie es als «sehr schwierig, sicherzustellen, dass die Religion der Lehrperson keinen Einfluss auf den Inhalt»" ${ }^{25}$ habe.

In seinem Beitrag an der im Jahre 2004 von der Pädagogischen Hochschule Zürich und der Universität Zürich organisierten Fachtagung zum geplanten neuen Schulfach Religion und Kultur befasste sich der Religionspädagoge Friedrich Schweitzer ebenfalls mit der Rolle der Lehrperson im schulischen Religionsunterricht. Er vertrat dezidiert die Ansicht, «dass in Fragen von Religion und Weltanschauung niemand einfach neutral sein kann», da «auch von einer der Intention nach neutralen Religionskunde ein religiöser oder weltanschaulicher

2I Zürcher Lehrerinnen- und Lehrerverband (ZLV), Medienmitteilung vom 7. 3. 2006.

22 Das Votum von E. Scheffeldt ist auf der Webseite der SP Kanton Zürich zu finden. Das Datum der Kantonsratssitzung, in der dieses Votum angeblich gehalten wurde, ist nicht angegeben (vgl. Scheffeldt, 28. I 2. 2009).

23 Tages-Anzeiger, 28. 2. $201 \mathrm{I}$.

24 Vgl. Tages-Anzeiger, 28. 2. 20 I.

25 Wäckerlin, Positionspapier Laizismus, 22. I. 20 I4. 
Einfluss auf die Kinder und Jugendlichen ${ }^{26}$ ausgehe. Dieser kritische Einwand kann seiner Meinung nach auch nicht durch den Verweis auf die vergleichbare Situation im Politikunterricht entkräftet werden, «weil religiöse oder weltanschauliche Überzeugungen in aller Regel weit tiefer reichen als eine politische Parteizugehörigkeit». Eine andere Frage als diese scheint ihm jedoch didaktisch gewichtiger. Die Frage nämlich, ob Lehrpersonen «möglichst nach persönlicher Zurückhaltung und Neutralität streben» oder ob «sie Partner im Dialog mit Kindern und Jugendlichen sein» sollten. Auf Grund des Befunds weit auseinandergehender erziehungswissenschaftlicher Auffassungen zieht Schweitzer den Schluss, «dass die Option für die Lehrperson als Partner im Dialog jedenfalls nicht einfach von vornherein ausgeschlossen werden kann. Auch in dieser Hinsicht stellt sich die Frage, wie ein Unterricht Interesse wecken soll, wenn die Kinder und Jugendlichen ihre Lehrperson nicht einmal ernsthaft fragen dürfen, woran sie denn eigentlich selber glaube und von welchen Überzeugungen sie ihr eigenes Leben leiten lassen will. $»^{27}$ Neben der erziehungspolitischen Dimension bringt Schweitzer hier auch noch den didaktischen Aspekt in die Diskussion ein.

Zusammengefasst lässt sich am Ende dieses Unterkapitels festhalten, dass zu Beginn des 2 I. Jahrhunderts im Unterschied zu I 870 viel stärker die Rolle und Aufgabe der Lehrperson in den Fokus der Diskussion gerückt ist. Wenngleich anzumerken ist, dass bereits um I 870 kritisch erwähnt wurde, dass auch der Lehrer - und nicht bloss der Pfarrer - einer bestimmten religiösen Richtung angehöre oder sich explizit von der Religion abwende und somit ebenso wie der Geistliche die Kinder in die eine oder andere Richtung beeinflussen könne. ${ }^{28}$

\subsection{Obligatorium}

Die Legitimität eines Obligatoriums für den schulischen Religionsunterricht wurde sowohl im I9. Jahrhundert wie auch im 21. Jahrhundert kontrovers diskutiert. Hinsichtlich der Argumentationsmuster lassen sich verschiedene Ähnlichkeiten aufzeigen. Das zentrale Argument gegen die Obligatorischerklärung des schulischen Religionsunterrichts war im I9. wie auch im 2I. Jahrhundert die durch die Bundesverfassung garantierte Glaubens- und Gewissensfreiheit, die auch beinhaltet, dass niemand zu religiösem Unterricht gezwungen werden darf. ${ }^{29}$ Bis zur Einführung des Schulfaches Religion und Kultur war der

26 Schweitzer $2005 \mathrm{~b}, \mathrm{I} 68$.

27 Ebd.

28 Vgl. Diakon Spyri in Unterkapitel 6.2.

29 Bundesverfassung vom i8. April 1999, Art. I5; Bundesverfassung vom 29. Mai i 874, Art. 49. 
schulische Religionsunterricht im Kanton Zürich kein obligatorisches Fach. ${ }^{\circ}$ Das Fach Biblische Geschichte auf der Primarstufe war lange Zeit ein Fach mit Abmeldemöglichkeit, das heisst, die Kinder mussten dafür nicht angemeldet, konnten aber davon abgemeldet werden..$^{31}$

Das geplante Obligatorium für den Religion-und-Kultur-Unterricht auf der Oberstufe wurde im Zürcher Kantonsrat kontrovers verhandelt. In der Sitzung vom I 3. Februar 2006 wurde das Postulat von Stefan Dollenmeier (EDU) und Hans Fahrni (EVP) vom 27. September 2004 diskutiert, in welchem der Regierungsrat aufgefordert wurde, «im Volksschulgesetz das geplante Fach Religion und Kultur auf der Oberstufe als <obligatorisches Schulfach mit Abmeldemöglichkeit zu verankern und nicht - wie angekündigt - als obligatorisches Schulfach». Die beiden Postulanten führten zur Begründung ihres Anliegens vier Argumente an. Als erstes wurde auf Art. I s der Bundesverfassung verwiesen, der Glaubens- und Gewissensfreiheit garantiert: «Obwohl das neue Fach Religion und Kultur seinen Schwerpunkt auf reine Wissensvermittlung legt, besteht dabei trotzdem die Gefahr, wertend zu vergleichen und damit den verfassungsmäs-

30 In der Übergangsphase, als unklar war, ob das Fach Biblische Geschichte nun definitiv abgeschafft oder bei einer Annahme der Initiative doch beibehalten würde, konnte Biblische Geschichte gemäss Bildungsratsbeschluss im Kanton Zürich als Freifach angeboten werden (vgl. Beschluss des Bildungsrates, 29. I I. 2004; Medienmitteilung des Bildungsrates, 7. I 2. 2004). Im Mai 2004 hat der Bildungsrat jedoch entschieden, einzelne Ziele und Inhalte des Faches Biblische Geschichte, welche dem «konfessionellen Neutralitätsgebot der Schule» (Beschluss des Bildungsrates, I0. 5. 2004) nicht widersprechen, in den obligatorischen Unterricht bestehender Fächer zu integrieren. Mit Bezug auf Entscheide des Bundesgerichts bestimmte der Bildungsrat, dass «nur Ziele und Inhalte integriert werden, von denen Eltern ihre Kinder, gestützt auf die Glaubens- und Gewissensfreiheit, nicht dispensieren lassen können» (Beschluss des Bildungsrates, I0. 5. 2004). Den Schülerinnen und Schülern sollte «den Zugang zu unserer Geschichte und Kultur [...] anhand von Überlieferungen, ausgewählten biblischen Geschichten und weiteren religiösen Geschichten aus verschiedenen (insbesondere nichtchristlichen) Kulturen» eröffnet werden. Dies erschien dem Bildungsrat genauso wenig verfassungswidrig wie «das Wiedererkennen biblischer Geschichten und Legenden in künstlerischen Darstellungen aus verschiedenen Epochen», da dies «zum Wissen über unsere kulturellen Wurzeln» gehöre. Unproblematisch erachtete der Bildungsrat auch «die Vermittlung von Orientierungswissen über die christlichen Feiertage und ihre Bedeutung sowie über die Feiertage anderer grosser Religionen» (Beschluss des Bildungsrates, I0. 5. 2004).

3 I In der Übergangsphase war dies anders, weil Biblische Geschichte auf das Schuljahr 2004/05 in der Lektionentafel neu als Freifach aufgeführt werden sollte. Im Dezember 2003 informierte das Volksschulamt über die Sanierungsmassnahmen 04. Hinsichtlich der Organisation von Biblischer Geschichte hiess es, dass die Gemeinden selber entscheiden dürfen, ob sie Biblische Geschichte als Freifach anbieten oder darauf verzichten wollen. Neu war, dass die Schülerinnen und Schüler von den Erziehungsberechtigten für den Unterricht angemeldet werden mussten. Im Gegensatz zu andern Freifächern wurde beim Freifach Biblische Geschichte auf Grund der verfassungsmässig garantierten Glaubens- und Gewissensfreiheit die Möglichkeit der Abmeldung im Laufe des Schuljahres vorgesehen, falls sich Eltern in dieser Freiheit verletzt fühlen sollten (Brief des Volksschulamtes an die Gemeindeschulpflegen des Kantons Zürich, 9. I 2. 2003). 
sigen Grundsatz zu verletzen». Als zweites zogen die Postulanten nebst der Bundesverfassung auch den Zürcher Lehrplan zur Begründung ihres Anliegens bei, der die Anweisung enthalte, die religiösen Gefühle aller Beteiligten stets zu achten. «Je nach Herkunft und Prägung der Jugendlichen wird dies in einem so breit gefächerten Unterricht aber kaum möglich sein», meinen die beiden Postulanten. Aus diesem Grund plädierten sie für die Möglichkeit, die Jugendlichen von diesem Unterricht abzumelden. Um jedoch Abmeldungen aus Bequemlichkeit (zur Reduktion der Schulstunden) zu verhindern, sollten die Jugendlichen nicht frei bekommen, sondern in dieser Zeit auf andere Weise sinnvoll beschäftigt werden. Drittens erachteten sie es als inkonsequent, wenn man das Fach Biblische Geschichte auf Primarschulstufe staatlich nicht weiter unterstütze und vom Entscheid der Gemeinden abhängig mache, während Religion und Kultur auf der Oberstufe zu einem obligatorischen Fach erklärt werde. Nach Ansicht der Postulanten sollten beide Fächer «gleich behandelt und als <obligatorische Schulfächer mit Abmeldemöglichkeit ausgestaltet werden».32 Als vierten und letzten Punkt verwiesen die Postulanten auf die Möglichkeit, «dass Eltern den Besuch des Faches Religion und Kultur bis vor Bundesgericht - oder gar vor den Europäischen Gerichtshof für Menschenrechte - anfechten werden».33

Der Regierungsrat verwies in seiner Stellungnahme zu diesem Postulat auf ein bereits im Jahre 1999 verfasstes Gutachten zur Frage der Durchsetzung des Obligatoriums für das neue Fach. Dieses Gutachten weise darauf hin, dass das Gebot der konfessionellen Neutralität seitens des Bundesgerichts bisher sehr streng ausgelegt worden sei. Zugleich sei im Gutachten auch auf den Europäischen Gerichtshof für Menschenrechte verwiesen worden, in dessen Praxis die Unterscheidung zwischen «teaching in religion» und «teaching about religion» eine zentrale Rolle spiele. «Unter Ersterem [teaching in religion] wird der Unterricht verstanden, der das Verhältnis des Menschen zu Gott, zum Transzendenten thematisiert, das Verhältnis des Menschen und seine Pflichten gegenüber Gott erörtert und Kulthandlungen erklärt und einübt. Die überkonfessionelle vergleichende Betrachtung religiöser Lehren, die Morallehre, der Sittenunterricht sowie die Religions- und Bibelgeschichte ohne Unterweisungscharakter gelten dagegen als «Lehre von der Religion〉. Dieser [teaching about religion] kann nach Auffassung des Europäischen Gerichtshofes für Menschenrechte obligatorisch ausgestaltet werden.»34

Der Regierungsrat schloss aus dieser Praxis des Europäischen Gerichtshofes für Menschenrechte, dass «die bisherige Praxis des Bundesgerichts als nicht mehr zeitgemäss» einzustufen sei und «einem Verfahren vor den EMRK-Organen [...]

32 Protokoll des Zürcher Kantonsrates vom I 3. 2. 2006, S. I050 I.

33 Ebd., S. Iо502.

34 Protokoll des Zürcher Kantonsrates vom I3. 2. 2006, S. I0505. 
nach dem Gesagten wohl nicht standhalten» ${ }^{35}$ würde. Auf Grund dieser Rechtslage entschied sich der Bildungsrat, das neue Schulfach Religion und Kultur gemäss den Grundsätzen des teaching about religion zu konzipieren und somit als obligatorisches Fach ohne Abmeldemöglichkeit zu planen. ${ }^{36}$ Der Regierungsrat war sich des Risikos bewusst, dass im Einzelfall versucht werden könnte, die Abmeldemöglichkeit auf dem Rechtsweg durchzusetzen. Er verwies darauf, dass dieses Risiko auch in anderen Fächern, zum Beispiel Schwimmunterricht, bestehe.

Die religionspädagogische Unterscheidung zwischen teaching about religion und teaching in religion wurde in der Folge dann auch für die Primarstufe zu einem entscheidenden Argument für die Obligatorischerklärung des Faches Religion und Kultur. Die dieser Unterscheidung zu Grunde liegende religionswissenschaftliche Annahme einer neutralen Perspektive auf die verschiedenen Religionen ist auf diese Weise im 19. Jahrhundert noch nicht zu finden. Als paralleles Begründungsmuster für einen obligatorischen schulischen Religionsunterricht zu dieser religionspädagogischen Distinktion ist im I9. Jahrhundert die Annahme der Möglichkeit eines konfessionslosen und nicht dogmatischen Religionsunterrichts zu nennen. Vielleicht könnte man diese Unterscheidung sogar als Vorläuferin der heutigen Unterscheidung bezeichnen. Bei der Unterscheidung zwischen konfessionellem und konfessionslosem, nicht dogmatischem Religionsunterricht ging es jedoch nicht um eine angenommene Vermittlung von reinem Wissen über Religionen (teaching about), sondern um die Vermittlung eines allgemeinen christlichen Glaubens, das heisst eines Glaubens, von dem angenommen wurde, dass er von den Angehörigen aller Konfessionen geteilt werden könne. So gesehen müsste die Idee und Praxis eines konfessionslosen Religionsunterrichts als teaching in verstanden werden. ${ }^{37}$

Im 19. Jahrhundert wurde das Obligatorium des schulischen Religionsunterrichts mit dem nicht konfessionellen Charakter des Unterrichts begründet. Im Unterschied dazu wurde 2004 als Begründung für die Obligatorischerklärung des Faches Religion und Kultur angeführt, dass «es seine eindeutige christliche Prägung verliert»..$^{8}$ Auch der Zürcher Lehrerinnen- und Lehrerverband (ZLV) begrüsste im Jahr 2007 den Beschluss des Kantonsrates, das Fach Biblische Geschichte abzulehnen und stattdessen das Fach Religion und Kultur auch auf der Primarstufe einzuführen. Dies mit der folgenden Begründung: «Die Zielsetzung

35 Ebd.

36 In diesem Zusammenhang handelte es sich noch um das Obligatorium auf der Oberstufe und noch nicht auf der Primarstufe.

37 Dazu noch mehr in Unterkapitel I0.4 zum Verhältnis von Universalitätsanspruch und historischer Kontingenz und Partikularität.

38 NZZ, 26. 8. 2004. 
des Fachs «Religion und Kultur ist breiter gefasst als beim bisherigen Fach 〈Biblische Geschichte〉. Neben christlichen Werten und Traditionen werden auch Kenntnisse anderer Religionen vermittelt. Für den ZLV ist entscheidend, dass das Fach obligatorisch ist - dadurch einen festen Platz im Lehrplan erhält - und kein Bekenntnisunterricht stattfindet.»39

Der ZLV konnte sich so klar für ein Obligatorium von Religion und Kultur einsetzen, weil er in einer ein Jahr zurückliegenden Medienmitteilung dezidiert die Auffassung äusserte, «dass dieser Unterricht wertneutral sein muss [und] religiöse Unterweisung [...] dem kirchlichen Unterricht vorbehalten» ${ }^{40}$ sei.

Das Obligatorium für Religion und Kultur wurde jedoch nicht bloss mit der Forderung eines mit der Bundesverfassung kompatiblen Unterrichts legitimiert. Als weiteres zentrales Argument für das Obligatorium wurde die Förderung des Zusammenlebens von Menschen mit unterschiedlichem kulturellem Hintergrund genannt. Gemäss Tages-Anzeiger erachtete beispielsweise Regierungsrätin Regine Aeppli als «Hauptziel des neuen Faches, das Verständnis zwischen den Kulturen zu vertiefen: 〈Das Wissen über Religionen gehört zur Allgemeinbildung.> Darum sei es auch nötig, dass es keine Abmeldemöglichkeiten gibt».4 ${ }^{\mathrm{I}}$

Dieser Art von Argumentation wird in Unterkapitel 9.6 im Zusammenhang mit der Frage nach der Aufgabe der öffentlichen Schule noch vertiefter nachgegangen werden. An dieser Stelle soll nun noch ein Blick auf die Gegner des Obligatoriums geworfen werden, die es neben den Befürwortern natürlich auch gab. Im Unterschied zum ZLV sahen beispielsweise die Sektionen Zürich und Winterthur der Freidenkervereinigung der Schweiz (FVS) in ihrer im März 2006 verfassten Stellungnahme das geplante Obligatorium als hoch problematisch an. So könne das neue Fach Religion und Kultur «eine religiöse Unterweisung nicht mit Sicherheit ausschliessen» ${ }^{2}$ und somit würden Artikel 49 der Bundesverfassung $^{43}$ sowie Artikel 9 der Europäischen Menschenrechtskonvention (EMRK) von i950 verletzt.

Der Einwand der Freidenker wird durch die Forschungsergebnisse von Ansgar Jödicke und Andrea Rota bekräftigt, die diese im Schlussbericht ihrer Untersuchung mit dem Titel Unterricht zum Thema Religion an der öffentlichen Schule

39 Zürcher Lehrerinnen- und Lehrerverband, Medienmitteilung vom I 2. 3. 2007.

40 Zürcher Lehrerinnen- und Lehrerverband, Medienmitteilung vom 7. 3. 2006.

4I Tages-Anzeiger, 8. 3. 2006.

42 Freidenkervereinigung Schweiz, Stellungnahme von März 2006.

43 In der Stellungnahme der Freidenker ist in der Tat von Artikel 49 der Bundesverfassung die Rede. Vermutlich ist aber Artikel is (Glaubens- und Gewissensfreiheit) der neuen Bundesverfassung von 1999 gemeint. In der alten Bundesverfassung von I 874 wurde die Glaubens- und Gewissensfreiheit in Artikel 49 behandelt. 
im Jahre 2010 präsentierten. ${ }^{44}$ Jödicke und Rota erklären den momentanen «Trend zu einem staatlichen Unterricht und die im politischen Diskurs relativ einheitlichen Argumentationsmuster» mit der «Allianz zweier verschiedener Traditionslinien».45 Zum einen werde die «zivilreligiöse Interpretation» des Religionsunterrichts sichtbar, die Jödicke und Rota als «Fortentwicklung eines liberalen christlichen Religionsunterrichts» beschreiben. Zum andern die «religionskundliche Interpretation», die «stärker den wachsenden nicht-religiös praktizierenden Bevölkerungsschichten ${ }^{46}$ entspreche. Beide Interpretationslinien treffen sich gemäss Jödicke und Rota «in der Unterscheidung eines kirchlich-sozialisierenden und eines konsequent historischen Unterrichts», doch werde die «ethisch-zivilreligiöse Thematisierung von Religion unterschiedlich bewertet». Aus zivilreligiöser Perspektive sei diese auch in einem staatlich getragenen schulischen Religionsunterricht möglich, sofern sie «frei von konfessionellen Inhalten und frei von religiöser Praxis» sei. Aus religionskundlicher Perspektive geht dies nicht, da die ethisch-zivilreligiöse Thematisierung von Religion «Teil des liberalen Christentums und deshalb Kennzeichen eines religiösen Unterrichts»47 sei.

Bereits in der Diskussion um I 872 gab es Stimmen, die befürchteten, dass mit einem obligatorischen schulischen Religionsunterricht, der von einem angeblich religionslosen Sittenunterricht ausgehe, ${ }^{48}$ die «zürcherische Staatstheologie» über die Verfassung gestellt, deren Lehren als unfehlbar erklärt und die Schulbücher zu Staatskatechismen würden. ${ }^{49}$ Der Einsender, der diese Bedenken I 87 I in der NZZ äusserte, gehörte höchstwahrscheinlich ins Lager der Positiven, die sich gegen die staatliche Vermittlung einer christlich-liberalen Theologie wehrten. Interessanterweise wurde im 2I. Jahrhundert das Obligatorium von Religion und Kultur jedoch nicht nur von den Positiven, sondern auch von distinkt areligiösen Kreisen wie den Freidenkern bekämpft. Während

44 Die Untersuchung Unterricht zum Thema Religion an der öffentlichen Schule von Ansgar Jödicke und Andrea Rota war Teil des Nationalen Forschungsprogrammes 58 Religionsgemeinschaften, Staat und Gesellschaft.

45 Jödicke/Rota 2010, I3.

46 Jödicke/Rota 2010, I3 f.

47 Ebd., I4.

48 Im Unterrichtsgesetz von I 859 wurde in $\$ 65$ bei der Aufzählung der Lehrgegenstände an erster Stelle «christliche Religions- und Sittenlehre» aufgeführt (vgl. Gesetz über das gesammte Unterrichtswesen des Kantons Zürich I 859). Im ersten Entwurf des neuen Unterrichtsgesetzes von 1872 hiess es in $\$ I 4 unter Absatz I bloss noch: «Anregungen und Belehrungen aus dem Gebiete des sittlichen und geistigen Lebens» (Gesetz betreffend das gesammte Unterrichtswesen des Kantons Zürich (Antrag des Regierungsrathes), veröffentlicht in Der Landbote vom 17. Oktober I871). Religion als eigenständiger Unterrichtsaspekt sollte also nach Meinung der Verfasser keinen Raum mehr in der öffentlichen Schule erhalten (vgl. Unterkapitel 6.3).

49 NZZ I87I, 25. I I. I 87I; vgl. auch Unterkapitel 6.4. 
aus Sicht der Positiven der christlich-liberal geprägte Unterricht ein falsches christliches Glaubensverständnis vermittelt, ist aus Sicht der Freidenker auch ein christlich-liberal geprägter Unterricht noch als religiös zu bezeichnen und steht somit im Widerspruch zum Neutralitätsgebot der Bundesverfassung. Wie bereits erwähnt wurde, stellt sich allerdings die Frage, ob gegenüber dem von den Freidenkern geforderten Ethik-Unterricht nicht ebenso der Vorwurf der Verletzung des Neutralitätgebotes erhoben werden könnte und somit auch ein obligatorischer Ethikunterricht fragwürdig wäre. Wie das Verhältnis zwischen Religionsunterricht, Ethikunterricht und Werteerziehung debattiert worden ist, soll im folgenden Unterkapitel näher besehen werden.

\subsection{Religionsunterricht, Ethikunterricht oder Werteerziehung?}

Sittenlehre anstatt Religionsunterricht? Diese Frage wurde in der Diskussion um I 870 kontrovers diskutiert (vgl. Unterkapitel 6.3.I). Die Gründe, die gegen den schulischen Religionsunterricht sprachen, waren die zunehmende Ausdifferenzierung von Staat, Schule und Kirche sowie die verfassungsmässig verbriefte Glaubens- und Gewissensfreiheit. Gemäss dem Spiritus rector des geplanten Unterrichtsgesetzes von I872, Johann Caspar Sieber, sollte mit einer reinen Sittenlehre der Anstoss bei Andersgläubigen vermieden und dem Verfassungsgrundsatz Genüge geleistet werden. Im 2I. Jahrhundert spricht niemand mehr von Sittenlehre. Die Ausdrücke Werteerziehung oder Wertevermittlung haben die Sittenlehre ersetzt. Inwiefern sich von dieser sprachlichen Ablösung auch auf Veränderungen in der inhaltlichen Diskussion schliessen lässt, wird nachfolgend anhand konkreter Beispiele punktuell erläutert.

Eines der Argumente, die im I9. Jahrhundert als Begründung für einen schulischen Religionsunterricht und gegen einen reinen Sittenunterricht ins Feld geführt wurden, war die Annahme einer «religiösen Anlage», die allgemein menschlich sei und somit wie alle anderen Anlagen der Kinder von der Schule entwickelt werden sollte (vgl. Unterkapitel 6.3.I). Eine solch «anthropologische Begründungsfigur» ${ }^{\circ}$ habe ich in den von mir untersuchten Quellen in der Diskussion um 2004 so explizit formuliert nicht gefunden. Für die Beibehaltung von Biblischer Geschichte wird vielmehr mit soziologischen und historischen Gründen argumentiert. So sei beispielsweise das Christentum «die am weitesten verbreitete Religion unseres Kantons (mehr als 80 Prozent) und geschichtlich die bedeutendste Grundlage für die Kultur Europas». ${ }^{\text {s }}$

50 Diesen Ausdruck verdanke ich Johannes Bellmann (Bellmann 2006, 206).

5I Protokoll des Zürcher Kantonsrates vom I 3. 2. 2006, S. I0502. 
Ein weiteres Motiv gegen die Abschaffung des schulischen Religionsunterrichts war im 19. Jahrhundert die Annahme, dass Sittlichkeit einer religiösen Grundlage nicht entbehren und somit das Fach Sittenlehre nicht losgelöst von einer bestimmten Glaubenstradition erteilt werden könne (vgl. Pfarrer Scheller in Unterkapitel 6.3.I, I 36). Eine solche Auffassung stand der Vorstellung entgegen, dass in der Sittenlehre vermittelt werde, was den verschiedenen Konfessionen gemeinsam sei. In der medial ausgetragenen Debatte zu Beginn des 2 I. Jahrhunderts waren es allein die Freidenker, die das Verhältnis von Religion zu Moral und Ethik in ihrer Auseinandersetzung mit dem schulischen Religionsunterricht explizit thematisierten. Sie kamen aber zum gegenteiligen Schluss von Pfarrer Scheller im 19. Jahrhundert. In ihrer Vernehmlassungsantwort zum Fach Religion und Kultur war es den Freidenkern ein Anliegen, die Unabhängigkeit von Religion und Moral und den grundlegenden Unterschied zwischen diesen zwei Aspekten zu betonen. Religion sei «ein wandelbarer und kritikbedürftiger Teil der Kultur, auf den viele Menschen, auch solche von hohem Ethos, ohne Nachteil verzichten können». Moral sei zwar «historisch mit religiösen Vorstellungen verknüpft, aber in der Sache von Religion so verschieden wie Kunst und Wissenschaft; sie setzt auch keine religiösen Überzeugungen voraus». Aus diesem Grund sei es «tendenziell irreführend und für Unreligiöse diskriminierend», wenn «ethische Fragen im Rahmen eines Religionsfachs für alle zu behandeln»`2 sind. Während Pfarrer Scheller im I9. Jahrhundert eine «abstrakte Sittenlehre» als «ein Unding» bezeichnete, da er Sitte und Moral nicht losgelöst von einer religiösen Grundlage sehen konnte, empfahlen die Freidenker als Gegenvorschlag zu Religion und Kultur in ihrer Vernehmlassungsantwort einen «diesseitsbezogenen Ethik-Unterricht», ${ }^{33}$ der sich am Brandenburgischen Modell «Lebensgestaltung - Ethik - Religionskunde (LER)» orientieren sollte. Denn im Unterschied zu Pfarrer Scheller gingen sie von einer philosophischen Theorie der Moralbegründung aus, gemäss der Moral als von Religion unabhängig zu betrachten ist.

Der Freidenker Andreas Kyriacou verdeutlichte dieses Anliegen in seinem Blog. Er kritisiert, dass zu den Rundtischgesprächen zur Erarbeitung des Lehrplanvorschlages für das geplante Fach Religion und Kultur nur «VertreterInnen der dominanten Religionen» eingeladen worden seien. Deshalb fehle «eine Würdigung weltlicher Aspekte». Es könne jedoch nicht sein, «dass in unserer weitgehend säkularisierten Gesellschaft nun den Kindern der Eindruck gegeben wird, dass Religion zwingend zum Leben eines jeden Einzelnen gehört. Wenn ein solcher Lehrplan dazu verwendet werden soll, gegenseitige Rücksichtnahme

52 Freidenkervereinigung Schweiz, Stellungnahme von März 2006.

53 Ebd. 
und gegenseitiges Verständnis zu vermitteln, muss auch klar sein, dass es völlig normal ist, sich dem Religiösen $\mathrm{zu}$ entziehen und trotzdem ein anständiger Mensch zu sein, der z. B. moralisch handeln kann auch ohne Angst vor einem Fegefeuer oder aus reiner Gottesgefälligkeit».54

Obwohl in der medialen und politischen Debatte bloss die Freidenker die Trennung zwischen Moral und Religion explizit affirmierten, wurde diese Trennung von anderen Akteuren jedoch implizit vorausgesetzt. So schien beispielsweise die Bildungsdirektion davon auszugehen, dass sich ethische und religiöse Anteile säuberlich voneinander trennen lassen. Dies zeigte sich folgendermassen: Als noch nicht klar war, dass Biblische Geschichte durch Religion und Kultur ersetzt würde, stand die Option zur Diskussion, gewisse Inhalte des Faches Biblische Geschichte in den Bereich Mensch und Umwelt zu integrieren. In einer Sitzung der Kirchensynode berichtete die Kirchenrätin Anemone Eglin über das Ansinnen der Bildungsdirektion, dass bloss «die ethischen Anteile, aber keine biblisch-christlichen Inhalte des B-Unterrichts»ss in den Bereich Mensch und Umwelt integriert würden.

In Spannung zur Annahme, dass sich ethische und religiöse Aspekte trennen lassen, steht die in der politischen und medialen Debatte ebenso verbreitete Annahme, dass ein obligatorisches Fach Religion und Kultur zu Integration und friedlichem Zusammenleben in einer zunehmend multikulturellen Gesellschaft beitrage. Ein Beispiel dafür ist das am i9. September 2005 von den drei Kantonsrätinnen Andrea Widmer-Graf (parteilos, Mitglied des Synodalvereins in der Kirchensynode), Yvonne Eugster (CVP) und Ursula Braunschweig (SP) im Kantonsrat eingereichte dringliche Postulat, das forderte, «in den Lehrplan der Primarstufe ein eigenständiges Fach «Religion und Kultur» aufzunehmen». ${ }^{56}$ Dieses Anliegen richtete sich einerseits dagegen, dass Biblische Geschichte bloss noch freiwillig von den Gemeinden angeboten werde und andererseits gegen das Ansinnen, einen Teil des bisherigen Faches Biblische Geschichte in andere Fächer zu integrieren. Die drei Politikerinnen erachteten dies als keine gute Lösung, da sie befürchteten, dass dann wichtige Themen «wie ethische und philosophische Fragen, christliche Traditionen und andere Religionen»\$7 untergingen. Ihrer Ansicht nach sollten im Fach Religion und Kultur «Fragen nach ethischem Handeln und nach Werthaltungen zur Sprache kommen». ${ }^{8}$ Der

54 Kyriacou, Blogeintrag vom 26. I I. 2006.

55 Protokoll der evangelisch-reformierten Kirchensynode des Kantons Zürich vom 25. II. 2003, I4.

56 Postulat KR-Nr. 258/2005 von Andrea Widmer-Graf (FDP, Zürich), Yvonne Eugster (CVP, Männedorf) und Ursula Braunschweig-Lütolf (SP, Winterthur) betreffend Fach «Religion und Kultur» an der Primarstufe.

57 Ebd.

58 Ebd. 
Vorteil eines obligatorischen Faches sei, dass alle Kinder einbezogen würden und somit ein «Beitrag zur Integration und zu einem friedlichen Zusammenleben in einer multikulturellen Gesellschaft» $\$ 9$ geleistet werde.

Man darf allerdings Zweifel daran anmelden, ob ein solch normatives Ziel mit der blossen Analyse von Werthaltungen aus neutraler Beobachterperspektive zu erreichen ist. Vielmehr bedarf es dazu der Einübung bestimmter Werthaltungen, die für das friedliche Zusammenleben und die Integration als notwendig erachtet werden. Die Vermittlung einer solchen Werthaltung spielt sich jedoch auf dem Hintergrund einer stark von der christlichen Tradition geprägten Kultur ab. Es ist diese mit der ethisch-moralischen Werthaltung zusammengewachsene implizite und oft wohl auch unbewusste Religiosität, die sowohl in Spannung zum geforderten Obligatorium steht, das nur auf der Basis der Garantierung von Glaubens- und Gewissensfreiheit legitim ist, als auch zur angenommenen Möglichkeit der Trennung von ethischen und religiösen Aspekten.

Auf eine ähnliche Spannung wies bereits die Geistlichkeitssynode in der Diskussion im 19. Jahrhundert hin. So sah die Geistlichkeitssynode zwar das Problem einer möglichen Verletzung der Glaubens- und Gewissensfreiheit im Religionsunterricht, sah dieselbe Gefahr aber auch hinsichtlich der Sittenlehre, da diese ebenso das Gewissen in Anspruch nehme. Interessanterweise wird diese Thematik im 2 I. Jahrhundert primär in der wissenschaftlichen Debatte problematisiert. Als Beispiel sei hier die Expertentagung im Jahre 2002 erwähnt, ${ }^{60}$ an der Peter Schreiner als Teil seines Referates mit dem Titel Das Konzept eines nicht-konfessionellen Religionsunterrichts im europäischen Kontext das damals im Bundesland Brandenburg neu eingeführte Schulfach «Lebensgestaltung Ethik - Religionskunde (LER)» für die Sekundarstufe I vorstellte. ${ }^{61}$ LER wurde im Unterschied zum Religionsunterricht, der in Brandenburg anders als in anderen Bundesländern kein Pflichtfach an den Schulen war und konfessionell getrennt erteilt wurde, zu einem verpflichtenden und ordentlichen Schulfach. Gemäss Schreiner gab das Schulgesetz vor, dass das Fach LER «bekenntnisfrei, religiös und weltanschaulich neutral unterrichtet» ${ }^{62}$ werde. Die Obligatorischerklärung des Faches LER führte zu Kritik. Es wurde gefragt, «wie sich die weltanschauliche Neutralität des Staates mit der inhaltlichen Verantwortung

59 Ebd.

60 Noch vor der Diskussion um die Abschaffung von Biblischer Geschichte auf der Primarstufe wurde über die Einführung des Faches Religion und Kultur auf der Oberstufe diskutiert. Am I6. Dezember 2002 fand an der Universität Zürich eine Expertentagung statt. Peter Schreiner vom Comenius Institut in Münster war einer der geladenen Experten.

6I Vgl. Schreiner 2002, I3.

62 Schreiner 2002, 13. 
eines allgemeinen, verpflichtenden Faches quasi als Monopol im Blick auf Werteerziehung in der Schule vereinbaren [lasse]». ${ }^{63}$

Kann das Fach LER «den Nachweis erbringen, dass Wertorientierung weltanschaulich neutral möglich ist? Kann der erlebnis- und handlungsbezogene Anspruch des Faches eingelöst werden, ohne mit der negativen Religionsfreiheit zu konkurrieren, die gerade die Konfessionslosen beanspruchen?» ${ }^{64}$

Würde Ethikunterricht in der öffentlichen Schule als praktische Philosophie oder ethische Reflexion verstanden, würde sich diese Frage so wohl nicht stellen. Doch damit will man sich, wie es scheint, nicht zufriedengeben. Impliziert ethisches Lernen in der Schule jedoch nicht bloss ethische Reflexion, sondern auch Moral- bzw. Werteerziehung, müsste sich hinsichtlich des Neutralitätsgebots in der Tat dieselbe Frage stellen wie beim Religionsunterricht. ${ }^{65}$ Denn in Anlehung an Alasdair MacIntyres 1988 erschienenes Buch Whose justice? Which Rationality $^{66}$ müsste in diesem Zusammenhang gefragt werden, wessen Moral und wessen Werte zu vermitteln sind.

\subsection{Die Rede von den Werten}

Ein auffälliger Unterschied zur Diskussion um I 870 ist die - man muss fast sagen inflationäre - Rede von Werten. Um I 870 sprach man in der Diskussion um den schulischen Religionsunterricht von Moral und Sittlichkeit, aber nicht von Werten. Der Ausdruck Wert entstammt zwar in seiner nicht ökonomischen Verwendungsweise der deutschen Philosophie des i9. Jahrhunderts, entfaltete jedoch erst im 20. Jahrhundert öffentliche Breitenwirkung. ${ }^{67}$

\subsubsection{Die Allgegenwart der Werterhetorik}

In der Diskussion um die Abschaffung von Biblischer Geschichte und die Einführung von Religion und Kultur diente der Ausdruck Wert sowohl den Befürwortern wie auch den Gegnern des schulischen Religionsunterrichts in seinen unterschiedlichen sprachlichen Kombinationen als rhetorisch-argumentative

63 Ebd., I3 f.

64 Ebd., I4.

65 Bis in die aktuellsten Diskussionen im Zusammenhang mit dem Lehrplan 2 I hinein wird über das Fachverständnis von Ethik diskutiert. Andreas Kessler verweist in seiner Analyse des Lehrplans 2 I bezüglich des ethischen Lernens auf die noch ungeklärte Verhältnisbestimmung zwischen Moralerziehung und ethischer Reflexion (vgl. Kessler 2016, 6).

66 MacIntyre 1988.

67 Vgl. Joas 1997, 37. Für eine ausführliche Diskussion des Zusammenhangs zwischen Werten und Pädagogik ist auf die Arbeiten des Erziehungswissenschaftlers Elmar Anhalt zu verweisen. Aus Anhalts Sicht ist die Pädagogik «eine der Disziplinen, deren Gegenstand die Werteorientierung eingeschrieben ist» (Anhalt 20I 2b, 66). Vgl. ebenfalls Anhalt 20I 2a. 
Kampfwaffe. Man sprach von christlichen, moralischen und/oder gesellschaftlichen Werten bzw. Grundwerten, von unterschiedlichen Wertvorstellungen, von der Unterscheidung von Werten in materielle und immaterielle, von Werten als Voraussetzung fürs Handeln und von Wertneutralität sowie Wertfreiheit, Werteverlust oder Werthaltungen usw. Im Folgenden soll anhand konkreter Beispiele die Verwendung des Ausdrucks Wert in der Diskussion um den schulischen Religionsunterricht illustriert werden. Die Funktion, die der Wertbegriff in dieser Debatte einnimmt, soll im Kapitel über Zivilreligion (vgl. Unterkapitel I0.4) noch weiter erläutert werden.

Der Zürcher Lehrerinnen- und Lehrerverband (ZLV) und der Verband des Personals Öffentlicher Dienste Zürich (VPOD) begründeten die Forderung, die Angebotspflicht für Biblische Geschichte aufrechtzuerhalten, in ihrer Petition «Ja zur Biblischen Geschichte - Ja zu einer ganzheitlichen Bildung» folgendermassen: «Biblische Geschichten eröffnen Zugänge zur christlichen Tradition unserer Kultur. Sie bieten Ansatzpunkte für Fragen nach dem Sinn unseres Daseins. Die Schülerinnen sollen erkennen, dass es materielle und immaterielle Werte gibt und dass persönliche Wertvorstellungen sehr verschieden sein können. Die Unterzeichnenden fordern daher, dass die Angebotspflicht für Biblische Geschichte aufrecht erhalten bleibt. ${ }^{68}$

Es ist erstaunlich, dass für ein Schulfach mit Abmeldemöglichkeit, das Geschichten zweier spezifischer religiöser Traditionen - der jüdischen und der christlichen - zum Inhalt hat, zum einen mit dem erhofften Erwerb der abstrakt-allgemeinen Unterscheidung zwischen materiellen und immateriellen Werten geworben wird und zum andern mit der Vielfalt persönlicher Wertvorstellungen. Weshalb solche Erkenntnisse speziell durch die Auseinandersetzung mit biblischen Geschichten gefördert werden sollen - und nicht zum Beispiel durch die Beschäftigung mit Märchen oder anderer Literatur - wird nicht deutlich gemacht.

Ähnlich wie die Petitionäre rekurrierte Kantonsrätin Lisette Müller (EVP) auf ihrer persönlichen Webseite in einem Plädoyer für die Beibehaltung von Biblischer Geschichte auf die moralische Dimension der biblischen Geschichten. Wissen alleine nütze nichts, Menschen brauchten auch eine «Handlungsbasis» und diese setze Werte voraus, die Orientierung gäben. Diese würden in Form von Geschichten überliefert. Im Unterschied zum Petitionstext betonte Müller jedoch auch noch den kulturellen Aspekt der biblischen Geschichten. Sie leitete daraus nebst einem Sozialisierungsauftrag - die Vermittlung «unserer Kultur [...] muss früh geschehen, sie ist wichtig für alle Kinder» - auch einen Bildungsauftrag ab:

68 Petition «Ja zur Biblischen Geschichte - Ja zu einer ganzheitlichen Bildung», 3I. I. 2004, Hervorhebung R. K. 
«Auch wer sich heute nicht ausdrücklich zu Gott und zu Jesus Christus bekennt, zweifelt keinen Moment daran, dass gegenseitiger Respekt, das Recht auf Leben und Nächstenliebe grundlegende Werte unserer Gesellschaft sind. Sie werden in der Schule und im Religionsunterricht gezielt vermittelt. Die biblischen Geschichten sind wichtiger Bestandteil unseres Kulturguts und gehören daher zur Allgemeinbildung.» ${ }^{69}$

Eine weitere Dimension neben der moralischen, erzieherisch-sozialisierenden und bildenden, zu der das schulische Fach Biblische Geschichte beitragen sollte, kam in einem Leserbrief der NZZ zur Sprache - die <identitätsstiftende> Dimension. Der Verfasser des Leserbriefes bediente sich dazu ebenfalls des Arsenals der Wertrhetorik. Anders als Kantonsrätin Müller sprach er nicht bloss von allgemein gesellschaftlichen Werten, sondern von spezifisch christlichen. Er formulierte sein Erstaunen darüber, dass «heute auf die Vermittlung christlicher Grundwerte verzichtet werden soll, wie sie etwa in den zehn Geboten festgeschrieben sind». Und anders als der Petitionstext schien es ihm gerade nicht ein primäres Ziel zu sein, die Vielfalt der persönlichen Wertvorstellungen zu unterstreichen, wenn er den «Werteverlust unserer Zeit» an den Pranger stellt, den er als «mitverantwortlich für die Gewaltverherrlichung» ansieht. So fragte er: «Was soll dem aggressiven Islamismus entgegengehalten werden, wenn wir der Jugend die eigenen moralischen Werte aus Feigheit oder Opportunismus vorenthalten? Wie stellt man sich eine ‘wertfreie Vermittlung von Werten> vor? [...] Toleranz gegenüber andern Religionen und Kulturen kann nicht auf nihilistischem Grund gedeihen, sondern setzt ein eigenes moralisches Gerüst voraus - als Vergleichsgrösse und Rückfallposition. Schon immer haben autoritäre Kräfte versucht, dieses Fundament zu zerstören, um die eigene Ideologie hineinzupflanzen. Worum geht es dem Bildungsrat?»>0

Der Leserbriefschreiber spricht zwar zuerst dezidiert von spezifisch christlichen Grundwerten, die den Kindern vermittelt werden sollen, um jedoch unmittelbar anschliessend viel allgemeiner vom «Werteverlust unserer Zeit» oder von den «eigenen moralischen Werten» zu sprechen. Warum spricht er nicht ebenso vom Verlust christlicher Werte oder der christlich-moralischen Werte? Manifestiert sich in dieser verallgemeinernden Ausdrucksweise eine Unsicherheit, ob die eigenen Werte tatsächlich für alle Menschen dieser Gesellschaft die christlichen sind und ob bloss der angebliche Verlust christlicher Werte den möglichen Widerstand gegen den militanten Islamismus verhindert?

69 Müller Lisette 2004.

$70 \mathrm{NZZ}$, 3. 6. 2004. Bruno Nüsperli reagierte in seinem Leserbrief auf den NZZ-Artikel «Zeit für ein Bekenntnis», in welchem der Autor am Ende seines Artikels von denjenigen, die «am alten christlich geprägten Bibelunterricht festhalten wollen», forderte, «zu bekennen, um was es ihnen wirklich geht» (NZZ, I4. 5. 2004). 
Nachdem sich in Zürich die Sache mit dem schulischen Religionsunterricht geklärt hatte und noch vor Beginn der Diskussion um den Lehrplan 2 I, positionierte sich im Dezember 2008 der Dachverband Schweizer Lehrerinnen und Lehrer (LCH) in einem Papier zum Stellenwert der Religionen im Bildungsauftrag und im Schulbetrieb..$^{71}$ Dieses Positionspapier ist von einer geradezu exzessiven Wertrhetorik geprägt. Die Geschäftsleitung des LCH plädiert in diesem Papier für einen Lehrplanbereich «Werte und Religionen», dem als Teil der obligatorischen Grundbildung ein dreifacher Auftrag zukomme. Als erster Auftrag wird genannt: «Den unverbrüchlichen Kern unserer gesellschaftlichen Grundwerte vermitteln».72 Als Werte werden Freiheit, Gleichheit, Chancengleichheit, Solidarität, Ausgleich zwischen Bedürftigkeit und Überfluss, Recht auf Eigentum, Gewaltentrennung, Meinungsfreiheit und Pressefreiheit, Schutz des Lebens, Garantierung der körperlichen und seelischen Intaktheit, Prinzipien der Subsidiarität, der Nichtwillkürlichkeit und der Verhältnismässigkeit von staatlichem Handeln genannt. Die Geschäftsleitung des LCH forderte, dass die Bedeutung dieser «Grundwerte» den Kindern in der Schule nahegebracht werden müsse und «dabei gleichzeitig unmissverständlich deutlich gemacht werden [müsse], dass es sich bei diesen Werten um unverhandelbare ‘Tarife> des Lebens in unserer Gesellschaft» handle, wobei diese Werte auch untereinander in Konkurrenz stehen können, so dass im Einzelfalle «eine Austarierung der verschiedenen Ansprüche unvermeidlich» sei. Als zweiter Auftrag wird genannt: «In der Wertelandschaft die Religionen situieren». Der dritte Auftrag lautet: «Raum schaffen für die individuelle Auseinandersetzung der Kinder und Jugendlichen mit den Phänomenen 〈Glauben〉 und 〈Wissen〉».73 Der LCH benennt in diesem Papier auch Zielkonflikte: So müsse die Schule «in ihrem Auftrag der Vermittlung von Werthaltungen/Einstellungen [...] normativ wirken. Das geht nicht ohne Grundwerte, d. h. nicht ohne Bekenntnis zu bestimmten Grundwerten und Abgrenzung gegenüber Wertsystemen, welche diese Grundwerte bedrohen». ${ }^{74}$

Im Unterschied zu den anderen genannten Akteuren in dieser Diskussion erkannte und benannte der LCH das Problem, das angesichts der Verpflichtung zu konfessioneller Neutralität entsteht, wenn der öffentlichen Schule der Auftrag zugesprochen wird, sogenannte «Grundwerte» zu vermitteln.75 Dieser Punkt führt mich zur Frage der Wertneutralität.

7I LCH, Dachverband Schweizer Lehrerinnen und Lehrer 2008. Auf Grund des Bundesgerichtsurteils vom 24. Oktober zum Schwimmunterricht-Obligatorium wurde das Papier am I9. Januar 2009 überarbeitet.

72 LCH 2008, 5 .

73 Ebd.

74 Ebd., 3.

75 Vgl. ebd. 


\subsubsection{Wertneutralität}

In der Diskussion um die Abschaffung des Faches Biblische Geschichte und die Einführung von Religion und Kultur war häufig nicht von konfessioneller Neutralität die Rede, sondern viel allgemeiner von Wertneutralität. Da das Fach Religion und Kultur für alle obligatorisch sei, schrieb beispielsweise die NZZ im Mai 2004, werde vorausgesetzt, «dass der Unterricht wertneutral gestaltet wird, mehr, als dies im bisherigen, christlich geprägten Bibelunterricht der Fall war». ${ }^{7}$ Und in einer Medienmitteilung vom 7. März 2006 drückte der Zürcher Lehrerinnen- und Lehrerverband (ZLV) seine Freude über den Entscheid des Bildungsrates aus, das Fach Religion und Kultur in den Lehrplan der Primarschule aufzunehmen: «Es ersetzt das Fach Biblische Geschichte und wird - wie vom ZLV verlangt - ein eigenständiges und obligatorisches Fach ohne Abmeldemöglichkeit sein. [...] Der ZLV ist dezidiert der Auffassung, dass dieser Unterricht wertneutral sein muss; religiöse Unterweisung ist dem kirchlichen Unterricht vorbehalten.»77 Am Tag nach der Medienmitteilung des ZLV titelte die NZZ Moderne Religionskunde an der Volksschule und schreibt in ihrem Bericht über das neue Schulfach Religion und Kultur: «Um die Glaubens- und Gewissensfreiheit in der Schule nicht zu verletzen, muss der Unterricht so weit als möglich «wertneutral〉 geführt werden». Wertneutralität bedeute, dass «über die Religionen unterrichtet und nicht in einen Glauben eingeführt» ${ }^{8}$ werde.

Die Forderung nach einem sogenannt wertneutralen Unterricht im Fach Religion und Kultur wurde von unterschiedlichen Seiten her mit Skepsis betrachtet. Einerseits kam Kritik von den Sektionen Zürich und Winterthur der Freidenkervereinigung der Schweiz (FVS). In ihrer Stellungnahme zum geplanten Schulfach Religion und Kultur erörterten sie «das Problem der Neutralität gegenüber Lehren, die keine Neutralität kennen».79 So begrüssten sie zwar die Absicht des Bildungsrates, dem Neutralitätsgebot zu genügen, indem der Unterricht auf Religionskunde beschränkt und andere Religionen neben dem Christentum «gleichermassen berücksichtigt» würden. Sie hielten die Umsetzung jedoch nicht für möglich. Zum einen sei unklar, "was unter sgleichermassen` zu verstehen sei»: Blosse Stundenzahlen oder ein «gerechter» Schlüssel? Zum andern sei auch unklar, «was als Religion zu gelten hat und was nicht». Zudem erachteten sie es auch als unmöglich, dass «der Staat die verfassungsmässig nötige klare Trennung zwischen dem «teaching in religion> und dem steaching about religion> garantieren könne». Eine solche Trennung sei grundsätzlich unmöglich, «weil die

76 NZZ, I 4. 5. 2004: Bildungsrat will obligatorisches Fach für Religionskunde.

77 Zürcher Lehrerinnen- und Lehrerverband 2006.

78 NZZ 8. 3. 2006: Moderne Religionskunde an der Volksschule, 5 I.

79 Freidenkervereinigung Schweiz, Stellungnahme vom März 2006. 
Behandlung von Wertvorstellungen, wie sie die Religionen umfassen, Wertungen von Lehrenden und Lernenden» erfordere. Somit könne weder ein teaching in religion noch ein teaching against religion ausgeschlossen werden. Zudem erachteten die Freidenker die Trennung zwischen teaching in und teaching about als «nicht konsensfähig, weil viele zentrale Aussagen, die in einer Religion als unbezweifelbar gelten, für Andersgläubige und Andersdenkende ebenso eindeutig ins Reich der Mythologie gehören». Die Freidenker nannten hier als Beispiel «die angebliche historische Existenz Jesu», die auch von namhaften Gelehrten in Frage gestellt würde. Müssten Lehrpersonen in der Schule auch solch fragwürdige Inhalte thematisieren, sei dies höchst problematisch. Denn würden sie die Probleme erörtern, könne dies zu Konflikten mit Schülern, Eltern und Glaubensorganisationen führen. Würden «im Interesse des Religionsfriedens alle Ungereimtheiten religiöser Lehren teils verschwiegen, teils willkürlich» umgedeutet, würde damit gelehrt, «alles in der Kulturgeschichte zu Macht und Ansehen Gekommene trotz furchtbarster Folgen unkritisch hochzuachten». Es scheint, als ob die Verfasserschaft dieser Vernehmlassungsantwort den Ausdruck teaching about so versteht, dass nur Inhalte von Religionen vermittelt werden dürften, die auch von «Andersgläubigen und Andersdenkenden» geglaubt werden können, da sie unbezweifelbar seien. Aus kritischer Distanz betrachtet stellt sich allerdings die Frage, ob, wer Unbezweifelbarkeit zum Kriterium von Inhalten macht, die legitimerweise an der öffentlichen Schule vermittelt werden dürfen, konsequenterweise nicht auch andere Schulfächer wie zum Beispiel Geschichte oder Biologie problematisieren müsste. Denn zu Wesen und Methode der (Natur)wissenschaften gehört, dass prinzipiell alles in Frage gestellt werden kann und soll und nichts prinzipiell als unbezweifelbar gelten kann. So weit gehen die Freidenker in ihrer Vernehmlassungsantwort jedoch nicht. Zudem dürfte das about gerade dann missverstanden sein, wenn damit auf bestimmte, angeblich von allen rationalen Menschen geteilte Überzeugungen oder Wahrheiten abgehoben wird. Es geht wohl eher darum, die Wahrheitsfrage insgesamt einzuklammern.

Andererseits wurde gegenüber der Forderung nach wertneutralem Unterricht auch Kritik von christlich-theologischer Seite geäussert. In einem NZZ-Artikel mit dem Titel Wertneutral über den Wassern schweben ${ }^{80}$ beschäftigte sich der in München lehrende evangelische Theologe Friedrich Wilhelm Graf mit dem «Zürcher Streit um die Aufhebung des Fachs «Biblische Geschichte», der ihn an die Kulturkämpfe des 19. Jahrhunderts erinnert. Er warf der Zürcher Bildungsdirektion vor, mit der geplanten Einführung des konfessionsneutralen Faches Religion und Kultur «etatistischen Mustern» zu folgen und mit ihrem Reform- 
konzept «zutiefst illiberal» zu sein. Die «Rede vom «wertneutralen» Unterricht» erachtete er als «nur irreführend», denn niemand könne «einen Ort über den vielen konkurrierenden Glaubenswelten einnehmen». Er fragte sich, wie die Zürcher Primarlehrkräfte, von denen die meisten wohl «immer schon von christlichen Kontexten geprägt sein» dürften, «einen «objektiven Standpunkt jenseits einander ausschliessender Glaubenswelten einnehmen können». Er fragte weiter: «Müssen sie ihren eigenen Glauben verleugnen, um «kritisch distanziert alles religiös Mögliche zu lehren? Sollen auch harte, aggressive Religionsformen «rein wertneutral> vorgestellt werden? Oder wird um des multireligiösen Friedens willen von den Schülern das Credo verlangt, indifferenter Allerweltsglaube sei besser als bindende, fundamentalistische> Glaubensgewissheit?» ${ }^{81}$ Graf versteht sich jedoch keineswegs weder als Vertreter des Status quo noch als Vertreter «der wertkonservativen Abendlandsrhetorik». Seiner Ansicht nach sind «für die Vermittlung des Christlichen [...] primär die Kirchen zuständig und nicht der Staat». Er fügt hier gleich auch eine Kritik an der reformierten Landeskirche an, die es «dank alter Staatsnähe viel zu lange unterlassen [habe], religiöse Bildungsprozesse zu initiieren». Nebst der Kritik am Begriff der Wertneutralität deckt Graf Widersprüche im Volksschulgesetz auf. Im selben Paragraphen, der die Religionsfreiheit betone, heisse es auch, dass die Primarschule «zu einem Verhalten erziehen [solle], das sich an christlichen, humanistischen und demokratischen Wertvorstellungen orientiert». Dies führt Graf zur Frage: «Darf der Staat über «christliche Werte» entscheiden, oder sieht er trotz seiner Akzeptanz vorstaatlicher Glaubens- und Gewissensfreiheit im Christentum noch eine Art 〈Staatsreligion〉?» «Wenn die Primarschule zu christlich geprägtem Verhalten erziehen soll, muss sie auch von nichtchristlichen Schülern wie Lehrern eine aktive Identifikation mit christlichen Normen erwarten können. Man mag dies als eine repressive, illiberale Erwartung der christlichen Mehrheit an die nichtchristlichen Minderheiten ablehnen. Aber eine schulische Religionskunde, in der alle religiösen Gewissheiten in vermeintlicher Neutralität als gleich gültig gepriesen werden, ist im Kern viel illiberaler. Denn hier droht sich der Staat eine Deutungskompetenz anzumassen, auf die er um seiner Liberalität willen verzichten sollte.» ${ }^{82}$

Graf spricht mit seiner Kritik an der geplanten Wertneutralität des schulischen Religionsunterrichts das klassische liberale Dilemma an: Grundlegend für das Funktionieren einer liberalen Gesellschaftsordnung ist das Bemühen aller Bürgerinnen und Bürger, die Freiheit sowohl für sich als auch für andere zu ermöglichen und $\mathrm{zu}$ bewahren. ${ }^{8}$ Erziehung und Bildung zu normieren, um dieses

8 I Ebd.

82 Ebd.

83 Vgl. Schweitzer 2005, 75 . 
Ziel zu erreichen, kommt jedoch einem Erziehungsstaat gleich, was wiederum den liberalen Prinzipien widerspricht. Das liberale Dilemma scheint auch im Hintergrund der Frage der Freidenker zu stehen, ob Lehrkräfte im schulischen Religionsunterricht auch Lehren gegenüber neutral sein sollen, die selber nicht «neutral» ${ }^{{ }_{4}}$ sind. Während die Freidenker jedoch nicht die Wertneutralität als solche problematisieren, sondern primär die Umsetzung der Forderung nach wertneutralem Unterricht, stellt Graf das Prinzip der Wertneutralität als solches in Frage.

Folgt man Grafs Überlegungen, kann auch ein scheinbar neutrales religionskundliches Fach das liberale Dilemma nicht auflösen. Im Gegenteil: Wer wie Graf die menschliche Möglichkeit eines vogelperspektivischen Blickes auf die Welt in Frage stellt, muss auch das religionskundliche Bemühen, die verschiedenen Religionen und Weltanschauungen gleich gültig nebeneinanderzustellen, als eine mögliche Perspektive neben anderen betrachten. Präferiert der Staat diese Perspektive, verletzt er damit die Freiheit derjenigen, für die eine bestimmte Religion oder Weltanschauung nicht eine gleich gültige Option neben anderen bedeutet. In Grafs Kritik manifestiert sich eine Sensibilität für die Grenzen unterschiedlicher gesellschaftlicher Sphären, wenn er beispielsweise den Kirchen und nicht dem Staat die Aufgabe der Vermittlung «des Christlichen» zuspricht, und für die Gefahr, die die Verletzung dieser Grenzen für eine freiheitliche Gesellschaftsordnung mit sich bringt.

Eng verknüpft mit den Fragen nach der Umsetzung von wertneutralem Unterricht sowie der grundsätzlichen Möglichkeit von (Wert-)Neutralität ist die Frage, was die zentrale Aufgabe der öffentlichen Schule in einer freiheitlichen Gesellschaft sein soll und darf. Den Antworten auf diese Frage ist das folgende Unterkapitel gewidmet.

\subsection{Aufgabe der öffentlichen Schule?}

Um I 870 wurde die Frage nach der Aufgabe der öffentlichen Schule wegen der geplanten Änderung des Zweckartikels (Paragraph 2) im Unterrichtsgesetz kontrovers diskutiert (vgl. Unterkapitel 6.5). Man stritt sich darüber, ob es Aufgabe der Schule sei, die Kinder zu sittlich religiösen oder zu sittlich guten Menschen heranzubilden. Die Frage war also, ob der Schule ein religiös-moralischer oder

84 Die Freidenkervereinigung wandte in ihrer Stellungnahme den Begriff der Neutralität in Bezug auf den Begriff der Lehre an. Dies scheint mir im Unterschied zur Anwendung auf einen <unparteiischen〉 Akteur nicht sinnvoll. Denn eine Lehre kann zwar bezüglich anderer Dinge neutral sein - im wörtlichen Sinne von neuter weder das eine noch das andere befürworten -, aber nicht in Bezug auf sich selbst. Denn dann wäre sie unbestimmt und hätte keinen Gehalt. 
bloss ein moralischer Auftrag zukomme. Die Ausrichtung des schulischen Religionsunterrichts stand in engem Zusammenhang mit der Antwort auf diese Grundsatzfrage.

Auch um 2004 beschäftigten sich die in der Diskussion engagierten Akteure mit der grundlegenden Frage nach der Aufgabe der öffentlichen Schule. Ganz konkret stellte sich die Frage, ob Religionsunterricht zum Bildungsauftrag einer staatlichen Schule gehöre. Bezüglich der Antwort auf diese Frage bestand keine Einigkeit.

Positiv wurde diese Frage von drei Kantonsräten beantwortet, die am 22. September 2003 eine Motion zur Sicherstellung des biblischen Unterrichts an der Volksschule einreichten. In der Motion wurde bemängelt, dass der Regierungsrat mit den geplanten Sanierungsmassnahmen «die religiöse Dimension aus dem Bildungsauftrag des Staates herauslösen» wolle. Die Streichung des schulischen Religionsunterrichts im Zuge der Sparmassnahmen markiere «ein Desinteresse des Staates am wichtigen Bereich der religiösen Bildung, gerade zu einer Zeit, wo 〈Sinn-Fragen〉 die Menschen vermehrt beschäftigen». Aus Sicht der Motionäre gehört es «zu einem ganzheitlichen Bildungsauftrag, dass unsere Jugend mit den christlichen Wurzeln unserer abendländischen Kultur vertraut wird. Deshalb soll an der Angebotspflicht für Biblische Geschichte festgehalten werden». ${ }^{85}$

Der Regierungsrat antwortete negativ auf dieses Begehren und beantragte dem Kantonsrat, die Motion nicht zu überweisen. ${ }^{86}$ Seine Begründung lautete folgendermassen: «Es gehört zu den wesentlichen Aufgaben der staatlichen Schulen, die Kinder und Jugendlichen für ein friedliches Zusammenleben in der Gesellschaft zu befähigen. Die Gemeinschaftsfähigkeit des Individuums sowie der Aufbau einer toleranten Haltung werden gefördert, wenn in der Schule unterschiedliche Ansichten Platz haben, Wertvorstellungen offen dargelegt, kontroverse Fragen aus unterschiedlichen Perspektiven behandelt und andersartige Meinungen geachtet werden. Dies muss gemäss Leitbild des Lehrplans der Volksschule des Kantons Zürich in allen Fächern geschehen und ist nicht auf die Biblische Geschichte zu beschränken.» ${ }^{87}$

Der Unterricht in Biblischer Geschichte sei auch in anderen Kantonen der Schweiz nicht in der Stundentafel enthalten und werde von den Kirchen an-

85 Motion KR-NR. 284/2003, vgl. auch Auszug aus dem Protokoll des Regierungsrates des Kantons Zürich, Sitzung vom I I. I 2. 2003.

86 Neben einer inhaltlichen Kritik an der Motion beinhaltete die Antwort des Regierungsrates allerdings auch noch eine formale Kritik. So gehöre die Bestimmung von Unterrichtsangeboten nicht in den Zuständigkeitsbereich des Kantonsrates und sei deshalb gar nicht motionsfähig (vgl. Auszug aus dem Protokoll des Regierungsrates des Kantons Zürich, Sitzung vom II. I2. 2003, 3).

87 Auszug aus dem Protokoll des Regierungsrates des Kantons Zürich, Sitzung vom II. I 2. $2003,2$. 
geboten oder als Freifach aufgeführt. Der Kanton Zürich sei diesbezüglich keine Ausnahme. Der Regierungsrat erachtete christlich-religiöse Bildung nicht als Bildungsauftrag der Schule, sondern wies diese Aufgabe der Kirche zu: «Es ist grundsätzlich Aufgabe der Kirchen, die religiöse Bildung sicherzustellen, Kenntnisse der Bibel zu vermitteln und die christlichen Wurzeln Kindern und Jugendlichen näher zu bringen.» ${ }^{88}$

Ein beträchtlicher Teil der Bevölkerung war mit der Position des Regierungsrates nicht einverstanden. Nur so ist es zu erklären, dass für die Initiative zur Weiterführung des Faches Biblische Geschichte innert kürzester Zeit weit mehr als die erforderlichen Unterschriften gesammelt werden konnten. Gemäss NZZ sah das Komitee «in der hohen Zahl von Unterschriften den Beweis dafür, dass die Bevölkerung das Vermitteln von Grundwissen über Religion an der Primarschule für wichtig hält». ${ }^{89}$

Ein Jahr später, als im Kantonsrat darüber debattiert wurde, ob das dringliche Postulat der drei Kantonsrätinnen Widmer Graf, Eugster und Braunschweig-Lütolf für das Fach Religion und Kultur an der Primarschule überwiesen oder abgelehnt werden soll, $9^{\circ}$ setzte sich Braunschweig-Lütolf für die Überweisung des Antrags ein mit dem Argument, dass auf dem Hintergrund einer zunehmend religiösen Vielfalt der «Religionsunterricht zum Bildungsauftrag einer staatlichen Schule» ${ }^{91}$ gehöre. Um dieses Anliegen zu unterstreichen, verwies sie auf den Kanton Genf. Nachdem dort «I 50 Jahre religiöse Indifferenz in Sachen Religion und Schule» geherrscht habe, sei vom Genfer Erziehungsdepartement eine Arbeitsgruppe initiiert worden, die der Frage nach «dem Platz der jüdisch-christlichen Kultur in der laizistischen Schule nachgehen sollte». Auslöser dafür war der Massenselbstmord von Mitgliedern des «Ordre du temple solaire», der einen wichtigen Standort in Genf hatte. Im Anschluss an dieses Drama sei in den Medien die Frage nach der Rolle der Schule gestellt worden angesichts des «offensichtlich verbreiteten Unwissen[s] und der kritischen Haltung gegenüber Sekten, in der Unkenntnis in Sachen Religion». Die Genfer Regierung habe realisiert, «dass die Zukunft der Demokratie gefährdet war, ohne das Wissen und Bewusstsein über den Ursprung der Werte, auf denen sie basiert».92 Braunschweig-Lütolf warb am Ende ihres Plädoyers für Überweisung des Postulats damit, «dass wir im Kanton Zürich eben nicht Religions- und Kulturbanausen sein wollen, sondern unter staatlicher Aufsicht den Religions-

88 Ebd., 3.

89 NZZ, I4. 9. 2004: 50000 Unterschriften für Biblische Geschichte.

90 Der Kantonsrat beschloss nach einer längeren Diskussion, die hier nicht wiedergegeben werden soll, mit 108 zu 40 Stimmen, das dringliche Postulat an den Regierungsrat zu überweisen (vgl. Protokoll des Zürcher Kantonsrates, I 4. I I. 2005, S. 934I).

9I Protokoll des Zürcher Kantonsrates, I4. I I. 2005, S. 9337.

92 Ebd., S. 9338. 
unterricht weiterhin anbieten als Ort des Lernens über Gott und die Welt, als Ort, wo der Blick über den eigenen Tellerrand gelernt und geübt wird, als Ort, wo kritische Offenheit und Toleranz entstehen können».93

In ihrer Stellungnahme zum geplanten Schulfach Religion und Kultur erachteten die Sektionen Zürich und Winterthur der Freidenkervereinigung der Schweiz (FVS) «ein Grundwissen über belegbare (!) religionsgeschichtliche und religionsphänomenologische Tatsachen» im Rahmen einer Allgemeinbildung ebenso als notwendig und nannten als Beispiel «den Einfluss des Islams auf die abendländische Kultur». Diese Aufgabe würde jedoch «seit jeher» vom Geschichtsunterricht und von den Sprachfächern übernommen - als Beispiel wurde Max Frischs Werk «Andorra» genannt, in welchem Menschen auf Grund von Vorurteilen gegeneinander aufgehetzt würden. Aus diesem Grund sei ein obligatorisches «Religionsfach» ${ }^{94}$ nicht notwendig.

In den Argumentationen für einen schulischen Religionsunterricht - zuerst war es noch Biblische Geschichte, dann Religion und Kultur - stechen insbesondere zwei Argumentationsmuster ins Auge, denen sich die unterschiedlichsten Beteiligten (kirchliche Vertreter, Politikerinnen) in der Diskussion bedienten. Zum einen wurde dem schulischen Religionsunterricht zugesprochen, die gesellschaftliche Integration und die Toleranz zwischen den Mitgliedern unterschiedlicher kultureller und religiöser Zugehörigkeit zu fördern. Zum andern wurde angeführt, der schulische Religionsunterricht leiste einen wichtigen Beitrag zur Orientierung und Identitätsstiftung. Nachfolgend sollen diese wiederkehrenden rhetorischen Argumentationsmuster an einigen Beispielen illustriert werden.

\subsubsection{Integration und Toleranz als Rezepte für das friedliche Zusammenleben?}

In der «Resolution für die Beibehaltung der Angebotspflicht für biblischen Unterricht an der Volksschule», die die vier Fraktionspräsidenten der evangelisch-reformierten Kirchensynode des Kantons Zürich gemeinsam einreichten, wurde als erster von drei ergänzenden Punkten darauf aufmerksam gemacht, dass die Abschaffung dieses Schulfaches ein Zeichen für die Verkennung der Bedeutung der Religion für die Gesellschaft sei: «Mit dem Religionsunterricht an unserer Volksschule kann fundamentalistischen, divergierenden Kräften in unserer Gesellschaft entgegengewirkt werden. Er ist somit grundlegend für Kirche und Staat, dies vor allem in der Zielsetzung eines friedlichen Zusammenlebens.»95

Ähnlich argumentierte auch die römisch-katholische Synode des Kantons Zürich in ihrer Resolution für die Beibehaltung der Angebotspflicht für

93 Ebd.

94 Freidenkervereinigung Schweiz, Stellungnahme von März 2006. Ausrufezeichen steht so im Original.

95 Protokoll der evangelisch-reformierten Kirchensynode des Kantons Zürich vom 24. 6. 2003, I 8. 
Biblische Geschichte an der Primarschule. Sie erachte es als notwendig, «die Inhalte des Faches in unserer multikulturellen und multireligiösen Gesellschaft als Angebotspflicht beizubehalten. Eine vertiefte Kenntnis anderer Religionen fördert Toleranz und Respekt ihnen gegenüber». ${ }^{96}$ In seiner Erläuterung des Resolutionstextes verwies der Referent des Synodenbüros der römisch-katholischen Kirche Zürichs, René Baumgartner, auf die Erfahrung, «dass der religiöse Fundamentalismus überall dort zunimmt, wo die Bildung in Religion und Kultur einseitig extremen religiösen Gesellschaften überlassen wird».97

Ähnliche Töne waren aber auch von politischer Seite zu hören. Im August 2004 schrieb die NZZ, der Bildungsrat erachte es als «Aufgabe der Schule, das Verständnis für religiöse und kulturelle Eigenheiten und Differenzen zu wecken, um damit die Toleranz unter den verschiedenen religiösen Gruppen einer liberalen Gesellschaft zu fördern»..$^{8}$

Und in der Begründung des von den drei Kantonsrätinnen Widmer Graf, Eugster und Braunschweig-Lütolf eingereichten dringlichen Postulats für die Einführung eines eigenständigen und obligatorischen Fachs Religion und Kultur hiess es: «Ein obligatorisches Fach hat den grossen Vorteil, dass alle Kinder einbezogen werden. Auf diese Art kann das Fach einen wesentlichen Beitrag zur Integration und zu einem friedlichen Zusammenleben in einer multikulturellen Gesellschaft leisten. Es trägt zu einem besseren Verständnis von unterschiedlichen Kulturen und Religionen bei und fördert Solidarität, Rücksichtnahme und Toleranz.»99

Die Regierungsrätin und Vorsteherin der Zürcher Bildungsdirektion, Regine Aeppli, schien die Dinge ähnlich zu sehen wie die Postulantinnen, wenn sie als «Hauptziel des neuen Faches [bezeichnete], das Verständnis zwischen den Kulturen zu vertiefen». ${ }^{100}$

Der Grosse Gemeinderat von Winterthur diskutierte im April 200 s über Annahme oder Ablehnung einer Initiative, die die nahtlose Weiterführung des Unterrichts in Biblischer Geschichte forderte. ${ }^{10 I}$ In praktisch allen befürwor-

96 Protokoll der römisch-katholischen Synode des Kantons Zürich: Resolution betreffend die Beibehaltung der Angebotspflicht für Biblische Geschichte an der Primarschule, 4. I 2. 2003.

97 Ebd.

98 NZZ, 26. 8. 2004.

99 Protokoll des Regierungsrates, Sitzung vom 26. I0. 2005.

ı०० Wieder Religion an Zürcher Schulen, Tages-Anzeiger, 8. 3. 2006.

IOI Der Bildungsrat des Kantons Zürich entschied im Juli 2003, dass der Unterricht in Biblischer Geschichte ab dem Schuljahr 2004/os ein Freifach werde. Für die Gemeinden hatte dies zur Folge, dass sie dieses Fach zwar weiterführen durften, aber für sämtliche anfallenden Kosten selber aufkommen mussten. Im Juli 2004 bewilligte der Gemeinderat von Winterthur einen Kredit von rund I Million Franken für die Weiterführung des Fachs für ein Schuljahr. Der Gemeinderat ging bei diesem Entscheid - Bewilligung bloss für ein Jahr und nicht für zwei Jahre, wie von der Zentralschulpflege in einem Antrag gefordert worden war - davon aus, 
tenden Voten wurde der integrationsfördernde Aspekt dieses Faches betont. Die Sachkommission Bildung, Sport und Kultur (BSKK) beispielsweise sprach sich für die Weiterführung aus, da sie «dem B-Unterricht hinsichtlich Bildung, Integration und Wertvermittlung eine grosse Bedeutung ${ }^{102}$ zumass. Ähnlich argumentierte der Vertreter der SVP-Fraktion: «Dieser Unterricht vermittelt Inhalte der abendländischen Kultur und leistet damit einen wertvollen Beitrag an die Integration». ${ }^{103}$ Der Vertreter der EDU meinte: «Es ist ein wichtiges Fach, um Weltgeschichte zu lernen, und es fördert die Integration». ${ }^{104}$ Die Mehrheit der SP-Fraktion sprach sich zwar aus finanzpolitischen Gründen gegen das Initiativbegehren aus. Gleichwohl war sie der Ansicht, dass die Stadt «es sich im Grunde nicht leisten [könne], den B-Unterricht abzuschaffen. Integrationsanliegen hätten gerade in diesem Unterricht Platz». ${ }^{105}$ Die Minderheit der SP-Fraktion, die den Antrag unterstützte, den Unterricht in Biblischer Geschichte ohne Unterbrechung weiterzuführen, meinte: «Die Million ist aktiv angelegtes Geld für Integration und Sozialkompetenz» ${ }^{106}$ Es gab allerdings auch kritische Stimmen, die es vertretbar fanden, den Unterricht in diesem Fach für ein Jahr ausfallen zu lassen. Der FDP-Vertreter meinte beispielsweise: «Die Integrationswirkung des Fachs muss realistisch eingeschätzt werden. Die Kinder, die es wirklich nötig hätten, besuchen im Normalfall den B-Unterricht nicht. Soziales Verhalten und Integration müssen zudem in jeder Schulstunde gelehrt werden - eine Stunde genügt nicht. ${ }^{107}$

Die sich in diesen Voten zeigenden Anforderungen an den schulischen Religionsunterricht - und damit an die öffentliche Schule - sind sehr hoch. Aus der medialen, kirchenpolitischen und politischen Diskussion sind mir praktisch keine Stimmen bekannt, die diese Anforderungen an die öffentliche Schule in Frage stellten. Von Seiten der SVP wurde zwar weniger das Ziel gegenseitiger Solidarität, Rücksichtnahme und Toleranz betont als vielmehr die Vermittlung einer

«dass der Bildungsrat im Verlaufe dieses Schuljahres über die Integration des Fachs Biblische Geschichte in den obligatorischen Lehrplan entscheiden» (Protokoll des Grossen Gemeinderates von Winterthur vom I 8. 4. 2005, S. 429) werde. Im November 2004 kam vom Bildungsrat jedoch die Meldung, diese Integration könne noch nicht zum Schuljahr 2005/06 stattfinden. Die Zentralschulpflege verzichtete aus finanzpolitischen Erwägungen auf einen erneuten Kreditantrag. Daraufhin wurde die Volksinitiative Ja zur Biblischen Geschichte lanciert und kam zustande.

I02 Protokoll des Grossen Gemeinderates von Winterthur vom, I 8. 4. $2005,429$.

I03 Ebd., 429.

I04 Ebd.

I05 Ebd., 430.

Io6 Ebd., 43 I.

I07 Ebd., 430. 
sogenannten Leitkultur ${ }^{108}$ und die Integration. ${ }^{109}$ Die Freidenker kritisierten in ihrer Vernehmlassungsantwort zwar in vielerlei Hinsicht das geplante Fach Religion und Kultur, doch ebenso wie dem Bildungsrat erschien es ihnen wichtig, «junge Leute zu Toleranz im besten Sinne zu erziehen». Damit sei jedoch nicht Erziehung «zur Achtung jeglicher Meinung, sondern zur Achtung des Mitmenschen und seines Rechts auf eigene Meinungen» ${ }^{\text {IIo }}$ gemeint. Zur Erreichung dieses Erziehungsziels sollte ebenso die Schule beitragen, allerdings nicht mittels eines schulischen Religionsunterrichts, sondern mittels eines Lebenskunde- oder Ethik-Faches.

\subsubsection{Orientierung und Identitätsbildung}

Sowohl vom Fach Biblische Geschichte wie auch vom Fach Religion und Kultur wurde neben der Förderung von Integration und Toleranz erwartet, zur Identitätsbildung und Lebensorientierung beizutragen. In der im September 2003 im Kantonsrat eingereichten Motion zur Sicherstellung des biblischen Unterrichts an der Volksschule hiess es beispielsweise: «Schon jetzt wird in weiten Kreisen eine Unkenntnis der Bibel und der Hauptanliegen des christlichen Glaubens sowie der christlichen Ethik beklagt. Je weniger die Zürcher Kinder Kenntnis von der hiesigen Religion haben, welche unsere Kultur und das Gemeinwesen von Grund auf geprägt hat, desto schwächer bildet sich ihre religiöse Identität aus. Damit fehlt auch eine Voraussetzung für den Dialog mit religiös anders geprägten Menschen. Es gehört zu einem ganzheitlichen Bildungsauftrag, dass unsere Jugend mit den christlichen Wurzeln unserer abendländischen Kultur vertraut wird.» ${ }^{\text {II }}$

In einer funktional ausdifferenzierten Gesellschaft würde man erwarten, dass die Aufgabe der religiösen Identitätsbildung den Eltern und Religionsgemeinschaften zugesprochen werde. Dass die Motionäre auch von der öffentlichen Schule erwarteten, zur Erfüllung dieser Aufgabe beizutragen, begründeten sie damit, dass eine ausgebildete religiöse Identität für den interreligiösen Dialog grundlegend sei. Offenbar bezweifelten sie, dass diese den Kindern zu Hause in genügendem Masse vermittelt werde.

Die CVP/EVP-Fraktion des Gemeinderates von Zürich war gar der Überzeugung, dass das Fach Biblische Geschichte einen wesentlichen Beitrag zur

Io8 Der SVP-Kantonsrat Matthias Hauser schrieb in seinem Blog: «Die Bildung in christlichen Grundwerten ist ein wichtiges Anliegen, angesichts von Multikulti wichtiger denn je. Es geht um Leitkultur.» (Blog von Matthias Hauser, I 4. 3. 2007).

I09 Vgl. Protokoll des Grossen Gemeinderates von Winterthur, I 8. 4. 2005.

I Io Freidenkervereinigung Schweiz, Stellungnahme von März 2006.

I I Motion KR-Nr. 284/2003 betreffend Sicherstellung des biblischen Unterrichtes an der Volksschule; vgl. auch Auszug aus dem Protokoll des Regierungsrates des Kantons Zürich, II. I 2. 2003 , I. 
Erhaltung der Gesellschaft leiste. Im April 2004 reichte die CVP/EVP-Fraktion ein Postulat ein, das den Stadtrat bat zu prüfen, wie das Fach Biblische Geschichte im Schuljahr 2004/05 im Rahmen der Blockzeiten erteilt werden könne. Ihr Anliegen begründete sie unter anderem damit, dass ohne Unterricht in Biblischer Geschichte die Gefahr drohe, «dass in unserer Schule die Vermittlung dieser wesentlichen Grundlagen unserer Gesellschaft verloren» ${ }^{12}$ gehe. Auch der Resolutionstext der römisch-katholischen Kirche Zürichs, betreffend die Beibehaltung der Angebotspflicht für biblische Geschichte an der Primarschule, wurde an der Synodensitzung im Dezember 2003 unter anderem damit erläutert, dass mit dem Schulfach Biblische Geschichte, «der Jugend die Bedeutung von unserem kulturellen und religiösen Erbe weiter gegeben» ${ }^{113}$ werde.

Ebenso sahen die Initianten der kantonalen Volksinitiative für die Weiterführung des Faches Biblische Geschichte an der Primarschule im Unterricht in Biblischer Geschichte einen wichtigen Aspekt der Vermittlung «unserer Kultur» sowie der Beschäftigung mit den sogenannt «eigenen Wurzeln». In der Begründung des Initiativtextes heisst es: «Unsere Kinder haben ein Anrecht darauf, sich mit der biblischen Tradition und dem religiösen Erbe als Grundlagen unserer Kultur vertraut zu machen. Dies gehört zum umfassenden Bildungsauftrag der Schule. Die Initiative will sicherstellen, dass die Primarschule diesen Auftrag erfüllt. Die Auseinandersetzung mit den eigenen Wurzeln fördert das kritische Urteilsvermögen der Heranwachsenden und dient dem gesellschaftlichen Frieden. ${ }^{1{ }^{114}}$

In der Diskussion von April 2005 im Grossen Gemeinderat von Winterthur (vgl. Unterkapitel 9.6. I sowie die Anmerkung Ior, S. 254) wurde insbesondere in den Voten politisch rechts stehender Kreise nebst dem Integrationstopos immer wieder auch auf den identitätsbildenden Beitrag des Faches Biblische Geschichte verwiesen. Gemäss der EVP-Vertreterin werde darin «der Blick auf die Grundwerte der Kultur, die Geschichte und die Gesetze geöffnet und damit das Zusammenleben gefördert». ${ }^{\text {Is }}$ Die CVP-Vertretung wog in ihrem Votum gesellschaftspolitische und finanzpolitische Gesichtspunkte gegeneinander ab. Trotz der prekären Finanzlage unterstützte sie jedoch die nahtlose Weiterführung des Unterrichts in Biblischer Geschichte «im Wissen um die Verantwortung als C-Partei für gesellschaftliche Werte einzustehen und diese Werte an die Kinder weiter zu vermitteln». ${ }^{16}$ Die Schweizer Demokraten (SD) hatten sich gemäss ihrem Vertreter trotz - vermutlich müsste man eher sagen: wegen - der

I 2 Postulat GR Nr. 2004/I 49, CVP/EVP-Fraktion, Gemeinderat von Zürich, 24. 3. 2004.

I 3 Protokoll der römisch-katholischen Synode vom 4. I 2. 2003.

I 4 Antrag des Regierungsrates vom 24. November 2004. Beschluss des Kantonsrates über das Zustandekommen der Volksinitiative für die Weiterführung des Faches «Biblische Geschichte» an der Primarschule. In: Amtsblatt des Kantons Zürich, IO. I 2. 2004, S. I483.

I Is Protokoll des Grossen Gemeinderates von Winterthur, I8. 4. 2005, 432.

II6 Ebd. 
zunehmenden religiösen Vielfalt für die Weiterführung des Faches Biblische Geschichte entschieden. Nach Ansicht der SD dürfe die zunehmende religiöse Vielfalt nicht dazu führen, in der Schule auf das Fach Biblische Geschichte zu verzichten. Denn: «Das friedliche Zusammenleben in einem Staat kann nur gelingen, wenn ein Minimum an gemeinsamer Kultur erhalten bleibt, trotz der viel beschworenen multikulturellen Gesellschaft. Die Gesellschaft muss sich auf die in unserem Land seit Jahrhunderten bestehende Kultur abstützen. Eine der Hauptgrundlagen dieser Kultur geht - neben der Aufklärung - auf jüdisch/ christliche Wurzeln zurück, unabhängig davon, ob die Menschen kirchennahe sind oder nicht.» ${ }^{117}$

Da der Unterricht in Biblischer Geschichte nicht missionarischer Art sei, könne er «auch Mitgliedern aus anderen Religionsgemeinschaften» zugemutet werden. Eine gewisse Anpassung könne von den Kindern gefordert werden: «Nur so kann eine kulturelle Gemeinsamkeit entstehen, die für ein friedliches Zusammenleben notwendig ist. Multikulturelle Zustände können wesensgemäss nur vorübergehend sein. Auf die Länge kann keine Gesellschaft überleben, in der nicht ein Minimum an Gemeinsamkeit vorhanden ist. [...] Verzichtet die Gesellschaft auf diese Forderungen entsteht ein geistig/kultureller Leerraum, in den andere Unterrichtsformen eindringen werden - zum Beispiel Koranunterricht oder der Unterricht durch Mullahs.» ${ }^{\text {I18 }}$

Bezüglich des schulischen Religionsunterrichtes lassen sich hinsichtlich der Stiftung von Orientierung und Identität grob zwei unterschiedliche Erwartungshaltungen auseinanderhalten. Die einen erachten die sogenannte Auseinandersetzung mit den eigenen Wurzeln als notwendig für den interreligiösen und interkulturellen Dialog, im Sinne von: Wer das Eigene kennt, kann sich auch auf das Fremde einlassen. Insofern der interreligiöse und interkulturelle Dialog häufig als Grundlage für den gesellschaftlichen Frieden betrachtet wird, trägt aus dieser Sicht auch das Fach Biblische Geschichte massgeblich dazu bei. So gesehen wird nicht gesellschaftliche Homogenität angestrebt, sondern bloss die Auseinandersetzung mit der eigenen religiösen und kulturellen Geschichte, um - so die Hoffnung - dem Andern friedlich begegnen zu können.

Andere Stimmen wie die SD erwarteten von diesem Fach hingegen einen gesellschaftlich homogenisierenden Effekt. Dieser Effekt soll dadurch erreicht werden, dass alle Kinder an diesem Unterricht teilnehmen und somit in die angeblichen Grundlagen «unserer» Gesellschaft eingeführt werden. Das Fach Biblische Geschichte wird zu einem Garanten für das Überleben der Gesellschaft, da diese von einem minimalen Mass an Homogenität abhängig gemacht wird.

I 17 Ebd., 433.

I 8 Ebd. 


\section{Zivilreligiöse Erwartungen in der Diskussion um den schulischen Religionsunterricht im 21. Jahrhundert}

Basierend auf den fünf zentralen Punkten meines Eingrenzungsversuchs zum Begriff der Zivilreligion (vgl. Unterkapitel 2.6) und analog zu Kapitel 7 soll in diesem Kapitel die Diskussion über den schulischen Religionsunterricht im 2I. Jahrhundert ebenso hinsichtlich zivilreligiöser Erwartungen untersucht werden. Die in Kapitel 2 erarbeiteten fünf Merkmale von Zivilreligion seien hier nochmals zusammenfassend erwähnt: I) Funktionale Ausdifferenzierung der Gesellschaft; 2) Spannungsfeld zwischen Religionsfreiheit und Streben nach gesellschaftlichem Zusammenhalt; 3) Paradoxie von Zivilreligion; 4) Universalitätsanspruch versus historische Kontingenz und Partikularität; 5) Zwei Typen von Zivilreligion.

\subsection{Funktionale Ausdifferenzierung}

Gemäss der in Kapitel 2 dargelegten inhaltlichen Bestimmung kann von Zivilreligion sinnvoll nur auf dem Hintergrund einer ausdifferenzierten Gesellschaft gesprochen werden. Im Unterkapitel 7.I habe ich gezeigt, dass dies um I870 im Kanton Zürich nur zum Teil der Fall war und deshalb im Blick auf diese Zeit auch nur im uneigentlichen Sinne von Zivilreligion die Rede sein kann. Insbesondere das Konzept der Volkskirche, demgemäss die Kirche weder eine staatliche Institution noch ein privater Verein ist, sondern eine Institution mit einem öffentlichen Auftrag im Dienste des Volkes, verhinderte eine vollständige Ausdifferenzierung von Kirche und Staat. ${ }^{I}$ Die Frage ist nun, wie es mit der funktionalen Ausdifferenzierung von Kirche und Staat im 2 I. Jahrhundert aussieht.

Im Jahre 1963 wurden die evangelisch-reformierte, die römisch-katholische sowie die christkatholische Kirche und ihre Gemeinden öffentlich-rechtlich anerkannt und somit staatskirchenrechtlich gesehen einander gleichgestellt. Die öffentlich-rechtlich anerkannten Kirchen haben das Recht, bei den Mitgliedern und den juristischen Personen Kirchensteuern zu erheben. Der Staat übt jedoch eine formelle Oberaufsicht aus. Dies bedeutet, dass Jahresbericht und Rechnung der Kirchen vom Kantonsrat abgenommen werden müssen. ${ }^{2}$

I Vgl. Schmid I994, 2 10 und Unterkapitel 3.I.

2 Vgl. Weiss 2000, 146. 
In den Jahren 1977 und I995 wurden an der Urne über Trennungsinitiativen abgestimmt, die aber beide scheiterten. Die Initiativen hatten in beiden Fällen zum Ziel, die öffentlich-rechtlich anerkannten Kirchen in privat-rechtliche Verhältnisse überzuführen und somit alle Religionsgemeinschaften in rechtlicher Hinsicht gleichzustellen. Dies hätte auch den Wegfall des Steuerrechts sowie der staatlichen Besoldung der Pfarrpersonen und Religionslehrkräfte bedeutet. ${ }^{3}$

In der Abstimmung vom 30. November 2003 konnten die Stimmberechtigten im Kanton Zürich über drei kirchenpolitische Vorlagen abstimmen, die, wären sie angenommen worden, zwar nicht zu einer Trennung, aber zu einer weiteren Entflechtung zwischen Kirche und Staat geführt hätten. Die erste Vorlage betraf die Neuregelung des Verhältnisses zwischen Staat und Kirche auf Verfassungsebene. Die Verfassungsänderung wäre die Grundlage gewesen für die zwei anderen Vorlagen, die das Verhältnis zwischen Staat und Kirche auf Gesetzesebene hätten regeln sollen. Es ging primär um drei Neuerungen: Erstens, die öffentlich-rechtliche Anerkennung weiterer Religionsgemeinschaften neben den drei Landeskirchen; zweitens, weitreichende Autonomiezugeständnisse für die anerkannten Religionsgemeinschaften, was besonders hinsichtlich des Stimmund Wahlrechts von Bedeutung gewesen wäre - zum Beispiel Stimmrechtsalter ab i6 oder Stimmrecht für Ausländer; drittens, die Ersetzung «historischer Rechtstitel» durch staatliche zweckgebundene Beiträge. ${ }^{4}$

Mit der Annahme der vollständig revidierten Kantonsverfassung im Jahre 2005 kam es dann tatsächlich zu weiteren Entflechtungsschritten zwischen Kirche und Staat, obwohl bei der Ausarbeitung der Kantonsverfassung gemäss Röhl das Ergebnis der Volksabstimmung vom 30. November 2003 berücksichtigt wurde. 5 Die kantonalen kirchlichen Körperschaften erlangten mit der revidierten Kantonsverfassung Autonomie in zwei Bereichen: Einerseits bezüglich des Stimmund Wahlrechts in innerkirchlichen Belangen; andererseits bezüglich Festlegung der Zuständigkeit für die Neubildung, den Zusammenschluss und die Auflösung von Kirchgemeinden. ${ }^{6}$ Des Weiteren erfordert die revidierte Kantonsverfassung, dass ein Teil der Steuererträge einer negativen Zweckbindung unterstellt wird. So kann neu verhindert werden, dass die Steuerträge juristischer Personen für kultische Zwecke verwendet werden.7 Eine weitere Neuerung ist die Anerkennung zweier (kleiner) jüdischer Gemeinden, nämlich der Israelitischen Kultus-

3 Vgl. ebd., I47.

4 Vgl. Zurlinden 2015, 78.

5 Vgl. Röhl 2006, 200.

6 Vgl. Verfassung des Kantons Zürich 27. Februar 2005 (KV), Art. I30 Abs. 2 lit. a und b.

7 Vgl. Röhl 2006, 205; vgl. auch KV Art. I30 Abs. 4. Am I 8. Mai 2014 wurde über eine von den Jungliberalen lancierte Initiative abgestimmt, die im Kanton Zürich die Kirchensteuern für juristische Personen gänzlich abschaffen wollte. Die sogenannte Kirchensteuerinitiative wurde mit einem Ja-Anteil von lediglich 28,2 Prozent jedoch deutlich verworfen. 
gemeinde und der Jüdischen Liberalen Gemeinde. Auf Grund des Widerstands gegen das Anerkennungsgesetz bei der Abstimmung im Jahre 2003 wird in der revidierten Kantonsverfassung die Anerkennung auf diese zwei Gemeinden beschränkt. Zudem hat die Anerkennung dieser zwei jüdischen Gemeinden in KV Art. I3 I nicht dieselben Rechtswirkungen wie die Anerkennung der drei kirchlichen Körperschaften in KV Art. I 30 . So werden die beiden jüdischen Gemeinden nicht zu Körperschaften öffentlichen Rechts, sondern behalten ihren Status als privatrechtliche Vereine. Doch werden sie dazu verpflichtet sicherzustellen, dass die Mitwirkung der Mitglieder nach rechtsstaatlichen und demokratischen Prinzipien erfolgt. Dies betrifft insbesondere die Gleichberechtigung von Mann und Frau sowie einen öffentlichen Rechenschaftsbericht über die Finanzen der Gemeinde. ${ }^{8}$

Im Unterschied zu den Kantonen Genf und Neuenburg, in denen die Kirchen am stärksten vom Staat gelöst sind und bloss «öffentlich und nicht öffentlich-rechtlich anerkannt sind», konnte sich im Kanton Zürich eine klare Trennung zwischen Kirche und Staat nicht durchsetzen. ${ }^{9}$ Dennoch kam es immer mehr zu einer Entflechtung zwischen diesen beiden Institutionen. ${ }^{10}$ Insofern Ausdifferenzierung nicht notwendig Trennung bedeuten muss, kann auf Grund zunehmender Entflechtungsmassnahmen trotz der zwei gescheiterten Trennungsinitiativen zu Beginn des 2r. Jahrhunderts von einer weitgehenden Ausdifferenzierung zwischen Kirche und Staat gesprochen werden.

Im Zusammenhang mit der Thematik dieser Arbeit ist nun aber nicht bloss die Frage nach der funktionalen Ausdifferenzierung von Kirche und Staat von Bedeutung, sondern auch die Frage nach dem Verhältnis zwischen Kirche und Schule oder Staat und Schule. Hinsichtlich des Verhältnisses von Kirche und Schule ist der Beginn der Einführung des Faches Religion und Kultur auf der Oberstufe der Volksschule im Schuljahr 2007/08 zu erwähnen. Mit der Einführung dieses neuen obligatorischen Faches wurde eine der letzten Verflechtungen zwischen Kirche und Schule gelöst. Das Obligatorium hatte zur Folge, dass

8 Vgl. Röhl 2006, 206.

9 Vgl. Gilg 2008. Im Kanton Basel-Stadt wurde I910 das System der «hinkenden Trennung» von Kirche und Staat eingeführt. Kirche und Staat wurden organisatorisch so getrennt, dass auch hinsichtlich der äusseren Angelegenheiten den Kirchen Autonomie zugesprochen wurde. «Hinkend» war die Trennung, weil «die Kirchen weiterhin am öffentlichen Recht partizipierten und ihre Rechtserlasse vom Regierungsrat zu genehmigen waren. Überdies wurde den öffentlich-rechtlich anerkannten Kirchen eine demokratische Organisationsform - insbesondere die demokratische Wahl der Geistlichen - und die Einrichtung eines Schutzes für innerkirchliche Minderheiten vorgeschrieben» (Hafner 2008, I94).

Io Seit dem Jahre 2010 werden beispielsweise auch die Pfarrpersonen von den Kirchen und nicht mehr durch den Staat besoldet (vgl. Personalverordnung der Landeskirche - Antrag und Bericht des Kirchenrates 2009). 
dieses Fach nicht mehr von Katecheten und Pfarrpersonen erteilt werden durfte, sondern nur noch durch speziell ausgebildete Oberstufenlehrkräfte. ${ }^{11}$

Hinsichtlich des Verhältnisses zwischen Staat und Schule ist zu fragen, inwiefern von einer Ausdifferenzierung gesprochen werden kann, wenn gemäss Kantonsverfassung Kanton und Gemeinden Schulen nicht bloss beaufsichtigen, sondern «qualitativ hochstehende öffentliche Schulen» auch selber fübren.$^{{ }^{2}}$ Ein gewisses Mass an Ausdifferenzierung ist insofern gegeben, als neben staatlich geführten Schulen auch die Möglichkeit zur Führung von Privatschulen besteht, sofern diese «die gleichen Aufgaben wie die öffentliche Volksschule erfüllen». ${ }^{13}$ Diese privaten Schulen werden vom Kanton jedoch nur finanziell unterstützt, wenn «deren Leistungen von öffentlichem Interesse sind». ${ }^{14}$ Dass die Verhältnisbestimmung zwischen Staat und Schule auch anders - in gewisser Hinsicht ausdifferenzierter - denkbar ist, zeigt das Beispiel der Niederlanden. Dieses System hat seinen Ursprung im sogenannten Schulstreit zu Beginn des 19. Jahrhunderts, der durch das königliche Verbot, konfessionelle Schulen zu gründen, ausgelöst wurde. Als Resultat dieses Streites kam es I917 zu einer finanziellen Gleichstellung der privaten konfessionellen Schulen mit der Staatsschule. ${ }^{\text {Is }}$

Eine weitere Voraussetzung, um sinnvollerweise von Zivilreligion sprechen $\mathrm{zu}$ können, ist gemäss meiner Arbeitsdefinition (vgl. Unterkapitel 2.6) eine religiös-weltanschaulich heterogene Gesellschaft, in der ein gewisses Mass an Religionsfreiheit auch wahrgenommen wird. Konkret bedeutet dies, dass die Abwendung von der Mehrheitsreligion salonfähig wurde. Im Vergleich zum 19. Jahrhundert hat sich die religiös-weltanschauliche Landschaft zu Beginn des 2I. Jahrhunderts deutlich verändert. Um 1870 bewegte sich die grosse Masse im Kanton Zürich im evangelisch-reformiert christlichen Rahmen innerhalb der Distinktion - etwas grob formuliert - von fromm oder liberal. Juden und Katholiken waren eine Minderheit. In der eidgenössischen Volkszählung von I 870 machten die Reformierten im Kanton Zürich 92,6 Prozent, die Katholiken 6,3 Prozent und «Andere» I, I Prozent der gesamten Bevölkerung aus. Die Volkszählung von 2000 zeigte eine viel ausgeglichenere Verteilung: 39,9 Prozent Reformierte, 30,5 Prozent Katholiken und 29,6 Prozent «Andere». ${ }^{16}$ Die «Anderen» legten massiv zu mit der Folge, dass in den Statistiken neue Religionsgruppen auftauchten. Neu wurden die Muslime erwähnt, die, bedingt durch die Zuwanderung, mit 5,3 Prozent die drittgrösste Religionsgruppe bildeten.

I I Vgl. Bildungsratsbeschluss vom 23. August 2004, I $\mathrm{f}$. sowie Unterkapitel 3.3.

I 2 Verfassung des Kantons Zürich 27. Februar 2005 (KV), Art. I I6, I.

I 3 Ebd., Art. I I7, I.

I4 Ebd., Art. I 17,2.

is Vgl. Glenn 2002, 50 ff.; Hardegger 2005, I6.

I6 Vgl. Statistisches Amt des Kantons Zürich. Bevölkerung, Gemeinde, Geschlecht, Heimat, Konfession I 850-2000. 
Mehr als doppelt so viele Personen wie die Muslime gaben an, keiner Konfession zugehörig zu sein, nämlich I 3,2 Prozent. ${ }^{17}$

Dieses Erscheinungsbild entspricht dem, was der kanadische Philosoph Charles Taylor das «säkulare Zeitalter» genannt hat. Dieses Zeitalter ist dadurch gekennzeichnet, dass der Glaube an Gott zu einer Option unter anderen wurde. Taylor betont, dass es zwar bereits im i 8. und 19. Jahrhundert Agnostiker und Atheisten gab, doch beschränkte sich diese Weltanschauung auf eine Minderheit. ${ }^{18}$ Erziehungsrat Sieber gehörte in der Diskussion um den schulischen Religionsunterricht zu dieser Minderheit. Wie in Kapitel 7 gezeigt worden ist, fand die Diskussion der grossen Masse jedoch im evangelisch-reformiert-christlichen Denkrahmen zwischen theologisch Liberalen und Konservativen statt. Dass zu Beginn des 2 I. Jahrhunderts auch Konfessionslosigkeit normal geworden ist, bildet sich beispielsweise in der medienwirksamen Präsenz der Freidenker ${ }^{19}$ in öffentlichen Diskussionen ab. Die Anerkennung areligiöser Lebensorientierungen ging jedoch nicht so weit, dass in die im November 2002 vom Bildungsrat festgelegte bildungsrätliche Kommission Religion und Kultur auch Interessenvertreter oder -vertreterinnen einer areligiösen Gruppierung wie beispielsweise der Freidenker aufgenommen worden wären. ${ }^{20}$

Die Inanspruchnahme von Religionsfreiheit wurde als weitere Voraussetzung für eine sachgemässe Verwendung des Begriffs der Zivilreligion beschrieben. Religionsfreiheit beinhaltet sowohl eine positive wie auch eine negative Dimension und ist durch die Schweizerische Bundesverfassung in Art. Is «Glaubens- und Gewissensfreiheit» garantiert. ${ }^{21}$ Die positive Dimension beinhaltet das Recht, die eigene Religion und weltanschauliche Überzeugung «frei zu wählen und allein oder in Gemeinschaft mit anderen zu bekennen» (Abs. 2) sowie «das Recht, einer Religionsgemeinschaft beizutreten oder anzugehören und religiösem Unterricht zu folgen»(Abs. 3). Die negative Dimension von Religionsfreiheit bedeutet, dass niemand gezwungen werden darf, «einer Religionsgemeinschaft beizutreten oder anzugehören, eine religiöse Handlung vorzunehmen oder religiösem Unterricht zu folgen»(Abs. 4). Das Minarettverbot, das in der Volksabstimmung vom 29. November 2009 angenommen wurde, sowie die Diskussion um einen islamischen Kindergarten in Volketswil in den Jahren 2014/I $5^{22}$ zeigen, dass der Religionsfreiheit Grenzen gesetzt

17 Vgl. Weber 2003.

I 8 Vgl. Taylor 2007, 3 .

I9 Die deutsch-schweizerische Freidenker Vereinigung konstituierte sich 1908 (vgl. Dellsperger 20I 2).

20 Vgl. Beschluss des Bildungsrates vom I 3. September 200 I und vom 5. November 2002.

2 I Bundesverfassung vom i8. April 1999, Art. is.

22 Das Zürcher Volksschulamt und der Regierungsrat hatten im Dezember 2014 die Bewilligung für einen islamischen Kindergarten verweigert, worauf der Verein Al Huda, der dieses Kin- 
werden, wenn das Recht auf Religionsfreiheit mit der säkular-liberalen Tradition in Konflikt zu geraten scheint oder mangelnde Kontrollmöglichkeiten befürchtet werden.

Zum Schluss dieses Unterkapitels lässt sich feststellen, dass im Vergleich zur Situation im I9. Jahrhundert zu Beginn des 21. Jahrhunderts mehr Voraussetzungen gegeben sind, um in methodisch kontrollierbarem Sinn von Zivilreligion sprechen zu können: I) Auf Grund verschiedener Entflechtungsmassnahmen kann von einer weitgehenden Ausdifferenzierung von Kirche und Staat gesprochen werden, obwohl der Kanton Zürich auch mit der neuen Kantonsverfassung aus dem Jahr 2005 nach wie vor keine strikte Trennung zwischen Kirche und Staat kennt. 2) Die Statistiken zeigen im Vergleich zum i 9. Jahrhundert eine zunehmende religiös-weltanschauliche Heterogenität, die auch für die breite Masse die Option Areligiosität beinhaltet. 3) Die Glaubens-, Kultus- und Lehrfreiheit wurde bereits in der Kantonsverfassung von I 869 gewährleistet, doch mit der zunehmenden gesellschaftlichen Heterogenität wird diese im 2 I. Jahrhundert vermehrt in Anspruch genommen.

\subsection{Religionsfreiheit und Streben nach gesellschaftlichem Zusammenhalt - ein Spannungsfeld}

Im Unterkapitel 7.2 habe ich gezeigt, dass es im 19. Jahrhundert in der Diskussion um den schulischen Religionsunterricht sowohl diejenigen gab, die das Fehlen eines die Gesellschaft einigenden sittlich-religiösen Bandes nicht als Problem wahrnahmen, wie auch andere, die die durch die Verfassung garantierte Glaubens- und Gewissensfreiheit zwar klar befürworteten, darin zugleich aber auch Spannungspotential im Hinblick auf die gesellschaftliche Einheit sahen. Ebenfalls habe ich zu zeigen versucht, dass es unterschiedliche Arten gab, mit dieser Spannung umzugehen.

\subsection{1 (K)ein Bewusstsein für Spannung}

Wer der Überzeugung ist, dass das Zürchervolk de facto eine konfessionell-religiöse Einheit bildet - eine Überzeugung, die sich auch im I9. Jahrhundert nachweisen lässt ${ }^{23}$-, hat wenig Anlass, sich mit der Frage zu beschäftigen, wie der gesellschaftliche Zusammenhalt angesichts unterschiedlicher konfessionell-religiöser Ausrichtungen gewährleistet werden kann. Man steht so auch nicht vor

dergartenprojekt in Volketswil ZH initiieren wollte, eine Beschwerde an das Verwaltungsgericht richtete, die dieses jedoch ablehnte (vgl. NZZ, I8. I2. 2014 und 21. 7. 201 5).

23 Vgl. Unterkapitel 7.2.I. 
dem Problem, dass das Bemühen um den gesellschaftlichen Zusammenhalt unter Umständen in Spannung zum Recht auf Religionsfreiheit stehen könnte.

In den Quellen, die ich zur Analyse der Diskussion zu Beginn des 2 I. Jahrhunderts herbeigezogen habe, bin ich auf keine Stimmen gestossen, welche die zunehmende gesellschaftliche Heterogenität religiöser und kultureller Art in Abrede gestellt hätten. Im Gegenteil: Die religiös-weltanschaulich-kulturelle Heterogenität war zentraler Bestandteil äusserst divergierender Argumentationsrichtungen. In der politischen und medialen Diskussion wurde jedoch nur von wenigen Akteuren ein Bewusstsein für die Spannung signalisiert oder artikuliert, dass das Streben nach Einheit in Konflikt mit der Religionsfreiheit stehen könnte. Auf Grund des untersuchten Materials kann im Rahmen dieser Arbeit nicht beurteilt werden, ob dies den pragmatischen Umständen geschuldet ist die Redezeit in politischen Gremien ist beschränkt, deshalb werden mit Bedacht nicht die kritischen Punkte hervorgehoben, wenn man ein bestimmtes Anliegen, beispielsweise die Beibehaltung von Biblischer Geschichte, durchbringen will oder ob diese Spannung tatsächlich ausserhalb des Wahrnehmungshorizontes der jeweiligen Akteure liegt.

Den Beiträgen der Freidenker kann ein begrenztes Mass an Bewusstsein für diese Spannung attestiert werden. In der Vernehmlassungsantwort der Freidenker wurde die fehlende religiös-weltanschauliche Neutralität des Faches Religion und Kultur erkannt und benannt. ${ }^{24}$ Als Alternative forderten sie ein Fach Ethik für alle. Auffällig ist jedoch, dass in dieser Vernehmlassungsantwort kein Hinweis für ein Problembewusstsein zu finden ist, dass auch mit einem Ethikunterricht die Religionsfreiheit verletzt werden könnte, insofern eine säkular-liberale Thematisierung ethischer Fragen ebenso wenig religiös-weltanschaulich neutral ist wie zum Beispiel eine christliche oder islamische.

Ein solches Problembewusstsein für das Spannungsfeld Einheitsstreben und Religionsfreiheit lässt sich im Unterschied zur medialen und politischen Diskussion im wissenschaftlichen Diskurs feststellen. Einigen solchen wissenschaftlichen Beiträgen wende ich mich im Folgenden ausführlicher zu. Ich beziehe mich bei diesen Darstellungen hauptsächlich auf den Sammelband Religion und Kultur - Ein Schulfach für alle?, ${ }^{25}$ der auf eine im Januar 2004 von der Pädagogischen Hochschule Zürich und der Universität Zürich organisierte Tagung zurückgeht, an der das geplante Schulfach Religion und Kultur vorgestellt und von verschiedenen Seiten beleuchtet wurde.

Auf dem Hintergrund vergleichbarer europäischer Modelle und Idealtypen von Religionsunterricht äussert Ansgar Jödicke aus religionswissenschaftlicher

24 Vgl. Freidenkervereinigung Schweiz, Stellungnahme von März 2006.

25 Kunz et al. 2005. 
Perspektive seine Einschätzung zum Schulfach Religion und Kultur. Die verschiedenen Modelle des Religionsunterrichts an der öffentlichen Schule sind gemäss Jödicke Versuche, die Aporien der Anforderungen, die an einen modernen Religionsunterricht gestellt werden, auf unterschiedliche Weise zu lösen. Als aporetisch beschreibt Jödicke einerseits den Wandel «von einer ausserschulisch-kirchlichen, bekenntnisgebundenen Unterweisung zu einem schulischen Religionsunterricht mit zivilgesellschaftlichen Aufgaben» und andererseits den Wandel «von einem kirchlichen Instrument konfessioneller Sozialisation zu einem staatlichen Instrument kultureller Integration» ${ }^{26}$ Sowohl der Wechsel des institutionellen Ortes der religiösen Unterweisung (von der Kirche zur öffentlichen Schule) wie auch der Wandel des Auftrags (von der Katechese zur Vermittlung zivilgesellschaftlicher Normen) sowie der Wandel des Unterrichtszieles (von der Einführung in die Konfession zur Einfügung in die staatliche Ordnung) sind gemäss Jödicke also aporetischer Natur. Die von ihm beschriebenen idealtypischen Modelle interpretiert Jödicke als Versuche, diese Schwierigkeiten auf ihre je eigene Art zu lösen.

Das erste Modell - der «allgemeine Religionsunterricht $»^{27}$ - basiert auf einem anthropologischen Religionsbegriff, gemäss dem jeder Mensch eine religiöse Disposition habe. Es ist diese anthropologische Grundannahme, die einen schulischen «Religionsunterricht für alle〉 legitimiert. Seine Vorbilder findet dieses Modell in der christlichen Religionspädagogik. Wie in den Kapiteln 6 und 7 gezeigt worden ist, wurde diese anthropologische Grundannahme in der Diskussion um 1870 deutlich sichtbar. Obwohl in diesem Modell eigentlich alle Schülerinnen und Schüler hätten angesprochen werden sollen, habe man gemäss Jödicke in allen ähnlichen Konzeptionen bisher nie auf das Dispensationsrecht verzichtet. ${ }^{28}$ Der Grund dafür sieht Jödicke darin, dass der anthropologische Religionsbegriff eng verbunden ist «mit der spezifisch modernen Entwicklung des Christentums zu einer subjektorientierten Religiosität. Er ist deshalb nur ein möglicher Religionsbegriff, zu dem es auch innerhalb des Christentums prominente Gegenentwürfe gibt».29

Religionsgeschichtlich gesehen ist «der anthropologische Zugang zur Religion» ${ }^{\circ}$ nur einer unter anderen. Dies bedeutet, dass sowohl explizit areligiöse wie auch explizit religiöse Erziehungsberechtigte sich in ihrer Religionsfreiheit eingeschränkt fühlen könnten, müssten sie ihre Kinder in einen «allgemeinen

26 Jödicke 2005, 2 I 4.

27 Ebd., 2 I4 f.

28 Vgl. Unterkapitel 6.4.

29 Jödicke 2005, 215.

30 Ebd. 
Religionsunterricht» ${ }^{1}$ schicken. Areligiöse Menschen können die Unterstellung einer religiösen Disposition in Frage stellen und damit auch die Notwendigkeit schulischen Religionsunterrichts. Angehörige einer religiösen Glaubensgemeinschaft hingegen können die Vermittlung einer angeblich allgemeinen Religion in Frage stellen, wenn sie davon ausgehen, dass Religion immer nur in bestimmten Traditionen gelebt und vermittelt wird. So gesehen kann eine allgemeine Religion per definitionem nie gelebter, konkreter religiöser Tradition entsprechen.

Das zweite von Jödicke dargestellte Modell versucht die Aporien eines modernen Religionsunterrichts durch eine Wahlmöglichkeit zu ersetzen. Die Wahl besteht zwischen einem «bekenntnisgebundenen Religionsunterricht von einer oder mehreren Religionsgemeinschaften» und «eine[m] meist mit religionskundlichen Elementen kombinierten Ethikunterricht».32 Man geht davon aus, dass die Alternative für den konfessionellen Religionsunterricht «eine äquivalente Leistung erbringen» ${ }^{33}$ müsse. Da gemäss Jödicke die Erziehungsziele des bisher üblichen Religionsunterrichts «immer stärker zivilreligiös formuliert» 34 worden seien, wird gefordert, dass der Alternativunterricht dieselben Inhalte, lediglich auf andere Weise vermittle. "Aus säkularer, staatspolitischer Perspektive bietet Ethik», so Jödicke, «eine gleichwertige Alternative zur Religion».35 Das heisst, der Ethikunterricht führt aus nicht konfessioneller Perspektive in die als relevant angeschauten ethischen Normen der Gesellschaft ein bzw. regt eine Auseinandersetzung darüber an. ${ }^{36}$ Zur Illustration stellt Jödicke die - auch rechtlich-juristische - Auseinandersetzung um das Fach LER (Lebensgestaltung - Ethik - Religionskunde) des deutschen Bundeslandes Brandenburg dar. $\mathrm{Zu}$ Beginn der I990er Jahre wurde dieses Fach im Bundesland Brandenburg

3 I Ebd., 2 I4.

32 Ebd., 215.

33 Ebd.

34 Ebd. Jödicke verwendet in seinem Artikel den Ausdruck Zivilreligion, ohne ihn zu erläutern. Er scheint ihn im Sinne einer gesamtgesellschaftlichen Klammer zu verwenden, als eine Art Wertekanon, der von der Mehrheit der Mitglieder der Gesellschaft geteilt wird. Dieses eingeschränkte Verständnis von Zivilreligion unterscheidet sich von dem in dieser Arbeit verwendeten insofern, als Zivilreligion im Sinne der französischen Version davon auch als 〈Gegenreligion〉 verstanden werden kann (vgl. Unterkapitel 2.2).

35 Jödicke $2005,216$.

36 Jödickes Rede von «säkularer, staatspolitischer Perspektive» ist in diesem Zusammenhang irreführend. Denn auch ein konfessionell-religiöser Mensch kann in seiner Rolle als Bürger oder Bürgerin eine säkulare, staatspolitische Perspektive einnehmen und diese in einem konfessionsgebundenen Religionsunterricht als solche vermitteln. Der Ausdruck säkular wird hier unpräzise verwendet, insofern er in diesem Zusammenhang eine weltanschauliche Positionalität suggeriert. Doch «säkular kann verschiedene Dinge bedeuten. Es ist zu differenzieren zwischen «säkular〉 bezogen auf eine nicht kirchliche Sphäre der Gesellschaft und «säkular im Sinne der Verneinung einer religiösen Weltanschauung. Jödicke scheint «säkular hier im zweiten Sinne zu verwenden. Deshalb wäre wohl die Rede von einer säkularistischen Perspektive oder eines säkularen Humanismus präziser. Diesen Hinweis verdanke ich Johannes Corrodi. 
eingeführt. Geplant war es als obligatorisches Fach. Nach einer 1996 eingereichten Klage von Kirchen sowie einer Elterninitiative kam es zu einem Vergleichsvorschlag des Bundesverfassungsgerichts, der von allen Beteiligten akzeptiert wurde. Mit diesem Kompromiss wurde die Eigenständigkeit des konfessionellen Unterrichts gestärkt und die Möglichkeit zur Abmeldung von diesem Fach implementiert. In den Informationen des Ministeriums für Bildung, Jugend und Sport wurde die Abmeldemöglichkeit folgendermassen begründet: «Die Befreiungsmöglichkeit wird im Grund sogar wegen der weltanschaulichen Neutralität und Bekenntnisfreiheit von LER eröffnet. Dadurch sollen die Empfindungen derer respektiert werden, die einen wertorientierten Unterricht nur in bekenntnisgebundener Ausprägung wünschen und sich durch eine bekenntnisfreie, also nicht auf Glaubensüberzeugungen beruhenden Thematisierung ihrer Religion beschwert fühlen können.» 37

In dieser Begründung scheint der Begriff der weltanschaulichen Neutralität regelrecht ad absurdum geführt zu werden. Denn dass man sich von diesem Unterricht auf Grund von dessen weltanschaulicher Neutralität befreien kann, zeigt, dass der Unterricht eben gerade nicht weltanschaulich neutral ist und sich der Begriff der Neutralität als wertlos erweist. Somit wird das Fach LER hinsichtlich seiner weltanschaulichen Nicht-Neutralität auf dieselbe Stufe gestellt wie der bekenntnisgebundene Religionsunterricht. Nach Jödicke ist der «bekenntnisgebundene Religionsunterricht [...] nur eine andere Ausprägung des wertorientierten Unterrichts LER». ${ }^{8}$ Und darin zeigt sich seiner Ansicht nach, dass im LER «die Konsequenzen einer religionskundlichen Konzeption ausgelotet, aber noch nicht konsequent bis zum Ende geführt» 39 worden sind.

Nach Jödicke könnten die oben genannten Aporien - dem einst bekenntnisgebundenen, kirchlichen Religionsunterricht werden gesamtgesellschaftliche sowie kulturell integrative Aufgaben zugemutet ${ }^{40}$ - durch einen rein religionskundlichen Unterricht, der als Teil des schulischen Bildungsauftrages verstanden wird, umgangen werden. Ein religionskundlicher Unterricht ist durch die Art und Weise gekennzeichnet, «wie man sich in diesem Unterricht mit den Religionen befasst».4 Die Aus- oder Umbildung einer religiösen Identität darf nicht das Ziel dieses Unterrichts sein. «Die Behandlung von Religion in einem konsequent religionskundlichen Unterricht muss über die als relevant eingeschätzten Religionen in Geschichte und Gegenwart informieren. Der Charakter

37 Land Brandenburg, Ministerium für Bildung, Jugend und Sport: Lebensgestaltung - Ethik Religionskunde an den Schulen des Landes Brandenburg, 8., aktualisierte Auflage 2003, S. 22 und 25 . Zit. in Jödicke $2005,216$.

38 Jödicke 2005, 216.

39 Ebd.

40 Vgl. ebd., 2 I 4.

4 I Ebd., 2 I 8. 
der Religionskunde ist damit dem Fach Geschichte um vieles näher als dem Fach Ethik. Ein religionskundlicher Unterricht ist nicht wertneutral, da er in das Schulcurriculum eingeordnet ist und sich systematisch von den Ansprüchen religiöser Botschaften distanziert.»42

Obwohl auch ein religionskundlicher Unterricht gemäss Jödicke nicht «wertneutral» ist, sieht der Autor offenbar dennoch einen Unterschied zum LER-Unterricht. Dieser Unterschied scheint für ihn darin zu bestehen, dass der religionskundliche Unterricht nicht «wertorientiert» ist wie der LER-Unterricht, der unter anderem der Vermittlung zivilreligiöser Werte dient. Das heisst, der Religionskundeunterricht beansprucht, keine bestimmte religiöse oder antireligiöse Botschaft $\mathrm{zu}$ vermitteln.

Es ist allerdings nicht ganz einsichtig, warum nicht auch ein konsequent religionskundlicher Unterricht mit Verweis auf die Religionsfreiheit sollte angefochten werden können. Dies analog zum LER-Unterricht mit der Begründung, dass auch die blosse Information über andere Religionen nicht bekenntnisungebunden erfolgen kann oder soll bzw. Informationen und Fakten nur im Kontext einer bestimmten Wertorientierung vermittelt werden können oder sollen. Wer so argumentiert und dabei nicht davon ausgeht, dass in anderen Fächern reine Informationsvermittlung möglich sei, müsste dann allerdings auch den Unterricht in anderen Schulfächern (Biologie, Geschichte usw.) als potentiell problematisch erachten.

Der Theologe und Religionspädagoge Friedrich Schweitzer problematisiert im selben Tagungsband einen rein religionskundlichen Unterricht nochmals auf eine andere Weise. Ein religionskundlicher Unterricht komme dort an seine Grenzen, "wo Kinder und Jugendliche sich auch existentiell mit religiösen Fragen und Themen auseinandersetzen wollen».43 Biblische Geschichten seien beispielsweise geradezu darauf angelegt, solche existentiellen Herausforderungen aufzuwerfen. Ein auf religiöse Neutralität bedachter religionskundlicher Unterricht stehe daher «ständig vor der Herausforderung, seine eigenen Inhalte zu domestizieren und ihnen gerade dort, wo sie religiös gesehen am interessantesten sind, von vornherein jede Ernsthaftigkeit zu nehmen. [...] Folge ist nicht zuletzt eine gesteigerte Form der Langeweile». ${ }^{4}$

Nebst der potentiellen Langeweile stellt sich für Schweitzer jedoch auch die Frage, wie für Religion oder Religionen «sensibilisiert» werden soll, ohne den Boden der Neutralität zu verlassen. Oder auch, wie «Orientierung» möglich sein soll, wenn es keine Orientierungspunkte gebe bzw. wenn jeder Versuch, Orientierung zu bieten, religiöse oder weltanschauliche Wertungen und Entscheidun-

42 Ebd., 219.

43 Schweitzer 2005 b, 167 .

44 Ebd. 
gen impliziere. Mit der Frage «Darf niemand seinen Glauben für sich behalten?»45 hinterfragt er aber auch die «Neutralität` der Forderung, dass man lernen müsse, sich miteinander zu verständigen. Ebenso nimmt er auch «die so harmlos erscheinenden Ziele im Bereich von ‘Wissen〉 oder 〈Verstehen ${ }^{46}$ ins Visier. Angesichts der knapp bemessenen Unterrichtszeit muss eine Auswahl getroffen werden und eine solche setzt notwendigerweise Wertungen voraus.

Die Spannung zwischen «Religionskunde und religiöser Überzeugung» ist jedoch bloss eine von fünf «Aporien religiöser Bildung in der Schule», die Schweitzer in seinem Kommentar zu einem «Religionsunterricht für alle» beschreibt. Insbesondere in seiner Beschreibung der vierten Aporie «Universalismus vs. partikulares Ethos» wird das Spannungsfeld zwischen Religionsfreiheit und dem Streben nach gesellschaftlicher Einheit deutlich. Schweitzer verweist darauf, dass Religionsunterricht in der Regel auch «mit Erwartungen einer ethischen Erziehung verbunden» war und ist. Ein Religionsunterricht für alle ist vor die Herausforderung gestellt, «dass er sich bei der ethischen Erziehung nicht auf eine bestimmte religiöse Tradition und deren Moral stützen darf».47 Dieses Problem werde in der Moralpädagogik mit einem ethischen Universalismus zu lösen versucht. Als bekanntestes Beispiel erwähnt Schweitzer Lawrence Kohlbergs Theorie der Moralentwicklung, die stark beeinflusst ist von Kants Theorie einer universalen Ethik und einer Moral- und Normbegründung durch Verallgemeinerung. Die oberste Stufe der Moralentwicklung nach Kohlberg ist die postkonventionelle Moral und diese wird als Ziel des Moralunterrichts angesehen. Schweitzer verweist darauf, dass aus entwicklungspsychologischer Perspektive jedoch nicht davon ausgegangen werden könne, dass Kinder und Jugendliche sich bereits auf dieser postkonventionellen Stufe befänden. Dies hat zur «Folge, dass die pädagogische Praxis eben nicht postkonventionell, sondern vielfach von konventionellen Normen einer Gruppe oder Gemeinschaft bzw. des Staates bestimmt sein muss». $4^{8}$

Dazu kommt, dass «ethische Normen ihre bindende Kraft nicht unabhängig von der Zugehörigkeit zu Gruppen und Gemeinschaften, die ein bestimmtes Ethos pflegen», ${ }^{49}$ gewinnen. Religionsgemeinschaften sind Beispiele für solch partikulare Gemeinschaften, die sich durch ein bestimmtes Ethos auszeichnen. Dies zeigt die unerlässliche Bedeutung der Zivilgesellschaft für das gute Funktionieren einer Staatsgemeinschaft. 
In seinem ersten Beitrag (von zweien) im selben Tagungsband beschäftigt sich Schweitzer denn auch mit der Rolle des Religionsunterrichts in der Zivilgesellschaft. Zum einen skizziert er mit Verweis auf Rousseau die Problematik des modernen Staates, der zwar auf «religiöse Grundlagen von Moral und Pflichtgefühl» ${ }^{\circ}$ angewiesen sei, diese aber nicht selbst gewährleisten könne. Zum andern stellt sich ihm auf dem Hintergrund der Annahme, dass die für eine funktionierende Demokratie nötigen Tugenden und Werte sich ohne Zivilgesellschaft nicht herausbilden können, und ausgehend von der durch die amerikanische Verfassung etablierten, strikten Trennung zwischen Kirche und Staat die Frage, wie «der Staat Kirchen und Religionsgemeinschaften als Teil der Zivilgesellschaft stützen [könne], ohne dadurch der Trennung von Staat und Kirche oder Religion Abbruch zu tun». ${ }^{\text {I }}$ Die Forderung nach einem obligatorischen Religionsunterricht in der Zivilgesellschaft kann nach Schweitzer sowohl als «Problemanzeige» wie auch als «Lösungsformel» für die Herausforderungen der pluralistischen Gesellschaft verstanden werden. Ein obligatorischer Religionsunterricht muss dann als problematisch erachtet werden, wenn «der obligatorische Charakter auf einen dominanten normierenden Einfluss des Staates hinausläuft, der sich weder mit der Trennung von Staat und Kirche noch mit einer wirklich vom Staat unterschiedenen Zivilgesellschaft verträgt».52 Die Spannung, die auf der einen Seite darin besteht, dass der Staat auf eine starke Zivilgesellschaft angewiesen ist und auf der anderen Seite seine Einflussnahme notwendigerweise zurücknehmen muss, könnte gemäss Schweitzer dahingehend aufgelöst werden, dass der Staat zwar formell die Teilnahme an einem Religionsunterricht verlangt, dessen inhaltliche Ausgestaltung aber der Zivilgesellschaft überlässt. ${ }^{53}$

Mit Begründungsfiguren religiöser Bildung an öffentlichen Schulen beschäftigte sich auch der Erziehungswissenschaftler Johannes Bellmann. ${ }^{44}$ Bellmann diskutiert vier verschiedene Begründungfiguren: die anthropologische, die zivilreligiöse, die eschatologische und die liberal-demokratische. Insbesondere in seiner Darstellung der zivilreligiösen Begründungsfigur bringt er das Spannungsfeld Religionsfreiheit und Streben nach gesellschaftlichem Zusammenhalt präzise auf den Punkt. Die zivilreligiöse Begründung für religiöse Bildung an öffentlichen Schulen gehe «von der Prämisse aus, dass eine religiöse Bildung der gesamten

50 Schweitzer 2005 a, 68.

5 I Ebd.

52 Ebd., 69.

53 Vgl. ebd.

54 Johannes Bellmann war zwar nicht direkt an der Zürcher Diskussion zum schulischen Religionsunterricht beteiligt. Sein Beitrag zu dieser Thematik entstand jedoch zur selben Zeit im Rahmen eines internationalen Forschungskolloquiums, das 2004 auf dem Monte Verità zum Thema «Pädagogische Modernisierung. Säkularität und Sakralität in der modernen Pädagogik» stattfand. 
nachwachsenden Generation für den Zusammenhalt der Gesellschaft als Ganzes unverzichtbar ist. Nicht nur der Staat, sondern die Öffentlichkeit hätte dann ein Interesse daran, dass öffentliche Schulen ihren Beitrag zur Stiftung und Bewahrung dieses Zusammenhalts leisten».5s

Bellmann zeigt sogleich auch die Probleme einer solchen zivilreligiösen Begründungsfigur auf. Das eine Problem besteht darin, dass das Ziel eines «Gemeinsinns» nur erreicht wird, wenn es tatsächlich $\mathrm{zu}$ einem «gemeinsamen Glauben» kommt. Hat der schulische Religionsunterricht zu diesem «zivilreligiösen Projekt» beizutragen, dann «könnte er sich folglich nicht auf einen bloss 〈hinweisenden〉 Charakter beschränken; es ginge in der Tat um eine 〈Einweisung〉 in die Gesinnung des Miteinander, mit der notwendigerweise ein entsprechendes Verhalten einhergeht». ${ }^{6}$

Der schulische Religionsunterricht könnte sich dann nicht - um denselben Gedanken noch mit anderen Worten auszudrücken - auf reine Religionskunde beschränken. Als zweites Problem der zivilreligiösen Begründungsfigur nennt Bellmann deren begrenzte Pluralismustauglichkeit. Das Streben nach einem Gemeinsinn zielt auf Homogenisierung, nicht aber auf den «Umgang mit unterschiedlichen Ideen des Guten als nicht-hintergehbares Faktum moderner Gesellschaft».57 Bellmanns Ausweg aus den mit Problemen behafteten ersten drei Begründungsfiguren - anthropologische, zivilreligiöse und eschatologische - ist die liberal-demokratische Begründung, die sich an Rawls Theorie der liberalen Gesellschaft orientiert. Die Diskussion darüber, ob und inwiefern mit einer liberal-demokratischen Begründungsfigur die aufgeworfenen Probleme der anderen Begründungsfiguren tatsächlich gelöst werden können, würde jedoch die Thematik dieser Arbeit sprengen.

Zusammenfassend lässt sich an dieser Stelle festhalten, dass im wissenschaftlichen Kontext im Unterschied zur medialen und politischen Diskussion das Bewusstsein für die Spannung zwischen Religionsfreiheit einerseits und dem Streben nach gesellschaftlichem Zusammenhalt andererseits sehr wohl vorhanden ist und dieses Spannungsfeld auch differenziert artikuliert worden ist. In der medialen und politischen Diskussion hingegen wurde diese Spannung kaum benannt und reflektiert. Es scheint, als ob das potentiell problematische Verhältnis zwischen Religionsfreiheit und gesellschaftlichem Zusammenhalt mit der Evokation von Einheit übertüncht oder aus strategischen Gründen und politischem Kalkül sogar bewusst ausgeklammert wird. Die Einheitsrhetorik bietet insofern auch keine Lösung dieses Problems. 


\subsubsection{Ausklammerung der Spannung und die Evokation von Einheit}

Unterkapitel 9.6 diente der Darstellung der medialen und politischen Diskussion über die Frage nach der Aufgabe der öffentlichen Schule. Auffallend dabei war die Rede von «unserem kulturellen und religiösen Erbe», «unserer abendländischen Kultur», den «Grundlagen unserer Gesellschaft», von «grundlegenden Werten unserer Gesellschaft», vom «unverbrüchlichen Kern unserer gesellschaftlichen Grundwerte». Mit dieser Rhetorik wird eine Einheit suggeriert, die so lange Wirkung entfalten kann, wie die Niederungen der Konkretion nicht betreten werden. Doch spätestens dann, wenn man die Frage stellt, worin konkret <unser> kulturelles und religiöses Erbe bestehe bzw. was genau mit <unserer abendländischen Kultur gemeint sei, könnte deutlich werden, dass die Antworten auf diese Frage nicht einheitlich ausfallen. Doch diese Frage wird in der medialen und politischen Diskussion in der Regel gar nicht thematisiert.

Einheit wird in dieser Diskussion auf unterschiedliche Weise evoziert. In jedem Fall aber wird auf den gesellschaftlichen Frieden abgezielt. Bei den einen steht dabei der Integrationsgedanke im Zentrum. Die «Fremden`sollen in die unterstellte bereits bestehende Einheit integriert werden. Die mögliche Gefahr der Kollision des Integrationsgedankens mit der Religionsfreiheit wird dabei aber nicht bedacht oder zumindest öffentlich nicht benannt. Bei den anderen steht der Dialoggedanke im Zentrum. Die Auseinandersetzung mit dem «Eigenen〉 wird als notwendiges Mittel für den interreligiösen und interkulturellen Dialog gesehen. Es wird nicht, wie im ersten Fall, explizit eine gesellschaftliche Homogenisierung angestrebt. Doch implizit wird der Dialog selbst zum gemeinschaftsstiftenden Moment entsprechend dem demokratischen Motto «agree to disagree ${ }^{8}{ }^{8}$ stilisiert. Dialog funktioniert nur unter der Voraussetzung, dass die Dialogpartner einander mit ihren je unterschiedlichen Auffassungen respek-

58 Der Politikwissenschaftler Patrick J. Deneen unterscheidet in seinem 2005 erschienenen Buch Democratic Faith zwischen einem liberal-demokratischen und einem agonistisch-(radikal-) demokratischen Glauben (faith). Für die Liberal-Demokraten bedeutet Demokratie Diskussion. Sie gehen aus von der Vernunft als Basis für Konfliktlösungen. Sie glauben an die Fähigkeit der Menschen, mittels vernünftiger Diskussionen und prinzipiengesteuerter Reflexion zu einem Konsens zu kommen: Die Vernunft transzendiert Verschiedenheiten. Religiöse Rechtfertigungen (zum Beispiel biblische Begründungen) werden von der Diskussion ausgeschlossen, da diese als nicht vernünftig taxiert werden. Doch die Frage stellt sich unweigerlich, wer bestimmt, was als vernünftig gilt. Eine selbsternannte Elite? Für die agonistischen Radikal-Demokraten bedeutet Demokratie Machtkampf, das heisst ein Kampf der Weltanschauungen und Lebenshaltungen. Grundlegende Spielregel ist die Akzeptanz von Meinungsverschiedenheiten: «agree to disagree». Im Unterschied zu den Liberal-Demokraten dürfen alle ihre Meinung im öffentlichen Raum darlegen, nicht nur diejenigen, die eine sogenannt vernünftige Meinung vertreten. Es wird davon ausgegangen, dass die Teilnahme am demokratischen Leben die Menschen transformiere. Deneen beschreibt das Problem des liberal-demokratischen Denkansatzes so, dass die Menschen bereits transformiert sein müssen, um überhaupt an diesem Prozess teilnehmen zu können (vgl. Deneen 2005). 
tieren. Auch der interreligiöse und interkulturelle Dialog setzt eine Integrationsleistung voraus: Die Anerkennung und Einhaltung der Gesprächsregeln. Es sind diese Regeln, die stillschweigend vorausgesetzt werden, ohne zu bedenken, dass möglicherweise auch gerade diese Regeln zu einem Konflikt mit der Religionsfreiheit führen könnten. Denn die Forderung, das Gegenüber nicht bloss zu respektieren, sondern mit ihm auch in einen Dialog zu treten, kann als Ausdruck einer westlichen Erwartungshaltung aufgefasst werden, die allen ungefragt übergestülpt wird. Oder anders gesagt: Dialog wird als etwas per se Wünschenswertes angesehen.

Explizite Kritik an der im Zusammenhang mit dem Fach Religion und Kultur häufig verwendeten interreligiösen Dialogrhetorik erfolgte jedoch nicht von Kulturkritikern westlichen Denkens, sondern von Seiten der Freidenker, die in ihrem Selbstverständnis zutiefst von einem aufklärerischen Geist geprägt sind. Wie ihrer Stellungnahme zu entnehmen ist, basiert gesellschaftlicher Frieden nicht auf einem Wissen über Religionen, sondern im Gegenteil «vielmehr auf der Vernachlässigung anerzogener Glaubenslehren und auf einer Haltung, welche die religiöse Optik für nebensächlich oder bedeutungslos hält».59 Der Verzicht auf dieses Fach - und damit die Absage an den interreligiösen Dialoggedanken wäre aus freidenkerischer Perspektive friedensförderlicher. Zudem wird kritisiert, dass dieses Fach «für Unreligiöse diskriminierend $»^{60}$ sei, da ethische Fragen im Rahmen eines Religionsfaches für alle behandelt würden. Die Freidenker verweisen hier auf einen zentralen Punkt, nämlich auf das Recht, sich in einem freiheitlichen Rechtsstaat nicht für Religion zu interessieren. ${ }^{6 I}$ In dieser Kritik wird die Spannung zwischen Religionsfreiheit und dem Streben nach Einheit manifest. Das Spannungspotential wird in dieser Vernehmlassungsantwort jedoch nur einseitig bedacht. Die von den Freidenkern geforderte Alternative zum schulischen Religionsunterricht - ein Ethik- bzw. Lebenskunde-Fach - scheint von ihnen als (Auf)lösung dieser Spannung betrachtet zu werden. Dass die Behandlung ethischer Fragen abgelöst von einer religiösen Orientierung umgekehrt für Religiöse zu einem Problem werden könnte, wird nicht erwähnt. Homo-

59 Freidenkervereinigung Schweiz, Stellungnahme von März 2006.

60 Ebd.

6I Das Ideal der Freidenker, sich gegenüber der religiösen Optik gleichgültig verhalten zu dürfen, konsequent durchdacht, würde bedeuten, sich auch nicht mehr an der Unterscheidung zwischen säkular und religiös zu orientieren und sich deshalb von aller Vehemenz der Abgrenzung gegen Religion oder religiöse Orientierungen zu distanzieren. Es entbehrt nicht einer gewissen Ironie, dass ein Theologe, Ingolf U. Dalferth, das Ideal der Freidenker weiterreflektiert als diese selbst. Dalferth weist in seinem Buch Transzendenz und säkulare Welt darauf hin, dass «in den Sinn von «säkular〉 die Negation von 〈religiös> in irgendeinem Sinn stets eingezeichnet zu sein» scheint. Deshalb könne man «nicht von «säkular〉 oder 'Säkularität reden, ohne den Bezug zum Religiösen ins Spiel zu bringen. Auch wer ein säkulares Zeitalter propagiert, bleibt religionsfixiert» (Dalferth 2015, 32). 
genisierung in ethischer Hinsicht scheinen auch die Freidenker anzustreben, wenn sie Toleranz, weltoffenes und kritisches Denken sowie die Entwicklung eines gesunden Selbstwertgefühls als zentrale Erziehungsziele beschreiben.

\subsubsection{Bewusster Umgang mit Spannung und Förderung eines institutionellen Pluralismus}

Im Unterkapitel 7.2.3 wurde gezeigt, dass sich im I9. Jahrhundert die Positiven mit ihrer Forderung nach freien Kirchen und freien Schulen im Unterschied zu den Religiös-Liberalen und den Radikal-Demokraten für einen institutionellen Pluralismus einsetzten. Eine solche Forderung war in der Diskussion um 2004 nicht $\mathrm{zu}$ vernehmen. In der medialen und politischen Diskussion bestand hinsichtlich eines schulischen 〈Religionsunterrichts für alle〉 eine erstaunliche Einigkeit sowohl über Parteigräben wie auch über konfessionelle Grenzen hinweg. Auch in der wissenschaftlichen Diskussion fanden sich keine begründeten Forderungen nach einem institutionellen Pluralismus. Friedrich Schweitzer und Ansgar Jödicke streiften in ihren Kommentaren zum Fach Religion und Kultur ansatzweise pluralistische Positionen. ${ }^{62}$ Schweitzer befasste sich in besagtem Tagungsband mit der Frage, welche Form von Religionsunterricht zum einen als obligatorisches Angebot in Frage komme und zum andern «den Anforderungen in der Zivilgesellschaft gerecht» werde. Als Vorteil eines religionskundlichen «Religionsunterrichts für alle» erachtet er, dass dieser die Gelegenheit biete, «mit religiösen und weltanschaulichen Unterschieden umzugehen». Den Nachteil eines solchen Religionsunterrichts sieht er darin, dass die «Verstaatlichung von Religionsunterricht zugleich eine entscheidende Schwächung der Zivilgesellschaft» bedinge sowie «eine Verringerung der zivilgesellschaftlichen Mitverantwortung für Schule und Bildung». ${ }^{63}$ Ein konfessionell-kooperativer Religionsunterricht hingegen, der sowohl gemeinsame Phasen wie auch nach Konfessionen getrennte Phasen beinhalte, werde beiden Polen gerecht: Sowohl würden Identitätsbildungsprozesse unterstützt wie die Verständigungsfähigkeit gefördert. Zudem bleibe durch die Beteiligung der Religionsgemeinschaften «eine konstitutive Verbindung zur Zivilgesellschaft erhalten». ${ }^{64}$ Inwiefern auch die Ansprüche von Areligiösen wie den Freidenkern mit einem solchen Modell kompatibel wären, diskutiert Schweitzer an dieser Stelle allerdings nicht.

Ansgar Jödicke verfolgt in seinem religionswissenschaftlichen Kommentar eine ähnliche Richtung wie Schweitzer. Einen obligatorischen religionskundlichen Unterricht erachtet er als prinzipiell möglich, da dieser staats- und bildungspolitisch legitime Ziele erfülle. Insofern ein solcher Unterricht jedoch «nicht

62 Vgl. Jödicke 2005; Schweitzer 2005a; Schweitzer 2005b.

63 Schweitzer 2005a, $80 \mathrm{f}$.

64 Ebd. 
das gesamte Problemfeld der Religion in der Schule lösen» könne, werde «er die ebenfalls legitimen Interessen der Religionsgemeinschaften nach einem sozialisierenden Unterricht nicht erfüllen». ${ }^{65}$ Die «angemessene Antwort der Bildungspolitik auf die religiöse Pluralisierung» sieht Jödicke in einem Gesamtkonzept, das sowohl einen konfessionellen Religionsunterricht «einiger privilegierter Religionsgemeinschaften» beinhalte, der der religiösen Sozialisation diene, als auch einen Religion-und-Kultur-Unterricht als «staatliches Instrument kultureller Integration».66

\subsection{Paradoxie von Zivilreligion}

Die Paradoxie von Zivilreligion steht in engem Zusammenhang mit der in den Unterkapiteln 7.2.2 und I 0.2.2 beschriebenen Evokation von Einheit. Sie besteht darin, dass einerseits ein gewisser Grad an funktionaler gesellschaftlicher Ausdifferenzierung vorausgesetzt ist, andererseits aber das durch die Wahrnehmung der religiös-weltanschaulichen Heterogenität ausgelöste Streben nach Einheit eine Infragestellung, Missachtung oder Auflösung ebendieser gesellschaftlicher Sphärengrenzen zur Folge haben kann. Dedifferenzierende Tendenzen im I9. Jahrhundert wurden im Unterkapitel 7.3 am Beispiel Salomon Vögelins aufgezeigt. Das paradoxe Moment von Zivilreligion zeigt sich jedoch auch im 2 I. Jahrhundert: Die funktionale Ausdifferenzierung der gesellschaftlichen Sphären ist vorausgesetzt und wird von niemandem ernsthaft in Frage gestellt. Gleichwohl lassen sich dedifferenzierende Tendenzen aufzeigen; allerdings nicht wie bei Vögelin zwischen Schule und Kirche (vgl. S. I90 ff.), sondern zwischen Schule und Staat.

Es sind primär die an die öffentliche Schule gerichteten kulturellen Integrationserwartungen, die zu einer Verwischung der gesellschaftlichen Sphärengrenzen führen. Mit dem Anspruch, dass in der Schule - und im Speziellen im schulischen Religionsunterricht - sogenannte gesellschaftliche Grundwerte zu vermitteln sind, wird die Schule im Dienste des Staates bzw. der Gesellschaft instrumentalisiert (vgl. Unterkapitel 9.5). Der Schule kommt so nicht bloss eine bildende Aufgabe zu, sondern sie nimmt selbst den Charakter einer Wertegemeinschaft an, die potentiell mit anderen Gemeinschaften - Familie, Religionsgemeinschaften, weltanschauliche Gruppierungen usw. - im Konflikt stehen kann.

Ein Beispiel für einen über einen blossen Bildungsanspruch hinausweisenden Anspruch an den schulischen Religionsunterricht ist die in einem Bildungsrats-

65 Jödicke 2005, 2 I 9.

66 Ebd., 220. 
beschluss aus dem Jahre $2004 \mathrm{zu}$ findende Begründung der bildungsrätlichen Kommission für das Schulfach Religion und Kultur: «Die Kommission geht davon aus, dass wechselseitige Toleranz den Kern des Zusammenlebens verschiedener religiöser Gruppen innerhalb einer liberalen Gesellschaft ermöglicht. Dies setzt voraus, dass genügend Kenntnisse über die verschiedenen Religionen, ihre historische Herkunft, die wichtigsten Grundlagen des Glaubens und der Erkenntnis daraus vorhanden sind. Die zentrale Aufgabe des Faches ist es, Religion als grundlegenden Bestandteil von Allgemeinbildung sichtbar zu machen und dabei Ziele der interreligiösen Toleranz zu verfolgen.» ${ }^{67}$

Dass dieses Fach mehr als ein reines Bildungsfach sein soll, zeigt sich im Ausdruck Toleranz, der hier unreflektiert eine doppelte Bedeutung annimmt. Im ersten Satz wird wechselseitige Toleranz in einem ergebnisoffenen Sinn als Ermöglichungsbedingung für die Kommunikation und das Zusammenleben innerhalb einer liberalen Gesellschaftsordnung konstatiert. ${ }^{68}$ Wie der letzte Satz zeigt, will der Bildungsrat Toleranz aber nicht bloss in diesem ergebnisoffenen Sinne verstanden wissen. Denn er schreibt, es gelte bestimmte inhaltliche Ziele nämlich die der interreligiösen Toleranz - zu verfolgen. Das Fach Religion und Kultur soll also der Vermittlung bestimmter Verhaltensweisen dienen, die beitragen, das Ziel der interreligiösen Toleranz zu erreichen. Der Bildungsrat führt diese Verhaltensweisen in seiner Begründung nicht genauer aus. Häufig werden in diesem Zusammenhang Interesse und Offenheit gegenüber und Fähigkeit zur Verständigung mit Menschen anderer Religionen und Kulturen sowie die gleichwertige Behandlung unterschiedlicher Religionen und Weltanschauungen genannt. ${ }^{69}$

Ein Rechtsstaat kann jedoch von seinen Bürgern nicht verlangen, dass sie sich für die Religion der Mitbürger interessieren. Es fragt sich deshalb, warum dies die Schule einfordern darf. Wie die Stellungnahme der Freidenker zeigt, erachten diese den Anspruch, dass ein Kind Interesse für die Religion seiner Mitschüle-

67 Erläuterungen des Bildungsrates zum BRB vom 23. August 2004, 5 .

$68 \mathrm{Ob}$ mehr Wissen über die unterschiedlichen Religionen tatsächlich die Toleranz fördert, wie hier vom Bildungsrat behauptet wird, und nicht ebenso eine gegenteilige Wirkung haben könnte, ist eine andere Frage, die an dieser Stelle nicht weiter diskutiert werden soll.

69 Im Lehrplan für Religion und Kultur heisst es unter der Rubrik «stufenübergreifende Richtziele» beispielsweise: «Schülerinnen und Schüler können sich mit Menschen verschiedener Überzeugung und Weltanschauung, mit Menschen anderer Religionen und Kulturen verständigen und respektieren deren Lebens- und Werthaltungen» (Bildungsdirektion Kanton Zürich (Hg.) (20I0). Religion und Kultur. Ergänzung zum Lehrplan für die Volksschule des Kantons Zürich, 4). Bei den didaktischen Grundsätzen heisst es im selben Lehrplan: «Das Fach «Religion und Kultur» wird auf der Basis der Gleichwertigkeit der grossen Religionen unterrichtet.» (Ebd., I 8) Im Lehrplan 2 I steht unter den didaktischen Hinweisen: «Mit Menschen unterschiedlicher Traditionen und Weltanschauungen zusammenzuleben, erfordert, ihnen mit Interesse und Offenheit zu begegnen» (Lehrplan 2I 2016, 242). 
rinnen zeigen müsse, keineswegs als religiös-weltanschaulich neutral. Denn zum Recht auf eine nicht religiöse bzw. säkulare Lebensweise gehört auch, dass ich mich nicht für die Religion oder Weltanschauung meiner Mitmenschen zu interessieren brauche. Abgesehen davon ist es fraglich, ob empirisch nachgewiesen werden könnte, dass friedliches Zusammenleben das Interesse an der Religion oder Weltanschauung unserer Mitmenschen erfordert. Nach Ansicht der Freidenker würde gerade religiöse Ignoranz zum gesellschaftlichen Frieden beitragen und nicht das Wissen über Religionen. ${ }^{70}$ Die Freidenker können allerdings ebenso wenig empirische Evidenz zur Stützung ihrer Überzeugung herbeiziehen wie diejenigen, die dem Wissen über Religion(en) friedensfördernde Wirkung zuschreiben. Doch zumindest könnten sie ihre Ansicht mit Beispielen aus dem Alltag illustrieren (was sie jedoch nicht tun): So setzt beispielsweise ein faires Fussballspiel weder die gegenseitige Kenntnis der Religion oder Weltanschauung der Mit- oder Gegenspieler noch das Interesse dafür voraus. Und es ist zweifellos möglich, konfliktfrei in einem Mehrfamilienhaus zusammenzuwohnen und dieselbe Waschmaschine zu benutzen, ohne dass man sich für die Religion der Mitbewohner interessiert oder darüber etwas weiss. Es kann zumindest nicht a priori ausgeschlossen werden, dass dies auch für das politische Zusammenleben im Staat gilt.

Ebenso wenig religiös-weltanschaulich neutral - und einem entsprechenden Glaubensbekenntnis gleichkommend - ist die Idee der gleichwertigen Behandlung der Religionen..$^{71}$ Aus der Innenperspektive einer religiösen Tradition bzw. Gemeinschaft kann es nicht sein, dass andere Religionen oder Weltanschauungen den gleichen Wert besitzen. Dies bedeutet allerdings nicht, dass man nicht Menschen mit anderer Religionszugehörigkeit oder Weltanschauung gleichwertig behandeln könnte und sollte. Die Verfasserschaft des Lehrplans könnte hier wohl einwenden, dass es nicht darum gehe, den Kindern die Haltung zu vermitteln, dass alle Religionen gleichwertig seien, da der Verweis auf die Gleichwertigkeit der Religionen vielmehr eine didaktische Anweisung für die Lehrpersonen enthalte. Der Anspruch der Gleichwertigkeit der Religionen wird im Lehrplan folgendermassen konkretisiert: «Die Darstellung von religiösen Traditionen und Überzeugungen und weltanschaulichen Positionen soll die Schülerinnen und Schüler weder festlegen noch vereinnahmen.» ${ }^{72}$ Erachtet man jedoch - wie dies zum Beispiel Friedrich Wilhelm Graf tut - das religionskundliche Bemühen um eine gleichwertige Behandlung der verschiedenen Religionen als bloss eine mögliche Perspektive neben andern - mit ihren Möglichkeiten und Limitatio-

70 Vgl. Freidenkervereinigung Schweiz, Stellungnahme von März 2006; siehe oben, S. 205.

7I Vgl. Bildungsdirektion Kanton Zürich (Hg.) (2010). Religion und Kultur. Ergänzung zum Lehrplan für die Volksschule des Kantons Zürich, 6.

72 Ebd., 6. 
nen -, dann greift die Schule mit der Präferenz dieser Perspektive in die Freiheit derjenigen ein, für die eine bestimmte Religion oder Weltanschauung nicht eine gleich gültige Option neben anderen bedeutet.73 Man könnte sagen, dass das Aussparen des Wahrheitsanspruchs des Andern mit einem eigenen Wahrheitsanspruch - einem vermeintlich allgemein-gesellschaftlichen - verbunden ist. Mit der Suspendierung der Wahrheitsfrage wird jedoch ein wesentlicher Aspekt von Religion ausgeklammert. Nipkow diskutierte diesen Punkt in seinem Diskussionsbeitrag an der wissenschaftlichen Fachtagung: «Der Ernst des Ringens um diesen religiösen Wahrheitsaspekt gehört zum Wesen und zur Würde von Religionen. Unbedingt religiös gewiss zu sein, gehört konstitutiv zu Religion und Religiosität. Die Wahrheitsebene als die Ebene religiöser Gewissheiten kann nicht künstlich aus dem Unterricht abgedrängt werden.»74

Wird der Wahrheitsanspruch der Religionen ignoriert, beraubt man sie ihres Zentrums. Auch andere haben auf diesen Punkt hingewiesen. So versucht der Theologe Matthias Pfeiffer die Thematik der Wahrheitsfrage dahingehend zu präzisieren und zu differenzieren, dass der Wahrheitsanspruch der jeweiligen im Unterricht thematisierten Religion nicht ausgeklammert werden soll, die Antwort auf die Wahrheitsfrage aber offengelassen werde. ${ }^{75}$ Das Problem scheint aber auch damit nicht gelöst. Denn auf diese Weise wird ebenso eine bestimmte Position nahegelegt, nämlich eine agnostische. Was es konkret bedeutet, die Frage offenzulassen, bleibt unklar. Denn mit dem Offenlassen der Wahrheitsfrage muss eine Haltung vermittelt werden, die dem Einzelnen gar nicht möglich ist. Denn jede Person muss diese Frage in irgendeiner Form beantworten - sei es im bejahenden oder ablehnenden Sinn. Dass alles, was mit Religion zu tun hat, als Nonsens, unwichtig oder unentscheidbar erachtet wird, ist ebenso eine Form von Wahrheit wie die, dass Jesus Christus der eingeborene Sohn Gottes oder Mohammed der Prophet Allahs ist.

Ralph Kunz, Professor für praktische Theologie an der Universität Zürich, versucht in seinem Beitrag an derselben wissenschaftlichen Fachtagung die Problematik eines strikt religionskundlichen Unterrichts zu entschärfen, indem er auf «das Interesse des Staates an der gesellschaftlichen Rolle der Religionen» ${ }^{6}$ verweist. Kunz zielt in seinem Beitrag darauf, «den möglichen Gewinn»77 eines religionskundlichen Unterrichts für die religiöse Bildung aufzuzeigen gegenüber dem «Zerrbild einer strikt neutralen Religionskunde», ${ }^{78}$ das Religions-

73 Vgl. Graf 2004 sowie Unterkapitel 9.5.2, $248 \mathrm{f}$.

74 Nipkow 2005 , I 53.

75 Pfeiffer 2005, 43, Anm. 28.

76 Kunz 2005, 223.

77 Ebd., 222.

78 Ebd., 223. 
kunde als «blutleere und witzlose Information über Religion»79 darstellt. Nach Kunz ist «das Engagement des Staates für das Schulfach Religion [...] politisch begründet. Für das Curriculum muss eine Auswahl der Inhalte getroffen werden, die einerseits für das Verständnis einer Religion und andererseits für das Zusammenleben verschiedener Religionen zentral sind. Denn der Staat hat kein <religiöses Interesse im engeren Sinn des Wortes, insofern Religion nur soweit <interessant ist, als von ihr ein Beitrag zur Wertebildung in der Konvivenz ${ }^{80}$ erwartet wird.» ${ }^{81}$

Eine solche Auswahl der Inhalte könne nicht strikt weltanschaulich neutral genannt werden. Dennoch bleibe der Staat «konfessionell neutral, wenn er sein (positives) Interesse an der Lehre jener Religionsgemeinschaften zeigt, die das Gemeinwesen stützen». ${ }^{82}$ Das politische Interesse des Staates wird gemäss Kunz im Zweckparagraphen der Volksschule deutlich. Dieser lautet folgendermassen: « I. Die Volksschule erzieht zu einem Verhalten, das sich an christlichen, humanistischen und demokratischen Wertvorstellungen orientiert. Dabei wahrt sie die Glaubens- und Gewissensfreiheit und nimmt auf Minderheiten Rücksicht.» ${ }^{8_{3}}$ Kunz verweist auf den «spannungsvollen Zusammenhang» dieser drei Elemente der Aufzählung, löst die Spannung jedoch sogleich auf, indem er nach dem gemeinsamen Nenner dieser unterschiedlichen Wertvorstellungen sucht: Toleranz und Respekt. Der zitierte Zweckparagraph des Volksschulgesetzes ist nach Kunz für den religionskundlichen Religionsunterricht deshalb von Interesse, weil darin «in expliziter Weise ein Zusammenhang zwischen den Grundlagen des Staatswesens und der christlichen Tradition geltend gemacht wird». ${ }^{84}$ Der Staat hat nach Kunz ein Interesse an Religion, weil Religionen mit ihren Werten zum gesellschaftlichen Frieden beitragen. Es stellt sich hier jedoch die Frage, warum nicht auch explizit areligiöse Bürgerinnen und Bürger wie beispielsweise die Freidenker an einem friedlichen Zusammenleben interessiert sein sollten und in ihren Gemeinschaften genau diese Werte zu fördern suchen. Oder anders gefragt: Warum sollte der Staat nicht auch von den moralischen Ressourcen Gebrauch machen, die ihre historischen Wurzeln anscheinend weder in der christlichen

79 Ebd., $22 \mathrm{I}$.

80 Die Verwendung des Begriffs Konvivenz im Zusammenhang mit dem staatlichen Interesse lässt eine etwas ausgeprägtere Sensibilität für die Souveränität gesellschaftlicher Sphären vermissen. Der Begriff Konvivenz wurde im Deutschen geprägt von Theo Sundermeier, Professor i. R. für Religions- und Missionswirtschaft in Heidelberg, im Kontext der Ökumene und des interreligiösen Dialogs (vgl. Sundermeier 2012).

8I Kunz 2005, 227.

82 Ebd.

83 Volksschulgesetz vom 7. Februar 2005.

84 Kunz 2005, 228. 
Religion noch in anderen Religionen haben, zumal im Volksschulgesetz neben den christlichen explizit auch die Rede von humanistischen Werten ist?

Ein säkular-liberaler Rechtsstaat, der sich auf religiös-weltanschauliche Neutralität beruft, müsste an allen zivilgesellschaftlichen Akteuren unabhängig von ihrer religiösen oder areligiösen Fundierung ein Interesse haben und diese fördern, sofern sie in ihren Gemeinschaften Werte vermitteln, die zu einem friedlichen gesellschaftlichen Zusammenleben beitragen. So gesehen manifestiert sich in der Aussage von Kunz, dass der Staat ein intrinsisches Interesse an Religion habe, eine Verletzung der Sphärensouveränität, wenn sie nicht ergänzt wird durch das staatliche Interesse an allen zivilgesellschaftlichen Akteuren - auch areligiösen -, die für das friedliche gesellschaftliche Zusammenleben als notwendig angeschaute Werte vermitteln.

Kunz interpretiert den Zweckartikel des Volksschulgesetzes dahingehend, dass darin «der konkrete und kontingent-geschichtliche Hintergrund der staatlichen Schule, die in einer bestimmten Kultur ihren Ort und ihre Bestimmung erhalten hat» ${ }^{85}$ auftauche. Angesichts einer zunehmend weltanschaulich-religiös heterogenen Gesellschaft fragt sich, inwiefern der säkular-liberale Rechtsstaat, der weltanschaulich-religiös neutral zu sein hat, die bevorzugte Behandlung von bestimmten religiösen Traditionen legitimieren kann, ohne selbst den Charakter einer Wertegemeinschaft - im Unterschied zu einer Rechtsgemeinschaft - anzunehmen, die sich für kompetent hält, inhaltlich darüber zu urteilen, was an einer Religion wertvoll ist und deshalb - sofern förderlich fürs Gemeinwohl - im schulischen Religionsunterricht legitimerweise vermittelt werden darf und soll.

Kunz weist auf das Problem hin, dass eine zu starke Betonung «der Rolle des Christentums bei der Entstehung der offenen Gesellschaft und des freiheitlichen Staates» Gefahr laufe, «das Christentum zur Staatsreligion zu erheben». ${ }^{86} \mathrm{Zu}$ gleich ortet er aber auch eine Gefahr in der Entstehung einer «Geisterreligion», wenn «die Spuren der kulturellen Erinnerung getilgt oder bis zur Unkenntlichkeit verwässert» ${ }^{87}$ werden. Mit der einseitigen Betonung der Religion scheint Kunz jedoch die gewachsene kulturelle Identität bzw. Kontinuität mehr zu gewichten als die religiös-weltanschauliche Neutralität des Staates. Abgesehen davon, dass sich auch areligiöse Gemeinschaften auf die Geschichte berufen können, ist nicht einsichtig, warum ein religiös-weltanschaulich neutraler Staat nicht ebenso Religionsgemeinschaften fördern sollte, die sich nicht auf dieselbe geschichtliche Verankerung in der Schweiz berufen können. Zudem fragt sich, ob mit der historischen Legitimation nicht alte konfessionelle Gräben aufgerissen werden. Denn im I9. Jahrhundert wurde den Katholiken mit dem Schimpfwort Ultramonta-

85 Ebd.

86 Ebd., $228 \mathrm{f}$.

87 Ebd., 229. 
nisten unterstellt, antifreiheitlich zu sein. Und mit Christentum wird Kunz wohl schwerlich bloss den liberalen Protestantismus vor Augen haben.

Wenn also das staatliche Interesse am Schulunterricht in der Vermittlung derjenigen Werte besteht, die das friedliche gesellschaftliche Zusammenleben fördern, dann fragt sich, warum dazu eigens ein Religionsunterricht nötig sei. Ethisch-politische Werte könnte man in verschiedensten Fächern vermitteln (Geschichte, Staatskunde, Kunst usw.). Dafür brauchte es kein eigenes Fach Religion. Da es sich hierbei um eine gewichtige Frage handelt, werde ich diesen Punkt im Unterkapitel I I.I nochmals aufgreifen.

\subsection{Universalitätsanspruch versus historische Kontingenz und Partikularität}

Im Unterkapitel 7.4 habe ich am Beispiel von Pfarrer Konrad Furrer und Friedrich Salomon Vögelin, die beide von einer allgemein-universalen Sittlichkeit ausgingen, die Ausblendung der historischen Partikularität von Universalitätsansprüchen in der Diskussion um i 870 dargestellt. Furrers Argumentation für den konfessionslosen Religionsunterricht basierte einerseits auf der Annahme des Sittlich-Religiösen als anthropologischer Konstante und andererseits auf der Unterscheidung zwischen Theologie bzw. Dogmatik und Religion. Aus seiner Sicht trenne die dogmatische Bestimmtheit des Glaubensvollzugs die Menschen voneinander, während Religion im schleiermacherschen Sinne als religiöses Gefühl verstanden verbindenden Charakter habe. Vögelins Universalismus zeigte sich einerseits in seiner Rede von «der Humanität», die anstelle des dogmatischen und konfessionellen Elements gefördert werden sollte, in der Rede von «der Menschheit» oder «dem Menschheitsgefühl» sowie der Annahme einer überzeitlichen und alle Religionen und Parteien transzendierenden «historischen Wahrheit», zu der hin sich die Menschheit notwendigerweise bewege. Die Ausdrücke, die im 21. Jahrhundert in den Argumentationen zur Legitimierung des Fachs Religion und Kultur verwendet werden, sind nicht dieselben wie in den Forderungen eines konfessionslosen Religionsunterrichts im 19. Jahrhundert. Die Rede von Wertneutralität, von Toleranz, Respekt, Solidarität, von der Vertiefung des Verständnisses zwischen den Kulturen usw. basiert aber ebenso auf einem vermeintlich omniperspektivischen Denken wie dasjenige der in Teil II dieser Arbeit genannten Protagonisten im 19. Jahrhundert. Dieses Denken manifestiert sich auf doppelte Weise. Zum einen mit der Evokation von angenommenen allgemeinen in der Schule zu vermittelnden Werten, mit denen die Hoffnung verbunden wird, dem Auseinanderbrechen der Gesellschaft durch die zunehmende religiös-weltanschauliche Heterogenität entgegenwirken zu kön- 
nen. Zum andern auf der Metaebene in der Annahme eines religionskundlichen Ansatzes für den schulischen Religionsunterricht. Dieser aus der vergleichenden Religionswissenschaft stammende Ansatz basiert auf der Annahme einer objektiven bzw. vogelperspektivischen Zugangsweise zum zu vermittelnden Gegenstand Religion. Dieser religionskundliche Zugang konkretisiert sich auf Volksschulstufe in der für die didaktische Umsetzung relevanten Unterscheidung zwischen teaching about und teaching in. Während gemäss dieser Unterscheidung ein traditioneller Religionsunterricht in die Religion einführt und den Schülerinnen und Schülern ermöglicht, sowohl Glaubenserfahrungen zu machen als auch darüber zu sprechen, beansprucht ein religionskundlicher Unterricht ein Wissen über verschiedene Religionen zu vermitteln, ohne eine bestimmte religiöse Position zu ergreifen oder eine solche von den Schülerinnen und Schülern zu erwarten. Im Lehrplan Religion und Kultur für die Primarstufe heisst es: «Das Vollziehen religiöser Handlungen (z. B. Beten) hat keinen Platz in der Schule. Beheimatung in einer Glaubensgemeinschaft und religiöse Unterweisung sind nicht Aufgabe der öffentlichen Schule, sondern Sache der einzelnen Glaubensgemeinschaften. Im Fach «Religion und Kultur〉 lernen die Schülerinnen und Schüler die religiösen und kulturellen Wurzeln der Gesellschaft, in der sie leben, aber auch Merkmale und Überlieferungen anderer Religionen und Kulturen kennen und achten. Ethische Gemeinsamkeiten der verschiedenen religiösen Traditionen erfahren eine besondere Beachtung.» ${ }^{88}$

Wie diese Formulierung zeigt, soll die Orientierung an der religionskundlichen Unterscheidung zwischen teaching about und teaching in einen religiös neutralen Unterricht ermöglichen. Konsequent neutral ist dieser Unterricht jedoch nicht. Ein konsequent neutraler Unterricht hinsichtlich weltanschaulich-religiösen Positionen müsste verschiedenste Optionen ermöglichen: dass man sich durch die Kenntnis über eine Religion von ihr angezogen fühlt oder sie zu verabscheuen beginnt. Auch das Entstehen von Indifferenz gegenüber Religionen müsste ein konsequent neutraler Unterricht ermöglichen. Doch wie das vorhergehende Lehrplanzitat zeigt, bezweckt dieser Unterricht nicht bloss die Kenntnis über Religionen und der religiösen und kulturellen Wurzeln der Gesellschaft, sondern auch eine bestimmte Haltung gegenüber religiösen Traditionen, nämlich Achtung. Ebenso zeigen auch die wegleitenden Fragen zu Beginn des Lehrplans, dass sich dieser Unterricht nicht in einem reinen Bildungsanspruch erschöpfen soll: «- Welche Kenntnisse christlicher Traditionen und Werte brauchen Kinder, um die Gesellschaft, in der sie leben, zu verstehen und sich in ihr zurechtzufinden? - Welche Kenntnisse verschiedener Religio-

88 Bildungsdirektion Kanton Zürich (Hg.) (2010). Religion und Kultur. Ergänzung zum Lehrplan für die Volksschule des Kantons Zürich Religion und Kultur, 5. 
nen brauchen Kinder, um Menschen verschiedener Religionszugehörigkeit und kultureller Herkunft in unserer Gesellschaft zu respektieren und sich in einer globalisierten Welt zurechtzufinden?» ${ }^{89}$

Nicht irgendwelche Kenntnisse über Religionen sollen in der Schule vermittelt werden, sondern ganz bestimmte: solche Kenntnisse, die Respekt gegenüber Menschen aus den vorgestellten religiösen Traditionen erzeugen. Während spezifisch religiöse Werte als strittig gelten und deren Vermittlung in der öffentlichen Schule deshalb tabu sind, scheinen unstrittige und als allgemein geltende Werte - hier beispielsweise die Achtung vor anderen Religionen und Kulturen in der Schule vermittelt werden zu dürfen, wenn sie das Gemeinwesen stärken. Man könnte also sagen, dass ein teaching in sogenannt allgemeiner Werte wie Achtung, Respekt oder Toleranz im Unterschied zum teaching in sogenannt religiöser Werte nicht nur als legitim, sondern von vielen gar als eine politische Notwendigkeit betrachtet wird (vgl. Unterkapitel 9.3).

Die Unterscheidung zwischen teaching about und teaching in ist im spezifischen Kontext der öffentlichen Schule, die einen religiös neutralen Unterricht ermöglichen soll, selbst nicht weltanschaulich neutral, sondern stellt eine normative Unterscheidung dar. Sie basiert auf der Annahme der Möglichkeit einer vogelperspektivischen Zugangsweise zum vermittelten Gegenstand der Religion(en), die es erlauben soll, ein Wissen über Religionen $\mathrm{zu}$ vermitteln, ohne selbst Position zu ergreifen. Diese Zugangsweise ist eng verknüpft mit der Disziplin der Religionswissenschaften, die selber eine noch relativ junge Wissenschaft ist. ${ }^{90}$ Die Annahme eines solch vogelperspektivischen Zugangs steht beispielsweise in Konflikt mit der Überzeugung, dass auch die Vermittlung sogenannt allgemeiner Werte nur im Kontext einer spezifischen Glaubens- oder Weltanschauungsgemeinschaft stattfinden kann oder soll. Dies kann folgendermassen illustriert werden: Der Entscheid darüber, was aus einer anderen religiösen Tradition als respektabel erachtet wird bzw. die Achtung oder den Respekt fördern kann und dessen Kenntnis somit in der öffentlichen Schule vermittelt werden kann und soll, wird aus der partikularen Perspektive der Lehrperson bzw. der Verfasserschaft der Lehrmittel gemacht. Das spannungsvolle Verhältnis von universal und partikular wird jedoch nicht kritisch reflektiert.

Unabhängig von der Perspektivität der Werte und im Zusammenhang mit der Thematik dieses Unterkapitels - der Ausblendung der Partikularität von Universalitätsansprüchen - scheint mir die Frage von Bedeutung, wie es überhaupt

89 Ebd., 4 .

90 In dieser Arbeit geht es mir um die Unterscheidung zwischen teaching about und teaching in im spezifischen Kontext der öffentlichen Schule und ihres normativen Auftrags. An dieser Stelle würde es sich nahelegen, der Logik dieser Unterscheidung im akademischen Kontext nachzugehen, doch dies kann hier, obwohl sachlich naheliegend, nicht weiterverfolgt werden. 
zur inflationären Rede von den Werten gekommen ist bzw. welche Funktion diese Rede erfüllt. Ich vertrete die These, dass die Wertrhetorik (Grundwerte, Leitwerte usw.) ein Vakuum füllt. Dieses Vakuum entstand durch die zunehmende Individualisierung und religiös-weltanschauliche Heterogenität der Gesellschaft, die es nicht mehr erlaubte, unbesehen von der (wie auch immer verstandenen) Christlichkeit der Gesellschaft auszugehen.9 ${ }^{91}$ Auf die unterstellte Christlichkeit als einheitsbildenden Faktor der Gesellschaft konnte je länger, je weniger zurückgegriffen werden. Die Furcht vor Zwist und Krieg auf Grund einer fehlenden einheitsstiftenden gesellschaftlichen Klammer lässt nach einer solchen suchen. Mit der Rede von Grundwerten werden bestimmte für das friedliche Zusammenleben als notwendig erachtete Vorstellungen evoziert oder unterstellt. Luhmann nennt als Beispiele: «Gerechtigkeit, Fairness, Durchsetzungswürdigkeit des Rechts, Gleichheit des Zugangs aller zu allen Funktionen».92 Die Werte erfüllen folgenden Zweck: Sie suggerieren eine gewisse gesellschaftliche Einheit, die sich aber nicht auf eine bestimmte traditionelle Glaubenstradition abzustützen scheint und somit nicht mit dem Recht auf Glaubens- und Gewissensfreiheit kollidiert.

Die Vermittlung von sogenannt allgemeinen Grund- oder Leitwerten ersetzt das spezifisch christliche Ethos, in das angesichts der verfassungsmässig garantierten Glaubens- und Gewissensfreiheit an der öffentlichen Schule nicht mehr eingeführt werden darf. Das Dilemma der liberalen Gesellschaftsordnung wird somit auf eine höhere Ebene geschoben, aber damit keineswegs gelöst, wenn man davon ausgeht, dass auch sogenannt allgemeine Werte partikularen Ursprungs sind und deshalb nicht von allen Menschen notwendig geteilt werden. Solange die verschiedenen Grundwerte nicht konkretisiert werden, kann zumindest ein Schein der Nicht-Perspektivität aufrechterhalten werden. ${ }^{93}$ Wer keine Sensibilität für die Perspektivität von sogenannt allgemeinen Grundwerten äussert oder diese negiert, unterliegt der Gefahr eines unkritischen, zivilreligiösen Glaubens.

\subsection{Zwei Typen von Zivilreligion}

Im parallelen Kapitel zur Situation im I9. Jahrhundert (vgl. Unterkapitel 7.5) habe ich aufgezeigt, dass sich in der Diskussion um i 870 in Reinform weder die französische noch die amerikanische Form von Zivilreligion findet, sondern auf

9I Vgl. die bereits in Unterkapitel I0.I (S. 263) erwähnten Ausführungen Charles Taylors über den Wandel des Glaubens an Gott zu einer gesellschaftlichen Option neben andern.

92 Luhmann 2004, I75.

93 Vgl. Unterkapitel 2.5: Luhmann bringt den Begriff der Zivilreligion in Verbindung mit der Grundwerte-Diskussion (vgl. Luhmann 2004). 
subtile Weise Elemente beider Typen manifest werden. Als ein zentraler Unterschied zur französischen Version haben sich die Richtungskämpfe, die innerhalb der Landeskirche stattfanden, herausgestellt. Durch die Verbreitung der liberalen Theologie im Volk nahm die zürcherische Form von Zivilreligion den Charakter einer Symbiose zwischen Schule und liberaler Volkskirche an und ist nicht wie bei der französischen Version als Wandel von religiös-kirchlich-katholischen Inhalten zu national-zivilreligiösen zu beschreiben (vgl. Unterkapitel 7.5.I). Das Kontrastmodell zur amerikanischen Version von Zivilreligion ist das Modell der Landeskirche, denn grundlegend für den amerikanischen Typus von Zivilreligion ist die Trennung von Kirche und Staat. Mit dem landeskirchlichen Modell werden im Unterschied zu Amerika bestimmte Religionsgemeinschaften staatlich bevorzugt. Ähnlich wie im denominationalistischen Amerika war jedoch auch im landeskirchlichen Zürich um I 870 die Verwendung religiöser Symbolik im öffentlichen Raum Usus. Im Folgenden soll gezeigt werden, auf welche Weise sich in der Diskussion zu Beginn des 20. Jahrhunderts Elemente des französischen und amerikanischen Typus von Zivilreligion manifestieren.

Von theologischen Richtungskämpfen innerhalb der reformierten Kirche in der Art wie sie im I9. Jahrhundert ausgefochten wurden, kann im 2 I. Jahrhundert nicht mehr die Rede sein. Die liberale Theologie nahm den atmosphärischen Charakter von Luft an, die beim alltäglichen Ein- und Ausatmen gar nicht mehr wahrgenommen wird. Die liberalen Reformierten sind Teil des gesellschaftlichen Mainstreams geworden. Während im 19. Jahrhundert ein Pfarrer und Theologe wie Friedrich Salomon Vögelin mit seinen theologisch-liberalen Predigten die Massen - <das Volk $>$ sowohl für als auch gegen sich mobilisieren konnte, ist die reformierte Kirche im 21. Jahrhundert für das Gros der Bevölkerung weitgehend irrelevant geworden. ${ }^{94}$ Dies zeichnet sich auch in den Statistiken ab, die für die beiden grossen öffentlich-rechtlich anerkannten Kirchen und seit 1970 insbesondere die evangelisch-reformierte Kirche einen drastischen Rückgang der Kirchenmitgliederzahlen aufweisen. So waren 1990 im Kanton Zürich noch knapp 48 Prozent evangelisch-reformiert, im Jahr 2000 sank ihr Anteil unter 40 Prozent.95 Dem gegenüber hat insbesondere die Gruppe der konfessionslosen Personen zahlenmässig stark zugelegt; von I,6 Prozent im Jahre I970 auf I 3,3 Prozent im Jahre 2000.

94 So auch der ehemalige Basler Münsterpfarrer Bernhard Rothen, der in einem Zeitungsinterview die zunehmende Bedeutungslosigkeit der evangelischen Kirche hervorhebt: «Die Kirche vertritt fast nur Gemeinplätze, sie betätigt sich als religiöses Megafon für die moralischen Forderungen der Zeit und tut niemandem weh. Im Moment ist sie noch gegen Sterbehilfe, irgendwann wird sie nicht mehr dagegen sein. Die Kirche passt sich an und wird irrelevant» (Die evangelische Volkskirche geht kaputt, Tages-Anzeiger, 21. 4. 2015). 
Angesichts dieses Rückgangs der Mitgliederzahlen mag erstaunen, dass das Thema Volkskirche zumindest unter evangelischen Theologen nach wie vor hochaktuell zu sein scheint. Diesen Eindruck gewinnt man zumindest, wenn man sich auf dem einschlägigen theologischen Büchermarkt umschaut. ${ }^{6}{ }^{6} \mathrm{Ob}$ die Thematisierung der Volkskirche in einer Zeit des beschleunigten Mitgliederschwundes ein (letzter) Versuch ist, die evangelische Kirche vor dem vollständigen Absinken in die Bedeutungslosigkeit zu retten, kann und soll in dieser Arbeit jedoch nicht diskutiert werden. Es sind diese sich im Volkskirchengedanken manifestierenden staatskirchlichen Reminiszenzen, die die Situation im Kanton Zürich auch im 2r. Jahrhundert nur schwer mit dem amerikanischen Typus von Zivilreligion parallelisieren lassen. Einzig darin, dass auch in jüngster Zeit Politiker und Politikerinnen an kirchlichen und kirchennahen Veranstaltungen wie zum Beispiel Abdankungsfeiern oder Gedenkfeiern teilnehmen und «damit die Wertschätzung und die gesellschaftliche Relevanz von Religion» ${ }^{97}$ ausdrücken, ist eine Parallele zum amerikanischen Typus von Zivilreligion auszumachen..$^{98}$

In der Diskussion um 1870 wurde, am Beispiel von Vögelin, das durch das liberale Volkskirchentum entstandene - fast als Symbiose zu bezeichnende Verhältnis zwischen Schule und Kirche beschrieben. Auf diese Weise kann das Verhältnis zwischen Schule und Kirche im 2 1 . Jahrhundert nicht mehr beschrieben werden. Doch die Untersuchungen und Interpretationen von Jödicke und Rota (2010) lassen eine diesbezügliche Kontinuität erkennen, wenn sie, wie bereits weiter oben in Unterkapitel 9.3 (vgl. S. 238) gesagt wurde, die «zivilreligiöse Interpretation» ${ }^{99}$ des Religionsunterrichts an der öffentlichen Schule als «Fortentwicklung eines liberalen christlichen Religionsunterrichts» ${ }^{100}$ verstehen.

96 Im Herbst 2016 haben die drei evangelischen Theologen Matthias D. Wüthrich, Matthias Zeindler und David Plüss einen Sammelband herausgegeben mit dem Titel Ekklesiologie der Volkskirche. Theologische Zugänge in reformierter Perspektive. Ein Jahr zuvor kam von Claudia Kohli Reichenbach und Matthias Krieg ebenfalls im TVZ Verlag ein Band zur selben Thematik heraus: Volkskirche und Kirchenvolk. Ein Zwischenhalt.

97 Kley 2008, 92. Ob Politiker und Politikerinnen mit der Teilnahme an religiös-kirchlichen Anlässen nicht bloss die «Wertschätzung und die gesellschaftliche Relevanz von Religion ausdrücken», sondern sich damit «selbst als gläubige Christen» (Kley, S. 92) zeigen, scheint mir jedoch keineswegs zwingend zu sein. Es muss niemand religiös oder gar Christ sein, um mit der Teilnahme an einem Trauergottesdienst öffentliche Anteilnahme für die Angehörigen von bei einem Unfall oder einem Selbstmordattentat getöteten Menschen zu äussern.

98 Im Juni 2016 lichteten die Zeitungen zum Beispiel die Zürcher Stadträtin Corine Mauch ab, wie sie an der Gedenkfeier für die Opfer des Homosexuellenklubs in Orlando/FL Kerzen anzündete und sich im Kondolenzbuch einschrieb (vgl. Meldung auf Watson, I3. 6. 20I6).

99 Da der Ausdruck Zivilreligion im Schlussbericht von Jödicke und Rota nicht genauer erläutert wird, verzichte ich hier darauf, den Unterschied zwischen ihrer und meiner Verwendung zu analysieren. Eine diesbezügliche Begriffsklärung scheint mir in diesem Zusammenhang auch nicht relevant, da es Jödicke und Rota primär um die Unterscheidung zweier unterschiedlicher Interpretationen des schulischen Religionsunterrichts geht.

ı०० Jödicke und Rota 20ı, I 3 f.; vgl. auch Unterkapitel 9.3. 
Die zivilreligiöse Traditionslinie beschreiben Jödicke und Rota folgendermassen: «Insofern die staatlichen Instanzen die Verantwortung tragen und die katholische und evangelische Kirche wenig oder keinen direkten Einfluss haben, fallen Initiative, Gestaltungsspielraum und Verantwortung in die Hände von staatlichen engagierten Personen, die sich (häufig auch theologisch ausgebildet) liberalen religiösen Vorstellungen im weitesten Sinn verpflichtet fühlen. Insbesondere, wenn die Verbindung mit Ethik oder Lebenskunde eine entscheidende Rolle spielt, kann von einem zivilreligiösen, von kirchlichen Institutionen losgelösten Programm gesprochen werden. Das zentrale Deutungsmuster ist hierbei die Unterscheidung zwischen einer konfessionell-spezifischen Religiosität verbunden mit religiöser Praxis, die in der Gemeinde sozialisiert wird, und auf der anderen Seite einer allgemeinen Religiosität, die in der Schule sozialisiert werden kann, weil sie Wissenskomponenten, Ethik und basale religiöse Aufgeschlossenheit umfasst». ${ }^{\text {10I }}$

Die Kontinuität zum beschriebenen, symbiotischen Verhältnis zwischen Schule und Kirche im 19. Jahrhundert bei Vögelin besteht im 21. Jahrhundert nicht darin, dass die Kirche als Institution ihren Einfluss in der Schule würde geltend machen wollen, sondern darin, dass - wie Jödicke und Rota in ihrem Schlussbericht schreiben - der schulische Religionsunterricht (oder der Unterricht zum Thema Religion) von Personen mit einem christlich liberalen Hintergrund gestaltet wird. So gesehen kann auch die Situation zu Beginn des 2 I. Jahrhunderts weder dem französischen noch dem amerikanischen Typus von Zivilreligion zugewiesen werden.

Anders als in der Diskussion um I 870 ist im 2 I. Jahrhundert mit der Freidenkerbewegung jedoch eine Argumentationslinie vertreten, die eine starke Parallele zum französischen Typus von Zivilreligion aufweist. ${ }^{102}$ Im Unterschied zu praktisch allen anderen an der Diskussion beteiligten Akteuren wandten sich die Freidenker in ihrer Vernehmlassungsantwort dezidiert gegen das Ansinnen, die Vermittlung bestimmter «Tugenden wie Nachdenklichkeit und Weltoffenheit [...] mit einer Unterweisung über Religionen zu verquicken». ${ }^{103}$ Der Kampf der Freidenker ist in der zürcherischen Diskussion um den schulischen Religionsunterricht nicht, wie zur Zeit der Französischen Revolution, gegen die katholische Kirche und ihre Vertreter gerichtet, sondern gegen die Thematisie-

IOI Jödicke und Rota 20I0, I $3 \mathrm{f}$.

I02 Bereits im 19. Jahrhundert gab es Atheisten und Personen und Gruppierungen, die sich für eine Trennung von Kirche und Staat einsetzten. Doch eine volksnahe Gruppierung wie die deutschschweizerische Freidenkervereinigung, die es sich dezidiert zur Aufgabe gemacht hat, die in Art. I s der Bundesverfassung verankerte Glaubens- und Gewissensfreiheit zu verwirklichen sowie sich für die Trennung von Kirche und Staat und auch von Kirche und Schule einzusetzen, wurde erst 1908 gegründet (vgl. Dellsperger 20I 2).

I03 Freidenkervereinigung Schweiz, Stellungnahme von März 2006. 
rung von Religion im Zusammenhang mit Moralvermittlung per se. Auch einen religionskundlichen Unterricht sehen sie nicht gefeit gegen jede Gefahr einer christlichen Prägung. Insofern die Freidenker aber mit ihrem Gegenvorschlag für ein Lebenskunde- oder Ethikfach nicht bloss einen reinen Philosophieunterricht anstreben, sondern es dabei immer auch um Moralerziehung geht - es soll zu Toleranz, Weltoffenheit, kritischem Denken erzogen werden - und weil diese von einer explizit weltlich-humanistischen und antidogmatischen Ausrichtung bestimmt ist, kann von einem Wandel von christlich-religiösen Inhalten zu zivilreligiösen gesprochen werden.

\subsection{Fazit Teil 3}

Als Abschluss des dritten Teils dieser Arbeit soll die diese Studie leitende Frage nach zivilreligiösen Tendenzen in der Diskussion um den schulischen Religionsunterricht zu Beginn des 2 I. Jahrhunderts im Kanton Zürich zusammenfassend beantwortet werden. Analog zum Fazit des ersten Teils orientiert sich die Antwort ebenfalls an den fünf Punkten, der im Unterkapitel 2.6 dargelegten genaueren Bestimmung und Eingrenzung des Begriffs der Zivilreligion.

I. Funktionale Ausdifferenzierung und weltanschaulich-religiöse Heterogenität als Voraussetzung von Zivilreligion: Mit der Einführung des obligatorischen Schulfachs Religion und Kultur auf der Oberstufe der Volksschule ab dem Schuljahr 20II/I $2^{104}$ wurde die letzte strukturelle Verflechtung zwischen Schule und Kirche gelöst. Hinsichtlich des Aspekts der Ausdifferenzierung sind mit dieser Entflechtung im Vergleich zur Situation im I9. Jahrhundert mehr Voraussetzungen gegeben, um begrifflich kontrolliert von Zivilreligion zu sprechen. Die weltanschaulich-religiöse Heterogenität der Gesellschaft hat zugenommen. Dieser Umstand lässt den Ruf nach gesellschaftlichem Zusammenhalt stärker werden.

2. Es wurde festgestellt, dass das Bewusstsein für die Spannung zwischen Religionsfreiheit einerseits und dem Streben nach gesellschaftlichem Zusammenhalt andererseits im wissenschaftlichen Kontext vorhanden war und auch differenziert artikuliert wurde. In der medialen und politischen Diskussion aber ist diese Spannung kaum sichtbar geworden. Vielmehr scheint das problematische Verhältnis zwischen Religionsfreiheit und Integration mit der Evokation von Einheit übertüncht oder aus strategischen Gründen und politischem Kalkül

I04 Gemäss Bildungsratsbeschluss vom 4. Dezember 2006 konnten die Gemeinden ab dem Schuljahr 2007/08 das Fach Religion und Kultur einführen, falls sie über genügend Lehrpersonen mit der erforderlichen Lehrbefähigung verfügten. Im Schuljahr 20 I I/ I 2 mussten alle Schulgemeinden mit der Einführung des neuen Schulfachs auf der Oberstufe begonnen haben. 
sogar bewusst ausgeklammert worden zu sein. Meist wurde mit dem Ziel gesellschaftlichen Friedens Einheit durch Integration bzw. gesellschaftliche Homogenisierung oder durch interkulturellen Dialog angestrebt. Obwohl von Seiten der Freidenkerbewegung Kritik an der interreligiösen Dialogrhetorik erfolgte, da gerade der Verzicht auf jeden interreligiösen Dialog als friedensförderlich erachtet wurde, strebten auch die Freidenker in ethischer Hinsicht nach Homogenisierung.

3. Obwohl die funktionale Ausdifferenzierung der gesellschaftlichen Sphären von niemandem ernsthaft in Frage gestellt wird, führen die an die öffentliche Schule gerichteten kulturellen Integrationserwartungen tendenziell zu einer Verwischung der gesellschaftlichen Sphärengrenzen. Die an die öffentliche Schule gerichtete Erwartung - die im Besonderen im schulischen Religionsunterricht deutlich wird -, sogenannte gesellschaftliche Grundwerte zu vermitteln, ist Ausdruck der Instrumentalisierung einer Bildungsinstitution zu staatspolitischen bzw. national-gesellschaftlichen Zwecken. Gesellschaftliche Kohäsion gerät in ein Konkurrenzverhältnis zu Bildung als Leitfunktion der Schule. Die Schule nimmt den Charakter einer Wertegemeinschaft an, deren Ziele potentiell mit denjenigen anderer Wertegemeinschaften konfligieren, zum Beispiel Familie, Religionsgemeinschaften, weltanschauliche Gruppierungen usw.

4. Ein weiteres zentrales Merkmal zivilreligiöser Tendenzen ist die Annahme einer scheinbar allgemeingültigen, geschichtslosen Perspektive nicht nur auf Religion, sondern auf menschliche Erkenntnis und Erfahrung ganz allgemein. Dieses omniperspektivische Denken manifestiert sich auf zweifache Weise: zum einen mit der Evokation von vermeintlich allgemeinen in der Schule zu vermittelnden Werten, mit denen die Hoffnung verbunden wird, dem Auseinanderdriften der Gesellschaft durch die zunehmende religiös-weltanschauliche Heterogenität entgegenwirken zu können. Zum andern auf der Metaebene in der Annahme eines religionskundlichen Ansatzes für den schulischen Religionsunterricht, der sich auf didaktischer Ebene in der Unterscheidung zwischen teaching about und teaching in konkretisiert.

5. Als zentrales Unterscheidungsmerkmal zwischen dem französischen und amerikanischen Idealtypus von Zivilreligion und der für Zürich charakteristischen Form von Zivilreligion hat sich die Nähe zwischen dem schulischen Religionsunterricht und dem in der breiten Bevölkerung zur Normalität gewordenen liberaltheologischen Gedankengut sowie dem Gedanken einer Volkskirche herausgestellt. Im Unterschied zum 19. Jahrhundert lässt sich jedoch in den Argumentationen der Freidenkerbewegung eine Parallele zum französischen Typus von Zivilreligion aufzeigen. 
Am Ende des dritten Teils soll zusammenfassend folgende These festgehalten werden. Zivilreligion zeigt sich in den Diskussionen über den schulischen Religionsunterricht zu Beginn des 2r. Jahrhunderts in zwei Formen: einer liberal-theologischen und einer aufklärerisch-freidenkerischen. Letztere hat sich bereits im I9. Jahrhundert mit einer Figur wie Johann Caspar Sieber angebahnt, fand aber damals noch keine nennenswerte Verbreitung. Beiden Formen von Zivilreligion gemeinsam ist ein gewisses Streben nach gesellschaftlicher Homogenisierung und die Indienstnahme der öffentlichen Schule zu einem überhöhten Zweck, indem von der Schule Friedensförderung oder gesellschaftliche Integration erwartet wird.

Zivilreligion in liberal-theologischer Form manifestiert sich auf folgende Weise: Das homogenisierende, einheitsstiftendes Moment tritt meist implizit in der Forderung nach Auseinandersetzung mit dem Thema Religion bzw. Religiosität hervor. Der für die liberale Theologie zentrale Gedanke der Volkskirche geht nicht von einer kultischen Gemeinschaft mit ihren eigenen Lehren und Dogmen aus, die sich von anderen religiös-weltanschaulichen Gemeinschaften notwendigerweise unterscheidet, sondern basiert auf der Annahme einer übergeordneten Lerngemeinschaft, die sich mit dem Thema Religion beschäftigt, und der potentiell alle Menschen angehören.

Zivilreligion in aufklärerisch-freidenkerischer Form manifestiert sich auf folgende Weise: Das homogenisierende, einheitsstiftende Moment offenbart sich in der Forderung nach Nicht-Thematisierung von Religion in einem schulischen Ethikunterricht, der nicht bloss als philosophischer Unterricht im Sinne einer metaethischen Reflexion der Moralbegründung, sondern viel eher als ethisch reflektierte Wertevermittlung gedacht wird. Im Unterschied zur theologischliberalen Form kann hier von einer negativen Religionsfixierung gesprochen werden, die für dieses Verständnis eines schulischen Ethikunterrichts konstitutiv zu sein scheint. 
Teil 4 AUSBLICK 


\section{Zivilreligiöse Erwartungen an die Schule - so what?}

Ausgangspunkt dieser Arbeit war das Spannungsfeld zwischen gesellschaftlicher Ausdifferenzierung und gesellschaftlicher Integration. Anhand der Frage nach zivilreligiösen Tendenzen in den öffentlichen Diskussionen um den schulischen Religionsunterricht Ende des 19. Jahrhunderts und zu Beginn des 21. Jahrhunderts im Kanton Zürich wurde versucht, den Umgang mit dieser Spannung darzustellen. Zivilreligiöse Erwartungen an die öffentliche Schule haben sich als Ausdruck der Tendenz herausgestellt, diese Spannung aufzulösen. Nach einem ausführlichen deskriptiven Teil soll in diesem letzten Kapitel die Problematik zivilreligiöser Erwartungen an die öffentliche Schule anhand der Erläuterung dreier normativer Thesen umrissen werden:

I. Zivilreligiöse Erwartungen haben die öffentliche Schule primär als Erziehungsinstitution im Blick und sind somit Ausdruck totalisierender bzw. homogenisierender Tendenzen. (Kapitel I I.I)

2. Die zur Evokation gesellschaftlicher Einheit bemühte Rede von Werten ist semantisch unbestimmt und steht in der Gefahr, reale Machtverhältnisse und machtförmige Interessen zu kaschieren. (Kapitel i I.2)

3. Zivilreligiöse Tendenzen stehen pluralistischen Tendenzen entgegen und gefährden eine echte Multikulturalität. (Kapitel I I.3)

Diese drei Thesen werden im Folgenden ansatzweise entfaltet. Diese Ausführungen erheben jedoch nicht den Anspruch, ein abschliessendes Urteil zu geben. Im besten Fall bieten sie Anlass zu weiterführenden Diskussionen.

\subsection{Zivilreligiöse Erwartungen als Indikator totalisierender Tendenzen}

Die Indienstnahme der öffentlichen Schule zu einem überhöhten Zweck Friedensförderung und gesellschaftliche Integration - wurde im vorangehenden Unterkapitel I0.6 als Ausdruck von Zivilreligion beschrieben. Dass der Staat von der durch ihn unterstützten Schule auch Leistungen erwarten kann, ist naheliegend und legitim. Die Frage aber ist, wie zwischen legitimen staatsbürgerlichen und überböbten zivilreligiösen Zwecken unterschieden werden kann. Ich schliesse mich in dieser Frage einem Staatsverständnis an, das öffentliche Gerechtigkeit als zentrale Aufgabe des modernen Rechtsstaates ins Zentrum stellt und auf der Theorie der Sphärensouveränität basiert, das heisst, von der Bedeutung und Integrität distinkter gesellschaftlicher Sphären ausgeht und zum Ziel hat, 
diese zu fördern. ${ }^{\text {I }}$ Dieses Staatsverständnis kann im Rahmen dieses Ausblicks freilich nur ansatzweise dargelegt werden. Ich beziehe mich hauptsächlich auf diesbezügliche Ausführungen des politischen Philosophen Jonathan Chaplin, die er im Aufsatz Beyond Multiculturalism - But to Where? Public Justice and Cultural Diversity dargelegt hat. ${ }^{2}$

Die primäre Aufgabe des Staates wird hier darin gesehen, das Verhältnis von Individuen und Kollektiven als Träger von verschiedenartigen Rechten untereinander gerecht zu regulieren. «[T] he central idea of public justice is that the task of the state is the establishment of justice in the public relationships of a society. This involves not the imposition of a blueprint, but rather the taking up of a dynamic, on-going struggle to justly balance the many legitimate jural interests rising up within a complex society at any time.»3

Der staatliche Einflussbereich wird auf die Durchsetzung politisch-rechtlicher Gerechtigkeit beschränkt und nicht auf Gerechtigkeit schlechthin. Politisch-rechtliche Gerechtigkeit bedeutet die Gleichbehandlung aller Menschen vor dem Gesetz. So werden beispielsweise alle Menschen mit einer Geldbusse für Geschwindigkeitsüberschreitungen beim Autofahren bestraft - sowohl derjenige, der dies aus moralischen Motiven tut, weil er seine in den Wehen liegende Frau ins Spital fährt, als auch derjenige, der sich mit einem Kollegen ein Wettfahren liefert. Politisch-rechtliche Gerechtigkeit ist jedoch nicht bloss im strafrechtlichen, retributiven Sinn zu verstehen, sondern auch im Sinne einer Förderung der Zivilgesellschaft durch das Setzen von fairen Rahmenbedingungen. Traditionellerweise wird in diesem Zusammenhang von öffentlichem Wohl oder dem öffentlichen Gut gesprochen.

Weiterhin zu beachten ist die Unterscheidung von politischer und moralischer Gerechtigkeit. Im Kontrast zur politischen Gerechtigkeit impliziert moralische Gerechtigkeit nicht zwingend die Gleichbehandlung aller Menschen. Einem behinderten Kind mehr Aufmerksamkeit zu schenken als dem nicht behinderten Geschwister, kann durchaus legitim sein, sofern das Geschwister nicht vernachlässigt wird. Dies aber nicht, weil es ein gesetzlich verbrieftes Recht hat auf mehr Aufmerksamkeit, sondern weil es mehr Zuwendung benötigt.

Chaplin nennt drei Implikationen der öffentlich-rechtlichen Grundbestimmung des Staates: I) Obwohl die staatlichen Gesetze moralische ${ }^{4}$ Verpflichtungen der

I Vgl. Unterkapitel I.4.

2 Chaplin 2008; vgl. auch die zusammenfassende Darstellung von Chaplins Verständnis der Sphärensouveränität in Katzenstein 2009.

3 Chaplin 2008, 197.

4 In der Theorie der Sphärensouveränität wird der Begriff der Moral anders gefasst als seit Kant gemeinhin üblich. Im ersten Fall bezieht sich Moral typischerweise auf ein Interaktionsverhältnis zwischen near and dear, (Familien- und Freundschaftssphäre), das sich durch die Norm der solidarischen Liebe auszeichnet. Moralische Richtigkeit oder Falschheit bemisst 
Bürgerinnen und Bürger reflektieren und moralisch nie neutral sind, gehört es deswegen nicht zum Aufgabenbereich des Staates, in seinen Bürgerinnen moralische Tugenden oder Einstellungen auszubilden. Der Staat hat zum Beispiel durchzusetzen, dass alle Bürger ihre Steuern bezahlen und dass diejenigen bestraft werden, die des Steuerbetrugs überführt werden. Es obliegt dem Staat jedoch nicht, in seinen Bürgern die richtige moralische Motivation zur Bezahlung ihrer Steuern herauszubilden, zum Beispiel aus empfundener Solidarität mit den ökonomisch weniger gut gestellten Mitbürgern. Dies schliesst allerdings nicht aus, dass gerechte Gesetze und politische Massnahmen bei der Vermittlung moralischer Tugenden eine unterstützende Wirkung haben können. So könnte zum Beispiel das Gesetz für ein gemeinsames Sorgerecht im Falle einer Scheidung dazu führen, dass sich die Eltern zu Gunsten ihrer Kinder um eine Versöhnung bemühen, die es ihnen trotz Trennung erlaubt, auf gute Weise gemeinsam für das Wohl der Kinder zu sorgen (dasselbe Gesetz könnte den Streit allerdings auch noch verschärfen). 2) Der Schutz der bisherigen Nationalkultur vor allen möglichen Fremdeinflüssen gehört nicht zur Aufgabe des Staates. Der Staat hat sich sehr wohl für das öffentliche Gut einzusetzen, zu dem durchaus auch Elemente einer Nationalkultur, beispielsweise Sprache oder Gegenstände von wichtiger, historischer Bedeutung, gehören können. Doch ist das öffentliche Gut nicht mit der Nationalkultur zu verwechseln. 3) Zuletzt besteht die Aufgabe des Staates auch nicht darin, die individuelle Wahlfreiheit zu maximieren oder einer breit gefächerten Bürgerschaft ein Regime der forcierten Gleichheit überzustülpen. ${ }^{5}$

Nach dieser kurzen Skizze des von mir hier vorausgesetzten Staatsverständnisses kehre ich zur Ausgangsfrage zurück: Was kann der Staat legitimerweise von der von ihr unterstützten öffentlichen Schule erwarten? Der Staat kann von der Schule erwarten, dass sie den angehenden Bürgerinnen und Bürgern diejenigen Fähigkeiten und Fertigkeiten ${ }^{6}$ beibringt, die nötig sind, damit diese ihre staatsbürgerlichen Pflichten und Rechte wahrnehmen können. Dazu gehören ele-

sich daran, ob in Beziehungen zu Freunden und/oder Familienmitgliedern diese solidarische Liebe gelebt wird. Staatliche Gesetze können deshalb in einem üblichen Sinn nicht als moralisch bzw. unmoralisch bezeichnet werden, denn sie beziehen sich nicht auf Interaktionsverhältnisse zwischen Menschen mit familiär-freundschaftlicher Verbindung, sondern auf Interaktionsverhältnisse zwischen Menschen qua Bürgerinnen und Bürger. Die staatlichen Gesetze können aber gerecht oder ungerecht sein. Staat und Moral sind deswegen nicht zwei völlig verschiedene Dinge. Insofern das Verhältnis zwischen den Bürgerinnen und Bürgern von Solidarität geprägt ist, ähnelt die Beziehung zu meinen Mitbürgern den familiär-freundschaftlichen Beziehungen und reflektiert somit die moralische Norm (vgl. Dooyeweerd 1997 [i955], is I ff.).

5 Vgl. Chaplin 2008, 197.

6 In derzeitig gängiger Redeweise müsste man von Kompetenzen sprechen. Auf die Kompetenzdebatte kann hier jedoch nicht eingegangen werden. 
mentare Kulturtechniken wie Lesen, Schreiben und Rechnen, Grundkenntnisse in den verschiedenen natur- und geisteswissenschaftlichen Fächern, aber auch Informatik und Medienbildung sowie personale und überfachliche Fähigkeiten wie zum Beispiel die Anwendung von Lernstrategien oder die Fähigkeit, bei Bedarf geeignete Hilfe und Unterstützung zu suchen. ${ }^{7}$ Darüber hinaus kann und soll durchaus auch innerhalb der verfassungsmässig garantierten Glaubens- und Gewissensfreiheit eine staatsbürgerliche Ethik vermittelt werden. ${ }^{8}$ Es muss hier jedoch betont werden, dass es nicht um Ethik schlechthin geht bzw. um die Vermittlung von Moral oder menschlichen Tugenden per se. In einer öffentlichen Schule kann nur die Vermittlung einer politischen Moral und ziviler Tugenden legitim sein. ${ }^{9}$ Chaplin nennt als Beispiele für zivile Tugenden: «respect for law, the capacity for political participation and critical deliberation». Zum Respekt für das staatliche Gesetz gehört beispielsweise die Anerkennung dessen, dass meine Mitmenschen - auch diejenigen, die weder meine weltanschaulich-religiösen noch politischen Überzeugungen teilen - dieselben politischen Rechte besitzen wie ich und ich sie nicht daran hindern darf, von diesen Rechten Gebrauch zu machen. Die Partizipation am politischen Prozess sowie die kritische Deliberation setzen die bereits oben genannten Fähigkeiten und Fertigkeiten voraus. Das kritische Erwägen verschiedener Möglichkeiten und Argumentationen, um bei Abstimmungen zu einem begründeten Entscheid zu kommen, setzt beispielsweise voraus, dass ich mir Informationen verschaffen, verschiedene Ansichten zu einer bestimmten Thematik rezipieren und verstehen und mit anderen darüber diskutieren kann. Eine gelingende Diskussion wiederum setzt die Einhaltung von Gesprächsregeln voraus, zum Beispiel offenes Zuhören, einander ausreden lassen, alle zu Wort kommen lassen usw. Bei der Vermittlung ziviler Tugenden muss - das ist entscheidend - das Resultat der Deliberation jedoch offenbleiben, denn rationaler Dissens auf inhaltlicher Ebene ist immer möglich.

Wie in dieser Arbeit gezeigt worden ist, haben zivilreligiöse Erwartungen an die öffentliche Schule viel mehr im Blick als die blosse Vermittlung einer politischen Moral bzw. ziviler Tugenden. Aus zivilreligiöser Perspektive wird von der öf-

7 Weder beanspruche ich hier eine ausführliche und detaillierte Aufstellung dessen, was in einen Lehrplan gehört, zu bieten, noch vertrete ich die Ansicht, dass die Klärung des Staatsverständnisses dazu verhelfen kann, die Inhalte des Lehrplans der öffentlichen Schule eindeutig zu bestimmen. Bei einzelnen Unklarheiten mag das Staatsverständnis aber sehr wohl als Entscheidungsgrundlage dienen.

8 Jonathan Chaplin spricht von politischer Moral und zivilen Tugenden: «It [the state] may certainly require and stimulate adherence to the shared political morality, or civic virtue - respect for law, the capacity for political participation and critical deliberation, and so on - necessary for the sustenance and healthy functioning of the political community itself.» (Chaplin 201 I, 294, Hervorhebung im Original).

9 Vgl. ebd. 
fentlichen Schule die Vermittlung von menschlichen Tugenden als solchen - die Förderung des Humanum - gefordert. Doch sobald der Staat via Schule Einfluss nehmen will auf den ganzen Menschen, den Menschen per se, läuft er Gefahr, übergriffig zu werden und totalisierende Züge zu entwickeln.

Auf dem Hintergrund des eben skizzierten Staatsverständnisses sollen in der öffentlichen Schule keine Einstellungen und Haltungen vermittelt werden, die über staatsbürgerliche Ziele hinausweisen. Der Versuch, in der öffentlichen Schule möglichst nur Einstellungen und Haltungen zu vermitteln, die der politischen Moral dienen, bedeutet natürlich nicht, dass zum Beispiel das Trainieren des Einhaltens von Gesprächsregeln - mit dem Ziel der Einübung kritischer Deliberation - nicht auch einen Einfluss darauf haben kann, wie die Kinder sich später in Gesprächen zu ihren (Ehe-)Partnern oder Arbeitskolleginnen verhalten werden.

An dieser Stelle ist es angebracht, auf die am Ende von Unterkapitel I0.3 gestellte Frage nach der Funktion des schulischen Religionsunterrichts einzugehen. Aus zivilreligiöser Perspektive anerbietet sich dieses Schulfach besonders, ein solches Humanum bzw. sogenannte gesellschaftliche Grundwerte zu vermitteln. Nach dem von mir geteilten Staatsverständnis bedarf es zur Vermittlung von zivilen Tugenden jedoch keines eigens dazu eingerichteten Schulfaches. Da diese ethisch-politischen Tugenden eine Vielfalt von Fähigkeiten, Fertigkeiten, Einstellungen und Haltungen beinhalten, können und sollen sie in jedem Fach vermittelt werden. Dazu ist kein spezifisches Fach Religion nötig bzw. könnte dieses allein diesen $Z$ weck nicht erfüllen.

Chaplin betont, dass die vom Staat initiierte Integration öffentlich-rechtlicher Art sein müsse und nicht religiöser, ethischer, ethno-kultureller oder ökonomischer Art sein dürfe. ${ }^{\circ}$ Auf die Bedeutung der Unterscheidung zwischen der staatlich-rechtlichen Sphäre und anderen gesellschaftlichen Sphären weist indirekt auch der Philosoph Robert Spaemann in seinem Aufsatz Vorsicht: "Wertegemeinschaft»! ${ }^{11}$ hin. Spaemann hebt in diesem Aufsatz die freiheitliche Rechtsordnung als Errungenschaft des neuzeitlichen Staates hervor und warnt vor der «Tendenz, die Rede von Grundrechten allmählich mehr und mehr zu ersetzen durch die Rede von Grundwerten». ${ }^{12}$ Auf die Werterhetorik als Ausdruck zivilreligiöser Tendenzen soll im folgenden Unterkapitel vertiefter eingegangen werden.

Io Vgl. ebd., 294.

I I Spaemann 200 I.

I2 Ebd., 2. 


\subsection{Die semantische Unbestimmtheit der Werterhetorik}

Im Unterkapitel 9.5 wurde der exzessive Gebrauch der Werterhetorik in der Diskussion um den schulischen Religionsunterricht thematisiert. In Kapitel ı० (vgl. ı 0.2.2 und I0.6) wurde die These geäussert, dass die Werterhetorik Ausdruck zivilreligiöser Tendenzen sei, insofern sie der Evokation von gesellschaftlicher Einheit dient, und dass die Rede von «grundlegenden Werten unserer Gesellschaft» oder vom «unverbrüchlichen Kern unserer gesellschaftlicher Grundwerte» usw. diese Wirkung entfalten kann, solange niemand erläutert oder präzisiert, was mit diesen Werten eigentlich genau gemeint ist. Es ist also gerade die semantische Unbestimmtheit des Wertbegriffs, der diese einheitsstiftende, zivilreligiöse Wirkung ermöglicht. Eine nicht näher bestimmte Einheit soll dem gesellschaftlichen Frieden dienen.

Doch die Frage stellt sich, ob denn für die Erhaltung des gesellschaftlichen Friedens die Evokation von Einheit mittels der Werterhetorik nötig ist. Von der öffentlichen Schule wird legitimerweise gefordert, integrative Leistungen zu erbringen. Doch warum werden dazu Werte bemüht? Reicht Integration über das Recht bzw. über Regeln nicht aus? Ist schulische Integration nicht erreicht, wenn die Kinder gelernt haben, sich an die Schulhausordnung und an die Verhaltensregeln im Klassenzimmer zu halten? Oder anders gefragt: Warum spricht man von Werten, anstatt die Dinge beim Namen zu nennen?

Unweigerlich kommen Einstellungen und Haltungen ins Spiel, wenn es darum geht, Regeln oder Gesetze zu vermitteln bzw. zu plausibilisieren. Kinder verlangen (zu Recht) nach Begründungen für die von ihnen verlangten Verhaltensweisen. Als Lehrerin an einer öffentlichen Schule kann (und sollte ich) die Regel, dass kein Kind ausgelacht, geschlagen oder von den anderen marginalisiert wird, damit begründen, dass in der Schweiz alle Kinder sowohl das Recht wie auch die Pflicht auf Unterrichtsbesuch haben und den Lehrpersonen die Aufgabe zukommt, ein für alle Kinder möglichst optimales Lernumfeld zu schaffen. Wer körperlich oder emotional beeinträchtigt ist, kann jedoch nicht optimal lernen. Diese pädagogische Begründung für die Anti-Mobbing-Regel basiert auf der Annahme, dass Lernen ein Wert oder ein Gut ist. Ein Jurist könnte die im Schulhaus-Knigge ${ }^{13}$ festgehaltene Anti-Mobbing-Regel mit Verweis auf die Schweizerische Strafgesetzgebung begründen, die Beschimpfung, Verleumdung oder Körperverletzung unter Strafe stellt. Natürlich basieren diese Gesetze auch auf Werten, zum Beispiel der körperlichen oder emotionalen Unversehrtheit. Derselbe könnte auch auf die Verfassung des Kantons Zürich verweisen, die un-

I 3 Vgl. Knigge des Schulhauses Rotweg in Horgen/ZH, https://www.rotweg.net/infos-a-z/knigge/ (I8. I2. 20I8). 
ter den Grundrechten den Schutz der Menschenwürde garantiert. Ein gläubiger Christ oder eine praktizierende Jüdin könnten dieselbe Anti-Mobbing-Regel wiederum mit der Gottes-Ebenbildlichkeit des Menschen begründen, die einen respektvollen Umgang mit allen Mitmenschen fordert. Und selbstverständlich könnten noch weitere Begründungen angeführt werden. Die Ausgangsfrage aber war: Reicht es nicht, dass die Kinder die Schulhausregeln einhalten? Oder müssen sie auch noch eine bestimmte Begründung dafür gutheissen und Zeugnis für die rechte Gesinnung, mit der sie sich daran halten ablegen? Ich meine nicht. Dies sei im Folgenden etwas weiter ausgeführt.

Der Bezug auf sogenannte Werte der Aufklärung wie Toleranz, Respekt oder Gleichheit wird häufig als Lösung des Problems der Spannung zwischen gesellschaftlicher Ausdifferenzierung und Religionsfreiheit einerseits und dem Bemühen um politische Einheit und gesellschaftliche Integration andererseits propagiert. Gleichzeitig lässt sich aber zeigen, dass die Aufklärung dieses Problem noch verschärft hat, indem sie mittels einer innerweltlichen Eschatologie versucht hat, die Spannung aufzulösen. Werte können im Gegensatz zu Rechten und Pflichten nur freiwillig übernommen werden. Und wo Rechte sind, gibt es Sanktionen. Die Sanktionsgewalt ist konstitutiv für die rechtlich-politische Sphäre und lässt sich nicht eliminieren. Wo nun die Grenzen zwischen Wertgemeinschaften und Rechtsgemeinschaft verwischt werden, besteht die Gefahr, dass die Sanktionsgewalt eine subtile und verdeckte Form annimmt. Dies ist ein Grund, warum man sich nicht der Utopie einer graduellen Annäherung der Rechtsgemeinschaft an eine Wertgemeinschaft hingeben sollte.

Bereits am Ende des vorhergehenden Unterkapitels wurde auf Robert Spaemann hingewiesen, der in Bezug auf den modernen freiheitlichen Rechtsstaat die Werterhetorik zur Diskussion stellt. Spaemann formuliert diese Problematik folgendermassen: «Ein auf allgemeinem Wahlrecht beruhender, durch Grundrechte eingeschränkter Parlamentarismus kann nur existieren, wenn die Mehrheit des Volkes das will. Aber eben dies kann durch die Institutionen des Rechts zwar gefördert, nicht aber garantiert werden. Wenn der Staat dies garantieren will, dann muss er selbst zu dem werden, was er gerade ausschliessen soll, zu einer Gesinnungsdiktatur, oder, wie es heute euphemistisch heisst, einer 'Wertegemeinschaft $\gg{ }^{.14}$

Im Hintergrund von Spaemanns Kritik erklingt das bekannte Diktum des Verfassungsrechtlers Ernst-Wolfgang Böckenförde, gemäss dem der Staat von Voraussetzungen lebt, die er selbst nicht garantieren kann. Doch auch Böckenförde erachtet es als hoch problematisch, wenn der Staat selbst zum Wertevermittler

I4 Spaemann 200I, 2. 
werden soll. ${ }^{15}$ Das Dritte Reich, das auch Volksgemeinschaft genannt wurde, dient Spaemann als Beispiel für die Gefahr, die droht, wenn ein Staat zu einer Wertegemeinschaft mutiert: «Die damals als die höchsten betrachteten Werte: Nation, Rasse, Gesundheit standen allemal über dem Recht, und der Staat war, ähnlich wie im Marxismus, nur eine Agentur dieser höchsten Werte. Darum stand die Partei, die den Werten unmittelbar verpflichtet war, im Zweifelsfall immer über dem Staat. Nun gibt es gewiss immer wieder Situationen, in denen Bürger den Gehorsam gegen ein Gesetz verweigern, weil dieses Gesetz ihren Überzeugungen von fundamentalen Rechten des Menschen widerspricht. Wo aber die Staatsgewalt sich unter Berufung auf höhere Werte für legitimiert hält, Menschen an etwas zu hindern, was zu verbieten ihr kein Gesetz erlaubt, da ist Gefahr im Verzug.» ${ }^{16}$ Die von Spaemann benannte Gefahr ist insbesondere auch hinsichtlich der Schule zu vergegenwärtigen. Denn wie der Blick in die Geschichte zeigt, wurden immer wieder Versuche unternommen, die Schule zu staatlichen Zwecken zu instrumentalisieren. Im Unterkapitel 2.3 wurde dies am Beispiel des zur Zeit der Französischen Revolution entstandenen Schulplans von Lepeletier gezeigt.

Doch, so mag man einwenden, wer kann heute etwas gegen die schulische Vermittlung von sogenannt allgemeinen Werten wie Toleranz, Respekt oder Solidarität haben? Die Probleme beginnen dann, wenn man diese meist sinnfreien Worthülsen zu füllen versucht. Was ist zum Beispiel konkret mit Toleranz gemeint? Jonathan Chaplin spricht von «regimes of tolerance», um zu verdeutlichen, dass die Linie nicht zwischen toleranten und intoleranten politischen Systemen verläuft, sondern dass jedes politische System tolerant und intolerant zugleich ist. Liberale und autoritäre politische Systeme unterscheiden sich nicht durch ihre Toleranz bzw. Intoleranz, sondern durch ihr "Toleranzmenu», ${ }^{17}$ das heisst durch das, was sie als toleranzwürdig bzw. als nicht toleranzwürdig erachten. Absolute Freiheit gibt es nirgendwo. Die Frage ist also, was in einem liberalen Rechtsstaat toleriert werden kann und soll. Darf und soll das Kopftuch des muslimischen Mädchens oder gar einer Lehrerin in der öffentlichen Schule toleriert werden? Muss es eine Lehrerin tolerieren, wenn ihr Jugendliche mit Angabe von religiösen Gründen verweigern, die Hand zu geben?, usw. Sobald wir beginnen, Toleranz auf konkrete Beispiele des (Schul)alltags anzuwenden, wird deutlich, dass die Antworten auf die in dem konkreten Zusammenhang gestellten Fragen nie einheitlich ausfallen werden. ${ }^{18}$

Is Vgl. Wolfgang Böckenförde in Schieder I997, 640.

I6 Spaemann 200I, 3 .

17 Chaplin 2006, 2.

I 8 Vgl. auch Niklas Luhmann im Unterkapitel 2.4.3. 
Warum aber - um auf die zu Beginn dieses Kapitels gestellte Frage zurückzukommen - werden in der öffentlichen Diskussion 〈die Werte〉 so häufig bemüht, anstatt die Dinge beim Namen zu nennen, das heisst zu konkretisieren, worum es geht? Oder anders gefragt, warum heisst es nicht ganz lapidar, dass die Kinder lernen sollen, die Schulregeln und das staatliche Gesetz zu befolgen? Ein Versuch einer Antwort: Zum einen deutet die Rede von den Werten im Zusammenhang mit der Schule bzw. dem schulischen Religionsunterricht darauf hin, dass man die Schülerinnen und Schüler nicht bloss zu guten Staatsbürgerinnen und Staatsbürgern, sondern zu ‘guten Menschen〉 erziehen will. Dahinter steht der zivilreligiöse Glaube, dass nur durch die Erzeugung eines «Gemeinschaftsgeistes» ${ }^{19}$ der gesellschaftliche Zusammenhalt garantiert werden könne. Dies strapaziert allerdings den Auftrag einer öffentlichen Schule und kann zudem auch nicht die Priorität bloss einer gesellschaftlichen Sphäre sein.

Zum andern hat die Werterhetorik die unweigerliche Tendenz, realpolitische Machtverhältnisse zu verschleiern. Vielleicht ist diese Rhetorik so verbreitet, weil man ein Unbehagen spürt, dass Regeln und Gesetze gesetzt und durchgesetzt werden müssen, auch wenn sie nicht freiwillig von allen gewählt und gutgeheissen worden sind. Vielleicht hat die Werterhetorik in der öffentlichen Diskussion die Funktion, dieses Unbehagen abzumildern. Sie wäre eine Form von make believe, dass 'wir eine harmonische, auf 〈Vernunft basierende Gesellschaft bilden. ${ }^{\circ}$ Das Verdrängte hat jedoch eine Tendenz zurückzukehren. Unterschwellige Machtausübung ist perfid - aber vielleicht gewollt. Die Frage stellt sich: Ist die gängige Rede von Offenheit und pluralistischer Gesellschaft ebenso leer wie die Werterhetorik, um den Anschein einer modernen pluralistischen Gesellschaftsordnung aufrechtzuerhalten?

\subsection{Zivilreligion versus Pluralismus}

Meine dritte These besagt, dass zivilreligiöse Tendenzen pluralistischen Tendenzen entgegenstehen und sich gegenüber genuiner Multikulturalität und Multireligiosität verschliessen. Zivilreligion basiert auf einem gesellschaftlichen Wertekonsens, während pluralistisches Denken von möglicherweise radikal unterschiedlichen, weltanschaulich-religiösen Orientierungen ausgeht und diese

I9 Vgl. den esprit d'ensemble bei Jules Ferry im Unterkapitel 2.4.I.

20 Anhalt verweist in diesem Zusammenhang auf den Einwand Nietzsches, der «die Geltung von Normen als Produkt der In-Geltung-Setzen von Menschen, die spezifische Absichten verfolgen», entlarve. Nietzsche «lässt den kalten Wind des Werterelativismus durch das nackte Normengerüst wehen und zerrt an seinen Wurzeln, indem er ihm den Boden entzieht.» (Anhalt 20I 2b, 23). 
zumindest in struktureller Hinsicht bejaht. Zivilreligiöse Tendenzen sind nicht immer deutlich ersichtlich, da sie häufig im Gewand eines sich pragmatisch gebenden Liberalismus daherkommen. Die Diskrepanz zwischen Zivilreligion und Pluralismus soll anhand der folgenden Unterscheidungen noch etwas verdeutlicht werden; zum einen anhand der Unterscheidung zwischen liberaler Gesellschaftsordnung und Liberalismus (Nicholas Wolterstorff) und zum andern anhand der Unterscheidung zwischen politischem und umfassendem Liberalismus (John Rawls).

Die Unterscheidung zwischen liberaler Gesellschaftsordnung und Liberalismus bildet die Grundlage für den pluralistischen Denkansatz des Philosophen Nicholas Wolterstorff. Eine liberale Gesellschaftsordnung kann von Menschen mit unterschiedlichen weltanschaulich-religiösen Orientierungen befürwortet werden. Sie setzt nicht zwingend eine säkularistische Weltanschauung voraus. Ein ideologischer Liberalismus hingegen würde als Begründung für eine liberale Gesellschaftsordnung nur eine säkularistische Weltanschauung gelten lassen. Diesen Gedanken entfaltet Wolterstorff in einem Artikel, in dem er sich mit der Kritik des Religionswissenschaftlers Jeffrey Stout an der neotraditionalistischen christlich-theologischen Kritik der Liberaldemokratie befasst. Wolterstorff geht mit Stout einig, dass eine säkularistische Weltanschauung nicht wesentlich zur Liberaldemokratie gehört. ${ }^{21}$ Stout zeige jedoch nicht, dass und inwiefern sich Christentum und Liberaldemokratie durchaus - und entgegen der neotraditionalistischen theologischen Kritik - vereinbaren lassen. Der Vorwurf der Neotraditionalisten, die Liberaldemokratie sei zutiefst säkularistisch und gestehe der Religion keinen Raum ein, setzt nach Wolterstorff ironischerweise bereits ein säkularistisches Narrativ über den Ursprung der Liberaldemokratie voraus. Ein solches Narrativ sei aber eben gerade nicht zwingend. Die Kernpunkte der Liberaldemokratie könnten auch aus christlicher Perspektive anerkannt werden. $\mathrm{Zu}$ diesen Punkten zählt Wolterstorff folgende: Die Rechenschaftspflicht der Regierung gegenüber dem Volk, die gleiche Gewichtung jeder Stimme bei Entscheidungsprozessen und die Ausstattung aller Mitglieder einer liberaldemokratischen Gesellschaft mit einer Reihe von Rechten. Auf der Ebene der Begründung unterscheiden sich jedoch säkularistische und christliche Befürworter einer liberalen Gesellschaftsordnung. Die Freiheitsrechte würden aus christlicher Perspektive mit der Menschenwürde und nicht mit dem reinen menschlichen Willen («sheer volition») begründet. ${ }^{22}$

Die Identifikation von liberaler Gesellschaftsordnung und säkularistischer Weltanschauung kann potentiell für alle religiösen Menschen, die eine liberale Ge-

2 I Vgl. Wolterstorff $2005,638$.

22 Vgl. ebd., 646. 
sellschaftsordnung gutheissen, zum Problem werden. Doch auch nicht religiöse Menschen können den performativen Selbstwiderspruch erkennen, den, streng genommen, alle diejenigen begehen, die davon ausgehen, dass eine liberale Rechtsordnung nur auf säkularistischem Hintergrund auf Dauer funktionieren kann - mit Menschen, die im Grunde so swie wir sind. Denn dann ist die individuelle Freiheit für alle, die nicht ‘wie wir〉 denken, sehr eingeschränkt. John Rawls beanspruchte mit seinem politischen Liberalismus einen solchen Selbstwiderspruch gerade zu vermeiden. Die ihn leitende Frage war, wie es möglich ist, dass eine stabile und gerechte Gesellschaft von freien und gleichberechtigten Bürgerinnen und Bürgern, die ganz unterschiedliche religiöse, philosophische und moralische Überzeugungen haben, bestehen kann. «[T]he problem of political liberalism is: How is it possible that there may exist over time a stable and just society of free and equal citizens profoundly divided by reasonable religious, philosophical, and moral doctrines? This is a problem of political justice, not a problem about the highest good.» ${ }^{23}$

John Rawls beantwortete diese Frage mit der bekannten Unterscheidung zwischen einem <politischen> und einem <umfassenden> Liberalismus. Im Unterschied zum umfassenden Liberalismus beansprucht der politische Liberalismus, zu dessen Begründung nicht auf eine spezifische Weltanschauung («comprehensive view») zurückgreifen zu müssen.

Wolterstorff und Rawls wurden hier als Vertreter der Möglichkeit eines genuinen Pluralismus angeführt. In der öffentlichen Diskussion bedienen sich viele der Rede von Pluralismus, doch schaut man genauer hin, handelt es sich häufig nur um eine oberflächliche Vielfalt. Vielfalt wird befürwortet im Hinblick auf die Dinge, die nicht zur ureigensten Identität eines unterstellten Wir gehören. Die vielgerühmte Offenheit gegenüber der Vielfalt kommt jedoch sehr bald an ein Ende, wenn sich grundlegende Divergenzen auftun, die sich beispielsweise in einem völlig unterschiedlichen Freiheitsverständnis äussern. Das Tragen eines Kopftuches, der Eintritt in ein Kloster, den Zölibat als Ausdruck von Freiheit zu verstehen, kann für einen Menschen säkularistischer Prägung nicht bloss völlig unverständlich sein, sondern so falsch, dass Menschen mit solchen Bestrebungen zum richtigen Freiheitsverständnis zu 〈bekehren`sind. Ähnliches gilt im Fall von Eltern, die ihre Kinder nicht in die öffentliche Schule schicken, weil sie sie nicht in einem Umfeld bilden lassen wollen, in dem Religion nicht als jeden Lebensbereich tangierend verstanden wird, sondern vergleichbar mit einem frei wählbaren Hobby.

In scheinbar harmlose Worthülsen wie Offenheit, Toleranz, Respekt oder Freiheit verpackt, strebt Zivilreligion nach ein und derselben Identität für alle und 
hat einen hegemonialen Anspruch, ohne diesen explizit zu kommunizieren. Vom Eigenen, Bekannten wird auf alle geschlossen; die kognitive Mehrheit bestimmt. Wer zur kognitiven Mehrheit gehört, hat in der Tat kein Problem damit, wenn die Kinder in der Schule nicht bloss gehalten werden, sich an die Regeln zu halten, sondern ihnen darüber hinaus Vorstellungen des guten Lebens vermittelt werden, denn sie können davon ausgehen, dass diese sich weitgehend mit den eigenen Vorstellungen decken - solche Menschen haben vielleicht kein Bewusstsein dafür, dass andere mit guten Gründen eine grundlegend andere Vorstellung vom guten Leben haben. Das Problem haben die Angehörigen der kognitiven Minderheiten. Eine solche Haltung ist jedoch selbst aus liberaler Perspektive potentiell unehrlich bzw. selbstwidersprüchlich.

Man kann nicht beides haben: eine pluralistische Gesellschaft und gesellschaftliche Einheit, die über rechtliche Integration hinausgeht. Der Staat kann und soll Rahmenbedingungen schaffen und aufrechterhalten, die eine geordnete Vielfalt ermöglichen. Will er aber diese Vielfalt in eine grössere, übergreifende Einheit einzubetten versuchen, dann überschreitet der Staat seine Kompetenzen. Rawls hat die Tiefendimension der Thematik erkannt, wenn er den Gegenstandsbereich des politischen Liberalismus mit folgender Frage umschrieb: «[H]ow is a just and free society possible under conditions of deep doctrinal conflict with no prospect of resolution?» ${ }^{24} \mathrm{Ob}$ diese Frage mit dem rawlschen Konzept des politischen Liberalismus überzeugend beantwortet werden kann, muss hier allerdings dahingestellt bleiben.

Angesichts grundlegender Divergenzen auf weltanschaulich-religiöser Ebene, die sich nicht harmonisieren lassen, ist zu fragen, ob tatsächlich einen genuin weltanschaulich-religiös-kulturellen Pluralismus anstrebt, wer von einer pluralistischen Gesellschaft spricht. Oder will man - psychologisch vielleicht nachvollziehbar - nur eine oberflächliche Vielfalt, die nicht die mögliche Gefahr mit sich bringt, die eigene weltanschaulich-religiös-kulturelle Prägung grundlegend in Frage stellen zu müssen?

Ausgangspunkt dieser Arbeit war die Spannung zwischen gesellschaftlicher Ausdifferenzierung und Integration. Die Realisierung von Religionsfreiheit kann Unterschiede deutlicher hervortreten lassen und somit auch Konflikte schüren. Der Versuch, diese Spannung mittels Zivilreligion zu lösen, bietet jedoch Potential für eine Verschärfung der Spannung. Ich hoffe, dass diese Arbeit dazu einlädt, die eigenen Prämissen deutlicher zu erkennen und zu benennen, so dass dadurch die Diskussionen an Transparenz und Klarheit gewinnen. 


\section{Bibliographie}

\subsection{Ungedruckte Quellen}

\section{Staatsarchiv des Kantons Zürich (StAZH)}

Eingaben und Antworten [auf die 42 Fragen der Erziehungsdirektion, in Bekanntmachung der Erziehungsdirektion vom 22. I I. I 869] I 870, U 8.I.

- Gutachten der Bezirksschulpflegen, U 8.r.Ia. (Bezirke: Winterthur, Affoltern, Horgen, Meilen, Hinweil, Bülach, Pfäffikon, Uster, Regensberg/Dielsdorf, Zürich, Andelfingen).

- Eingaben und Antworten von Privaten, U 8.r.2.

- Eingaben und Antworten von Vereinen, U 8.I.3.

- Eingaben und Antworten von Privaten betreffend Religionsunterricht, U 8.r.4.

- Petition des Christlichen Vereins, U 8.I.7.

- Revisionsbestrebungen und Abänderungen des Schulgesetzes I 865-I 872, U 8.i.8.

\subsection{Gedruckte Quellen 19. Jahrhundert}

Amtlicher Auszug aus Protokollen der Synode der Zürcherischen Geistlichkeit, Sitzung vom 23/24. I I. I 869 und I4./I 5. I I. I 87 I. Zürich: Druck von Zürcher und Furrer. Verfügbar im StAZH, III KKb I.

Bekanntmachung der Erziehungsdirektion (42 Fragen) vom 22. I I. I 869. Verfügbar in der Forschungsbibliothek Pestalozzianum, PH Zürich, ZH HA II I.

Bericht des Regierungsrats zu den Abstimmungsvorlagen, I. März I 872 . Verfügbar in der Forschungsbibliothek Pestalozzianum, PH Zürich, ZH HA II I.

Buisson, Ferdinand ( I 868). Une réforme urgente dans l'instruction Primaire.

Conférence donnée a la société d'utilité publique. Neuchatel: Imprimerie G.

Guillaume Fils.

Buisson, Ferdinand (1 869a). Die Biblische Geschichte in der Volksschule. Basel:

Schweighauserische Verlagsbuchhandlung.

Buisson, Ferdinand (1869b). Das Freie Christenthum und die Kirche der Zukunft. Ein Vortrag. Basel: Schweighauserische Verlagsbuchhandlung.

Buisson, Ferdinand (I9I2). La Foi laïque. Extraits de discours et d'écrits (I878-I9I I).

Paris: Librairie Hachette et Cie.

Bundesverfassung vom 29. Mai i 874. Verfügbar unter https://www.e-rara.ch/zut/content/titleinfo/8428867.

Der Kirchenfreund. Blätter für evangelische Wahrheit und Leben. (г 869). Basel:

Bahnmaier's Verlag. Verfügbar in der Zentralbibliothek Zürich.

Der Landbote und Tagblatt der Stadt Winterthur, i87 I bis I 872. Verfügbar in der

Zentralbibliothek Zürich. 
Der Unabhängige. Ein radikales Volksblatt für politische und Schulfragen. I 865 - I 868.

Uster. Verfügbar in der Forschungsbibliothek Pestalozzianum, Pädagogische Hochschule Zürich, ZS I 35 a.

Eingabe der Kirchensynode zu dem Gesetzesentwurf betreffend das Unterrichtswesen, i r. Dezember i 87 I. Verfügbar im StAZH, III EEa 6.

Evangelisches Wochenblatt, I 868-I 872. Zürich: Ulrich. Verfügbar in der Zentralbibliothek Zürich, MM 2 I 30.

Furrer, Konrad (i 872). Der confessionslose Religionsunterricht. Ein Beitrag zur

Verständigung. Zürich: Orell, Füssli \& Co.

Gesetz über die Organisation des gesammten Unterrichtswesens im Canton Zürich,

2. Weinmonath i 832. Verfügbar in der Forschungsbibliothek Pestalozzianum, PH Zürich, ZH HA I s.

Gesetz über das gesammte Unterrichtswesen des Kantons Zürich, 23. Dezember i 859.

Verfügbar in der Forschungsbibliothek Pestalozzianum, PH Zürich, ZH HA I 16.

Gesetz betreffend das gesammte Unterrichtswesen des Kantons Zürich (Antrag des

Regierungsrathes), veröffentlicht in: Der Landbote vom i7./19./20. Oktober I 87 I.

Gesetz betreffend das gesammte Unterrichtswesen des Kantons Zürich, 2 I. Februar I 872. (Abstimmungsvorlage). Verfügbar in der Forschungsbibliothek Pestalozzianum, PH Zürich, ZH HA II I.

Gesetz betreffend die Volksschule, I I. Juni I 899. Verfügbar in der Forschungsbibliothek Pestalozzianum, PH Zürich, ZH HA I 29.

Gesetz über die Abänderung des Gesetzes über die Volksschule vom I I. Juni I 899, 24. Mai 1959. Verfügbar in der Forschungsbibliothek Pestalozzianum, PH Zürich, ZH HA II 2.

Kantonsratsprotokoll vom I I. I. I 872. Verfügbar im StAZH, MM 24.35 KRP I 872/0026-I 872/0027. Online verfügbar unter www.staatsarchiv.zh.ch.

Lang, Heinrich (I 870). Die religionslose Schule II. Zeitstimmen aus der reformirten Kirche der Schweiz, I 2 ( 5 ), $85-87$.

Lang, Heinrich (I 87 I). Der Religionsunterricht in der Volksschule. Zeitstimmen aus der reformirten Kirche der Schweiz, I 3 (23), 4 I 9-42 I.

Lange, Friedrich Albert (1975). Pädagogik zwischen Politik und Philosophie. Joachim H. Knoll (Hg.). Duisburg: Walter Braun Verlag.

Neue Zürcher Zeitung (NZZ), November i 87 I bis April I 872. Verfügbar im StAZH. Pädagogischer Beobachter. Wochenblatt für Erziehung und Unterricht. I 879 (Hefte 37-39). Online verfügbar unter www.e-periodica.ch (I6. I2. 2016).

Spyri, Johann Ludwig ( 1872 ). Der Religionsunterricht und der Entwurf des neuen Schulgesetzes des Kantons Zürich. Ein Wort zur Verständigung. Zürich: Cäsar Schmidt (Schabelitz'sche Buchhandlung).

Staatsverfassung für den eidgenössischen Stand Zürich vom ıo. März I 83 I. Online verfügbar unter http://www.verfassungen.ch/zuerich/verf 3 I-i.htm (I8. I 2. 2018).

Verfassung des eidgenössischen Standes Zürich vom i 8. April i 869. Online verfügbar unter http://www 2.zhlex.zh.ch/appl/zhlex_r.nsf/o/CI 256C6I003964 I B Ci2568DAoor9i I 53/\$file/Ior_i 8.4.69_39.pdf (i 8. i 2. 2018).

Verhandlungs-Protokoll des zürcherischen Verfassungsrathes, 8./9. 7. I 868. Verfügbar im StAZH, III AAa I. 
Verordnung über die Volksschule und die Vorschulstufe (Volksschulverordnung) vom 3 I. März I 900. Verfügbar in der Forschungsbibliothek Pestalozzianum, PH Zürich, ZH HA II 2 oder online unter http://www2.zhlex.zh.ch/appl/zhlex_r.nsf/o/osE8FA80 IFo7BI 56CI256D5700223683/\$file/4I2.I I I_3 I.3.00_4I.pdf. (I. 5. 20I 8).

Volksblatt für die reformirte Kirche der Schweiz. Bern: Stämpfli’sche Buchdruckerei. Verfügbar in der Zentralbibliothek Zürich, WZ 28 a.

Vögelin, F. Salomon (i 864). Die Aufgabe des geistlichen Amtes in unserer Zeit. Antrittspredigt den 28. Februar I 864. Gott ist nicht ein Gott der Todten, sondern der Gott der Lebendigen. Predigten gehalten zu Uster von Weihnachten I 862 bis Pfingsten I 864. Zürich: Druck und Verlag von David Bürkli.

Vögelin, F. Salomon (I 865). Die Gemeinschaft der Kirche und ihr Grund. Drei Predigten. Zürich: David Bürkli.

Vögelin, F. Salomon ( 1867 ). Die Geschichte Jesu und der Ursprung der christlichen Kirche. Für das Volk und die höheren Volksschulen dargestellt. Rapperswyl am Zürichsee: Verlag von J. J. Bauer.

Vögelin, F. Salomon (I 874). Ueber Tendenz und Methodik des Geschichtsunterrichtes in der Ergänzungsschule. Vortrag gehalten auf Veranstaltung der Erziehungsdirektion in den Versammlungen der zürcherischen Schulkapitel. Zürich: Genossenschafts-Buchdruckerei.

Vögelin, F. Salomon ( 1879$)$. Eröffnungsrede zur Lehrersynode in Wädensweil. Pädagogischer Beobachter. Wochenblatt für Erziehung und Unterricht (Hefte 37-39). Verfügbar unter www.e-periodica.ch (I. 5. 20I 8).

Zürcherische Freitagszeitung. Zürich: David Bürkli. Verfügbar in der Forschungsbibliothek Pestalozzianum, PHZH, ZS I 89.

Zusammenstellung der Abänderungsanträge und Petitionen zu dem Gesetzesentwurfe betreffend das Unterrichtswesen. Verfügbar im StAZH, EEa 6.

\subsection{Gedruckte Quellen 21. Jahrhundert}

Antrag des Regierungsrates vom 24. I I. 2004. 4224. Beschluss des Kantonsrates über das Zustandekommen der Volksinitiative für die Weiterführung des Faches «Biblische Geschichte» an der Primarschule. In: Amtsblatt des Kantons Zürich, I0. I 2. 2004, Nr. I I6I0. Online verfügbar unter www.amtsblatt.zh.ch (2. 5. 20I8).

Antrag des Regierungsrates vom I 4. I 2. 2005. 4224a A. Beschluss des Kantonsrates über die Volksinitiative für die Weiterführung des Faches «Biblische Geschichte» an der Primarschule. In: Amtsblatt des Kantons Zürich 2006, 6. I. 2006, Nr. I I7 I 8. Online verfügbar unter www.amtsblatt.zh.ch (2. 5. 20I8).

Auszug aus dem Protokoll des Regierungsrates des Kantons Zürich, Sitzung vom I I. I 2. 2003. KR-Nr. 284/2003.

Auszug aus dem Protokoll des Regierungsrates des Kantons Zürich, Sitzung vom 22. I 2. 2004.

Auszug aus dem Protokoll des Regierungsrates des Kantons Zürich, Sitzung vom 26. 10. 2005: KR-Nr. $258 / 2005$. 
Beschluss des Bildungsrates des Kantons Zürich vom I 3. 9. 200I: Volksschule. Weiterentwicklung des Konfessionell-kooperativen Religionsunterrichts in das Fach «Religion und Kultur». Vernehmlassungsergebnisse. Weiteres Vorgehen.

Beschluss des Bildungsrates des Kantons Zürich vom 5. I I. 2002: Volksschule. Weiterentwicklung des Konfessionell-kooperativen Religionsunterrichts in das Fach «Religion und Kultur». Personelle Zusammensetzung der bildungsrätlichen Kommission (Änderung).

Beschluss des Bildungsrates des Kantons Zürich vom I0. 5. 2004.

Beschluss des Bildungsrates des Kantons Zürich vom 29. I I. 2004: Volksschule. Biblische Geschichte. Weiteres Vorgehen, Schulblatt des Kantons Zürich 2005, I. Beschluss des Bildungsrates des Kantons Zürich vom 4. I 2. 2006: Volksschule. Religion und Kultur an der Sekundarstufe I. Einführung. Online verfügbar unter www.bi.zh.ch (2.5. 2018).

Beschluss des Bildungsrates des Kantons Zürich vom 29. 6. 2007: Volksschule. Religion und Kultur an der Primarstufe. Einführung. Rahmenbedingungen. Online verfügbar unter www.bi.zh.ch (2. 5. 2018).

Beschluss des Bildungsrates des Kantons Zürich vom I9. 3. 20I 2: Volksschule. Religion und Kultur. Aufhebung der Übergangsregelung zur Zulassung zur Weiterbildung für die Sekundarstufe. Online verfügbar unter www.bi.zh.ch (2. 5. 2018).

Beschluss des Bildungsrates des Kantons Zürich vom I9. I 2. 20I 3: Wissenschaftliche Evaluation des Faches «Religion und Kultur». Abschluss der Evaluation und Veröffentlichung der Ergebnisse. Online verfügbar unter www.bi.zh.ch (2.5. 20I8).

Bildungsdirektion Kanton Zürich (Hg.) (20I0). Religion und Kultur. Ergänzung zum Lehrplan für die Volksschule des Kantons Zürich (3. unveränderte Ausgabe).

Brief des Volksschulamtes an die Gemeindeschulpflegen des Kantons Zürich vom 9. I 2. 2003: Sanierungsprogramm 04 . Auswirkungen auf die Organisation der Volksschule.

Bundesverfassung vom i 8. April i 999. Online verfügbar unter www.admin.ch (2. 5. 20I8).

Direktion der Justiz und des Innern. Rückzug der Volksinitiative für die Weiterführung des Faches «Biblische Geschichte» an der Primarschule und Veröffentlichung des Gegenvorschlages des Kantonsrates betreffend Volksschulgesetz. In: Amtsblatt des Kantons Zürich, I I. 5. 2007. Online verfügbar unter www. amtsblatt.zh.ch (2.5. 2018).

Erläuterungen des Bildungsrats zum BRB vom i 5. 8. 2000: Volksschule. Weiterentwicklung des Konfessionell-kooperativen Religionsunterrichts in das Fach «Religion und Kultur», Vernehmlassung.

Erläuterungen des Bildungsrats zum BRB vom I3. 9. 200I: Volksschule. Weiterentwicklung des Konfessionell-kooperativen Religionsunterrichts in das Fach «Religion und Kultur». Vernehmlassungsergebnisse. Weiteres Vorgehen.

Erläuterungen des Bildungsrats zum BRB vom 23. 8. 2004: Volksschule. Oberstufe. Schaffung eines neuen Fachs «Religion und Kultur».

Erläuterungen des Bildungsrats zum BRB vom 7. 3. 20I6: Ethik. Anforderungskatalog Lehrmittel I.-3. Zyklus. Online verfügbar unter www.bi.zh.ch. 
Freidenkervereinigung Schweiz (FVS): Kt. ZH: Vernehmlassung zum geplanten Fach Religion und Kultur. Stellungnahme von März 2006. Online verfügbar unter https://frei-denken.ch/news/2006-02-I I/kt-zh-vernehmlassung-zum-geplantenfach-religion-und-kultur (I8. I2. 2018).

Graf, Friedrich Wilhelm (2004). Wertneutral über den Wassern schweben. NZZ, 28. 6. 2004.

Hauser, Matthias (2007). Blogeintrag vom I 4 3. 2007: Sitzenbleiben zum Multikulti. Online verfügbar unter www.matthias-hauser.ch/sitzenbleiben-zum-multikulti (2. 5. 20I8).

Jödicke, Ansgar (2005). «Religion und Kultur» - ein religionswissenschaftlicher Kommentar. In: Ralph Kunz, Matthias Pfeiffer, Katharina Frank-Spörri, Jozsef Fuisz (Hg.). Religion und Kultur - ein Schulfach für alle?. Zürich: Theologischer Verlag, 205-2 I9.

Komitee Volksinitiative für die Weiterführung des Faches Biblische Geschichte an der Primarschule, Medienmitteilung vom I 2. 3. 2007. Christentum bleibt in der Volksschule. Online verfügbar unter www.kath.ch (2. 5. 20I8).

Kunz, Ralph. (2005). Schule als Lernraum für Religion. Der Beitrag der Religionskunde zur religiösen Bildung. In: Ralph Kunz, Matthias Pfeiffer, Katharina Frank-Spörri, Jozsef Fuisz (Hg.). Religion und Kultur - ein Schulfach für alle? Zürich: Theologischer Verlag.

Kunz, Ralph / Pfeiffer, Matthias / Frank-Spörri, Katharina / Fuisz, Jozsef (Hg.) (2005). Religion und Kultur - ein Schulfach für alle? Zürich: Theologischer Verlag.

Kyriacou, Andreas (2006). Blogeintrag vom 26. I r. 2006: Als hätte die Aufklärung nie stattgefunden - zum vorgeschlagenen Lehrplan «Religion und Kultur», https://web.archive.org/web/200903 I 2063203/http://www.kyriacou.ch:80/files/ zum_vorgeschlagenen_lehrplan_religion_und_kultur.html (I8. I 2. 20 I 8).

LCH Dachverband Schweizer Lehrerinnen und Lehrer, I 5. I 2. 2008. Die öffentliche Schule und die Religionen, www.lch.ch (2. 5. 2018).

Lehrplan 2 I. I r. April 2016 (zur Vernehmlassung freigegebene Version). www.vsa.zh.ch (2. 12. 2016).

Motion KR-NR. 284/2003 von Hans Fahrni (EVP, Winterthur) und Lisette Müller-Jaag (EVP, Knonau) betreffend Sicherstellung des biblischen Unterrichtes an der Volksschule. Online verfügbar unter www.kantonsrat.zh.ch (2. 5. 20I 8).

Müller, Lisette (2004). Wurzeln geben Halt. Online verfügbar unter www.lisettemueller.ch/artikel/artikel_kantonsraete_meinen_maerzo4.htm (2.5.2018).

Nipkow, Karl Ernst (2005). Der religiöse Bildungsauftrag der Schule im Pluralismus. In: Ralph Kunz, Matthias Pfeiffer, Katharina Frank-Spörri, Jozsef Fuisz (Hg.). Religion und Kultur - ein Schulfach für alle? Zürich: Theologischer Verlag.

Personalverordnung der Landeskirche - Antrag und Bericht des Kirchenrates (2009). In: Synodeprotokoll vom I 3 4. 20I0. Online verfügbar unter www.zh.ref.ch (2. 5. 20I8).

Petition «Ja zur Biblischen Geschichte - Ja zu einer ganzheitlichen Bildung», 3I. I. 2004 (Einsendeschluss). Zürcher Lehrerinnen- und Lehrerverband/vpod zürich (Archiv ZLV). 
Pfeiffer, Matthias (2005). «Religion und Kultur»-die Konturen des neuen Faches. In: Ralph Kunz, Matthias Pfeiffer, Katharina Frank-Spörri, Jozsef Fuisz (Hg.). Religion und Kultur - ein Schulfach für alle? Zürich: Theologischer Verlag.

Postulat GR Nr. 2004/I49, CVP/EVP-Fraktion, Gemeinderat von Zürich. Online verfügbar unter www.gemeinderat-zuerich.ch (2. 5. 2018).

Postulat KR-Nr. 354/2004 von Stefan Dollenmeier (EDU, Rüti)/Hans Fahrni (EVP

Winterthur) betreffend Gewichtung und Darstellung des Christentums im neuen Fach Religion und Kultur. Online verfügbar unter www.kantonsrat.zh.ch (2. 5. 20I8).

Postulat KR-Nr. 258/2005 von Andrea Widmer-Graf (FDP, Zürich) / Yvonne Eugster (CVP, Männedorf) / Ursula Braunschweig-Lütolf (SP, Winterthur) betreffend Fach «Religion und Kultur» an der Primarstufe. Online verfügbar unter www.kantonsrat.zh.ch (2.5. 2018).

Protokoll der evangelisch-reformierten Kirchensynode des Kantons Zürich, 24. 6. 2003. Verfügbar im Sozialarchiv Zürich, K 260:30.

Protokoll der evangelisch-reformierten Kirchensynode des Kantons Zürich, 25. I I. 2003. Verfügbar im Sozialarchiv Zürich, K 260:3 I.

Protokoll der römisch-katholischen Synode des Kantons Zürich, 4. I 2. 2003.

Protokoll des Grossen Gemeinderates von Winterthur, I 8. 4. 2005.

Protokoll des Regierungsrates des Kantons Zürich (Auszug), Sitzung vom I I. I 2. 2003, KR-Nr. 284/2003.

Protokoll des Regierungsrates des Kantons Zürich, Sitzung vom 26. I0. 2005, KR-Nr. $258 / 2005$.

Protokoll des Zürcher Kantonsrates, I 4. I I. 2005: Fach «Religion und Kultur» an der Primarstufe, www.kantonsrat.zh.ch (2.5. 2018).

Protokoll des Zürcher Kantonsrates, I 3. 2. 2006: Inhalte neues Schulfach Religion und Kultur / Religion und Kultur als obligatorisches Fach mit Abmeldemöglichkeit / Gewichtung und Darstellung des Christentums im neuen Fach Religion und Kultur, www.kantonsrat.zh.ch (2. 5. 20I8).

Protokoll des Zürcher Kantonsrates, I 5. I. 2007: Beschluss des Kantonsrates über die Volksinitiative für die Weiterführung des Faches «Biblische Geschichte» in der Primarschule, www.kantonsrat.zh.ch (2. 5. 2018).

Protokoll des Zürcher Kantonsrates, I 2. 3. 2007: Beschluss des Kantonsrates über die Volksinitiative für die Weiterführung des Faches «Biblische Geschichte» in der Primarschule. Nr. 4224b, www.kantonsrat.zh.ch (2. 5. 2018).

Regierungsrat Kanton Zürich, Medienmitteilung vom 8. 5. 2003: Sanierungsmassnahmen ${ }_{4}$ betreffen alle grossen Ausgabenpositionen. Online verfügbar unter www.rr.zh.ch/internet/regierungsrat/de/aktuell/medienmitteilungen.html (2. 5. 20I8).

Römisch-katholische Synode des Kantons Zürich: Resolution für die Beibehaltung der Angebotspflicht für Biblische Geschichte an der Primarschule, 4. I 2. 2003. Scheffeldt, Elisabeth (2009). Elisabeth Scheffeldt zum Religionsunterricht. Votum Sitzung Kantonsrat. SP Kanton Zürich, 28. I 2. 2009. Online verfügbar unter http://xn--sp-zrich-95a.ch/icc.asp?oid=32926 (3. 5. 2018). 
Schreiner, Peter. (2002). Das Konzept eines nicht-konfessionellen Religionsunterrichts im europäischen Kontext. Expertentagung «Religion und Kultur». Zürich, I6. Dezember 2002.

Schweitzer, Friedrich (2005a). Obligatorischer Religionsunterricht in der Zivilgesellschaft. In: Ralph Kunz, Matthias Pfeiffer, Katharina Frank-Spörri, Jozsef Fuisz (Hg.). Religion und Kultur - ein Schulfach für alle?. Zürich: Theologischer Verlag, 67-82.

Schweitzer, Friedrich (2005b). «Religion für alle» - ein religionspädagogischer Kommentar. In: Ralph Kunz, Matthias Pfeiffer, Katharina Frank-Spörri, Jozsef Fuisz (Hg.). Religion und Kultur - ein Schulfach für alle?. Zürich: Theologischer Verlag, I6I-I 80.

Verfassung des Kantons Zürich vom 27. Februar 2005 (KV). Online verfügbar unter www.zh.ch.

Volksschulgesetz (VSG) vom 7. Februar 2005.

Volksschulgesetz Kanton Zürich 2005.

Wäckerlin, Marc (20I4). Positionspapier Laizismus. Publiziert am 22. I. 20 I 4. http://zh.piratenpartei.ch/positionspapier-laizismus (2. 5. 2018).

Watson (I 3. 6. 20I6): Die Schweiz trauert um die Opfer von Orlando - und auch der Iran verurteilt den Anschlag, www.watson.ch/International/Schweiz/458998276Die-Schweiz-trauert-um-die-Opfer-von-Orlando-\% E2\% 80\% 93-und-auch-derIran-verurteilt-den-Anschlag (2.5. 2018).

Zürcher Lehrerinnen- und Lehrerverband (2006): Religion und Kultur. Bildungsrat handelt. Medienmitteilung vom 7. 3. 2006. ZLV-Archiv.

Zürcher Lehrerinnen- und Lehrerverband (2007): Religion und Kultur an der Primarschule. Erfolg im Kampf gegen Sanierungsmassnahmen. Medienmitteilung vom I 2. 3. 2007. ZLV-Archiv.

\subsection{Sekundärliteratur}

Altermatt, Urs (1989). Katholizismus und Moderne. Zur Sozial- und Mentalitätsgeschichte der Schweizer Katholiken im i9. und 20. Jahrhundert. Zürich: Benziger. Anhalt, Elmar (20I 2a). Erziehung zur Werteorientierung für ein vereinigtes Europa. Zur Aktualität des politischen Aspekts von Herbarts Theorie. In: Elmar Anhalt, Dariusz Stepkowski (Hg.). Erziehung und Bildung in politischen Systemen. Jena: Garamond Verlag, 95-I45.

Anhalt, Elmar (20 I 2b). Werteorientierung und Europa. Zur Einleitung. In: Elmar Anhalt, Klaudia Schultheis (Hg.). Werteorientierung und Wertevermittlung in Europa. Interdisziplinäre Perspektiven und Standpunkte junger Wissenschaftlerinnen und Wissenschaftler. Berlin: 20 2, го-73.

Baczko, Bronislaw (2000). Une Education pour la Démocratie. Textes et Projets de l'époque révolutionnaire. Genève: Librairie DROZ S. A.

Badertscher, Hans / Grunder, Hans-Ulrich (Hg.) (1997). Geschichte der Erziehung und Schule in der Schweiz im i9. und 20. Jahrhundert. Bern: Paul Haupt.

Behrens, Mathias (1997). ২Politische Religion〉- eine Religion? Bemerkungen zum Religionsbegriff. In: Hans Maier, Michael Schäfer (Hg.). 〈Totalitarismus〉 und 
〈Politische Religionen〉. Konzepte des Diktaturvergleichs. Band II. Paderborn: Ferdinand Schöningh.

Bellah, Robert N. (2004a). Zivilreligion in Amerika. In: Heinz Kleger, Alois Müller (Hg.). Religion des Bürgers. Zivilreligion in Amerika und Europa. Münster: LIT Verlag, I9-4I.

Bellah, Robert N. (2004b). Die Religion und die Legitimation der amerikanischen Republik. In: Heinz Kleger, Alois Müller (Hg.). Religion des Bürgers. Zivilreligion in Amerika und Europa. Münster: LIT Verlag, 42-63.

Bellmann, Johannes (2006). Begründungsfiguren religiöser Bildung an öffentlichen Schulen. Kontinuitäten und Widersprüche. In: Michèle Hofmann, Denise Jacottet, Fritz Osterwalder (Hg.). Pädagogische Modernisierung: Säkularität und Sakralität in der modernen Pädagogik. Bern: Haupt Verlag.

Benner, Dietrich (20I4). Bildung und Religion. Nur einem bildsamen Wesen kann ein Gott sich offenbaren. Paderborn: Ferdinand Schöningh.

Benner, Dietrich / Nikolova, Roumiana (20I3). Gutachten für die Bildungsdirektion des Kantons Zürich zum Abschlussbericht der Evaluation: «Neues Unterrichtsfach «Religion und Kultur〉. Bericht über die Evaluation der Einführungsphase». Verfügbar unter Beschlüsse 2013, www.bi.zh.ch (3. 5. 2018).

Benning, Alfons (1993). Das trojanische Pferd im Religionsunterricht. Zur Einführung des konfessionell-kooperativen Religionsunterrichtes im Kanton Zürich. Löningen: Verlag Dr. Alfons Benning.

Betulius, Walter (1956). Friedrich Salomon Vögelin i 837-1888. Sein Beitrag zum schweizerischen Geistesleben in der zweiten Hälfte des i 9. Jahrhunderts. Winterthur: Verlag P. G. Keller.

Bloch, Alexandra (1997). «Schreiben thut bleiben». Die Schulreform auf der Zürcher Landschaft in den I770er Jahren. In: Helmut Holzhey, Simone Zurbuchen (Hg.). Alte Löcher - neue Blicke. Zürich im I 8. Jahrhundert. Zürich: Chronos, 249-266.

Bloch, Alexandra (1999). Schulpflicht, Unentgeltlichkeit und Laizität des Unterrichts im Kanton Zürich zwischen 1770 und I 900. In: Lucien Criblez, Carlo Jenzer, Rita Hofstetter, Charles Magnin (Hg.). Eine Schule für die Demokratie. Zur Entwicklung der Volksschule in der Schweiz im i 9. Jahrhundert. Bern: Peter Lang, I 23-I 53 .

Bloch Pfister, Alexandra (2007). Priester der Volksbildung. Der Professionalisierungsprozess der Zürcher Volksschullehrkräfte zwischen I770 und I9I4. Zürich: Chronos Verlag.

Böhm, Winfried (2005). Sittliche Erziehung. Wörterbuch der Pädagogik. Stuttgart: Alfred Körner Verlag (I6., vollständig überarbeitete Auflage), 587-588.

Bohmann, Gerda (2009). «Politische Religionen» (Eric Voegelin und Raymond Aron) - ein Begriff zur Differenzierung von Fundamentalismen. Östereichische Zeitschrift für Soziologie, 34 (I), 3-22.

Bourdeau, Michel (2015). Auguste Comte. The Stanford Encyclopedia of Philosophy. https://plato.stanford.edu/archives/win20I s/entries/comte (3. 5. 2018).

Braun, Rudolf (1965). Sozialer und kultureller Wandel in einem ländlichen Industriegebiet. (Zürcher Oberland) unter Einwirkung des Maschinen- und Fabrikwesens im I9. und 20. Jahrhundert. Zürich: Eugen Rentsch Verlag. 
Brunschwig, Annette (2009). SIG Factsheet: Geschichte der jüdischen Gemeinde in Zürich. Online verfügbar unter https://www.swissjews.ch/pdf/de/factsheet/ SIG_Factsheet_Juden_in_Zuerich_de.pdf. (I8. I 2. 20I8).

Bürgi, Markus (2005). Escher, Alfred (vom Glas). In: Historisches Lexikon der Schweiz, www.hls-dhs-dss.ch/textes/d/D3626.php (3. 5. 2018).

Bürgi, Markus (2008a). Landbote, Der. In: Historisches Lexikon der Schweiz, www.hls-dhs-dss.ch/textes/d/D24775.php (3. 5. 2018).

Bürgi, Markus (2008b). Locher, Friedrich. In: Historisches Lexikon der Schweiz, www.hls-dhs-dss.ch/textes/d/Di3502.php (3. 5. 2018).

Bürgi, Markus (2009). Müller, Johann Heinrich. In: Historisches Lexikon der Schweiz, www.hls-dhs-dss.ch/textes/i/I5897.php (3. 5. 2018).

Bürgi, Markus (20I0). Rüegg, Reinhold. In: Historisches Lexikon der Schweiz, www.hls-dhs-dss.ch/textes/d/D23068.php (3. 5. 2018).

Bürgi, Markus (20 I I). Sieber, Johann Caspar. In: Historisches Lexikon der Schweiz, www.hls-dhs-dss.ch/textes/d/D5898.php (30. 8. 2018).

Bütikofer, Anna (2006). Staat und Wissen: Ursprünge des modernen schweizerischen Bildungssystems im Diskurs der Helvetischen Republik. Bern: Haupt.

Campi, Emidio (2008). Kirche und Theologie im Zürich des I 9. Jahrhunderts. In: Emidio Campi, Ralph Kunz, Christian Moser (Hg.). Alexander Schweizer (I 808-i 888) und seine Zeit. Zürich: Theologischer Verlag Zürich.

Casanova, José (I994). Public Religions in the Modern World. Chicago and London: The University of Chicago Press.

Chaplin, Jonathan (2006). Living with Liberalism: Understanding Regimes of Tolerance. Online verfügbar unter www.cardus.ca/comment/article/356/living-withliberalism-understanding-regimes-of-tolerance (3. 5. 2018).

Chaplin, Jonathan (2008). Beyond Multiculturalism - But to Where? Public Justice and Cultural Diversity. Philosophia Reformata, 73 (2), I90-209.

Chaplin, Jonathan (20I I). Herman Dooyeweerd. Christian Philosopher of State and Civil Society. Notre Dame, Indiana: University of Notre Dame Press.

Clessienne, Johannes (20I 2). Warum Bildungspolitik? Zur Begründung der Staatstätigkeit in Erziehung und Bildung im modernen Verfassungsstaat. Würzburg: Königshausen \& Neumann GmbH.

Clouser, Roy (2005). The Myth of Religious Neutrality. An Essay on the Hidden Role of Religious Belief in Theories. (2., überarbeitete Auflage). Notre Dame, Indiana: University of Notre Dame.

Condorcet, Marie-Jean (I966 [I792]). Bericht und Entwurf einer Verordnung über die allgemeine Organisation des öffentlichen Unterrichtswesens (Band 36 ). Weinheim: Julius Beltz.

Condorcet, Marie-Jean (I989 [I79I]). Ecrits sur l'instruction publique. Volume Premier. Cinq mémoires sur l'instruction publique. Paris: Edilig.

Criblez, Lucien (2008a). Der Bildungsartikel der Bundesverfassung von I 874 und die Diskussion über den eidgenössischen «Schulvogt». In: Lucien Criblez (Hg.). Bildungsraum Schweiz. Historische Entwicklung und aktuelle Herausforderungen. Bern: Haupt, 87-I 29. 
Criblez, Lucien (2008b). Zur Einleitung: Vom Bildungsföderalismus zum Bildungsraum Schweiz. In: Lucien Criblez (Hg.). Bildungsraum Schweiz. Historische Entwicklung und aktuelle Herausforderungen. Bern: Haupt, 9-32.

Criblez, Lucien / Jenzer, Carlo / Hofstetter, Rita / Magnin, Charles (Hg.) (I999). Eine Schule für die Demokratie. Zur Entwicklung der Volksschule in der Schweiz im I9. Jahrhundert. Bern: Peter Lang.

Dalferth, Ingolf U. (2015). Transzendenz und säkulare Welt. Tübingen: Mohr Siebeck. Dantzig, Tobias (1967). Number: The Language of Science. New York: Free Press.

De Vincenti, Andrea (2015). Schule der Gesellschaft. Wissensordnungen von Zürcher Unterrichtspraktiken zwischen I77 I und I 834. Zürich: Chronos Verlag.

De Vincenti, Andrea / Grube, Norbert (20I I). The Masters of Republicanism?

Teachers and Schools in Rural and Urban Zurich in the I 8th and the Long I 9 th

Centuries. In: Daniel Tröhler, Thomas S. Popkewitz, David F. Labaree (Hg.).

Schooling and the Making of Citizens in the Long Nineteenth Century. New York: Routledge.

De Vincenti-Schwab, Andrea (2008). Schule vor Ort. Die Zürcher Landschulen am Ende des I 8. Jahrhunderts. In: Daniel Tröhler, Urs Hardegger (Hg.). Zukunft bilden. Die Geschichte der modernen Zürcher Volksschule. Zürich: Verlag Neue Zürcher Zeitung.

Delfosse, Marianne (2008). Kempin (-Spyri), Emilie. In: Historisches Lexikon der Schweiz, www.hls-dhs-dss.ch/textes/d/D9342.php (3. 5. 20I8).

Dellsperger, Rudolf. (20I2). Freidenker. In: Historisches Lexikon der Schweiz, www.hls-dhs-dss.ch/textes/d/D i I396.php (3. 5. 20I 8).

Deneen, Patrick J. (2005). Democratic Faith. Princeton, N.J.: Princeton University Press.

Dooyeweerd, Herman (I997 [1955]). A New Critique of Theoretical Thought (Band 2). Lewiston, Queenston, Lampeter: Edwin Mellen Press.

Engi, Lorenz (20I7). Die religiöse und ethische Neutralität des Staates. Theoretischer Hintergrund, dogmatischer Gehalt und praktische Bedeutung eines Grundsatzes des schweizerischen Staatsrechts. Zürich: Schulthess.

Erlanger, Simon (2013). SIG Factsheet: Emanzipation (I798-1874). Online verfügbar unter http:// I 50. swissjews.ch/de/downloads/geschichte/factsheet-emanzipation.pdf (3. 5. 20I8).

Erziehungsrat des Kantons Zürich (Hg.) (1933). Volksschule und Lehrerbildung I 832-I932. Festschrift zur Jahrhundertfeier. Zürich: Verlag der Erziehungsdirektion.

Famos, Cla Reto (2007). Die Zürcher Kirchenordnungen von I 905 und 1967 und ihre Bedeutung für die Praktische Theologie. In: D. Kraus (Hg.). Schweizerisches Jahrbuch für Kirchenrecht. Bern: Peter Lang, 49-69.

Fatio, Olivier (2004). Buisson, Ferdinand. In: Historisches Lexikon der Schweiz, www.hls-dhs-dss.ch/textes/d/Di I063.php (3. 5. 2018).

Feller, Richard (1958 [1942]). Die Entstehung der politischen Parteien in der Schweiz. Schweizerische Zeitschrift für Geschichte, 8 (4), 433-449, www.e-periodica.ch (3. 5. 2018).

Ferry, Jules (1996a). La République des citoyens. Odile Rudelle (Hg.). Band I. Paris: Imprimerie nationale. 
Ferry, Jules (1996b). La République des citoyens. Odile Rudelle (Hg.). Band 2. Paris: Imprimerie nationale.

Frey, Paul (1953). Die zürcherische Volksschulgesetzgebung I 83 I-I95I. Ein Beitrag zur Geschichte der zürcherischen Volksschule. Affoltern a. Albis: Buchdruckerei Dr. J. Weiss.

Fries, Anna-Verena (2008). Vom Stoffplan zum pädagogischen Gesamtkonzept. Aus der Geschichte des Lehrplans der Primarschule im Kanton Zürich. In: Daniel Tröhler, Urs Hardegger (Hg.). Zukunft bilden. Die Geschichte der modernen Zürcher Volksschule. Zürich: Verlag Neue Zürcher Zeitung.

Fries, Anna-Verena (20I0). «Das religiöse Gefühl ist ein kräftiges Erziehungsmittel». Zur Säkularisierung des Fachs Religion. Vortrag gehalten an der vierten Arbeitstagung der Arbeitsgruppe Kultur- und Sozialwissenschaften an Pädagogischen Hochschulen. Online verfügbar unter http://www.lehrplanforschung.ch/wpcontent/uploads/201 I/08/2010-S\% C3\% A4kularisierung-des-Fachs-Religion I.pdf (I 8. I 2. 2018).

Fritzsche, Bruno / Lemmenmeier, Max (1994). Die revolutionäre Umgestaltung von Wirtschaft, Gesellschaft und Staat I780-I 870. In: Niklaus Flüeler, Marianne Flüeler-Grauwiler (Hg.). Geschichte des Kantons Zürich (Band 3). Zürich: Werd Verlag, 20-I 57.

Furer, Karin (20I 2). «Teaching about religion»- Religionskunde im Vergleich. Rechtsvergleichende und verhandlungstheoretische Betrachtung von integrierter Religionskunde in Frankreich und Religionskunde als gesondertem Fach im Kanton Zürich. Münster: LIT Verlag.

Furler, Frieder (2005). Volksinitiative für die Weiterführung des Fachs «Biblische Geschichte» im Kanton Zürich. In: Kraus, Dieter (Hrsg.). Schweizerisches Jahrbuch für Kirchenrecht (Band 9). Bern: Peter Lang.

Gebhard, Rudolf (20I I). Apostolikumsstreit. In: Historisches Lexikon der Schweiz, www.hls-dhs-dss.ch/textes/d/D43205.php (3.5. 2018).

Gilg, Peter (2008). Kirche und Staat. In: Historisches Lexikon der Schweiz, www.hls-dhs-dss.ch/textes/d/D I I 457.php (3. 5. 2018).

Glenn, Charles Leslie Jr. (2002). The Myth of the Common School. Oakland: ICS Press.

Graber, Rolf (2017). Demokratie und Revolten. Die Entstehung der direkten Demokratie in der Schweiz. Zürich: Chronos Verlag.

Greiner, Martha (1933). Der Wandel des Verhältnisses von Staat und Kirche zur Volksschule des Kantons Zürich. Von der Helvetik bis zur Gegenwart. Olten: Buchdruckerei Dietschi.

Guggenbühl, Gottfried (I933). Hundert Jahre zürcherischer Volksherrschaft. Zeiträume und Hauptströmungen. In: Erziehungsrat des Kantons Zürich (Hg.). Volksschule und Lehrerbildung I 832-1932. Festschrift zur Jahrhundertfeier. Zürich: Verlag der Erziehungsdirektion.

Hafner, Felix (2008). Staat und Religionsgemeinschaften. In: Denise Buser (Hg.). Neues Handbuch des Staats- und Verwaltungsrechts des Kantons Basel-Stadt. Basel: Helbing Lichtenhahn Verlag, i 8 5-236. 
Hardegger, Urs (2005). Katholizismus und Zürcher Volksschule am Beispiel der Auseinandersetzung um das Fach Biblische Geschichte und Sittenlehre nach I900. Unveröffentlichte Lizentiatsarbeit. Universität Zürich.

Hardegger, Urs (2008a). «Bis das sie wissen, dass sie nichts wissen.» Gründung und Persistenz des Evangelischen Lehrerseminars Zürich. In: Michael Göhlich, Caroline Hopf, Daniel Tröhler (Hg.). Persistenz und Verschwinden. Persistence and Disappearance. Pädagogische Organisationen im historischen Kontext. Educational Organizations in their historical Contexts. Wiesbaden: VS Verlag für Sozialwissenschaften, I I 9-I 29.

Hardegger, Urs (2008b). «Wer die Schule hat, der hat das Volk.» Zum Verhältnis der Zürcher Volksschule zur Religion. In: Daniel Tröhler, Urs Hardegger (Hg.). Zukunft bilden. Die Geschichte der modernen Zürcher Volksschule. Zürich: Verlag Neue Zürcher Zeitung.

Harten, Hans-Christian (1990). Elementarschule und Pädagogik in der Französischen Revolution. München: R. Oldenbourg Verlag.

Herms, Eilert (1999). Anforderungen des konsequenten weltanschaulich/religiösen Pluralismus an das öffentliche Bildungswesen. In: Christoph T. Scheilke, Friedrich Schweitzer (Hg.). Religion, Ethik, Schule. Bildungspolitische Perspektiven in der pluralen Gesellschaft. Münster: Waxmann Verlag, 2 I9-247.

Herms, Eilert (2002). Theologische Ethik und Rechtsbegründung. Marburger Jahrbuch Theologie XIV. Ethik und Recht. Marburg: N.G. Elwert Verlag.

Illi, Martin (2015). Der Zürcher Staat im I9. und 20. Jahrhundert. Regeneration und Folgezeit bis I 869. In: Historisches Lexikon der Schweiz, http://www.hls-dhs-dss.ch/textes/d/D738 I.php (I8. I2. 20I8).

Isler, Alexander ( (1892). Prof. Dr. Salomon Vögelin, Nationalrath. Lebensbild eines schweizerischen Volksmannes. Winterthur: Druck von Geschwister Ziegler (2. Auflage).

Jecker, Hanspeter (20I2). Täufer. In: Historisches Lexikon der Schweiz, www.hls-dhsdss.ch/textes/d/D I I 42 I.php (3. 5. 20I8).

Joas, Hans (1997). Die Entstehung der Werte. Frankfurt am Main: Suhrkamp.

Jödicke, Ansgar / Rota, Andrea (2010). Unterricht zum Thema Religion an der öffentlichen Schule. Untersuchung im Rahmen des NFP 58 «Religionsgemeinschaften, Staat und Gesellschaft». Universität Freiburg, Freiburg.

Katzenstein, Rahel (2009). Probleme der Wertevermittlung an der öffentlichen Schule in einer religiös-weltanschaulich heterogenen Gesellschaft. Eine Auseinandersetzung mit Amy Gutmanns Theorie der demokratischen Erziehung. Unveröffentlichte Lizentiatsarbeit. Universität Bern.

Katzenstein, Rahel (20I3). Sakralisierung der Pädagogik - Zu vermeidendes Problem oder unvermeidbare Tatsache? In: Tamara Deluigi, Michael Gabathuler, Rahel Katzenstein, Christina Rothen (Hg.). Sakralität, Demokratie und Erziehung. Auseinandersetzungen mit der historischen Pädagogik Fritz Osterwalders. Wien: LIT Verlag, I3-25.

Katzenstein, Rahel (20I7). Fort mit Dogma und Wunderglaube - Religiöse Aufklärung als schulisches «Entfehlerungsprogramm». Die Diskussion um die Abschaffung des konfessionell-dogmatischen schulischen Religionsunterrichts im Kanton Zürich um i 870. In: Anne Conrad, Alexander Maier (Hg.). Erziehung als 
¿Entfehlerung〉. Weltanschauung, Bildung und Geschlecht in der Neuzeit. Bad Heilbrunn: Verlag Julius Klinkhardt, i $85-$ - 98.

Kessler, Andreas (20I6). Der Lernbereich «Ethik» im Lehrplan 2 I. Darstellung, Fachverständnis, Würdigung und Kritik. In: erg.ch - Materialien zum Fach Ethik, Religionen, Gemeinschaft (Online-Publikation), www.ethik-religionengemeinschaft.ch/kessler-ethik-im-lehrplan-2 I (3. 5. 2018).

Kleger, Heinz / Müller, Alois (1986). Religion des Bürgers. Zivilreligion in Amerika und Europa. München: Chr. Kaiser Verlag.

Kley, Andreas (2008). Wie neutral ist die Rechtsprechung des Schweizerischen Bundesgerichts in Glaubens- und Weltanschauungsfragen? Die bisherige Gerichtspraxis zur religiösen Neutralität, die ausgeblendete Zivilreligion und die Möglichkeit ihrer Einblendung durch Art. 2 sa VwVG. In: René Pahud de Mortanges (Hg.). Religiöse Neutralität. Ein Rechtsprinzip in der multireligiösen Gesellschaft. Zürich: Freiburger Veröffentlichungen zum Religionsrecht FVRR, $65-104$.

Knoll, Joachim H./Schoeps, Julius H. (Hg.) (1975). Friedrich Albert Lange. Leben und Werk. Duisburg: Walter Braun Verlag.

Köhler, Michael (2003). Johann Caspar Sieber. Ein Leben für die Volksrechte (I 8 2 I-I 878). Zürich: Chronos Verlag.

Kohli Reichenbach, Claudia / Krieg, Matthias (Hg.) (20I 5). Volkskirche und Kirchenvolk. Ein Zwischenhalt. Zürich: TVZ.

Koller, Thomas (1987). Volksbildung, Demokratie und Soziale Frage. Die Zürcher Demokratische Bewegung und ihre Bildungspolitik in den Jahren I 862 bis i 872 : Ideen, Programm und Realisierungsversuch. Zürich: Juris Druck + Verlag.

Kölz, Alfred (2000). Der demokratische Aufbruch des Zürchervolkes. Eine Quellenstudie zur Entstehung der Zürcher Kantonsverfassung von I 869. Zürich: Schulthess.

Kraus, Dieter (I993). Schweizerisches Staatskirchenrecht. Hauptlinien des Verhältnisses von Staat und Kirche auf eidgenössischer und kantonaler Ebene. Tübingen: Mohr Siebeck.

Kreis, Hans (1933). Die zürcherische Volksschule von i 845 bis I 872 . In: Erziehungsrat des Kantons Zürich (Hg.). Volksschule und Lehrerbildung I 832-I932. Festschrift zur Jahrhundertfeier. Zürich: Verlag der Erziehungsdirektion, 345-55 I.

Kuhn, Thomas K. (2007a). Kambli, Conrad Wilhelm. In: Historisches Lexikon der Schweiz, www.hls-dhs-dss.ch/textes/d/Dio695.php (I3. I2. 2016).

Kuhn, Thomas K. (2007b). Lang, Heinrich. In: Historisches Lexikon der Schweiz www.hls-dhs-dss.ch/textes/d/Dio723.php (I 2. I2. 2016).

Ladner, Andreas (20I4). Politische Parteien. In: Peter Knoepfel et al. (Hg.). Handbuch der Schweizer Politik ( 5 ., überarbeitete und erweiterte Auflage). Zürich: Verlag Neue Zürcher Zeitung.

Landert, Charles / Brägger, Martina / Frank, Katharina / unter Mitarbeit von Joedicke, Ansgar (20I 2). Neues Unterrichtsfach «Religion und Kultur». Bericht über die Evaluation der Einführungsphase. Verfügbar unter Beschlüsse 20I3, www.bi.zh.ch (3.5. 2018).

Largiadèr, Anton (I944). Die zürcherische Kantonsverfassung von I 869 Zürcher Taschenbuch auf das Jahr I945. Zürich: Verlag Buchdruckerei a/d. Sihl A.-G. 
Legrand, Louis (I96I). L'influence du positivisme dans l'œuvre scolaire de Jules Ferry: Les origines de la laïcité. Paris: Librairie Marcel Rivière et Cie.

Lepeletier, Michel (I949 [I793]). Plan einer Nationalerziehung. In: Robert Alt (Hg.). Erziehungsprogramme der Französischen Revolution. Mirabeau, Condorcet, Lepeletier. Berlin; Leipzig: Volk und Wissen Verlags GmbH.

Lübbe, Hermann (2004). Staat und Zivilreligion. Ein Aspekt politischer Legitimät. In: Heinz Kleger, Alois Müller (Hg.). Religion des Bürgers. Zivilreligion in Amerika und Europa. Münster: LIT Verlag (2., ergänzte Auflage), I95-220.

Luhmann, Niklas (2004). Grundwerte als Zivilreligion. Zur wissenschaftlichen Karriere eines Themas. In: Heinz Kleger, Alois Müller (Hg.). Religion des Bürgers. Zivilreligion in Amerika und Europa. Münster: LIT Verlag, I75-I94.

Lüthi, Ruth (20I3). Wolff, Philipp Heinrich. In: Historisches Lexikon der Schweiz, www.hls-dhs-dss.ch/textes/d/D42065.php (3. 5. 2018).

MacIntyre, Alasdair (I988). Whose Justice, which Rationality? London: Duckworth. Maier, Hans (2007 [1995]). Politische Religion - Kirchenförmige Religion - Zivilreligion. In: Hans Maier. Politische Religionen. München: C. H. Beck.

Maissen, Thomas (2015). Neue Zürcher Zeitung (NZZ). Historisches Lexikon der Schweiz, www.hls-dhs-dss.ch/textes/d/D $48585 \cdot \operatorname{php}$ (3. 5. 20I8).

Marx, Karl (I983 [I 84 I]). Die Promotion von Karl Marx - Jena I84I. Eine Quellenedition. Berlin: Dietz Verlag.

Mathys, Hans-Peter (2006). Furrer, Konrad. In: Historisches Lexikon der Schweiz, www.hls-dhs-dss.ch/textes/d/Dio6I4.php (3. 5. 2018).

Miéville, Gabriel-Antoine (1798). Erklärung der helvetischen Konstitution in Fragen und Antworten (2. Auflage). Luzern: Balthasar und Meyer.

Moser, Christian (2013). Vögeli, Hans Heinrich. Historisches Lexikon der Schweiz, www.hls-dhs-dss.ch/textes/d/Di64 I 8.php (3. 5. 2018).

Müller, Alois (2005). Ist der freiheitliche Staat auf vorpolitische Ressourcen des Religiösen angewiesen und welcher Platz soll den Religionsgemeinschaften im öffentlichen Raum zukommen? In: René Pahud de Mortanges, Erwin Tanner (Hg.). Kooperation zwischen Staat und Religionsgemeinschaften nach schweizerischem Recht (Band I 5). Zürich: Schulthess Juristische Medien AG, $35-89$.

Nietzsche, Friedrich (I 999 [I 88 5-I 888]). Nachlass I 88 5-I 887 . München: Deutscher Taschenbuchverlag de Gruyter.

Osterwalder, Fritz (1998). Demokratie und laizistische Schule - die religiöse Grenze der Laizität. Die Konzepte von Demokratie und Schule in der Dritten Republik Frankreichs. In: Zeitschrift für Pädagogik, 38. Beiheft. Bildung, Öffentlichkeit und Demokratie, I I 5-I 42.

Osterwalder, Fritz (20I I). Demokratie, Erziehung und Schule. Bern: Haupt.

Osterwalder, Fritz / Weber, Karl (2004). Die Internationalisierung der föderalistischen Bildungspolitik. In: Schweizerische Zeitschrift für Bildungswissenschaften, 26 (I), I I-32.

Peter-Kubli, Susanne (201 2). Römer, Melchior. In: Historisches Lexikon der Schweiz, http://www.hls-dhs-dss.ch/textes/d/D368 I.php (I8. I 2. 20I8).

Pfister, Rudolf (1984). Kirchengeschichte der Schweiz. Dritter Band von I 720 bis I950. Zürich: Theologischer Verlag. 
Rabaut Saint-Etienne, Jean-Paul (2000 [1792]). Projet d'éducation nationale. In: Bronislaw Baczko (Hg.). Une Education pour la Démocratie. Textes et Projets de l'époque révolutionnaire. Genève: Librairie DROZ S.A, 296-30I.

Rawls, John (2005). Political Liberalism (erweiterte Auflage). New York: Columbia University Press.

Röhl, Martin (2006). Die staatskirchenrechtlichen Bestimmungen der neuen Zürcher Kantonsverfassung. In: Dieter Kraus (Hg.). Schweizerisches Jahrbuch für Kirchenrecht (Band Io). Bern: Peter Lang, 200-209.

Rota, Andrea / Müller, Stefan (2015). Die Entwicklung des Religionsunterrichts in der Schweiz im Spannungsfeld von Kirche, Staat und Schule im I9. und 20. Jahrhundert. Eine Übersicht am Beispiel ausgewählter Kantone. Teil I: Kanton Waadt. ZFRK / RDSR, I, 27-42.

Rousseau, Jean-Jacques (2008 [ I 762]). Gesellschaftsvertrag. Stuttgart: Reclam. Sander, Wolfgang (20I8). Schulische Bildung zwischen Religion und Säkularismus. In: Stefan Müller, Wolfgang Sander (Hg.). Bildung in der postsäkularen Gesellschaft. Weinheim Basel: Beltz Juventa.

Schaffner, Martin (1982). Die demokratische Bewegung der I $860 e r$ Jahre. Beschreibung und Erklärung der Zürcher Volksbewegung von i 867. Basel und Frankfurt am Main: Verlag Helbing \& Lichtenhahn.

Schepp, Heinz-Hermann (1989). Grundzüge der politischen Theorie der Französischen Revolution in ihren Konsequenzen für die Pädagogik. In: Ulrich Herrmann, Jürgen Oelkers (Hg.). Zeitschrift für Pädagogik: Französische Revolution und Pädagogik der Moderne, 24. Beiheft. Weinheim und Basel: Beltz Verlag, 47-62.

Schieder, Rolf (1997). Schule und Zivilreligion. In: Neue Sammlung. VierteljahresZeitschrift für Erziehung und Gesellschaft, 37, 623-643.

Schieder, Rolf (2004). Zivilreligion. In: Theologische Realenzyklopädie. Berlin: Walter de Gruyter, 7i 5-720.

Schleiermacher, Friedrich (2008). Der christliche Glaube. 2. Auflage (I 830/3 I). Berlin: Walter de Gruyter.

Schleiermacher, Friedrich (20I2). Über die Religion. Reden an die Gebildeten unter ihren Verächtern. I799/I 806/I 82 I. Studienausgabe. Anna Büsching, Frank Bestebreurtje, Niklaus Peter (Hg.). Zürich: Theologischer Verlag.

Schmid, Bruno (20I2). Schneider, Albert. In: Historisches Lexikon der Schweiz, www.hls-dhs-dss.ch/textes/d/D I 5804 .php (3. 5. 2018).

Schmid, Hans Heinrich (1988). Umbau der Kirche. Die Revision der Zürcher Kirchengesetzgebung I 943-1967 aus der Sicht eines ihrer Väter: Gotthard Schmid, Dr. theol. h.c. Zürich: Theologischer Verlag.

Schmid, Hans Heinrich (1994). Kirche und Staat im Kanton Zürich - geschichtliche Voraussetzungen der heutigen Situation. In: Alfred Schindler (Hg.). Kirche und Staat. Bindung, Trennung, Partnerschaft. Zürich: Theologischer Verlag, I 96-2 I 8.

Schumacher, Beatrice (20I3). In: Historisches Lexikon der Schweiz, www.hls-dhs-dss. ch/textes/d/D44724.php (3.5. 2018).

Schweizer, Paul (1972). Freisinnig-Positiv-Religiössozial. Ein Beitrag zur Geschichte der Richtungen im Schweizerischen Protestantismus. Zürich: Theologischer Verlag. 
Seitter, Walter (2003). Brauchen wir eine Zivilreligion? In: Michael Ley, Heinrich Neisser, Gilbert Weiss (Hg.). Politische Religion? Politik, Religion und Anthropologie im Werk von Eric Voegelin. München: Wilhelm Fink Verlag, i I 5-I 34 .

Sewing, Werner (1993). John G. A. Pocock und die Wiederentdeckung der republikanischen Tradition. Vorwort. In: John G. A. Pocock (Hg.). Die andere Bürgergesellschaft. Zur Dialektik von Tugend und Korruption. Frankfurt/Main: Campus Verlag GmbH, 7-32.

Spaemann, Robert (200I). Vorsicht: «Wertegemeinschaft!». Welt Online. Verfügbar unter www.welt.de/print-welt/article47008 s/Vorsicht_Wertegemeinschaft.html (3. 5. 2018).

Späni, Martina (1997). Umstrittene Fächer in der Pädagogik. Zur Geschichte des Religions- und Turnunterrichts. In: Hans Badertscher, Hans-Ulrich Grunder (Hg.). Geschichte der Erziehung und Schule in der Schweiz im I9. und 20. Jahrhundert. Bern: Paul Haupt.

Späni, Martina (I 999). Die Entkonfessionalisierung der Volksschulen in der Schweiz im I9. Jahrhundert. In: Lucien Criblez, Carlo Jenzer, Rita Hofstetter, Charles Magnin (Hg.). Eine Schule für die Demokratie. Zur Entwicklung der Volksschule in der Schweiz im I9. Jahrhundert. Bern: Peter Lang, 297-323.

Späni, Martina (2005). Säkularisierung und Schule im i9. Jahrhundert. In: Yvonne Leimgruber, Hansjörg Frank, Matthias Fuchs, Beatrice Küng (Hg.). Pädagoge Politiker - Kirchenreformer. Augustin Keller (I $805-1883$ ) und seine Zeit. Baden: hier + jetzt, Verlag für Kultur und Geschichte.

Sperisen, Vera / Schär, Bernhard C. (20I3). Akteure versus Strukturen - zum Spannungsverhältnis zwischen Lehrbuch- und Lehrpersonenkonzepten im Geschichtsunterricht. Das Schweizer Beispiel «Hinschauen und Nachfragen». In: Susanne Popp, Michael Sauer, Bettina Alavi, Marko Demantowsky, Alfons Kenkmann (Hg.). Zur Professionalisierung von Geschichtslehrerinnen und Geschichtslehrern. Nationale und internationale Perspektiven. Göttingen: V\&R unipress, I 87-202.

Stadler, Peter (1986). Das liberale Zürich. In: Robert Schneebeli (Hg.). Zürich. Geschichte einer Stadt. Zürich: Verlag Neue Zürcher Zeitung, I 7 I-202.

Statistisches Amt des Kantons Zürich. Konfessions- \& Religionsdaten. Bevölkerung, Gemeinde, Geschlecht, Heimat, Konfession I 8 50-2000. Online verfügbar unter www.statistik.zh.ch (3. 5. 2018).

Straubhaar, Thomas/Winz, Manfred (1992). Reform des Bildungswesens. Kontroverse Aspekte aus ökonomischer Sicht. Bern: Haupt.

Sträuli, Hans (1902). Verfassung des eidgenössischen Standes Zürich vom i 8. April I 869. Winterthur: Buchdruckerei Geschwister Ziegler.

Streuli, Jakob (1948). Der zürcherische Protestantismus an der Wende vom Liberalismus zur Demokratie. Ein Beitrag zum Problem Christentum und Eidgenossenschaft. Teildruck der Dissertation. Stäfa: Buchdruckerei Stäfa.

Streuli, Jakob (1950). Der zürcherische Protestantismus an der Wende vom Liberalismus zur Demokratie. Ein Beitrag zum Problem Christentum und Eidgenossenschaft. Dissertation. Philosophische Fakultät I. Universität Zürich. Zürich.

Stuber, Christine (2006). Heer, J. Justus. Historisches Lexikon der Schweiz, www.hls-dhs-dss.ch/textes/d/Dio664.php (3.5. 2018). 
Sundermeier, Theo (2012). Konvivenz: Ein Modell für Europa? International Journal of Orthodox Theology, 3 (4). Online verfügbar unter http://orthodox-theology. $\operatorname{com}(3.5 .2018)$.

Suter, Meinrad (20I3). Wyss, Georg von. In: Historisches Lexikon der Schweiz, www.hls-dhs-dss.ch/textes/d/D271 28.php (3. 5. 2018).

Taylor, Charles (2007). A Secular Age. Cambridge. Massachusetts, London: The Belknap Press of Harvard University Press.

Tenorth, Heinz-Elmar ( I999). Schule-Religion-Zivilreligion. Zur weiteren Problematisierung eines jetzt schon schwierigen Verhältnisses. In: Christoph T. Scheilke, Friedrich Schweitzer (Hg.). Religion, Ethik, Schule. Bildungspolitische Perspektiven in der pluralen Gesellschaft. Münster: Waxmann Verlag, 2 I9-247.

Tobler, Ruedi (2008). Reform des Einstiegs als Einstieg in eine allgemeine Schulreform? vpod bildungspolitik, I 57, 20-22.

Tosato-Rigo, Danièle (2009). Éduquer le nouveau citoyen: un défi de l’ère révolutionnaire en territoire lémanique. Revue historique vaudoise, i 77 (Éducation et société), 63-73.

Tröhler, Daniel (200 a). Pädagogische Historiographie und Kontext. In: Zeitschrift für pädagogische Historiographie, I, 26-34.

Tröhler, Daniel (200I b). Politischer Liberalismus und staatlicher Lehrmittelverlag? In: Daniel Tröhler, Jürgen Oelkers (Hg.). Über die Mittel des Lernens. Kontextuelle Studien zum staatlichen Lehrmittelwesen im Kanton Zürich des I9. Jahrhunderts. Zürich: Verlag Pestalozzianum, ı-48.

Tröhler, Daniel (2006). Republikanismus und Pädagogik. Pestalozzi im historischen Kontext. Bad Heilbrunn: Klinkhardt.

Tröhler, Daniel (2007). Die Zürcher Schulsynode: Ein demokratisches Kuckucksei in der liberalen Ära Zürichs im i 9. Jahrhundert. In: Claudia Crotti, Philipp Gonon, Walter Herzog (Hg.). Pädagogik und Politik. Historische und aktuelle Perspektiven. Festschrift für Fritz Osterwalder. Bern: Haupt Verlag, 53-68.

Tröhler, Daniel (2008). Verwaltung und Aufsicht der Zürcher Volksschule. In: Daniel Tröhler, Urs Hardegger (Hg.). Zukunft bilden. Die Geschichte der modernen Zürcher Volksschule. Zürich: Verlag Neue Zürcher Zeitung, 54-68.

Tröhler, Daniel (20 I I). Classical Republicanism, Local Democracy, and Education. The Emergence of the Public School of the Republic of Zurich, I770-1870. In: Daniel Tröhler / Thomas S. Popkewitz / David F. Labaree (Hg.). Schooling and the making of citizens in the long nineteenth century comparative visions. New York: Routledge, I 53-1 76.

Tröhler, Daniel, Hardegger, Urs (2008). Einleitung. In: Daniel Tröhler, Urs Hardegger (Hg.). Zukunft bilden. Die Geschichte der modernen Zürcher Volksschule. Zürich: Verlag Neue Zürcher Zeitung, 9-I 2.

Vial, Theodore M. (2004). Liturgy Wars. Ritual Theory and Protestant Reform in Nineteenth-Century Zurich. New York and London: Routledge.

Voegelin, Eric (1975). From Enlightenment to Revolution. Durham, North Carolina: Duke University Press.

Voegelin, Eric (1993). Die politischen Religionen. Peter J. Opitz (Hg.). München: Wilhelm Fink Verlag. 
Weber, Thomas (2003). Markanter Wandel in der Zürcher Religionslandschaft. Ergebnisse der Volkszählungen I970-2000 für den Kanton Zürich. Online verfügbar unter www.statistik.zh.ch (3. 5. 20I8).

Weibel, Andrea (2005). Finsler, Diethelm Georg. In: Historisches Lexikon der Schweiz, www.hls-dhs-dss.ch/textes/d/Dio603.php (3. 5. 2018).

Weiss, Reto (2000). Versuche zur Trennung von Kirche und Staat. In: Staatsarchiv des Kantons Zürich (Hg.). Kleine Zürcher Verfassungsgeschichte, I 2 I 8-2000. Zürich: Chronos, I46-I 49.

Wettstein, Walter (1907). Die Regeneration des Kantons Zürich. Die liberale Umwälzung der dreissiger Jahre. I 830-I 839. Zürich: Von Schulthess \& Co.

Wolterstorff, Nicholas P. (2005). Jeffrey Stout on Democracy and its Contemporary Christian Critics. Journal of Religious Ethics, 633-647.

Wüthrich, Matthias D. / Zeindler, Matthias / Plüss, David (Hg.) (20ı6). Ekklesiologie der Volkskirche. Theologische Zugänge in reformierter Perspektive. Zürich: TVZ.

Zimmerli, Walther Ch. (2006). Die Zukunft denkt anders. Wege aus dem Bildungsnotstand. Frauenfeld: Huber \& Co.

Zschokke, Heinrich (I 836). Volksbildung ist Volksbefreiung: eine Rede, gehalten in der Versammlung des schweizerischen Volksbildungsvereins zu Lausen den Io. April i 836. Sissach: Aktien-Buchdruckerei.

Zurlinden, Melanie (2015). Religionsgemeinschaften in der direkten Demokratie. Handlungsräume religiöser Minderheiten in der Schweiz. Wiesbaden: Springer.

Zurlinden, S. (I9I 5). Hundert Jahre. Bilder aus der Geschichte der Stadt Zürich in der Zeit von I 8I4-I9I4. (Band 2). Zürich: Buchdruckerei Berichthaus. 


\section{Historische Bildungsforschung}

herausgegeben von Patrick Bühler, Lucien Criblez, Claudia Crotti

und Andreas Hoffmann-Ocon

Thomas Ruoss

Zablen, Zäblen und Erzäblen in der Bildungspolitik

Lokale Statistik, politische Praxis und die Entwicklung städtischer Schulen

zwischen I 890 und 1930

Band 4, 2018. 240 Seiten. Gebunden

ISBN 978-3-0340-I 450-2. CHF 44 / EUR 44

Philipp Eigenmann

\section{Migration macht Schule}

Bildung und Berufsqualifikation von und für Italienerinnen und Italiener in Zürich, 1960-1980

Band 3, 2017. 328 Seiten, 20 Abbildungen s/w. Gebunden

ISBN 978-3-0340-I 38 I-9. CHF 48 / EUR 48

Christina Rothen, Lucien Criblez, Thomas Ruoss (Hg.)

Staatlichkeit in der Schweiz

Regieren und verwalten vor der neoliberalen Wende

Band 2, 2016. 424 Seiten. Gebunden

ISBN 978-3-0340-I 363-5. CHF 48 / EUR 43

Lucien Criblez, Lukas Lehmann, Christina Huber (Hg.)

Lebrerbildungspolitik in der Scbweiz seit 1990

Kantonale Reformprozesse und nationale Diplomanerkennung

Band I, 20I6. 376 Seiten, I 8 Farbabbildungen. Gebunden

ISBN 978-3-0340-I 342-0. CHF 48 / EUR 43 


\section{Bücher zum Thema}

Christina Rothen

Selbstständige Lehrer, lokale Behörden, kantonale Inspektoren

Verwaltung, Aufsicht und Steuerung der Primarschule im Kanton Bern, I 832-2008 20I 5. 296 Seiten, 5 Abbildungen s/w. Gebunden

ISBN 978-3-0340-I 309-3. CHF 58 / EUR 52

Andrea De Vincenti

Schule der Gesellschaft

Wissensordnungen von Zürcher Unterrichtspraktiken zwischen I 77 I und I 834

2015.384 Seiten, I Abbildung s/w. Gebunden

ISBN 978-3-0340-I 299-7. CHF 48 / EUR 43

Chronos Verlag

Eisengasse 9

CH-8008 Zürich

www.chronos-verlag.ch

info@chronos-verlag.ch 